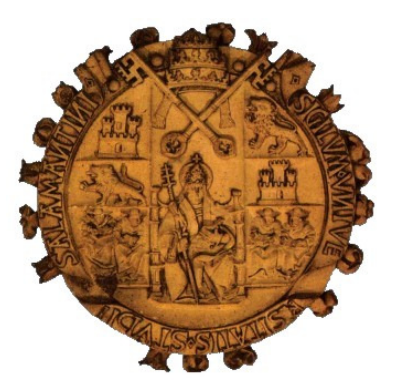

UNIVERSIDAD DE SALAMANCA

FACULTAD DE EDUCACIÓN

DEPARTAMENTO DE TEORÍA E HISTORIA DE LA EDUCACIÓN

\title{
DESARROLLO DE ESTRATEGIAS SINTÁCTICAS Y SEMÁNTICAS EN LECTURA A TRAVÉS DE LECTOR EN PERSONAS SORDAS ADULTAS EN CASTILLA Y LEÓN
}

TESIS DOCTORAL

Realizado por: Carolina de Castro Costa

Dirigido por: Ana Belén Domínguez Gutiérrez

Antonio Víctor Martín García 

en Castilla y León 
"Qué importa la sordera del oído cuando la mente oye; la verdadera sordera, la incurable sordera es la de la mente"

(Víctor Hugo) 

en Castilla y León 

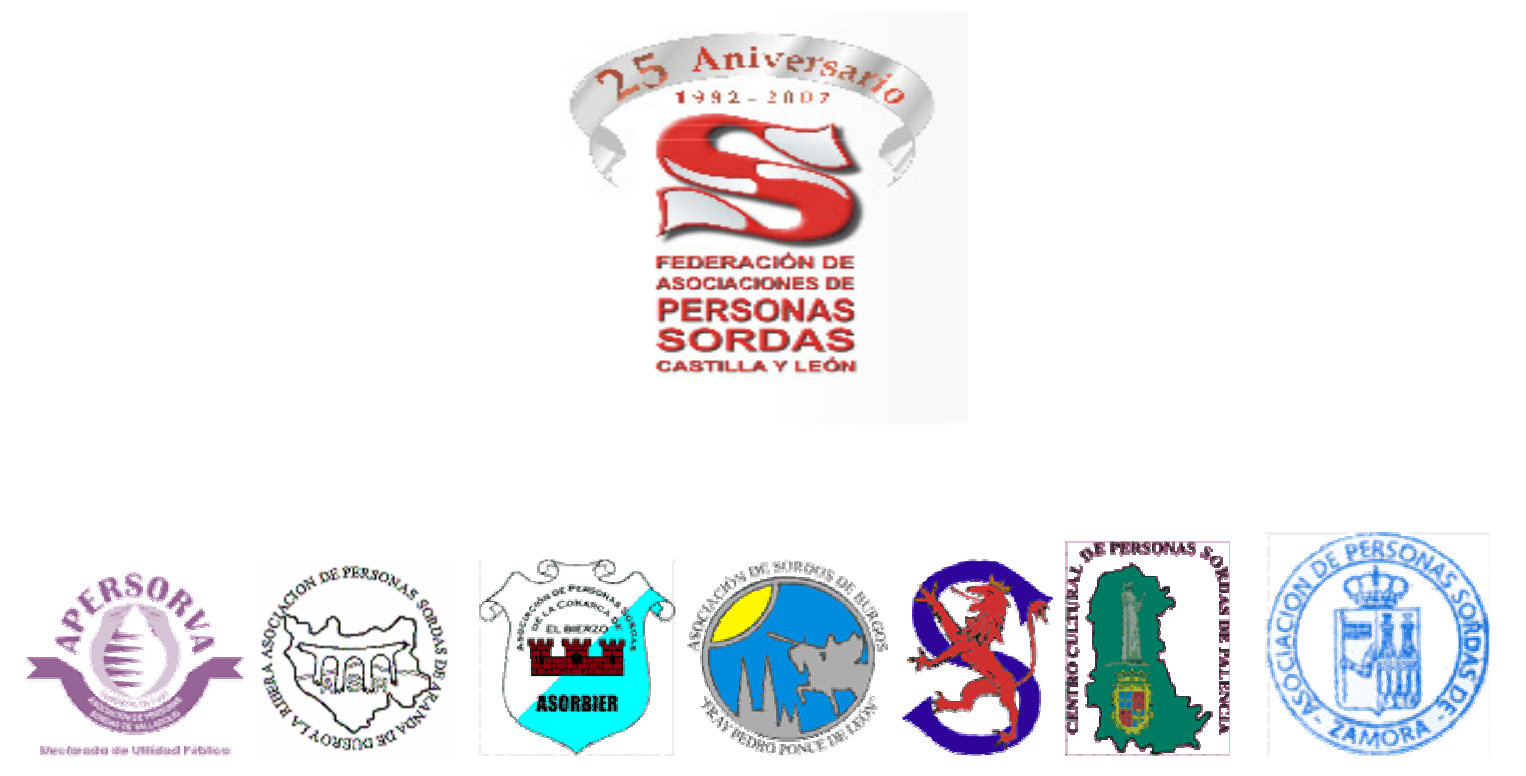

AGRADECIMIENTOS

Mis sinceros agradecimientos a Luís Alberto Redondo, director de la Federación de Asociaciones de Personas Sordas de Castilla y León, por la amabilidad y profesionalidad; a la comisión que aceptó que esta investigación fuese realizada; a los alumnos, presidentes y educadores de las distintas Asociaciones, que participaron con tanta dedicación y interés en todas las actividades.

A Luis y Vicente que me apoyaran durante el proyecto A Miguel, por su incondicional ayuda y su aportación de conocimientos informáticos. A Antonio Víctor Martín y a Ana Belén Domínguez Gutiérrez, que me han orientado para la realización de este proyecto. 

en Castilla y León 


\section{ÍNDICE}

ÍNDICE

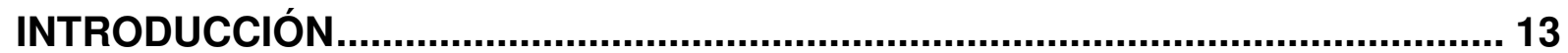

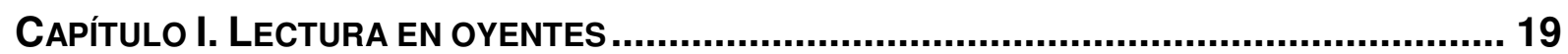

1.1. Lectura y Comprensión............................................................................ 19

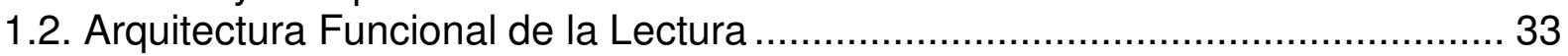

1.3. Procesos Psicológicos que Intervienen en la Lectura ..................................... 39

1.3.1. Procesos Perceptivos ............................................................... 39

1.3.1.1. Movimientos saccádicos y fijaciones .................................... 39

1.3.1.2. Análisis visual ............................................................. 41

1.3.1.2.1. Hipótesis del reconocimiento global de las palabras. 42

1.3.1.2.2. Hipótesis de reconocimiento previo de las letras ...... 43

1.3.2. Procesamiento Léxico ..................................................................... 45

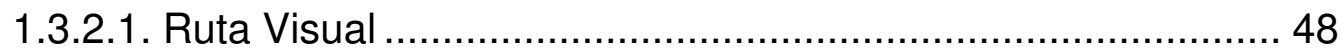

1.3.2.1.1. Léxico Visual..................................................... 48

1.3.2.1.2. Sistema Semántico ................................................ 48

1.3.2.1.3. Léxico fonológico ..................................................... 48

1.3.2.2. Ruta fonológica............................................................. 49

1.3.2.2.1. Mecanismos de conversión grafema a fonema......... 49

1.3.2.2.2. Léxico auditivo ..................................................... 50

1.3.2.2.3. Almacén de pronunciación...................................... 50

1.3.3. Procesamiento sintáctico .............................................................. 51

1.3.3.1. Estrategias de procesamiento sintáctico ………………....... 52

1.3.3.2. Modelos de procesamiento sintáctico.................................. 53

1.3.4. Procesamiento semántico ............................................................ 54

1.3.4.1. Extracción del significado ............................................... 55

1.3.4.2. Integración del significado en los conocimientos del lector .... 56

1.3.4.3. Conocimientos del lector: Los esquemas ............................. 57

1.3.4.4. El Procesamiento Estructural del Texto................................ 58

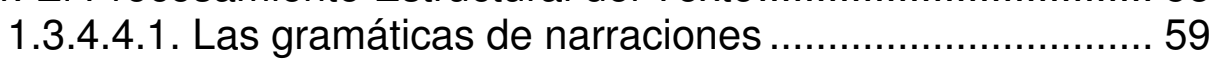

1.3.4.4.2. Teorías de macroestructura .................................... 62

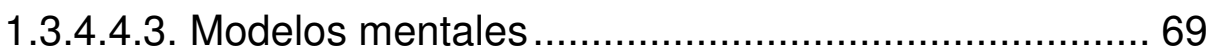

1.4. Desarrollo del sistema morfo-sintáctico ..................................................... 72

1.5. Trastornos en los componentes sintáctico y semántico.................................. 73

1.6. Los conocimientos previos en los procesos de enseñanza/aprendizaje ........... 74

1.7. La exploración de conocimientos previos .................................................... 78

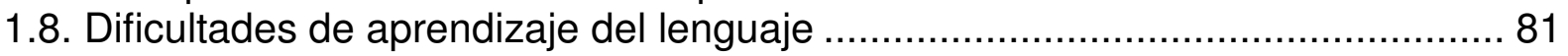

1.9. Dificultades en Comprensión Lectora........................................................ 82

1.9.1. Los Factores que influyen en la Comprensión Lectora Relativos al

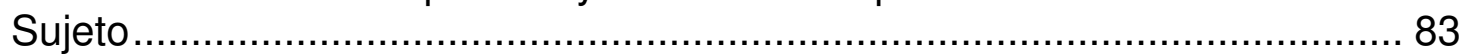

1.9.1.1. Desarrollo semántico y morfosintáctico …………………...... 83

1.9.1.2. Atención y memoria.......................................................... 83

1.9.1.3. Motivación y expectativas hacia la lectura............................. 84

1.9.2 Los Factores que influyen en la Comprensión Lectora Relativos al

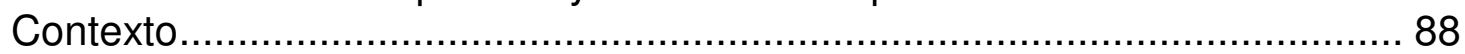

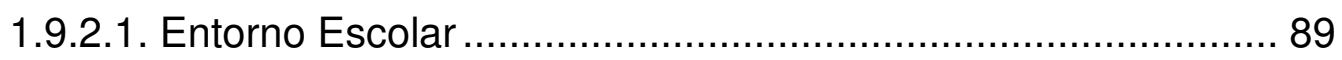




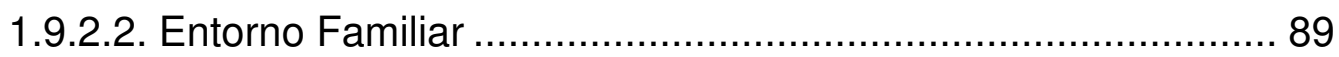

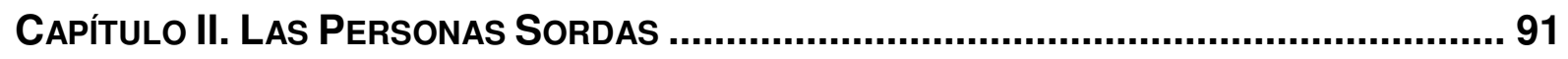

2.1. Perspectiva Sobre la Sordera .................................................................... 91

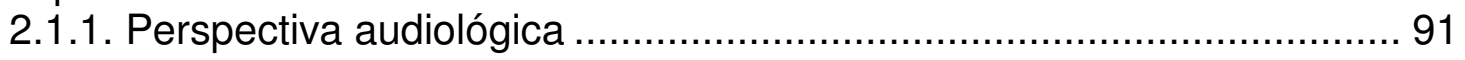

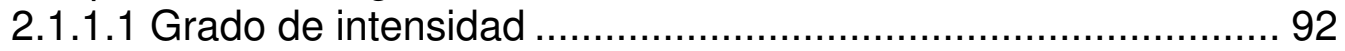

2.1.1.2. Localización topográfica ................................................... 93

2.1.1.2.1. Hipoacusia de conducción o transmisión .................. 93

2.1.1.2.2. Hipoacusia de percepción, sensorial o neurosensorial

2.1.1.2. Hipoacusia mixta........................................ 94

2.1.1.3. Momento de adquisición...................................................... 96

2.1.2. Perspectiva sociológica............................................................... 96

2.1.2.1. Comunicación en el Medio Familiar...................................... 97

2.1.2.2. Socialización en la Escuela Elemental ................................ 100

2.1.2.3. Adolescencia y Enseñanza Secundaria .............................. 103

2.1.2.4. La persona sorda en la vida adulta..................................... 105

2.1.3. Perspectiva multidimensional.......................................................... 108

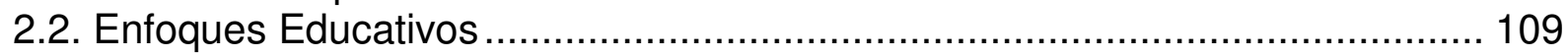

2.2.1. En relación a la modalidad comunicativa ....................................... 109

2.2.1.1. Monolingües ........................................................... 109

2.2.1.1.1. Sistemas Aumentativos y comunicativos de comunicación (SACC) ......................................................... 109

2.2.1.1.2. Lectura labiofacial ............................................... 113

2.2.1.1.3. El Alfabeto Dactilológico ……………………....... 115

2.2.1.1.4. Palabra complementada o Cued-Speech ............... 116

2.2.1.1.5. Bimodal ............................................................ 119

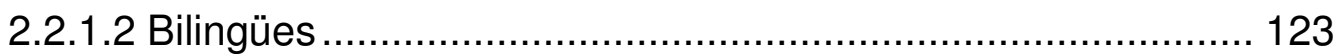

2.2.1.2.1. Lengua de Signos .............................................. 127

2.2.1.2.2. Evolución histórica de la LSE............................... 131

2.2.1.2.3. Historia de la Lengua de Signos en España ............ 134

2.2.2. En relación al contexto educativo................................................... 138

2.2.2.1. Centros ordinarios ......................................................... 139

2.2.2.2. Educación especial........................................................ 141

2.2.2.3. Centros de Integración social ........................................... 144

2.2.2.4. Niveles de Integración .................................................... 144

2.2.2.4.1. Integración completa........................................... 145

2.2.2.4.2. Integración combinada........................................ 145

2.2.2.4.3. Integración parcial................................................ 145

2.2.2.4.4. Integración de centro específico ............................ 146

2.2.2.5 Requisitos básicos de un centro de integración de sordos.... 147

2.2.2.6. Repercusiones de la sordera en el desarrollo cognitivo y social

2.2.3. El adulto sordo en la educación de sordos ............................................. 153

2.3. La Ley de Lengua de Signos ................................................................. 154

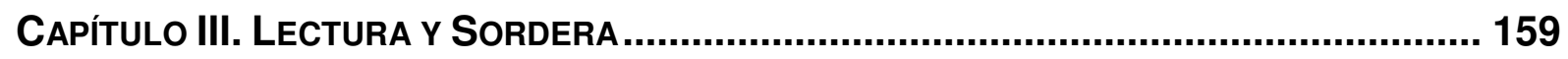

3.1. Comunicación con Personas Sordas........................................................ 164

3.1.1. La escritura y la alfabetización de los niños sordos .......................... 166

3.1.2. El proceso de construcción de la escritura y las personas sordas ..... 167 


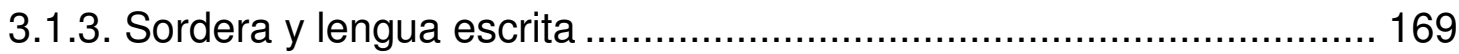

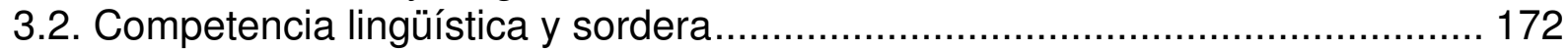

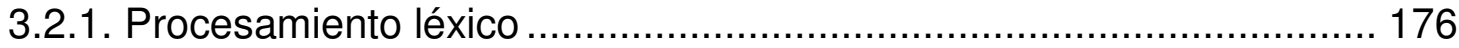

3.2.1.1. Léxico fonológico ....................................................... 181

3.2.2. Procesamiento Sintáctico............................................................ 184

3.2.3. Procesamiento semántico ........................................................... 187

3.3. Reconocimiento de palabras y dificultad lectora......................................... 191

3.4. Habilidad lingüística y fracaso lector en los estudiantes sordos ..................... 194

3.5. Configuración del contexto de aprendizaje.................................................. 197

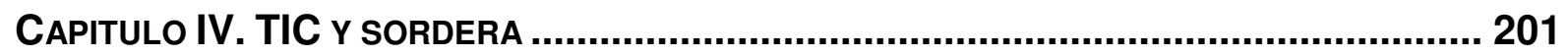

4.1. Ayudas Técnicas basadas en Recursos Humanos: Los Intérpretes de Lengua de Signos ....................................................................................... 207

4.2. Tecnologías de Ayuda para el aprovechamiento de restos auditivos .............. 209

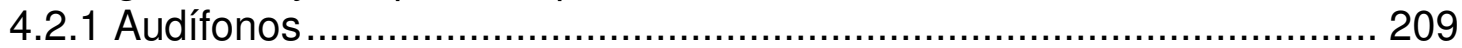

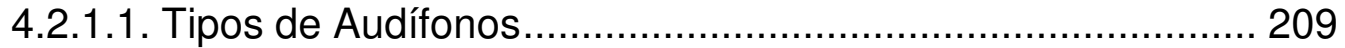

4.2.1.2. Problemas de adaptación.................................................. 211

4.2.1.3. Modelos nuevos ........................................................ 212

4.2.1.4. Nuevas investigaciones con Audífonos ............................. 212

4.2.2. Implante coclear.................................................................... 213

4.2.2.1. Criterios generales para implantes cocleares.................... 214

4.2.2.2. Limitaciones de un implante coclear................................... 214

4.2.2.3. Criterios de selección ..................................................... 215

4.2.2.4. Intervención y post-operatorio ………………………….... 216

4.2.2.5. Rehabilitación ............................................................. 216

4.2.2.6. El implante coclear ayuda al paciente ................................ 218

4.2.3. Los nuevos implantes ............................................................... 219

4.3. Ventajas e inconvenientes de los ordenadores en la educación ..................... 220

4.3.1. Ventajas de los ordenadores en la educación .................................. 221

4.3.1.1. Los estudiantes se divierten utilizando los ordenadores ...... 221

4.3.1.2. Individualización ............................................................... 221

4.3.1.3. Interacción .................................................................. 222

4.3.1.4. Aprender más deprisa ................................................... 223

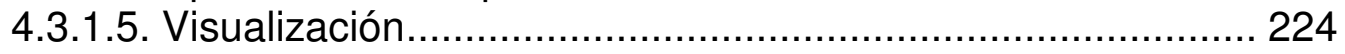

4.3.1.6. Comunicaciones ......................................................... 224

4.3.2. Inconvenientes de los ordenadores en la educación ......................... 224

4.4. Ayudas informáticas para alumnos con deficiencias auditivas ....................... 225

4.4.1. Ayudas informáticas para la visualización de parámetros del habla .. 230

4.4.1.1. El Sistema VISHA....................................................... 230

4.4.1.2. Speechviewer ....................................................... 232

4.4.1.3. Proyecto Fressa 2008 ................................................ 232

4.4.2. Ayudas informáticas para la estimulación del desarrollo del lenguaje 233

4.4.2.1. LAO ...................................................................... 233

4.4.2.2. PHONOS I y PHONOS II................................................ 234

4.4.2.3. DI. Programa de Iniciación en la Lectura Labial ................... 235

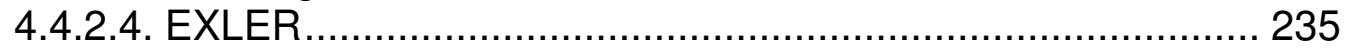

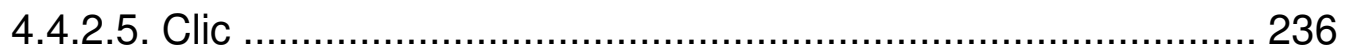

4.4.3. Ayudas informáticas para el desarrollo de la lecto-escritura.............. 237

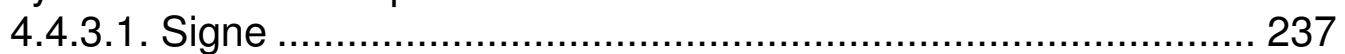

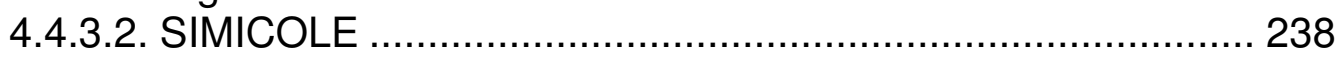


4.4.4. Ayudas informáticas para el aprendizaje de la lengua de signos....... 240

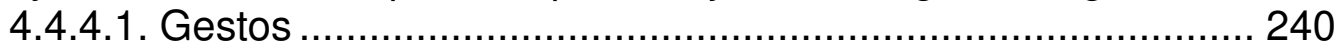

4.4.4.2. ¡A Signar!................................................................. 240

4.4.4.3. Signos 97-98 (Diccionario de Lengua de Signos Española). 240

4.4.4.4. DILSE. Diccionario Básico de Lengua de Signos ................. 241

4.4.4.5. DILSE. Diccionario de neologismos de la lengua de signos. 241

4.4.4.6. Diccionarios online .......................................................... 241

4.4.4.7. Aprendizaje a través de Internet...................................... 241

4.4.5. Ayudas informáticas para la formación en sistemas de comunicación aumentativos de aplicación en niños con deficiencias auditivas.................. 242

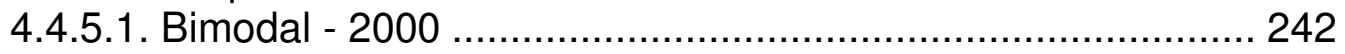

4.4.5.2. La Palabra Complementada .............................................. 243

4.4.5.3. Dactilología.................................................................. 243

4.5. Tecnologías de ayuda para la vida cotidiana de aplicación en el medio escolar

4.5.1. Avisadores luminosos y/o vibrotáctiles......................................... 245

4.5.2. Ayudas para la comunicación a distancia ...................................... 246

4.5.3. Ayudas visuales: Subtitulado ...................................................... 247

4.6. La lectura a través de los tiempos y las nuevas tecnologías ........................... 248

4.7. Aplicación de las Nuevas Tecnologías en los procesos educativos ................. 250

4.7.1. Servicios de un espacio virtual educativo ...................................... 251

4.7.2. Ventajas y riesgos de los servicios educativos virtuales ................... 252

4.8. El aprendizaje en entornos virtuales: e-formación ...................................... 254

4.8.1. Definición de e-formación ......................................................... 255

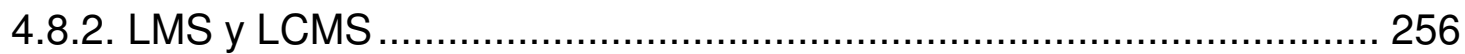

4.8.3. Importancia de la e-formación..................................................... 258

4.9. Importancia de los recursos educativos para las Personas Sordas ................ 258

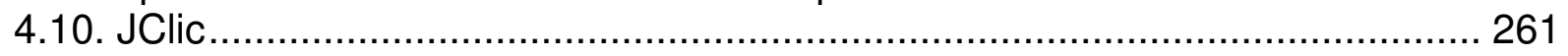

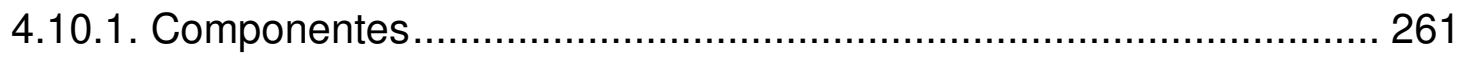

4.10.2. Compatibilidad y nuevas posibilidades ....................................... 262

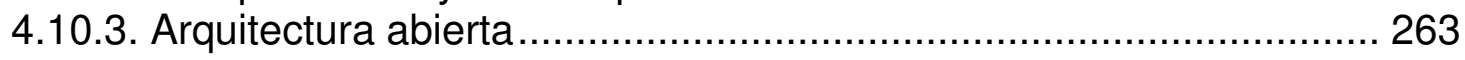

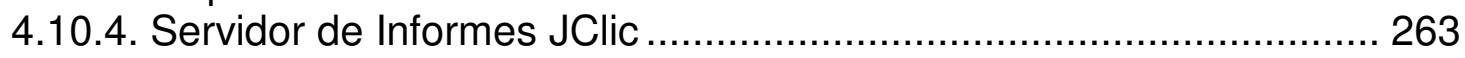

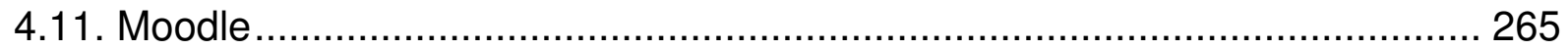

4.11.1. ¿Qué es Moodle?................................................................. 266

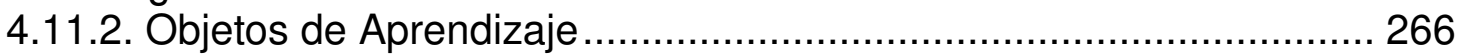

4.11.2.1. Perspectiva informática ................................................. 267

4.11.2.2. Perspectiva didáctica...................................................... 267

4.11.3. Arquitectura de Moodle .......................................................... 268

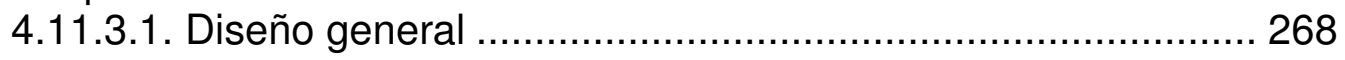

4.11.3.2. Administración del sitio Moodle ........................................ 269

4.11.3.3. Gestión de usuarios ........................................................ 269

4.11.3.4. Gestión de cursos....................................................... 270

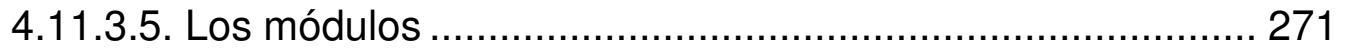

4.11.4. Ventajas y desventajas de Moodle............................................ 271

4.12. Integración de JClic y Moodle............................................................. 272

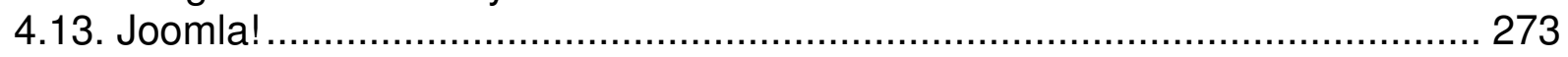

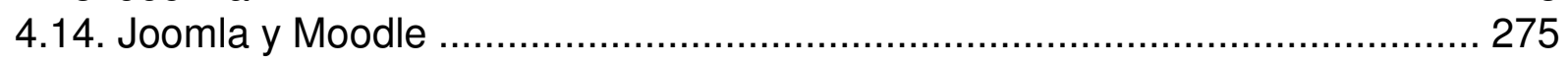

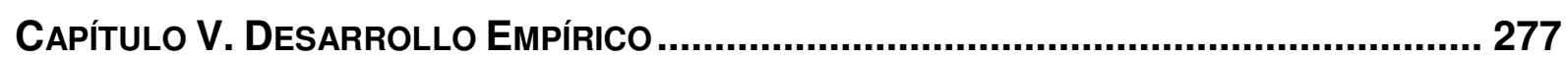

5.1. Objetivos e Hipótesis ........................................................................ 280 


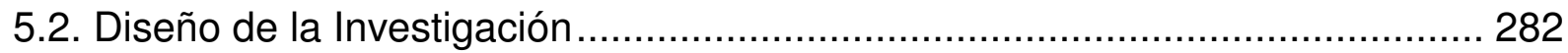

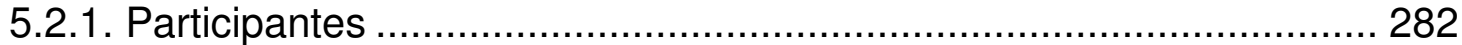

5.2.1.1. Formulario de información personal .................................. 283

5.2.1.2 Características de los Participantes .................................. 286

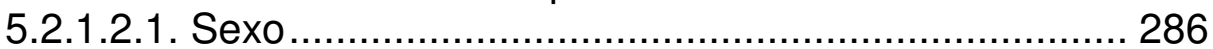

5.2.1.2.2. Nivel de Estudios ............................................... 287

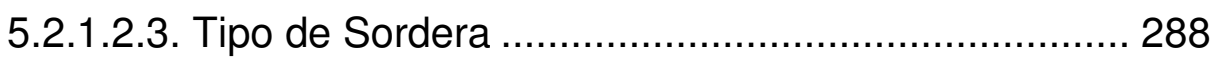

5.2.1.2.4. Número de Audífonos .......................................... 288

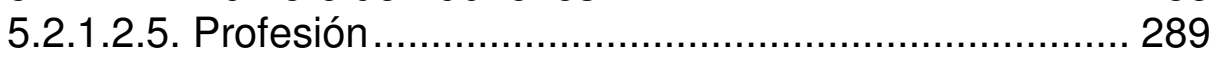

5.2.1.2.6. Lengua de Signos .............................................. 289

5.2.1.2.7. Lengua Oral .................................................... 290

5.2.2. Instrumentos de Recogida de Datos ............................................... 291

5.2.2.1. Prueba de Eficiencia Lectora ........................................... 291

5.2.2.1.1 Material ........................................................... 291

5.2.2.1.2. Criterios de corrección ......................................... 293

5.2.2.2. Prueba de Evaluación de Estrategias Sintácticas ................ 293

5.2.2.2.1. Material y criterios seguidos para su elaboración ... 294

5.2.2.2.2. Criterios de corrección ........................................... 297

5.2.2.3. Procedimiento seguido para la administración de las pruebas

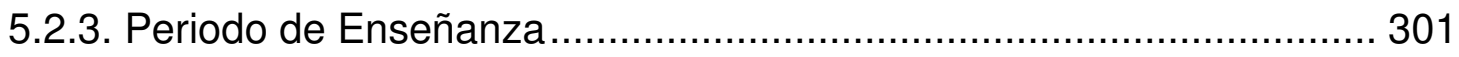

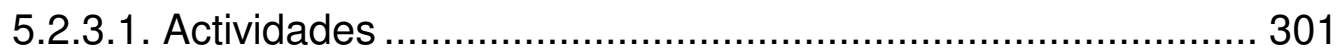

5.2.3.2. Curso Lector .................................................................... 302

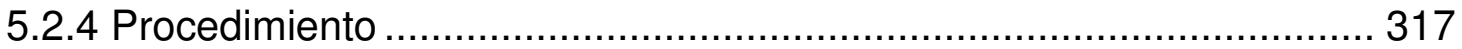

5.2.4.1. Esquema Cronológico del Trabajo ................................... 317

5.2.4.2. Método.................................................................... 320

5.3. Resultados y Discusión de los Resultados ................................................ 323

5.3.1. Evaluación del Nivel de Eficiencia Lectora..................................... 323 5.3.1.1. Estudio de la Eficiencia Lectora en función del Nivel de Estudios................................................................................. 325

5.3.1.2. Estudio de la Eficiencia Lectora en función del Lenguaje Oral 327

5.3.1.3. Estudio de la Eficiencia Lectora en función del Número de Audífonos ......................................................................... 328 5.3.1.4. Estudio de la Eficiencia Lectora en función del Tipo de Sordera 329

5.3.1.5. Estudio de la Eficiencia Lectora en función de la Edad Media 330

5.3.2. Evaluación de las Estrategias Sintácticas ........................................ 331

5.3.2.1. Análisis del tipo de Estrategia Lectora............................... 332

5.3.2.2. Estudio del uso de estrategias sintácticas y semánticas en función del Nivel de Estudios ...................................................... 335

5.3.2.3. Estudio del empleo de estrategias sintácticas y semánticas en función del Uso de Lenguaje Oral ................................................ 336 5.3.2.4. Estudio del uso de estrategias sintácticas y semánticas en función del Número de Audífonos .................................................. 338 5.3.2.5. Estudio del uso de estrategias sintácticas y semánticas en función del Tipo de Sordera ...................................................... 339

5.3.3. Relación entre Nivel Lector y uso de Estratégias Sintácticas ............. 340 5.4. Discusión General e Implicaciones Educativas ............................................. 342 
BIBLIOGRAFÍA............................................................................................. 351

ANEXO I. Prueba de Eficiencia Lectora ...................................................... 363

ANEXO II. Prueba de EStrategias SintÁcticas ............................................ 369

ANEXO III. CURSO LECTOR VISTA DEL ADMINISTRADOR ..................................... 379

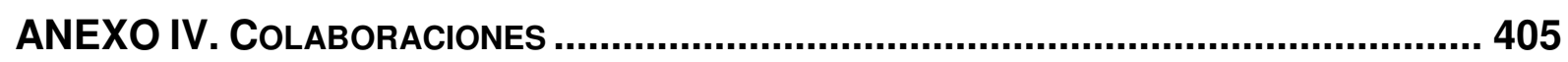




\section{INTRODUCCIÓN}

A lo largo del presente trabajo, se presenta una serie de fundamentos teóricos relacionados con la lectura; se realizará una descripción en función de diferentes perspectivas o enfoques de lo que son las personas sordas hoy en día. Con esta información se aplicarán los fundamentos de la lectura sobre el colectivo de personas con discapacidad auditiva, comprendiendo las dificultades que estas personas presentan para enfrentarse a un mundo de lectores oyentes. Conocer las ayudas técnicas existentes que pueden facilitar la comunicación entre oyentes y sordos es uno de los puntos importantes de este trabajo. En esta última parte teórica, se explicará entre otras muchas cosas que es JClic y Moodle y como se usan. Adquirir esta serie de conocimientos y en este orden permitirá comprender lo objetivos de esta investigación.

Para comprender un texto se precisa reconocer las relaciones semánticas y sintácticas que se establecen entre ellas. Para poder llegar a comprender los procesos que llevan a la comprensión lectora, es necesario reconocer las palabras que forman un texto.

Para comprender la capacidad lectora de las personas sordas es necesario partir de una base teórica que permita comprender la lectura desde la perspectiva del colectivo de las personas oyentes. Gracias a estos conocimientos teóricos se puede llegar a comprender y a solucionar los problemas que actualmente presentan las personas sordas al enfrentarse a un texto. A lo largo del capitulo I (Lectura en oyentes) de esta tesis, se aborda este tema. Conocer y dar la importancia necesaria a la lectura y por lo tanto a la comprensión lectora, supone valorar en gran manera los trabajos de investigación que se han realizado hasta ahora. De estos trabajos como se verá mas adelante, se pueden sacar múltiples conclusiones.

La educación de la capacidad lectora desde la escuela sienta las bases para un dominio de la lengua escrita. Hay que recordar que la lengua escrita, como la conocen los oyentes esta basada en el lenguaje oral. Hoy en día, el acceso a la información se considera un privilegio. Existen muchos métodos para llegar a percibir la información como puede ser a través de la literatura. Pero para comprender lo que esta literatura dice es necesario además de saber leer, comprender lo que allí esta escrito. El trabajo de hacer que un conjunto de palabras tengan sentido es un trabajo que debe partir desde los esfuerzos que realizan los profesores en las escuelas primarias.

A lo largo del aprendizaje de la lectura, de forma natural, se van adquiriendo conocimientos relacionados a la estructura funcional de la lectura. Sobre esta arquitectura se han realizado diversas investigaciones; por un lado Fodor (1983, citado en De Vega et al., 1990), defiende una concepción modular. Postuló que los mecanismos de análisis de entradas, entre los que incluye los sistemas perceptivos y el lenguaje, son modulares. Este concepto supone que el sistema está compuesto de unidades funcionales autónomas o módulos. 
Por otro lado McClelland, (1987 citado en de Vega et al., 1990), defiende una concepción interactiva. Esta asume un procesamiento en paralelo entre los diferentes niveles, y además una comunicación bi-direccional entre ellos.

Profundizando en los procesos psicológicos que intervienen en la lectura y basándose en la definición en Cuetos, $(2006,23)$ se definen cuatro procesos. El primero de estos procesos son los procesos perceptivos que incluyen los movimientos que realizan los ojos en la lectura y realizan un primer análisis visual. De este primer análisis se pasa a realizar un procesamiento léxico utilizando para ello la ruta visual que se apoya en los procesos perceptivos indicados anteriormente y una ruta fonológica. En los dos siguientes procesamientos se realiza primer un procesamiento sintáctico y posteriormente un procesamiento semántico. En este momento se extrae el significado del texto leído. Para poder llegar a extraer e integrar el significado en los conocimientos del lector es necesario hacer uso de lo que se conoce como esquemas. Los esquemas no son más que grupos de información relacionada sobre ciertos temas. Dentro del procesamiento semántico se puede hablar de la existencia de un procesamiento estructural del texto. Dentro de las estructuras se pueden encontrar las gramáticas de narraciones, las teorías de macroestructura y los modelos mentales. Una vez comprendidos estos procesos se puede pasar a evaluar los trastornos en los componentes sintácticos y semánticos y dificultades de aprendizaje del lenguaje y comprensión lectora que las personas oyentes presentan en la lectura.

Como parte fundamental de esta tesis, es conveniente y necesario hablar sobre las personas sordas. De esta forma en el capitulo II (Las personas sordas) se recogen las perspectivas sobre la sordera, recordando que el colectivo de la personas sordas es heterogéneo. Se pueden presentar diversas perspectivas relacionadas con las personas sordas como puede ser una perspectiva audiológica, donde se ve al grupo de personas sordas diferenciándolas por su tipo, grado y momento de adquisición de la sordera. También se puede ver desde una perspectiva sociológica donde influye la comunicación con su familia, la socialización en la escuela, el comportamiento en la adolescencia y en la enseñanza secundaria, así como ver el comportamiento de las personas sordas en la vida adulta. Existe además una perspectiva multidimensional gracias a la cual se puede tomar consciencia de los diferentes grupos que se han formado a lo largo de la historia y el cambio de concepto actual, gracias al cual las personas sordas se definen por algo que no tienen y no algo que les falta.

Desde del punto de vista educativo existen actualmente múltiples mecanismos dirigidos a la educación de personas con discapacidad auditiva. En este sentido la aportación de una modalidad comunicativa bien sea monolingüe o bilingüe, a través de los sistemas aumentativos y comunicativos de comunicación, o a través del alfabeto dactilológico o la palabra complementada, o el uso de bimodales y la lengua de signos, suponen un amplio abanico de modalidades comunicativas.

Pero no son solo necesarias herramientas de comunicación, si no que es necesario englobar estos mecanismos dentro de un contexto educativo, considerando la posibilidad de ingresar a los alumnos sordos en Centros Ordinarios o Centros con educación especial o Centros de Integración social. A este respecto existen innumerables opiniones apoyando la integración de los alumnos sordos en 
diferentes tipos de escuelas. En un primero momento se consideró necesario crear escuelas especiales donde estudiaran los alumnos sordos. Este tipo de educación era completamente excluyente y no fomentaba la integración de los sordos con el resto de alumnos oyentes. Con el paso del tiempo se considera necesario que los alumnos sordos asistan a un cierto número de clases con alumnos oyentes. Además el Centro educativo debe albergar alumnos sordos y oyentes. De esta forma se consigue una integración total, al hacer necesario que el alumno sordo interactúe con el oyente y viceversa.

Una vez definidos por un lado los conceptos relacionados con la lectura y por otro lado a las personas sordas, y teniendo en cuenta que el ámbito de investigación de esta tesis es el trabajo de aprendizaje de la lectura por parte de las personas con discapacidad auditiva, cabe pensar que sea necesario hablar de la lectura desde el punto de vista de las personas con discapacidad auditiva, como se hace a lo largo del capitulo III, de la Lectura y Sordera. En este capitulo se pueden descubrir las capacidades necesarias de comunicación que las personas sordas han desarrollado y han utilizado hasta ahora. Este grupo de capacidades son necesarias y por lo tanto deben ser conocidas, por las personas que se encargan de la educación de alumnos sordos. Existen actualmente, diferentes modalidades de comunicación con alumnos sordos que dependen de muchos factores como: la edad en la que sobrevino el déficit, la severidad del mismo, las capacidades comunicativas, el entorno familiar y educativo, la atención temprana y las posibilidades con que se cuenten los profesionales que intervengan con estos alumnos. Comprender y manejar la comunicación que los alumnos sordos utilizan, facilitará en el futuro la comprensión de las materias que los educadores quieren hacer llegar a los alumnos sordos. Mantener una educación de la lectura basada únicamente en el lenguaje escrito o hablado, es un gran error cuando se está hablando de educación de alumnos sordos. La utilización de Lengua de Signos, fomentando el bilingüismo en la educación, aporta innumerables beneficios cuando los educadores la dominan, presentando una vía de comunicación entre profesor y alumno. A lo largo de este capítulo se realiza un análisis de los diferentes procesos implicados en la lectura, como se hace en el capítulo I pero esta vez desde la perspectiva de la sordera, se analizan los procesos mostrando los momentos, dentro de este procesamiento, en los cuales los alumnos sordos presentan mayores problemas y el porque de estos problemas.

Aumentar las habilidades lingüísticas en las personas sordas supone un gran esfuerzo a ambas partes, pero este esfuerzo no queda sin recompensa ya que puede ayudar a los alumnos sordos a comprender el entorno que les rodea. Sin embargo, no aumentar estas habilidades suele llevar a un fracaso lector en los estudiantes, este fracaso lector, como se verá en este trabajo se hace mas patente en el trabajo con alumnos adultos sordos que no han recibido una educación temprana y que no presentan una serie de conocimientos previos básicos.

Las nuevas tecnologías, han y están jugando un papel muy importante en la integración y educación de las personas sordas, gracias al gran número de ayudas técnicas que se han desarrollado. Por este motivo, el capitulo IV (TIC y Sordera) de esta investigación analiza los diferentes tipos de ayudas técnicas que se han desarrollado hasta ahora. Se comenzará hablando sobre las tecnologías de ayuda para el aprovechamiento de restos auditivos; en este apartado hay que recordar el gran avance mostrado en aparatos electrónicos como audífonos, cada vez mas 
pequeños y ligeros, o implantes cocleares cada vez mas discretos, que hacen que las personas sordas hagan uso de sus restos auditivos. Pero las tecnologías avanzan y esto hace que los elementos antes indicados sean cada vez más pequeños, más ligeros y con tiempos de utilización mayores. A lo largo de la primera mitad del 2008 se ha hablado en los medios de comunicación de lo que dieron en llamar "oído biónico", el cual no es mas que un implante que se realiza sobre el nervio auditivo, pero su mayor peculiaridad es que todo el mecanismo que forma este oído, se encuentra integrado dentro del cráneo de los pacientes.

Tampoco hay que olvidar que existen otros tipos de ayudas, como son las ayudas informáticas para alumnos con deficiencia auditiva, que permiten visualizar los parámetros del habla, estimulan el desarrollo del lenguaje y de la lecto-escritura, ayudan a aprender Lengua de Signos o sistemas de educación aumentativos como bimodal, palabra complementada o dactilología. Ayudas que en muchas ocasiones no solo van dirigidas a las personas con discapacidad auditiva, como ya se ha dicho; conocer los sistemas de comunicación de las personas con las que se trabaja es fundamental de esta forma muchos de estos cursos pueden ser realizados por oyentes que o bien van a trabajar en este entorno o por personas que forman parte del entorno al tener a una persona allegada con discapacidad auditiva.

Pero además de las ayudas "físicas" y las ayudas educativas, existen las ayudas dirigidas a la vida cotidiana, en este aspecto, los progresos de las comunicaciones a distancia supone un gran avance para la comunicación con personas sordas. En gran medida, este tipo de ayudas ha conseguido fomentar la interrelación entre personas que se encuentran distantes. En el caso de personas sordas supone una gran ventaja, antes de la existencia de estas evoluciones, la comunicación en ciertos casos de aislamiento era imposible.

No se puede olvidar, que el motivo de esta investigación es demostrar que una herramienta informática puede favorecer el aprendizaje y el entrenamiento de estrategias sintácticas y semánticas. Explicándolo de forma muy simple, esta herramienta se encuentra en forma de curso dentro de una página Web en Internet, es decir, se está hablando de un concepto relativamente nuevo conocido como eformación (e-learning en inglés); a lo largo del punto 6 del capítulo IV se hablará del aprendizaje en entornos virtuales, mostrando sus inconvenientes y sus ventajas. Pero si se aborda la descripción desde un punto de vista algo más técnico, el curso LECTOR, como se le ha llamado, es un curso formado por actividades creadas con Jclic que se encuentran integradas en un entorno LMS muy utilizado llamado Moodle, que permite la creación y administración distribuida de cursos de todo tipo. A partir del punto 8 del capítulo IV se ahonda más en este tipo de conceptos. La utilización de este tipo de recursos, supone un nivel de conocimientos informáticos mas altos que en otras circunstancias. El educador puede crear actividades adaptadas a las necesidades de un grupo de trabajo, haciendo para ello uso de sus conocimientos. Pero conseguir que estas ideas se vean reflejadas en un curso en la red supone un trabajo extra y este esfuerzo se ve recompensado al saber que el curso que recoge una serie de actividades creadas a partir de los conocimientos académicos del profesor, será accesible desde cualquier punto a través de una conexión a Internet, además permite recuperar todo tipo de informes relacionados con la marcha del curso. 
Una vez definida la fundamentación teórica sobre la que se basa esta investigación no queda más que hablar de la parte empírica. En este apartado se mostrará todo el proceso que se ha seguido para conseguir demostrar la hipótesis propuesta. Para la realización de la investigación se ha contado con el curso Lector, y se ha usado no solo para mostrar las actividades educativas. Las dos primeras actividades son los test que los usuarios han tenido que realizar en calidad de pretest. Estas pruebas se pueden revisar en los Anexos I. Prueba de Eficiencia Lectora y Anexo II. Evaluación del uso de estrategias sintácticas en lectura para alumnos sordos, de este trabajo. Que los usuarios trabajen con los test, adaptados con Moodle, en red supone obtener los resultados rápidamente, al realizar la aplicación la corrección automáticamente. A lo largo de este apartado se definen este tipo de métodos utilizados, se muestran las actividades que los participantes han tenido que realizar y se definen los tiempos estimados de entrenamiento con el curso Lector.

Evaluar y analizar el grupo que forma la muestra es una de las tareas más importantes a la hora de sacar conclusiones. Es necesario conocer las características de los alumnos para poder definir junto con sus resultados las actividades que posteriormente tendrán que hacer. En este trabajo se valorarán dos aspectos como son: el nivel de eficiencia lectora y el uso de estrategias semánticas y sintácticas que presentan los participantes. Analizando detalladamente los resultados de los test, que se realizaron previa y posteriormente al trabajo con las actividades, se sacarán una serie de conclusiones, en cada uno de los dos valores a tratar. Uniendo los resultados se sacarán los resultados finales de la investigación.

Todo el trabajo se remata con la lista de autores consultados, importantes creadores de anteriores investigaciones, que han ayudado a la creación de esta, y que con sus conocimientos han posibilitado que hoy en día se plantee la educación de personas adultas sordas como un tema a investigar.

Los anexos mostrarán como ya se ha indicado las pruebas de evaluación en los Anexos I y II. Como tercer Anexo se incluye una completa guía de administración del curso Lector, visto desde la perspectiva del administrador, el curso está integrado dentro de educa.signando.com; esta página se ha creado específicamente para esta investigación, aunque el contenido y los usuarios han seguido trabajando con el curso una vez finalizados los tiempos en los que se enmarcaba la investigación.

Para la realización de este trabajo se ha contado con la colaboración de la Federación de Asociaciones de Personas Sordas de Castilla y León (FAPSCyL). Las asociaciones que forman esta Federación aceptaron participar. Se realizó una visita, previa cita, a cada Asociación para explicar el funcionamiento del entorno Web y del curso a los responsables y/o educadores de cada centro, en el Anexo IV se puede ver los documentos donde se refleja esta visita y colaboración. 

en Castilla y León 


\section{Capítulo I. Lectura en oyentes}

\subsection{Lectura y Comprensión}

Leer es una actividad valiosa tanto desde el punto de vista social, como individual. Las sociedades plenamente alfabetizadas tienen indudables ventajas culturales, políticas, y económicas, frentes a aquellas cuyos miembros son, en su mayoría, iletrados.

Podríamos considerar que "leer es un proceso de interacción entre el lector y el texto, proceso mediante el cual el primero intenta satisfacer los objetivos que guían su lectura" (Solé, 1987, citado en Solé, 1992), dar sentido a lo que está escrito; interpretar lo que dice un texto; descubrirle significado. Es una interacción entre el pensamiento activo del lector y lo que dice el texto. Implica, además, que siempre debe existir un objetivo que guíe la lectura, o dicho de otra forma, siempre se lee para algo, para alcanzar alguna finalidad.

Desde el punto de vista de la enseñanza, las propuestas que se basan en esta perspectiva señalan la necesidad de que los alumnos aprendan a procesar el texto y sus distintos elementos así como las estrategias que harán posible su comprensión (Alonso y Mateos, 1985; Solé, 1985; Solé, 1987; Colomer y Camps, 1991, citados en Solé, 1992).

La lectura es una actividad múltiple. Al leer el sistema cognitivo identifica las letras, realiza una transformación de letras en sonidos, construye una representación fonológica de la palabra, accede a los múltiples significados de ésta, selecciona un significado de la frase, integra el significado de las frases para elaborar el sentido global del texto, realiza inferencias basadas en el conocimiento del mundo, etc. La mayoría de estos procesos ocurren sin que el lector sea consciente de ellos y, además, son procesos muy veloces, pues la comprensión del texto tiene lugar casi al mismo tiempo que el lector desplaza su vista por las palabras. No sólo hay que explorar los procesos y construir modelos detallados de cada uno de ellos. Además, hay que conocer cómo se ensamblan entre si, de qué modo se trasvasan información, cooperan o compiten para alcanzar el producto final: la comprensión del texto.

En la comprensión oral el oyente debe realizar un análisis de pautas acústicas del habla, mientras que el lector analiza las pautas visuales del texto escrito. Esto parece reducir la especificidad de la lectura a las destrezas más periféricas que recodifican las letras en sonidos. Esta impresión es engañosa, ya que la comprensión oral y la comprensión escrita difieren en muchos detalles.

He aquí algunas diferencias señaladas por Perfetti (1985, citado en de Vega, Carreiras, Gutiérrez-Calvo y Alonso, 1990):

- "En la comprensión del habla se tienen en cuenta factores prosódicos (entonación) y gestuales, ausentes en la lectura. 
- Si mantenemos la igualdad del mensaje, el habla supone una mayor demanda de memoria que la lectura. En aquella el mensaje es transitorio, mientras que en ésta permanece disponible y puede ser reinspeccionado.

- El habla es una parte característica de la interacción social, mientras que la lectura es una actividad generalmente individual.

- El contenido del habla no suele ser arbitrario, ya que existe un contexto compartido por los interlocutores. En cambio, el contenido del texto escrito no suele relacionarse con un contexto externo inmediato.

- El contenido del habla es ajustado por los interlocutores, mientras que el contenido del texto escrito es determinado por el escritor.

- La lectura supone un aprendizaje de un código convencional que requiere generalmente la ayuda de algún agente educativo y un método especial. En cambio, la comprensión oral es una actividad natural que se aprende espontáneamente en el contexto de la interacción con la comunidad parlante."

No se puede, por tanto, identificar totalmente la comprensión oral con la comprensión lectora, pero tampoco se puede olvidar el parentesco entre ambas.

"El lenguaje muestra de modo particular el papel del símbolo en la inteligencia humana. Se aprende por medio de la imitación social y se incorpora al repertorio de la conducta del niño junto con su inteligencia, en desarrollo, en el nivel primero de manifestaciones simbólicas." (Fhurt, 1981, 209).

El lenguaje es uno de los logros más importantes en la escala evolutiva. Los investigadores que intentan profundizar en los secretos de la competencia lingüística y de su uso, encuentran que su trabajo requiere una comprensión del funcionamiento psicológico del organismo humano.

A medida que nos damos cuenta del lenguaje interno, privado, durante el período de resolución de un problema, estamos tentados, dice Piaget (Futh, 1981, p. 210), de conceptualizar el pensamiento, como mirando a una pantalla interna, o lo que el filósofo Price (1953, citado en Futh, 1981) llama una clase de "inspección". Engañados por nuestra propia evidencia interna, hacemos del habla interna el objeto de esta inspección e identificamos el símbolo verbal con el mismo proceso del pensamiento. El defecto básico de cualquier teoría, que intenta explicar el pensamiento en términos de unidades verbales o simbólicas, radica en tres falsas suposiciones:

- que los conceptos son unidades reales del pensamiento.

- que el concepto y el símbolo, especialmente el símbolo verbal, son uno y lo mismo.

- que los símbolos se transmiten y funcionan como señales o estímulos sustitutivos. 
Al estudiar los símbolos, se debe, como dice Piaget, invertir este movimiento natural de la mente. La acción es la raíz y el medio de la inteligencia; la realidad de los conceptos se debe buscar en la acción del pensamiento que puede estar comprendido en un medio simbólico. Pero la inteligencia humana no está ligada a ningún tipo particular de imágenes internas ni de símbolos. A medida que aumentan las necesidades, añadimos nuevos términos a nuestro vocabulario. La mente tiene la suficiente capacidad para crear los símbolos adecuados que sirven a la inteligencia y a la comunicación humana.

Se es más competente en la lectura en la medida en que lo que interpretamos corresponde bien a lo que está escrito. Por eso, nunca se alcanza la perfección ni al leer ni al escribir.

Beaugrande (1984, citado en González, 1992) distingue entre "aprender a leer" y "leer para aprender". Aprender a leer abarca todas las actuaciones en las que los textos son procesados con la intención principal que no única, de mejorar el proceso lector. Leer para aprender, o aprender leyendo, incluye otras situaciones en las que los textos se procesan con la intención preferente de adquirir conocimientos sobre el tema del que tratan. La primera actividad podría identificarse con la adquisición de destrezas, la segunda alude a su utilización en situaciones complejas.

Para Fischer y Mandl (1984, citado en González, 1992), "leer es aprender a partir de un texto". El principal objetivo de la lectura es comprender el texto y extraer la información que contiene, integrándola con los conocimientos previos del lector. Esa nueva información ha de ser fácil y rápidamente recuperable.

También Just y Carpenter (1987, citado en González, 1992) afirman que leer es fundamentalmente comprender el lenguaje en sus distintos niveles- palabras, frases, textos- que son elaborados por alguno de los procesos que integran la actividad lectora.

De lo dicho por estos autores, podemos deducir que la lectura alude a una amplia variedad de actividades relacionadas con el texto y podemos citar el aprendizaje de los niños en sus distintos niveles de edad escolar.

Por ejemplo un niño de tres años, ante un texto escrito acompañado de una imagen que le dé pistas y referencias puede interpretar que aquello dice...pelota, si el dibujo muestra una pelota. A lo mejor no "acierta", pero ha dado una respuesta lógica y reflexiva que constituye el primer paso de la lectura: lo que hacemos todos, adelantar hipótesis.

En definitiva de acuerdo con (Maruny, Ministral y Miralles, 2003, 110), lo que hace un niño cuando se enfrenta a un texto, es, fundamentalmente, lo mismo que hacen los adultos:

- Formular una hipótesis: Imaginar lo que dirá aquello a partir de indicios o señales (contexto, ilustraciones, tamaño y forma de las palabras, etc.)

- Comprobar la hipótesis: Usando sus conocimientos (descifrado, contexto, etc.) 
- Avanzar o retroceder en la lectura: Si lo que se haya escrito no corresponde con la idea que se había formulado, probablemente se detendrá, volverá a leer para confirmar y cambiar la idea, etc.

Las actitudes en relación con la lectura son las siguientes:

- Motivación, curiosidad e interés por la lectura de textos que rodean al individuo;

- Autoexigencia en la lectura y valoración de la propia comprensión del texto.

- Autoevaluación del grado de comprensión y de las dificultades en la lectura.

- Actitud crítica ante mensajes transmitidos por los textos escritos, mostrando especial sensibilidad hacia los que suponen discriminación social, sexual, racial, etc.

- Atención, concentración, silencio y orden en la lectura individual o en grupo y participación activa en tareas de preparación y comentario del texto.

- Hábitos de lectura en la escuela y en la casa. Uso de bibliotecas.

Con respecto a finalidad y objetivos de la lectura se puede apuntar las siguientes cuestiones:

- Anticipar el contenido

- Activar conocimientos previos

- Uso del contexto y otros indicadores

- Formulación de cuestiones: guía de lectura

- Lectura interactiva

- Construcción progresiva del significado

- Verificación y reformulación de hipótesis

- Identificar y corregir errores de lectura

- Recapitulación de lo leído

- Ampliación de la lectura

- Evaluar la comprensión alcanzada

- Comentario del texto

- Resumen e idea principal

Los lectores expertos no empiezan a leer directamente por el principio, se aproximan al texto, lo sitúan, le dan una ojeada, miran la extensión, las ilustraciones, la tipografía... 
Eso les aporta mucha información útil para representarse el contenido de lo que van a leer, es decir, para hacerse una imagen, anticipar el contenido. Y a partir de ahí elaboran una guía para la lectura, que sirven para activar las neuronas y ponerlas en acción frente a una lectura que no es simplemente recepción, sino esfuerzo mental activo.

En primer lugar hay que apoyarse en los conocimientos previos sobre el contenido del texto. Si el texto se refiere a una noticia, debemos recordar que aquellas noticias informan de sucesos importantes; que indican qué pasó, dónde, cuándo, cómo, por qué y qué consecuencias tuvo. Este conocimiento de la estructura de la noticia facilita nuestra lectura sucediendo lo mismo respecto a la estructura típica de los cuentos o narraciones.

En segundo lugar el uso de contexto e indicadores hace pensar que el título orienta acerca de los que vamos a leer. Especialmente en textos expositivos o informativos el título de una noticia sirve para decidir si interesa leerla o no; en una librería, el titulo del libro indicará si interesa o no.

Toda esta información previa al inicio sirve para prepararse mentalmente a la actividad de leer. Permite elaborar un cierto plan, una guía de lectura: el grado de interés imaginado determinará una lectura más o menos superficial. Se buscan sólo los elementos principales o se entretendrá en los detalles y matices.

Un elemento clave es la formulación de cuestiones, a partir de la información previa disponible. Por ejemplo, una ilustración del cuento sugerirá preguntas acerca de los personajes, de su orden, de los aspectos llamativos de su vestimenta, de los objetos sorprendentes que llevan y otros.

Una forma de estimular la actitud de los alumnos, según (Maruny, Ministral y Miralles, 2003, 111) es motivar la lectura y orientar su trabajo mental mientras leen. Es la mejor forma de hacer rentable la actividad de leer. En la fase de preparación, sería importante escribir a los alumnos una guía de lectura que incluya cuestiones importantes que han surgido del texto, para que sepan el contexto del texto y distingan el contenido de lo mismo.

En la construcción progresiva del texto, lo que se va leyendo se ajusta a las expectativas del lector y durante la lectura no permanecemos pasivos si queremos profundizar en el significado. Cuando leemos, simultáneamente pensamos, evaluamos, criticamos, formulamos preguntamos. Incluso retrocedemos para aclarar aspectos oscuros o dudosos. Aceleramos el ritmo o lo hacemos más lento según la dificultad o el interés de lo que se lee; nos saltamos párrafos que juzgamos aburridos o innecesarios, sentimos emociones: nos infunde temor, o risa, o preocupación, o placer. Estos procedimientos de lectura activa, de inter-relación con el texto, de implicación del lector, deben ser practicados, para que haya comprensión básica e interés en la lectura.

Para comprobar hipótesis, es necesaria una actitud activa por parte del lector. $\mathrm{O}$ sea, será el contenido, la coherencia de la frase y de las ideas, lo que confirme que nuestra apreciación es correcta 0 , en caso contrario, nos haga retroceder y hacer una lectura lenta y minuciosa para descifrar. 
En la lectura, lo fundamental es en primer lugar identificar el problema. Los errores que afectan a la comprensión del texto deben ser identificados rápidamente o darán lugar a malas nterpretaciones. Los errores, además, indican, casi siempre, procedimientos defectuosos. Procedimientos de descifrado: por ejemplo, dejarse engañar por las primeras letras y aventurar el final de las palabras: ello puede alterar el género, el número, el tiempo verbal, la concordancia. Analizar la causa del error quizás sea más lento, pero es una actividad muy valiosa para comprender la estructura del texto.

Al finalizar la lectura (Maruny, Ministral y Miralles, 2003, 117), sería conveniente elaborar una representación global del texto como resultado de lo leído y de lo que se ha comprendido. Es una buena actividad de construcción de textos, que les enseña a redactar y a escribir, además de aprender a comprender lo leído.

Recapitular al término de la lectura es una actividad frecuente en las escuelas y hay algunos aspectos que resaltaremos:

- La recapitulación debe ser elaborada por los propios alumnos, no por el profesor. Los elementos que van apareciendo deben ser discutidos y revisados por los propios alumnos, en un proceso de debate compartido.

- El profesor guía la recapitulación mediante preguntas: las mismas que se incluyeron en la guía de lectura y otras nuevas que se han ido planteando.

- También es importante que el profesor escriba en la pizarra, ante los niños, lo que se va acordando como recapitulación; es imprescindible para posteriores tareas de ampliación de la lectura: re-escribir el texto, comentarlo, resumirlo y otros. En estos casos, la recapitulación sirve como pre-texto de la actividad posterior.

Con relación a la evaluación de la comprensión lectora (Maruny, Ministral y Miralles, 2003, 118), hay algunos criterios para orientar la actividad de evaluación de la comprensión del texto:

- La evaluación debe referirse a los objetivos y a la finalidad de la lectura, previamente acordadas. Es decir, debe corresponder a las preguntas de la guía de lectura.

- Es preferible formular preguntas que estimulen la reflexión y el aprendizaje de procedimientos útiles para mejorar la comprensión. Por ejemplo:

- Procedimientos de deducir el significado de la palabra por el contexto, antes que acudir al diccionario. Seleccionar, de entre las palabras desconocidas, aquellas que son realmente importantes para la comprensión global del texto.

- Hacer inferencias. Es decir, deducir informaciones no explícitas en el texto, a partir de los elementos que aporta. 
- Identificar los elementos más importantes del texto, ideas principales, hechos relevantes...

- Proponer títulos para un texto es una buena forma de asegurar que se ha comprendido la idea principal.

- Elegir el mejor resumen entre varios es una actividad asimismo interesante para la evaluación de la comprensión... y enseña a resumir.

Menéndez Pelayo, (citado en Pastor, 2000) cercana ya su despedida de este mundo afirmaba: "Lo único que siento es la cantidad de libros que aún me quedan por leer".

En los paises desarrollados, el número de personas analfabetas absolutas ha descendido considerablemente en los últimos años, convirtiendose en un hecho residual. Sin embargo, sí son importantes las cifras de adultos analfabetos funcionales. En este sentido, estudios estadisticos como el Barómetro de Hábitos de Lectura y Compra de Libros, elaborado por Conecta Research \& Consulting para la Federación de Gremios de Editores de España (FGEE), con el patrocinio de la Dirección General del Libro, Archivos y Bibliotecas del Ministerio de Cultura, muestran que el porcentaje de lectores en España se situó en el 54,8\% de la población mayor de 14 años en el primer trimestre de 2009 y de ellos, el $42,1 \%$ se declara lector frecuente, es decir, afirma leer libros diaria o semanalmente.

La progresión del índice de lectores frecuentes confirma la tendencia al alza de este tipo de lectores en los últimos años. España es el único país de Europa que, además del informe anual, hace un seguimiento trimestral de los datos de lectura y los segmenta por franjas de edad. Además de los lectores frecuentes, otro 12,7\% dice ser lector ocasional, es decir, lee alguna vez al mes o al trimestre. Entre los no lectores, un $45,2 \%$ de la población dice no leer y, de éstos, el 30,5\% que no lo hace nunca.

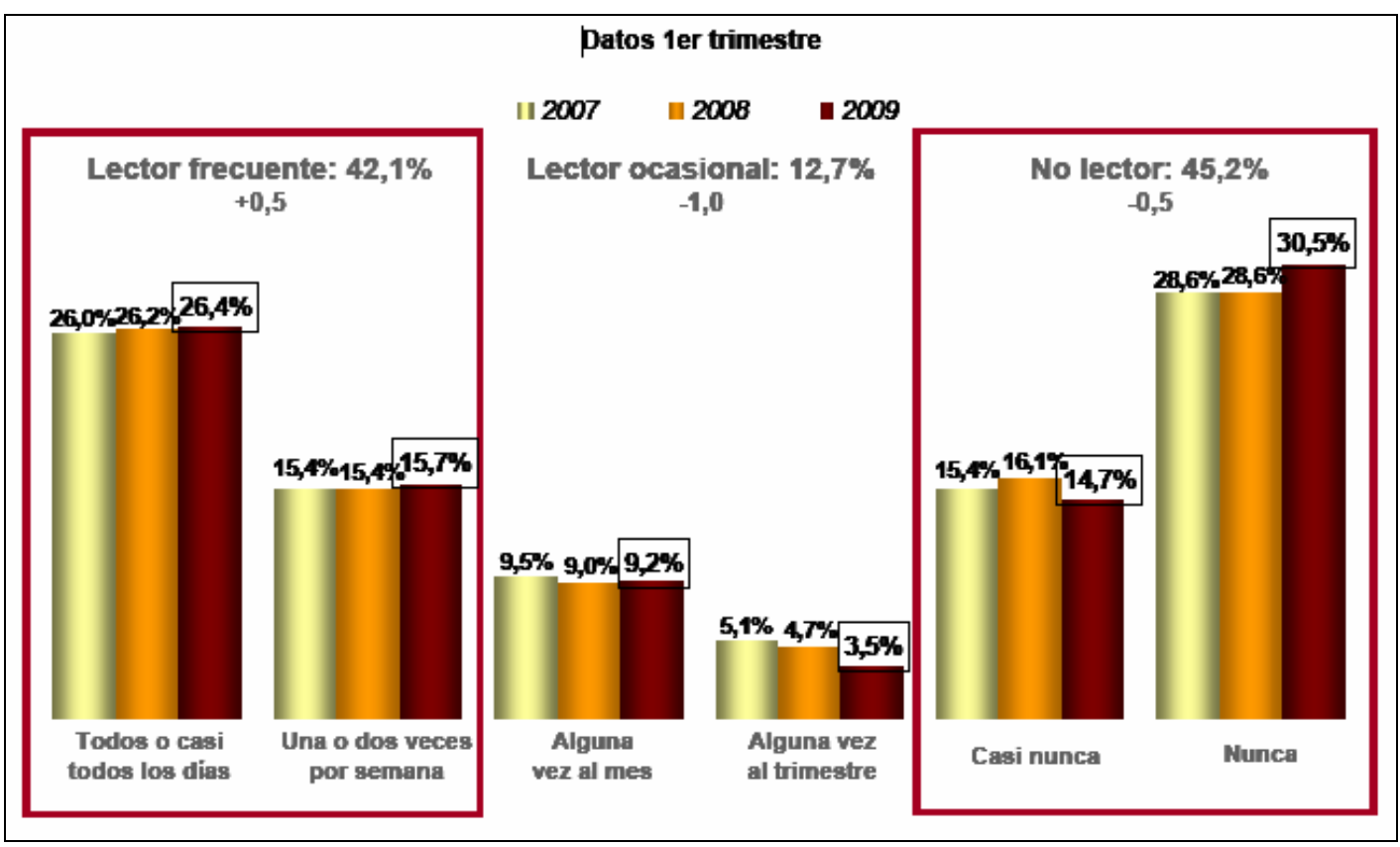

Tabla 1. Barómetro de hábitos de lectura en el primer trimestre del 2009. 
Los lectores frecuentes dedican a la lectura unas seis horas semanales y la principal motivación es el placer de la misma. El $88,0 \%$ de la población lectora lee por entretenimiento.

Las estadísticas sobre hábitos de lectura en la población escolar son difíciles de elaborar, pues el niño que dice leer, posiblemente lo hace por las necesidades del currículo escolar, pero estas lecturas no responden a lo que es un hábito lector. Entre los jóvenes de 14 a 24 años, un 22,1\% lee por motivos de estudio.

Al analizar la relación entre el hábito lector y el núcleo de residencia, los datos del Barómetro destacan la diferencia en el porcentaje de lectores en el ámbito rural y el urbano. Se lee más en las poblaciones de mayor tamaño.

Los que habitan en poblaciones de mayor número de habitantes superan en más de 20 puntos a los de hasta 10.000 habitantes -donde sólo lee el 45,9\% de la población, frente al $67,5 \%$ que lo hace en núcleos de más de un millón de habitantes- sin que en las series estudiadas hasta ahora, se aprecie una mejora de la tasas de lectores en las poblaciones más pequeñas, sino todo lo contrario.Estas zonas concentran el $21,4 \%$ de la población española, de ahí la importancia de potenciar en las mismas las campañas de fomento de la lectura.

En cualquier caso, hay que destacar que aunque el hábitat es importante, al estudiar las prácticas lectoras, estás se explican no tanto por el tamaño del medio poblacional como porque en los núcleos rurales y de menor tamaño concentran más población de Tercera Edad y sin estudios.

Como dato curioso, el Barómetro pone de relieve que el índice de lectura se dispara al $74,5 \%$ entre los lectores de periódicos y al $44,5 \%$ entre los de revistas y también que un $18,8 \%$ leen libros, periódicos y revistas a través de Internet y desde el mismo canal, el $14,0 \%$ lee cómics.

Contrastando con esos datos estadísticos, la producción editorial de libros infantiles y juveniles sigue un ritmo desproporcionado: anualmente se publican más de cinco mil títulos. Este elevado número de publicaciones puede generar cierta confusión en los padres y en los educadores escolares, e incluso en los libreros, a la hora de orientar la lectura de sus hijos y de sus alumnos: es difícil acceder, con la suficiente profundidad, a todo lo publicado, y distinguir el buen libro del malo; resulta por tanto complicado elegir y recomendar lo mejor y más adecuado para cada uno.

Y, sin embargo, como indicaba Pastor $(2000,56)$ esta elección y orientación resultan fundamentales, especialmente para los que se están iniciando en el hábito de la lectura. En esos inicios es muy importante que las primeras lecturas sean atractivas, capaces de llamar y mantener la atención y el interés del lector novel; que su lenguaje, vocabulario, estilo..., se adecue a su edad; que la temática responda a sus intereses y madurez; etcétera. En caso contrario, es fácil sembrar la decepción (con dos o tres decepciones de este tipo, se corre el riesgo de perder un lector, suponiendo un posible fracaso personal, con lo que esto supondrá para su futuro crecimiento personal). 
Junto a esta necesidad de orientación, cada vez es mayor el número de padres que solicitan estrategias concretas, sencillas y eficaces, que les permitan realizar con sus hijos una animación lectora y conseguir despertar en ellos el deseo y el gozo de leer.

Aunque no existen fórmulas infalibles, ni se ha encontrado ningún sortilegio que pueda convertir de la noche a la mañana a una persona en amante de los libros, sí conocemos técnicas y procedimientos que pueden facilitar esta importante acción educativa de la familia: fomentar la afición y el gozo por la lectura.

A través de la lectura llegan a la persona un cúmulo de bienes que la mejoran, proporcionando información (instrucción), formándola (educa), creando hábitos de reflexión, análisis, esfuerzo, concentración... y recrea, hace gozar, entretiene y distrae (Pastor, 2000, 17-20).

- La lectura ayuda al desarrollo y perfeccionamiento del lenguaje. Mejora la expresión oral y escrita y hace el lenguaje más fluido. Aumenta el vocabulario y mejora la ortografía.

- La lectura mejora las relaciones humanas, enriqueciendo los contactos personales.

- La lectura da facilidad para exponer el propio pensamiento y posibilita la capacidad de pensar.

- La lectura es una herramienta extraordinaria de trabajo intelectual ya que pone en acción las funciones mentales agilizando la inteligencia. Por eso tiene relación con el rendimiento escolar.

- La lectura aumenta el bagaje cultural; proporciona información, conocimientos. Cuando se lee se aprende.

- La lectura amplía los horizontes del individuo permitiéndole ponerse en contacto con lugares, gentes y costumbres lejanas a él en el tiempo o en el espacio.

- La lectura estimula y satisface la curiosidad intelectual y científica.

- La lectura despierta aficiones e intereses.

- La lectura desarrolla la capacidad de juicio, de análisis, de espíritu crítico.

- La lectura fomenta el esfuerzo pues exige una colaboración de la voluntad. La lectura exige una participación activa, una actitud dinámica. El lector es protagonista de su propia lectura, nunca un sujeto paciente.

- La lectura potencia la capacidad de observación, de atención y de concentración. 
- La lectura facilita la recreación de la fantasía y el desarrollo de la creatividad. El lector, durante la lectura, recrea lo que el escritor ha creado para él.

- La lectura favorece el desarrollo de las virtudes morales siempre que los libros se seleccionen adecuadamente. Las lecturas proponen modelos para admirar e imitar; y, mientras los modelos vivientes (padres, profesores, etc.) pasan, los protagonistas de los libros permanecen.

- La lectura es un medio de entretenimiento y distracción, que relaja, que divierte.

- La lectura es una afición para cultivar en el tiempo libre, un hobby para toda la vida. Una afición que puede practicarse en cualquier tiempo, lugar, edad y situación....

Es así como la lectura se presenta ante las personas, como una necesidad para interactuar con el entorno, tomar decisiones y continuar su proceso de formación. En este sentido, el lector competente no es aquel que puede llegar tan sólo al gusto literario (si acaso la expresión significa algo concreto), sino quien puede transitar por un amplio elenco de textos, obteniendo lo que les es característico.

La escuela tiene un papel fundamental en la incorporación de las personas al bien de la lectura y al parecer en ésta se implica en gran medida el vínculo de las mujeres y los hombres con el texto. Algunas líneas de investigación en la formación de hábitos lectores indican que la escuela es responsable en gran medida de que la lectura sea una experiencia aversiva o apetecible.

Si la escuela asume la lectura como una actividad eventual o rutinaria, ajena a los intereses cotidianos y vivos de los alumnos, probablemente no colabore en la formación de lectores.

De igual modo, si el docente no muestra aprecio por la lectura en su propio proceso de formación humano y profesional, difícilmente podrá persuadir a los estudiantes de las bondades de esta actividad. "El lector no nace, se hace. Es el resultado de un largo proceso de intencionalidad docente" (Díaz, 1996, 8).

En la lectura, pues, las profesoras y profesores de educación básica tienen una de sus responsabilidades más importantes, ya que su tarea concreta, más allá de lo dictado en el currículo o la demanda de la sociedad, consiste en impulsar el acceso de los alumnos al conocimiento a través del empleo adecuado de la información.

Respecto al papel del docente en la formación de hábitos lectores, Tébar refiere algunas de las conclusiones del "Informe Lundberg y Linnakylä" (1993), correspondiente a un estudio que "intenta establecer la relación que existe entre las lecturas de los profesores y su estilo de enseñanza":(Tébar, 1996, 136).

Uno de los resultados especialmente interesante es la correlación entre las lecturas frecuentes en cualquier campo y los estilos de enseñanza. Los profesores que leían con cierta frecuencia sobre educación, literatura o ciencia, tendían ha: tener más discusiones sobre libros, conocer los intereses de los estudiantes y hacer uso de dichos intereses; enfatizar las habilidades relacionadas con el uso de la biblioteca, 
hacer mayor uso de materiales preparados por ellos mismos. Se puede decir, por tanto, que los profesores que leen más, tienden a enseñar en un estilo que sugiere que la lectura es un proceso constructivo y activo.

Como se puede adivinar a partir de las declaraciones anteriores, la lectura debe ser una actividad habitual en el aula, donde ha de reflejarse la diversidad de textos disponibles en el entorno, con la conciencia de sus diferentes destinatarios, propósitos, formatos, registros lingüísticos y contenidos, pues de ello depende la elección de un "plan lector".

Justamente el predominio de la literatura, más concretamente de una manera de entender la literatura, ha sido durante mucho tiempo uno de los obstáculos más importantes para conceder oportunidades al tratamiento de otros materiales de lectura en el aula. Es decir, al respetar, lo denominado por Hauser, "lo literario" durante décadas enteras, se tuvo menos en cuenta a todos los demás tipos de texto.

Esa supremacía parece un reflejo tardío de la cultura humanística que dio origen a las instituciones educativas modernas, cuyo concepto de la literatura como algo artístico, se basó en el academicismo del siglo XVIII. Este hecho se acentuó en las escuelas normales por su carácter normativo, el cual se ajusta a la posición del academicismo.

Las reacciones en contra de éste, libradas desde el terreno de la creación artística y la historia y crítica del arte, no influyeron de manera decisiva en el magisterio. Sólo muy tarde se asimiló la rebelión romántica del siglo XIX, cuyos rasgos se manifiestan todavía en la contextura estética del docente contemporáneo en México y otras naciones (Hauser, 1998, 70).

Del academicismo y el romanticismo, por irreconciliables que sean a la luz de la historia del arte, surgen los elementos que explicarían la supremacía del texto literario en el aula, todavía en fechas recientes. El academicismo aporta un marco preceptivo que permite definir sin dificultades aparentes, qué es y qué no es lo literario: qué amerita leerse y qué es prescindible. Este marco ofrece certidumbre, un elemento que facilita la enseñanza cuando ésta se entiende como una actividad acrítica. El romanticismo, por su parte, aporta una actitud, interpretada como complementaria, que se expresa en nociones como "la emoción", "la sensibilidad", "la belleza".

Así, mientras por un lado el tratamiento del texto literario permite, aparentemente, la identificación de elementos objetivos (las figuras retóricas y los géneros literarios), por otro lado, al apelar a la subjetividad enraizada en el romanticismo, queda abierta toda posibilidad de interpretación del texto pues "la emoción", "la sensibilidad" y "la belleza" descubiertas en el texto dependen de cada lector.

Cuando tuvo lugar la reforma curricular del 81 en España, el texto literario conservó su lugar prominente entre los materiales de lectura, ya que a la par de la adopción de la gramática estructural se adoptaron los principios del análisis estructural de la literatura, desarrollado en París, Praga y Francfort (citados en Tébar 1996). En una mayoría de los casos, la lectura se limitó a la detección de los elementos 
estructurales del texto; esto es, a una descripción de la obra a partir del sustento objetivo de lo escrito.

Cabe aclarar que no se pone en duda la importancia del estructuralismo como método de análisis literario, pues sin él sería imposible comprender el desarrollo de las teorías literarias posteriores, pero su aplicación en la enseñanza no se tradujo en la formación de mejores lectores, ni dio claridad a los docentes acerca de la importancia de la lectura. Leer no es describir lo leído, es interiorizarlo.

Por lo anterior, la reforma curricular del 93 no debe comprenderse como "un cambio", como la incorporación a "una moda": comporta un replanteamiento del para qué de la lectura, y a partir de esa cuestión, una reflexión acerca de cómo se lee (Díaz, 1996, 23).

Tal replanteamiento afecta al total de las fases del proceso educativo. Significa recuperar la mayor cantidad posible de materiales de lectura, implica abordar su contenido de manera estratégica y supone replantear las prácticas evaluativas. Respecto al último punto es de subrayarse que un instrumento centrado en los aspectos descriptivos de un texto sería ajeno a la propuesta actual: el tipo de instrumento consecuente debe explorar si los estudiantes son capaces de alcanzar el contenido del texto, así como el proceso a través del cual lo logran.

Sin duda no es la lectura el único proceso de alta complejidad que es capaz de desempeñar el ser humano, pero su importancia cultural y civilizadora es en tal medida importante que en este momento constituye uno de los tópicos de mayor importancia en la agenda educativa.

Tébar (1996, 135), puntualiza que la importancia de la lectura radica en lo siguiente:

- Mediante la lectura se accede a un vasto mundo de informaciones, las cuales son necesarias para estar al día y de esa manera responder a las exigencias sociales e intelectuales.

- En el ámbito escolar, la lectura es un instrumento fundamental para el aprendizaje posterior, de tal manera que las dificultades de lectura producirán problemas porque obstaculizan el aprovechamiento escolar.

- La lectura implica una variedad de procesos y destrezas cognitivas: atención, percepción, memoria, etc.

La adquisición de la habilidad lectora es un derecho humano fundamental y un requisito básico para el desarrollo individual y de las naciones. La habilidad de leer ya no es un hecho individual, tiene repercusiones sociales, es por ello por lo que las naciones demuestran un especial interés en su desarrollo.

El énfasis en el tema de la lectura se corresponde con la cuantiosa investigación llevada a cabo en el campo, desde hace casi tres décadas. De ésta han surgido un conjunto de conclusiones que comienzan a ser capitalizadas por la Didáctica. Es importante destacar que las teorías cognitivas del proceso lector se han desprendido 
por completo de las aproximaciones precedentes, relacionadas con la hermenéutica, las teorías literarias y la psicometría.

Se ha señalado que una de las aproximaciones al estudio del texto parte de la hermenéutica. Esta disciplina surgió en la Edad Media en el seno de la Iglesia católica, con el propósito de explicar el correcto significado de las Sagradas Escrituras (Dhondt, 1998, 60). El supuesto de este método consiste en plantear que si las Sagradas Escrituras son resultado de una revelación divina, su significado no puede quedar sujeto a la interpretación de ningún lector, pues su significado es categórico, no relativo. Es decir, el texto posee todas las claves para alcanzar su sentido, el cual es único. Dentro de la hermenéutica, la acción de alcanzar el sentido del texto se llama exégesis, vocablo de origen griego que indica guiar, exponer, explicar.

De su contexto original, la hermenéutica fue trasladada al estudio de otros textos, dando pie a enfoques formalistas de la lectura, pues el supuesto de este método (que el texto posee todas las claves para su interpretación) obliga a considerar al escrito como el único elemento referencial para su comprensión: se piensa que ni el lector, ni el contexto, intervienen en la elucidación del significado del texto.

Es fácil entender que a lo largo de todo el siglo XIX, cuando las disciplinas humanas pretendieron equipararse con las ciencias naturales en cuanto al uso de un criterio de objetividad, para así legitimar su propia búsqueda del conocimiento, aquellas relacionadas con la lectura adoptaron enfoques formalistas con la estéril intención de suprimir la intervención de la subjetividad portada por el lector.

Por su parte, una mayoría de las teorías literarias descansan en bases formalistas, pero en éstas lo más importante es según Hauser $(1998,75)$ :

- que no aportan métodos generalizables a otros tipos de texto.

- que se plantean como problema la demostración o estudio de los valores estéticos de las obras literarias.

Al considerar como una tarea importante de la escuela, la incorporación de las personas a las expresiones del arte, desde mucho tiempo atrás se han introducido en el currículo criterios y categorías provenientes de alguna teoría de la literatura. Esta decisión no es perniciosa en sí misma; antes resulta consecuente con los fines sociales de la educación, pero a menudo ha implicado esquivar otros materiales de lectura. Cuando no ha ocurrido así, el inconveniente ha consistido en convertir los elementos de las teorías literarias en sustento de "teorías" de la lectura.

Es importante subrayar que el objeto de estudio de estas teorías es el texto literario, el cual representa una organización lingüística que involucra procesos de expresión, creación y comunicación, así como una propuesta de connotación cultural que lo diferencian de los textos expositivos o utilitarios. Las teorías literarias abordan, precisamente, alguno o algunos de estos aspectos (Pérez, 2001, 27). De acuerdo con sus fundamentos, las teorías literarias pueden suponer que los valores estéticos son intrínsecos o extrínsecos; algunos enfoques concilian ambas posiciones. Las teorías literarias basadas en el primer supuesto, examinan la forma del texto y la 
función de sus elementos constitutivos. El análisis de las figuras retóricas (metáfora, símil, prosopopeya...), así como del género literario, cobran gran relevancia para estos enfoques. Por su lado, las teorías que parten del segundo supuesto estudian la obra en relación con la historia de la literatura, las circunstancias personales del autor o las del momento histórico-social. La Estética, el Psicoanálisis, la Historia, la Sociología y la Antropología, entre otras disciplinas, constituyen un apoyo fundamental en este caso. Por último, los enfoques eclécticos reúnen aportes de una y otra postura con el propósito de explicar el mérito de una obra literaria.

Así pues, existe un error de principio cuando se adopta una teoría literaria como base de una didáctica de la lectura, o cuando se presume que el conocimiento de alguno de sus elementos (como las figuras retóricas, que han estado presentes en el currículo durante décadas) alude a las habilidades lectoras de los alumnos. No obstante, en numerosas ocasiones ha existido este equívoco, cuyo resultado más grave ha sido el alejamiento de los estudiantes de la lectura en general, pues al presentarla en un marco "analítico" se transmite la idea de que lo sustancial de la lectura no es acceder al contenido, sino a consideraciones sobre la forma 0 al conocimiento del contexto.

Finalmente, la psicometría se interesa en lo que llama "razonamiento verbal" en la medida que a través de aspectos lingüísticos pretende obtener un indicio de la percepción, memoria y/o inteligencia de los sujetos. En este sentido, la psicometría no estudia la lectura, aunque utilice textos, sino procesos intelectuales. En su indagación de la psique, la psicometría desarrolló una metodología de gran importancia, en la cual se contemplan los test de razonamiento verbal. Los ejercicios de sinonimia y antonimia, las analogías y variantes simples del test de cloze (Condemarín y Milicic, citados en González, 1988) o de paráfrasis de textos fueron acreditados por la psicometría como recursos válidos para realizar inferencias acerca de los atributos intelectivos de los sujetos.

Por el rigor de su metodología, derivado de un soporte científico, este campo de la Psicología tuvo un impacto sin precedente en los modelos educativos desde los años 40 , de ahí que se hayan trasladado muchos de sus aspectos a los programas de instrucción, en ocasiones de manera acrítica. Para la comunidad educativa actual es un hecho comprobable el vigor que tienen aún varios supuestos de la psicometría, tanto en la configuración teórica de la docencia por parte de profesoras y profesores, como en su práctica misma.

A diferencia de las perspectivas anteriores, el problema que han abordado las teorías cognitivas es cómo indagan las personas el contenido de un texto, a través de qué recursos cognitivos lo hacen y de qué modo puede optimizarse tal proceso. En virtud de la novedad del campo de estudio, así como de una natural depuración de las metodologías empleadas, existen divergencias entre los teóricos, pero de igual modo existen coincidencias que propician el trabajo de investigación.

La primera de éstas consiste en definir el proceso lector como una actividad compleja, orientada por los intereses y la motivación del sujeto, que tiene como propósito obtener los significados del texto; la ejecución de dicha actividad involucra varios procesos intelectuales de distinto nivel. Dichos procesos tienen lugar en el sujeto, de modo que su realización efectiva sólo es observable de manera indirecta, 
interpretando los productos logrados por el lector: las inferencias y los significados que atribuye al texto.

\subsection{Arquitectura Funcional de la Lectura}

La lectura estimula y satisface la curiosidad intelectual y científica. La curiosidad no se puede forzar, hay que despertarla. Y la curiosidad del lector es insaciable; leyendo va encontrando respuestas a sus interrogantes, al tiempo que genera nuevas preguntas. "Estimular la lectura será pues, promover interrogantes" (G. Janer Manila, citado en Pastor, 2000).

Existe un consenso general al considerar la lectura como una actividad que incluye varios "niveles" o componentes de procesamiento. Una buena teoría de la comprensión debe incluir una arquitectura funcional (de Vega, Carreiras, GutiérrezCalvo y Alonso 1990, 19).

Para establecer esta arquitectura se deben satisfacer al menos tres tipos de objetivos teóricos relacionados entre sí:

- Identificar los componentes cognitivos.

- Establecer la disposición temporal de los componentes cognitivos. En dos mecanismos o respuestas habituales:

- Modo de procesamiento Serial, siguiendo un turno predeterminado en su operación

- Modo de procesamiento Paralelo, donde los mecanismos se solapan temporalmente.

- Determinar el modo en que los componentes se comunican entre sí.

Para los investigadores cognitivos, la lectura implica la puesta en marcha de procesos en dos niveles fundamentales: el de los microprocesos y el de los macroprocesos. Los microprocesos se relacionan con la decodificación de grafías a fonemas, de sílabas a palabras, y de palabras a enunciados. Los macroprocesos son operaciones cognitivas relacionadas con la representación mental de la información contenida en un texto.

El solo estudio de los microprocesos constituye un vasto campo de investigación, en el cual se encuentran comprometidos muchos investigadores en el mundo. De acuerdo con De Vega, Carreiras, Gutiérrez-Calvo y Alonso $(1990,18)$ y colaboradores, al interior de estos estudios se reconocen dos tendencias:

- Modelo Modular. Investigadores que plantean la existencia de una línea continúa entre los microprocesos. 
- Modelo Interactivo. Investigadores que plantean la posibilidad de "saltos" y desfasamientos entre un microproceso y otro.

Los microprocesos de los que se está hablando son los siguientes:

- Percibir los rasgos visuales del texto;

- Identificar las letras;

- Asociar las letras con fonemas;

- Constituir sílabas;

- Constituir palabras;

- Atribuir un significado a cada palabra;

- Identificar enunciados;

- Atribuir un significado al enunciado.

De acuerdo con De Vega et al., J. A. Fodor (1990, 22) identifica cada microproceso como un módulo, a los que define como "mecanismos altamente especializados", pues cada uno "ejecuta una operación única". Para funcionar cada módulo, requiere la información del módulo precedente (inputs). Estos autores indican que las hipótesis sobre la arquitectura funcional de la comprensión se pueden reducir a dos:

- La comprensión modular

- La concepción interactiva

Normalmente, cualesquiera que sean los niveles de análisis tratados, los modelos propuestos suelen ser versiones de una de estas dos alternativas. 


\section{A. Concepción modular}

El término "modular" fue popularizado por Fodor (1983, citado en de Vega et al., 1990) quien postuló que los mecanismos de análisis de entradas, entre los que incluye los sistemas perceptivos y el lenguaje, son modulares. Este concepto supone que el sistema está compuesto de unidades funcionales autónomas o módulos. En la figura 1 se puede observar una posible concepción modular de la comprensión. Los niveles o módulos que se muestran podrían ser otros, pero lo importante es la arquitectura general.

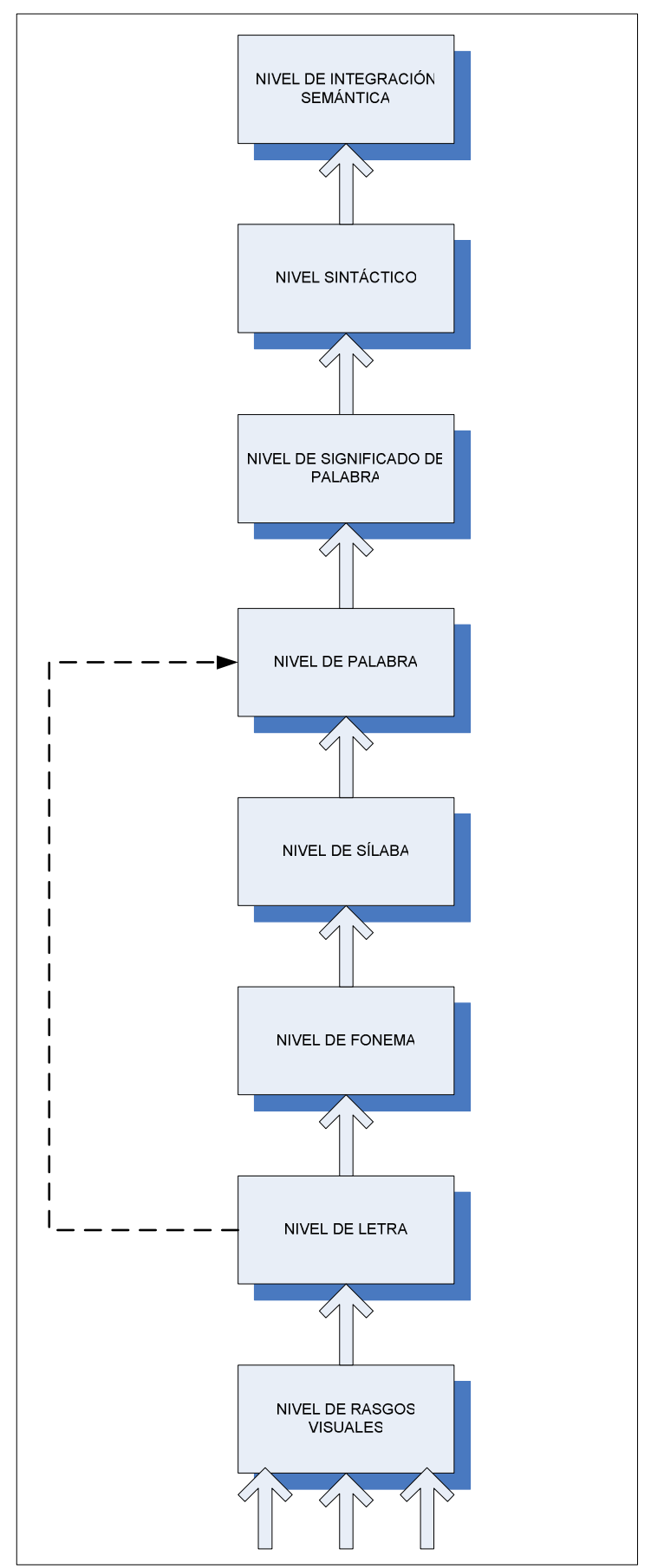

Figura 1. Concepción Modular. Fodor (1983). 
El flujo de información discurre sólo desde los módulos inferiores a los superiores. De esta forma los rasgos que analiza un procesador de alto nivel no deberán influir nunca en las funciones de un procesador de nivel inferior. Los módulos son mecanismos altamente especializados, de modo que cada módulo ejecuta una operación única. Además, los módulos funcionan de forma automática u obligatoria. En presencia de una entrada adecuada, este debe ejecutar sus funciones de modo inevitable y a gran velocidad.

El sujeto tiene acceso limitado a las representaciones generadas por los módulos. El lector es habitualmente consciente del significado del texto, pero las representaciones intermedias generadas por los módulos no alcanzan el umbral de la conciencia y se desvanecen rápidamente en la memoria. En muchas ocasiones no se es consciente de que una palabra puede tener varias acepciones, ni de que existe una selección de una de ellas para cada contexto. La impresión subjetiva es que durante la lectura de un texto, las palabras no encierran ambigüedad y que su significado se "dispara" por si mismo.

Muchos autores, citados en de Vega et als (1990), apoyaron la teoría de concepciones seriales de los procesos mentales en los primeros años de la Psicología Cognitiva (Sternberg, 1969; Chase y Clark 1972), incluso existen algunos modelos seriales de lectura (Laberge y Samuels, 1974) y la comprensión (Forster y Olbrei, 1973).

Hoy en día casi nadie acepta una arquitectura totalmente serial. Primero porque seria lenta e ineficiente, ya que las operaciones de un nivel determinado no podrían iniciarse hasta culminar todas las operaciones de los niveles previos, provocando tiempos de espera excesivos y una sobrecarga en la memoria operativa. $Y$ segundo, se opone a lo que se sabe sobre la organización funcional del cerebro, que opera como una red de miles de millones de procesadores interconectados que operan en paralelo, seguir viendo el sistema cognitivo como un conjunto de mecanismos que operan por riguroso turno no tiene mucha justificación.

\section{B. Concepción interactiva}

La concepción interactiva asume un procesamiento en paralelo entre los diferentes niveles, y además una comunicación bidireccional entre ellos.

Para los estudiosos ubicados en la concepción interactiva, los microprocesos no tienen carácter obligatorio, ya que pueden darse "saltos" y traslapes. Es decir, pueden funcionar en paralelo, y no exclusivamente de manera serial. El modelo interactivo es sostenido, entre otros autores por McClelland (citado en Tébar, 1996). Los "interactivistas" concuerdan en la existencia de fases o módulos (los microprocesos), pero descartan la restricción del flujo de abajo a arriba. Sostienen que "cada nivel consulta a otros niveles para realizar sus funciones".

En la figura 2 se puede ver una representación de un posible modelo interactivo de comprensión. 


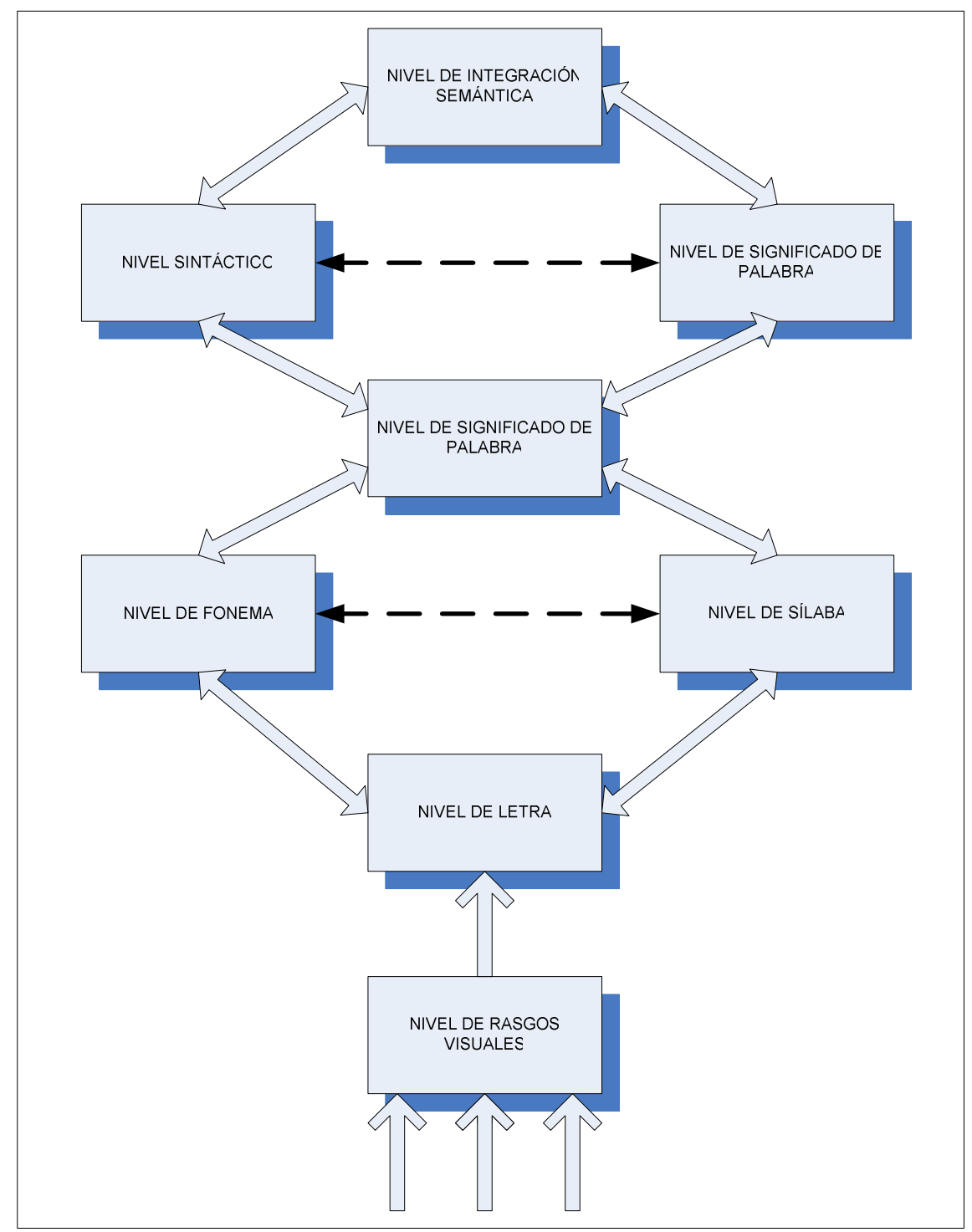

Figura 2. Concepción Interactiva.

Como se observa, los elementos son los mismos que los de la vertiente serial, pero la relación entre éstos es dinámica pues admite solapamientos, así como tareas simultáneas. El esquema muestra que se conserva el criterio de complejidad.

En cierto sentido siguen existiendo módulos pero se relaja la comunicación unidireccional. Aun así la comunicación bidireccional solamente se realiza con los niveles continuos (McClelland, 1987 citado en de Vega et al., 1990)

Los principales argumentos que se ofrecen a favor de la concepción interactiva se relacionan con la existencia de fenómenos contextuales en la comprensión, que sugieren procesos de arriba-abajo. De esta forma, las palabras significativas se leen más deprisa que las pseudopalabras, lo cual induce a pensar que el procesador léxico (responsable de reconocer las palabras) trasvasa información al procesador fonológico. Otro ejemplo tiene lugar en la lectura de material 
manuscrito: algunas letras suelen estar muy distorsionadas y, sin embargo, el lector es capaz de leerlas aprovechando el contexto de la palabra o de la frase en que aparecen (Rumelhart, 1985 citado en, de Vega et al., 1990). Finalmente, existen también efectos contextuales entre niveles superiores, de modo que ciertos textos construidos con frases intencionalmente ambiguas se entienden y se recuerdan mejor simplemente proporcionando al lector un título que rompe la ambigüedad como indicaban Bransford y jonson (1973, citados en de Vega et al., 1990).

A pesar de las restricciones, el efecto contextual podría explicarse: el módulo de palabras es un procesador probabilística que admite información incompleta y selecciona la hipótesis léxica que mejor se adecua a la información recibida del modulo de letras. No es preciso, por tanto, postular una retroalimentación del procesador léxico sobre el procesador de letras.

El constructor con que trabaja esta línea de investigación, "especula con el carácter biogenético de los módulos", pues plantea que éstos constituyen en realidad una especie de órganos psíquicos "neurológicamente bien definidos y que se desarrollan tempranamente en los niños, como corresponde a dispositivos de origen filogenético". (De Vega et al., 1990).

En realidad, las diferencias entre la concepción modular y la interactiva se reducen casi exclusivamente a las direcciones admitidas para el flujo de información. La decisión entre interacción o modularidad no es fácil ya que los datos empíricos disponibles hasta el momento son interpretables desde ambas concepciones (de Vega et al. 1990).

La representación léxica desempeñaría un importante papel en la integración de información lingüística y no lingüística. No sólo serviría de puente entre los sonidos y el significado, sino que además, ofrecería un marco en el que valorar las distintas interpretaciones sintácticas (Tyler, 1989, citado en González, 1992).

En el modelo propuesto por este autor se afirma que el análisis se realiza en dos etapas. En la primera de las estructuras sintácticas, no desempeña ninguna función la información léxica. Sí sería importante en la segunda fase en la que esas estructuras son revisadas para comprobar su consistencia interna.

Aunque la discusión entre los dos enfoques anteriores es vigente, la perspectiva interactiva parece ir ganando terreno a causa de que explica más satisfactoriamente algunos fenómenos del proceso lector. 


\subsection{Procesos Psicológicos que Intervienen en la Lectura}

Desde el punto de vista de la psicología de la lectura se podía dividir el proceso de leer en varios procesos claramente diferenciados pero a su vez fuertemente unidos:

- Procesos Perceptivos

- Procesamiento Léxico

- Procesamiento Sintáctico

- Procesamiento Semántico

\subsubsection{Procesos Perceptivos}

La primera operación que se tiene que realizar al leer es la de extraer los signos gráficos (letras) para su posterior identificación. Esta tarea a su vez se puede subdividir en varias operaciones, siendo la primera de ellas la de dirigir los ojos a los diferentes puntos del texto.

\subsubsection{Movimientos saccádicos y fijaciones}

Cuando se lee se tiene la falsa sensación de que nuestros ojos perciben las palabras a medida que avanzan por el texto de forma continua y uniforme a través de las líneas escritas. Realmente, se sabe desde 1887 (cuando Javal se dedicó a observar los ojos de las personas mientras leían), que los ojos avanzan a pequeños saltos, estos saltos son conocidos como movimientos saccádicos, entre salto y salto existe un periodo de fijación en el cual los ojos permanecen inmóviles (Mitchell, 1982, citado en Cuetos, 2006).

Los periodos de fijación permiten al lector percibir un trozo del material escrito, y los movimientos saccádicos le trasladan al siguiente punto del texto con la finalidad de que quede situado frente a la fóvea, zona de máxima agudeza visual, y pueda continuar asimilando la información. "De esa forma el proceso que realiza una persona durante la lectura consiste en fijar un trozo de texto; a continuación, mediante un movimiento saccádico, pasar al trozo siguiente, en donde permanece con sus ojos fijos otro intervalo de tiempo; nuevo movimiento saccádico y nueva fijación, y así sucesivamente mientras continúe leyendo" (Cuetos, 2006, p. 23).

Los periodos de fijación oscilan entre 200 y 250 milisegundos (Duna y Pirozzolo, 1984; Colmes y O'Reagan, 1981, citados en Cuetos, 2006) y los movimientos saccádicos entre 20 y 40 milisegundos (Duna y Pirozzolo, 1984, citados en Cuetos, 2006). Esto indica que aproximadamente el $90 \%$ del tiempo se emplea en percibir el material y un $10 \%$ en cambiar buscando nueva información. Hay que considerar que estos valores no son fijos y dependen enormemente de cada persona y del texto que se lee en cada momento,

De forma que se podría definir dos factores: 
- Distribución de las fijaciones sobre las páginas. Lugares a los que se dirige el ojo en los movimientos saccádicos.

- Cantidad de información recogida durante la fijación. Se cree que la información recogida durante los movimientos saccádicos no contribuye para el procesamiento del material escrito.

Una característica importante de los movimientos saccádicos es que no son de naturaleza balística, es decir, una vez que se emprende el movimiento ya no se les puede corregir, de manera que la elección del próximo punto de fijación tiene que ser hecha antes de iniciar el movimiento. La mayoría de las personas que investigan sobre los movimientos saccádicos están de acuerdo en que las variaciones, tanto en la duración de las fijaciones como en la amplitud y dirección de los movimientos saccádicos durante la lectura, no son debidas a fluctuaciones arbitrarias, sino que reflejan características distintivas del texto y en consecuencia de los procesos cognitivos.

Una vez que los ojos se detienen en un punto del texto, comienza la recogida de la información. El tiempo que los ojos están detenidos depende del material de lectura. Cuanto más difícil o importante es la lectura mayor es el tiempo de fijación. Por ello, las fijaciones que se producen en los espacios entre oraciones son más cortas que las que se producen en cualquier otro punto del texto (Rayner, 1975; Rayner y McConkie, 1976, citados en Cuetos, 2006). Las palabras largas o raras producen pausas mayores que las cortas y frecuentes (Rayner, 1977; Just y Carpenter, 1980, citados en Cuetos, 2006). Los verbos principales de las oraciones consumen más tiempo que otras palabras similares (Rayner, 1977, citado en Cuetos, 2006). El comienzo de un tema nuevo también supone un tiempo de fijación extra (Just y Carpenter, 1980, citado en Cuetos, 2006).

Las diferencias en las fijaciones no se deben a la operación de extracción en sí, sino que más bien se producen en los niveles superiores, ya que de todo el tiempo que dura la fijación sólo una pequeña parte se emplea en la extracción.

Rayner, Inhoff, Morrison, Slowiaczek y Bertera (1981, citado en Cuetos, 2006), comprobaron experimentalmente que la extracción de la información se produce durante los 50 primeros milisegundo de fijación.

Qué es lo que sucede durante el resto del tiempo es algo que aún no está muy claro, Mitchell (1982, citado en Cuetos, 2006) formuló un hipótesis que dice que esa información se registra sucesivamente en dos almacenes diferentes antes de ser reconocida: primero, se almacena en una memoria sensorial llamada memoria icónica y a continuación pasa a la memoria visual a corto plazo.

En la memoria icónica permanece la información durante un tiempo muy breve, apenas una centésima de segundo, pero conservando la mayor parte de los rasgos del estímulo. Esto sucede porque la memoria icónica tiene una enorme capacidad de almacenamiento, aunque su duración es muy breve: no consigue mantener los estímulos más de $250 \mathrm{mseg}$. En esta memoria no se realiza ningún tipo de interpretación cognitiva, ya que es un almacén que mantiene la información en su 
formato primitivo, tal que aparece (Neisser, 1967; Cuetos, 1983 o De Vega et al., 1984, citados en Cuetos, 2006).

En necesario entonces suponer la existencia de otro almacén capaz de retener la información durante más tiempo, desde el cual se pueda analizar el material. Esta función parece que la realiza la memoria a corto plazo o memoria operativa. Desde la memoria icónica la información pasa a la memoria a corto plazo y desde aquí se llevan a cabo las operaciones destinadas a reconocer esa información como determinada o determinadas palabras.

Las propiedades de la memoria a corto plazo difieren en varios aspectos de las que caracterizan a la icónica. Su duración es mucho mayor, pues los estímulos se pueden conservar perfectamente hasta los 15020 segundos, tiempo suficiente para llevara cabo las principales operaciones. Además en este almacén la información no se destruye con la llegada del material procedente de nuevas fijaciones. En contrapartida, su capacidad es mucho más limitada que la memoria icónica, ya que tiene dificultades para retener más de 6 o 7 estímulos visuales (De Vega et al., 1994, citado en Cuetos, 2006). Por ultimo en la memoria a corto plazo se realizan análisis categoriales del estímulo: si en la memoria icónica la información se almacena como un conjunto de rasgos visuales y su enorme capacidad servía para retener el mayor número de esos rasgos, en la memoria a corto plazo la información se retiene ya como material lingüístico. Esto quiere decir que si en la memoria icónica la letra "b", por ejemplo, se identifica como una serie de rasgos visuales, en la memoria a corto plazo se identifica ya como la letra concreta "b". Para ello obviamente se tiene que consultar algún almacén de memoria a largo plazo en el que se encuentren representadas todas las letras del alfabeto.

\subsubsection{Análisis visual}

En el punto anterior ya se ha hablado sobre el proceso de identificación de los signos gráficos, de las letras, realmente cuando se lee ies necesario identificar las letras que componen las palabras o se reconocen las palabras globalmente a través de sus formas gráficas sin necesidad de identificar cada letra individualmente?

Cabria suponer que si las palabras están formadas por letras, cuando queremos reconocer una palabra tendremos que reconocer las letras que la forman previamente. Existen varios experimentos que se llevan haciendo desde hace tiempo que ponen en entre dicho esto.

En estos experimentos se ha encontrado un fenómeno muy interesante denominado el efecto palabra. Este fenómeno indica que es mas fácil reconocer o encontrar una letra cuando forma parte de una palabra, que cuando esta aparece aislada en una serie aleatoria de letras.

A partir de esta idea se han creado dos hipótesis. 


\subsection{Hipótesis del reconocimiento global de las palabras}

Como indica Cuetos $(2006,27)$, "esta postura se inicio con los trabajos pioneros de Cattell (1886) sobre reconocimiento de palabras", comprobó que los sujetos requerían el doble de tiempo para leer en voz alta letras aisladas que cuando forman palabras. Pillsbury (1897) encontró otro dato que apoyaba esta hipótesis al mostrar brevemente palabras que tenían una letra borrosa por llevar una "x" encima y los sujetos tenían que identificar y además señalar las letras que no fuesen vistas claramente. La mayoría de las veces los sujetos indicaban haber visto claramente las palabras y con todas sus letras en perfecto estado.

Más recientemente Reicher (1969, citado en Cuetos, 2006) creo nuevos métodos que evitaban los problemas criticados en las anteriores investigaciones, basados en presentar series de letras (formando palabras o pseudopalabras) en muy breves periodos de tiempo. Reicher presentaba una serie de letras durante un breve tiempo. Luego se muestran dos letras alternativas para que el sujeto indique cuál de las dos estaba en una posición determinada de la serie. Estas dos letras de prueba se seleccionan teniendo mucho cuidado de que no puedan ser adivinadas. Así, por ejemplo, si se presenta el estímulo ABRIR, las letras utilizadas en la prueba podrían ser: _ R $\mathrm{R}$ __ L, puesto que en ambos casos se forma una palabra (abrir o abril, respectivamente). La ejecución en esta condición se compara con otras condiciones en las cuales las letra $R$ puede ser presentada sin contexto ( R) o formando parte de una no-palabra (AIBR). Con esta metodología, diversos estudios (Reicher, 1969; Smith, 1971; Johnston y McClelland, 1974; Jonson, 1975) siguieron encontrando el efecto de superioridad de la palabra, lo que reforzaba notablemente la hipótesis del reconocimiento global de la palabra.

Las principales dificultades con que se encuentra esta hipótesis es que se ha demostrado repetidamente que se reconoce con mayor rapidez las series de letras que se ajustan a las reglas de ortografía - las pseudopalabras - que las series de letras no relacionadas (McClelland, 1976; Spoehr y Smith, 1975, citados en Cuetos, 2006). En ciertos casos se ha encontrado que se reconocen antes pseudopalabras que palabras familiares (Baron y Thurstone, 1973, citado en Cuetos, 2006).

Por otra parte esta hipótesis no tiene una respuesta clara a la cuestión de qué es exactamente lo que nos permite identificar una palabra. Venezky y Massaro (1976, citado en Cuetos, 2006) exponen una serie de argumentos y datos experimentales que desacreditan la hipótesis anterior. Uno de los argumentos más fuertes es que sin una identificación previa de las letras sería extremadamente fácil confundirse con las palabras que tienen perfiles similares 0 identificar erróneamente una pseudopalabra con su palabra parecida. 


\subsection{Hipótesis de reconocimiento previo de las letras}

El razonamiento en que se basa esta hipótesis es que puesto que las palabras están formadas por un pequeño conjunto de elementos visuales o grafemas, es natural considerar que el reconocimiento de las palabras está basado en la identificación preliminar de las letras.

Los psicólogos alemanes Goldscheider y Müller fueron los principales defensores en el siglo pasado; demostraron que en las exposiciones breves de palabras, los errores aumentaban cuando las letras que faltaban eran las básicas (Venezky, 1984, citado en Cuetos, 2006). Más actualmente, la teoría ha contado con un buen número de seguidores (Adams, 1979; Allport, 1979; Gough, 1972; Henderson, 1982; McClelland, 1976, citados en Cuetos, 2006). Dentro de estos investigadores existen dos modelos o tendencias: los que defienden la idea de que las letras son procesadas serialmente, es decir, de izquierda a derecha (Gough, 1972, citado en Cuetos, 2006) y los que afirman que el procesamiento se produce en paralelo, es decir, todas las letras de la palabra son procesadas simultáneamente (Massaro, 1975; McClelland, 1976, citado en Cuetos, 2006).

Tanto en su forma serial como paralela, la hipótesis de identificación previa de las letras también se cuenta con dificultades. Una de ellas procede de los experimentos con cajas alternadas (por ejemplo "eStudlaNtE"). Smith, Lott y Cronnel (1969, citado en Cuetos, 2006) comprobaron que los sujetos leían más lentamente párrafos presentados en caja alternada que en caja normal. Aunque se podría argumentar que el hecho de que las letras alternantes tengan distintos tamaños puede entorpecer su identificación.

Vellutino (1982, citado en Cuetos, 2006) apunta la posibilidad de que ambas teorías tengan su parte de razón y que el utilizar como unidad de procesamiento la letra o la palabra global depende de la tarea. Varios estudios han demostrado que el nivel de análisis visual puede variar de acuerdo con las demandas de la tarea, implicando que el lector dispone de una variedad de estrategias para reconocer las palabras. Vellutino afirma que la unidad de percepción es relativa y viene determinada por tres factores:

a) el contexto en que se encuentra la palabra

b) las características de la palabra

c) la destreza del lector

Esta teoría es muy razonable, pero lo datos más recientes, procedentes tanto de los experimentos de laboratorio realizados con lectores normales como de los pacientes disléxicos parecen apoyar el reconocimiento previo de las letras.

Pero, ¿de que forma se explican los argumentos de los defensores del reconocimiento global de las palabras? El modelo de activación interactiva (PDP) propuesto inicialmente por McClelland y Rumelhart (1981, citados en Cuetos, 2006) proporciona una buena explicación a estos datos. Según este modelo la causa de que las letras pertenecientes a palabras se identifican mejor que las que aparecen 
aisladas, se debe a que en el primer caso reciben un efecto facilitador procedente del procesador léxico o del nivel de palabra, que no existe con las letras aisladas.

Según el modelo PDP, en la identificación de las palabras intervienen tres niveles: nivel de rasgos, nivel de letras y nivel de palabra.

La figura 3 muestra los tres niveles de procesamiento y la relación existente en entre ellos. Las flechas representan conexiones excitatorias y los círculos, conexiones inhibitorias.

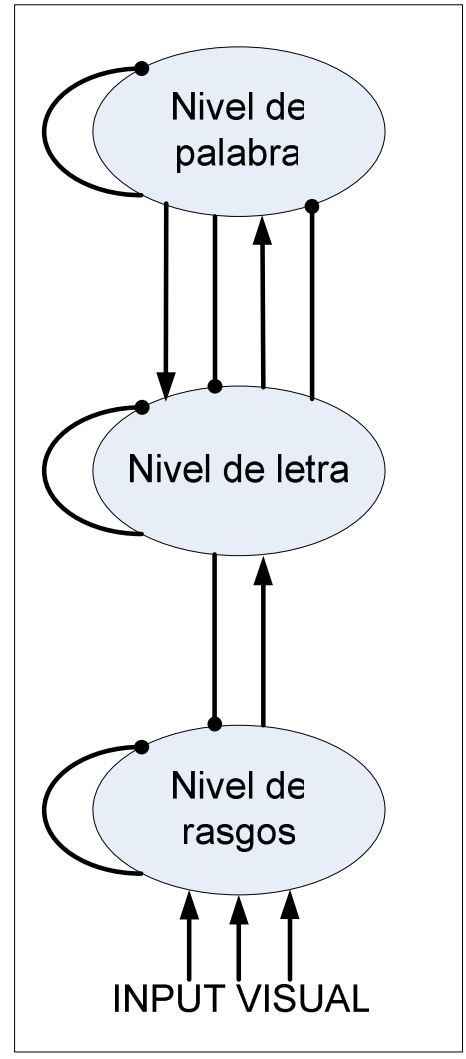

Figura 3. Niveles de procesamiento y relación entre ellos.

Cuando un estímulo llega al sistema se activan ciertos rasgos, que a su vez, envían la activación a todos los nodos letras que contienen ese rasgo. Al mismo tiempo se establecen conexiones inhibitorias con los nodos letra que no poseen esos rasgos. A su vez los nodos de las letras comienzan a enviar activación a los nodos a nivel de la palabra con lo que son consistentes e inhiben a los que no lo son. Además, dentro del nivel de las letras, los diferentes nodos letras intentan inhibirse unos a otros. Cuando se activan lo nodos de nivel de la palabra comienzan a competir unos con otros y a enviar activación a los nodos de nivel de letras. Algo similar ocurre con las letras que a su vez envían activación al nivel de rasgos.

Vistas estas características del modelo se puede entender fácilmente el efecto de superioridad de las palabras: mientras que las letras aisladas sólo reciben activación del nivel de rasgos, las letras que forman parte de una palabra reciben activación de ambos niveles: el de rasgos y el de palabra. Similarmente, también se puede entender por qué es mas fácil identificar una letra perteneciente a una 
pseudopalabra, que una letra aislada o que forma parte de una serie de letras no relacionadas: "las pseudopalabras activan nodos de palabras similares y éstos a su vez activan lo nodos de las letras componentes, con lo cual las letras de las pseudopalabras también reciben activación del nivel de rasgos y del nivel de palabra" (Cuetos, 2006, 31).

\subsubsection{Procesamiento Léxico}

Una vez identificadas las letras que componen la palabra el siguiente paso es el de recuperar el significado de esa palabra. Si se estuviera leyendo en voz alta también habría que recuperar su pronunciación.

Mediante los microprocesos o procesos de bajo nivel el lector reconoce o identifica la palabra escrita (por ejemplo, pato), asignándole un significado (ave que...) y evocando una serie de conocimientos sintácticos (sustantivo, masculino...), pragmáticos (animado, comestible...), etc., sobre esa palabra, a la vez que otros conceptos relacionados con ella (laguna, Donald...) y el código fonológico (/pato/) correspondiente a la misma (Alegría, 1985, citado en Clemente y Domínguez, 1999).

Se puede hacer un análisis del párrafo anterior comparando la idea de Jesús Alegría con otros autores, cuando dice que gran parte de las dificultades en el aprendizaje de la lectura podrían situarse en el proceso de reconocimiento de las palabras (Crowder, 1985, citado en Clemente y Domínguez, 1999).

¿Y por que los investigadores siempre se preocuparon tanto con el reconocimiento de la palabra?

Ellos siempre intentaron durante las últimas décadas, determinar cómo el niño va a encontrar los medios adecuados para realizar esta conexión entre la representación gráfica de las palabras y el conocimiento lingüístico que posee y que le permite dotar de significado a la palabra escrita.

Hay un acuerdo bastante generalizado entre los distintos investigadores en el campo de la lectura (ejemplo: Alegría, 1985; Baron y Treiman, 1980; Coltheart, 1978; Jorm y Share, 1983, citados en Clemente y Domínguez, 1999) a la hora de considerar la existencia de dos vías o estructuras para acceder a esta información sobre las palabras (esto es, a los conocimientos sintácticos, pragmáticos, fonológicos, etc.) que está almacenada en algún lugar de nuestro sistema cognitivo. Este lugar se ha denominado léxico interno. El reconocimiento o la identificación de la palabra escrita consistiría en la activación de una determinada entidad lexical, es decir, en la evocación de todos los conocimientos que el lector tiene en relación con esa palabra.

En el lenguaje oral usamos una representación interna del habla para acceder al léxico interno; esta representación interna ha sido denominada por distintos autores como "código fonológico", "código fonético", "código articulatorio", o "código acústico" (Jorm y Share, 1983, citados en Clemente y Domínguez, 1999). Sin embargo, en el lenguaje escrito podemos disponer de dos posibilidades o estrategias para acceder al léxico interno: 
1. Ruta Léxica. Una de ellas consiste en comparar la forma ortográfica de la palabra con una serie de representaciones almacenadas en la memoria para comprobar con cuál de ellas encaja. La lectura con este sistema supone varias operaciones:

a) análisis visual de la palabra.

b) el resultado de este análisis se transmite a un almacén de representaciones ortográficas de palabras denominado "léxico visual", donde por comparación con las unidades allí almacenadas se identifica esa palabra.

c) la unidad léxica activada, a su vez activará la correspondiente unidad de significado situada en el "sistema semántico".

Si además de comprender la palabra hay que leerla en voz alta, la representación semántica activará la correspondiente representación fonológica, localizada en otro almacén léxico, el denominado "léxico fonológico", y desde aquí se depositará con el "almacén de pronunciación" dispuesta para ser emitida. "A esta ruta se la conoce con el nombre de ruta léxica o también ruta visual” (Cuetos, 2006, 32).

Esta ruta sólo es valida con palabras que el sujeto conoce visualmente. Pero no son validas con palabras desconocidas o pseudopalabras al no tener representación léxica. Sin embargo, el sujeto es capaz de leerlas, de forma que además de la ruta léxica existe otro procedimiento de lectura.

2. Ruta Fonológica. Este procedimiento consiste en identificar las letras de las palabras y transformar estas letras en sonidos para reconocer las palabras a través de los sonidos, tal como sucede en el lenguaje oral. La lectura de este segundo sistema consiste en:

a) identificar las letras que componen la palabra en el sentido de análisis visual.

b) Recuperar los sonidos que corresponden a esas letras mediante un mecanismo denominado: "mecanismo de conversión grafema a fonema".

c) Una vez recuperada la pronunciación de la palabra se consulta el "léxico auditivo" la representación que corresponde a esos sonidos, tal como sucede con el lenguaje.

d) Esa representación, a su vez, activa el significado correspondiente en el sistema semántico.

Para que este sistema funcione es necesario que exista una relación consistente entre los grafemas y los fonemas. 
En castellano se puede leer todas las palabras por la ruta fonológica porque es un idioma transparente en el que todas las palabras se ajustan a las reglas grafema-fonema. Pero en otros idiomas (francés, inglés,...) existen muchas palabras, llamadas irregulares, cuya pronunciación no se ajusta a esas reglas, sino que es arbitraria y sólo se sabe cuando se conoce específicamente esa palabra. Este tipo de palabras solo se pueden leer a través de la ruta léxica.

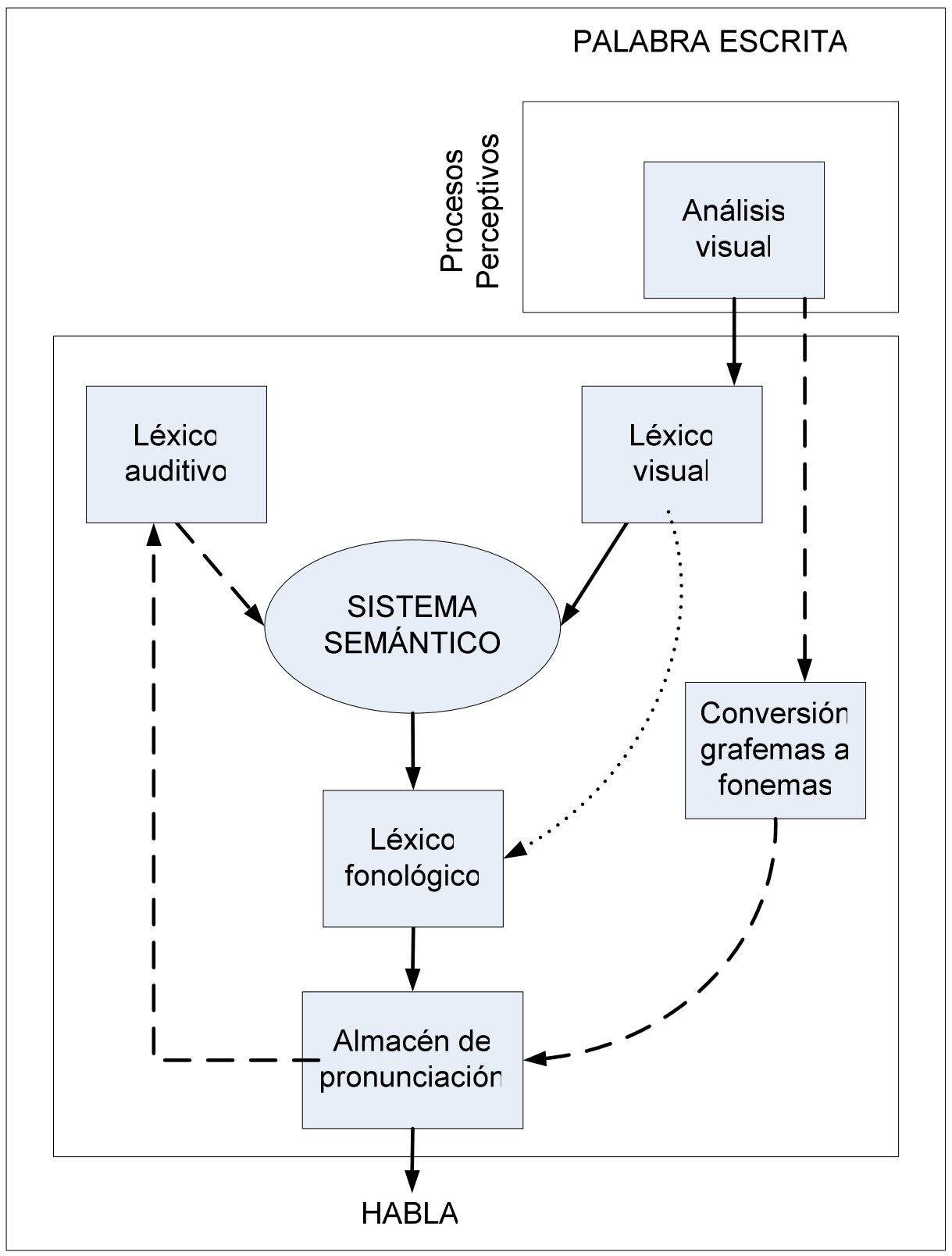

Figura 4. Procesos Léxicos 


\subsubsection{Ruta Visual}

\subsection{Léxico Visual}

En el léxico visual se encuentran representadas las palabras escritas. Se trata de un almacén en el que existe una representación para cada una de las palabras que somos capaces de reconocer visualmente.

El modelo Logogen, creado por Morton (1969, 1979, citado en Cuetos, 2006) consigue explicar sin demasiada dificultad los principales datos experimentales que se han ido obteniendo sobre reconocimiento de palabras. Uno de los hallazgos más importantes es el efecto frecuencia referido a que las palabras más frecuentes se reconocen con mayor rapidez que las menos frecuentes.

Otro importante hallazgo experimental es el referente al efecto contexto (se reconocen más rápidamente las palabras cuando están dentro de un contexto que cuando aparecen aisladas) y al efecto "priming" (cuando una palabra va precedida por otra relacionada).

\subsection{Sistema Semántico}

Cuetos $(2006,36)$, asegura que "se tiene la impresión de que inmediatamente que vemos una palabra escrita accedemos a su significado, en realidad se trata de procesos independientes". El léxico permite identificar la palabra pero no nos indica a qué concepto representa. En ocasiones el lector se puede encontrar con palabras poco familiares que reconoce como perteneciente a su idioma, pero no es capaz de indicar lo que significa. Para consultar el significado hay que consultar con el sistema semántico.

En el sistema semántico se encuentra el significado de las palabras o conceptos. Es único para todas las palabras independientemente de la modalidad por la que se acceda, sea ésta visual, auditiva, pictórica, etc. Se sabe gracias a las investigaciones de Warrington y Shallice (1984, citado en Cuetos, 2006) que el sistema semántico está organizado por categorías, tales como frutas, nombre de animales, etc.

\subsection{Léxico fonológico}

En este almacén se encuentra representadas las pronunciaciones de las palabras. Y, como sucede con el léxico visual, existe un dispositivo para cada palabra con un nivel de activación dependiente de su frecuencia de uso, como indica el hecho de que se tenga más facilidad para encontrar la pronunciación de las palabras más frecuentes. 
Este léxico, aunque sigue muy unido al sistema semántico, es funcionalmente independiente de él. El fenómeno "de la punta de la lengua" muestra casos en los cuales se quiere expresar un concepto pero no disponemos de las palabras adecuadas para expresarlo. Las palabras a las que no se puede llegar son normalmente reemplazadas por otras más generales (eso, o lo que sirve para hacer...). Este problema no se presenta en el sistema semántico porque se tiene claro lo que se quiere decir.

La activación de las entradas léxicas no es un fenómeno de todo o nada, ya que muchas veces se recupera parte de la información de la palabra (tamaño aproximado, sonido inicial o final, etc.) aunque se pueda conseguir la palabra completa, lo que se supone se produce porque se activa parte de la representación.

"Salvo en estos casos, la representación semántica activará a la correspondiente representación fonológica donde se encuentran los sonidos correspondientes a esa palabra, y esos sonidos se depositan en el almacén de pronunciación dispuestos para ser emitidos" (Cuetos, 2006, 37).

\subsubsection{Ruta fonológica}

\subsection{Mecanismos de conversión grafema a fonema}

Este es el proceso encargado de asignar los sonidos a cada una de las palabras que componen la palabra. La evidencia empírica indica que no es un proceso único, sino que está formado por varios mecanismos. Coltheart (1986, citado en Cuetos, 2006) distinguió tres:

a) Análisis grafémico. Se encarga de separar los grafemas que componen la palabra. En castellano la mayoría de las palabras tienen el mismo número de letras que de grafemas (pato), pero existen palabras que no tienen el mismo número (perro). En estos casos es necesario realizar un agrupamiento de las letras a grafemas previo a la conversión a sonido.

b) Asignación de fonemas. Este subproceso es el más importante ya que es el encargado de asignar a cada grafema el sonido correspondiente para cada idioma.

c) Unión de los fonemas. Se encarga de combinar los fonemas generados en el paso anterior para producir la pronunciación conjunta. En los niños que están aprendiendo a leer se observa claramente este fenómeno, leen de forma segmentada y posteriormente vuelven a repetirlos más rápido y es entonces cuando se entiende la palabra.

La pronunciación resultante de este último subproceso se deposita en el almacén de pronunciación. Si la tarea fuera leer en voz alta desde el almacén se enviarán las órdenes a los músculos y articulaciones para generar el sonido. Si por el contrario se trata de una lectura comprensiva desde este almacén se activaría la correspondiente 
representación auditiva en el léxico auditivo, tal como sucede en el lenguaje oral y desde aquí se activaría la representación semántica.

\subsection{Léxico auditivo}

Los datos experimentales y clínicos obligaron a Morton a distinguir dos léxicos diferentes para el reconocimiento de la palabra. Uno para el lenguaje escrito (léxico visual) y otro para el lenguaje oral (léxico auditivo). Los principales datos que forzaron a concebir dos léxicos fueron los que demostraron que cuando el "priming" es visual influye en el reconocimiento de las palabras escritas pero no en las orales y viceversa (Morton, 1982, citado en Cuetos, 2006). La Neuropsicología Cognitiva vino a confirmar tiempo después este hallazgo. Existen pacientes que reconocen sin dificultad las palabras en el lenguaje escrito y son incapaces de reconocerlas en el lenguaje oral, a pesar de que no padecen ningún problema perceptivo (Kohn y Friedman, 1986, citados en Cuetos, 2006), también existen pacientes que reconocen palabras en el lenguaje oral y no las reconocen en el escrito (Marshall y Newcombe, 1973, citados en Cuetos, 2006).

En el léxico auditivo, cada palabra está representada por un dispositivo que se activa por la llegada de información tanto procedente del exterior como del sistema semántico. Igualmente cada representación tiene un umbral diferente de activación dependiente de la frecuencia de uso.

La única diferencia está en el tipo de información exterior que activa las representaciones, ya que en el léxico visual son las palabras escritas y en el léxico auditivo los fonemas de las palabras.

\subsection{Almacén de pronunciación}

Es una unidad de memoria operativa, una unidad que almacena información codificada fonológicamente (Miceli, 1989, citado en Cuetos, 2006). El almacén de pronunciación retiene las informaciones procedentes del léxico fonológico y del sistema de conversión grafema-fonema. Aquí permanece temporalmente hasta que se articulan en sonidos 0 se pronuncian internamente para que puedan ser reconocidas por el léxico auditivo. 


\subsubsection{Procesamiento sintáctico}

Queda claro que el procesamiento léxico, es un componente necesario para llegar a entender un mensaje que aparezca en un mensaje escrito, pero no es suficiente. Las palabras sueltas no tranmiten información, es la unión de varias palabras donde se encuentra el mensaje. De forma que "el lector debe, además de reconocer las palabras, determinar como están relacionadas entre sí" (Lluisa y Brucart, 1987, 54). Para esto se dispone de una serie de estrategias o reglas sintácticas que permiten segmentar la oración en varias constituyentes, clasificar esos constituyentes de acuerdo a sus papeles sintácticos y finalmente construir una estructura o marco sintáctico que posibilite la extracción del significado. El proceso de análisis sintáctico comprende por tanto tres operaciones principales:

a) asignación de las etiquetas correspondientes a las distintas áreas de palabras que componen la oración (sintagma nominal, verbo, frase subordinada, etc.);

b) especificación de las relaciones existentes entre estos componente;

c) construcción de la estructura correspondiente, mediante ordenamiento jerárquico de los componentes.

El procesamiento sintáctico, se diferencia claramente del procesamiento semántico ya que no tiene en cuenta el significado de la oración. De forma que estas dos frases son semánticamente diferentes:

El perro asustó al gato.

El gato asustó al perro.

Sintácticamente son equivalentes. En cambio estas dos, semánticamente equivalentes tienen una estructura sintáctica diferente:

El perro asustó al gato.

El gato fue asustado por el perro.

Es decir, el analizador sintáctico descubre la relación entre los constituyentes, pero no analiza el significado de las oraciones.

Existen muchos autores que no consideran necesario incluir un componente sintáctico en la arquitectura funcional del sistema de comprensión lectora, basados en el supuesto de que el contenido semántico es suficiente para conseguir un análisis adecuado de la oración. Sin embargo, cada vez existen mayores evidencias sobre la existencia independiente de este proceso. Los investigadores que trabajan con Inteligencia Artificial sobre comprensión lectora ven la necesidad de que sus programas sean capaces de establecer relación entre las palabras como paso previo a la extracción del significado. Los afásicos de Broca comprenden sin dificultad las oraciones en que los papeles sintácticos están claramente definidos a partir de la información semántica, tal como ocurre por ejemplo con la oración "El hueso es comido por el perro", en la que el conocimiento de las palabras "comer", "hueso" y "perro" le permiten adivinar que el "perro" es quien necesariamente hace de sujeto, y 
"hueso" de predicado. Pero en las oraciones reversibles tales como "El lobo es atacado por el perro", en que ambos sustantivos pueden hacer de sujeto y de predicado, estos pacientes tienen verdaderas dificultades para interpretar su significado. "Ocurre así porque estos pacientes, aunque mantiene intacto el léxico y los conocimientos del mundo, tienen deteriorado el componente sintáctico" (Cuetos, 2006, 39-40).

\subsubsection{Estrategias de procesamiento sintáctico}

El analizador sintáctico gracias a una serie de claves presenten en la oración, es capaz del agrupamiento correcto de palabras en sus constituyentes, así como el establecimiento de la interrelación entre los constituyentes.

Estás con algunas de las claves más importantes, propuestas por Cuetos (2006, 40):

a) "Orden de las palabras": En castellano, como en otras muchas lenguas, el orden de las palabras proporciona información sobre su papel sintáctico. De forma que:

i. Luís besó a María. No representa lo mismo que;

ii. María besó a Luís.

Esto es debido a que en castellano está establecido que, si no hay ninguna preposición o indicador de lo contrario, el primer nombre hace de sujeto y el segundo de objeto.

b) "Palabras funcionales": Las palabras funcionales con las preposiciones, artículos, conjunciones, etc. Estas palabras juegan un papel principalmente sintáctico ya que informan de la función de los constituyentes más que de su contenido. En la frase anterior basta con anteponer "a" a la frase para que cambie su sentido.

\section{i. A Luís le besó María.}

c) "Significado de las palabras": El significado de las palabras es, en muchos casos, una clave importante para conocer su papel sintáctico. Muchas oraciones ambiguas sólo pueden dejar de serlo por el significado de las palabras:

i. Juan miraba la hamburguesa con plásticos.

Es ambigua, "plásticos" puede referirse al objeto a través del cual miraba Juan, o alguno de los ingredientes de la hamburguesa.

Esta frase pierde ambigüedad si se sustituye "plásticos" por "microscopio" o "tomate".

ii. Juan miraba la hamburguesa con microscopio.

iii. Juan miraba la hamburguesa con tomate. 
Igualmente, las dos siguientes frases tienen distintas interpretaciones, en función del significado de las palabras componentes:

iv. Vi los patos salvajes volando hacia el Sur.

v. Vi los Picos de Europa volando hacia el Sur.

d) "Signos de puntuación": Mientras que el lenguaje hablado los límites de las frases y oraciones vienen determinados por las pausas y la entonación, en el lenguaje escrito son los signos de puntuación quienes indican estos límites. Las comas de las frases y los puntos de las oraciones señalan el final de los constituyentes. Los textos que no están puntuados son mucho más difíciles de comprender porque el lector no sabe donde tiene que segmentar los constituyentes.

\subsubsection{Modelos de procesamiento sintáctico}

Se han propuesto muchos modelos sobre el funcionamiento del analizador sintáctico desde campos como la Psicología, la Lingüística y la Inteligencia Artificial. Cuetos (2006) propone estudiar el modelo propuesto por Mitchell (1987) ya que trata de explicar los procesos cognitivos sobre los que influyen las claves sintácticas.

El sistema de análisis que propone Mitchell (1987, citado en Cuetos, 2006), sigue la línea de otros modelos propuestos (Frazier y Rayner, 1982, citados en Cuetos, 2006).

Consta de dos estadios relativamente independientes.

1. Primer estadio. El analizador sintáctico construye una estructura sintáctica provisional, basándose exclusivamente en las claves gramaticales:

a. Orden de las palabras.

b. Categoría gramatical de las palabras. Si son palabras de función o de contenido, o es un verbo o un sustantivo, etc.

c. Signos de puntuación.

2. Segundo estadio. Haciendo uso de la información semántica y pragmática, comprueba la integridad de esa estructura. Si esta estructura provisional es compatible con la información procedente de otras fuentes se toma como estructura definitiva. Si, por el contrario, en este segundo estadio se detecta alguna anomalía, se elimina esa estructura y se construye otra nueva.

En la frase:

i. Mientras el granjero bebía el pollo...

En su primera lectura se asume que "pollo" es el objeto directo de la frase, esto sucede porque cuando se encuentra una frase del tipo Nombre-Verbo-Nombre se 
tiende a construir la estructura Sujeto-Verbo-Objeto, sin comprobar si la estructura es correcta. Pero si se coloca una coma después del verbo, un signo de puntuación influye en el primer estado.

ii. Mientras el granjero bebía, el pollo...

Estos errores son rápidamente descubiertos por el Segundo Estadio y el procesador hace cambios adecuados para conseguir un análisis correcto.

Relacionado con este modelo existe actualmente una cuestión muy discutida, la universalidad de estas claves. Hay que recordar que existen más de 5000 idiomas con construcciones gramaticales muy distintas. Es probable que claves importantes para el inglés o el castellano (orden de las palabras), no lo sea en absoluto para otros idiomas (Ej. en ruso, existe casi total libertad en el orden de las palabras). (Mitchell, Cuetos y Zagar, en prensa, citados en Cuetos, 2006).

Frazier en 1987 (citado en Cuestos, 2006), propuso unas estrategias que afirmaba eran universales, es decir, validas para todos los idiomas ya que no se basan en estructuras gramaticales sino en principios cognitivos:

- Adjunción Mínima

- Cierre Tardío

Sin embargo, evidencias empíricas parecen contradecir la universalidad de estas estrategias (Cuetos y Mitchell, 1988; Tabaran y McClelland en prensa). Pero se considera, que "es posible que exista un analizador universal siempre que sea lo suficientemente flexible como para acomodarse a las variables estructurales de las diferentes lenguas" (Cuetos, 2006, 43).

\subsubsection{Procesamiento semántico}

Este proceso consiste en extraer el significado de la oración o texto y de integrarlo junto con el resto de los conocimientos que posee el lector. Siguiendo lo indicado por Cuetos $(2006,43)$ esta operación consta de dos subprocesos: "La extracción del significado y la integración en la memoria".

"La concepción del significado en la Teoría semántica de Fray Luís de León se mueve dentro de dos coordenadas: el isomorfismo ontológico-lingüisto de la gramática especulativa medieval y la visión ejemplarista del mundo, de honda raigambre platónica, defendida por la escuela agustiniano-franciscana" (Muñiz, 1992, 39).

Gazdar (1979, citado en González, 1992) hace una propuesta al respecto que ha sido aceptada igualmente por lingüistas y psicólogos. Sugiere que el término "semántico" se aplique a los estudios de aquellos aspectos de significado que contribuyen a las condiciones de verdad o falsedad de una frese. En las teorías 
semánticas, tanto lingüistas como psicólogos han centrado su atención en la frase y no en entidades de significados superiores, no abordadas en dichos lenguajes.

La interpretación semántica opera, para este autor, a diferentes niveles: utiliza la información del léxico mental sobre cada palabra y, además combina el significado de las palabras para construir el de la frase; finalmente, combina el de las frases para obtener el del texto.

\subsubsection{Extracción del significado}

Esta operación consiste en construir una representación o estructura semántica de la oración o texto en la que vienen indicados los papeles de actuación (no los gramaticales) de los elementos que intervienen en la acción señalada por el verbo.

Aunque la estructura semántica se forma a partir de la estructura sintáctica es diferente de ella, ya que no conserva los papeles gramaticales que juegan los individuos sin o las funciones que realizan. Una prueba de esto es que se olvida pronto la estructura sintáctica aun cuando se conserva durante mucho tiempo el significado.

El pensamiento de Wittgenstein (1921, citado en Muñiz, 1992) en torno al significado descansa previamente en el modo cómo concibe la posibilidad de representar el mundo por parte del lenguaje. Esta representación marca, en consecuencia, los límites de la expresión lingüística. La palabra más comúnmente utilizada par designar representación es Bild, que ha sido traducida al inglés por picture y al castellano por pintura, unas veces, y otras por figuración. De aquí, la denominación de la teoría wittgensteiniana como de "pictórica" o "figurista".

Aunque los psicolingüistas (Sachs, 1967; Fillmore, 1968.1972, citados en Cuetos, 2006) han investigado sobre la forma en que se construye la estructura semántica y sus propiedades, han sido los investigadores del área de la Inteligencia Artificial quienes han aportado más información sobre esta estructura (Garnham, 1985, citado en Cuetos, 2006). La mayor parte de los modelos diseñados en esta disciplina (Anderson y Coger, 1973; Rumelhart, Lindsay y Norman, 1972, citados en Cuetos, 2006) usaron el sistema de redes para representar estas estructuras. Según Lindsay y Norman (1972, citados en Cuetos, 2006), la acción, representada por el verbo, se representaría en un nodo central y el resto de los caracteres (lugares, instrumentos, etc.) unidos a ese nodo central.

Otros investigadores como Clark y Clark (1977, citado en Cuetos, 2006) utilizan el formato proposicional, consistente en separar la oración en sus proposiciones constituyentes. Así para representar la estructura semántica de la oración "El caballo no es blanco", separan las dos proposiciones que la forman mediante paréntesis (falso (caballo blanco)).

La teoría referencial del significado a que aludimos fue formulada gráficamente por M. Schlick (1936, citado en Muñiz, 1992) del siguiente modo: "el significado de una proposición consiste en el método de su verificación". Aunque este criterio pertenece 
al campo de la metodología de las ciencias empíricas, ha ejercido, sin embargo, influencia importante en las discusiones filosóficas acerca del lenguaje. De aquí que nos veamos obligados a exponer esta doctrina. Con este fin, escogemos a dos autores significativos: A. J. Ayer y R. Carnap.

Cuando se trata de textos en vez de oraciones sueltas, el proceso es el mismo, se va extrayendo la información de cada oración, esta información se va acumulando junto con la información del resto de oraciones, formando al final una única representación de todo el texto, esta representación incluye toda la información aportada por cada oración. Los trabajos más conocidos acerca de la integración de información en una estructura única son los de Bransford y Franks (1971, citados en Cuetos, 2006).

Una de las teorías más conocidas sobre la formación de estructuras a partir de textos fue la propuesta por Kinstch y Van Dijk (1978, citados en Cuetos, 2006). Estos autores sostienen que el significado del texto se representa en la memoria como una red de proposiciones a la que denominan base del texto. Cada nueva oración va añadiendo información a las anteriores, se va integrando con las anteriores, con lo cual la representación se va haciendo más compleja cuanta más información se introduce. No obstante, habrá oraciones que aporten datos básicos y otras detalles, con lo cual la estructura será de tipo jerárquico, es decir, habrá informaciones importantes y otras secundarias. "Kinstch y Van Dijk demostraron que las preposiciones que están colocadas en los niveles más altos de la estructura del texto son recordadas mucho mejor que las que se hallan en los niveles más bajos" (Cuetos, 2006, 45).

\subsubsection{Integración del significado en los conocimientos del lector}

El proceso de comprensión no termina en la extracción del significado de la oración o texto, sino cuando se integra ese significado en la memoria, ya que comprender, no sólo implica construir una estructura, sino además, añadir esta nueva estructura con los conocimientos que el lector ya posee (Schank, 1972, citado en Cuetos, 2006).

Para poder integrar los mensajes en la memoria es necesario establecer un vínculo entre esta nueva estructura y los conocimientos que ya se poseen y que le servirá para activar los conocimientos correspondientes. En cualquier frase siempre hay una parte que es conocida por el lector (u oyente) que recibe el nombre de "información dada", y una parte desconocida, que es la que se quiere dar a conocer, llamada "información nueva". La información dada sirve para unir la información nueva con la frase anterior, o con los conocimientos del sujeto.

Cuando se introduce un nuevo tema siempre se comienza con una información que se supone el oyente o lector ya conoce. Clark (1977, citado en Cuetos, 2006) afirma que el lector solo puede comprender oraciones cuando tiene en mente un antecedente para la información dada. 
Cuando se escribe o dice una frase siempre se tiene en cuenta qué es conocido y qué es nuevo para el lector u oyente. Esto hace que un mismo mensaje se transmita de formas muy diferentes.

En algunos casos la información dada no está explícita y el lector tiene que hacer complicadas inferencias. Por ejemplo, en la oración, "Juan entró en la habitación y la ventana estaba abierta", hay que inferir que "la ventana" está en la habitación. Clark llama a esta operación "inferencia puente". Si el lector no fuera capaz de realizar inferencia puente no llegaría a comprender la oración. Cuanto más complejo sea crear el puente mayor será el esfuerzo cognitivo, como demostraron Haviland y Clark (1974, citados en Cuetos, 2006).

Estas inferencias al formar parte de la estructura también son almacenadas en la memoria. Particularmente si es una información necesaria para establecer vínculos entre diferentes partes del texto como demostaron Bransford, Barclay y Frank, 1972; Bransford y Jonson, 1973, citados en Cuetos, 2006).

Comprender una oración o texto consiste en construir un modelo mental sobre lo que allí está descrito. Este modelo se va formando con la información que se extrae del texto, pero a su vez, se usa como referente para la realización de inferencias y para guiar la interpretación de lo que va leyendo.

Algunas veces, el lector puede haber construido una representación de la oración y sin embargo no es capaz de integrarlo en sus conocimientos. Esto sucede, por ejemplo, cuando se lee o escucha una oración fuera de contexto y no se entiende simplemente porque no se sabe con que conocimientos se tiene que integrar, en otras ocasiones se poseen los conocimientos adecuados pero no se dispone de claves que permitan poner en relación la información de la frase con nuestra propia información.

\subsubsection{Conocimientos del lector: Los esquemas}

Como ya se ha dicho, el proceso de comprensión termina cuando el lector integra el mensaje de la oración o texto en sus conocimientos. De esta forma, necesita ciertos conocimientos donde integrar cada texto que lee.

En la actualidad, es ampliamente admitido que los conocimientos que tenemos acerca de las cosas se agrupan en bloques o paquetes denominados esquemas. Cada esquema comprende un campo de conocimientos o actividades determinado, así como las reglas que indican cómo deben ser usados esos conocimientos. "Un solo esquema sirve para todas aquellas situaciones que son esencialmente iguales, no es válido pensar que existe un esquema particular para cada situación. Esto es posible porque el esquema solo proporciona el esqueleto alrededor del cual se interpreta la situación" (Cuetos, 2006, 48).

Los esquemas vienen a ser como modelos internos de las diferentes situaciones en las que se puede encontrar una persona. El conjunto total de esquemas, de que 
dispone cada individuo para interpretar los diferentes objetos, sucesos y personas que existen a su alrededor, constituyen su teoría particular del mundo.

Los esquemas facilitan nuestra comprensión de las situaciones ya que proporcionan un marco de referencia en el que encajar los estímulos sin tener que estar organizándolos constantemente. Al activar un esquema se activan los conocimientos que abarca, especialmente los principales personajes y elementos que componen el esquema, y los traslada a la memoria a corto plazo.

Por otra parte, como indica Cuetos (2006, 49) "los esquemas posibilitan la elaboración de las inferencias necesarias para la comprensión". Ningún texto es totalmente explicito, el lector tiene que hacer inferencias que van más allá de la información escrita.

Existe un tipo de esquemas muy útiles para los lectores que son los referentes a la estructura de los textos, es decir, sobre su organización interna o gramática. Cuando la estructura del texto se ajusta con las expectativas que sobre el se tiene, su comprensión y posterior recuerdo mejorará considerablemente.

\subsubsection{EI Procesamiento Estructural del Texto}

Dentro del enfoque psicolingüístico de la lectura, los distintos modelos desarrollados consideran la lectura como una actividad múltiple, compleja y sofisticada, que exige coordinar una serie de procesos, siendo la mayoría de ellos automáticos y no conscientes para el lector.

Éste debe identificar las palabras escritas y acceder a los significados de las mismas, después de lo cual debe asignar un significado a cada palabra en una oración dentro del texto y construir la estructura de ese texto. Posteriormente, tiene que comprender cada oración dentro del texto y construir la estructura de ese texto. $\mathrm{Y}$, finalmente, debe asimilar el texto, es decir, debe integrarlo en los conocimientos que ya posee.

La lectura es un proceso sumamente dinámico ya que debe extraerse el máximo de información en el menor tiempo posible. Dadas las limitaciones del sistema cognitivo, no es posible almacenar el texto en un almacén de memoria para analizarlo más tarde con toda calma. Lo único que el lector retiene a largo plazo es el significado, mientras que las representaciones intermedias generadas por los mecanismos más periféricos se "olvidan" rápidamente, para dar paso a nueva información.

Pese a su innegable interés y valor, los modelos modular e interactivo, se han concentrado en los microprocesos, que son parte de los mecanismos periférico, El estudio de los macroprocesos es la alternativa complementaria y en torno a éste han surgido tres teorías:

a) Las gramáticas de narraciones. Que dividen el texto en macro-constituyentes de conocimiento y de trama o argumento. A su vez estos macro- 
constituyentes se dividen en episodios definidos por metas, acciones que intentan alcanzar la meta, y el resultado de las acciones (Thorndyke, 1977; Mandler y Jonson, 1977, citados en de Vega, 1990).

b) Las teorías de macroestructura, que incluyen al menos dos niveles de representación del texto: un nivel microscópico que representa minuciosamente los sucesos de la narración y un nivel macroscópico que abstrae el sentido más global o general del texto (Kintsch y vanDijk, 1978; van Dijk y Kintsch, 1983; Schank y Abelson, 1977, citados en de Vega et al.1990).

c) Enfoque de los modelos mentales. En este caso, a diferencias de las anteriores, no establece mecanismos específicos para el procesamiento estructural. "La organización estructural no está en el texto ni en la mente del lector como una "plantilla" previa, sino que es un producto dinámico resultante de la génesis y transformación de escenarios mentales en el curso de la lectura" (de Vega et al., 1990, 110).

\subsection{Las gramáticas de narraciones}

Las gramáticas de narraciones constituyen el enfoque más conocido sobre los aspectos estructurales del significado global del texto. Las gramáticas de narraciones, pretenden especificar formalmente la estructura que subyace a tipos representativos de narraciones, tales como los cuentos, de modo semejante a como las gramáticas convencionales sirven para analizar la estructura sináptica de las frases. Las unidades de análisis de las gramáticas de narraciones son nodos o proposiciones, que se combinan jerárquicamente entre sí de acuerdo con ciertas reglas. Estas son formalmente reglas recursivas o de re-escritura. En tabla 2 se ofrecen las reglas correspondientes a una gramática de narración, propuestas por Thorndyke en 1977 (citado en de Vega et al., 1990).

1. Narración $\rightarrow$ Marco + Tema + Trama + Resolución

2. Marco $\rightarrow$ Personajes + Localización + Tiempo

3. Tema $\rightarrow$ (Suceso) + Meta

4. Trama $\rightarrow$ Episodio

5. Episodio $\rightarrow$ Submeta + Intento + Resultado

6. Intento $\rightarrow$ Suceso / Episodio

7. Resultado $\rightarrow$ Suceso / Estado

8. Resolución $\rightarrow$ Suceso / Estado

9. Submeta $\rightarrow$ Meta $\rightarrow$ Estado deseado

10. Personajes / Localización / Tiempo $\rightarrow$ Estado

Tabla 2. Reglas recursivas de una gramática de narraciones según Thorndyke (1977).

Las gramáticas de narraciones son modelos acerca de la estructura del texto. Pretenden que al menos ciertos tipos de texto convencionales puedan describirse de acuerdo con estructuras formales abstractas independientes de su contenido 
específico. Por ejemplo, una trama narrativa aplicable a muchas narraciones puede implicar: un problema al que se enfrenta el personaje principal, una secuencia de intentos de resolver el problema, un resultado de estos intentos.

La principal virtud de las gramáticas de narraciones, es que han estimulado la investigación sobre la comprensión y la memoria de narraciones. Algunos hallazgos empíricos indican que los sujetos son sensibles a la importancia estructural de las frases. Así, las proposiciones que pertenecen a niveles jerárquicos más elevados de la estructura del texto, se recuerdan mejor que las de bajo nivel jerárquico (Kintsch y Keenan, 1973; Kintsch et al, 1975; Meyer, 1975, citados en, de Vega et al., 1990).

En opinión de Trorndyke (1977, citado en de Vega et al., 1990) el análisis estructural que realiza el lector es una actividad psicológica diferente del procesamiento del significado.

Las gramáticas de narraciones son descripciones estructurales aplicables a algunos textos, pero no describen el modo en que los lectores procesan la estructura del texto. Desde una perspectiva psicológica su valor es mínima. Estos son algunos de los motivos para esta valoración negativa:

1. Las reglas de re-escritura no tienen un claro estatus psicológico. Hay que tener en cuenta que se trata de reglas formales, por tanto independientes del contenido del texto, y que se supone que el lector las ejecuta cada vez que comprende una narración (Cirilo y Foss, 1980, citado en de Vega et al., 1990).

2. Las reglas de re-escritura no tienen un estatus computacional. No se han diseñado procedimientos efectivos (capaces de ser ejecutados en un ordenador que realicen las funciones atribuibles a las gramáticas de narraciones (Jonhson-Laird, 1983 citado en de Vega et al., 1990)

3. El análisis estructural requiere algo más que reglas sintácticas de reescritura. Debido a la ausencia de procedimientos efectivos en las gramáticas de narración, la aplicación de las reglas de re-escritura se convierte en una tarea esencialmente subjetiva. Los psicolingüistas que analizan textos de acuerdo con una gramática de narraciones segmentan y categorizar los elementos estructurales basándose en su propia intuición semántica y pragmática (por ejemplo, la categorización de una frase como META, como INTENTO, etc. Requiere un conocimiento del mundo por parte del sistema). Pero el conocimiento semántico y pragmático del mundo son elementos externos al modelo (de Vega et al., 1990).

4. Incapacidad para realizar inferencias. Se ha demostrado en muchas ocasiones que los sujetos realizan inferencias temáticas durante la lectura, añadiendo información ausente en el texto, gracias a su conocimiento del mundo. Las gramáticas no incluyen ningún mecanismo inferencial (de Vega et al., 1990, 113).

5. La complejidad y variedad estructural de los textos es tal que resulta dudoso que haya una gramática de narraciones para todos ellos. Las gramáticas de narraciones existentes se ajustan, en el mejor de los casos, a 
un tipo muy particular de narraciones sumamente estereotipadas, tales como los cuentos infantiles (Jonson-Laird, 1983, citado en de Vega et al., 1990, 113).

En definitiva, las gramáticas de narraciones proponen que los diferentes tipos de textos se ajustan a estructuras estables, que responden a ciertas reglas. De aquí el nombre de la corriente: del mismo modo que una gramática describe las reglas de operación de un sistema lingüístico, la gramática de narraciones describe combinaciones de secuencias a cada una de las cuales llama nodos.

Mandler y Jonson (1997, citados en Díaz, 1996) plantean que las combinaciones constituyen estructuras que los lectores llegan a conocer y a utilizar para optimizar la comprensión del contenido de un texto. En este sentido, son un recurso (aunque no de tipo cognitivo) que permite reconocer lo fundamental por encima de lo trivial. Ambos autores señalan que lo trascendente, en forma de proposiciones de un alto nivel de complejidad, se ubica en la estructura nodal básica, mientras que el resto de la información es una "elaboración".

De acuerdo con las secuencias "gramaticales", los elementos tienen un marcado tinte literario. Pero la pauta de las gramáticas de narraciones se ha extrapolado a otros tipos de texto, como los expositivos y utilitarios, donde ha encontrado abundantes hallazgos. 


\subsection{Teorías de macroestructura}

Estas teorías reconocen la importancia de la estructura de los textos, pero aportan un modelo de procesamiento psicológico, que es donde reside su mayor valor. "En esta corriente han trabajado dos prominentes estudiosos de la comprensión lectora: Teun A. Van Dijk y Walter Kintsch" (Díaz, 1996, 40).

El estudio de la macroestructura ha originado por razones prácticas y metodológicas, una distinción en dos bloques: identificación de la palabra escrita (también llamados "procesos de nivel inferior", de "bajo nivel o "microprocesos"); y, por otro lado, estarían los procesos que tienen relación con la comprensión del texto, macropocesos o procesos de alto nivel.

Una vez que se accede al significado de estas palabras, presentes en la oración, por medio de la inferencia perceptiva y cognitiva, se inicia un complejo proceso de interrelación entre los diversos significados.

En cuanto a la estructura de los textos, Van Dijk y Kintsch (1983) proponen el concepto superestructuras para denotar la organización adecuada de distintos tipos de textos, según se diferencian por su registro lingüístico, intención o uso. Como los teóricos de las gramáticas de narraciones, estos autores postulan que los elementos integrantes de una narración responden a organizaciones genéricas; de ahí postulan que otros tipos de texto poseen también organizaciones esquemáticas; es decir, superestructuras. La propuesta de estos autores consiste en plantear que las superestructuras se incorporan a los esquemas cognitivos de los sujetos, quienes gracias a esta acción poseen un recurso que les permite disponer estrategias adecuadas para la obtención del significado de los textos.

Al final, comprender es crear relaciones y, estas relaciones se ordenan de un modo progresivo de tal modo que se crea la necesidad de construir otras. De acuerdo con el modelo simplificado de los procesos implicados en la comprensión Sánchez $(1998,10)$ adaptó la siguiente construcción del texto base:

- Microestructura

a. Reconocer palabras

b. Construir proposiciones

c. Integrar las proposiciones

- Macroestructura

d. Construir ideas globales

- Superestructura

e. Integra ideas en esquemas de relaciones

- Modelo de la situación

f. Construir un modelos situacional"

Así mismo, hay que distinguir distintos tipos de relaciones: 
a. Unas nos permiten interconectar local y globalmente la información extraída del texto. Estas actividades suponen alcanzar lo que técnicamente se denomina, la construcción de la base del texto (Van Dijk y Kinsdch, citado en Sánchez, 1998).

b. Otras nos permiten integrar la información del texto en nuestro conocimiento.

c. Al mismo tiempo se requieren estrategias y habilidades de autorregulación que permiten al lector precisar con que objetivos emprende la lectura (planificación), detectar las dificultades que surgen durante la lectura (supervisión) y, por último, valorar tras concluir la lectura en que medida ha alcanzado sus objetivos (evaluación).

Aunque el reconocimiento de las palabras es un componente necesario para llegar a entender el mensaje presente en el texto escrito, no es suficiente. Las palabras aisladas no transmiten ninguna información nueva, sino que es la relación entre ellas donde se encuentra el mensaje. En consecuencia, una vez que han sido reconocidas las palabras de una oración, el lector tiene que determinar como están relacionadas entre sí esas palabras. Por ello, a continuación, se describen los componentes implicados en la comprensión del texto teniendo en cuenta las aportaciones de diversos autores que explican con profundidad el estudio de estos procesos (Kinstch y Van Dijk, 1978; Van Dijk y Kinstsch, 1983; Orrantia y Sánchez, 1994, Solé, 1992).

\subsection{Construcción del texto base}

En la representación textual o base del texto se llevan a cabo las siguientes actividades: construir proposiciones y ordenar las ideas del texto, extraer el significado global e interrelacionar globalmente las ideas. Incluye, por tanto, tres niveles de estructuración (Kinstch y Van Dijk, 1978, citados en Sánchez, 1998): microestructura, macroestructura y superestructura.

\subsection{Microestructura}

Con esta actividad se extrae del texto las diferentes ideas o proposiciones que lo constituye y se establecen entre ellas una relación de continuidad u orden.

Es lo que Cuetos (1990), como ya se ha visto, llama procesamiento sintáctico.

Además de la construcción de las distintas proposiciones en este nivel microestructural, se lleva a cabo el establecimiento de las relaciones de continuidad temática o progresión temática entre esas proposiciones.

Es decir, el lector debe ser capaz de establecer una continuidad entre las ideas, identificando un elemento común a todas ellas que permita conectarlas unas con otras. Esto es lo mismo que reconocer qué es lo dado y qué es lo nuevo en cada una de las ideas que se van interpretando. 
Britton y Gulgoz (1991, citados en Sánchez, 1998) mostraron que cuando en un texto se facilita las proposiciones, mejora la capacidad de recuerdo y disminuye el tiempo de lectura necesario.

\subsection{Macroestructura}

En segundo lugar, el lector genera la Macroestructura del texto, es decir, una representación semántica de naturaleza global que refleja el sentido general del discurso. "La macroestructura es formalmente análoga a la microestructura, pues ambas están constituidas por sendos conjuntos de proposiciones. Sin embargo, la macroestructura es una versión más abstracta y reducida que la microestructura" (De Vega, 1990, 114).

Un texto no es un conjunto aleatorio de frases, sino un conjunto de frases coherentes que comparten un tema. Para considerar coherente un texto debemos extraer su significado global o ser capaces de resumirlo en sus ideas esenciales.

La microestructura y la macroestructura están vinculadas entre sí de manera funcional pues han sido elaboradas con el propósito de obtener los significados del texto. Para conseguir llegar al significado global del texto, el lector pone en marcha una serie de estrategias que tienen la misión de transformar y reducir la información semántica de un texto, a estas estrategias se les ha denominado macrorreglas (Van Dijk, 1980, citado en Sánchez, 1993).

Las macrorreglas son una reconstrucción de aquella parte de nuestra capacidad lingüística, con la que enlazamos significados convirtiéndolos en totalidades significativas más grandes. Es decir; introducen un orden en lo que a primera vista no es más que una larga y complicada serie de relaciones, como por ejemplo entre proposiciones de un texto.

Si se consideran las proposiciones como una representación abstracta de aquello que normalmente se llama información (semántica), las macrorreglas organizan en cierta manera la información extremadamente complicada del texto. En cierto modo esta consideración implica una reducción de la información, de manera que, en el plano cognitivo, también se puede considerar las macrorreglas como operaciones para reducciones de información semántica (Van Dijk, 1978, 170):

Estas reglas son cuatro:

- Supresión, supone la posibilidad de seleccionar aquellas proposiciones relevantes para interpretar el texto y suprimir las que son triviales $\mathrm{y} / \mathrm{o}$ redundantes. Omitir, es una macrorregla que consiste en eliminar toda información de poca importancia y no esencial. Van Dijk (1978) ejemplifica la macrorregla del siguiente modo:

a. Proposición 1: Pasó una muchacha.

b. Proposición 2: Llevaba un vestido. 
c. Proposición 3: El vestido era amarillo.

Que por omisión se expresaría sólo con la proposición 1 (Pasó una muchacha), bajo dos supuestos: A) que la información de las proposiciones 2 y 3 no tenga una función posterior para el texto, no sea una presuposición; y B) aporte datos casuales, no inherentes

- Seleccionar, significa eliminar proposiciones que sean presuposiciones, integrantes o consecuentes de otra, de modo que quedan sobreentendidas en la proposición seleccionada, a diferencia de la macrorregla anterior, en la cual la información eliminada es "irrecuperable". En este caso el ejemplo es el siguiente:

a. Proposición 1: Pedro se dirigió hacia su coche.

b. Proposición 2: Subió.

c. Proposición 3: Se fue a Francfort.

Es importante llamar la atención acerca de que en este punto Van Dijk apela a los conocimientos del lector como un elemento que le permite decidir cuándo una proposición forma parte de otra. Esto es: saber que Francfort es un lugar, conlleva las nociones de traslado y vehículo; en caso de que se ignorarse esta situación sería imposible tomar la decisión de seleccionar la proposición 3 como aquella que implica a las demás.

- Generalización, que nos permite entender que los elementos del texto son ejemplos de una idea más general. Generalizar es una macrorregla que consiste en sustituir varias proposiciones con una nueva producida por el lector; esta nueva proposición es un planteamiento que rescata el sentido de las otras:

a. Proposición 1: En el suelo había una muñeca.

b. Proposición 2: En el suelo había un tren de madera.

c. Proposición 3: En el suelo había cubos.

Donde la proposición resultado de la aplicación de la macrorregla dice: "En el suelo había juguetes". Como se observa, el concepto juguetes rescata lo esencial de "una muñeca", "un tren de madera" y "cubos".

- Integración, mediante la cual entendemos que los elementos del texto son parte de una idea más compleja que no aparece en el texto. Construir o integrar, implica la formulación de una nueva proposición, pero a diferencia del caso anterior, no se basa en la abarcabilidad de un concepto, sino en la posibilidad de reducir una serie de hechos o situaciones implicando sus respectivas condiciones. Una proposición creada por el lector como "Viajé en tren", comprende las siguientes proposiciones, según el ejemplo de Van Dijk $(1978,172)$ :

a. Proposición 1: Fui a la estación.

b. Proposición 2: Compré un boleto.

c. Proposición 3: Me acerqué al andén. 
d. Proposición 4: Subí al tren.

e. Proposición 5: El tren partió.

Las dos primeras coinciden en anular información mientras que las dos últimas coinciden, en que sustituyen la presentación original de la información por una más económica.

Las macrorreglas comentadas hasta aquí son parte del proceso de la comprensión lectora. Como se ha señalado, de acuerdo con Van Dijk, la aplicación es esencial para la elaboración de la macroestructura del texto, la cual constituye una representación semántica que refleja el sentido general de la información. Conviene insistir en la idea de que los lectores no pueden conservar en la memoria activa el total del texto, de modo que requieren estrategias para conservar lo esencial. En la teoría de macroestructura, las estrategias son precisamente las macrorreglas.

Como corresponde a toda teoría, las de macroestructura son objeto de revisión a fin de enmendar los postulados parcialmente insatisfactorios o disprobados por las evidencias empíricas. El propio Van Dijk señala que el modelo que propuso en 1988 junto con Kintsch ha sido adecuado en dos ocasiones. Según De Vega et al. (1990, 40), "la reconsideración más reciente ha significado la reponderación de los procesos inferenciales que realiza el lector, al mismo tiempo que se ha encaminado el modelo hacia principios conexionistas". Con todo, este modelo sigue representando un avance de primera importancia en la comprensión del proceso lector, al tiempo que ha enriquecido la didáctica de la lectura.

Aun cuando estas teorías carecen todavía de un amplio desarrollo, son sugestivas por el hecho de que corresponden a ideas como la de la vivencia que manifiesta el lector en relación con los acontecimientos de un texto, lo que parece probar la creación de la situación como un recurso cognitivo.

La compilación de los distintos estudios al respecto, pone de manifiesto que se atribuyen a los modelos mentales las siguientes características: a) dinamismo, pues de una configuración tosca y provisional, el lector pasa a una elaboración refinada en la que a menudo fue necesario realizar inferencias puente; b) isomorfismo referencial, lo cual significa que el modelo mental mimetiza los objetos personajes y datos mencionados en el texto; c) accesibilidad de la información, en virtud de que mantiene en primer plano objetos, sucesos, personajes y entidades presentes en el texto, por lo que el lector puede identificar los giros y actualizaciones de la información pese a los recursos anafóricos y correferenciales empleados en la escritura.

"Existen evidencias respecto a que si se enseña a los alumnos a operar con las macrorreglas mejora su comprensión" (Sánchez, 1989, 13). 


\subsection{Superestructura}

Otro nivel de estructuración referido a la organización formal de los textos es la superestructura. Responde a la idea de que existen diferentes "tipos" de textos que interrelacionan las ideas de manera diferente, concretamente en los textos expositivos, podemos encontrar textos concebidos como respuesta a un problema , explicación y argumentación de una tesis, contraste la analogía entre dos o más fenómenos, descripción y secuencia de acontecimientos...

Para comprender un texto, el lector deber reconocer estas estructuras y saber cómo se relaciona entre sí. Para ello se emplea la llamada "estrategia estructural" (Meyer, 1985, citado en Sánchez, 1998), que contiene los siguientes componentes: en primer lugar, reconocer el patrón organizativo del texto a través de las claves o señales que aparecen en los textos; a continuación, utilizar ese patrón como instrumento para asimilar la información que se va derivando del texto, ordenándola en las distintas básicas y creando una representación en la memoria a la estructura del texto; y, por último, utilizar esa representación para recordar la información del texto.

Distintas investigaciones señalan que si se ayuda a los lectores a comprender la naturaleza de los textos mediante conectores, frases explicativas, etc., se mejora el recuerdo (Beck et al., 1991; McNamara et al., 1996; ambos citados en Sánchez, 1998). Y "si se enseña a los alumnos a reconocer y operar con estas estructuras, también mejora la calidad de su recuerdo" (Carriedo y Alonso, 1995, 16).

Así dentro del proceso de reconocimiento o identificación de la palabra escrita están implicadas una serie de operaciones: la detección de los signos gráficos para su posterior identificación y el acceso al léxico interno o "estructura hipotética donde el individuo tiene almacenados de manera organizada sus conocimientos lexicales, semánticos y sintácticos" (Alegría, 1985; 83).

Los esquemas que forman la figura 5 ilustran dos superestructuras.

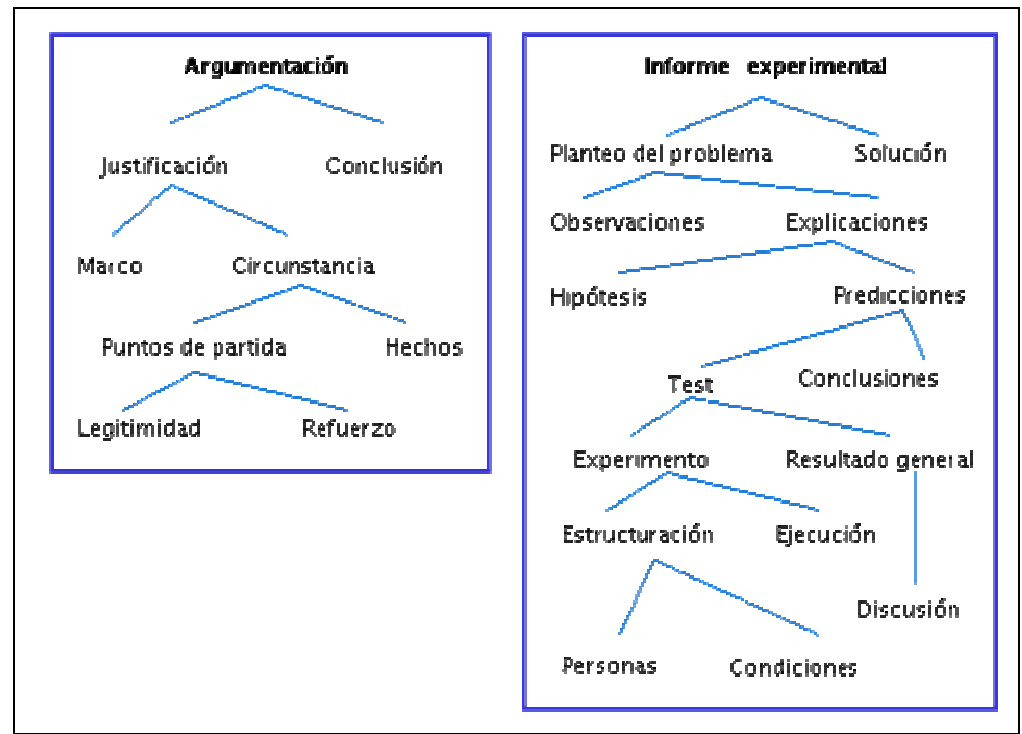

Figura 5. Superestructuras 
Además de la superestructura de las narraciones y de las dos anteriores, Van Dijk y Kintsch aventuran que existen al menos las mostradas en la figura 6 (Van Dijk, 1978, 167).

\begin{tabular}{|c|c|c|c|}
\hline $\begin{array}{l}1 \\
2 \\
5 \\
4 . \\
5 \\
5 \\
7 \\
8 \\
9 \\
10 .\end{array}$ & 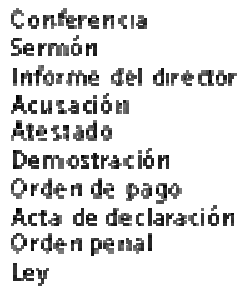 & $\begin{array}{l}11 . \\
12 \\
13 \\
14 \\
15 \\
15 \\
17 \\
18 \\
19 \\
20 .\end{array}$ & 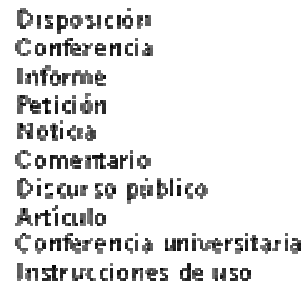 \\
\hline
\end{tabular}

Figura 6. Superestructuras por Van Dijk (1978)

El lector parte del texto superficial y construye una doble interpretación estructural del texto.

\subsection{Limitaciones de las teorías macroestructurales}

El modelo macroestructural de Kintsch y Van Dijk tiene mayor grado de elaboración computacional y de plausibilidad psicológica que las gramáticas de narraciones. Tiene en cuenta las limitaciones funcionales de la memoria operativa y el carácter serial o de "izquierda a derecha" del procesamiento lector. Además establece mecanismos relativamente detallados del cómputo de la macroestructura a partir de la microestructura. Sin embargo, un análisis más detallado de la teoría encuentra notables ausencias no muy distintas de las halladas en las gramáticas de narraciones.

1. Ausencia de procedimientos efectivos en la construcción del texto base en formato proposicional a partir del texto superficial. Aunque la construcción de proposiciones se realiza de acuerdo con ciertas reglas, no existe el procedimiento efectivo que ejecute estas reglas, sino que es de nuevo el psicolingüista el que genera la lista proposicional basándose en su intuición semántica. El modelo toma la lista proposicional como punto de partida, pero no es capaz de generarla por sí mismo.

2. Ausencia de procedimientos efectivos en la aplicación de las macro-reglas y los esquemas de control. En realidad, quien aplica las macrorreglas, determinando si una proposición es o no importante, 0 si varias proposiciones se pueden combinar en una más abstracta, es un agente ajeno al modelo: el propio científico. El problema es substancialmente el mismo que en las gramáticas de narración. Se requiere una sensibilidad semántica para categorizar y construir la macroestructura del texto. Las reglas sintácticas no pueden, en principio, ejecutar esta función. Kintsch parece sensible a este problema, ya que en la versión de su teoría elimina 
las macrorreglas y los esquemas de control y los sustituye por un proceso conexionista aparentemente más mecánico.

3. Descuido de las inferencias. Aun cuando el modelo reconoce que el lector realiza inferencias (macrorregla constructiva) no especifica cuáles son los mecanismos inferenciales. La misma ausencia existe en la versión más avanzada de la teoría (Kintsch, 1988, citado en de Vega et al., 1990).

En resumen, tratándose de población adulta, se hace especial hincapié sobre los macroprocesos, de acuerdo con la distinción establecida por Cuetos (1994, citado en Ferrer, Andréu, Martínez, Asensi, Romero, 2004) que considera los procesos lectores jerárquicamente, distinguiéndose cuatro grupos que desarrollan por parte del lector.

Por un lado, los micropocesos relacionados con la decodificación más automática del texto. Se trataría de los procesos perceptivos, léxicos y sintácticos que se realizan de una manera muy rápida y con un mínimo consumo de recursos atencionales, sin que el lector sepa muy bien cómo los produce. Por otro lado, los macroprocesos, más ligados a lo que en sí constituyen los procesos de comprensión del texto, y que requiere en su desarrollo de plena consciencia por parte del lector, consumiendo gran cantidad de recursos cognitivos. En este apartado quedaría el procesamiento semántico, las operaciones relativas a la construcción y organización de significados.

\subsection{Modelos mentales}

Para explicar el funcionamiento cognitivo de los sujetos, con relación a las representaciones que usan para razonar y al modo en que lo hacen, se emplea como referencial, la Teoría de los Modelos Mentales Johnson-Laird (1983, 1990a, 1990b, 1996, citado en de Vega et al., 1990). Funciona como una forma de representación del conocimiento, y donde la inferencia abductiva juega un papel importante, en tanto se considera junto con los modelos, un medio para dar cuenta del camino del descubrimiento. Pretende dar una explicación de los mecanismos involucrados en el razonamiento, postulando que los humanos representan el mundo con el cual interactúan a través de modelos mentales. En este sentido, la conexión con el mundo se establece a partir de una equivalencia entre un modelo mental y las partes del mundo que son designadas. A partir de esto, se postula que el razonamiento científico está basado en modelos.

Los modelos mentales por lo tanto, constituyen una representación o "estructura análoga" del mundo-real o de una situación-imaginada específica. Un modelo mental construye a su vez imágenes, que corresponden también a modelos mentales particulares y constitutivos de ese modelo mental (es decir, un modelo contiene submodelos). Se pueden representar principalmente a partir de tres fuentes: de percepción visual, analógica y sobre experimentos del pensamiento.

De acuerdo con la hipótesis de los modelos mentales, el lector construye una representación sobre el contenido del texto, incluyendo la situación, objetos, 
personajes, sucesos, procesos, causas o intenciones descritas en el texto. La estructura está implícita en el modelo mental del discurso, de modo que no es tanto una propiedad del texto, como un producto derivado del procesamiento de la situación a la que se refiere el texto, más que una representación del texto mismo (Johnson-Laird 1983: van Dijk y Kintsch, 1983, Garnham, 1987; Garrod y Sanford, 1983; Glenberg, et al., 1987, citados en de Vega et al., 1990). Si un lector no puede descubrir un referente plausible del texto, su comprensión fracasa y el recuerdo es escaso, aun cuando las palabras y las frases sean inteligibles por sí mismas, como demostraron las investigaciones pioneras de Bransford y Johnson (1973, citados en de Vega et al., 1990).

Los experimentos realizados con textos ambiguos demuestran que el simple cómputo lingüístico es insuficiente para establecer el significado de un texto. No basta con procesar las palabras en un "módulo léxico", y las frases en un "módulo sintáctico" o "proposicional". Se requiere ir más allá de los símbolos y de las relaciones lingüísticas para establecer la referencia del texto. Precisamente, en ese cómputo referencial se inscribe la noción de modelo mental.

Si se examina cada una de esas categorías de representaciones, en la óptica de Johnson-Laird (1983):

- Las representaciones proposicionales no están formadas por palabras; sin embargo, captan el contenido abstracto, ideativo de la mente que estaría expresado en esa especie de lenguaje universal de la mente, que es el "mentalés". Es decir, por ejemplo, la frase "el libro está sobre la mesa" no estaría expresada así mentalmente. No obstante, dichas representaciones son susceptibles de ser expresadas verbalmente.

- Los modelos mentales son análogos estructurales del mundo; su estructura, y no su aspecto, corresponde a la estructura de la situación que representan. Un modelo mental representa un estado de cosas, y consecuentemente su estructura no es arbitraria, tal y como lo es la de una representación proposicional (por ejemplo, la frase anterior, "el libro está sobre la mesa", puede referirse a cualquier libro, abierto, cerrado, nuevo, viejo, sobre cualquier mesa, en la medida en que es abstracta y puede representarse de maneras diversas); el modelo mental desempeña un papel representacional analógico estructural y directo. Su estructura refleja aspectos relevantes del estado de cosas correspondiente en el mundo real o imaginario.

- Los modelos mentales no tienen estructura sintáctica; su estructura es análoga a la que tienen los estados de cosas del mundo, tal como los percibimos o concebimos. Así, los modelos mentales, por su carácter dimensional, pueden ser manipulados más libremente, de manera controlada sólo por las propias dimensiones del modelo. Los modelos pueden tener dos o tres dimensiones, pueden ser dinámicos e, incluso, pueden tener un número mayor de dimensiones en el caso de determinados individuos con talento.

- Las imágenes, para Johnson-Laird (1983) son producto tanto de la percepción como de la imaginación. Representan aspectos perceptibles de los objetos 
correspondientes en el mundo real. En un primer momento correspondían para el autor a vistas concretas de un modelo mental subyacente, a visiones relevantes o "visuales" del mismo; pero en un trabajo más reciente el propio Johnson-Laird (1996) revisa esta idea diferenciando las imágenes de los modelos mentales y no considerándolas solamente como vistas de un modelo mental que actúe como sustrato. "Las imágenes representan cómo algunas cosas son vistas desde un punto de vista particular" (Johnson-Laird, 1996, 124) y no suponen necesariamente la construcción o la posesión de un modelo mental explicativo y predictivo del que deriven. Las imágenes, así como los modelos mentales, son altamente específicas. También las imágenes son susceptibles de continuas transformaciones. Lo que JohnsonLaird nos dice al revisar este concepto es que algunas personas razonan con ellas, usándolas en sus modelos mentales, pero no todas y no necesariamente supone una mayor eficacia en los procesos de razonamiento, aunque parece haber ciertos indicios de ello. 


\subsection{Desarrollo del sistema morfo-sintáctico}

La evolución de las diversas variantes morfemáticas, simplemente se dejará constancia de las mismas sin entrar exhaustivamente en los pormenores de su desarrollo. Cuando se habla de variantes morfemáticas hay que tener en cuenta las siguientes cuestiones:

a) Género. Que según diversos autores es el primer morfema que hacen los niños.

b) El número. El uso de los plurales está logrado hacia los tres años.

c) Los artículos. Determinados e indeterminados, antes de utilizados masivamente hasta los tres años.

d) Pronombres. Los posesivos son más rápidos, los personales como "yo" no son utilizados masivamente hasta los tres años.

e) Las preposiciones. Las más sencillas son las de lugar (en, por, a, de, entre), las de instrumento (con), las de tiempo (hasta), las últimas en adquirirse son las de causa o con valores significativos múltiples (para, desde, sin), las formas verbales se van adquiriendo enfrentándose a diferentes componentes (modo, números, persona, tiempo y aspecto).

En cuanto al desarrollo sintáctico, siguiendo a Cols (1990, citado en Solé, 1992), cabe decir que el orden sintáctico es un proceso continuo y, por lo tanto, el dividir en estudios es bastante arbitrario auque se hará para clarificar la explicación de las siguientes etapas:

a) Estadio de las emisiones de una sola palabra y transición hacia las combinaciones de elementos (12/18 meses). Muchos autores defienden la idea de que las emisiones de una palabra parecen ser algo más que palabras sueltas de tal forma que esto ha dado lugar al empleo del término "holofrase" para denominarlas; es decir, traducir una palabra por el valor implícito de una oración.

b) Las frases de dos palabras (18-24 meses): Uno de los rasgos principales que caracterizan a estas frases de dos palabras es la omisión de elementos de tipo morfológico (flexiones) así como las preposiciones, artículos, verbos auxiliares, etc., es decir, los elementos con menor carga de significado y los sufijos morfológicos. Esto ha dado lugar a que algunos autores denominen al lenguaje característico de esa etapa como "telegráfico", por similitud al lenguaje empleado en los telegramas.

c) Las oraciones de tres elementos (24-30 meses): Uno de los rasgos más relevantes de esta etapa es que las emisiones van dejando de ser telegráficas y, los elementos función y los morfemas gramaticales hacen su aparición. 
Algunas oraciones típicas en esta etapa son aquellas del tipo agente "acciónobjeto" (ej. mama dame pan) o agente "acción- localización" (ej. mamá-venaquí).

d) Oraciones de cuatro elementos o más (a partir de 30 meses): en esta etapa la estructura oracional se hace más compleja. La oración simple se amplía a todas las personas; sujeto, a muchos más tiempos del verbo y a diferentes casos que expresan objetos y circunstancias. Simultáneamente aparece la oración compuestas coordinadas y las primeras oraciones subordinas. La conjunción se emplea como un modo de mantener el flujo narrativo (ej. En el patio del cole había charcos y los pisaba y me mojaba el pantalón). Tradicionalmente se considera que el desarrollo morfo-sintáctico ha concluido hacia los cinco años, aunque a partir de esta edad y al menos hasta la pubertad continúan produciendo-se avances en la estructura del discurso.

El desarrollo verbal se inicia a partir de los 10 meses. Comprenden el balbuceo mixto y el desarrollo fonológico, léxico y morfo-sintáctico que se va conformando a partir de esa edad.

\subsection{Trastornos en los componentes sintáctico y semántico}

Algunos sujetos pueden reconocer sin dificultad cada una de las palabras que componen la oración, pero fracasan en los procesos superiores. Aunque a estos pacientes no se les denomina estrictamente disléxicos, obviamente tienen trastornos de lectura. En unos casos, el trastorno si sitúa a nivel sintáctico ya que los pacientes son incapaces de combinar las palabras en las estructura sintáctica correspondiente. En otros casos, el déficit es semántico puesto que el fallo se produce en el proceso de extracción del mensaje. Al primer tipo de trastorno se le denomina agramatismo (más exactamente "comprensión asintáctica") y al segundo afasia semántica. Algunos de los principales rasgos de estos dos tipos de alteraciones son los siguientes:

- Agramatismo. El déficit en el uso del componente sintáctico, o agramatismo, se manifiesta dramáticamente en los afásicos de Broca. Aunque obviamente existen diferencias individuales, la característica general de estos pacientes es la dificultad para hacer uso de las claves sintácticas (palabras funcionales, sufijos, orden de palabras, etc.). En consecuencia, su habla espontánea se caracteriza por el uso de frases cortas, de estructura sintáctica tremendamente simple, y en las que la mayor parte de las palabras son de contenido (lenguaje telegráfico). Además de este déficit, los afásicos de Broca suelen padecer trastornos articulatorios.

- Afasia de conducción. Otros pacientes, que también parecen tener dificultades en el procesamiento sintáctico, son los afásicos de conducción. No obstante, sus dificultades son de otro tipo. Caramazza y Berndt (1982, citados en Cuetos, 2006) afirman que los mecanismos de procesamiento sintáctico están intactos en estos pacientes, pero no se utilizan 
adecuadamente debido a su limitada capacidad de la memoria a corto plazo. Si la capacidad de retención de palabras en una frase es pequeña, surgirán dificultades para mantener todas las palabras agrupadas, para el entendimiento de la frase.

- Afasia semántica. Los déficit en el componente semántico se pueden producir por dificultad en construir la estructura semántica; es decir, por dificultad en integrar la información contenida en las oraciones y/o párrafos en una representación unificada o por dificultades en conexionar esa estructura con sus propios conocimientos.

En cuanto a la dificultad de integrar la información en los propios conocimientos, se pueden citar todas las personas que por deterioro cerebral han perdido parte de sus conocimientos (los casos de amnesia) y por ello tienen dificultades para entender mensajes simples.

\subsection{Los conocimientos previos en los procesos de enseñanza/aprendizaje}

El interés de la concepción constructiva por las cuestiones relativas al estado inicial de los alumnos ( $y$ en este caso por los esquemas en que se hallan organizados sus conocimientos), no es tanto un interés por estudiar y analizar estas cuestiones en si misma, sino en tanto que repercuten e inciden directamente en los procesos de enseñanza y aprendizaje que se llevan a cabo en el aula.

Para Adams y Collins (1985, citado en González, 1992) la fuerza del esquema deriva de dos hechos: la representación del nivel superior de cualquier esquema proporciona una abstracción de un marco conceptual para todos los sucesos incluidos en esa clase. También se deriva, como acabamos de ver, de la suposición de que los esquemas de nivel inferior son elementos o subesquemas dentro de otro de más alto nivel, proporcionando una estructura para conceptualizar las relaciones entre los distintos niveles de procesamiento.

Aún estando básicamente de acuerdo con esta sentencia, suponemos que cualquier profesor, estará de acuerdo en concretar esta afirmación, siendo que no es una tarea clara y sencilla.

Para empezar, parece sensato suponer que, al iniciar un determinado proceso educativo, no es necesario (ni probablemente posible) conocer todo lo que sabe el alumno. El primer criterio lógico de selección respecto a los conocimientos del alumno que es necesario explorar es el contenido básico sobre el que se centrará el proceso de enseñanza y aprendizaje.

$\mathrm{Si}$, por ejemplo, nos proponemos trabajar con alumnos sordos adultos, frases bien elaboradas, siendo que ellos no sepan comprender una pequeña oración, tendremos que replantear estas frases, de acuerdo con las necesidades de estos alumnos, por 
medio de una evaluación detallada y precisa a cerca de sus capacidades lectoras y el interés que tienen por determinadas actividades, motivándoles a la lectura.

En definitiva, al tener en cuenta los objetivos se puede seleccionar de manera más precisa, en cada caso concreto, cuáles son los conocimientos previos realmente pertinentes y necesarios para llevar a cabo un determinado proceso de enseñanza y aprendizaje.

La consideración simultánea y relacionada de ambos factores, el contenido y los objetivos al respecto, debería llevar a plantear preguntas tales como: ¿Qué se pretende que los alumnos aprendan concretamente en relación a este contenido? ¿Como se pretende que lo aprendan? ¿Que necesitan saber para poder contactar y atribuir un significado inicial a estos aspectos del contenido que se pretende que aprendan? ¿Qué cosas pueden saber ya que tengan alguna relación o que puedan llegarse a relacionar con estos aspectos del contenido? Las respuestas a esas preguntas deben tener relación con los contenidos, que en atención a las perspectivas, son pertinentes y necesarias para que los alumnos puedan aprender el contenido que pretendemos enseñarles y constituyen, por tanto los aspectos básicos que es necesario explorar y conocer en cuanto a los que ya saben los alumnos.

Y ¿qué pasa si no saben nada?. Con relativa frecuencia los profesores se quejan de que los alumnos no tienen los conocimientos previos necesarios para poder ayudarlos a aprender los nuevos contenidos. -No sé que les enseñaron en primero-, -No tienen ni idea-. Por suerte, en la mayoría de los casos, estas afirmaciones son un tanto extremas. La construcción del conocimiento es un proceso progresivo, no es una cuestión de todo o nada, si no cuestión de grado. Así entendida, la mayoría de las veces lo que puede ocurrir es que los alumnos sepan poco o muy poco, tengan unos conocimientos contradictorios o mal organizados o tengan, como se ha demostrado reiteradamente, ideas previas total o parcialmente erróneas.

Cooper (1990, citado en Solé, 1992) señala que la discusión sobre las aportaciones de los alumnos es uno de los mejores medios para actualizar su conocimiento previo, pero simultáneamente advierte del peligro de que si no es acertadamente conducida, puede desviar de la temática o aspectos principales de la lectura, cansar a los alumnos o no proporcionarles organizadores claros. En opinión de este autor, es fundamental que se sinteticen los aspectos más relevantes, que ayudarán a los niños a afrontar el texto.

Aunque estas son las situaciones más habituales, puede llegar a darse el caso en que los conocimientos que hemos determinado que son necesarios para el aprendizaje de los nuevos contenidos sean prácticamente inexistentes, es decir, que no hayan sido adquiridos a un mínimo nivel razonable por el alumno. En este caso, si se tienen en cuenta los principios básicos de la concepción constructiva, las consecuencias de iniciar un proceso de enseñanza de un nuevo contenido, sin que los alumnos tengan los conocimientos previos necesarios para poder contactar con dicho contenido son fácilmente previsibles.

En primer lugar, y en el supuesto de que los alumnos tengan tendencias a enfocar su aprendizaje de manera superficial, la consecuencia más probable es que lleven a cabo un aprendizaje fundamentalmente memorístico, poco significativo. En segundo 
lugar, y en el supuesto de que los alumnos tengan intenciones de enfocar su aprendizaje de manera más profunda, es decir, relacionando el nuevo contenido con lo que ya saben, podemos prever que echarán mano de sus esquemas e intentarán atribuir un sentido inicial al nuevo contenido partiendo de conocimientos que suponen o intuyen relacionados.

Tanto en el supuesto de detectar, que los conocimientos previos necesarios son inexistentes, como en el supuesto de que éstos sean pobres, desorganizados o erróneos, es conveniente plantearse la necesidad de revisar los objetivos que se persiguen, con el fin de poder subsanar esta situación en la media de los posible. En primer lugar, en el caso de que los conocimientos previos sean total o prácticamente inexistentes, es preciso suplirlos antes de abordar la clase. En segundo lugar, en el caso de que los conocimientos previos de los alumnos sean excesivamente desorganizados o erróneos, y en la medida en valores que estas características pueden dificultar en manera notable los procesos de enseñanza y aprendizaje de los nuevos contenidos, es conveniente solucionar estos problemas mediante actividades específicas que vayan encaminados a resolver estas cuestiones antes de iniciar al aprendizaje de los nuevos contenidos.

Si el texto está bien escrito y si el lector posee un conocimiento adecuado sobre él, tiene muchas posibilidades de poder atribuirle significado. Sí ello no ocurre, y manteniéndonos ante un texto razonablemente redactado, puede ser debido a tres tipos de motivos (Baker y Brown, 1984, citados en Solé, 1992, 104): Puede ser que él no posea los conocimientos previos suficientes para abordar el texto, puede ocurrir que posea el conocimiento previo, pero que el texto en sí no ofrezca ninguna pista que acuda a él, o , por último, puede ocurrir que el lector pueda aplicar unos determinados conocimientos, pero que ésta no coincida con la que pretendía el autor.

Por otra parte, es importante tener en cuenta que, aunque los alumnos tengan unos conocimientos previos suficientes para abordar el nuevo contenido, el hecho de que posean estos conocimientos no asegura que los tengan presentes en todo momento a lo largo de su proceso de aprendizaje. En este sentido, tan importante es que los alumnos tengan unos conocimientos previos pertinentes como que los utilicen en el momento adecuado para establecer relaciones con el nuevo contenido. En otras palabras, la actualización y la disponibilidad de los conocimientos previos que poseen los alumnos es una condición necesaria para que puedan llevar a cabo un aprendizaje lo más significativo posible, pero esta condición no se puede dar por supuesta aun sabiendo que los alumnos poseen estos conocimientos.

Que los alumnos pongan en juego los conocimientos previos necesarios en el momento adecuado pueden depender del número factores. En ocasiones, la no disponibilidad puede ser tan sólo un problema transitorio de falta de atención. A veces, el hecho de que los alumnos no actualicen sus conocimientos previos puede ser debido a la falta de sentido que atribuyen a la actividad o a una escasa motivación para establecer relaciones entre los elementos y la memorización mecánica del nuevo contenido.

Otras veces, la organización general de la enseñanza de los alumnos o la planificación concreta de la secuencia didáctica en la que se aborda el aprendizaje 
de los nuevos contenidos pueden llegar a ser un impedimento para que los alumnos se den cuenta de que es necesario movilizar sus conocimientos previos. En este sentido, la falta de relación entre áreas, una secuencia incorrecta entre ciclo o niveles o una excesiva fragmentación de las actitudes, especialmente en las etapas superiores de la escolarización, pueden hacer que la tarea de detectar qué conocimientos previos son importantes para entrar en contacto con los nuevos contenidos sea difícil o sumamente costosos para los alumnos.

Ante estas situaciones en las que se observa que los alumnos no actualizan sus conocimientos previos, la ayuda es absolutamente necesaria. En primer lugar, teniendo presentes a lo largo del proceso de enseñanza los conocimientos previos de los alumnos que se han considerado necesarios para atribuir sentido y significado al nuevo contenido.

Con ellos en mente, puede ser útil ir haciendo alusión de manera más o menos directa a dichos conocimientos en el momento en que se entiende que deberían ser actualizados por los alumnos, así como explicar las relaciones que pueden establecer entre los conocimientos previos, los nuevos contenidos, los resúmenes, las síntesis y las recapitulaciones periódicas pueden ser algunos de los momentos privilegiados en los que llevar a cabo estas tareas.

Hablando de los conocimientos previos se ha introducido de lleno en el propio proceso de enseñanza y aprendizaje de los contenidos.

Winograd (1985, citado en Solé, 1992) señaló que las dificultades que, según muchos profesores, encuentran algunos alumnos para dilucidar la idea principal de un texto remite a que lo que ellos consideran esencial es distinto de lo que desde un punto de vista adulto, se considera fundamental.

En primer lugar, habría que determinar el punto de vista para calificar un conocimiento como previo, pues en este sentido las perspectivas del profesor y de los alumnos no tienen porqué coincidir necesariamente (por no hablar de la perspectiva del experto en la materia). Pero situándose en el punto de vista del que enseña, se puede hablar de conocimientos previos a distintos niveles, en la medida en que las unidades organizativas de los procesos de enseñanza y aprendizaje pueden ser de diferente magnitud.

Sin entrar en consideración relativas a las etapas o ciclos, las unidades organizativas dentro de un mismo nivel pueden abarcar desde la planificación del curso (a nivel general, en relación a las distintas áreas) hasta la planificación de unidades didácticas concentradas que en cada uno de estos niveles. Tiene sentido hablar de conocimientos previos de los alumnos, conocimientos que, aunque lógicamente relacionados, pueden ser diferentes en función del grado de generalidad o especificidad con que se contemplan los nuevos contenidos generales de un curso, que son habitualmente distintos de los conocimientos previos que conviene explorar al iniciar una unidad didáctica concentrada o una lección específica de esta unidad. 


\subsection{La exploración de conocimientos previos}

Las cuestiones que se acaban de comentar en los apartados anteriores y, en definitiva, la perspectiva en la que sitúa la concepción constructivista en cuanto a la problemática de los conocimientos previos, permite esbozar una serie de indicaciones al qué, cuando y cómo explorar y evaluar los conocimientos previos de los alumnos.

En relación al primer interrogante, qué explorar, de los comentarios anteriores se desprenden dos indicaciones de tipo general que deben concretarse y matizarse en función del nivel y el momento temporal del proceso en que se lleve a cabo la exploración. En primer lugar, el objeto de la indagación deben ser los conocimientos previos de los alumnos que son pertinentes y necesarios para poder abordar el aprendizaje de los nuevos contenidos.

Ahora bien, determinar qué conocimientos pueden ser pertinentes y necesarios no es algo que pueda hacerse de manera genérica, en abstracto, fuera del ámbito concreto en el que se desarrollará nuestra tarea. Aunque se puede contar con el recurso de instrumentos ya elaborados (listas, mapas, cuestionarios, etc.), en último término son los objetivos respecto al nuevo contenido y las actividades que planificamos en relación a ellos los que acaba definiendo los esquemas de conocimiento que los alumnos van a tener que actualizar y movilizar ante la nueva situación de aprendizaje.

En este sentido, un recurso útil para decir qué conocimientos previos explorar es la propia experiencia docente. Aunque esta siempre pueda mejorarse y revisarse, lo cierto es que la práctica docente continuada en determinados niveles y áreas de contenido proporciona indicaciones bastantes fiables sobre cuáles son las dificultades más habituales de los alumnos respecto al aprendizaje de un determinado contenido, cuáles son las actitudes, conceptos y procedimientos que tiene que poner en juego para llevar a cabo dicho aprendizaje, qué errores sistemáticos suelen cometer o qué lagunas se detectan año tras años en sus conocimientos previos. Esta experiencia acumulada es, sin duda, referente importante a la hora de determinar qué es lo que se debe explorar.

Por otra parte, la caracterización de los esquemas de conocimiento de los alumnos que se ha expuesto anteriormente lleva a considerar que es tan importante conocer los elementos que forman parte de los esquemas de conocimiento de los alumnos como las relaciones que tienen (o no tienen) entre sí estos elementos, relaciones que determinar el grado de organización de estos esquemas. Así pues, es necesario tener en cuenta que los aspectos que hay que explorar no pueden limitarse a un listado de hechos, conceptos, procedimientos o actitudes sino que deben ampliarse necesariamente a la relación o relaciones que se han establecido entre dichos elementos.

Así, las indicaciones que proporciona la concepción constructiva amplían notablemente la respuesta tradicional a la cuestión del cuándo, es decir, en qué momento conviene llevar a cabo la exploración y evaluación de los conocimientos 
previos. En todo caso, tiene sentido llevar a cabo la evaluación en cualquiera de los distintos niveles organizativos de la docencia, a este respecto, dada la dificultad de poder valorar en detalle el conjunto de los conocimientos previos necesarios, puede ser conveniente y a la vez más útil, llevar a cabo una exploración global de tipo general al iniciar un curso o una unidad didáctica amplia y posponer la evaluación de aspectos más específicos o puntuales al inicio o a lo largo del desarrollo de las lecciones concretas.

La estrategia de "diseminar" la evaluación de los conocimientos previos de los alumnos en distintos niveles y momentos (estrategia que sin duda utilizan de manera más o menos organizada numerosos profesores), además de permitir una exploración más amplia y detallada, puede cumplir un papel importante como ayuda para intentar asegurar, en la medida de lo posible, la disponibilidad de los conocimientos previos de los alumnos en el momento en que se necesitan.

La última cuestión, cómo llevar a cabo la exploración de los esquemas de conocimiento de los alumnos, es probablemente una de las que más preocupa en relación al tema que se está tratando. Ello es hasta cierto punto comprensible, entre otras cosas debido a la diversión de instrumentos con los que se cuenta para llevar a cabo la evaluación de los conocimientos previos, instrumentos que van desde pruebas más o menos estandarizadas y cerradas hasta instrumentos de carácter más abierto y flexible. A este respecto, y sobre la base de la concepción constructiva, aunque no es posible tomar partido de manera general y excluyente por unos instrumentos concretos, esta concepción proporciona algunas indicaciones que permiten valorar la pertinencia de los distintos tipos de instrumentos.

En este sentido, dadas las características de los procesos de enseñanza y aprendizaje, parece más adecuada utilizar instrumentos de tipo abierto siempre que sea posible. El diálogo entre profesores y alumnos (a partir de preguntas más 0 menos abiertas de problemas o situaciones que hay que resolver, ejemplos, etc.) permite una exploración más flexible y consecuentemente más rica, pero además, permite preservar la dinámica del aula, evita el riesgo de que los alumnos (y los profesores) vivan la exploración de los conocimientos previos como algo parecido a un "examen" que a una de ayuda o una preparación para el nuevo aprendizaje.

Partiendo de este supuesto, las características concretas del contexto, los alumnos o los contenidos pueden ser criterios adicionales para valorar la mayor o menor pertinencia de un determinado instrumento. Así, por ejemplo, según las características evolutivas de los alumnos parece conveniente reservar el uso de instrumentos de tipo más cerrado (cuestionarios, mapas, redes, etc.) para los noveles medios y superiores de la escolaridad obligatoria, empleando instrumentos de tipo abierto en los niveles iniciales de está.

Como señalan acertadamente Colomer y Camps (1991, citados en Solé, 1992), sería muy productivo dedicar buena parte del tiempo que en las escuelas actualmente se consagra a oralizar los textos, a discutir y comentar qué y cómo se ha leído, que se ha pretendido...etc. En este sentido, sin que ello suponga excluir a los restantes, los cuestionarios, diagramas y mapas pueden ser un recurso útil para explorar los conocimientos previos de tipo conceptual, mientras que la evaluación de los conocimientos previos de tipo procedimental requiere de tareas en las que sea 
posible observar de manera más o menos directa la secuencia de pasos que llevan a cabo los alumnos en relación al procedimiento que hemos determinar explorar.

Por último, respecto a los conocimientos previos de tipo actitudinal y normativo parece adecuado recurrir a la exploración mediante instrumentos de carácter más abierto, como la observación, el diálogo entre profesores y alumnos a partir de unas cuestiones guía o de situaciones en que los alumnos deban aportar soluciones o respuestas a un problema, recurriendo a las actitudes o valores que ha ido construyendo hasta este momento.

En todo caso, en término generales es conveniente que, sea cual sea el instrumento de exploración que utilicemos, intentemos incardinarlo de la forma más clara posible en el proceso de enseñanza y aprendizaje. El valor potencial de un instrumento puede verse hacer el profesor como el alumno, si se plantea como una actividad al margen, -previa- en el sentido de desconectado o vagamente relacionado con las actividades en las que se llevará a cabo el aprendizaje de los nuevos contenidos.

Así, aunque el instrumento de evaluación que se emplea sea fiable, completo y riguroso, gran parte de su utilidad puede perderse si no se consigue articularlo como un elemento más en el proceso de enseñanza y aprendizaje. En este sentido, a veces una excesiva distancia temporal entre la exploración de los conocimientos previos de los alumnos y su uso efectivo en el proceso de aprendizaje puede reducir de manera notable la posible utilidad de esta exploración.

Por último, un criterio adicional para valorar la posible pertinencia de los instrumentos para evaluar los conocimientos previos es considerar las posibilidades que ofrecen como recurso a lo largo del proceso de enseñanza y aprendizaje, especialmente en niveles educativos superiores. En este caso, los instrumentos que permiten conservar las respuestas iniciales de los alumnos por escrito (cuestionarios, mapas, etc.) o por otros medios pueden ser útiles para llevar a cabo una reflexión conjunta sobre el proceso de aprendizaje que se está desarrollando.

Desde la perspectiva de los alumnos, el volver a considerar en determinado momento sus respuestas iniciales puede ser una ayuda para tomar conciencia de los cambios que se han producido al respecto. De manera similar, desde la perspectiva del profesor esta vuelta atrás puede serle útil para valorar el camino recorrido por los alumnos y, por qué no, para darse ánimo en el camino que aún puede quedar por recorrer de nuestra lengua y llegar a conocer cómo el procesador sintáctico opera, teniendo en cuenta que, además de los componentes sintácticos, hay una serie amplia de restricciones de tipo pragmático, de tipo semántico y de conocimiento del mundo que influyen. 


\subsection{Dificultades de aprendizaje del lenguaje}

El aprendizaje del lenguaje es muy complejo y supone algo más que los sonidos, las palabras y las frases. No es un proceso unidireccional de combinación progresiva de los sonidos en palabras y de éstas en frases. El aprendizaje del lenguaje supone la adquisión de forma integrada de al menos tres tipos de componentes: (Bloom, 1980; Kaiser, Alpert y Warren, 1988, citados en García, 1997)

El aprendizaje de las formas del lenguaje o categorías formales del lenguaje incluye el aprendizaje de la fonología, la morfología y la sintaxis. De la fonología se trata de aprender los aspectos "segmentales", tales como los fonemas y las sílabas, y los "suprasegmentales" como la entonación, el acento, la pausa.

El aprendizaje de la fonología incluye el "léxico", sea de sustantivos o relacional, sea de palabras de contenido como los verbos, adverbios y nombres, o sea de palabras funcionales. La adquisión y aprendizaje de la sintaxis supone el aprendizaje del orden de las palabras. "Estos tres aspectos del lenguaje, la fonología, la morfología y la sintaxis han de integrarse y conjugarse para la producción de formas particulares" (García, 1997, 174).

Otro aspecto que es preciso aprender de manera integra es el contenido del lenguaje o los aspectos semánticos del lenguaje. Aprender la semántica implica aprender, por lo menos, tres subcomponentes:

- Conocimiento de los objetos

- Relaciones entre los objetos

- Relaciones entre eventos

"Encajar todos estos aspectos es muy difícil y puede dar lugar a dificultades en el aprendizaje del lenguaje, al igual que es posible observar estas dificultades en personas mayores con dificultades de aprendizaje" (García, 1997, 147).

Los lectores han de aprender muchas cosas en relación con este componente. Son dos los aspectos que habría que incluir aquí, las intenciones y la adaptación al contexto para provocar los efectos o funciones deseadas.

"Aristóteles fue el primero en establecer una diferenciación rigorosa entre las formas lingüísticas y la lógica de las palabras" (Stenzel, 1935, 170). La diferencia entre frase y juicio es que la frase significa algo y por medio de su ensamble gramaticalmente correcto reduce un sentido a expresión dotada de unidad como expresión, auténtica o no, de una intención, mientras el juicio enuncia una sustancia objetiva, según su validez, como verdadera o falsa.

Las dificultades en relación a la adquisición y aprendizaje del lenguaje pueden ser originadas por afecciones sensoriales (sorderas). En este caso no se puede hablar de dificultades de aprendizaje del lenguaje o disfasias. Si bien se han utilizado diferentes terminologías para describir este tipo de trastornos disfásicos: "afasia 
congénita", "disfasia evolutiva", "trastornos específicos del desarrollo del lenguaje" o "problemas de aprendizaje del lenguaje".

Según varios autores (Cuetos, 1990; Sebastián y Maldonado, 1984, citados en Domínguez y Alonso, 1993) para aprender a leer el niño/a debe haber desarrollado su conciencia fonológica, es decir, ha de poder segmentar el habla en sus sílabas y fonemas correspondientes.

\subsection{Dificultades en Comprensión Lectora}

Analizando el concepto del proceso de comprensión lectora y de los factores envueltos en dicho proceso, se puede decir, como hacen Romero y González, $(2001,23)$, que "los sujetos que tienen bajo rendimiento en las tareas de comprensión lectora presentan problemas en los procesos descendentes, de acceso al léxico y/o supralexicales". Generalmente estos sujetos presentan una capacidad intelectual normal, no suelen presentar problemas sensoriales, neurológicos o emocionales graves y han recibido una enseñanza ordinaria. Sin embargo, su motivación hacia la lectura suele ser, en general, escasa y el tiempo dedicado a la lectura es muy limitado. Romero y González (2001) hacen referencia también a que estos sujetos son de estatus sociocultural bajo, usan un lenguaje poco rico, normalmente con jergas, han recibido pautas inapropiadas por parte de sus padres en lo relativo al hábito lector, tienen escasa exposición a la lectura, actitudes y expectativas poco adaptativas acerca de la lectura y su utilidad, etc.

Estos individuos presentan una lectura apegada al texto, sólo se preocupan por el reconocimiento de las unidades lingüísticas sin acceder al significado de lo que ellas trasmiten. Se centran en la decodificación del texto y descuidan la comprensión. Presentan también problemas para construir un significado global o parcial sobre lo que han leído y carecen de conocimientos previos necesarios para procesar los textos. Son sujetos que no aprenden con la lectura, utilizan estrategias de listado y tienen, en definitiva, dificultades para construir un significado global sobre el texto y para ordenar la información textual. Lo que provoca dificultades en memoria de trabajo.

Las principales características de los sujetos con problemas de rendimiento en Comprensión Lectora (Cooper, 1990; Johnston, 1989, Sánchez, 1993; Carriedo y Alonso, 1994; Vidal-Abarca, 1995, citados en Romero y González, 2001) son las siguientes:

1. Carecen de, y/o no utilizan eficazmente, conocimientos previos sobre conceptos (vocabulario) y contenidos e ideas del texto. Presentan, por lo general, un desarrollo semántico y morfosintáctico pobre.

2. Carecen de, y/o no utilizan eficazmente, los conocimientos o estrategias necesarias para detectar los diferentes tipos de textos o estructuras textuales. 
3. Presentan dificultades para construir un significado global o macroestructura; es decir, no distinguen ni organizan las ideas principales y de detalle que hay en el texto. No utilizan estrategias estructurales de rehacer o de selección e integración de información; es decir, no hacen uso de las macrorreglas. Suelen utilizar exclusivamente estrategias de suprimir y copiar literalmente, como los escolares más inmaduros, o estrategias de listado, analizando el texto de forma lineal; es decir, oración a oración y, no considerando el listado, la supresión y copia, el tratamiento global del párrafo o de la oración.

4. No realizan una supervisión y una autorregulación del proceso de comprensión. No tienen autoconciencia sobre el proceso lector, sobre la construcción deliberada del significado global del texto y sobre la articulación de proposiciones. No utilizan estrategias de control y/o evaluación de la propia comprensión.

5. No realizan inferencias entre lo leído y lo conocido. Son sujetos que no hacen uso de estrategias inferenciales y presentan una lectura basada en el texto. Se consideran sujetos que no aprenden leyendo.

\subsubsection{Los Factores que influyen en la Comprensión Lectora Relativos al Sujeto}

\subsubsection{Desarrollo semántico y morfosintáctico}

"Los sujetos que presentan problemas semánticos y sintácticos suelen confundir palabras que ortográficamente son diferentes pero semánticamente son similares (galleta, dulce), o bien confunden palabras que guardan relación semántica (cuchara/tenedor). También se puede encontrar errores entre masculinos y femeninos; singulares y plurales; presente, pasado y futuro; coordinadas, subordinadas y pasivas. O presentan problemas en ordenar frases, seleccionar frases incoherentes sintácticamente o realizar cierres gramaticales" (Romero y González, 2001, 24).

\subsubsection{Atención y memoria}

Algunas variables cognitivas están relacionadas con la comprensión lectora y el aprendizaje en general.

- Atención sostenida, da importancia de la concentración

- Atención selectiva hace referencia a la capacidad del sujeto para seleccionar las características específicas de las letras o de las palabras necesarias para el buen reconocimiento y comprensión, respectivamente. 
- Memoria a corto y largo plazo. Hacen referencia a la capacidad de almacenar y recuperar información relativa a las características y secuencias de las letras o de las palabras que tenemos guardadas en nuestra mente.

- Memoria de trabajo. Hace referencia a la memoria que se va guardando mientras se trabaja (o lee). Para la comprensión es necesario almacenar información que se recupera sobre la marcha y que se va almacenando de nuevo; esta es la memoria que se llama de trabajo (Romero y González, 2000; González y Romero, 2000; Romero, 1999, citados en Romero y González, 2001, 25).

\subsubsection{Motivación y expectativas hacia la lectura}

La importancia de la motivación en el aprendizaje es fundamental. Se dice que la motivación es un impulso a la acción y para la obtención de resultados. Castañeda y Almaguer $(1993,50)$, señalan que "Al tratar el tema de la motivación es interesante establecer una distinción entre lo extrínseco o intrínseco de ella, en el sentido de que los satisfactores que se desean lograr guardan o no relación con lo que se hace para obtenerlos". La motivación intrínseca se pone de manifiesto cuando el aprendiz tiene un verdadero interés por aprender y comprender los conceptos estudiados y no sólo por pasar un examen, acreditar la materia, u obtener otro tipo de beneficios externos.

Betancourt $(2001,58)$ destaca que "Los estudiantes se comprometen en las actividades docentes intrínsicamente motivadas, porque traen consigo cierto tipo de estado interno que ellos encuentran reconfortante, no por alcanzar una recompensa externa..." La motivación extrínseca se refiere a los estímulos agradables que el estudiante recibe del entorno y que puede consistir en premios adicionales, el reconocimiento del entorno social 0 , simplemente sensaciones placenteras. Una diferencia importante entre la motivación intrínseca y la extrínseca es que en esta última la motivación puede desaparecer al momento de conseguir la recompensa buscada, mientras que en la intrínseca la motivación tiende a ser permanente. "El grado de motivación intrínseca varía positivamente con respecto a la magnitud de las recompensas intrínsecas en la tarea" (Betancourt, 2001, 59-62).

Otro tipo de motivación es la llamada motivación defensiva. De acuerdo con este tipo de motivación, los estudiantes muy ansiosos o bajo condiciones de prueba altamente estresantes, obtienen un rendimiento más bajo en el aprendizaje, mientras que los estudiantes con poco nivel de ansiedad o en condiciones no estresantes obtienen mejores niveles de rendimiento y aprendizaje.

La motivación por logro, es "definida como la motivación por tener éxito, por ser bueno en algo" (Gagné y Berliner, 1988, citados en Arancibia, Herrera y Strasser, 1999). Es importante que se impongan retos superables para los alumnos ya que de lo contrario es posible que se sientan frustrados y pierdan el interés por aprender. Keller (citado en Khan, 1998), desarrolló un modelo motivacional en 1993. 
De acuerdo con su modelo, la motivación puede clasificarse en cuatro categorías: interés, relevancia, expectativas y satisfacción. El interés se refiere a mantener y manejar la curiosidad del aprendiz; la relevancia se refiere a relacionar la situación de aprendizaje con las necesidades y motivos del aprendiz; las expectativas se refieren a las aspiraciones individuales del aprendiz; la satisfacción se refiere a la motivación continua para seguir trabajando por conseguir metas similares.

La motivación hacia la tarea está estrechamente relacionada con otras variables, tales como las características de los textos, las atribuciones causales de éxito y fracaso, las expectativas de éxito y fracaso (estimación subjetiva sobre las posibilidades y sobre el contenido de la tarea) y la persistencia en la tarea: muy relacionado con las atribuciones a la tarea. (Romero y González, 2001, 25).

Igual que ocurre en psicología de la motivación en general, tampoco en su estudio en el ámbito del aprendizaje existe un único modelo, ni siquiera uno que prevalezca. "Coexisten, pues, varios intentos explicativos, entre los que se citan los siguientes" (González, 2004, 38 y 39):

- Motivación intrínseca y extrínseca. Se considera una conducta intrínsecamente motivada aquella que se ejecuta por sí misma, por la satisfacción que produce, el aprendizaje que posibilita, o el sentimiento de realización que despierta en el sujeto. La que se lleva a cabo con el fin de obtener un premio o evitar un castigo del tipo que sean se considera extrínsecamente motivada. Respecto a la comprensión lectora, se apuntan algunas variables en las que se diferencian ambas modalidades: el momento en que se inicia o se da por concluida la lectura, y el tiempo invertido en ella; la cantidad de atención que el sujeto está dispuesto a asignarle; la dedicación de esfuerzo mental en el proceso de aprendizaje; la elección de metas intermedias y la dificultad de éstas; la selección de las estrategias de aprendizaje; y la propia conceptualización de la tarea, como un fin en sí misma o como un medio.

- Orientación o metas generales. Son consideradas por algunos como una versión moderna de la dicotomía extrínseca vs. intrínseca. En función de esas metas generales, se diferencian varias categorías de alumnos: sujetos orientados a la tarea, que consideran que una mayor comprensión es un fin en sí mismo; alumnos orientados a la actuación, cuyo objetivo es evidenciar determinadas habilidades ante los demás, y suscitar en ellos juicios favorables sobre su capacidad comparada con la de los compañeros.

- Interés. Se concibe como una preferencia duradera por ciertas actividades, tareas o áreas de conocimiento, y actúa de fuerza impulsora de la elección y la facturación del sujeto. Esta variable incide en la comprensión de los textos, especialmente en sus aspectos más profundos.

- $\quad$ Autoeficacia percibida. Suele definirse como aquellos juicios de cada sujeto sobre sus capacidades para organizar y poner en práctica las acciones necesarias para alcanzar el rendimiento deseado. Estos sentimientos suelen condicionar el modo en que las personas sienten, piensan o actúan. 
- Autoconcepto académico. Es la percepción que tiene el sujeto acerca de su propia capacidad para llevar a cabo determinadas actividades y tareas escolares, o lo que es lo mismo, la visión que tiene el sujeto de sí mismo como estudiante. Esta percepción es específica de cada área o materia agrupándose posteriormente en otros componentes de segundo orden y culminando la estructura jerárquica en el factor más global de capacidad académica.

- Valor del éxito escolar. Se asume que cuanto mayor sea el valor concedido al éxito académico, más fuerte será la motivación para implicarse en las tareas escolares. Este valor se refleja en los siguientes factores: la importancia que se concede a la perfecta realización de las tareas escolares; el disfrute obtenido por el sujeto al realizar una determinada actividad; la utilidad, entendida como el modo en que la tarea se relaciona con metas futuras; y el coste, en términos de todos los aspectos negativos asociados a la realización de esa tarea.

La lectura y, sobre todo, la escritura, siguen siendo dos procesos que no tienen el suficiente reconocimiento y valoración por parte de los estudiantes, independiente del nivel de estudios que cursen. No obstante las potencialidades que leer y escribir encierran, más allá de acceder y acumular información, se les sigue mirando como dos tareas (con todas las implicaciones que esta expresión encierra) que impone la escuela a quienes a ella asisten.

Existen diversas hipótesis y múltiples estudios frente a la situación antes señalada, desde las que responsabilizan a los medios de comunicación (en especial a la televisión) por distraer a los jóvenes de los procesos textuales, pasando por los que exaltan el poder de los medios audiovisuales y, de paso, decretan la muerte de los libros y con ello la pérdida de importancia de prácticas tan antiguas, pero valiosas; hasta aquellas que explican dicho distanciamiento por el tratamiento que se le da a los textos en el ámbito escolar.

Seguramente mucho de verdad puede haber en cada uno de los maestros que tienen la responsabilidad de descubrir qué hay detrás de dicha apatía de los niños por la lectura y crear otros posibles caminos para llegar a que los estudiantes asuman la escritura y la lectura como prácticas que formen parte de su vida diaria, como otras formas de comunicación.

Un primer paso, indispensable por cierto, es reflexionar acerca del sentido que se les asigna a los procesos citados, una mirada crítica lleve a cuestionar incluso la verdad construida en la escuela.

"En buena medida leer y escribir han tenido dos características esenciales: imposición por parte del maestro y monólogo del autor" (Ortiz y Burgos, 1999, 25).

Con la primera característica, la imposición, se puede lograr obediencia, pero nunca despertar amor por lo que se hace.

La lectura y la escritura son fenómenos de índole cultural y no de carácter biológico, por lo cual es necesario que exista alrededor del niño una serie de 
prácticas que hagan posible que éste vea dichas actividades como algo ligado consustancialmente a su existencia misma. Los padres, como los seres más cercanos física y afectivamente a los niños, deberán mostrar con sus ejemplos el interés que sienten por leer y escribir. Allí no podremos hablar de imposición y, por el contrario, se despierta el interés y se genera la motivación que todo tipo de aprendizaje requiere.

Ahora, en el marco de la escuela, dicha situación es posible de lograr si el maestro asume un rol de orientador, de guía. El maestro constituye en un ejemplo, en un modelo por imitar. Es precisamente esa imagen, ese reconocimiento, el que le da la posibilidad, la invaluable posibilidad de motivar mediante el ejemplo para que los/las estudiantes se lancen a la aventura de explorar y de construir textos. El comentario (oral y escrito) del fragmento de un libro y las breves lecturas seleccionadas, serán algunos de los medios con los cuales se puede mover a sus estudiantes a familiarizarse cada vez más con los textos.

Una segunda estrategia para lograr motivar a los estudiantes hacia la lectura y la escritura es hacer de ellas parte constitutiva de cada curso, sin importar el tipo de asignatura que oriente. Se puede pensar que ciertas disciplinas casi no se prestan para ello, como podría ser el caso de las matemáticas, pero la lectura de biografías de destacados personajes de este campo, el recorrido por anécdotas y paradojas matemáticas, unido a aprender a leer/interpretar y formular/escribir problemas matemáticos, son sólo unos pocos ejemplos de medios a través de los cuales se puede lograr la presencia de la lectura y de la escritura en un campo que tradicional y erróneamente se ha querido ver como desligado del mundo de las letras.

Como tercera posibilidad está la de invitar a los/las estudiantes a realizar prácticas de escritura sobre temas seleccionados de mutuo acuerdo, que conduzcan a la socialización de los textos que se produzcan y en la cual el/la docente presente su producción, la someta al análisis y la crítica de los/las estudiantes, con el ánimo de estimular la reflexión acerca del contenido y del tratamiento dato al objeto/sujeto sobre el cual se escribe. Será en esa medida que quien oriente un proceso pedagógico muestre no sólo su labor desarrollada, sino también asuma una actitud receptiva frente al aprendizaje permanente de lo que implica leer y escribir.

La segunda característica hace referencia a la manera como se han asumido tradicionalmente la lectura y la escritura en nuestra escuela, como monólogos, lo cual nos remite necesariamente a reflexionar sobre la importancia de la comunicación entre las personas.

Si el proceso textual que realiza una persona (bien sea de lectura, como una forma de acceso al mundo de las ideas concebidas por el autor, o, en caso contrario, escribir como la posibilidad de construir y reconstruir el mundo que nos rodea para darlo a conocer a otras personas), es una comunicación bidireccional, es decir, diálogos entre personas que pueden no conocerse, la lectura y la escritura se constituyen en el medio ideal para establecer dicho intercambio de ideas. 
...Y, ¿cuál es la importancia que se le asigna a la comunicación y a sus nexos con la lectura y la escritura...? Así como se puede asegurar que el lenguaje construyó al hombre como un ser social, podemos afirmar, a su vez, que el ser humano es, en esencia, lenguaje, comunicación. Piénsese lo que constituye el quehacer diario de una persona; lo que hacemos todos los días y a todas horas las personas es hablar: habla el conductor en la manera como dirige su vehículo, aunque no musite palabra alguna; habla el médico cuando lee un diagnóstico, aunque sus labios ni su pluma se muevan para nada; habla el peatón que dirige sus pasos hacia un sitio predeterminado, eludiendo obstáculos y acortando caminos, aunque vaya solo y en silencio.

El ser humano es comunicación permanente, es el ser con capacidad de conversar con el otro, con el entorno y consigo mismo. Habla hasta en los sueños, lenguaje bastante - pero aún no suficientemente- estudiado.

Pues si el ser humano habla de diversas, de múltiples maneras, en variedad de espacios y contextos, despierto y dormido, ¿por qué la escuela no ha sabido emplear esta capacidad-necesidad que tiene el ser humano de estarse comunicando permanentemente...?

Y, ¿cuándo esa lectura se vuelve diálogo y, por lo tanto, tiene sentido para las personas involucradas...? Cuando el autor habla y le hablamos; cuando el autor expresa sus ideas y nosotros - con respeto, pero también con coraje- somos capaces de responderle, de decirle que sí compartimos sus puntos de vista, pero que aun así se quedó corto, le faltó algo, olvidó u omitió expresar que... Esto es lectura: "la capacidad de escoger un sitio tranquilo, sosegado, para sentarnos junto con el autor para dejar que él, palabra por palabra, línea por línea, nos hable, párrafo tras párrafo nos cuente de su cosmovisión, nos haga saber qué piensa y cómo lo piensa" (Ortiz y Burgos, 1999, 25) sólo cuando la escuela esté dispuesta a invitar a los/las estudiantes a descubrir en el libro la escritura y la lectura como otras manifestaciones de la capacidad, de la infinita capacidad de comunicar que habita en todos, sólo a partir de ese instante estudiantes y profesores podrán dimensionar lo que en realidad es leer y escribir y, de este modo, lanzar a la aventura de construir personajes y acciones, dramas y tragedias, mitos y leyendas, así como de poder hablar con los seres vivos que habitan en ellos.

\subsubsection{Los Factores que influyen en la Comprensión Lectora Relativos al Contexto}

Romero y González $(2001,25)$ indican que "cabe distinguir factores relativos al entorno escolar y factores relativos al entorno familiar". En función de estos factores existen una serie de variables que se pasan a detallar a continuación 


\subsubsection{Entorno Escolar}

- Relación profesor-alumno y relaciones de iguales, esta variable está relacionada con la disposición y tamaño de la clase, dinámica y estructura de la clase (actividad en grupo o individual, estructuradas o no), actitud del profesor sobre cómo enseñar y sobre los métodos, el apoyo entre los iguales, la existencia de competitividad, el liderazgo. Estas son variables que precipitan los problemas de comprensión lectora y de aprendizaje en general

- Tiempo de exposición a la lectura. Los alumnos que más tiempo dedican a leer en clase, dada la planificación del maestro, suelen presentar una más adecuada actitud para la lectura y su rendimiento también es considerablemente más alto.

- Materiales y tipo de textos. Si los temas que se utilizan en lo inicios de la enseñanza escapan del interés del sujeto, el proceso de aprendizaje puede verse obstaculizado. Por otra parte, los textos deben tener ciertas características para que sean eficaces y faciliten la comprensión, por ejemplo, que tengan una unidad interna sin información excesivamente irrelevante, que sean coherentes (tengan título, esquemas, diagramas, expresiones conectivas que identifiquen el tipo de texto), que posean una organización de sus ideas y que sean adecuadas a la audiencia (Vidal-Abarca, 1994, citado en Romero y González, 2001).

- Métodos de enseñanza. La influencia de los métodos de enseñanza en cuanto a la aparición de dificultades de aprendizaje es una cuestión polémica. En este sentido parece que el método utilizado es importante en el inicio de la lectura, pero posteriormente no: es decir, sí existen diferencias entre los lectores novatos con respecto al método, pero luego estas diferencias desaparecen. Hay que decir que el método será eficaz en función de las características del sujeto.

- Adecuación de los objetivos y procedimientos educativos. Es decir, al diseño de programas de aprendizaje en cuando a contenidos y procedimientos, tanto en una etapa, de un ciclo, como de un curso, de un trimestre... Suelen coincidir con las fases de adquisición de la lectura y la escritura.

\subsubsection{Entorno Familiar}

- Relaciones padre-hijo y pautas educativas. Son buenos predoctores del éxito o fracaso lector, el que el adulto preste ayuda al sujeto en la realización de la tarea en casa, el exponer al niño a la lectura y crearle un hábito, la administración de refuerzos contingentes con el comportamiento lector en casa del niño, etc. 
- Expectativas parentales hacia el papel de la escuela en el aprendizaje de la lectura, hacia el futuro de su hijo, hacia la necesidad de aprender a leer y escribir, y hacia las actitudes y modos de afrontar el problema.

- Comportamiento lector en casa, esta variable es un alto predictor del éxitofracaso en el aprendizaje de la lectura. De forma que los hábitos lectores de los padres, la existencia de lectura conjunta, la lectura de cuentos... son factores que facilitan y determinan cierta actitud hacia la lectura y hacia el sentido de la misma.

- Nivel sociocultural, este factor es considerado como un factor de referencia no sólo en cuanto al comportamiento lector y a las expectativas, actitudes o pautas educativas parentales, sino que también se refiere al vocabulario, a los estilos lingüísticos, al conocimiento, etc.

"Todos estos son factores que influyen en el aprendizaje y en el desarrollo cognitivolingüístico de los sujetos” (Romero y González, 2001, 28). 


\section{Capítulo II. Las Personas Sordas}

\subsection{Perspectiva Sobre la Sordera}

En la mayoría de las ocasiones, cuando se habla de sordera, gran parte de la sociedad se hace una idea equivocada; muchos piensan que la sordera no tiene matices, es decir, muchos no tienen conocimiento de la existencia de diferentes grados de sordera que, lógicamente, tienen diferentes repercusiones en el lenguaje y en la comunicación.

La OMS (Organización Mundial de la Salud) define como persona sorda a aquella que no es capaz de percibir los sonidos con ayuda de aparatos amplificadores.

Pero, la realidad de las Personas Sordas, como la de cualquier otra, es multidimensional y, por lo tanto, puede y debe ser analizada desde distintos planos 0 dimensiones.

\subsubsection{Perspectiva audiológica}

En primer lugar, consideramos la necesidad de hacer una distinción entre el término sordo e hipoacúsico. Se denomina terminológicamente como sordo a aquella "persona cuya audición residual imposibilita la comprensión de la palabra por vía auditiva exclusivamente, con o sin ayuda de prótesis auditivas". Y se establece el término hipoacúsico para "aquellas personas cuya audición residual hace difícil pero no imposible, la comprensión de la palabra por vía auditiva exclusivamente, con o sin ayuda de prótesis auditivas, teniendo formación básica del lenguaje interior" (Sánchez, 2003, citados en Torres, Rodríguez, Santana, González, 1995).

Si bien hay que dejar claro que el término debe utilizarse más bien para los casos en que la lesión auditiva es grave o total, la pérdida de audición (hipoacusia) puede clasificarse atendiendo a tres criterios:

1. Cantidad o Grado de Intensidad

2. Cualidad o Localización topográfica

3. Momento de Adquisición

Todos y cada uno de estos criterios conllevan matices que se pasarán a detallar a continuación. 


\subsubsection{Grado de intensidad}

- Normoaudición

El umbral de audición tonal no sobrepasa los $20 \mathrm{~dB}$ en la gama de frecuencias conversacionales. Ésta es la intensidad que percibe un oído que no sufre ningún tipo de pérdida auditiva.

- Hipoacusia leve. Este tipo de pérdida puede hacer más difícil la comunicación, especialmente en ambientes ruidosos, pero no impiden un desarrollo lingüístico normal, es decir, no produce alteraciones significativas en la adquisición y desarrollo del lenguaje. El grado de pérdida se encuentra entre los umbrales de 20 y $40 \mathrm{~dB}$.

- Hipoacusia media. La pérdida auditiva se sitúa entre 40 y $70 \mathrm{~dB}$. El niño tendrá problemas para la adquisición del lenguaje, por lo que es necesario la adaptación de una prótesis, así como la intervención logopédica. Pero ha de tenerse en cuenta que, por norma general, podrán adquirir el lenguaje por vía auditiva. Desde el punto de vista educativo es necesario intervenir antes de los 35 meses, pues hasta ese momento sordos y oyentes son equiparables en capacidad para categorizar el sistema fonológico (Clarkson, 1988; Burnham et al. 1991; Kuhl y Millar, 1990; Liebermen y Blusmstein, 1988; Millar, 1990, citados en Torres et al., 1995)

- Hipoacusia severa. La pérdida auditiva se sitúa entre 70 y 90 dB. Esta pérdida supone importantes problemas para la comunicación hablada y para la adquisición del lenguaje oral. La voz no se oye, a no ser que ésta sea emitida a intensidades muy elevadas. Las personas con este grado de sordera necesitan el apoyo de la lectura labial, y para ellas, es imprescindible el uso de audífono y el apoyo logopédico para el desarrollo del lenguaje.

- Hipoacusia profunda. La pérdida auditiva supera los $90 \mathrm{~dB}$. Esta pérdida provoca alteraciones importantes en el desarrollo global del niño; afecta a las funciones de alerta y orientación, a la estructuración espacio-temporal y al desarrollo intelectual y del niño. Será imprescindible el uso de audífonos o implante coclear, una enseñanza intencional y sistemática del lenguaje. La rehabilitación debe iniciarse antes de los 18 meses de edad.

- $\quad$ Cofosis. La cofosis supone la pérdida total de la audición. Supone la ausencia de restos auditivos se sitúa por encima de los $120 \mathrm{~dB}$, aunque en muchas ocasiones una pérdida superior a los $100 \mathrm{~dB}$. Implica una auténtica cofosis funcional. Sin embargo, la pérdida total de audición es poco frecuente. 


\subsubsection{Localización topográfica}

Atendiendo a una clasificación cualitativa te tienen tres tipos

- Sordera de transmisión o Hipoacusias de transmisión .La alteración de la transmisión del sonido se produce a través del oído externo y medio.

- Sordera neurosensorial o Hipoacusias de percepción. Cuando existen lesiones en el oído interno o en la vía auditiva nerviosa.

- Sordera mixta o Hipoacusias Mixtas. Cuando existe al mismo tiempo una sordera de transmisión y neurosensorial.

Es evidente que cualquier sordera de transmisión, percepción o mixta es sordera precisamente porque conlleva una determinada cantidad de déficit auditivo. Por tanto, cualquiera de estos tres tipos de sordera puede ser, tiene que ser, al mismo tiempo: leves, moderadas, severas o profundas, si bien es cierto que las sorderas de transmisión no suelen ser profundas.

\subsection{Hipoacusia de conducción o transmisión}

Como ya se ha indicado, estas pérdidas auditivas son debidas a una alteración en la función de conducción o transmisión por vía aérea del sonido, están localizadas en el oído externo o medio. Las causas pueden ser muy variadas:

- Aumentos de masa (tumores, inflamaciones, líquidos, cuerpos extraños, tapones...), que provocan pérdidas en la transmisión de sonidos de frecuencia alta;

- Pérdida de elasticidad;

- Edad (perforación timpánica, anquilosis de la cadena, otosclerosis...), que provoca pérdida en frecuencias bajas;

- Aumentos de fricción (mala articulación de la cadena), que provocan pérdidas en la transmisión de los sonidos de frecuencia media.

Hay muchas afecciones del oído externo que dificultan o impiden la transmisión del sonido, las más destacables son:

- Malformaciones del pabellón y del conducto auditivo externo: anotia o ausencia de pabellón; microtia o pabellón pequeño y deformado; atresia o ausencia de canal auditivo.

- Traumatismo (hematomas) y tumores del pabellón auditivo y del conducto auditivo externo.

- Inflamaciones del conducto auditivo externo: micosis si es por hongos y virosis si es por gérmenes.

En el oído medio, a nivel de membrana timpánica y cadena de huesecillos, se dan: 
- Alteraciones de la ventilación y drenaje del oído medio: estenosis y obturación tubárica, disfunción en el mecanismo de apertura tubárica.

- Edema de la mucosa tubárica por un proceso inflamatorio en estructuras vecinas (sinusitis, adenoiditas o vegetaciones).

- Cierre del orificio tubárico epifaríngeo o externo por amígdala hiperplásica (anginas).

- Infiltración (extensión) hacia la trompa de un tumor de la epifaringe.

- Otitis media aguda y crónica

- Otitis media colesteomatosa

- Inflamaciones del oído medio (otosclerosis, secuelas posquirúrgicas, traumatismos del oído medio y del oído externo, barotraumas).

El audiograma de las hipoacusias de conducción es normal, pero con la curva más elevada que la de un oído normal. En estos casos, "si se comparan audiometrías ósea y aérea la apariencia es similar, sólo que la aérea requiere más intensidad" (Torres et al., 1995, 28).

\subsection{Hipoacusia de percepción, sensorial o neurosensorial}

También denominadas hipoacusias cocleares, por presentar alteraciones en la función de transducción del sonido en las células ciliadas, localizadas en la cóclea. Puede darse también alteración en la función de la percepción de la sensación sonora a nivel del SNC por afección de alguna región de la vía auditiva, en este caso se denominan hipoacusias retrococleares. Tanto las cocleares como las retrococleares suelen cursar con reclutamiento, que consiste en una disminución de la dinámica del oído, por lo que es normal que no se alcance el $100 \%$ de inteligibilidad agotando las posibilidades de aumento de la señal.

A lo largo de la vida el oído interno y las vías auditivas tienen muchas ocasiones de sufrir alguna alteración cuyo resultado sea la pérdida parcial o total de audición. La misma edad, cursa con algún grado de sordera de percepción en porcentajes muy elevados. Pero donde la sordera de percepción es una amenaza del lenguaje, pudiéndose clasificar en los cuatro grupos siguientes:

1. Sordera genéticas o hereditarias, ligadas al equipo genético y transmitidas de padres a hijos. Suelen manifestarse ya en el nacimiento. Suponen alrededor del $45 \%$ de las hipoacusias cuyo origen es conocido. De ésta, $2 / 3$ se deben a herencia recesiva, y el resto a herencia dominante.

2. Sordera congénitas, son adquiridas durante el embarazo a causa de distintas enfermedades sobrevenidas a la madre durante el primer trimestre de gestación. Algunas de estas enfermedades, en concreto la rubéola, hoy muy controlada, en el pasado causaron verdaderos estragos al aparecer de forma epidemiológica dejando a su paso miles de casos de sorderas irreversibles. 
3. Sordera neonatales, son las ocurridas en torno al nacimiento, bien en el mismo parto o por distintas afecciones a las que el recién nacido está expuesto en los primeros días de vida extrauterina.

4. Sorderas postnatales, pueden ocurrir en cualquier momento, siendo sus causas más frecuentes las infecciones víricas y la ototoxicidad, además de otras afecciones del oído interno y/o vía auditiva que también cursan con sordera de percepción, entre las que destacan:

- Síndrome coclear, que provoca hipoacusia de percepción progresiva, con distorsiones de la sensación sonora tanto a nivel cualitativo como cuantitativo, como pueden ser, acúfenos, vertigos, etc.

- Trauma acústico agudo o crónico.

- Ototoxicidad (exógena o endógena)

- Presbiacusia o hipoacusia progresiva debida al envejecimiento. Se pierde, por término medio, el $1 \%$ de audición cada año a partir de los 50 años, afectando principalmente a las frecuencias agudas. El audiograma vocal refleja cada vez más dificultades para entender el habla.

- Enfermedad de Menière: alteración en la presión y composición de los líquidos laberínticos, cursando con vértigo, hipoacusia y acúfenos y actívenos, que llega a hacerse crónica.

Finalmente, se dan distintas alteraciones centrales de la audición, como, agnosia acústica, también llamada sordera psíquica, afasia sensorial o sordomudez sensorial, que consiste en la lesión de la vía auditiva. "En niños prelocutivos retarda el lenguaje y tiene mal pronóstico. No hay que confundirla con disfasia o retardo del lenguaje, que cursa con audición normal” (Torres et al., 1995, 30).

\subsection{Hipoacusia mixta}

En este tipo de hipoacusia se encuentran afectados simultáneamente el oído externo, medio e interno. En estos casos, la pérdida es superior a $20 \mathrm{~dB}$ y si se comparan las audiometrías ósea y aérea la diferencia suele ser mayor de $10 \mathrm{db}$.

"A nivel estadístico, el $5 \%$ de las sorderas son conductivas, el $75 \%$ son perceptivas y el 20\% mixtas" (Torres et al., 1995, 30). 


\subsubsection{Momento de adquisición}

Según el momento de adquisión de la hipoacusia, ésta puede ser:

- Prelocutiva

Se denomina sordera prelocutiva a aquella que ha sido adquirida antes de los tres años de edad, aunque en muchas ocasiones sería más correcto hacer esta clasificación atendiendo al nivel de desarrollo lingüístico alcanzado, dada la variabilidad existente de unos casos a otros.

- Postlocutiva

Esta denominación se utiliza para designar aquellas sorderas que se adquieren entre los tres y los cuatro años, o más concretamente, cuando ya se haya desarrollado el lenguaje.

Esta clasificación aunque muestra unos limites muy difusos, basados en el momento de adquisión de la sordera y del desarrollo lingüístico alcanzado hasta ese momento, es de máxima importancia en educación de cara al pronóstico.

Las sordera prelocutivas, si son profundas ponen en serio peligro el normal desarrollo cognitivo y verbal. Las postlocutivas, no están exentas de riesgos, aunque siempre son menores y tanto menos significativos cuanto más tarde sobrevenga la lesión. Por el interés que tiene la edad en la adquisión lingüística y por el influjo que tiene la sordera en el desarrollo verbal, se ha prestado especial atención a las sorderas profundas prelocutivas. "En torno a este tipo de sorderas, máxime cuando son de percepción o neurosensoriales y profundas, se ha desarrollado una didáctica especial y tecnología aplicada, que cubren los contenidos académicos de varias especialidades universitarias, como, Audioprotesista, Maestro de Audición y Lenguaje, Logopeda y Médico Foníatra" (Torres et al., 1995, 31).

\subsubsection{Perspectiva sociológica}

La consecuencia más importante de la sordera prelocutiva, las dificultades en la adquisión del lenguaje, tiene lugar en la primera infancia. Hay que recordar que hasta no hace mucho a las personas sordas que no hablaban a cuenta de su sordera se las llamaba sordomudos, esta palabra aún es usada hoy en día en el lenguaje popular. El término sordomudo debería excluirse como una forma de referirse a la sordera, y la imagen de una persona sorda que no es capaz de articular palabra debería borrarse de nuestra mente porque la sordera no supone incapacidad para la adquisición del lenguaje. Además, la sordera no supone llevar asociada la mudez.

Lo que sucede realmente, es que el niño cuando nace tiene las mismas capacidades para desarrollar el lenguaje que un niño oyente, el problema es que mientras que el niño oyente progresa en sus balbuceos, en su afán por imitar los sonidos que le rodean, el niño sordo "enmudece" si no se le adaptan los audífonos y se le ayuda a completar por otros canales, como el visual, la recepción de las informaciones 
verbales del entorno. Esto provoca que los sonidos que debería emitir en situaciones normales carecen de sentido para el.

Este tipo de situaciones provocan grandes problemas posteriores en su capacidad de entonación, comprensión de significado de frases y de los elementos suprasegmentales del habla.

Estos problemas afectan su proceso de socialización. Sin embargo, como indica Silvestre, Cambra, Laborda, Mies, Ramospott, Rosich, Serrano y Valero, $(1998,59)$ "no hay ninguna evidencia de que ello conlleve unos rasgos específicos de organización de su personalidad o de que pueda hablarse de una "personalidad de sordo"'. Varios estudios han destacado algunos rasgos de personalidad, como por ejemplo, la impulsividad o la inmadurez social, pero no de forma univoca.

Silvestre y Cambra en un estudio sobre la visión social del sordo y las vivencias de un grupo de adolescentes sordos, encontraron notables discordancias, como, por ejemplo, que a los sujetos sordos se les percibía como poco sociables e introvertidos, los adolescentes sordos señalaban la amistad como una de las principales fuentes de bienestar y placer (Cambra, 1994, citada en Silvestre et al., 1998). Entrevistando a los mismos oyentes compañeros del alumnado sordo integrado, se vio que este último estaba bien integrado en actividades de equipo.

Esto indica que los estereotipos sociales pueden funcionar para ciertos casos, pero estos estereotipos desaparecen cuando existe una comunicación recíproca entre sordos y oyentes suficientemente potenciada, ya que esto no ocurre de forma espontánea.

\subsubsection{Comunicación en el Medio Familiar}

El sonido tiene un importante papel en el desarrollo social, la voz de la madre, los ruidos, la preparación del biberón, las estimulaciones producidas por sonidos (sonajeros, móviles de la cuna, etc.) no solo ejercitan y afinan la audición, sino que también tranquilizan y dan seguridad al niño. Por otro lado, los ruidos que acompañan un suceso o que lo producen, reducen el efecto de sorpresa y el carácter repentino e insólito de la situación. El bebe sordo no dispone de este "baño sonoro", por ello, los temores tienden a aumentar en ausencia de audición.

A medida que el niño oyente crece y se va socializando, sus conductas agresivas van disminuyendo y comienzan a ser expresadas por medio del lenguaje oral (chilla, grita); no obstante, el niño sordo expresa su enfado y su cólera mediante el cuerpo, ya que éste es su medio, más privilegiado, para expresar sus estado emocional.

Las interacciones que se desarrollan entre el niño sordo y los padres son fundamentales en su desarrollo psico-afectivo. Los principales factores que van a determinar el grado de interacción padres-hijo van a ser, por un lado, la actitud paterna ante el déficit auditivo del niño (reacciones de los padres ante la sordera de su hijo) y, por otro, las estrategias utilizadas con el fin de aumentar las interacciones 
comunicativas con su hijo sordo (uso de la Comunicación Bimodal, Lenguaje de Signos,...).

"Muchos padres oyentes, se sienten frustrados ante la falta de respuesta, por parte del niño, a sus intentos comunicativos verbales, llegando incluso a sentirse rechazados ante esa ausencia de respuesta, esto lleva a una disminución de la frecuencia de interacción y a un empobrecimiento progresivo de la misma, unido a un aumento de la ansiedad, lo cual puede llevar al niño y a sus padres a una situación de aislamiento" (Musselman, 1995, 45). Como consecuencia de los problemas comunicativos, los padres tienden más a regular la conducta de su hijo que a compartir información con él, son menos permisivos y más didácticos, sólo hablan con el niño sobre el "aquí" y el "ahora" y no son capaces de informar a su hijo sobre los acontecimientos futuros que van a ocurrir, por ello, el niño se muestra desconfiado y vive cualquier evento no habitual como amenazador. Esta situación varia considerablemente cuando el niño sordo tiene un sistema estructurado de comunicación, el cual es conocido y/o compartido por sus padres. En lo que respecta a las características de la personalidad, del niño sordo, la creencia general es que el niño sordo tiende a ser socialmente inmaduro, egocéntrico, rígido, impulsivo en la expresión de sus emociones, con un bajo nivel de autoestima, presentando, a menudo, problemas conductuales.

Sin embargo, los niños sordos hijos de padres sordos son capaces de controlar mejor su conducta, presentan menos impulsividad, una mayor madurez social y un grado más alto de responsabilidad. Esto es debido a que gracias a la adquisición temprana del lenguaje de signos (como forma natural de comunicación) las interacciones padres-hijo, son similares a las de los oyentes, así como su nivel de sobreprotección y sus estrategias comunicativas y educativas. Los hijos sordos de padres sordos presentan entonces mejores niveles académicos, mejores habilidades para el aprendizaje de la lengua hablada y escrita, niveles de lectura semejantes a los del oyente, una identidad construida y equilibrada, y no presentan los problemas socioafectivos propios de los hijos sordos de padres oyentes. Los niños sordos nacidos de familias de sordos están expuestos desde el nacimiento a una lengua de señas convencional. La adquisición de la lengua de señas en estos niños progresa de forma similar a la lengua hablada en niños oyentes hijos de padres oyentes. Es decir, que en ambientes lingüísticos apropiados (un ambiente "señante") los niños sordos no son discapacitados con respecto a la adquisición de esa lengua. Este niño construye su propia gramática y está inmerso en un proceso comunicativo natural al ser parte de una comunidad lingüística donde se usa una lengua de señas. La interacción social y lingüística de los padres sordos con sus hijos sordos es semejante y tan compleja como aquella de los padres e hijos oyentes. "Este proceso negociador madre/hijo o adulto socializador/niño contribuye a que el niño no sólo ponga en funcionamiento sus capacidades lingüístico comunicativas, sino que también vaya formando una identidad social propia de una cultura determinada y que acceda al conocimiento de su comunidad sorda y a la sociedad oyente en la que esta inmerso" (Veinberg, 2002, 2)

La familia, especialmente la que esta formada por algún individuo sordo debe seguir todo un proceso para asumir la sordera y progresivas adaptaciones para establecer una comunicación de este. 
Las criaturas sordas son recibidas de distinta forma, en función del conocimiento y las vivencias que la familia tenga y según el grado de asimilación de los estereotipos sociales.

La primera y gran diferencia se muestra, en este sentido, cuando existe alguna persona sorda dentro de la familia, esta diferencia es mucho mayor si los mismos padres son sordos. Esta ventaja de la criatura sorda no se sitúa tanto en la facilidad de utilización del lenguaje de signos como en la forma de comunicarse. Distintos estudios que analizan las díadas formadas por bebé y padres sordos encuentran que la calidad de la comunicación establecida procede que las madres sordas ceden más pausas al bebé y comparten con más sensibilidad los turnos de atención e intervención que las madres oyentes. En las familias de sordos esta forma de relacionarse con el entorno puede facilitar su equilibrio socioafectivo y la formación de la identidad de la criatura sorda. A la vez se pueden plantear otras dificultades derivadas de la integración como puede ser la falta de motivación para el aprendizaje del lenguaje oral.

Pero esta situación es totalmente opuesta a la mayoría de criaturas sordas que nacen en familias de oyentes, que en la mayoría de las situaciones no tienen una visión clara de las implicaciones de la sordera. Cuando las personas oyentes superan las primeras vivencias dolorosas sobre la sordera del hijo o hija puede adoptar una actitud de disponibilidad afectiva, necesaria para aprender a comunicarse. Es a lo largo de este proceso cuando estos familiares necesitan mayor apoyo por parte de profesionales y en muchos casos necesitan compartir sus vivencias.

La sobreprotección, frecuentemente es una de las posibles actitudes de los padres oyentes hacia la criatura sorda. La falta de percepción objetiva por parte de la familia de las posibilidades reales de su hijo o hija induce a limitar su autonomía dificultando en ocasiones su desarrollo. En uno de los estudios sobre el tema se destaca que las dificultades comunicativas para argumentar el castigo eran una de las razones aducidas por las familias para explicar su excesiva tolerancia (Gregory, 1976, citado en Silvestre et al., 1998). Estudios posteriores han puesto de manifiesto que los niños sordos reciben menos explicaciones respeto a los motivos o razones y sus consecuencias por parte de sus padres.

Estas dos tendencias de conducta, sobreprotección y escasez de explicaciones, pueden relacionarse con algunos de los rasgos frecuentemente descritos como característicos de las personas sordas, como son, la falta de independencia y autonomía y el carácter impulsivo. También es cierto, que estos rasgos están claramente ligados al procedimiento educativo empleado. 


\subsubsection{Socialización en la Escuela Elemental}

En este momento las vivencias familiares pierden protagonismo y pasan a primer plano los aprendizajes escolares como instrumentos de socialización y la relación con los pares de su edad. Esta socialización no siempre es espontánea y hay que recurrir a la integración escolar.

Los aprendizajes más destacables en esta época son los siguientes:

- canalización de los impulsos agresivos

- socialización sexual

- adopción de perspectivas y papeles de otros

- pensamiento moral

Distintas investigaciones han dejado manifiesto las dificultades del alumnado con sordera para situarse en la perspectiva de los demás y darse cuenta del estado psicológico y de la intención de estos. Esta distancia, según las investigaciones de Kunsché y Greenberg (1983, citado en Silvestre et al., 1998) entre sordos y oyentes se va reduciendo con la edad.

La integración escolar del niño sordo busca fundamentalmente su desarrollo armónico e integral, así como mejorar su desenvolvimiento en el mundo de los oyentes en el cual vive. La posibilidad de integrar a los alumnos sordos, y más aún a sordos profundos, en la escuela ordinaria ha sido contemplada con recelo tanto por los maestros como por las propias asociaciones de sordos. Las razones dadas en contra de dicha integración pueden resumirse en las siguientes:

- Los alumnos sordos en las escuelas normales reciben una atención menos individualizada y de menor calidad.

- El profesorado no está suficientemente preparado.

- Los alumnos sordos tienen dificultades de comunicación oral, por lo que la integración social con sus compañeros puede no llegar a producirse aunque estén en la misma clase.

- Los adultos sordos manifiestan su disconformidad con la integración porque margina el lenguaje de signos, el cual es fundamental para la educación del niño sordo.

Frente a estos argumentos, existen otras posiciones que defienden la integración escolar, argumentando las siguientes ventajas:

- Posibilidad de una mayor interacción con los compañeros oyentes, lo cual favorece la comunicación oral.

- Adaptación más completa al entorno social debido a un mayor conocimiento y experiencia de situaciones y problemas sociales.

- Necesidad de que el sistema educativo sea capaz de ofrecer una forma válida de escolarización a los niños sordos en los centros ordinarios.

- Las personas que son contrarias a la integración, no niegan estas afirmaciones, no obstante, piensan que es muy difícil que se den las condiciones escolares adecuadas para una integración satisfactoria. 
Según Majon (1993, 51-52), "los requisitos básicos que debe de cumplir un centro de integración para sordos son los siguientes: un Proyecto Educativo de Centro (PEC) que incorpore la educación del niño sordo, no como un añadido que se realiza en una u otra aula, sino como un objetivo del centro, para cuya consecución se establecerán todos los medios necesarios. Este proyecto debe de incluir el contacto del niño sordo con otros compañeros y personas adultas sordas".

Es importante, incorporar el Lenguaje de Signos entre los métodos que pueden utilizarse para la comunicación del niño sordo. Recomendándose, que el sistema elegido no sea sólo utilizado por el maestro especialista ya que el aprendizaje del mismo debe extenderse, también, a todos los profesores del colegio y a los compañeros del niño sordo (en muchos colegios se utiliza la Comunicación Bimodal, en vez del Lenguaje de Signos, ya que es más fácil de aprender para el oyente).

- Deben existir maestros especializados en la educación del niño sordo y en la adquisición y desarrollo del lenguaje oral.

- El asesoramiento de un equipo específico de profesionales formado por un otorrino, un psicólogo, un pedagogo, un audioprotesista y una asistente social, que realicen la evaluación de cada niño en sus aspectos intelectuales, lingüísticos, sociales, y sus posibilidades de aprendizaje. Estos profesionales deben colaborar en la elaboración del currículum del alumno, en la adaptación de textos y materiales y en el control de la prótesis.

- La posibilidad por parte de los maestros del colegio de integración, de conocer los problemas y las características de los niños sordos, sus procesos de aprendizaje, los sistemas de comunicación que pueden utilizar y los recursos técnicos más adecuados.

- La existencia en el centro de aulas disponibles con profesorado especializado y equipos técnicos suficientes para que se pueda trabajar con los niños sordos todo el tiempo que sea preciso.

- Medios técnicos adecuados que permitan una oportuna utilización de los restos auditivos del alumno e instrumentos suficientes para un trabajo satisfactorio en el aprendizaje de la lengua. El aula donde esté integrado el alumno debe de tener incorporados sistemas de amplificación, como aros magnéticos o aparatos de F. M., que faciliten la comunicación entre el maestro y el niño sordo. También, son imprescindibles aulas y gabinetes de logopedia con equipos de amplificación que permitan el trabajo individualizado.

- Contemplar la posibilidad de la presencia de un intérprete, conocedor del Lenguaje de Signos, que pueda estar en el aula con un profesor tutor y que traduzca al niño mediante mímica las explicaciones del maestro sobre las lecciones escolares.

- Una escuela integradora no puede ser una escuela competitiva sino cooperativa y personalizada, se recomienda que haya más de un niño sordo en cada aula con el fin de que el niño pueda elegir si quiere estar con niños oyentes o con sus compañeros sordos. La presencia física de alumnos sordos y oyentes en un aula de integración no determina automáticamente que se produzca entre ellos una buena relación; se ha observado, que los niños sordos integrados interactúan más con sus compañeros sordos que con sus compañeros oyentes y que se dirigen más al maestro que a los alumnos normo-oyentes; esto es debido a que los niños oyentes no se adaptan 
espontáneamente a las posibilidades comunicativas del niño sordo y no son capaces de utilizar sistemas de comunicación alternativos.

Sin duda, la formación del juicio moral es una de las dimensiones del pensamiento más dependientes de factores socioculturales e históricos, y una deficiencia en este aspecto en determinados sujetos sordos podría ser también reflejo de sus dificultades de integración social (Arnold, 1993, citado en Silvestre et al., 1998).

"Las dificultades comunicativas y lingüísticas pueden afectar su entendimiento con los demás y su integración social" (Silvestre et al., 1998, 62).

Una cuestión que es necesario plantearse, es saber cuales son los compañeros idóneos para contribuir al desarrollo de la toma de perspectivas sociales en el alumno sordo, así como de las capacidades cognitivas, comunicativas y lingüísticas con las que éste se relaciona. Agrupar a los alumnos sordos facilita el entendimiento mutuo, la solución de tareas en grupo, el intercambio de problemas comunes en la comunicación y el aprendizaje, pero, obviamente, no hacen ejercitar las adaptaciones comunicativas con los oyentes ni desarrollan el lenguaje oral. Por otra parte, "tanto la integración escolar a tiempo completo como a tiempo parcial facilitan las adaptaciones mutuas entre sordo y oyente, si bien no garantizan necesariamente que se produzcan con tanta eficacia, que, por sí solas, contribuyan al desarrollo social completo del alumnado con sordera" (Silvestre et al., 1998, 63).

Caissie y Wilson (1995, citados en Silvestre et al., 1998), realizaron una investigación sobre la integración de alumnos sordos y oyentes formando grupos de 3 alumnos o alumnas oyentes con 1 sordo. A lo largo de 6 semanas se comprobó como el alumnado oyente y el sordo experimentaban el uso de nuevas estrategias para resolver los problemas comunicativos que surgían, tales como ampliar o especificar una información inicial dada una incomprensión. Los resultados del postest mostraron que, aunque en una situación de aprendizaje cooperativo el alumnado con sordera tiene más dificultades comunicativas que el oyente, el programa es efectivo para adquirir nuevas destrezas interactivas y contribuye no sólo a mejorar la autoestima del chico y chica con sordera, sino también a potenciar las relaciones sociales y académicas entre todo el alumnado.

"La modalidad de institución especial para sordos presenta el riesgo de que el alumnado desarrolle mínimamente las destrezas comunicativas y sociales para relacionarse en la sociedad oyente" (Silvestre et al., 1998, 63).

Para el alumnado sordo la relación, por una parte, con compañeros y compañeras sordas y, por otra, con el alumnado oyente cumple funciones complementarias en su proceso de socialización. La relación con otros sordos permite compartir los mismos problemas e integrar la sordera en su propia identidad, como una característica que poseen también otras personas. La relación con los oyentes permite el aprendizaje de las adaptaciones comunicativas mutuas, tan necesarias para su futura integración social. En situación de integración, la agrupación de algunos alumnos sordos en el mismo centro, sin coincidir en el mismo grupo de clase, permite esta convivencia. También son interesantes, en este sentido, las experiencias que realizan algunos centros de recursos para la educación del deficiente auditivo, que agrupan periódicamente a chicos y chicas con sordera integrados en distintos centros para 
determinadas actividades: refuerzo pedagógico, aprendizaje de determinadas técnicas, etc.

\subsubsection{Adolescencia y Enseñanza Secundaria}

La entrada en la enseñanza secundaria representa un momento clave en la evolución del alumnado sordo. Por una parte, coincide con el período de la adolescencia, que significa una recapitulación de la propia identidad del alumnado y del concepto de uno mismo. Por otra, el rendimiento académico, que forma parte también de su autoconcepto y que es en parte el resultado del currículum seguido, plantea nuevos retos e, incluso en muchos casos, situaciones de más estrés para el adolescente o la adolescente con sordera. "Desde el punto de vista educativo es importante asegurar la continuidad en el paso de una etapa a otra y potenciar las adaptaciones necesarias a las nuevas características de la enseñanza secundaria" (Silvestre et al., 1998, 64).

Se entiende por autoconcepto la imagen que uno tiene de sí mismo en distintas dimensiones: autoestima, imagen académica e imagen social. El autoconcepto en el adolescente sordo ha sido muy estudiado teniendo en cuenta diferentes variables, tales como, evidentemente, la competencia comunicativa alcanzada y también el tipo de escolarización. Los datos respecto a esta última variable son contradictorios, debido a la diversidad de situaciones y técnicas empleadas. La investigación de Reich (1977, citado en Silvestre et al., 1998) presenta particular interés porque abarca la etapa de escuela elemental y secundaria, y estudia a sujetos con sordera procedentes de cuatro tipos de programas que comportan diferentes niveles de integración escolar, desde la integración total a la escolarización en un aula especial en la escuela ordinaria. En una prueba de autoconcepto los autores obtienen este resultado: en el nivel de escuela elemental no hay diferencia entre grupos, pero en el de secundaria el alumnado que sigue la integración total con ayuda es quien muestra un autoconcepto con un nivel de autoestima más alto. La interpretación de tales datos debe hacerse muy cautelosamente, ya que pueden influir otras variables, por ejemplo, el rendimiento académico o el nivel cognitivo de los sujetos, así como el contexto socioeducativo.

En el año 1989 se realizó en Cataluña un primer estudio sobre el autoconcepto en la población de 20 adolescentes sordos, integrados a tiempo completo en las escuelas ordinarias, y en un grupo de control de oyentes de edades comprendidas entre los 12 y los17 años, utilizando la prueba de "¿quien soy yo?" elaborada por Khan y McPartland en (1954, Silvestre et al., 1998). En esta prueba se trata de pedir la definición de uno mismo en 20 líneas.

Los principales resultados mostraron, en primer lugar, que no había diferencias respecto a la autoestima positiva entre los dos grupos. En cambio la población de deficientes auditivos difería de la de oyentes por sus predilecciones para autodefinirse. Así, los primeros preferían definirse por sus atributos corporales (alto, gordo, etc.), mientras que los segundos preferían hacerlo por su pertenencia a grupos (soy del Barça, soy de 1ํㅡ, etc.). La diferencia entre ambos grupos es la preferencia por referencias sociales por parte de los oyentes y por caracteres 
corporales por parte del grupo de sordos, aunque la sordera no se mencionaba en muchas ocasiones dentro de este grupo, aún siendo una característica física. La primera conclusión que se obtuvo es que los adolescentes sordos se sentían poco vinculados con grupos sociales de oyentes, pero tampoco parecía que tuvieran integrada la sordera en su autoconcepto (Martínez y Silvestre, 1995, citados en Silvestre et al., 1998).

En otro estudio realizado con 34 sujetos afectados por sordera profunda y severa, basándose en otros aspectos, en la cuestión de la identidad y en la vivencia de la sordera (Cambra, 1994, citado en Silvestre et al., 1998), al explorar la identidad, la técnica utilizada fue de Cole y Edelman (1991, citados en Silvestre et al., 1998). Estos autores aplicaran una escala de identidad a 51 sujetos sordos de edades comprendidas entre los 14 y los 16 años, y establecieron, a partir de los resultados obtenidos, tres tipos de identidad en la población con déficit auditivo: la identificación con los oyentes, la identidad, la integración en la cultura de los sordos y la dual, la cual supone la aceptación a la vez de la cultura de los oyentes y de la limitaciones implícitas en la sordera. En esta investigación la mayoría de los sujetos, un $62 \%$, mostró actitudes pertenecientes a una personalidad dual, mientras que un $18 \%$ se identificó con oyentes y sólo un $6 \%$, con la cultura de los sordos; estos últimos eran todos ellos sujetos pertenecientes a familias de sordos. Un 14\% presentó problemas en su definición.

Comparando los dos estudios mencionados, muestran un cambio importante en la aceptación de la sordera, ya que más de un $50 \%$ adopta una identidad dual.

La comparación de los resultados obtenidos en el mismo país y Comunidad Autónoma, con distintos sujetos, pero todos ellos con el mismo grado de sordera, y escolarizados en régimen de integración, con cinco años de diferencia, pone de manifiesto la influencia del cambio socio educativo en este corto periodo.

Son escasos los estudios que valoran la incidencia del grado de pérdida auditiva sobre el auto concepto. En el estudio citado anteriormente se encontraron diferencias importantes entre los chicos y chicas con sordera profunda y con sordera severa. Los sujetos con sordera severa, mostraron un auto estima más negativa que los afectados por sordera profunda. Así, los sordos severos producían un número más alto de referencias a rasgos negativos de la personalidad y mostraban una mayor falta de confianza en sus propias capacidades de aprendizaje. El alumnado con sordera profunda, destacaba aspectos positivos de su personalidad, de sus relaciones amistosas, de su apariencia física y de su rendimiento académico.

De esta forma el grado de perdida auditiva establece diferencias en el proceso de construcción del auto concepto.

Otra cuestión sobre la identidad de la persona sorda es la que se refiere a más personas con sordera postlocutiva. Este tipo de sordera no afecta el proceso de adquisición del lenguaje, pero, en cambio, en los casos de sordera profunda y severa, plantea la mayoría de problemas de comunicación social que provoca la sordera post - locutiva, y las personas afectadas necesian el aprendizaje de lectura labial. "Desde el punto de vista socio-afectivo, la aparición de la sordera en la vida 
de una persona oyente representa la necesidad de readaptaciones sociales y, incluso en algunos casos, laborales." (Silvestre et al., 1998, 67).

\subsubsection{La persona sorda en la vida adulta}

La integración de la persona sorda en el mundo de los oyentes no es un hecho que se produzca fácilmente ni el mismo modo en las diversas formaciones sociales. Las dificultades en la formación e inserción laboral y las barreras comunicativas y psicosociológicas aparecen de forma más o menos acusada en todos los países de cultura occidental.

A pesar de la mayoría del alumnado con sordera puede seguir, con adaptaciones, la enseñanza superior, lo cierto es que en general se encuentra un porcentaje mucho menor de personas sordas con estudios superiores que en la población oyente. En un estudio reciente, realizado en España sobre una población formada por 367 sujetos con sordera profunda y prelocutiva de entre 18 y 69 años, se encontró que, comparándolos con una población general de las mismas edades, solo un 1,9\% de la población sorda había realizado estudios superiores, mientras que el porcentaje en la población general de oyentes era de 21,1\% (Díaz-Estévanez, 1996, citado en Silvestre et al., 1998). Si se revisan estos valores en función de los datos aportados por FIAPAS, se constata que de los usuarios del Servicio de Empleo integrantes de la Red, el 7\% accede a estudios Universitarios (FIAPAS, 2004)

En la mayoría de las ocasiones, si no existe una suficiente competencia en lenguaje oral, finalizan estas etapas educativas previas alcanzando un nivel académico bajo $\mathrm{y}$, tal como revelan los estudios e investigaciones realizados, con una competencia lectora equivalente a un niño de 7-8 años de edad, lo que les impide completar su formación académica y, evidentemente, realizar estudios universitarios que exigen disponer del nivel de competencia lingüística oral necesaria para aprender de manera autónoma y adquirir los conocimientos académicos correspondientes.

Ese pequeño porcentaje de personas Sordas que acceden a los estudios Universitarios, además de haber tenido que superar los estudios precedentes, tienen que enfrentarse a una formación universitaria no adaptada y sin apoyos materiales y docentes. Hasta ahora estos alumnos necesitaban del apoyo y la buena voluntad de profesores y compañeros, con la reciente aprobación de la Ley de Lengua de Signos, todo aquel estudiante que desee contar con la presencia de un interprete en Lengua de Signos, recibirá este servicio facilitando en gran medida la comprensión de las materias recibidas.

A esta situación desfavorecida, en cuanto a formación, corresponde también una situación laboral de la persona sorda más precaria que la del oyente. La investigación citada anteriormente, así como otras investigaciones realizadas en otros países europeos, exponen que la desventaja no se refleja en la tasa de ocupación, que es aproximadamente la misma para las personas sordas y para las personas oyentes, si no en el tipo de trabajo. En el estudio español se señala que un $60 \%$ de la población sorda realiza trabajos de obrero no especializado. 
El tema de calificación laboral remite a la formación en la fase de transición escuelatrabajo y a la formación permanente y promoción laboral. Las experiencias más fructíferas en la fase de transición escuela-trabajo son aquellas que parten de la elaboración de perfiles laborales previos, análisis de las estrategias cognitivas y manuales necesarias, y formación consecuente. Los resultados son positivos, por ejemplo, en puestos de trabajo de programación con ordenador, diseño asistido por ordenador o fisioterapia, o ayudantes de ortodoncia, mecánico de prótesis dentaria, etc. (Rodríguez, 1993, citado en Silvestre et al., 1998).

A pesar de contar con la formación académica adecuada al puesto de trabajo, la persona sorda debe vencer los perjuicios que tienen la mayoría de empresas ante los problemas comunicativos que pueden ocasionar su presencia.

Existen en varios países europeos servicios de suporte para la integración laboral. Se prepara el candidato mejorando sus capacidades comunicativas específicas necesarias para pedir el empleo: habilidades básicas para seguir una entrevista, para realizar una entrevista vital, para rellenar cuestionarios, etc. La preparación de la empresa consiste básicamente en informar a los futuros compañeros y compañeras de trabajo, sobre las implicaciones de la sordera y en estudiar el entorno físico y humano en el que se desarrolla la actividad de la persona sorda para prever posibles adaptaciones en el caso de que sean necesarias. La asistencia de estas instituciones de suporte facilita no solo que la persona sorda pueda promocionarse en la empresa, sino también que pueda mantener una relación social con los oyentes en su vida laboral.

Esta desventaja social presenta algunas diferencias según los países, pero podemos diferenciar dos tipos de factores, íntimamente relacionados entre si:

- Percepción social de la sordera. A menudo falta información sobre la implicación de la sordera y, en general, hay una visión desvalorizadora de la persona afectada respecto, por ejemplo, a su nivel de desarrollo intelectual y a sus capacidades psíquicas.

- Conjunto de barreras comunicativas. En segundo lugar y claramente relacionado con lo anterior, se encuentra un conjunto de barreras comunicativas a distintos niveles de relación social de la persona sorda con el mundo de las personas oyentes.

En el caso de los medios de comunicación se encuentra a la vez barreras comunicativas, pues no están adaptados a la peculiaridad de la persona sorda. Las adaptaciones visuales son todavía muy escasas. Otra cuestión es la forma de adaptación, si debe consistir en subtítulos o en traducción de lenguaje de signos. Las opciones pueden ser mixtas para adaptarse a la diversidad de la población afectada por sordera. En todos los casos las adaptaciones deben realizarse, obviamente, con el asesoramiento y seguimiento de las personas sordas.

En cuanto la actuación sobre el tratamiento de la imagen de la persona sorda en los medios de comunicación, se debe sustituir la imagen de persona que debe ser asistida por una información que muestre sus capacidades para ejercer distintas profesiones, así como sus peculiaridades comunicativas, tipo de voz, necesidad de 
lectura labial, atención dividida en el tiempo y lenguaje de signos como elementos de la diversidad de la persona humana.

Así mismo, en la vida cotidiana con las personas oyentes, la persona sorda se encuentra a la vez con la falta de adaptación de la información en los lugares públicos en con dificultades de comunicación en las relaciones interpersonales.

El estudio mencionado anteriormente recoge algunos datos significativos en relación al grado de satisfacción vital. El 72,2\% de los participantes indicó estar satisfecho en general con la vida, y lo mismo ocurre con aspectos concretos, tales como relaciones familiares $(75,5 \%)$, barrio $(80,1 \%)$, etc., sin embargo solo un $38,4 \%$ dijo estar satisfecho con sus vecinos.

Este dato refleja las dificultades en las relaciones de la vida cotidiana de la persona sorda con los oyentes. Así, podemos distinguir entre las actividades cotidianas dos posibilidades: que la persona oyente conozca el estatus de sorda de la otra o que lo ignora. Aquí caben mal entendidos, ya que la sordera, no es visible. Otro foco de dificultades en tales interacciones entre personas oyentes y sordas es el lenguaje oral de estas. Por una parte, no siempre la persona sorda ha aprendido todos los usos sociales del lenguaje, tales como hacer comentarios banales sobre el tiempo, siendo otra la finalidad de la comunicación; ello puede ser mal interpretado por la persona oyente si la sorda no utiliza estas rutinas, o desorientar a la segunda cuando es la primera quién las utiliza. Por otra parte, la persona oyente no informada de la emisión oral de la persona sorda es tan anómala que, con frecuencia le lleva a concluir que la comunicación no es posible y la interrumpe.

El análisis de estos desencuentros en la vida cotidiana hace evidente la necesidad de adaptaciones mutuas, conocimiento objetivo de las competencias de la persona sorda por parte de la oyente y adquisición de las destrezas comunicativas de la sorda hacia la oyente.

De hecho, en la actualidad subsisten todavía importantes barreras entre el mundo oyente y de las personas sordas. La mayor parte de las personas sordas que viven en pareja lo hacen con otra sorda. Hay que recordar, sin embargo, que se trata de una población que, en su mayoría, fue escolarizada en instituciones especializadas para sordos. En España los programas de integración se aplicaron de forma gradual, empezando por los niveles inferiores de edad, hasta llegar a los superiores. Como indica Silvestre et al. (1998, 70). "Gran parte de las personas sordas que han seguido la integración es, pues, muy joven."

Existen Asociaciones de Personas Sordas con distintas características; todas ellas tienen en común el reconocimiento del colectivo de sordos como un grupo humano y no sólo como un grupo de personas con deficiencia auditiva. Estas Asociaciones pueden tener gran importancia en los deseables cambios sociales que favorezcan el respecto a la especificidad de la persona sorda, e incidir en la administración y en los medios de comunicación. "Otro tipo de Asociaciones son las de padres y amigos de sordos, que tienen también un peso muy importante en este sentido". (Silvestre et al., 1998, 70). 


\subsubsection{Perspectiva multidimensional}

Como ya se ha visto en los puntos anteriores, la realidad de las personas Sordas, como la de cualquier otra, es multidimensional y, por lo tanto, puede y debe ser analizada desde distintos planos o dimensiones.

A lo largo de la historia las dimensiones que más peso han tenido en la consideración de las personas Sordas están basadas, bien en el plano audilógico, mostrado en el punto 1.1 de este capitulo, donde se han podido ver y definir los distintos tipos de sordera y sus grados de pérdida auditiva, o bien, en el plano de la discapacidad, entendida como las limitaciones funcionales que se sitúan fundamentalmente, en el ámbito del desarrollo del lenguaje oral y escrito, tema sobre el cual versa esta tesis. También se puede ver desde una tercera dimensión, la dimensión sociocultural, vista en el apartado 1.2 de este capítulo.

Desde esta última dimensión, es desde donde se rescata lo importante que es que muchas personas Sordas se describan no por lo que les falta (la audición), ni por lo que no son (oyente), sino por lo que son, personas con discapacidad que además comparten con otros semejantes una lengua, una historia y una cultura propia, que les confiere una "identidad" que debe ser aceptada y reconocida en una sociedad que abogue por la "igualdad en la diversidad" (Minguet, 2001; Moreno, 2000, citados en Domínguez y Alonso, 2004).

La discapacidad en general está sufriendo un cambio copernicano (Barton, 1996; OMS, 2001, citados en Domínguez y Alonso, 2004), dejando de verse como un fenómeno individual, para ser vista como una construcción social fruto de las relaciones de poder y de la interacción entre los individuos y sus contextos sociales e históricos. En este sentido es evidente que cuando el entorno de una persona está lleno de "barreras" que impiden o limitan, por ejemplo, su movilidad o su comunicación, la discapacidad emerge, mientras que si en ese mismo entorno las barreras desaparecen o se minimizan, la discapacidad se diluye y sólo aparecen personas con capacidad para desarrollar una vida autodeterminada y con calidad (Echeita, 2003, citado en Domínguez y Alonso, 2004).

Recientemente en España con la aprobación de la Ley de Lengua de Signos, se ha dado un paso muy importante para llegar a definir y a unir a todo el Colectivo Sordo. Dando, aun si cabe, más fuerza al sentido y al sentimiento de Comunidad Sorda. Entregando más fuerza a la importancia a la Lengua de Signos como lengua de interacción y enseñanza para algunos niños y adultos Sordos.

En todo caso, como indica la reciente Ley de Lengua de Signos (LEY 27/2007, de 23 de octubre, Preámbulo I), el colectivo de las personas sordas, con discapacidad auditiva y sordociegas es muy diverso y no se ajusta a un único patrón comunicativo por el hecho de no oír, o de no oír ni ver en el caso de la sordoceguera, que combina ambas deficiencias. Por tanto, el uso de la lengua oral o de las lenguas de signos españolas y el apoyo a los medios de comunicación oral en su comunicación con el entorno, en su aprendizaje, en el acceso a la información y a la cultura, ha de responder a una opción libre e individual que, en el caso de tratarse de menores, corresponderá a sus padres o tutores. 
La Comunidad Sorda considera que la sordera es una diferencia, no una enfermedad ni una deficiencia. Potenciar la autoaceptación de la persona sorda, desarrolla el éxito personal y social, pero no es compartida por el sector social. La realidad de las personas sordas es el bilingüismo y el biculturalismo, porque además su lengua y cultura propias nacen en familias que están inmersas en sociedades con una lengua en una cultura oral.

\subsection{Enfoques Educativos}

Analizando la sordera desde un enfoque educativo, se pueden definir dos modalidades de análisis, en relación a la modalidad comunicativa y a modalidad escolar.

\subsubsection{En relación a la modalidad comunicativa}

\subsubsection{Monolingües}

\subsubsection{Sistemas Aumentativos y comunicativos de comunicación (SACC)}

Los SAAC son formas de lenguaje diferentes del habla, que se utilizan cuando ésta está seriamente afectada. Los elementos utilizados dependen de las necesidades y características del sujeto, fundamentalmente se emplean: lenguaje escrito, gestos, símbolos gráficos, fotografías y objetos reales.

Algunos de los SAAC más conocidos son: lenguaje escrito, Lenguaje Bimodal, SPC y BLISS y lenguaje oral.

En algunos casos, sí es necesaria la utilización de algún aparato. Las personas que tienen limitada su capacidad de movimiento se pueden beneficiar del uso de ayudas técnicas para mejorar su comunicación. Existen en el mercado utensilios como comunicadores, soportes, pulsadores, etc. que hacen más fácil el uso de Sistemas como el lenguaje escrito o el SPC.

Tan pronto cómo sospechemos que un niño tiene dificultades para utilizar el habla normalmente se debe comenzar el aprendizaje y el uso del SAAC.

Un equipo experto debe ser quien analice seriamente las características y necesidades del usuario y decida qué SAAC y/o Ayudas Técnicas son las más apropiadas.

Pero todas las personas deben saber, que el aprendizaje de un medio de comunicación es de vital importancia para el desarrollo de un niño y por lo tanto, padres y educadores deben estar preparados para utilizar estrategias de comunicación total en los casos necesarios. 
La utilización de un SAAC por un sujeto que no habla, a la edad en que normalmente los niños comienzan a utilizar el lenguaje oral, facilita la aparición del habla. No sólo esto, sino que permite al sujeto disponer de un canal de comunicación con su entorno previniendo, de esta manera, la aparición de conductas inapropiadas en unos casos y la actitud pasiva y de indefensión en otros.

Es imprescindible que todas las personas que rodean al sujeto conozcan SAAC, en caso contrario, el sujeto experimenta una sensación parecida a la de un extranjero que no conoce el idioma del país en el que se encuentra, con la dificultad añadida de que un usuario de SAAC puede tener muy afectada la capacidad de hacerse entender de otra forma.

La necesidad de que las personas que rodean al usuario conozcan los SAAC, y los utilicen con él, es imprescindible y decisiva en los primeros momentos de aprendizaje del mismo. En estos momentos, el niño tiene que establecer una relación sólida entre la utilización del SAAC y la satisfacción de sus necesidades o la posibilidad de incidir en su entorno inmediato.

Por otro lado, el aprendizaje de SAAC no entraña gran dificultad para la población general. El lenguaje escrito y el SPC solo necesitan una actitud de respeto al ritmo de producción del usuario. El Lenguaje Bimodal utiliza muchos gestos transparentes, que claramente hacen referencia a su significado: comer, dormir, correr, etc.

Hay que descubrir qué objetos, personas o lugares interesan más al usuario para comenzar la enseñanza de un SAAC.

Habrá que decidir qué SAAC y/o Ayudas Técnicas son las más apropiadas para él. Se elegirá el primer gesto o símbolo que haga referencia a un objeto de sumo interés para el usuario. Se le entrenará para que lo pida utilizando el SAAC y se le recompensará rápidamente, facilitándole el objeto deseado cada vez y cuantas veces lo reclame. Se elegirá el segundo gesto o símbolo de su interés y se procederá de la misma manera. A la vez, los interlocutores se dirigirán al sujeto utilizando gestos o símbolos del SAAC elegido, aunque el usuario aún no conozca (¿acaso el niño pequeño conoce el lenguaje oral cuando sus padres se dirigen a él de bebé?), acompañados siempre del habla. Se utilizarán estrategias de enseñanza dirigidas al aprendizaje de la comunicación aumentativa.

Es útil, sobretodo al principio, modificar los entornos en los que se desenvuelven los usuarios cuando se está aprendiendo el SAAC señalizando el entorno. Se pueden colocar en distintas partes de la casa o los centros, de forma accesible, tableros de comunicación específicos, por ejemplo un panel de comidas en la cocina, un cuadro de programas preferidos de TV junto a la tele, los juguetes en la habitación del niño, los distintos lugares a los que se puede uno desplazar en las puertas de las distintas habitaciones, etc.

Considerando algunos aspectos de los sistemas de comunicación:

- La utilidad de los sistemas consiste en favorecer la capacidad de expresión, por lo que cualquier posibilidad de lenguaje oral ha de ser explotada al máximo. 
- Un sistema alternativo y complementario de comunicación no es como el lenguaje oral, pero no por ello se ha de considerar inútil su implantación, al contrario, a pesar de las limitaciones de cualquier sistema de comunicación en comparación con el habla, su uso acerca a las personas a las ventajas que el habla conlleva.

- Cuando se comienza a trabajar con un sistema, su uso no sustituye la intervención logopédica, ya que el trabajo con ambas es necesario para la adquisición del lenguaje.

- Una clara limitación es que se necesita el conocimiento del sistema por parte de las personas que quieren interactuar con el niño o niña, y en ocasiones aprenderlo no es tan sencillo.

Es preciso clasificar los sistemas de comunicación según sean sistemas complementarios a la comunicación, como es el caso de la comunicación bimodal, la palabra complementada o Cued-Speech, o sistemas alternativos a la comunicación, en el caso de que el alumno no se pueda beneficiar del lenguaje oral, como el lenguaje de signos, SPC (Símbolos pictográficos para la comunicación) o Bliss.

Algunos de estos sistemas, para poder ser utilizados, precisan apoyos externos como un tablero de letras, palabras, imágenes o símbolos para la comunicación, como es el caso del SPC.

Son sistemas con muchas posibilidades ya que se pueden adaptar al nivel de desarrollo, comunicación y necesidades del niño o niña.

A continuación se comentan brevemente cada uno de ellos.

- El SPC tiene como objetivo principal facilitar la comunicación en sujetos no orales con dificultades motoras y auditivas. Consta de pequeñas tarjetas con dibujos muy sencillos y representativos para el alumno que están acompañados de la palabra escrita, se pueden fotocopiar en diferentes colores dependiendo de si representan personas, verbos... también se pueden añadir otros que no tenga el sistema y que se consideren útiles para el chico.

Para llevar a la práctica este sistema se eligen los símbolos según el nivel del alumno y se colocan sobre un tablero, para seleccionar este vocabulario inicial se tienen en cuenta, ante todo, las tarjetas con sus necesidades básicas (aseo, alimentación...), las actividades cotidianas y sus gustos 0 preferencias. Después se van incorporando al vocabulario existente aquellas palabras que vaya necesitando cada persona a medida que van cambiando 
sus necesidades comunicativas. Entonces se enseñará al niño o niña a encadenar palabras para ir formando frases.

- El BLISS se creó en principio como sistema internacional de comunicación, pero es usado sobre todo en personas con parálisis cerebral. Consta de tarjetas con dibujos pero sin palabras, de diversos colores dependiendo si son personas, acciones..., algunas con un gran parecido a la realidad, otras sugieren la idea, por ejemplo: arriba, abajo. El sistema no recomienda una metodología para ser enseñado sino que dependerá de las características del sujeto, por ejemplo se puede asociar las tarjetas a los objetos que representan, para que una vez que la asociación se produzca ir retirando el objeto

Hay que diferenciar entre sistemas alternativos y aumentativos de comunicación. Los sistemas alternativos de comunicación son los que sustituyen totalmente al habla (que no al lenguaje), por lo que se refieren más al lenguaje que al habla. Los sistemas aumentativos de comunicación son un complemento al habla, por lo que se refieren más al habla que al lenguaje. En la actualidad el concepto más amplio de comunicación aumentativa (CA) incluye todas aquellas opciones, sistemas 0 estrategias que se pueden utilizar para facilitar la comunicación de toda persona que tiene dificultades graves para la ejecución del habla. Así, el objetivo más general de la CA es instaurar o ampliar los canales de comunicación social de las personas con alteración o imposibilidad del habla, colaborando así a una mejor calidad de vida.

Cualquier persona con dificultades graves para la comunicación vocal es candidato potencial a la comunicación aumentativa, sin requisitos previos. Se podría hablar de tres grandes grupos de candidatos:

1. Sujetos que han podido desarrollar un buen lenguaje, espontáneamente o mediante rehabilitación, pero cuya expresión oral no es inteligible, Ej.: algunos sordos profundos y muchos sujetos con parálisis cerebral.

2. Sujetos sin impedimentos a nivel de órganos fonoarticulatorios, que teóricamente podrían hablar con normalidad, pero que no han podido desarrollar un buen sistema lingüístico, Ej.: sujetos seriamente afectados de déficit mental.

3. Sujetos que están afectados tanto a nivel de lenguaje como de habla, Ej.: plurideficientes.

Este método auxilia a que estos grupos tengan mayor autonomía en sus actividades de la vida diaria, inserción laboral y social, aumentando su comunicación y la capacidad de solucionar dificultades en su vida cotidiana. 


\subsection{Lectura labiofacial}

El primero de los sistemas aumentativos de comunicación, en lo que a pragmática y redundancia se refiere, es sin duda la lectura labiofacial (LLF o LL), tanto en personas con sordera como en oyentes. El estudio de la LLF en percepción del habla es un tema que ha ido cobrando importancia en la investigación básica y aplicada desde que McGurk y MacDonald (1976, citados en González, 2006) publicaran su breve (sólo dos páginas), pero sugerente artículo "Hearing lips and seeing voices", donde demuestran que la LLF no es un epifenómeno en el procesamiento normal del habla.

La LLF es una técnica para la adquisición del conocimiento mediante la vista (es percibir por medio de la vista, cuando por distintas razones no se puede recibir ni analizar el mensaje oral mediante el oído). En realidad, la LLF la realizan todas las personas de un modo inconsciente, tan sólo se percibe cuando se esta llevando a cabo, al enfrentase a condiciones anómalas, en situaciones ruidosas (donde no se recibe con claridad la voz del interlocutor), en las que se recurre a mirar la cara del mismo para comprender lo que está diciendo. Es pues, un gesto intuitivo que todos realizamos para mejorar y/o facilitar la comprensión del mensaje oral, aunque no se cuente con problema de audición alguno.

Siempre se ha hecho referencia a la LLF como una habilidad innata en todos los seres humanos, de ahí que algunos autores planteen que la LLF no se enseña, sino que se entrena. Dado que el objetivo del presente apartado es esclarecer el concepto así como analizar sus ámbitos de actuación, se va a considerar la LLF como una técnica para alcanzar el desarrollo del lenguaje verbal así como para lograr la comunicación en sujetos con percepción auditiva alterada.

Se ha definido la LLF como el arte de leer el habla en los labios. Hoy se sabe que es algo más que un arte, es un proceso cognitivo básico que, como todos los procesos básicos, se manifiestan casi desde el nacimiento, pues se ha demostrado experimentalmente, como indica González (2006, 2), que bebés de tres meses son sensibles a las variaciones visuoarticulatorias del habla. El tema es de especial interés en el caso de las personas con pérdida auditiva.

"En situación de habla normal cobra progresiva importancia la aportación visual a la percepción del habla, sin que el receptor sea consciente de ello" (Reisberg et al., 1987; Jordan, 1988, citados en González, 2006).

Uno de los mayores mitos en la educación de las personas que presentan sordera es que todas son excelentes labiolectoras. La persona con deficiencia auditiva, en cualquiera de sus grados, percibe el habla alterada auditivamente. En unos casos serán problemas de ruido, en otros de alteración de parámetros suprasegmentales, como es el caso del habla con acento extranjero, en otros casos será la complejidad cognitiva del mensaje, y en muchas ocasiones se dará todo a la vez.

Para comprender como soluciona la LLF los problemas de percepción del habla que tienen las personas con deficiencia auditiva, hay que analizar las situaciones antes expuestas: 
- relación señal-ruido: es un problema que la tecnología está solucionando cada día con mayor eficacia; el nivel de calidad alcanzado por los audífonos digitales, los implantes cocleares y las emisoras de FM han solucionado este viejo problema

- alteración de parámetros del habla: una vía de solución vendrá por la estimulación temprana oral, más que justificada en la investigación básica pero todavía no suficientemente tomada en serio en rehabilitación del bebé con deficiencia auditiva. Como indica González $(2006,3)$ los flirteos lengua de signos vs. lengua oral, por ocupar el primer puesto están desviando la atención de lo esencial. Dicho para que se entienda, la naturaleza ha puesto ahí antes del nacimiento la semilla del habla (no confundir aquí con lenguaje) y bastaría ponerla en contacto con el habla exterior, en condiciones estudiadas, para que se desarrollara. Es lo que ocurre en el caso del niño oyente.

- complejidad cognitiva del mensaje: esta es consecuencia del desarrollo limitado del lenguaje oral que adquieren la mayoría de las personas con deficiencia auditiva. Esta limitación lingüística se arrastrará a la lectura aumentando el problema. La solución podría venir aplicando modelos de intervención cognitiva donde el desarrollo lingüístico no sea el todo, sino una parte de la intervención.

El papel que juega la LLF en el caso de las personas con deficiencia auditiva es el mismo que en las personas oyentes, un papel secundario y limitado, cuyo aporte está directamente relacionado con la competencia lingüística oral, el conocimiento previo del mensaje y la dificultad cognitiva del mismo. Dicho de otra manera, el dominio del lenguaje oral facilita y mejora la LLF, pero la LLF por sí misma no mejora el desarrollo lingüístico. Sólo se puede ver en los labios lo que de antemano se conoce. La LLF siempre es parcial y ambigua, por eso en la tarea de descubrir visualmente el mensaje siempre semioculto, juegan un papel decisivo las inferencias, las deducciones y la suplencia mental, pero la calidad y eficacia de estos procesos dependen del desarrollo cognitivo-lingüístico del sujeto. Ante estas exigencias, ¿quién puede, inferir, deducir y suplir más y mejor? "El que tiene más recursos cognitivos y más conocimientos lingüísticos a los que recurrir" (González, 2006, 4).

La LLF es un complemento visual funcional y natural del mensaje presentado mediante la modalidad aural-oral, que enfatizan algunos métodos como la Palabra Complementada (Cued Speech) dentro de la rehabilitación o educación de las personas con deficiencias auditivas. En este sentido, la Lectura Labiofacial podría definirse como una técnica que permite la adquisición del conocimiento mediante la vista. Esto implica el entrenamiento a la persona para que intente "leer" o discriminar e interpretar los movimientos de labios y otros órganos articuladores, cuando el interlocutor pronuncia palabras aisladas u oraciones.

En la educación a personas con sordera se convierte en una técnica que complementa el entrenamiento auditivo y del habla. Para este propósito, hay mejores resultados en personas que presentan hipoacusia o sordera postlocutiva, con inteligencia normal o superior y conocimiento amplio de la lengua oral. 


\subsection{El Alfabeto Dactilológico}

A partir de los años 60 se empezó a producir un importante cambio en la educación de las personas sordas, debido sobre todo, a factores tales como los diferentes estudios que se realizaron sobre el lenguaje de signos, que pusieron de manifiesto su gran valor lingüístico y sus múltiples posibilidades de expresión. Estas investigaciones también pusieron de manifiesto que la adquisición temprana del lenguaje de signos por parte del niño con deficiencias auditivas eran muy importantes para el desarrollo cognitivo y lingüístico posterior. Además, los educadores de niños sordos iban tomando conciencia de que el método oral puro no proporcionaba a los alumnos un nivel suficiente de lenguaje, ni les permitía comunicarse con los oyentes. En los últimos veinte años, la polémica viene impulsada por las corrientes sociales y pedagógicas que defienden la incorporación del alumno con algún tipo de deficiencia a la Escuela Especial como sinónimo de escuelas separadas.

La dactilología consiste en deletrear las letras del alfabeto con las manos en el aire. En principio podría hacerse un paralelismo entre la escritura para el lenguaje oral y la dactilología para el lenguaje gestual. Según Buyssen (1967, citado en Torres et al., 1995) "la dactilología es una semia sustitutiva de segundo grado, mientras que los grafemas o letras escritas lo son de primer grado". Suele usarse con el lenguaje de signos y/o bimodal, aunque la dactilología es algo extraño al lenguaje de signos. Los lenguajes de signos no suelen tener palabras de tipo dactilológico, si exceptuamos algunos monosílabos. Los lenguajes de signos recurren a la dactilología ante una palabra nueva cuando no tienen un signo establecido para ella. Teniendo en cuenta los conocimientos actuales sobre procesamiento de la información en el proceso lectoescritor y las habilidades naturales de segmentación segmental, silábica y fonémica, se puede afirmar que la dactilología es la modalidad que más altera los esquemas naturales del desarrollo verbal y que viola en mayor medida los mecanismos del procesamiento de la información, pues desborda con frecuencia la capacidad humana de memoria sensorial icónica y de la memoria a corto plazo. Kyle y Woll (1985, citado en Torres y Sánchez, 2005), en contra de la opinión más generalizada, definieron la dactilología como "parte del lenguaje de los sordos, cuando es usada de forma no sistemática". Cuando es usada sistemáticamente junto con el habla da lugar al método Rochester y al Neooralismo. Desde la psicolinguistica cognitiva la dactilología despierta curiosidad y deja sin resolver cuestiones claves, tales como: ¿Cómo procesan los sordos profundos los signos manuales secuenciados en el aire? ¿Forman palabras que desconocen? ¿Qué imagen mental tienen de esas palabras?

Bornstein (1979, citado en Torres y Sánchez, 2005) califica de insuficiente la dactilología al comprobar que con dactilología se alcanza una medida de 5 letras/seg, que equivale a 60 palabras/min., frente a las 175 palabras $/ \mathrm{min}$, del habla normal como indicó Lewis (1991, citado en Torres y Sánchez, 2005). Y está comprobado que hablar por debajo de 100 palabras/min, disgusta a los niños.

En la actualidad están teniendo un gran auge los sistemas alternativos y complementarios de comunicación en los centros tanto específicos como de integración, y se han convertido en una elección para intervenir ante multitud de problemas de comunicación con muy buenos resultados. Aunque algunas 
personas carentes de lenguaje oral que han sido enseñadas a usar un sistema de comunicación han logrado la aparición de lenguaje oral de forma inesperada, esto no debe convertirse en el objetivo final de la implantación de un sistema ni en un foco de esperanza para las familias o personas allegadas al usuario de estos sistemas ya que todavía se sigue investigando sobre el tema.

De cualquier manera el uso de sistemas alternativos o complementarios es muy adecuado y, como opinan la mayor parte de los autores, no frenan la posibilidad del habla sino que, en todo caso, la potencian, favoreciendo el desarrollo del lenguaje así como la mejora global de las relaciones interpersonales y el desarrollo cognitivo, procurando con ello el desarrollo integral del alumno/a.

Los lenguajes de signos recurren a la dactilología ante una palabra nueva cuando no tienen un signo establecido para ella. Teniendo en cuenta los conocimientos actuales sobre procesamiento de la información.

Finalmente, la dactilología se equipara a la destreza del oyente que consiste en convertir cada grafema en su fonema correspondiente y viceversa, destreza que sólo se adquiere tardíamente y mediante el aprendizaje lectoescritor. La carencia fonológica de la dactilología aumenta las incógnitas acerca de su adquisición y uso por el sordo.

\subsection{Palabra complementada o Cued-Speech}

La Palabra Complementada (PC) es otro sistema aumentativo de comunicación en la educación de los alumnos sordos. Implica el uso simultáneo de lengua oral acompañada de signos, con el objetivo de "visualizar" la lengua oral al niño sordo. Se trata, pues, de ofrecer al niño sordo la lengua oral acompañada simultáneamente de signos: con la utilización conjunta de dos lenguas: la lengua de signos y al lengua oral. En su versión española consta de ocho configuraciones de la mano (para identificar las consonantes) que se ejecutan en tres posiciones distintas respecto al rostro (que corresponden a las vocales). (Acosta, 2006, 129)

Se denominan Kinemas a los complementos manuales y no poseen significado lingüístico. Se complementan sonidos en la palabra complementada (no letras), o sea, tienen una imagen visual similar $(\mathrm{Ej} . / \mathrm{m} /, / \mathrm{b} /, / \mathrm{p} /)$ y al contrario, se emplean los mismos complementos manuales cuando las imágenes visuales son claramente diferenciables (p. ej., /m/, /f/, /t/). La palabra complementada no es un sistema signado ni gestual, ya que las posiciones manuales por sí solas no ofrecen información suficiente para comprender el mensaje.

Las investigaciones realizadas en torno a las posibilidades que ofrece el empleo de la palabra complementada en el desarrollo de la lengua oral y en el aprendizaje de la lengua escrita son numerosas en la literatura sobre el tema (Lassaso y Metzger, 1998; Alegría, 2003, citado en Acosta, 2006) Estas investigaciones ponen en manifiesto que la palabra complementada favorece el desarrollo léxico y morfosintáctico. Con este sistema el niño sordo puede asimilar esquemas fonológicos, lo que facilitará la adquisición de un vocabulario más extenso. 
Los datos del grupo de Bruselas (Alegría, 1999; Alegría, 2003, citado en Acosta, 2006), muestran que los niños sordos que comienzan antes a emplear la palabra complementada (usada en casa) obtienen mejores resultados que los que únicamente se exponen a ella en el colegio.

Es muy simple: los fonemas confundibles en los labios (igual visema), son complementados por figuras distintas de la mano (distinto kinema). Y viceversa, los fonemas distinguibles en los labios (distinto visema) tienen una misma figura en la mano (igual kinema).

La Palabra Complementada (Torres et al., 1995, 127) hace uso de tres posiciones diferenciadas de la mano (lado, barbilla y garganta) para indicar todas las vocales, así como de ocho figuras de la mano para indicar todas las consonantes. Dentro de estas figuras se agrupan las consonantes de manera que en un mismo grupo no coincidan consonantes con igual imagen visual "visema". Su aplicación logra despejar las dudas que los fonemas similares tienen, proporcionando al alumno una discriminación visual, que le permitirá una adecuada recepción del mensaje.

Las configuraciones manuales (Nicholls y Ling, 1992; Périer et al, 1987, citados en Alonso, 1995) permiten identificar las consonantes mientras que las vocales se corresponden con los puntos de articulación. El acompañamiento simultáneo de estas claves junto al habla permite una mejor discriminación del mensaje, facilitando, asimismo, los procesos de comprensión.

La producción del habla viene acompañada silábicamente por complementos manuales, lo que permite que personas muy habituadas con el sistema puedan mantener una producción hablada fluida. Como todo sistema, los resultados obtenidos dependen de la edad en que se comienza a utilizar, de la variedad de usuarios que lo emplean con el niño y del grado de sistematicidad de su empleo.

El uso de la palabra complementada favorece la comprensión de los mensajes hablados, como señalan algunas investigaciones (Alegría y Leybaert, 1987; Alegría et al, 1992, citados en Alonso, 1995), la creación de representaciones fonológicas son fundamentales para el acceso posterior a la lectura.

Quizá la principal limitación de la palabra complementada sea que, a pesar de ser un sistema que facilita al niño sordo la lectura labial de los mensajes favoreciendo la comprensión de los mismos, no tiene un efecto facilitador similar en cuanto a la producción. Obviamente, una mejor comprensión supone, a la vez, mejor competencia lingüística, peor producción hablada del niño sordo, especialmente si éste es pequeño y tiene una sordera profunda Prelocutiva. Es por ello por lo que algunos profesionales combinan el empleo de la palabra complementada con el uso del bimodal, sobre todo en edades tempranas (Monfort y Juárez, 1992, y Charlier, 1992, citados en Alonso, 1995).

Las posibilidades que ofrece este sistema son:

- Mejora la percepción de la palabra. Los trabajos de investigación realizados en este sentido muestran que la PC proporciona una información fonológica más completa y menos ambigua que la proporcionada por la lectura labiofacial sola, lo cual contribuye a la adquisición de una fonología de calidad, 
como se deduce del uso que de ella hacen los alumnos Sordos en pruebas de memoria, juicios de homofonía y identificación de palabras presentadas oralmente. Los datos del grupo de Bruselas (ver Alegría, 1999, citado en Acosta, 2006), muestran también que los niños Sordos que comienzan a emplear la PC en etapa temprana tienen un nivel mejor de aprendizaje en el colegio. De lo cual se desprende la necesidad de utilizar la PC de forma sistemática en la educación de los alumnos Sordos y la conveniencia de emplearla en todos los contextos posibles.

- Favorece el desarrollo léxico y morfosintáctico. Gracias a la PC el niño Sordo puede asimilar esquemas fonológicos correctos, lo que le facilitará la adquisición de un vocabulario más extenso. También podrá captar las estructuras morfosintácticas de una forma más completa, siempre y cuando se produzca una simultaneidad exacta de la producción vocal y de su complemento manual, es decir, siempre que se complemente como se habla.

- Facilita el aprendizaje del lenguaje escrito. La PC permite el desarrollo de representaciones fonológicas completas y exactas, lo que posibilita que los niños Sordos puedan emplearlas en procesos de reconocimiento de la palabra escrita.

- El aprendizaje de la PC es relativamente rápido y sencillo. El hecho de que sea un sistema constituido únicamente por ocho configuraciones y tres posiciones distintas facilita su aprendizaje. Otra cuestión es la automatización del sistema, que exige constancia y práctica continuada para alcanzar unos buenos niveles de fluidez.

- Es un sistema compatible con cualquier orientación educativa. La PC es un sistema de comunicación oral que, dentro de los enfoques monolingües, puede utilizarse como apoyo exclusivo y sistemático a la comunicación oral; o en combinación con otros tipos de ayudas, como es la comunicación bimodal. En el segundo caso, las propuestas desarrolladas intentan potenciar las ventajas de ambos sistemas (Charlier, 1994 en Bélgica; Monfort y Juárez, 1992, en España, citados en Domínguez y Alonso, 2004). También es posible la utilización de la PC en la enseñanza del lenguaje oral en opciones bilingües.

Una vez presentados los sistemas de comunicación más utilizados en la actualidad, se pasa a comentar cómo se decide si un niño o niña puede beneficiarse de ellos, cuál es el proceso de toma de decisiones. No hay que olvidar que primero se ha debido intentar, sin resultado, la adquisición del lenguaje oral, entonces es cuando se recurre al sistema.

Al principio, aunque siempre dependiendo del caso, se podrían utilizar como un medio temporal de comunicación, hasta que se establezca el habla, un medio de comunicación permanente cuando el desarrollo del habla es imposible o un medio de comunicación complementario a un habla pobre. 
Por ejemplo, si un niño después de aprender algunos signos del lenguaje de signos empieza a imitar palabras, lo más adecuado en este caso es intentar de nuevo la imitación vocálica y el lenguaje verbal vocal productivo, sin interrumpir el sistema gestual.

Una vez que se ha decidido utilizar un sistema, hay que valorar cuál de ellos, ya sea complementario o alternativo a la comunicación se va a utilizar. Para esto hay que tener en cuenta las características del alumno: el nivel del lenguaje que posee el niño o niña, sus habilidades cognitivas, si tiene algún problema motor (por ejemplo, para la realización de los signos del lenguaje de signos, este es un dato muy importante). También es muy importante que el alumno tenga deseos de comunicarse y capacidad de atención, así como las características del contexto en el que esta inmerso ya que al introducir al niño en un sistema de comunicación se necesita el beneplácito de la familia y su disposición de colaboración.

Después, hay que valorar, entre los objetivos que se quieren lograr, que el sistema sea adaptable al desarrollo y evolución de las capacidades y posibilidades del sujeto, que sea motivador, que sea efectivo, que cubra todas sus necesidades básicas y que posibilite la comunicación con cualquier interlocutor.

Por todo ello, la palabra complementada facilita el aprendizaje de la lengua escrita, ya que permite: el aprendizaje de la lengua escrita y el desarrollo de representaciones fonológicas completas y exactas, que posibilitan que los niños sordos puedan emplearlas en procesos de reconocimiento de la palabra (Alegría, 1999 y 2003, Domínguez y Alonso, 2004, citado en Acosta, 2006).

\subsection{Bimodal}

"La comunicación bimodal o el idioma "signado" es un sistema complementario de comunicación que implica el uso simultáneo de lengua oral acompañada de signos (tomados en su mayoría de la lengua de signos), con el objetivo de visualizar la lengua oral al niño Sordo. A diferencia de la PC no es un apoyo que permite la visualización de la forma fonológica de las palabras, sino que más bien trata de ofrecer al niño Sordo información acerca de la estructura sintáctica de la lengua oral" ( Domínguez y Alonso, 2004, 83).

El término "bimodal" introducido por Schlesinger (1978) para designar la asociación dedos modalidad: signada y hablada; por ello, en algunos países, a esta forma de comunicar se la denomina "comunicación simultánea" (Domínguez y Alonso, 2004, 83).

Se trata, pues, de ofrecer al niño Sordo la lengua oral acompañándose simultáneamente de signos tomados de la lengua de signos; pero esto no supone la utilización conjunta de dos lenguas :la lengua de signos y la lengua oral. El mensaje se expresa de dos formas al mismo tiempo, pero la lengua base, la que marca el orden de la frase, la que determina la sintaxis de las producciones es la lengua oral. Los signos sólo acompañan las producciones orales (C.N.R.E.E, 1989, 1991, citado en Domínguez y Alonso, 2004). 
El objetivo de la comunicación bimodal es doble, por un lado facilitar el desarrollo precoz de la comunicación y por otro potenciar la adquisición del lenguaje oral.

La experiencia en la educación de los niños sordos y numerosos estudios sobre el tema, confirman que la utilización de la lengua de signos en edades tempranas, produce un efecto positivo tanto en el ámbito cognitivo como conductual y lingüístico, facilitando en el alumno la interacción con sus padres, profesores y en general con el medio que le rodea.

La ventaja que presenta la comunicación bimodal, es que el niño puede adquirir a una temprana edad un código de comunicación que le permitirá expresarse con fluidez, facilitando el desarrollo de su personalidad y su pensamiento.

En general la comunicación bimodal permite en niños no oralizados, el desarrollo de actividades que difícilmente podrían desarrollar con una comunicación exclusivamente oral:

- Contar cuentos y secuencias lógicas de acción.

- Planificar juegos, actividades, dramatizaciones, etc.

- Comentar hechos ocurridos en la escuela, en la familia, con los amigos, etc.

- Explicar situaciones y hechos cotidianos.

El sistema se centra en la adquisición del lenguaje oral, pero facilita al niño sordo un sistema (gestual) que le es asequible y con el que puede expresar desde sus primeros años, sus deseos, necesidades, preguntas, en resumen, que le permita comprender y expresarse e interaccionar con los demás.

El niño sordo podrá rápidamente utilizar la parte gestual de la comunicación bimodal para mantener una comunicación satisfactoria y si se realiza una buena rehabilitación, el niño de forma natural irá acompañando sus gestos de habla espontánea con palabras simples en un principio y más correctas e inteligibles después.

El bimodal aparece como un modelo conciliador entre ambos lenguajes, intentando cubrir las lagunas cognitivo-lingüísticas que el oralismo presenta. El bimodal como otros métodos, tiene sus lagunas y limitaciones, pero facilita al niño y a su entorno educativo y familiar un sistema de comunicación eficaz y fluido.

Es la mezcla de la utilización de algunos signos junto con el lenguaje oral, pero signando las palabras en el mismo orden que los oyentes utilizan al hablar.

Existen diferentes concepciones o formas de entender la comunicación bimodal, que tienen que ver con distintos grados de ajuste entre la modalidad oral-auditiva y la modalidad visual-gestual y las características de los signos que se emplean. Resulta necesario conocerlas, "pues implican unos planteamientos y recursos distintos a la hora de ponerlas en práctica. Los diferentes grados de ajuste y las características de 
los signos dependerán de los objetivos que se prendan cubrir con este sistema" (Domínguez y Alonso, 2004, 84-85):

- Estimular el aprendizaje de la lengua oral. En este caso, el sistema se centra más en la "forma" que en el "contenido", por lo que es fundamental obtener el mayor grado de visualización de todos y cada uno de los elementos de la lengua oral. Para ello será necesario, además de conocer vocabulario en lengua de signos (para marcar los sustantivos, verbos, adjetivos y adverbios), recurrir a la dactilología, a la PC, o crear signos arbitrarios ajenos a la lengua de signos, para marcar las palabras funcionales de la lengua oral. Así pues, la correspondencia palabra-signo es bastante estricta, lo que provoca que la comunicación resulte más lenta y pesada.

- Facilitar la comunicación de los alumnos Sordos. En esta concepción se da más importancia al "contenido", centrándose en la comprensión de los mensajes por parte del alumno Sordo. En este caso, es necesario conocer, además de los signos de la lengua de signos, muchos de sus mecanismos gramaticales, como por ejemplo la organización espacial. Sin embargo, el hecho de emplear estos elementos no significa que estemos en presencia de la lengua de signos propiamente dicha, ya que los signos no ajustan a la gramática de la lengua de signos, sino a la de la lengua oral.

La posibilidad que ofrece este sistema son:

- Ofrece a los niños Sordos un instrumento de comunicación eficaz que pueden emplear desde edades muy tempranas, por lo que facilita la comunicación desde el primer momento (tanto para los padres como para los educadores que opten por ello).

- Mejora la competencia lingüística de los alumnos Sordos. Los trabajos de investigación que comparan niños Sordos que emplean la comunicación bimodal frente a niños orales, muestran que el primer grupo es superior al segundo en el desarrollo verbal. No obstante, cuando se les compara con oyentes se observa un retraso en el desarrollo verbal en relación a éstos; así, por ejemplo, los niños Sordos entre 5 y 9 años de edad no alcanzan el nivel lingüístico de oyentes de 4 años y a los 6 años su competencia lingüística no es suficiente para el aprendizaje del lenguaje escrito.

- Es un sistema sencillo de aprender y de usar por parte de los profesionales y los padres, ya que sólo supone aprender un vocabulario en signos y simultanear su producción con la producción oral habitual, es decir, no implica una organización sintáctica diferente. Los signos aportan información semántica.

Por su contra, el bimodal presenta una serie de limitaciones o dificultades:

- Dificultad de simultanear la producción oral y la signada sin que ninguna de las dos se vea empobrecida o mermada. En concreto, estas dificultades pueden centrarse en alguno de estos aspectos. 
- Dificultad de simultanear un vocabulario de características semánticas distintas. Por un lado, existen palabras en la lengua oral que carecen de equivalente en la lengua de signos por expresarse sus significados mediante otros recursos lingüísticos .Hay palabras de la lengua oral que necesitan más de un signo para poder expresar con exactitud el concepto al que hacen referencia; y, a la inversa, algunos conceptos de la lengua oral que necesitan varias palabras para ser expresadas tienen su equivalente en la lengua de signos en un solo signo.

$\mathrm{Y}$, asimismo, una palabra tiene distintos significados en la lengua oral, pero en la lengua de signos disponen de un signo diferente para cada una de estas acepciones.

- Dificultad de conciliar características morfosintácticas sustancialmente distintas. Esto se evidencia con las marcas morfológicas, por ejemplo, con las que determinan el tiempo verbal, el género o el número, ya que, la lengua de signos tiene mecanismos gramaticales totalmente distintos a la lengua oral.

- Los sistemas bimodales no son totalmente eficaces para visualizar la estructura sublexical de la lengua oral. No aporta ningún elemento que permita visualizar los elementos fonológicos de la lengua oral, dejando este aspecto a las posibilidades de la LLF. Este hecho puede tener una repercusión importante en el aprendizaje del lenguaje escrita, sobre todo en el reconocimiento de las palabras escritas.

En la comunicación bimodal, "la producción hablada y signada debe realizarse simultáneamente, requiriendo para ello un buen conocimiento de los signos así como gran práctica en su uso" (Alonso, 1995, 306). No obstante, el ajuste entre la producción hablada y la signada pude tener diferentes grados, pudiendo existir un bimodal más o menos estricto. En EEUU, durante la década de los setenta se desarrollaron un buen número de sistemas de comunicación bimodal. Algunos de ellos buscaban una estricta correspondencia entre el habla y los signos que la acompañan debiendo ajustarse un signo a cada palabra y viceversa. Éste es el caso, por ejemplo, del Seeing Essential Esnglish (Anthony, 1971, citado en Alonso, 1995). Otros sistemas (Signed Supported English) optaron por acompañar sólo con algunos signos la producción hablada, mientras que, algunos, por último, se acercaron a una mayor mezcla de códigos signados y hablados dando lugar a una forma de comunicación conocida como Pidgin.

Algunos críticos del bimodalismo defienden que los códigos visogestuales no pueden representar adecuadamente una lengua de naturaleza auditivavocal como es la lengua oral. Sin embargo, otros profesionales señalan que el problema radica en el "inadecuado empleo de los mismos apuntando a la necesidad de una mayor entrenamiento por parte de aquellos que lo emplean en su comunicación con los niños sordos (en especial padres y profesores) así como a una mayor clarificación de los objetivos que se persiguen con su uso" (Alonso, 1995, 308). 


\subsubsection{Bilingües}

Al hablar de bilingüismo en la educación de alumnos sordos no sólo supone un planteamiento metodológico, lingüístico o de contexto educativo como puede suponer el bilingüismo referido a dos lenguas orales. En la base de los enfoques bilingües hay también una corriente de pensamiento que parte de un cambio de paradigma en cuanto a la concepción de las personas Sordas.

Este cambio conceptual viene motivado por varios acontecimientos y avances ocurridos a partir de los años sesenta del pasado siglo. En primer lugar, desde la psicología cognitiva, Furth (1966, citado en Almirall, Ardanuy, Casanova, Cedillo, Cervantes, Frigola, Fuertes, Galcerán, González, González, Valmaseda, Molins, Muño, Pájaro, Rexach, Rodríguez, Valmaseda, y Vinardell, 2006) fue el primero que afirmó que los sordos realizaban, igual que los oyentes, las pruebas que sirven para medir la inteligencia. Posteriores experiencias e investigaciones indican que los sordos pasan por las mismas etapas evolutivas que sus iguales oyentes siempre que cuenten con un lenguaje y un entorno estimulante (Marchesi, 1987, citado en Almirall et al., 2006).

Desde la pedagogía, algunas investigaciones llevadas a cabo en distintos países llaman la atención sobre el bajo rendimiento que consiguen los alumnos sordos al finalizar la escolarización obligatoria (Di Francesca, 1972; Rasmussen, 1973; Norden, 1975; Conrad, 1979; Valmaceda, 1998, citados en Almirall et al., 2006). Todas estas investigaciones independientemente de la nacionalidad de los alumnos sordos, arrojan los mismos resultados: En nivel lector de la mayoría de los alumnos sordos no superaba los niveles de los niños oyentes de 9 años.

Los términos bilingüismo y bilingüe se refieren, respectivamente, a la capacidad de manejar o de saber dos lenguas y al individuo que la posee. Esta definición es muy incompleta. Por una parte, "bilingüismo", por su etimología, parecería restringir el termino al manejo de solo dos lenguas, haciéndose necesario utilizar, según el caso, términos como "trilingüe", "cuadrilingüe" o, si el número aumenta más, decir simplemente "políglota", en realidad, la dificultad se ha obviado en la literatura utilizando los términos "bilingüismo" y "bilingüe" independientemente de si se trata de dos o más lenguas.

Existen diferentes definiciones, que varían en función del criterio que se utilice para definirlo. De esta forma se podría hablar de tres criterios:

- Competencia, el grado de dominio de las dos lenguas, se obtendrá una serie de definiciones que van, desde el extremo de no considerar a una persona bilingüe a menos que tenga un control de las dos lenguas igual al de los nativos, hasta el de considerar que una persona es bilingüe por el hecho de tener un conocimiento, así sea mínimo, de una segunda lengua. Podemos considerar bilingüe o no a un sordo que se comunica en lengua de signos y mediante las formas escritas del castellano.

- Imagen que proyecta, según esta visión, una persona es bilingüe solo si los nativos de las lenguas que maneja encuentran natural su forma de expresión, 
es decir, que no les cause incomodidad. Es posible, en este caso, que un oyente que sabe lengua manual se exprese con mayor facilidad unos días que otros.

- Funciones o usos para los cuales se utilizan los idiomas. Así se puede decir que un bilingüe es una persona que utiliza alternadamente dos o más lenguas, con diferentes grados de dominio, dependiendo de la situación.

Del mismo modo, un sordo puede comunicarse en la vida diaria con otros miembros de su comunidad en lengua de signos, pero a menudo utilizará el castellano escrito para efectos de estudio, trabajo o comunicación con oyentes que no signen. En ambos casos, se trata de personas bilingües, aunque no dominen perfectamente lo dos idiomas en todos los casos. Hay que recordar que, los monolingües tampoco tienen un dominio del lenguaje formal, académico, de la vida pública igual al que tienen del lenguaje cotidiano. Lo que para un monolingüe requiere el uso de estilos distintos, para el bilingüe requiere el uso de lenguas distintas.

En conclusión puede decirse que "no hay una sola definición de bilingüismo posible y que depende el criterio de quien lo necesita” (De Mejía y Tovar, 1999, 21).

"Las experiencias bilingües surgen a partir de un conjunto de variables: los desalentadores resultados académicos de alumnos sordos con grave pérdida auditiva; por otro lado, la evidencia de que los hijos sordos de padres sordos adquirían de manera natural una lengua que les permitía representar la realidad de forma lingüísticamente compleja, comunicarse con los otros, pensar y aprender; y, por último, por la demanda de un grupo de padres y el convencimiento de un pequeño grupo de profesores sordos y oyentes de que los niños sordos aprenden si se les da acceso para que lo hagan y que eso pasa, necesariamente, por el empleo de la LS." (Valmaceda, 1999, 18).

Nielsen (1987, citado en Almirall et al., 1998) en Dinamarca señala que los alumnos que se incorporaron a la educación bilingüe en 1987 presentan un mayor progreso en lectura que los que comenzaron en 1982. Este hecho, según este investigador podría explicarse por un acceso más temprano de los niños y bebés sordos y de sus padres a la lengua de signos.

Estos datos revelan, en los enfoques bilingües, que los niveles de aprendizaje actuales que los alumnos sordos alcanzan son superiores a los alcanzados por sus iguales sordos hace algunos años a los obtenidos por los alumnos oyentes.

También en España se ha iniciado experiencias de este tipo. Todas surgen del interés de padres, profesionales y también personas sordas por encontrar vías que ofrezcan una mejor calidad educativa a los niños sordos. "Su puesta en marcha es aún muy reciente y requieren, a mi modo de ver, una serie de condiciones para asegurar su éxito" (Almirall et al., 1999, 19).

- Criterios claros acerca del modelo bilingüe que se intenta desarrollar.

- Profesorado sordo y oyente competente en la lengua de signos (siempre que sea posible nativo de esa lengua). 
- Decisiones acerca de cómo enseñar la lengua de las personas oyentes, tanto en su modalidad oral como escrita.

- Profundizar e investigar en las relaciones que se pueden establecer entre la lengua de signos y la lengua escrita.

- Desarrollar el área curricular específica de lengua de signos.

- Desarrollar materiales deductivos con la lengua de signos como lengua vehicular.

- Seguimientos y evaluaciones exhaustivas que permitan conocer los progresos de los alumnos y alumnas y mejorar los procesos de enseñanza.

- Capacidad de diálogo, de reflexión y de autocrítica en todas las personas implicadas.

- Estrecho contacto familia/escuela.

Cuando una familia oyente decide introducir la lengua de signos en su vida, surge un fenómeno social. La convivencia de la lengua empieza a tener lugar en la vida del niño sordo y en la escuela pasa lo mismo cuando el bilingüismo aparece de esta manera.

La familia y la escuela introducen la LS de manera natural, aunque sepan que la lengua oral hablada y escrita sea mayoritariamente social. He aquí la primera evidencia de bilingüismo.

"El bilingüismo antes de ser una propuesta educativa aparece como una realidad relacional y social en la vida del niño sordo, en su propia familia y en la escuela" (Almirall et al., 1998, 13).

A la vista de los resultados de las experiencias bilingües con niños sordos se ha observado que estas experiencias educativas (Almirall et al., 1998, 14):

- "Requieren que la participación de los niños en la situación bilingüe escolar sea una opción voluntaria de los padres, y que estos tengan la oferta formativa en LS.

- Precisan de un apoyo institucional de modo que se garantice la dotación adecuada de recursos.

- Deben garantizar a los niños sordos modelos lingüísticos competentes y deberá desarrollar una formación permanente para que el conjunto del profesorado conozca la LS.

- Precisan la elaboración de un proyecto lingüístico por parte del centro educativo en el que se expliciten los objetivos en relación con las lenguas en convivencia (LS y lenguas orales). Proyecto que deberá incluir: 
- Explicitación curricular de objetivos en relación con la LS como materia de aprendizaje.

- La explicitación curricular de objetivos secuenciados en relación a LO así como los medios facilitadores a emplear para su aprendizaje.

- El uso funcional de una y otra lengua en relación con los diferentes alumnos y grupos de alumnos."

En el momento actual es necesario e imprescindible definir con rigor los objetivos y recursos necesarios, indicando así mismo los criterios de evaluación de resultados que se emplearán.

El bilingüismo presenta dos modalidades:

- Bilingüismo simultáneo: consiste en la presentación voluntaria pero no a la vez de ambas lenguas (lengua de señas y lenguaje oral o escrito).

El niño sordo desde edades tempranas tiene posibilidades de contacto lingüístico con adultos y niños sordos y oyentes.

- Bilingüismo sucesivo que consta de dos variantes:

- Primera variante: asume la lengua de signos como segunda lengua, se inicia con el lenguaje oral y sobre esta base lingüística se introduce la lengua de signos de forma semántica, se crea un semibilingüismo para el niño sordo, es decir, por esta vía no logran dominar ninguna de las dos lenguas.

- Segunda variante: reconoce la lengua de signos como la primera lengua, con la que se inicia el aprendizaje y constituye un punto de partida para la adquisición del idioma en su modalidad escrita, mientras que la expresión oral está en dependencia de las potencialidades del sujeto.

Entre las variantes esta última recibe mayor aceptación en su aplicación.

En la mayoría de las experiencias de bilingüismo la segunda lengua lo es en su modalidad escrita, debido a que se considera que el sordo profundo está capacitado para ser bilingüe si tiene a la lengua escrita como segunda lengua y no a la lengua oral, para lo que está biológicamente limitado. Este modelo educativo surge por los pobres resultados lingüísticos y académicos obtenidos por los escolares sordos durante todos estos años.

Se ha comprobado que la adquisición temprana de la lengua de señas, si se produce en etapas comparables a la que siguen los niños oyentes en su desarrollo del lenguaje, permitiendo obtener mejores resultados en su segunda lengua, pues el hecho de tener el lenguaje gestual como primera lengua beneficia cognitiva y afectivamente al niño sordo. 
Debido a que las necesidades y usos de las dos lengua son generalmente diferentes, el bilingüe es raramente igual de fluido y competente en ambas. Los niveles de competencia en una lengua dependerán de la necesidad que la persona tenga de utilizarla. La competencia lingüística desarrollada por el bilingüe hará uso de una lengua, la otra o una mezcla de ambas, dependiendo de la situación, del tema, del interlocutor, etc. Existen variaciones en el uso de las dos lenguas por el mismo hablante en diferentes situaciones, en diferentes etapas de su vida. Los individuos bilingües son capaces de cambiar, en diferentes situaciones, de una lengua a otra; una persona puede hablar una lengua en su casa, cambiar a una segunda lengua en la escuela o en el trabajo, cambiar nuevamente a la primera durante el almuerzo, y así sucesivamente. Las razones para cambiar están relacionadas con las características del interlocutor, del mensaje que se desea transmitir y del ámbito en el que se va a utilizar cada lengua.

Pero la adquisición de la segunda lengua en su modalidad no es sencilla para un sordo. La lengua oral se ha desarrollado en base a un sistema auditivo y oral, para la cual, el sordo está incapacitado y aprender esta lengua será un trabajo tedioso que muchas veces no brindará los resultados esperados. En este caso el aprendizaje de la segunda lengua oral no depende sólo de la necesidad y de la motivación, como sucede con otros niños bilingües, necesita de su destreza articulatoria y de su capacidad para decodificar los movimientos de los labios en mensajes significativos.

Sin embargo, y aunque la segunda lengua sea más difícil de aprender para un sordo comparado con un oyente que aprende una segunda lengua oral, la segunda lengua es necesaria para el sordo. Es necesaria, porque la lengua de señas no posee un sistema de escritura y para desenvolverse adecuadamente en la sociedad el sordo está obligado a usar lengua escrita y porque será el único medio de acceso a la información y al intercambio con los oyentes de la sociedad en la que vive. No todos los sordos usan las dos lenguas y las razones para que esto suceda varían de una persona a otra y están relacionadas con la educación que recibieron, con situaciones familiares y con la facilidad con la que puedan desenvolverse solo con la lengua de la mayoría. No obstante, todos los sordos necesitan ambas lenguas cuando llega el momento de comprender la totalidad de un mensaje.

\subsection{Lengua de Signos}

La Lengua de Signos es la lengua natural de las personas sordas, gracias a la cual pueden establecer un canal de información básica para la relación con su entorno social.

La Ley de Lengua de Signos (Ley 27/2007, 23 de octubre) en su Artículo 4, define la Lengua de signos diciendo que son las lenguas o sistemas lingüísticos de carácter visual, espacial, gestual y manual en cuya conformación intervienen factores históricos, culturales, lingüísticos y sociales, utilizadas tradicionalmente como lenguas por las personas sordas, con discapacidad auditiva y sordociegas signantes en España. "La Lengua de Signos hará que los alumnos sordos consigan una educación más "inclusiva” (Belles, 1995, 69-70; Diaz-Estébanez y Valmaseda, 1995, 45-60; E.I. Piruetas, 2002, 5; Laseras, 1999, 83-84). 
Mientras que con el lenguaje oral la comunicación se establece en un canal auditivo, la Lengua de Signos lo hace por un canal visual y espacial. Tiene una estructura gramatical propia que se caracteriza por los siguientes parámetros: la configuración de una o dos manos, de sus movimientos, de sus orientaciones, de su ubicación espacial, y de los elementos no manuales (movimientos labiales -que pueden ser verbales y orales-, faciales, linguales, etc.)

La Comunicación Gestual es el lenguaje más antiguo que se conoce y es el natural en las personas sordas para expresar sus ideas.

Fue un sacerdote, Carlos M.L' Epeé, quien crea en Pría en el año 1.755 la primera escuela publica para sordomudos, comunicándose con sus alumnos por gestos establecidos.

El lenguaje mímico fue proscrito en el Congreso de Milán de 1.880 al aprobarse la resolución "El método oral debe ser preferido al de la mímica para la educación e instrucción de los sordomudos". Pero fue Edward Miner Gallaudet, presente en dicho congreso y único oponente a la resolución, quien introdujo la lengua de signos en Estados Unidos y fue con posterioridad, Rector de la única Universidad del mundo para sordos "La Gallaudet", que cuenta en la actualidad con más de 2.500 alumnos, cursando diferentes carreras universitarias.

El lenguaje de signos (ASL americano, LSE español) que utilizan la mayor parte de los sordos adultos para comunicarse entre ellos, es una lengua en un sentido amplio del término, que posee las funciones características de comunicación, expresión, representación, etc. Tiene sus propias estructuras sintácticas y organizativas plasmadas a través de un canal visual.

Desde que Stokoe en 1.965 inició la investigación sobre el ASL, otros muchos investigadores han realizados estudios sobre el lenguaje de signos, si bien en nuestro país son escasos, entre ellos las investigaciones de $\mathrm{M}^{\mathrm{a}}$ Ángeles Rodríguez (1992, citado en Domínguez y Alonso, 2004). Hay que destacar que en los últimos años se han producido un importante aumento de los estudios, investigaciones y publicaciones sobre el lenguaje de signos. Dichos estudios pretenden darle un lugar como lengua y rebatir la creencia de que es un conjunto de gestos desordenados, incompletos y poco estructurados.

El lenguaje oral y el lenguaje de signos se rigen por diferentes reglas. En el lenguaje oral los fonemas se combinan para formar palabras y éstas a su vez para formar frases. En el lenguaje de signos no existe una disposición secuencial de los elementos, sino que de manera simultánea se combinan cada uno de los parámetros que lo forman. Estos parámetros formativos son unidades más pequeñas, en las que se puede dividir un signo, al igual que ocurre con las palabras, que se forman a partir de los fonemas.

Atendiendo a las relaciones semánticas básicas, podemos distinguir tres clases de signos:

1. Signos motivados, son aquellos que guardan relación con su referente y podemos dividirlos en: 
- Signos icónicos. Son aquellos que reproducen algún aspecto reconocible del objeto a que hacen referencia. Ejemplo: médico. Pueden representar la forma (pelota, autobús, delgado), el movimiento (caerse, caballo, rápido, carta, romper) o una relación espacial (arriba, abajo, lejos).

- Signos deícticos. Identifican o señalan el referente por medio de un gesto corporal en el contexto espacio/temporal (ojo, yo, aquí, etc.)

2. Signos intermedios. Hacen referencia al aspecto dactilológico, para expresar nombres propios de personas, lugares, etc.

3. Signos arbitrarios. Son signos que no guardan relación directa con su referente, no pueden ser identificados de manera natural y son totalmente convencionales. Ejemplo: lunes, azul, fácil, nuevo, persona, dolor, etc.

Las características que presenta el lenguaje de signos nos pueden suponer algunas dificultades a la hora de abordar el aprendizaje de la lectura. El niño oyente, a medida que aprende la lectura evoca el significado de lo que conoce por el hecho de hablar, al coincidir la lectura con las palabras que ya sabe pronunciar. El niño sordo piensa con gestos, por tanto le resulta imposible analizar un gesto, dado que el mismo, es global en su significado, no tiene partes.

Así mismo, al no coincidir la estructura de la lengua de signos con la estructura de la lengua oral y más concretamente con su organización sintáctico-gramatical, pueden aparecer dificultades significativas en el aprendizaje de la lecto-escritura.

La verdadera duda y motivo de controversia entre profesores, psicólogos y otros especialistas, es saber si el lenguaje de signos por si mismo es capaz o no de estructurar y desarrollar el pensamiento de la persona sorda, de la misma manera que el lenguaje oral lo hace en las personas oyentes.

El interés creciente hacia la lengua de signos de muchos profesionales que educan a alumnos Sordos y, fundamentalmente, de las familias de estos alumnos, está haciendo que se "resitúe" el papel de la lengua de signos en la educación de los Sordos en un lugar muy distinto, y mucho más positivo, al que ha ocupado años atrás. "Cada vez más se abren espacios para la reflexión, el diálogo y la creación de experiencias educativas diversas, en las que la lengua de signos tiene su función. Al mismo tiempo está dejando de ser algo utilizado y conocido exclusivamente por las personas Sordas signantes, para ser todo un campo de interés científico y una realidad social que cada vez está más presente entre nosotros." (Domínguez y Alonso, 2004, 37).

Las lenguas de signos implican una señal que se produce principalmente con las manos y se recibe visualmente, suponen una modalidad viso-manual a diferencia de las lenguas orales que son acústico-vocales. La entrada de la información, la que permite una posterior comprensión de los mensajes, se realiza básicamente a través de la visión. En cuanto a la producción, se realiza empleando una serie de mecanismos que permiten codificar la información que se quiere expresar (Alonso y 
Valmaseda, 1993, citados en Domínguez y Alonso, 2004). Estos mecanismos son básicamente los siguientes:

- Articuladores manuales. Las manos constituyen el principal articulador en la formación de signos. En base a su empleo, los signos pueden clasificarse como signos de mano dominante en los que solo se mueve una mano; signos de mano base en los que la mano no dominante permanece estática constituyendo el lugar de articulación y signos bimanuales, en los que ambas manos actúan como articulador activos.

- Articuladores no manuales. Además de las manos, los signantes también hacen uso de otros articuladores como las posiciones del cuerpo, expresiones faciales que implican los ojos, movimientos de cabeza, movimientos de labios, etc.

- Uso del espacio. Todas las lenguas de signos utilizan el espacio físico cercano al signante para realizar la producción signada. Los signos se producen en el "espacio sígnico o de signación" (Chapa Baixuli, en Minguet, 2001, citado en Domínguez y Alonso, 2004) que abarca, únicamente el área que los brazos del signante pueden alcanzar un esfuerzo o estiramiento excesivo.

- Modificaciones del movimiento con el que se producen los signos.

Estos mecanismos permiten una presentación simultánea y no solo lineal de las producciones. Las lenguas de signos brindan la posibilidad de producir distintos elementos léxicos al mismo tiempo, simultáneamente.

Sabemos hoy en día que los signos tienen "partes" (los parámetros formacionales"), equivalentes a los fonemas de las lenguas orales, y que para conocer el significado del un signo hay que identificar esas partes. A los primeros parámetros formacionales identificados por Syokoe (1960, citado en Domínguez y Alonso, 2004), configuración o forma que adopta la mano o las manos; lugar de articulación del signo y movimiento que realiza la mano o las manos, se han añadido otros que hacen más preciso el análisis de este sistema: la orientación de la mano; el contacto de la mano con el cuerpo del signante y la expresión corporal o componentes no manuales.

En cuanto a la sintaxis de las lenguas signadas, hay que destacar el principal mecanismo que marca las relaciones gramaticales a través del "espacio sígnico", denominado "espacio sintáctico). Independientemente de la posición que ocupen los signos en las oraciones, parece haber consenso al decir que el uso del espacio establece las relaciones gramaticales entre ellos (Chapa, 2001; Emmorey, Corina y Bellugui, 1995; Winston, 1995, citado en Domínguez y Alonso, 2004).

Las Lenguas de Signos pueden estudiarse también desde el punto de vista semántico y distinguirse en ellas la significación lingüística. También parece posible organizar el vocabulario de estas lenguas atendiendo a criterios semánticos: campos semánticos, agrupaciones en clases. Valdemoro (2000, citado en Domínguez y Alonso, 2004) en relación a la LSE, señala distintos mecanismos internos 
(composición, sinécdoque gestual...) que permite a esta lengua generar vocabulario nuevo, ampliar o modificar los significados de los signos ya existentes, lo que supone que en esta lengua también puede hablarse de fenómenos semánticos tales como el uso de eufemismos, de la existencia de signos "tabú", de la utilización de la metáfora, etc.

Los métodos utilizados en la enseñanza del lenguaje al sordo se basan, más que en las pruebas científicas, en la teoría y en la experiencia. "El lenguaje de signos manuales, utilizado, por muchos sordos, tiene una larga historia" (Myklebust, 1971, 252). Los defensores del método oral mantienen que el uso del lenguaje de signos impide y obstaculiza el desarrollo del lenguaje. El problema del comportamiento del niño sordo es más complejo de lo que suponen las bases de una relación simple, directa y inversa, entre el uso del lenguaje oral y del lenguaje de signos.

Una vez consideradas las ventajas e inconvenientes de la labiolectura y del lenguaje de signos, parece que el sistema verbal, es decir, la lectura labial, "ofrece más posibilidades y satisface mejor las exigencias de un sistema lingüístico adecuado" (Myklebust, 1971, 254). Esto no excluye que pueda haber sordos incapaces de adquirir una holgada habilidad en este tipo de lenguaje. Pero hay que advertir que esto ocurre en todo grupo de personas, sea cual sea el sistema lingüístico adoptado. Lo que importa resaltar es que sólo mediante un lenguaje verbal, podemos esperar que el ser humano obtenga su máxima potencialidad.

\subsection{Evolución histórica de la LSE}

Aun cuando la lengua de signos sea natural entre las personas con sordera, su origen es tan antiguo como la lengua oral en la humanidad, y también ha sido utilizada por comunidades de oyentes. De hecho, los amerindios de la región de las Grandes Llanuras de Norte América usaban una lengua de signos para hacerse entender entre tribus que hablaban lenguas diferentes, y a estas alturas aún lo siguen utilizando.

Otro caso, también amerindio, ocurre en la isla de Manhattan, donde vivía una tribu única en la que todos sus integrantes eran sordos, debido a la herencia expansiva de un gen dominante, y se comunicaban con una lengua de signos.

Pese a esto, no existen referencias documentales sobre este lenguaje antes del siglo XVIII. Los datos que se poseen tratan, sobre todo, de sistemas educativos para personas sordas.

Igual que pasa con el lenguaje oral, no hay necesariamente una lengua para cada país, y aún menos es una lengua universal, sino que hay varias lenguas de signos en el mundo ubicadas regionalmente. Existen al menos unas cincuenta lenguas prácticamente inteligibles entre sí, y numerosos dialectos, algunos de los cuales coexisten dentro de una misma ciudad.

Además, existe un Sistema de Signos Internacional (SSI), que se puede considerar como una mezcla artificial de los signos de las diferentes lenguas que forman una de nueva estándar o internacional, equivalente por ejemplo a la lengua oral del 
esperanto, y que es utilizada por personas que no comparten una lengua de signos común y que necesitan comunicarse sin la intermediación de un intérprete.

George Wilhelm Friedrich Hegel (1770-1831, citado en Storch, 2005), decía que como toda construcción filosófica comienza hoy por ser una conversación con Hegel, tenia que recordar la concepción desarrollada por este filósofo alemán acerca de la "lucha por el reconocimiento del otro en sí mismo en el otro".

En términos lingüísticos, la lengua de signos puede ser tan rica y compleja como cualquier otra lengua oral, pese a la generalizada concepción equivocada de que son "lenguas artificiales". En la Lingüística se han estudiado varias lenguas de signos y se ha encontrado que tienen todos los componentes lingüísticos necesarios para clasificarse como una lengua natural.

Las lenguas de signos no son simple mímica, y no son tampoco una reproducción visual de alguna versión simplificada de ninguna lengua oral. Tienen una rica y compleja gramática y, como cualquier otra lengua, se pueden usar para discutir cualquier tema, desde el más sencillo y concreto hasta aquello abstracto y denso. Las lenguas de signos, al igual que las orales, se organizan por unidades elementales sin significado.

Otro concepto equivocado y generalizado es que las lenguas de signos tienen alguna clase de dependencia de las lenguas orales, por ejemplo, que utilizan básicamente un deletreo de las palabras de una lengua oral mediante símbolos gestuales, o que fueron inventados por personas oyentes.

En las lenguas de signos se utilizan el alfabeto dactilológico, generalmente para los nombres propios, si bien sólo es una de las numerosas herramientas que poseen. Antiguamente, el uso de la dactilología en las lenguas de signos era una presupuesta evidencia de que sólo eran una pobre o simplificada versión de las lenguas orales.

En general, las lenguas de signos son independientes de las lenguas orales y siguen su propia línea de desarrollo. Por último, un área que tiene más de una lengua oral puede tener una misma lengua de signos, pese a que haya diferentes lenguas orales, como es el caso del Canadá, los EE.UU., y México, donde la lengua de signos americana convive con las lenguas orales inglesa, española, y francesa.

Una prueba más de la separación de las lenguas orales de las lenguas de signos es el hecho de que estas últimas explotan únicamente los disparos del medio visual. La lengua oral es auditiva y, consecuentemente, lineal. Sólo se puede emitir o recibir un sonido a la vez, mientras que la lengua de signos es visual y, por lo tanto, se puede referir un espacio entero al mismo tiempo. En consecuencia, la información puede fluir mediante varios "canales" y expresarse simultáneamente.

Otra característica que diferencia la lengua de signos del oral es la capacidad de ser escrita. Normalmente las lenguas de signos no se escriben, entre otras causas, porque la mayoría de las personas sordas leen y escriben en la lengua oral de su país. Pese a esto, ha habido propuestas de desarrollar sistemas para transcribir la lengua de signos, provenientes sobre todo del mundo académico, pero todas tienen 
deficiencias en el momento de captar todas las características físicas que utilizan las lenguas de signos (especialmente los elementos no-manuales y posicionales).

A partir de Fray Pedro de León, la educación del colectivo de personas sordas se fue extendiendo por el continente europeo y más tarde por el americano. Hasta el siglo XIX la utilización de estos códigos visogestuales en el ámbito educativo no admitía discusión alguna e incluso las personas sordas estaban directamente vinculadas a la enseñanza, tal es el caso de Berthier en Francia o Prádez en España pro citar algunos ejemplos. En nuestro país, "el Director del Colegio Nacional de Sordomudos de Madrid, Fernández Villabrille, publica en año 1851" (Gascón, 2006) el primer Diccionario de mímica y dactilología en un intento de sistematizar el léxico de la LSE y constituye el primer intento de sistematizar el léxico de la LSE y constituye el primer intento de normativización de esta lengua.

Según Bebían, la enseñanza del niño sordo debe empezar por la lengua de signos, a la que seguirá la enseñanza del francés. En realidad, primero debería enseñar a través de la LS (Lengua de Signos), después la lecto-escritura del francés, y el francés oral.

No obstante, en esta época (segunda mitad del siglo XIX) "la educación de estas personas basada en métodos exclusivamente orales fue ganando cada vez más apoyos. En la década de los 60 , se abrieron escuelas en las que se oponían a la utilización de los signos por considerarlos inadecuados y opuestos a los objetivos educativos que se estaban trazando" (Moreno, A.2000.99, Gascón, 2006).

Una fecha fatídica para la comunidad de personas sordas fue la de 1880, año en el que se celebró el $2^{\circ}$ Congreso Internacional de la Instrucción a este colectivo. En el citado Congreso la superioridad del método oralista sobre cualquier otro quedó de manifiesto. La enseñanza del habla era un objetivo primordial y la utilización de las Lenguas de Signos iba a perjudicar seriamente el aprendizaje de las lenguas orales, prejuicio que aún perdura en nuestra sociedad, concretamente en el ámbito educativo.

Las lenguas de Signos, desde finales del siglo XIX hasta bien entrada la segunda mitad del siglo XX, están relegadas a utilizarse en ámbitos muy restringidos, tan sólo en las Asociaciones y en los Colegios de Sordos pero siempre fuera del aula. Esa circunstancia tan prolongada afecta sin lugar a dudas al desarrollo normalizado de cualquier lengua.

En la década de los 60, en el Departamento de Lingüística del Gallaudet College de Washington, el lingüista norteamericano William Stokoe publicaba en 1960 "Sign Language Structure: An outline visual comunication system of the American deaf".

Estos estudios iniciados en el campo de la lingüística se extendieron a otros dominios como la sociolingüística o la psicolinguistica y comenzaron a realizarse investigaciones de otras Lenguas de Signos en países de nuestro entorno como Francia, Gran Bretaña, Suecia, Dinamarca, etc.

Más tarde, en 1975, el Congreso Mundial de Sordos, celebrado en Washington, se pronuncia a favor de la Comunicación Total. De esta manera, el movimiento 
asociativo de las personas sordas junto con algunos profesionales, comienza a reivindicar la importancia de la LS dentro de la escuela y de la educación en general.

Lo que está ocurriendo es un cambio en la metodología educativa y, en general, un cambio en la visión de las personas sordas. Por una parte, se empieza a hablar de una metodología bilingüe, y por otra parte, del derecho a ser respetadas las personas sordas como tales y con su propia lengua natural, la Lengua de Signos.

En el caso de las personas sordas, podemos afirmar que poseen una lengua natural, que es la Lengua de Signos. Pero, ¿Por qué considera la Lengua de Signos como un idioma, como una lengua extranjera? Por los siguientes motivos:

a- En primer lugar, el código lingüístico es de carácter visual, signado y deletreo. Por regla general, el niño sordo utiliza códigos visuales para memorizar datos, conceptos y acciones que lo hará capaz de comunicar con su mundo externo.

b- Se ha comprobado que los sordos utilizan la codificación signada cuando leen un texto escrito. El niño sordo utiliza el código signado porque es el lenguaje que ha interiorizado en edades tempranas con más facilidad.

c- Tiene una estructura gramatical diferente a la de la lengua verbal, por tanto, es una lengua rica, con diversos signos.

d- Cada lengua diferente posee una cultura diferente, una forma de pensar diferente, una forma de ser diferente. Aunque la persona sorda es tan humano como cualquiera, la única diferencia es que "escucha con los ojos", "habla con las manos", "piensa a través de los ojos".

\subsection{Historia de la Lengua de Signos en España}

Los antecedentes históricos sobre las lenguas de signos en España se inician, desde el punto de vista educativo, en el siglo XVI, cuando los monjes emprendieron la labor de educar a niños sordos. El monje benedictino D. Pedro Ponce de León enseñó a comunicarse a los niños sordos que estaban a su cargo, hecho que permitió la reevaluación de las creencias profesadas durante mucho tiempo respecto de las personas sordas, contribuyendo a un cambio gradual de la mentalidad que se tenía sobre las mismas y su lugar en la sociedad. Los monasterios en esa época estaban obligados a guardar silencio y se comunicaban utilizando signos manuales, así, por ejemplo, los benedictinos tenían a su disposición "signos para las cosas de mayor importancia, con los cuales se hacían comprender". Pedro Ponce de León debió comprender, que era posible expresar la razón sin habla, pues él mismo lo hacía cada vez que manifestaba sus pensamientos por medio de signos monásticos y empleó con los niños sordos un sistema gestual de comunicación.

En el siglo XVII la metodología cambia, y así D. Manuel Ramírez de Carrión utilizó la pedagogía de su época para instruir a los niños preparándoles para que se integraran en la sociedad (Gascón, 2006). 
En la segunda mitad del siglo XVIII, D. Lorenzo Hervás y Panduro publica su tratado: "Escuela española de sordomudos o arte para enseñarles a escribir y hablar el idioma español", que supone un hito fundamental en el esfuerzo pedagógico para la integración de las personas sordas (Gascón, 2006).

La escuela española alcanzará a producir aún obras de tanta trascendencia para la lengua natural de las personas sordas, como el diccionario de mímica y dactilología de Francisco Fernández Villabrille, que incluía 1500 signos de lengua de signos española descritos para su realización (Gascón, 2006). Sin duda, se trata del paso más importante hacia la estandarización de la lengua de signos española dado hasta entonces, y una demostración del carácter no sólo natural, sino histórico, de la lengua de signos española.

En el siglo XIX, con el establecimiento en España de los primeros colegios de sordomudos y ciegos, se posibilita la institucionalización de la educación de las personas sordas, ciegas y sordociegas, con la consecuencia de la interacción lingüística y social entre ellas, así como del inicio del desarrollo sistematizado de las portolenguas de signos española y catalana.

El último cuarto del siglo $X X$ supuso la reivindicación de las lenguas de signos española y catalana como los instrumentos de comunicación propios de las personas sordas que optan libremente por alguna de ellas. Numerosos encuentros nacionales e internacionales han debatido sobre la necesidad de su reconocimiento y uso para garantizar el acceso pleno a la educación, los servicios, la vida económica y cultural, los medios de comunicación y las nuevas tecnologías de la información, así como su necesidad para el correcto desarrollo personal y la participación social de las personas sordas que han optado por esta modalidad de comunicación.

La relevancia del uso y conocimiento de la lengua constituye en la actualidad una realidad incuestionable. No obstante, y a pesar de ello, esa construcción sobre la importancia y relevancia de la lengua, se ha configurado de espaldas a otras situaciones. En efecto, el reconocimiento sobre el valor de la lengua debe responder a las necesidades de las personas con discapacidad auditiva.

Las lenguas de signos españolas, siendo las lenguas propias de las personas sordas y sordociegas que han optado por esta modalidad lingüística, no han tenido el reconocimiento, ni el desarrollo que les corresponde, a pesar de que numerosas investigaciones llevadas a cabo en el ámbito nacional e internacional han puesto de manifiesto que las lenguas de signos cumplen todos los requisitos de una lengua natural y poseen unas características gramaticales sintácticas y léxicas propias. Recientemente esta situación se ha subsanado y prueba de ello es la aprobación de numerosas normas, entre las que cabe destacar varios Estatutos de Autonomía, que reconocen la importancia de las lenguas de signos.

La vice-presidenta dijo que la regulación de la LEY 27/2007, de 23 de octubre, por la que se reconocen las lenguas de signos españolas y se regulan los medios de apoyo a la comunicación oral de las personas sordas, con discapacidad auditiva y sordociegas beneficia a un millón de ciudadanos españoles sordos o con 
deficiencias auditivas, además de al resto de las personas que viven en España, y que se sitúa a la vanguardia en la protección de los derechos de este colectivo.

La norma reconoce la lengua de signos española como lengua de las personas sordas en España que libremente decidan utilizarla, así como su aprendizaje, conocimiento y uso.

Además, establecerá y garantizará los medios de apoyo a la comunicación de las personas sordas, con discapacidad auditiva y sordociegas. En el texto rige el principio de libertad de elección por parte de las personas afectadas, por lo que se reconocen y regulan de forma diferenciada el conocimiento, el aprendizaje y el uso de la lengua de signos española, así como de los medios de apoyo a la comunicación.

El proyecto establece que las Administraciones educativas dispondrán lo necesario para promover el aprendizaje de la lengua de signos española para este alumnado necesitado que libremente haya optado por esta lengua.

En caso de que esta persona sea menor de edad o esté incapacitada, la elección corresponderá a los padres o representantes legales.

Con el fin de disponer de profesionales debidamente cualificados para la enseñanza de la lengua de signos española y de los medios de apoyo a la comunicación, la Administración educativa competente determinará las titulaciones considere oportunas.

En cuanto al uso, la norma facilitará la utilización de intérpretes y el establecimiento de medios de apoyo a la comunicación, cuando lo precisen, en diferentes ámbitos públicos.

Se establece también la creación, en el Real Patronato sobre Discapacidad, del Centro de Normalización Lingüística de la Lengua de Signos Española, que tendrá como finalidad investigar, fomentar, difundir y velar por el buen uso de esta lengua.

El Gobierno creará también en el Real Patronato sobre Discapacidad el Centro Español de Subtitulado y la Audiodescripción con la finalidad de investigar, fomentar, promover iniciativas, coordinar actuaciones y extender la subtitulación y la audiodescripción como medios de apoyo a la comunicación de las personas sordas, con discapacidad auditiva y sordociegas.

Como indica la Ley de Lengua de Signos en su artículo l: "Las personas sordas, con discapacidad auditiva y sordociegas no siempre pueden acceder a la información y a la comunicación con el entorno, bien porque no disponen de intérprete de lengua de signos, caso de las personas sordas y sordociegas que sean usuarias de lengua de signos, bien porque no disponen de los recursos de apoyo necesarios para hacer posible la comunicación a través de la lengua oral. Efectivamente, en la mayoría de las áreas en las que debe aplicarse esta Ley no se dispone, en muchas ocasiones, de adaptaciones visuales y acústicas que permitan la mejora en la audición y recepción de la información auditiva, o de los medios de apoyo necesarios para la comunicación oral, o de servicio de intérpretes de lengua de signos. 
Especial dificultad reviste la sordoceguera, que es una discapacidad que resulta de la combinación de dos deficiencias sensoriales (visual y auditiva), que genera, en las personas que la padecen, problemas de comunicación únicos y necesidades especiales derivadas de la dificultad para percibir de manera global, conocer y, por tanto, interesarse y desenvolverse en su entorno. Algunas personas sordociegas son totalmente sordas y ciegas, mientras que otras tienen restos auditivos y/o visuales.

En todo caso, el colectivo de las personas sordas, con discapacidad auditiva y sordociegas es muy diverso y no se ajusta a un único patrón comunicativo por el hecho de no oír, o de no oír ni ver en el caso de la sordoceguera, que combina ambas deficiencias. Por tanto, el uso de la lengua oral o de las lenguas de signos españolas y el apoyo a los medios de comunicación oral en su comunicación con el entorno, en su aprendizaje, en el acceso a la información y a la cultura, ha de responder a una opción libre e individual que, en el caso de tratarse de menores, corresponderá a sus padres o tutores. "

La presente Ley viene a dar respuesta a ambas exigencias, desde el convencimiento de que tanto la normalización de la sociedad en relación con la cuestión de la discapacidad cuanto la integración de las personas con discapacidad en todo ámbito social, exige la promoción de su posibilidad de comunicarse a través de la lengua, sea oral y/o de signos. Posibilidad que no puede quedarse sólo en el establecimiento de un conjunto de medidas dirigidas directamente a las personas con discapacidad, sino que debe proyectarse también en el resto de la ciudadanía, garantizando la comprensión y el uso de la lengua oral y/o de signos en todas aquellas instituciones y entidades en las que se desempeña un servicio público, para conseguir así el disfrute real y efectivo de los derechos fundamentales. No debe olvidarse que la eliminación de barreras a la comunicación, hace desaparecer las dificultades de comunicación entre personas con y sin limitaciones auditivas -la comunicación implica un fenómeno relacional, intersubjetivo- por lo que los beneficios no se limitan a un grupo específico de personas sordas, con discapacidad auditiva y sordociegas sino al conjunto de la sociedad.

La Ley parte de las capacidades y potencialidades de los individuos, con el fin de garantizar la posibilidad de desarrollo de las capacidades individuales, siempre desde el respeto a la dignidad humana. Consciente de que las personas con limitaciones auditivas y las sordociegas -en las que se combinan dos deficiencias sensoriales (visual y auditiva)- tienen diferentes necesidades, lo que implica que algunas personas opten por la comunicación a través de la lengua de signos, mientras que otras prefieran la utilización de recursos que potencian y posibilitan la comunicación vía oral, la Ley reconoce el derecho de opción, y deja en definitiva la elección en manos de los principales interesados: las personas con discapacidad auditiva y sordociegas, o sus padres o tutores cuando se trate de menores.

Los avances tecnológicos permiten que una persona sorda o con discapacidad auditiva y sordociega, estimulada a través de sus prótesis auditivas y con recursos y medios de apoyo a la comunicación oral, pueda acceder a la lengua oral que es la de su entorno cultural, laboral y social. Hay que tener en cuenta que las pérdidas auditivas pueden ser congénitas, aparecer a edades tempranas y también adquirirse a lo largo de la vida adulta, por lo que hay que prever todos los recursos necesarios para favorecer su máximo desarrollo personal, laboral, cultural e incluso el académico, atendiendo a los principios de autonomía, normalización, integración 
social y educativa y participación en la vida en comunidad y contando con los profesionales adecuados y debidamente cualificados que puedan atender todas sus necesidades.

"Durante mucho tiempo, la sociedad ha tomado como referencia un modelo universal de ser humano a la hora de proyectar la idea de dignidad. Y a partir de ahí, y no sin un esfuerzo considerable, ha tratado de reconocer y valorar las diferencias mediante el uso del principio de diferenciación positiva. Este tipo de normas, maneja una idea de igualdad que parte, precisamente, del reconocimiento de la diferencia y que tiene como finalidad minimizar al máximo los efectos que la misma produce para el disfrute de los derechos y para el desarrollo de una vida humana digna. "(LEY 27/2007, de 23 de octubre)

El tratamiento de la discapacidad no ha permanecido al margen de esta tendencia. En los últimos años, tanto en el ámbito internacional como en el nacional, han aparecido una serie de normas que, entendiendo que la situación de discapacidad es una situación relevante, tienen como finalidad el reconocimiento de derechos específicos.

Finalmente, el reconocimiento de la Lengua de Signos (en castellano y en catalán) implica que el Gobierno garantiza su aprendizaje y su apoyo con los medios adecuados. El ministro de Trabajo y Asuntos Sociales, Jesús Caldera, anunció la creación de un Centro de Lenguaje de Signos y un Centro de Subtitulado, a fin de que los sordos puedan participar plenamente en la vida activa. En este sentido, anticipó la presencia de intérpretes en colegios, hospitales y centros públicos.

\subsubsection{En relación al contexto educativo}

Durante la etapa anterior a la elección del colegio más apropiado para el alumno sordo, el logopeda y los servicios de estimulación temprana, así como los equipos psicopedagógicos allí donde existan, deben informar progresivamente a los padres de las distintas opciones de escolarización existentes en su entorno.

La historia de la sordera se ha caracterizado por la presencia permanente de dos grandes temas polémicos: la confrontación en torno al sistema lingüístico más idóneo (lengua oral frente a lengua de signos) y la confrontación en torno a la modalidad de escolarización más adecuada (centro específico frente a centro integrado).

La polémica relacionada con la elección de un centro especial o uno integrado no es un debate cerrado en aún en España, aunque progresivamente es mayor el número de alumnos sordos que ingresa en el sistema educativo ordinario, y mayor el número de centros específicos que han sido cerrados o reconvertidos en centros de recursos de apoyo a la integración. Las opciones de escolarización del alumnado sordo son variadas, dependiendo de la interacción de variables diversas, entre las que sobresalen las condiciones particulares y diferenciadas de cada alumno sordo, y las características y condiciones del entorno familiar y escolar. "En relación con el contexto escolar y desde una perspectiva organizativa e institucional, tres son, 
básicamente, las opciones escolares existentes en la actualidad para el alumnado sordo" (Puyuelo, Torres, Santana, Segarra Suana y Vilalta Camps, 2001, 67).

\subsubsection{Centros ordinarios}

También, definidos por diversos autores como Centro ordinario "de al lado de casa". Es el centro escolar más cercano al domicilio del alumno sordo, donde probablemente estén escolarizados sus hermanos, si los hay, donde puede haber alumnado con discapacidades diversas integrado y donde no están garantizados a priori los servicios específicos que la educación del alumnado sordo requiere (elementos personales: tutores con formación, logopedas; elementos materiales: aula de apoyo, equipo técnico, material didáctico, etc.

En primer lugar hay que destacar la importancia que tiene el conocimiento de las respuestas posibles en los centros ordinarios a los alumnos que presentan Necesidades Educativas Especiales para el profesor de Educación Especial, tanto para las labores instructivas propias del mismo en relación con estos alumnos como para la intervención como orientadores-guía de otros profesores del equipo docente que atiende al alumno.

En segundo lugar, hay que indicar la importancia que posee los centros ordinarios y planifiquen previamente el conjunto de respuestas que se prevén en la legislación educativa actual para el tratamiento educativo adecuado de la diversidad y más en concreto para aquellos alumnos que presentan necesidades educativas especiales desde que con la LOGSE se ha asumido en nuestro Sistema Educativo un modelo de escuela integradora.

$Y$ en tercero, señalamos que hay que organizar los contenidos del tema en tres grandes bloques o partes:

1. La primera dedicada a plantear un tema tan polémico como actual como es el referido al proceso de integración educativa, analizando el concepto y los factores que participan en el mismo.

2. La segunda, centrada en el análisis de las respuestas educativas que se han de proporcionar desde la perspectiva de los centros ordinarios a la diversidad, en general, y de manera especial aquellos alumnos que poseen necesidades educativas especiales

3. Y la tercera parte, centrada en el concepto, tipos y procedimiento de la adaptación curricular como principal mecanismo de respuesta curricular a la diversidad.

La estructura y filosofía organizativa de la que se dote un centro resulta igualmente un elemento esencial para la atención a la diversidad, ya que resulta difícil creer que un centro, o un aula, con una estructura rígida o que pone la misma al servicio de otros intereses que no sean prioritariamente pedagógicos pueda proporcionar una oferta educativa capaz de responder a necesidades educativas muy variadas. El 
Proyecto Educativo de Centro debería tener en cuenta una serie de premisas educativas sin las cuales no es posible apostar por una respuesta educativa coherente a las N.E.E. Algunas de ellas son:

- Estructura organizativa. Una organización que pretenda atender a la diversidad desde el punto de vista educativo debería tener en cuenta una serie de características, como las señaladas:

1. Flexible

2. Abierta y creativa

3. Participativa

4. Funcional

5. Formativa

Características que adaptadas a la realidad de cada entorno educativo deberían permitir al centro adoptar una organización al servicio de sus propias finalidades educativas y que permita:

a) Coordinar los recursos humanos y materiales del centro.

b) Agrupar de manera flexible a los alumnos.

c) Racionalizar el tiempo escolar.

- Orientación educativa e intervención psicopedagógica: La atención de las N.E.E. en los centros ordinarios precisa la intervención coordinada de profesores y especialistas por lo que en la organización del centro ha de existir un mecanismo que regule dicha coordinación al tiempo que la optimiza; un subsistema organizativo del centro que tenga como objetivo básico la atención de la diversidad.

Es por ello que un centro que pretenda asumir la diversidad ha de tener como condición indispensable un plan de Orientación Educativa, entendido en el sentido de un plan especifico de actuación, que establezca y regule los mecanismos y recursos de las intervenciones psicopedagógicas y que tenga como objetivos básicos y generales:

a) Optimizar los procesos de enseñanza-aprendizaje

b) Impulsar el desarrollo psico-social de los alumnos

De acuerdo con los planteamientos actuales más aceptados, las intervenciones psicopedagógicas han de centrarse en la fundamentación psicológica y pedagógica del currículum escolar a tres niveles claramente diferenciados: el centro, el aula y las adaptaciones curriculares. De aquí se van a derivar un conjunto de actividades sobre profesores, alumnos y familias que es preciso articular en programas de orientación concretos que deben ser establecidos en el Plan de Orientación Educativa del centro y en el correspondiente Plan de Acción tutorías.

Resulta evidente que aunque el subsistema de orientación no se establece como respuesta especifica a los alumnos que presentan N.E.E., resulta para ellos un elemento facilitador importante tanto en lo que se refiere a los principios generales 
que deben fundamentar su atención educativa como desde la regulación de los procedimientos y recursos que resultan específicos en su tratamiento educativo.

\subsubsection{Educación especial}

La Educación Especial, como parte del Sistema Educativo Ordinario desde la publicación de la LOGSE y a raíz de la aplicación del Programa de Integración, tras la publicación del Vd., de marzo de 1985, en España, es el marco en donde han de entenderse las dificultades de aprendizaje. En el libro de Ferguson, Ferguson y Taylor (1992, citados en García, 1997) para una reflexión general sobre la Educación Especial y la discapacidad, también sobre la discapacidad de aprendizaje o dificultades de aprendizaje. Por lo general, hoy no se entienden las dificultades de aprendizaje sino dentro de la Educación Especial en general (Sigmon, 1990, citado en García, 1997). Las personas en edad escolar pueden presentar necesidades educativas especiales, sea de forma permanente o transitoria.

Una ilustración de la importancia y frescura de esta idea está en la celebración, del 7 al 10 del junio de 1994, de la Conferencia Mundial sobre "Necesidades Educativas: Acceso y Calidad, organizada por la UNESCO y por el Ministerio de Educación y Ciencia de España. Con participaciones de más de 90 países de culturas de lo más diversas:

“...que dieron lugar a que, en una misma sesión de trabajo, una madre manifestara que la aparición de un niño con discapacidad obliga a su familia a sufrir un auténtico calvario de médico en médico, de especialista en especialista. A lo que otra madre, de país no desarrollado, replicó que ella no tiene un solo especialista al que acudir". (Voces, 264, 1994, citado en García, 1997).

La Conferencia elaboró la "Declaración de Salamanca de principios, políticas y prácticas para las necesidades educativas especiales" recomendando los gobiernos:

- Que prioricen las políticas y los presupuestos en la mejora de sus sistemas educativos.

- Que transformen en leyes el principio de integración.

- Que promuevan la participación de los padres.

- Y que en la formación del profesorado se incluya la intervención en relación con necesidades.

El secretario de Estado de Educación, Álvaro Marchesi, resume muy bien la importancia de la Educación Especial, dentro del Sistema Educativo Ordinario y el papel tan crucial que está jugando en la mejora del mismo (García, 1997, p.134).

"La Educación Especial ha tenido históricamente un papel relevante en el conocimiento del desarrollo de los alumnos, en sus procesos de aprendizaje y en el cambio de los sistemas educativos. Los estudios sobre los alumnos discapacitados 
han permitido comprender mejor los procesos perceptivos, comunicativos y cognitivos y han destacado algunas variables relevan que influyen en su desarrollo. Pero no sólo la investigación evolutiva se ha visto considerablemente enriquecida con estudios comparativos centrados principalmente en niños con graves problemas de audición o de visión o de retraso comunicativo, motor o intelectual. También la práctica educativa, la organización escolar y la metodología didáctica han tenido en muchas ocasiones como punto de referencia la respuesta educativa proporcionada a los alumnos con necesidades especiales. Y, desde una perspectiva más general, es preciso reconocer, igualmente, que muchos de los cambios y de las innovaciones que se han producido en los distintos sistemas educativos proceden del impulso, de la reflexión y de las propuestas que se han generado en el campo de la Educación Especial.

No es extraño ni casual que esto haya sido así. La respuesta educativa a las necesidades especiales de los alumnos discapacitados exige un mayor conocimiento de las diferencias individuales y una mejor utilización de todas sus posibilidades. Esta respuesta debe ser en la cooperación de distintos profesionales y en el contacto permanente con los padres, los alumnos. Es, por tanto, comprensible, que cuando la escuela ordinaria intenta integrar a los alumnos con necesidades educativas especiales, tenga que plantearse al mismo tiempo un cambio en la manera de llevar a la práctica el proceso de enseñanza. Un cambio, una reforma, que ha de basarse en los principios que ostentan la Educación Especial" (Voces, 264, 1994, citado en García, 1997).

Estas necesidades educativas especiales (NEE) constituyen el concepto nuclear para la determinación y provisión de servicios educativos en Educación Especial, en nuestro país, y siempre dentro del Sistema Educativo, como un aspecto más, en plena integración. La respuesta a las nee, habría que darla desde el propio Sistema Educativo y el concepto de adaptaciones curriculares es clave para la determinación de la forma y el tipo de actuación pertinente en relación con las personas con necesidades educativas especiales. Igualmente, la Educación Especial se encuentra con las intervenciones más precoces en los niveles de Educación Especial.

Otros informes (Informe Fish, 1985, citado en González, 2007) han ampliado y matizado el concepto de necesidades educativas especiales, pero siempre en el mismo sentido que el informe de Warnock, Ainscow (1985, 2001, citado en González, 2007) señalaba en esa fecha que el futuro del campo de la educación especial se caracterizará por una aproximación a los niños que necesiten ayuda educativa bajo tres conceptos clave, que a su vez define el concepto de necesidad educativa especial. "Estos conceptos son: a) el concepto de necesidad; b) el concepto de currículo y c) el concepto de integración”. (González, 2007, 12).

Brennan (1988, 36, citado en Sánchez, 1997) se refiere a NEE. "Cuando se presenta una deficiencia (física, sensorial, intelectual, emocional, social o cualquier combinación de éstas) que afecta al aprendizaje hasta tal punto que sea necesarios algunos o todas las ayudas especiales al currículo especial o modificados, o a unas condiciones de aprendizaje especialmente adaptadas para que el alumno sea educado adecuada y eficazmente. La necesidad puede presentarse en cualquier punto en un continuo que va desde la leve hasta la aguda: puede ser permanente o una fase temporal en el desarrollo del alumno", en cualquiera de los supuestos 
anteriores, Hegarty (1998, 83, citado en Sánchez, 1997), se refiere a los alumnos que presentando graves deficiencias requieren de un "currículo general con modificaciones significativas".

Toda Educación Especial que se aprecie forzosamente ha de ser en primer lugar, una Educación individualizada, pues, de lo contrario- si no respetase las diferencias individuales de los educandos especiales a los que atiende-, no se entiende en qué puede consistir el carácter de "especial" que conceptualmente le califica. Esto acontece también y es igualmente válido en la educación ordinaria, aunque entre aquellos alumnos las diferencias no sean tan evidentes como entre los educandos a los que se dirige la EEP. García Hoz (1998, citado en Polaino-Lorente, Ávila y Rodríguez, 1991) lo expresa bien cuando afirma que "la educación especial responde al intento de estimular al sujeto para que vaya perfeccionando su capacidad de hacer efectiva la libertad personal, participando, con sus características peculiares, en la vida comunitaria. Pero lo cierto es que si bien en un grupo de alumnos todos ellos presentan rasgos comunes, también presentan rasgos claramente diferenciados."

Poco a poco las escuelas van perdiendo su carácter asilar y caritativo, y van apareciendo instituciones de mayor rigor científico entre el 1921 al 1931, como pudo constatarse en el exhaustivo y preciso análisis histórico realizado por Garanto (1990, citado en Sánchez, 1997), centrado especialmente, en el ámbito de Madrid y Barcelona.

El estímulo y la orientación para adquirir unos conocimientos y unas destrezas que permitan a un minusválido vivir sensiblemente con cierta normalidad son relativamente fáciles, dentro de la peculiar dificultad de cualquier educación especial. Pero lo que verdaderamente resulta difícil es estimular y orientar al deficiente hacia el trabajo y la comunicación social en el respeto a su libertad y, en palabras de los autores, "por el único camino posible: el del amor" (Polaino-Lorente, Ávila y Rodríguez, 1991, 18). 


\subsubsection{Centros de Integración social}

Los Centros de integración preferente de sordos, constituyen organizativamente una oferta novedosa. Son centros ordinarios a los que el organismo competente en cada caso, ha dotado de recursos materiales y técnicos específicos, formación, estabilidad laboral y personal especializada, concretamente un maestro especializado en audición y lenguaje o un logopeda. Los alumnos sordos inscritos constituyen un número suficiente para garantizar su interacción, no sólo con compañeros oyentes, sino también con compañeros sordos. Esto es posible puesto que los alumnos sordos no acuden al centro ordinario más cercano a su domicilio, sino a aquel que en su distrito, municipio o comarca ha sido expresamente organizado y dotado para dar respuesta a sus peculiaridades educativas.

En los centros de integración se abre paso esta vía más pragmática, ya que los niños se escolarizan en un medio oyente, luego deben aprender el lenguaje oral de los oyentes. Sin embargo, el lenguaje de signos es la forma de expresión de los sordos, basta dejar a dos niños sordos juntos para que empiecen a signar sin que nadie les haya enseñado. Es entonces cuando aparece el bimodal que tiene la estructura del lenguaje oral, pero en el que la comunicación es realizada simultáneamente por voz y signos y aunque no lo parezca para un observador iniciado en el tema, es un sistema que facilita más el aprendizaje del lenguaje oral que el lenguaje de signos, del que solo coge el vocabulario que se emite al mismo tiempo que la palabra hablada.

Cada un de estas opciones, especialmente los centros ordinarios y los centros de integración, pueden ofrecer a la vez diferentes niveles de integración.

\subsubsection{Niveles de Integración}

La normalización ofrece diversas posibilidades a modo de ajuste a las características propias de cada alumno y contexto escolar. Cuando se habla de normalización escolar no debe pretenderse, que todo niño sea escolarizado en el colegio común más cercano a su domicilio, ni en el mismo grado de integración. De forma que se puede decir que existen niveles de integración, dependiendo tanto de las características que presenta el niño sordo, como de las posibilidades de la escuela en la que vaya a ser integrado, y que una precisa valoración inicial y permanente debe sopesar (Torres et al., 1995, 224).

Como indica Torres et al. $(1995,223)$ a partir de Deno (1970, citado en Torres et al., 1995), "se conceptualizan los niveles de integración cómo...". 


\subsection{Integración completa}

Supone que el alumno sordo asiste al colegio normal y al aula normal según su edad, pero recibe alguna ayuda de cara a la realización de determinadas actividades más elaboradas para superar pequeñas dificultades o signos de inmadurez, normalmente pasajeros. Este tipo de integración se suele aconsejar a niños que sin padecer ningún tipo de deficiencia presentan dificultades específicas de aprendizaje. Por supuesto este nivel de integración es también recomendado a todos los niños antes de los 6 años, ya que hasta ese momento deben participar al igual que los demás de las actividades madurativas propias de esas edades. Puyuelo et al. (2001, 68), piensan que "esta no es un opción adecuada a las necesidades educativas especiales de los alumnos sordos."

\subsection{Integración combinada}

Supone que el niño sordo asiste a la clase normal según su edad y/o capacidad, pero recibe durante un tiempo extra, de longitud variable según sus dificultades de aprendizaje, atención específica por el profesorado de apoyo, es decir, por el especialista en audición y lenguaje o logopeda. Esta atención la recibe dentro del aula ordinaria, si se organiza de forma apropiada entre el profesor tutor y el especialista, y en el aula especial o de apoyo (aula de audición y lenguaje).

\subsection{Integración parcial}

En este caso, el alumno asiste a un colegio normal, pero recibe su escolarización en el aula especial dirigida por un profesor de apoyo especialista. Sin embargo, lo niños, participan de la vida habitual del centro y de los demás niños del colegio. Este tipo de integración es aconsejada para niños con niveles de discapacidad muy profunda y/o, plurideficiencias. Este nivel de integración ha ido desapareciendo o, en algunos casos, cambiando su objetivo, ya que, con frecuencia, ha sido fuente de segregación para los alumnos.

Este tipo de integración ha sido considerada negativa, al no haberse utilizado adecuadamente. Sin embargo, varios autores (Hegarty, Hodgson y Clunies-Ross, 1988; Brennan, 1988; Hegarty y Pocklington, 1989, citados en Torres et al., 1995) piensan que puede y deben ser muy positivas para todos los alumnos y puede servir como profundización de las actitudes de integración. Así de hecho sucede en muchos países donde se practican de forma habitual y enriquecedora. 


\subsection{Integración de centro específico}

Este tipo de integración, representa aquella en la que el niño no asiste al colegio normal, sino que su escolaridad se le imparte en jornada completa en un colegio especial. Aún en este caso se habla de integración ya que el centro específico debe procurar al niño situaciones integradoras en actividades de convivencia con otros niños oyentes de su edad. Este tipo de integración, se suele aconsejar a aquellos niños con deficiencias asociadas, o con niveles de retraso general severo y profundo, o en deficiencias no tan severas, pero cuando los centros ordinarios no han sido dotados de las adaptaciones y recursos necesarios.

Cuando las necesidades y posibilidades del alumno impidan su escolarización en alguno de los dos modelos anteriores será preciso recurrir a tomar como referencia básica de su emplazamiento escolar un centro especializado en el tratamiento de su minusvalía, sin excluir su asistencia, cuando sea posible, a un centro ordinario, bien para participar en actividades curriculares o extraescolares.

Aunque las dificultades de coordinación entre centros ordinarios y específicos son grandes, existe la posibilidad de que un alumno comparta ambos entornos cuando sus necesidades educativas lo precisen De esta manera podemos diferenciar dos fórmulas de escolarización:

1) En centro específico a tiempo parcial

2) En centro específico al $100 \%$

Se ha definido cuatro tipos de integración, pero hay que tener en cuenta que es un modo artificial de presentar estadios, ya que la integración debe considerarse como un continuo teniendo en cuenta que al niño hay que darle el máximo de integración posible en cada momento, es decir que su situación podrá y deberá ir variando a medida que vayan modificándose sus condiciones de aprendizaje.

De esta forma, existen múltiples alternativas para la escolarización de alumnos sordos, dependiendo más bien de la interacción de variables diversas, entre las que sobresalen las condiciones particulares y diferenciadas de cada alumno sordo, y las características y condiciones del entorno familiar y escolar.

La primera sugerencia sería, por tanto, estudiar cada caso particularmente, en compañía de padres, equipos psicopedagógicos específicos y logopeda que haya realizado la intervención temprana y decidir al respecto.

Puyuelo et al. (2001), indican que su experiencia sugiere que la opción escolar más acorde con las necesidades específicas de aprendizaje del alumnado sordo, y su desarrollo personal y social, suele ser la escolarización en un centro de integración preferentemente de sordos que reúna los requisitos pertinentes, en régimen de integración combinada o parcial, ya que de esta forma se asegura una atención especializada en torno al 50\% del currículum, especialmente para el apoyo en las áreas de comunicación y representación, en Educación Infantil, y lengua castellana, matemáticas y conocimiento del medio, en Educación Primaria. 


\subsubsection{Requisitos básicos de un centro de integración de sordos}

Distintas instituciones e investigadores han estudiado los requisitos básicos para el funcionamiento adecuado de la integración del alumnado sordo. El Comité Internacional de Audiofonología (BIAP) definió el alcance, las condiciones y modalidades de integración, mediante la promulgación en 1986 de la Recomendación 15/1 (Perder, 1987, p. 357, citado en Torres et al., 1995).

De esta forma Puyuelo et al. $(2001,68)$ "recogen los siguientes requisitos básicos:

- Información específica previa, seguida de formación y un compromiso activo por parte del equipo escolar.

- Proyecto Educativo y Proyecto Curricular que tengan en cuenta las necesidades educativas especiales del alumnado sordo.

- Organización flexible del centro que permita diversos modos de atender las necesidades educativas de los alumnos sordos.

- Profesores tutores preparados para realizar las adaptaciones curriculares necesarias y trabajar junto con el profesorado de apoyo.

- Profesorado de apoyo con reconocida formación pedagógica en el diseño, desarrollo y evaluación del currículo y especializado en audición y lenguaje o logopedia, con especial formación práctica en sistemas alternativos y aumentativos de comunicación.

- Debate y toma de decisiones en torno a los sistemas de comunicación que van a utilizarse preferentemente con los alumnos sordos: conocimiento progresivo por el profesorado, padres y alumnos oyentes.

- Asesoramiento o intervención del equipo psicopedagógico especifico para deficientes auditivos o equipo psicopedagógico de zona.

- Recursos materiales, especialmente aula de apoyo con equipamiento técnico (sistemas de amplificación tipo SUVAG) y didáctico.

- Colaboración estrecha de parientes y personas sordas."

Estos requisitos básicos deben ser comprendidos a partir de la aceptación de los siguientes principios básicos (Torres et al., 1995):

1. La integración de alumnos sordos no es un problema que debe resolver el tutor de dichos alumnos, o entre éste y el profesorado de apoyo. No son estos profesores quienes integran. Es el centro quien incorpora alumnos con unas determinadas necesidades educativas al mismo. Es el centro quien tiene la responsabilidad de asumir que en su Proyecto Educativo se tomen y 
desarrollen las adaptaciones didácticas y organizativas adecuadas para dar respuesta a dichos alumnos.

2. La integración del alumnado sordo no está resuelta por el hecho de contar en el centro con profesorado de apoyo, y con recursos técnicos y didácticos enviados por la administración educativa. Un Proyecto Educativo que dé respuesta a las necesidades educativas de los alumnos sordos, es algo que debe estudiarse, reflexionarse, debatirse y concretarse desde el propio centro escolar. Será la propia dinámica y desarrollo de la puesta en escena del pensamiento del profesorado, de sus ideas, prejuicios, actitudes, métodos didácticos en uso, etc., lo que se descubra y modele sobre la base de la reflexión y el trabajo en equipo.

3. El proceso de planificación de la integración de los alumnos sordos en un marco de trabajo reflexivo y colaborativo de los profesores del centro, debe ser coordinado y asesorado por el profesorado de apoyo. Dicho asesoramiento, debe realizarse en base a los principios de los enfoques de asesoramiento curricular conocidos como "Desarrollo Basado en la Escuela" (DBE), o "Desarrollo Centrado en la Escuela". Estos modelos, con fuerte arraigo en países anglosajones, quedan caracterizados siguiendo a Peter Holly (1989; citado en Area y Yanes, 1990; citados a su vez en Torres, 2001) por los principios siguientes:

a. Para el DBE el centro escolar es la unidad de cambio

b. El DBE implica aumento de la autonomía y del poder de los profesores.

c. El DBE implica, determinados procesos de internalización o toma de conciencia.

d. EI DBE utiliza el "modelo de proceso" o de resolución de problemas.

e. El DBE implica simultáneamente: apoyo externo y asociación de agentes externos e internos para el desarrollo.

Con respecto al último principio mencionado, la intervención del profesorado de apoyo se entiende como "compañero de viaje" que ofrecen su asesoramiento a partir de las necesidades del centro, de las de sus compañeros profesores, y de los alumnos, y ello desde una relación profesional y afectiva colaborativa, de igual a igual (Torres et al., 1995, 228).

"En los Centros donde hay alumnos sordos integrados, el maestro tutor es el responsable principal de la educación de su grupo de alumnos, incluido los propios sordos que le haya sido asignado" (Puyuelo, 2001, 69). Dicha tarea debe desarrollarla corresponsable y colaborativamente con el logopeda, también conocido con el profesor de apoyo, y con equipos de apoyo externo, conocidos como equipos psicopedagógicos de zona o equipos psicopedagógicos específicos para deficientes auditivos.

"El profesor de apoyo es un profesor más del claustro y con presencia permanente en el centro" (Puyuelo, 2001, 70). La figura humana y profesional del profesor especialista es uno de los recursos personales centrales para llevar a buen puerto la educación del alumnado sordo. 


\subsubsection{Repercusiones de la sordera en el desarrollo cognitivo y social}

Los resultados de los estudios experimentales realizados hasta ahora con sordos profundos prelocutivos no implantados, con escaso dominio de un lenguaje eficaz, muestran menor amplitud y diversidad en el juego simbólico, reflejan retraso en el acceso a las operaciones lógicas complejas, menor habilidad en la representación mental de la realidad, en la formalización del pensamiento, en la formulación de hipótesis, en la planificación de estrategias, en la abstracción y en la memoria verbal.

Experimentan estas dificultades y hay estudios que explican la razón de este acontecimiento, como de la Escuela Piagetiana que admiten que los sordos acceden con retraso a las distintas etapas evolutivas, y que el desfase se hace más pronunciado a medida que aumenta la complejidad de las operaciones lógicas (Furth, 1981, citado en FIAPAS, 2004).

Los estudios realizados por P. Oleron (1972 y 1983) y R. Conrad (1979) (citados en FIAPAS, 2004), dentro de la línea cognitiva, encuentran mayor diferencia entre sordos y oyentes que la aceptada por los seguidores de Piaget. Los autores encuadrados en esta tendencia admiten parcialmente las conclusiones de Furth, aceptan que el déficit informativo y experencial es un problema importante que interfiere en el desarrollo cognitivo del sordo, pero insisten en el que no se limita a este déficit experencial. La exposición de los niños sordos a ambientes estimulantemente ricos y normalizados, no han sido suficientes para eliminar las diferencias entre sordos y oyentes ni para evitar las dificultades de los sordos en aspectos formales y abstractos del pensamiento.

En otra línea, se podrían inscribir las investigaciones que concentran su atención en la calidad de mediador lingüístico, y que subrayan la conveniencia de primar la lengua oral por las ventajas que ofrece su estructura fonológica de cara a la lectura y a determinados procesos cognitivos relacionados con la memoria (Kail, 1994; Alegría, 1999, citados en FIAPAS, 2004).

Las funciones superiores del pensamiento no son sólo un requisito de la comunicación, sino que son, al mismo tiempo, un resultado de la comunicación misma. La interacción posibilita que las funciones superiores que aparecen primero entre personas, interpsicológicas, se interioricen y se conviertan en funciones intrapsicológicas.

"La sordera dificulta la apropiación de información e impide al niño sacar el máximo provecho de su experiencia" (Maxwell, 1984, 191). La menor información y experiencia conlleva, casi siempre, menor curiosidad y motivación por los sucesos del entorno, se preguntará en menor medida por las causas y razones que originan los hechos, y su conocimiento del mundo que le rodea será inferior al de sus compañeros oyentes.

La pobreza de información a la que se ven sometidos, el no entender en toda su complejidad las opiniones y matizaciones de los demás, el quedar reducidos a explicaciones breves e incompletas, contribuye, además, al desarrollo de 
personalidades simples, inmaduras, egocéntricas e impulsivas complicando la comprensión e interiorización de normas, reglas y valores.

"El déficit cognitivo del niño sordo también se debe, en buena parte, al funcionamiento defectuoso de los mediadores simbólicos" (Padden y Permutter, $1987,335)$. La posesión de un lenguaje pobre, parcializado, limitado en recursos, le origina importantes inconvenientes. La escasa calidad de su código comunicativolingüístico afecta a funciones tales como la representación mental de la realidad, la formalización del pensamiento, la formulación de hipótesis, la planificación de estrategias, la memoria, etc.

Por otra parte, la interacción social menos productiva que disfruta el niño sordo como consecuencia de los problemas de comunicación (lenguaje pobre, audición reducida...), termina por ocasionarle un notable perjuicio. El niño construye su conocimiento del lenguaje $y$ del medio y adquiere formas complejas de razonamiento, a partir del "input" que recibe al participar en intercambios conversacionales. Cuando existe sordera, estos intercambios suelen ser más infrecuentes, menos complejos y menos eficaces.

En estudios realizados siguiendo la metodología de la teoría piagetiana queda de manifiesto que "los alumnos sordos pasan por las mismas etapas y utilizan las mismas estrategias que sus compañeros oyentes, pero lo hacen con un retraso aproximado de, al menos dos años" (Maxwell, 1984, 44). Las diferencias observadas entre sordos y oyentes son imperceptibles en las tareas relacionadas con la inteligencia práctica y se van haciendo más evidentes cuanto más complejas son las operaciones lógicas implicadas.

"En las tareas en las que el lenguaje ejerce un peso importante (abstracción, razonamiento, formulación de hipótesis, proposiciones posibles, alternativas...), los sordos encuentran grandes dificultades" (Maxwell, 1986, 14). Para algunos sordos, los que poseen peor lenguaje y menor capacidad intelectual, estas dificultades resultarán insalvables. En suma, las dificultades que experimentan los sordos en su desarrollo cognitivo se deben al déficit informativo y experiencial, a la menor motivación que esto lleva consigo, a la posesión de un lenguaje de menor calidad y a la interacción social menos productiva. No todos los sordos, sin embargo, se atienen a la descripción anterior. Dependerá de las circunstancias en la que se desenvuelva, de la estimulación del medio, y de la competencia lingüística alcanzada, para que su desarrollo se atenga más a las pautas habituales de los oyentes o se acentúen las dificultades antes mencionada.

La educación tradicional del deficiente auditivo ha reducido su acción, con excesiva frecuencia, al propio niño, cuando en realidad es todo el entorno familiar, el sistema de interacción del hogar, el que hay que establecer o restablecer, ya que es este sistema el que genera afecto, comunicación, lenguaje, complejidad y crecimiento.

Pese a lo expuesto anteriormente no hay nada en la sordera que en sí misma impida aprender el lenguaje oral y desarrollar un pensamiento abstracto de máxima complejidad. 
"El niño sordo conserva totalmente sus potencialidades intelectivas" (Furth, 1979, 71). Es capaz e inteligente pero necesita aprender a pensar y disponer de herramientas que pueda manejar. Necesita información, experiencia, un sistema simbólico de calidad que le permita formalizar su pensamiento e interactuar con los demás y poder utilizar estrategias de pensamiento y de acción ejecución.

Aunque nada impide que el alumno sordo adquiera un desarrollo cognitivo y lingüístico normal, un elevado número de jóvenes sordos no consigue aprender a interiorizar un lenguaje oral de calidad ni llega a adquirir habilidad para el manejo de razonamientos abstractos.

Existe, o debería existir, una insatisfacción generalizada respecto a los logros que se alcanzan en la educación de los deficientes auditivos. Se conoce, no obstante que cualquier solución al problema pasa por:

- Iniciar muy pronto la rehabilitación potenciando la estimulación temprana.

- Acometer un entrenamiento plurisensorial, aprovechar los restos auditivos e intentar establecer las funciones que el oído tiene asignadas en el entramado sensorial.

- Dotar al sordo de un sistema simbólico de calidad desde los primeros años, facilitándole el acceso a un lenguaje oral correcto siempre que sea posible.

- Garantizar la comunicación e interacción del niño con las personas que le rodean desde los primeros años. Conseguir que participe en los mismos juegos, experiencias, informaciones y tópicos culturales, que sus coetáneos.

Conviene servirse del lenguaje de signos y de estrategias de Comunicación total siempre que sea preciso.

- Facilitarle la mayor información sobre la realidad y la experiencia más rica posible.

- Enseñarle a pensar, a planificar, a reflexionar y a utilizar su inteligencia.

- Enseñarle estrategias de organización, de repetición organizada de la información y técnicas para mejorar el almacenamiento y la recuperación de la información.

- Mostrarle siempre la complejidad de las cosas, fomentar el análisis de la realidad desde distintos puntos de vista, hacerle pensar en otras soluciones posibles, idear otras opciones, imaginar que las cosas pueden ser de otra manera, etc.

- Despertar su deseo por explorar y conocer.

- Conseguir una interacción compleja y un entramado de relaciones sociales rico. 
- Procurar que conozca en profundidad y de forma razonada los valores, normas y convenciones que regulan la sociedad.

- Desarrollar las habilidades sociales.

- Fomentar la seguridad en sí mismo y el ajuste personal. Procurar que se vaya formando un autoconcepto positivo y realista.

- Cualquier proyecto educativo o adaptación curricular para la educación de las personas sordas habrá de basarse no en sus carencias sino en sus posibilidades. Hay que rentabilizar las capacidades perceptivas que la persona sorda conserva intacta. El joven sordo debería alcanzar un grado de desarrollo similar al del normo-oyente, necesitará, no obstante, vías complementarias e, incluso, caminos diferentes.

"La integración social menos productiva, consecuencia de los problemas de comunicación y de la poca calidad del lenguaje que impone la sordera, repercute de forma muy negativa en el desarrollo global de la persona" (FIAPAS, 2004, 193). Cuando existe dificultad grave para percibir el habla, los intercambios con las personas, suelen ser menos frecuentes, menos complejos y menos eficaces.

En suma, las dificultades que han experimentado los sordos en su desarrollo cognitivo no se deben a la sordera en sí misma, se deben al déficit informativo y experencial, a la menor motivación que esto lleva consigo, a la posesión de un lenguaje de menor calidad y a la interacción social menos productiva. 


\subsubsection{El adulto sordo en la educación de sordos}

Veinberg $(2002,10)$ considera que a fin de aplicar los desarrollados modernos de la lingüística y sus disciplinas a la pedagogía para la educación de niños sordos, sean o no hijos de padres sordos u oyentes, es necesario entender que la escuela no puede suministrar solo modelos oyentes en los que los sordos jamás podrán no solo reconocerse, sino ni siquiera comprender. Por otro lado la inclusión del adulto sordo en el contexto del aula dentro de un proyecto bilingüe-bicultural implica una doble integración: por un lado, a la minoría sorda y, por el otro, a la mayoría oyente, otorgándole al sordo la posibilidad de integrarse desempeñando roles jerárquicos.

Así como el niño oyente aprende la lengua en un entorno natural, en un proceso comunicativo natural, a partir de la gramática adulta que oye, pero sin enseñanza sistémica comete errores a lo largo del proceso, el niño sordo necesita también un contexto igual: natural con adultos significativos es decir, adultos que manejen la gramática adulta de LSE, a partir de la cual el niño construirá su gramática.

Para el niño sordo hijo de padres oyentes la presencia de un modelo sordo con el cual identificarse en la escuela presenta ventajas adicionales ya que sus padres no pueden o darle la lengua para la que está naturalmente capacitado o un modelo completo y real de identidad, puesto que son oyentes y el niño sordo no puede proyectarse como un adulto oyente. Solo un adulto sordo puede cumplir el de adulto mediatizador y socializador del niño sordo por lo tanto es necesario que esté en la escuela como figura preponderante. Si se pretende que no se sigan repitiendo los fracasos del sordo en la escuela se debe considerar que la mera presencia de la LSE en el aula no permite un desarrollo normal del niño sordo. La LSE es mucho más que un conjunto de señas: es una lengua diferente; el español ya tiene una compleja estructura gramatical, característica las lenguas polisintéticas, una organización morfológica sintáctica simultánea y secuencial constituida por elementos manuales y no manuales. Es el maestro sordo hablante de LSE que tiene un dominio total de la lengua para desempeñarse como guía en el proceso de adquisición de la lengua.

El sordo adulto asegurará que el niño desarrolle la LSE naturalmente como un elemento que dé significado a la realidad y por lo tanto que le permita aprender el mundo, ser el mismo un miembro significativo con una identidad sorda, no enferma, sino plena de posibilidades y diferente del oyente.

"Las presencias del maestro sordo y de la lengua de señas en la escuela no amenazan ni al maestro oyente ni a la lengua hablada, sino que se convierten en la mejor garantía de una eficiente educación." (Veinberg, 2002, 10). 


\subsection{La Ley de Lengua de Signos}

Recientemente se ha aprobado una de las leyes mas esperadas dentro del colectivo de Personas Sordas en España. La conocida como Ley de Lengua de Signos (ley 27/2007) fue publicada en el BOE número 255 el miércoles 27 de octubre de 2007, y en ella se reconocen las lenguas de signos españolas y se regulan los medios de apoyo a la comunicación oral de las personas sordas, con discapacidad auditiva y sordociegas. El texto reconoce dicha lengua como oficial para las personas sordas y discapacitados auditivos, que podrán solicitar intérpretes en un amplio número de servicios.

En el objeto de la Ley se indica que "La presente Ley tiene por objeto reconocer y regular la lengua de signos española como lengua de las personas sordas, con discapacidad auditiva y sordociegas en España que libremente decidan utilizarla, sin perjuicio del reconocimiento de la lengua de signos catalana en su ámbito de uso lingüístico, así como la regulación de los medios de apoyo a la comunicación oral... También es objeto de esta Ley la regulación de los medios de apoyo a la comunicación oral destinados a las personas sordas, con discapacidad auditiva y sordociegas."

A lo largo de su preámbulo, su título preliminar, su titulo I dividido a su vez en dos capítulos, su título II dividido también en dos capítulos y sus disposiciones, sitúa a la lengua de signos y a las ayudas destinadas a las personas sordas en una posición muy deseada hasta ahora.

En este punto, así como a lo largo del trabajo (como ya se ha hecho anteriormente este capítulo), se tratará de comentar los artículos de esta Ley que se han considerado importantes para esta investigación.

La aprobación de una ley de este tipo, permite conocer desde el punto de vista del gobierno cual es la situación actual de las personas sordas y cuales son sus necesidades. Como queda reflejado en el Preámbulo I donde indica que.

"Las personas sordas, con discapacidad auditiva y sordociegas viven en una sociedad formada mayoritariamente por personas oyentes por lo que, para su integración, deben superar las barreras existentes en la comunicación que son en apariencia, invisibles a los ojos de las personas sin discapacidad auditiva. La presente Ley intenta subsanar esta situación y propiciar su acceso a la información y a la comunicación, teniendo presente su heterogeneidad y las necesidades específicas de cada grupo. Igualmente, en la Ley rige el principio de libertad de elección en la forma de comunicación por parte de las personas sordas cualquiera que sea su discapacidad auditiva y sordociegas, por lo que se reconoce y regula de manera diferenciada el conocimiento, aprendizaje y uso de la lengua de signos española, así como de los medios de apoyo a la comunicación oral". En este apartado quedan reflejadas las necesidades y las posibles soluciones que a lo largo de la Ley se presentan. En otro de los apartados del Preámbulo dice "Las personas sordas, con discapacidad auditiva y sordociegas no siempre pueden acceder a la información y a la comunicación con el entorno, bien porque no disponen de intérprete de lengua de signos, caso de las personas sordas y sordociegas que sean 
usuarias de lengua de signos, bien porque no disponen de los recursos de apoyo necesarios para hacer posible la comunicación a través de la lengua oral". La necesidad que las personas sordas presentan a la hora de enfrentarse a la comunicación de la lengua oral es la base de esta investigación. Relacionado con esto también se dice que "Por tanto, el uso de la lengua oral o de las lenguas de signos españolas y el apoyo a los medios de comunicación oral en su comunicación con el entorno, en su aprendizaje, en el acceso a la información y a la cultura, ha de responder a una opción libre e individual que, en el caso de tratarse de menores, corresponderá a sus padres o tutores“.

Desde el punto de vista de las ayudas de comunicación oral la Ley indica que "La utilización de recursos que potencian y posibilitan la comunicación vía oral, a través de los medios de apoyo a la comunicación oral, como la labiolectura, las prótesis auditivas, el subtitulado y cualquier otro avance tecnológico, supone un derecho fundamental y básico de las personas sordas, con discapacidad auditiva y sordociegas que han optado libremente por este medio de comunicación." Dentro de la educación de personas adultas sordas contar con este tipo de ayudas y avances tecnológicos, supone una ventaja considerable respecto a las personas que nos las utilizan. A lo largo de la ley se trata de regular las ayudas destinadas a conseguir estos avances.

A lo largo del Titulo I la Ley trata de definir el aprendizaje, conocimiento y uso de las lenguas de signos españolas. A lo largo del capítulo I se definen las opciones con las que van a contar los alumnos sordos que podrán aprender lengua de signos en los centros indicados y también pueden llegar a recibir una educación bilingüe en estos centros, también se define la posibilidad de impartir como asignatura opcional el aprendizaje de lengua de signos para los alumnos oyentes fomentando la integración. También es considerado en este punto la necesidad de contar con educadores debidamente cualificados, estableciendo planes de formación al profesorado. El trabajo conjunto de educadores de los centros con las distintas asociaciones es fundamental para conseguir la formación deseada, desde la Administración se fomenta la cooperación con este tipo de asociaciones

En el capítulo II, se trata el tema del uso de las Lenguas de Signos Españolas, indicando claramente en el Artículo 9 que se prestará el servicio de intérpretes a toda aquella persona de este colectivo que lo requiera en las diferentes áreas públicas o privadas que se definen a lo largo del capítulo II. Desde el punto de vista del acceso a servicios públicos en el Artículo 10 se definen las opciones con las que contarán las personas sordas en materia de Educación, "facilitarán a las personas usuarias de las lenguas de signos españolas su utilización como lengua vehicular de la enseñanza en los centros educativos que se determinen". Fomentando la igualdad de trato dentro del ámbito laboral. Respecto a la Salud, se contará con intérpretes de lengua de signos en aquellos centros donde se traté a personas sordas, siempre y cuando se realice una solicitud previa. Lo mismo sucederá en aquellas actividades culturales, deportivas, de esparcimiento y de ocio que se determinen, tales como cines, teatros y museos nacionales, monumentos históricoartísticos del

Patrimonio del Estado y visitas guiadas. Algo similar sucederá con los transportes donde se podrá contar con intérpretes en aquellas ubicaciones que el estado considere. 
Respecto a los medios de comunicación social, telecomunicaciones y sociedad de la información, punto importante para esta investigación, la Ley indica que los medios de comunicación social así como las campañas de publicidad institucional deberán ser accesibles para estas personas. Se incentivará el uso de subtitulado y los medios de apoyo a la comunicación oral. En el punto 4 del artículo 14 se indica que "Las páginas y portales de Internet de titularidad pública o financiados con fondos públicos se adaptarán a los estándares establecidos en cada momento por las autoridades competentes para lograr su accesibilidad a las personas sordas, con discapacidad auditiva y sordociegas mediante la puesta a disposición dentro de las mismas de los correspondientes sistemas de acceso a la información en la lengua correspondiente a su ámbito lingüístico". Se entiende, por tanto, que las personas con deficiencia auditiva consideran Internet como un elemento socializante de gran interés, que debe adaptarse a sus necesidades.

En el Titulo II la Ley habla sobre "Aprendizaje, conocimiento y uso de los medios de apoyo a la comunicación oral". Queda clara la voluntad por parte de la Administración de facilitar el acceso al aprendizaje de la lengua oral, por parte de personas con discapacidad auditiva que así lo soliciten, utilizando para ellos los medios de apoyo a la comunicación oral. Este apoyo vendrá realizado por profesionales que verán regulados sus estudios, de igual manera los profesores que trabajen con alumnos sordos recibirán programa y planes educativos por parte de la Administración.

Conseguir que el entorno que rodea a las personas sordas pueda comunicarse con ellos es otra de las acciones que promueve esta Ley.

En el capítulo II tambien se trata, el uso de los medios de apoyo a la comunicación oral, igual que sucedía en el capitulo II del titulo I, en este caso habla del uso de los medios de apoyo y no de la Lengua de Signos. De esta forma se definen diferentes usos en función de las diferentes áreas de aplicación. En este caso el uso de ayudas sustituye a la necesidad de contar con intérpretes a Lengua de Signos, dejando claro que las ayudas de otra índole también tienen su utilidad dentro de cada área.

Respecto a las disposiciones adicionales, cabe destacar la cuarta: "Régimen transitorio de la situación de los intérpretes y profesionales de las lenguas de signos españolas". Donde indica que se regularan los estudios de intérprete y se considerara la validez de titulaciones que anteriormente no contaban con esa categoría. En la disposición quinta se apoya esta necesidad de conseguir intérpretes con titulaciones regladas.

Dentro de la disposición séptima se recoge una información que puede ser de gran importancia para las personas sordas, se financiará la adquisición de apoyos técnicos para personas sordas, con discapacidad auditiva y sordociegas. Con esto el gobierno quiere conseguir que todas las personas independientemente de su situación económica tengan acceso a este tipo de ayudas técnicas.

Sin lugar a dudas, esta Ley viene a traer un soplo de aire fresco a todas aquellas personas que han trabajado duro para conseguir el reconocimiento de la Lengua de Signos como una lengua oficial. 
Desde el punto de vista educativo, conseguir la integración completa entre oyentes y sordos dentro de una sociedad de educación tiene gran valía. Esta ley defiende los intereses de las personas que deciden recibir una educación en lengua de signos y la de aquellos que prefieren la comunicación oral. En ambos casos se proporcionarán las ayudas necesarias. 

en Castilla y León 


\section{Capítulo III. Lectura y Sordera}

Siendo la lectura una fuente para adquirir conocimientos del mundo, aumentando las relaciones humanas y sociales, los profesionales que trabajan en el área de educación de personas adultas sordas tienen la misión de aplicar actividades motivadoras y creativas, aumentando así, el incentivo a la lectura.

Aunque los niveles de lectura de los sordos se han estudiado de forma exhaustiva los procesos de lectura han recibido poca atención. Para examinar esta cuestión es necesario "especificar un marco teórico general en datos empíricos que puedan ser entendidos." (Nunes y Bryant, 2004, 461).

El fenómeno de los niños sordos y de los adolescentes sin un lenguaje verbal será una fuente de constante ampliación de la paciencia inventiva del intelecto humana. Las personas oyentes, se pueden considerar afortunadas de poseer gran cantidad de símbolos y de poder emplearlos en consecuencia. Estos símbolos les facilitan la comunicación social y les proveen de numerosas oportunidades de información y curiosidad intelectual.

Una pregunta lógica ante las pruebas del desarrollo intelectual normal del sordo sería: ¿Si piensan, en qué piensan?

La inteligencia de los sordos no se puede explicar como un producto del lenguaje, pero, tampoco el lenguaje puede explicar la conducta inteligente de la persona normal. Al hacer esta pregunta, podemos especular sobre los símbolos visuales, cenestésicos y de gestos. Al mismo tiempo, nos damos cuenta que una gran parte del crecimiento intelectual del niño "normal" puede manifestarse más fácilmente en simbolismos no verbales mejor que en los verbales.

A pesar de todo, es sorprendente que la mayoría de los niños sordos crecen sin un sistema de símbolos para comunicarse y, por lo tanto, sin ese sistema abstracto de símbolos por los que relacionamos los conceptos. Se encuentra abandonado a sus propios medios de comunicación con los demás y también en su pensamiento interno. La evidencia de pensamiento conceptual en el sordo, deficiente lingüísticamente, lleva a la conclusión de que el pensamiento se desarrolla a través del contacto en el medio ambiente, exista o no un sistema de símbolos lingüísticos.

Constituye un punto de debate si el pensamiento de los sordos ha alcanzado alguna vez un alto nivel de realización intelectual y creativa. El medio ambiente puede haberles favorecido para un desarrollo intelectual en general, incluido el lingüístico.

Los puntos de vista de Piaget corresponden al problema de cómo comprender el desarrollo de los sordos, para esto, se explica el carácter no verbal de la vida mental del sordo y adoptar un punto vista teórico sobre el pensamiento que no incluye a la competencia lingüística como factor explicativo. La originalidad de las teorías de Piaget están en su descubrimiento de la relación entre muchos tipos de conducta no verbal y la estructura intelectual que como símbolos revelan. Piaget no ha 
investigado mucho con los sordos ni profundizado en el significado de su desarrollo intelectual. A pesar de esto, sus teorías dan sentido al funcionamiento intelectual de los sordos.

Cuando se habla de lectura, siempre vienen a la mente preguntas básicas que nunca terminan de responderse. Como por ejemplo, ¿desde cuándo lee el ser humano?, ¿cuál fue el motor que propulsó esta invención?, ¿por qué, a seis mil años de la invención de la lectura una tercera parte de la población es aún analfabeta? Pero sobre todo, ¿cuál es el procedimiento por el cual transformamos un juego de símbolos gráficos secuenciales en significados, en sensaciones, en emociones, o incluso en una deliciosa tarta de chocolate? La lectura fue desde sus comienzos un gran salto para la humanidad.

La lectura y la escritura han servido de respaldo a muchos imperios. Tenemos bastante clara su función social, su función histórica. Sin embargo, en los actuales momentos no tenemos claro cuáles son los procesos por los cuales el individuo común lee. Casi nadie guarda recuerdos claros de su propio proceso de adquisición de la lectura. En otras palabras, es muy difícil para cada uno de nosotros recordar una época sin lectura. El largo proceso de formación como profesionales está relacionado con la lectura. Y hoy en día a través de Internet y la telefonía móvil es posible que más y más gente se incorpore a ella. Los sordos por ejemplo, tradicionalmente poco ganados a la lectura y escritura por los métodos tradicionales, están convirtiéndose en lectores a través de los mensajes de texto de los móviles y de los chats en Internet. El hecho es que, a pesar de que todo el sistema humano se mueva en buena parte alrededor de la lectura, poco sabemos a ciencia cierta sobre el proceso lector en sí mismo, su anatomía, su fisiología, su psicología, su sociología. Sistemas de lectura/escritura,

Encontramos que el ser humano ha acometido el problema de la codificación/descodificación (escritura/lectura) de significados desde dos puntos de vista diferentes pero no opuestos. Los niños sordos hasta ahora han iniciado el aprendizaje de la lectura en clara desventaja respecto a los oyentes.

La historia de un lector oyente puede resumirse así: Un niño nace con una capacidad específica para desarrollar una lengua cualquiera en un tiempo preestablecido, al contrario de un niño sordo, que parte de un pésimo dominio de la lengua oral: sus representaciones fonológicas son muy deficitarias, sus habilidades para descifrar las claves morfosintácticas son mínimas, la competencia semántica y pragmática es ínfima, tanto más si carecían de habilidades comunicativas.

El entorno proporciona los datos que el niño requiere para, en unos pocos años, ser un hablante eficiente de la comunidad en que se desarrolla. Ese niño va a estar rodeado de una lengua completa y estructurada desde muy temprano. Va a observar activamente cómo se usa la lengua para pedir, para protestar, para amar o rechazar, para orar, para insultar, para mentir o para narrar. Pero sobre todo, va a observar la retroalimentación, el intercambio, lo que hace que la lengua no sea una mera encriptación de información, sino un sistema social. También este niño va a estar rodeado de escritura desde temprano. Los libros o revistas que se leen en casa, los textos cada vez más complicados de los productos que consumimos, la publicidad, los graffiti de la calle, los subtítulos de películas extranjeras, los mensajes de texto 
de móviles, las computadoras. Cuando el niño oyente comienza a ir a la escuela, las primeras nociones de lectura son sobre cómo lo que decimos, sonido a sonido, puede representarse a grosso modo de letra por letra para reproducir ese proceso de representar significados en símbolos. Una vez que se atrapa el secreto de la reconstrucción de un significado cualquiera, sonido a sonido, el proceso se hace automático y veloz de tal manera que un lector maduro avanzado ya no lee, predice. Ya no ve, intuye y se sumerge en los textos integrando, mezclándose con los significados del autor, enriqueciéndolos con sus propias vivencias. Esta última experiencia es lo que llamamos lectura.

Los lectores sordos aún están muy por debajo de los oyentes, independientemente del método empleado y de otros factores que se consideran importantes en el éxito de la adquisición de la lectura. Nos dicen por ejemplo que un sordo con el bachillerato terminado tiene típicamente un nivel de escritura equivalente al sexto grado de un oyente. Muchos profesores de sordos han pretendido utilizar la lectura para mejorar el desarrollo lingüístico general de sus alumnos y, hay que hacer notar, de acuerdo con Alegría (1990, citado en Villalba, 2005), que la lectura sólo puede ejercer esta función a condición de que el niño posea previamente una masa suficiente de conocimientos lingüísticos.

En otras palabras, los datos dicen que el lector/escritor sordo tiene usualmente un nivel por debajo del correspondiente a los oyentes. Sin embargo, a pesar de los bajos niveles de lectura/escritura los sordos avanzan en todos los países en el escalafón de la educación. Pasan de la primaria a la secundaria y de aquí a la universidad. ¿Significa esto que los sordos están recibiendo una educación de segunda? ¿O que la integración es una utopía? ¿Que en el momento de evaluar las diferentes competencias de los sordos ponemos también en la balanza su condición de sordo? Responder sí, a las interrogantes anteriores trae serias consecuencias laborales para el futuro profesional sordo.

Vygotsky (1934, citado en Guedes) reconoce ser la sordera, por excelencia, un defecto social. Es más directa que la ceguera y altera las relaciones sociales de la personalidad. Así, el primer problema de la sordopedagogía es devolver al sordo el habla. Para él, la rigurosidad excepcional y sin precedentes es un acompañamiento inevitable del método oral, pues, como reconocen sus defensores, de todos los métodos de enseñanza, el método oral es el que mas contradice la naturaleza del sordo, pero ninguno de los métodos está en condiciones de devolver al sordo a la sociedad humana, como puede hacerlo por el método oral. Todavía, critico con vehemencia los métodos de enseñanza de la lengua oral, opinando que la enseñanza del lenguaje al sordo está construida en contradicción con su naturaleza, pero también dudó que la lengua de señas fuese un verdadero lenguaje al servicio de la formación social de los sordos y como un instrumento para la mediación de los procesos psicológicos superiores.

Se observa una paradoja: si no es adecuado enseñar a los sordos a hablar, pues de esos métodos solamente se obtiene la articulación del habla pero no el lenguaje, y si la lengua de señas no es un lenguaje pleno, ¿en que términos y con cuales medios comunicativos y lingüísticos propone una educación, una pedagogía válida para los niños sordos? En verdad, Vygostky modificó su perspectiva sobre los sordos y la lengua de señas en un trabajo posterior. 
Otra característica crucial de la Pedagogía de Vygotsky: el concepto de heterogeneidad de los procesos humanos, donde defiende el derecho que el sordo tiene, como cualquier ser humano, en convivir con el otro en un contexto heterogéneo social, a través de la convivencia armoniosa de las interacciones sociales, criticando la directriz educacional de evaluar niños sordos para clasificarlos y educarlos en grupos uniformes, en contextos homogéneos de instrucción. Para él, el argumento para no segregar estaba en la concepción de heterogeneidad como instancia favorable de desarrollo, pues las relaciones interpersonales que incluyen niveles diferentes de funcionamiento permiten al niño sordo transformar sus capacidades. En otras palabras, para Vygostsky, toda etapa crítica del desenvolvimiento humano, comenzando por el lenguaje y pensamiento, tiene que, necesariamente, pasar por el proceso de las relaciones sociales humanas.

Hay que observar la sordera, también, desde su perspectiva audiológica, comprendiendo la importancia que ejerce el tipo de sordera sobre la capacidad educativa. La diversidad en el grupo de personas sordas es obvia, Moores (1992, citado en Sánchez, 2005) indicaba que el éxito académico depende de un cúmulo de factores interdependientes y carece de sentido atribuir malos resultados a una sola variable. No obstante y aunque se ha sido testigo de que alumnos sordos profundos congénitos, y con modalidad de comunicación signada, han finalizado sus estudios universitarios, los resultados de este subgrupo quedan relegados a un producto muy por debajo del nivel alcanzado por oyentes de un similar contexto socioeconómico.

Está claro que se ha de superar la división de base en cuanto a los dos grandes grupos educativos cuya línea de intervención no puede generarse tan sesgada desde el principio:

- Hipoacúsicos, cuya audición resulta más o menos funcional con prótesis o sin ella, capaces de alcanzar una formación básica de lenguaje interior en palabras, con procesos mentales basados en el habla porque la vía auditiva facilita y determina su mayor capacidad. Este grupo puede alcanzar un dominio más o menos productivo en lengua oral, gracias al entrenamiento auditivo y toda una larga lista de materiales electroacústicos. Estas ayudas les permiten mejorar el residuo auditivo indemne: desde los audífonos digitales hasta la adaptación protésica infantil, desde el diagnóstico precoz por otoemisiones y potenciales hasta la intervención educativa temprana e, incluso, los implantes cocleares practicados en las primeras etapas de la vida que permiten aprovechar la plasticidad cerebral sin perder un solo momento de estimulación y es que en el periodo de 0 a 6 meses es el núcleo de trabajo primordial.

Todo lo cual ha hecho posible, que dentro de este grupo de alumnos se incorporen muchos con pérdidas auditivas medias e incluso superiores a $90 d B$. Sánchez $(2005,26)$ y su equipo piensan que, "a tenor de los resultados de los últimos dos años de la subunidad pacense para el diagnóstico precoz de la sordera, que cada vez este grupo se incrementará". Lo positivo de estos resultados es que el rendimiento de este colectivo, con las ayudas apropiadas son capaces de seguir el curriculum ordinario con adaptaciones más o menos importantes en el 
acceso. Su traducción escolar más relevante es que no encontrarán como los sordos profundos y prelocutivos tantos problemas con el lenguaje oral y escrito, ni tampoco en la adquisición de contenidos académicos.

- Sordos profundos prelinguales, cuya audición no les resulta funcional para la vida ordinaria. Los propósitos de la vida normalizada se ven sensiblemente mermados y casi imposibles de conseguir, aún bajo los auspicios de ayudas técnicas de última generación; por tanto se ven obligados a percibir el habla fonoarticulatoria utilizando primordialmente la vía visual, con lo que, como indica Sánchez $(2005,26)$, "categorizan la realidad", esto es, almacenan el lenguaje interior base de pensamiento por medio de códigos visotáctiles, manuales o cinestésicos, como ya apuntaba Conrad en 1979, Löwe en 1981 o Schraegeren 1983 (citados en Sánchez, 2005).

Así, la lengua oral es mantenida por el recuerdo visual y propioceptivo, donde la vía auditiva apenas cuenta como tal, puesto que su ayuda es insignificante y la vía visual es el principal acceso tanto de información como de comunicación. Muchos de los alumnos pertenecientes a este grupo terminan su escolaridad sin el pretendido dominio de la lengua oral mayoritaria, ni tan siquiera obtener el beneficio de la lectoescritura como medio para adquirir conocimientos. Es un conjunto que necesita, en la mayor parte de los casos, acceder a los contenidos del curriculum ordinario mediante el empleo de otros códigos de comunicación diferentes o complementarios a la lengua oral.

Contando con todos estos datos en los siguientes puntos se detallarán, aún más, los procesos que intervienen en la comunicación de las Personas Sordas. Analizar el procesamiento que realizan las personas sordas para comprender lo escrito es necesario para poder comprender y solucionar los posibles problemas que muestra este colectivo. 


\subsection{Comunicación con Personas Sordas}

La escritura es el medio más común y eficaz del sordo para comunicarse con las demás personas normales. Contrariamente a lo que la gente cree, hay pocos sordos que sepan leer por el movimiento de los labios. Algunos tienen cierta facilidad, pero la gran mayoría no lo domina, e igual sucede con el lenguaje. Se supone que debe existir un conocimiento básico del lenguaje para entender el habla o el movimiento de los labios.

Según Schilesinger (citado en Sacks, 1994) y sus colegas que llevan trabajando en este campo hace veinte años, los primeros intercambios comunicativos entre padres y hijos, son muy importantes para el desarrollo del mundo perceptivo y conceptual de los niños. Y nos han demostrado que para este "salto dialéctico" del que habla Vygotsky (el salto de la sensación al pensamiento), no sólo ha de haber conversación, sino el tipo de conversación adecuado.

Hay colegios como la Escuela de California para Sordos (Sacks, 1994, 85), de Fremont, donde "muchos de los alumnos tienen un nivel razonable en cuanto a lectura y escritura, casi similar al de los estudiantes oyentes, mientras la media de los alumnos de la escuela de Braefield sólo alcanza al finalizar los estudios, más característicamente, un nivel de lectura y escritura correspondiente a un cuarto curso".

Muchos niños de Fremont poseen un vocabulario más amplio, hablan bien por señas, tienen confianza en si mismos. Estos niños proceden de hogares estables y los profesores son también sordos. Estos profesores transmiten a los alumnos una imagen positiva de la sordera y poseen una escolarización formal. Este es un ejemplo de una escuela que integra padres, profesores y alumnos sordos, haciendo con que el nivel de aprendizaje sea alto.

La comunicación en las personas sordas es un aspecto fundamental para despertarlas al mundo del pensamiento y del lenguaje. Un ejemplo claro de esta expresión es cuando Helen Keler descubre la primera palabra (agua), la primera seña, que conduce a todas las demás, que libera la inteligencia y la mente encarceladas" (Sacks, 1994, 85). Esa explosión intelectual ha sido un momento emocionante y produjo el significado y el sentido del mundo.

Las diferentes modalidades de comunicación con alumnos sordos dependen de muchos factores como: la edad en la que sobrevino el déficit, la severidad del mismo, las capacidades comunicativas, el entorno familiar y educativo, la atención temprana y las posibilidades con que se cuente a nivel de profesionales que intervengan con estos alumnos.

Las tres corrientes en las que se pueden enmarcar los métodos de comunicación con sordos son: 
- oralistas

- signistas o manualistas.

- mixtas o bimodales

Los oralistas, que tuvieron su auge hace algunos años, defienden la enseñanza del lenguaje oral al niño sordo mediante el aprovechamiento de los restos auditivos, entrenamiento en discriminación auditiva, entrenamiento en la labio lectura, etc. Los métodos exclusivamente orales se apoyan en entrenamiento auditivo mediante aparatos que le permitan al niño detectar el lenguaje oral como los vibro táctiles.

Los signistas, que toman auge en nuestros tiempos, consideran que el lenguaje de signos es el natural del sordo (por ello lo practican mayoritariamente), constituyendo un recurso simbólico fundamental para su comunicación. El lenguaje signado es un lenguaje propio, con sus características definitorias y en el que se sigue las mismas etapas evolutivas que en el lenguaje oral. La evolución lingüística, cognitiva y social de los niños que aprenden un sistema de signos sigue un ritmo más regular y superior que el sordo oralista. Los diferentes métodos se desarrollarán en el tema antes citado así como los de los demás sistemas.

La corriente bimodal (oral-gestual) está integrada por aquellos que piensan que el niño sordo debe comunicarse mediante el lenguaje de signos que es el suyo natural pero también debe aprender el lenguaje oral para integrarse en la sociedad oyente. La adquisición de la lengua de signos junto al aprendizaje del lenguaje oral puede ser necesaria para el niño sordo planteado en términos de bilingüismo. Siguiendo a Anguera $(1991,235)$ diremos que "las dificultades que plantea la enseñanza y el aprendizaje anterior, por parte de los educadores, del lenguaje signado hace que las tendencias actuales aboguen que en la educación del niño sordo deben plantearse alternativas encaminadas a una intervención lo más eficaz posible. Ésta podría ser la educación bilingüe (oral y signada) no sólo para favorecer un buen nivel de intercambio social sino para facilitar al niño la construcción de su conocimiento y acceder por tanto a las funciones psicológicas superiores".

"El sordo recibe sensaciones, las percibe y desarrolla sus procesos de imaginación, de simbolización y de conceptualización. Sin embargo, cuando las sensaciones auditivas están ausentes se altera la naturaleza de sus percepciones" (Furth, 1981, 242). Posiblemente, el individuo afectado de sordera profunda desde temprana edad está muy ligado a su imaginación, especialmente a su imaginación visual, que puede ser un factor predominante que imponga restricciones a su desarrollo psicológico.

El lenguaje es un factor crítico para la obtención de los niveles superiores de la experiencia y cuando la persona sorda es capaz de comunicarse con el mundo exterior y que las personas la comprendan, ha logrado la comunicación social. 


\subsubsection{La escritura y la alfabetización de los niños sordos}

El lenguaje, como argumenta Vygotsky (1978, citado en Fernández y Petusa, 1995) es una forma de comunicación y a la vez una forma de representación que facilita el desarrollo cognitivo. Lo que determina el potencial semiótico del lenguaje no es su formalización, sino que esté inmerso en el flujo de actividades interpersonales. De ahí la importancia de que exista una lengua como sistema de comunicación compartido por los interlocutores. Las personas oyentes desde el momento del nacimiento están inmersas en un mundo social del cual reciben estímulos por el canal auditivo, entre otros. Ello les permite ir aprendiendo el lenguaje oral sin que sea necesaria una intencionalidad por parte de los adultos (Fernández, 1992a, 93; Wells, 1987). Así, por ejemplo, Wells recoge cómo, normalmente, los padres oyentes, al hablar con sus hijos oyentes, "crean, espontánea e intuitivamente, oportunidades para que los niños aprendan sobre los muchos sucesos que se producen en el curso de un día cualquiera. Estos padres no sienten ninguna urgencia por enseñar... Al aprender hablando, los niños son constructores activos de sus propios conocimientos (...) Los padres que tratan a sus hijos de igual a igual en la conversación, dejándose guiar y negociando los significados y las intenciones, no sólo les están ayudando a hablar, además les están allanando el camino para descubrir que, hablando, se aprende"(Wells, 1987, 85,86).

Es conocido que las lenguas de signos de las comunidades de personas sordas son lenguas naturales, que tienen estructura propia y cumplen las mismas funciones que las lenguas orales. "Diferentes autores han enfatizado el interés de la lengua de signos para la población sorda como instrumento de mediación semiótica para el acceso a la comunicación, a la alfabetización y a la cultura, desde una perspectiva bilingüe o bicultural" (Triadó y Fernández, 1992, 213). Al referirnos a las lenguas de signos se incluye también la dactilología o deletreo manual.

Cuando se habla de bilingüismo para la educación de niños sordos y remitiéndose a las conclusiones de la Conferencia Internacional de bilingüismo celebrada en Estocolmo en 1992, que respaldó este modelo educativo para los niños sordos, estableciéndose en las siguientes etapas: (1) Lengua de signos; (2) Lengua escrita; (3) Lengua hablada.

Cada vez está siendo menos cuestionado que "La lengua de signos puede y debe ser utilizada, de forma bilingüe, como soporte didáctico en la educación lingüística, para la adquisición, memorización del léxico y de la morfosintaxis de la lengua vocal y escrita" (Caselli y Pagliari, 1991, 70).

Desde un enfoque bilingüe, se puede plantear también que la adquisición de la lengua escrita en el niño sordo puede vehicularse sin la mediación de la lengua oral. 


\subsubsection{El proceso de construcción de la escritura y las personas sordas}

Desde una perspectiva tradicional, se entendía la escritura como el traspaso de la lengua oral a unos signos gráficos. Es a partir de la última década cuando se reformula esta concepción, entendiendo el lenguaje escrito como un lenguaje diferente del lenguaje oral. No se considera el lenguaje escrito únicamente como la trascripción directa del lenguaje oral, sino como objeto de conocimiento sociocultural. Ferreiro y Teberosky $(1991,40,41)$ han puesto de relieve que "la representación escrita es una construcción activa por parte del sujeto, caracterizada por una secuencia evolutiva que comienza mucho antes de que el niño sea expuesto a la acción sistemática de la alfabetización".

En este sentido, los niños, cuando inician el aprendizaje formal de la escritura, ya poseen unos conocimientos previos que han adquirido a partir de la interacción con los otros en los diferentes contextos de desarrollo. La mayoría de niños, al iniciar la escolaridad, saben que la escritura consiste en una serie de grafías que, en nuestra cultura, se organizan siguiendo una línea horizontal de izquierda a derecha, y reconocen qué tipo de objetos son escritura.

Además, si se trata de niños oyentes, éstos poseen un considerable bagaje de lengua oral que han adquirido de forma natural en su entorno. La competencia lingüística previa va a incidir en la adquisición de la lengua escrita. La información auditiva que el niño oyente percibe facilita también la construcción de las representaciones fonológicas. Esta información, como veremos más adelante, va a ser diferente en el caso de los niños sordos.

Han sido muchas y diversas las definiciones que se han dado acerca de lo que es escribir. Así, entre otras: "La lengua escrita puede caracterizarse, al igual que todas las lenguas, como un sistema arbitrario de signos estructurados para representar la realidad -ideas, objetos, hechos de la experiencia- y para la comunicación entre los seres humanos que comparten el conocimiento de su funcionamiento. (...) La lengua escrita se expresa mediante la escritura, así como la lengua oral se pone de manifiesto a través del habla. La lengua escrita utiliza significantes gráficos, para ser vistos, en tanto que la lengua oral utiliza significantes sonoros, para ser oídos. Ambas lenguas son expresión del lenguaje, son dos formas alternativas de lenguaje" Ferreiro y Teberosky $(1991,40,41)$.

"La escritura es un sistema arbitrario de representaciones del lenguaje, consistente en establecer correspondencias entre representaciones mentales y en virtud del cual las relaciones que entre ambos sistemas se establecen son de presencia y ausencia de correspondencias". "La escritura es el instrumento que sirve para representar el lenguaje escrito. Por lenguaje escrito entendemos el lenguaje que se escribe, siendo éste independientemente de la representación gráfica" (Belles y Teberosky, 1989, 433).

Desde estas interpretaciones no se puede identificar la escritura con la copia de un modelo. No es la copia pasiva de unos grafismos, sino que el niño, cuando escribe, 
pone en juego sus hipótesis sobre el significado de esa representación gráfica. Además, "La lengua escrita tiene términos que le son propios, expresiones complejas, un uso particular de los tiempos de verbos, un ritmo y una continuidad propios" (Ferreiro y Teberosky, 1991, 90 y 91).

La escritura no es sólo habla escrita, implica una relación entre lenguaje y pensamiento, diferente a la que se da en una conversación. Vygotsky (1978) y Dyson (1990, citados en Fernández, 1993), justifican que el lenguaje escrito está muy ligado al lenguaje oral, ya que ambos se inician socialmente. Pero el lenguaje escrito no es justamente lenguaje hablado, sino que puede ser considerado como un segundo sistema de símbolos que emergen de un complejo desarrollo de las habilidades simbólicas. Lengua escrita y lengua hablada son lenguas distintas, que presentan semejanzas y diferencias. Entre las semejanzas generales se encuentran aquellas que se derivan de los rasgos universales que tienen en común todas las lenguas humanas. A estas similitudes se agregan, en el caso de las lenguas escritas alfabéticas, semejanzas particulares provenientes del hecho que estas lenguas permiten una codificación parcial de los sonidos del habla. Ya hemos dicho anteriormente que entre lenguas orales y lenguas escritas existen importantes diferencias; éstas marcan las distintas funciones que cumplen unas y otras, y que justifican la existencia (y la coexistencia) de ambas en las culturas que las utilizan.

Halliday $(1985,63)$ indica que "el habla y la escritura son diferentes formas de decir; son diferentes modos de expresar significados lingüísticos”. En el lenguaje, una red de significados (sistema "semántico") es codificada a través de una red de ordenamientos de palabras (sistema "léxico-gramatical"), y los ordenamientos de palabras son a su vez codificados a través de una red de expresiones. La expresión, en todas las culturas, hace uso del medio sonoro (sistema "fonológico"); en algunas de estas culturas también hace uso del medio visual (sistema "ortográfico" o "grafológico").

Ferreiro y Teberosky $(1991,98)$ en su trabajo sobre el acceso a la escritura en niños oyentes, consideran tres fases en el proceso de construcción de la lengua escrita: a) "Fase presilábica": Se centra en el descubrimiento de las diferencias entre grafía y dibujo. b) "Fase silábica": Los niños intentan establecer correspondencias entre las partes de lo escrito y partes de las emisiones sonoras. c) "Fase alfabética": El niño conoce las correspondencias entre fonema-grafema.

En el caso de los niños oyentes, lo que parece implicar mayor dificultad en este proceso es "comprender la estructura del sistema alfabético, (...) puesto que aprender a escribir no implica aprender a inventar letras nuevas, sino aprender las reglas de combinación que definen al sistema y que permiten engendrar nuevas representaciones, sin necesidad de recurrir a un modelo externo" Ferreiro y Teberosky $(1991,100)$.

$\mathrm{Y}$, ciertamente, la comprensión constituye un elemento fundamental para asegurar el éxito de la comunicación. En consecuencia, la lengua escrita es una lengua. Pero, se trata de una lengua particular, diferente en ciertos aspectos de las lenguas naturales, cuyo origen, en principio, no tenía el tipo de relación con la lengua oral que pueden tener en la actualidad nuestras escrituras alfabéticas. 


\subsubsection{Sordera y lengua escrita}

Son conocidas las dificultades que presenta la población sorda para acceder a la información a través de la vía auditiva. Es un hecho, tal vez poco difundido, que la comunidad de personas sordas es una comunidad, en general, iletrada. Ciertamente, los sordos en pocas ocasiones han hecho suyas la lectura y la escritura, como para poder aprovecharlas en sus posibilidades: no son lectores y escritores competentes por lo que, habitualmente, no leen ni escriben. Estas personas tienen grandes dificultades para comprender los textos escritos y su escritura está alejada de la escritura convencional, y esto pese a los posibles largos años de escolaridad obligatoria, bien sea en aulas de integración o en aulas de escuelas especiales. En consecuencia, esta cuestión tiene repercusiones tanto en los procesos de instrucción como en su posterior acceso al mercado laboral.

La evidencia de esta situación ha dado argumentos para focalizar la preocupación de muchos educadores de sordos en torno a esta temática y para la elaboración, en algunos centros, de programas de intervención específicos. Podríamos agrupar las investigaciones realizadas sobre la escritura de las personas sordas en dos grandes bloques. El primero de ellos, desde enfoques descriptivos, recogería aquellos estudios que se han focalizado en determinar los errores de sus producciones escritas, comparándolos con los de los niños oyentes. El segundo bloque intentaría argumentar las causas de tales errores.

Las investigaciones incluidas en el primer bloque han evidenciado incoherencias, escasa cohesión y errores morfosintácticos en los escritos de los estudiantes sordos. Su léxico parece más limitado que el de sus iguales oyentes (Caselli, Massoni, Ursono, Pace y Skliar, 1996; Gil, 1994; Fernández y Pertusa, 1995, 70). Encontraron que los pronominales, los tiempos verbales, los relativos y los complementos eran las escrituras sintácticas de mayor complejidad en los textos escritos de los jóvenes sordos.

Cooper y Rosenstein (1966) ya en su trabajo recopilaron algunas investigaciones referentes a este primer bloque, concluyendo que: "El lenguaje escrito en los niños sordos, comparado con el de los niños oyentes, se vio que contenía sentencias más cortas y simples, mostrando diferencias en la distribución de las partes de la oración, apareciendo más rígido y con estereotipias y exhibiendo numerosos errores del uso del inglés estándar" (Dyson, 1990, 76).

Es cierto que la mayoría de autores han investigado en escritura de las personas sordas, coinciden en su afirmación de que alcanzan un nivel inferior al de la población oyente. Esto repercute, en consecuencia, en que sean escasas las personas sordas que superen el nivel de Educación Secundaria Obligatoria y, más aún, las que logren acceder a estudios superiores. Pero también es cierto que son escasos los trabajos que se han dedicado a buscar una justificación sobre posibles causas que se alejaran de visiones clínicas y patológicas que focalizaban en la no audición la responsabilidad del problema. 
El segundo bloque de trabajos se ha centrado más en la búsqueda y argumentación de las causas de aquellas diferencias. En su mayoría establecen una relación entre la competencia en lengua oral y en lengua escrita de las personas sordas, de manera que fundamentan las dificultades en la lengua escrita en el bajo nivel de lengua oral que presentan (Newport y Meier, 1985; Taeschner, Devescovi y Volterra, 1988; Bellés y Teberosky, 1985, 65).

Indudablemente, la sordera "afecta la representación de las palabras en el lexicón mental de los sujetos. Las representaciones mentales de los sordos son diferentes a las de los oyentes: contienen representaciones signadas de las palabras, y las representaciones fonológicas son menos precisas" (Alegría, 1999, 126).

Bellés y Teberosky $(1989,435)$ plantean que "la distinta competencia lingüística verbal entre los sujetos sordos y oyentes, incide en la representación inicial del lenguaje en los siguientes aspectos: a) En la amplitud lexical: los niño sordos tienen dificultades para conocer las denominaciones de referentes. b) Variaciones sonoras: dadas las dificultades para producir enunciados verbales correctos, es imposible que el niño sordo realice correcciones de la correspondencia fonográfica. c) Variaciones semánticas: cuando los niños encuentran referentes para los que no tienen denominación, en muchos casos se observa la utilización de diminutivos, o de neologismo". Según estas autoras, uno de los factores responsables de que los niños sordos no avancen en los diferentes niveles del acceso a la lengua escrita, pesen a conocer el procedimiento de construcción de la escritura es su insuficiente conocimiento del lenguaje. Ciertamente, si la lengua escrita se adquiere como una segunda lengua, sobre la base de un lenguaje normalmente desarrollado, en el caso de los niños sordos, esta capacidad puede verse limitada. En este sentido, como han puesto de manifiesto estudios anteriores (Fernández, 1994, 138),"cuando los niños sordos están inmersos en un entorno lingüístico adecuado a sus posibilidades perceptuales, tienen incomparables ventajas frente a otros sordos que no tienen acceso a un código compartido". Esto se refleja en el proceso de apropiación de la lengua escrita, de manera que los primeros muestran un dominio muy superior que los segundos.

Wilcox (1994) sostiene que a un mayor incremento en competencia en lengua de signos, más posibilidades en la comprensión y mejor producción del lenguaje escrito. Kyle (1985) comenta cómo en los escritos de muchos sordos puede extraerse más fácilmente su significado si se recurre a las reglas de la lengua de signos, que de hecho han servido para expresarse en el "otro lenguaje". En esta misma línea, Marchesi (1987) y Wilcox (1994), citados en Alegría, (1999), han argumentado que los sordos tienen dificultades para recordar los códigos fonológicos, pero no para los visuales. Los niños sordos cometen menos errores cuando utilizan codificación signada o dactilológica que cuando la codificación es fonológica. Según estos autores se tratan de un proceso secuencial, y conocer la lengua de signos facilita la posterior codificación fonológica. Algunas de las aportaciones de Leybaert (1994, citado en Alegría, 1999), así lo corroboran: "Para los niños que conocen la comunicación manual, realizada en dactilología, pueden también facilitarles la adquisición de los contrastes fonológicos del lenguaje (...) Como el alfabético ortográfico, la dactilología constituye una representación compleja del lenguaje hablado. (...) Se demuestra que la dactilología puede proveer a los niños sordos de un sentido temprano de las letras, las cuales ofrecen información sobre los 
contrastes fonológicos de la lengua hablada" Parece hacerse cada vez más evidente que, para facilitar el acceso a la escritura en las personas sordas, el instrumento de mediación semiótica más potente va a ser la lengua de signos.

Ésta facilita a los niños sordos una aproximación a los conocimientos periféricos y sociales, imprescindibles para aprender a escribir, y es muy probable que la dactilología pueda ser un instrumento vehiculador del conocimiento alfabético. Parece bastante probado que, pese a que la correspondencia entre un signo del lenguaje de signos y una palabra de la lengua oral o escrita es arbitraria, y tampoco existen correspondencias sub-lexicales (a nivel silábico o fonológico) entre las dos lenguas, el uso consistente de una lengua, en este caso, la lengua de signos, permite un mejor acceso a la lengua escrita. Apoyan esta idea los textos realizados por niños sordos, hijos de padres sordos, que muestran mejores niveles que los de niños sordos con padres oyentes. Así, "El lenguaje de signos sirve para que los niños sordos adquieran todo un conjunto de habilidades lingüísticas que favorezcan posteriormente el desarrollo de las habilidades lingüísticas del lenguaje oral de la comunidad a la que pertenecen (...) de la misma manera el lenguaje de signos puede propiciar el acceso a una serie de habilidades lingüísticas y metalingüísticas que posibilitarán el acceso a la lengua escrita" (Domínguez, 1994, 51). "Éstas y otras consideraciones avalan la opción del bilingüismo para la enseñanza de las personas sordas" (Fernández, 1994, 138). Así, por ejemplo, en Suecia, a partir de 1981 se adoptó esta propuesta y se considera la lengua de signos como el primer lenguaje del niño sordo; una vez que ésta se consolida, se inicia la enseñanza del sueco a partir de la lectura y de la escritura. Se utiliza la lengua de signos para llegar al contenido del texto y, posteriormente, se extraen las unidades constituyentes: "... Más tarde las unidades pueden romperse en sus constituyentes (morfemas), pero en el primer nivel de lenguaje deben guardarse los significados que expresan y sus correspondientes expresiones en lenguaje de signos" (Alegría, 1999, 130).

En un estudio piloto realizado durante los años 1994 y 1995 en Barcelona en un centro de actividades de tiempo libre para niños sordos (Gemis, Alsica y Asu, citados en Fernández, 1994), comprobamos cómo los adultos y educadores sordos recurren sistemáticamente a la lengua de signos y a la dactilología para auxiliarse en la comprensión de su discurso por parte de los niños sordos y para realizar reflexiones metalingüísticas sobre el uso de la lengua y de las normas de escritura con los niños, de manera que éstos captan entonces con rapidez y de manera comprensiva el contenido de la explicación del adulto. En la actualidad los registros observacionales realizados en dichas sesiones están en fase de microanálisis. "Pensar en la lengua escrita quiere decir pensar en una segunda lengua." (Fernández, 1994, 137). Es bien conocida la esencial importancia del acceso a la comunicación y al lenguaje para los seres humanos y, en particular, el interés de que el niño se desarrolle inmerso en un entorno lingüístico donde la comunicación sea accesible, desde el principio, de manera que se le facilite la apropiación de una primera lengua. En el caso de los niños sordos debe propiciarse una inmersión en entornos lingüísticos signados, en los que la lengua de signos sea utilizada normalmente por usuarios habituales, competentes, que inunden el entorno infantil de un sistema de comunicación eficaz. 


\subsection{Competencia lingüística y sordera}

El lenguaje es una función compleja que nos permite expresar y percibir estados afectivos, conceptos e ideas por medio de signos acústicos, gestuales o gráficos que se rigen por una serie de códigos. Es un sistema arbitrario y convencional con la función de comunicar y representar la realidad. En las personas con deficiencias auditivas se ha insistido desde hace mucho tiempo en establecer con ellos un lenguaje oral, ello ha llevado a considerar la respuesta educativa como eminentemente rehabilitadora, es decir, educación y rehabilitación como un mismo proceso en el que la intervención educativa sea igual a la intervención rehabilitadora del lenguaje oral.

Andrews y Mason $(1991,537)$ apuntan tres posibles causas que explican las dificultades en lectura de los estudiantes sordos.

- "Falta de conocimientos del medio y las pocas experiencias previas con los principales temas de los textos, como una causa de los bajos niveles en lectura de estos estudiantes. Los sordos inician el aprendizaje formal de la lectura con un repertorio lingüístico y conceptual reducido, debido a que en la generalidad de los casos el diagnóstico de la sordera ocurre después de los dos años de edad y a que la gran mayoría de los niños sordos nace en familias oyentes que desconocen la lengua de signos.

- Pobreza en las habilidades lingüísticas orales de los lectores sordos, ya que presentan un léxico limitado, un menor conocimiento de palabras polisemánticas, un desconocimiento de expresiones idiomáticas e igualmente tienen dificultades con el lenguaje figurativo, las formas sintácticas y las inferencias.

- La forma del lenguaje de signos, comúnmente el más usado entre la población sorda, es estructuralmente diferente del lenguaje oral. "

"La falta de eficiencia en la lectura también se atribuye a que, para los niños que se comunican con signos, el lenguaje oral es un lenguaje extranjero" (Paul y Gustafson, $1991,54)$. Otros autores han señalado que una posible causa es que "los niños sordos no formulan suficientes preguntas cuando se enfrentan a un texto escrito 0 que tienen menos interacciones con el significado de la lectura durante sus años preescolares" (LaSasso, 1993, 436). Por consiguiente, el déficit en la competencia lingüística se postula como uno de los principales factores del fracaso lector de los estudiantes sordos.

Asimismo, Limbrick, McNaughton y Clay (1992, 308-314) destacan dos explicaciones atribuidas a los bajos niveles de lectura obtenidos por los estudiantes sordos.

- Déficit lingüístico global del lenguaje oral observado en las personas sordas 
- La pobreza lectora puede estar relacionada con la calidad y cantidad de la instrucción lectora que reciben. En este sentido, los datos aportados por estos autores coinciden con los de King y Quigley (1985, citados en Limbrick, McNaughton y Clay 1992), al recalcar que los profesores de los niños sordos no reciben la instrucción suficiente en las metodologías de la enseñanza de la lectura."

El aprendizaje de la lectura constituye una de las tareas más importantes a las que se tiene que enfrentar el niño con sordera. Aunque el lenguaje escrito tiene el potencial para suministrar al niño con sordera un modo alternativo de comunicación que le permite acceder a mucha información, gran proporción de niños con sordera nunca llegan a alcanzar unos niveles de lectura competentes (Allen, 1986; Asensio, 1989; Conrad, 1979; Di Francesca, 1972; Lewis, 1996; Trybus y Karchmer, 1977, citados en Puyuelo y Alagón, 1999). El $80 \%$ de los adolescentes con sordera son analfabetos, y la fuente principal de estas dificultades es de origen lingüístico. Los niños con sordera leen mal porque conocen mal la lengua oral (Alegría y Leybaert, 1986, citados en Coll, Martín, Mauri y Miras, 1994). Sin embargo, esta afirmación resulta muy general y un tanto obvia.

Según la mayoría de los modelos teóricos, el reconocimiento de la palabra escrita requiere de la intervención de las representaciones fonológicas del individuo -sean éstas pre o post-lexicales- (González, Romero y Blanca, 1995; Rondal y Seron, 1999, citados en Acosta, 2003). En el pasado, los investigadores postulaban que las personas con sordera no tenían acceso a la información fonológica, dado que las representaciones fonológicas no podían desarrollarse más que a partir de información acústica (Gibson y Shurdiff, 1970, citados en Ardila, 19991).

Los trabajos de McCurk y MacDonald (1976, citados en Gallego, 2000) y el descubrimiento del Ilamado «efecto McGurk» (la presentación sincronizada de una cara pronunciando la sílaba/ga/mientras se escucha la sílaba/ba/ conduce a la percepción de la sílaba /da/) constituyen el elemento central de una nueva concepción del papel de la información visual en la percepción de la palabra. La lectura labial pasa a reconocerse así como una parte del proceso de percepción del habla, tanto para personas con sordera como para oyentes (Campbell, Dodd y Burnham, 1998; Dodd y Campbell, 1987, citado en Hanson, 1989). Este reconocimiento cambia radicalmente el panorama de las posibilidades de los niños con sordera para adquirir habilidades lectoras.

En los estudios sobre conocimiento lexical realizados con participantes con sordera se han utilizado dos enfoques diferentes: la amplitud y el tipo de vocabulario (con relación a los oyentes). Entre los autores que han trabajado preferentemente bajo un enfoque cuantitativo, el acuerdo es unánime: la cantidad de vocabulario conocido por el niño con sordera en edad escolar es muy inferior al de los niños oyentes de edades similares (Silverman-Dresner y Guilfyle, 1972; Trybus y Karchmer, 1977; Conrad, 1979, citados en Carmona, Gómez y González, 1998).

Por el otro lado, el enfoque cualitativo trata de investigar los (numerosos) factores que contribuyen a la dificultad de una palabra: conocimiento anterior, carga conceptual, capacidad para usar indicaciones del contexto, pronunciación, contexto limítrofe de palabra, frecuencia y multiplicidad de significados (Anderson y Freebody, 
1985; Nagy y German, 1987; Paul y Gustafson, 1991; Paul y O'Rourke, 1988, citados en Aguado, Ripio y Domezáin, 2003). Estos estudios cualitativos muestran una utilización mayor de nombres y verbos y un uso menor de proposiciones, adjetivos y pronombres.

En segundo lugar, al analizar el desarrollo de la comprensión de estructuras sintácticas de niños con sordera, numerosos estudios apuntan hacia un desarrollo bastante más lento que los lectores normo-oyentes (Asensio, 1983; Quigley y Kretschmer, 1982; Quigley, Power y Steinkamp, 1977; Quigley, Smith y Wilbur, 1974, citados en Bisguera, 1996).

Marschark (1993, citado en Bravo, 2004), controlando el estatus parental (oyente y/o sordo) y la experiencia lingüística de los niños, realizó un estudio en el que los datos revelaron que el grupo de niños con sordera que utilizaba inglés signado se situó muy cerca del grupo de oyentes en la realización de la tarea. Esto nos lleva a dos conclusiones: 1) los niños con sordera pueden mostrar habilidades sintácticas semejantes a las de los oyentes, y 2) la variable «modo de comunicación» resulta tener una importancia incluso mayor que la variable «estatus parental» como factor predictivo del éxito en la tarea.

Esta influencia del procesamiento sintáctico en la comprensión lectora queda patente en dos habilidades sobre las que se han centrado los estudios sobre comprensión lectora: el uso de las señales contextuales y estructurales para la comprensión de frases y la utilización de inferencias por parte de los niños con sordera. Si dentro de la primera corriente se sitúan los trabajos de McGrill-Frazen y Gormley (1980, citados en Acosta, 2003) y Nolen y Wilbur (1985, citado en de Vega y Cuetos, 1999), dentro de la segunda corriente se hallan los estudios realizados por Strassman, Kretschmer y Bilsky (1987), que descubrieron que los niños con sordera podían hacer uso de las frases del contexto cuando se les dirigía para hacerlo de ese modo, pero no eran capaces de realizarlo espontáneamente. Según los autores esta incapacidad puede ser debida a un empobrecimiento de las representaciones semánticas y/o a problemas con procesos integrativos o inferenciales al leer. La conciencia fonológica (también conocida como conocimiento metafonológico) es considerada como una habilidad metalingüística, que hace referencia a la conciencia sobre los elementos fonológicos del lenguaje oral. La conciencia metafonológica no constituye una entidad homogénea, sino que se consideran distintos niveles: conocimiento silábico, conocimiento de rima y aliteración y conocimiento fonémico. Esto plantea una pregunta: $\mathrm{Si}$ el conocimiento fonológico no descansa (exclusivamente) en la percepción auditiva del habla, dicho conocimiento podría ser alcanzado por las personas con sordera.

En una serie de experimentos realizados por Dodd y Hermelin (1977, citado en Coltheart, 1980) con niños con sordera profundos prelingüísticos educados oralmente, descubrieron que las palabras que tienen un parecido en los labios eran juzgadas como pares que riman. Sin embargo, no todas las palabras con similares representaciones en labiolectura tienen que rimar o ser homófonas. Los resultados señalan la coincidencia entre similitud del movimiento de los labios y rima, pero no revelan si los niños con sordera hacen distinción entre ambos. La confusión entre similitud de lectura labial y similitud articulatoria lastraría el desarrollo exitoso de los niños con sordera, dada la no accesibilidad a un feedback de sus producciones y por 
tanto a un reajuste de sus representaciones fonológicas. La afirmación A anteriormente expuesta sería la posición más consensuada entre los investigadores: los niños con sordera pueden desarrollar un conocimiento fonológico de sílabas, rimas y fonemas que, sin embargo, no alcanza al adquirido en condiciones normales por sus iguales oyentes (Campbell y Wright, 1988; Hanson y Fowler, 1987; Matagne, Charlier y Alegría, 1999; Transler, Leybaert y Gombert, 1999; Sterne y Goswani; 2000, Bravo, 2004, 25).

En lengua francesa, Charlier (1997, citado en Román, 2001); Charlier y Leybaert (2000); Leybaert, Alegría, Hage y Charlier (1998) encontraron resultados muy diferentes en cuanto a la habilidad fonológica de las personas con sordera utilizando el método de comunicación denominado Palabra Complementada o Cued Speech (gracias al cual se especifican visualmente todos los contrastes fonológicos, lo que permite el desarrollo de representaciones fonológicas adecuadas). Datos como los anteriores sugieren que la sordera no es el factor causal de los déficit cognitivos usualmente asociados con ella, sino que tales déficit, estarían causados por una falta de experiencia lingüística.

Esta hipótesis permitiría a su vez esclarecer el papel del «estatus parental» como variable predictora en el éxito de éstas y otras habilidades, pero reinterpretada como «habilidades de comunicación de los padres con el niño con sordera», algo compatible con los resultados obtenidos en algunos estudios sobre la superioridad de resultados de los niños con sordera con padres con sordera (donde la exposición al lenguaje de signos se realiza de forma espontánea y precoz) y con aquellos que centran su análisis en el tipo de comunicación y la exposición temprana. Una consideración similar puede encontrarse en Padden y Hanson (1997, citado en Román, 2001).

Cuando se pretende develar las principales dificultades de los estudiantes sordos en el momento de enfrentarse con el aprendizaje de la lectura, uno de los primeros factores que aparece es la competencia lingüística. Para realizar este análisis es fundamental considerar las variables individuales que influyen en la sordera (grado de pérdida, edad de comienzo, sistemas de comunicación, estatus de audición de los padres, etc.), puesto que de ellas depende, en gran medida, el nivel lingüístico que presenta el estudiante sordo y el dominio del lenguaje oral o gestual que posee al iniciar el aprendizaje de la lectura.

Habitualmente los niños sordos inician el aprendizaje de la lectura sin un dominio suficiente del lenguaje oral, es decir, sin haber conseguido niveles mínimos de comprensión y producción lingüística. Por ello, varios autores recalcan que "en los lectores sordos el aprendizaje del lenguaje oral y la lectura se superponen, e incluso se utiliza el lenguaje escrito como soporte para mejorar el lenguaje oral" (Andrews y Mason, 1991,538). En este sentido, señalan que, debido a la naturaleza interactiva de la lectura, el lenguaje y la cognición, los problemas de lectura de estos estudiantes pueden Waters y Doehring (1990, citados en Andrews y Mason, 1991) ser causados por insuficiencias específicas en el lenguaje, más que por deficiencias en las habilidades de lectura.

Por ello, investigadores explican que los problemas de lectura presentados por los niños sordos no son específicos de la lectura, sino el reflejo de un déficit global en su 
conocimiento léxico, sintáctico, semántico y pragmático del lenguaje oral, que limita sus progresos en el aprendizaje de la lectura. En este sentido, Alegría y Leybaert (1989, citado en Villalba et al., 2005) señalan que la impotencia lingüística constituye el principal obstáculo en la adquisición de la lectura por parte de los sordos. Argumentan que el problema central del sordo, comparándolo con el mal lector, es que ninguno de ellos transforma el texto escrito en una representación fonológica.

Por otra parte (Paul y Gustafson, 1991, 56) subraya que "mientras el oyente inicia el proceso de aprendizaje de la lectura con un buen desarrollo de las habilidades de comprensión general del lenguaje, el sordo inicia el mismo proceso con un mal desarrollo de las habilidades de comprensión general del lenguaje como resultado de su deficiencia lingüística". Estas carencias acumuladas no se deben a una falta de habilidad inherente en los sordos, sino a un empobrecido medio inicial originado por la falta de experiencia e input lingüístico apropiado.

En consecuencia, se hace evidente que para aprender a leer y escribir son necesarias ciertas habilidades lingüísticas de las cuales los sordos carecen al iniciar este aprendizaje. Sin embargo, como recalca Asensio (1989) esta afirmación puede resultar demasiado general. Por ello es imprescindible precisar cuáles son los aspectos de la incompetencia lingüística general de los sordos, que son responsables de las dificultades en el aprendizaje de la lectura.

\subsubsection{Procesamiento léxico}

Analizar la competencia lingüística implica revisar las destrezas léxicas, ya que son un componente esencial en la comprensión del lenguaje y que permiten conocer el significado de las palabras y en última instancia comprender los mensajes orales y escritos. De esta forma, la palabra constituye la unidad semántica básica desde la cual se construye el discurso. Al respecto, son varios los autores que han investigado extensamente el rol primario que juega un vocabulario amplio en las habilidades de lectura.

La mayoría de ellos concluye que los niños que desconocen el significado de varias palabras probablemente serán malos lectores. Los estudios sobre conocimiento léxico han demostrado repetidamente que los problemas en el procesamiento de las palabras son el mejor discriminador entre buenos y malos lectores, ya que los lectores novatos y los malos lectores presentan pobres habilidades en el análisis de las palabras.

Igualmente, muchos investigadores se han centrado en el deficiente conocimiento del significado de las palabras del lenguaje oral, como el mayor inconveniente para la lectura. Del mismo modo, se han realizado extensos estudios sobre el desarrollo del vocabulario de los sordos y confirmado que en todos los niveles de edad comprenden sustancialmente menos palabras escritas que los lectores oyentes y que la distribución del tipo de palabras es diferente entre ellos. A comienzos de los años sesenta, Myklebust (1960) realizó una encuesta nacional en EE.UU. sobre los procesos psicológicos de los niños sordos, la cual incluyó una evaluación sobre la lectura. Dicha evaluación consistió en aplicar una adecuación de la prueba 
estandarizada de vocabulario Columbia, sobre una muestra de 564 niños sordos y 201 niños oyentes entre 9 y 15 años. Las conclusiones de dicho estudio revelan que los sordos presentan un déficit en su vocabulario expresivo, tanto en las producciones signadas como en las habladas y escritas, indicando que dicho déficit va más allá de las dificultades con el lenguaje oral y están vinculadas con factores lingüísticos y experiencias de nivel general. El autor agrega que los sordos no sólo tienen vocabularios más pobres que sus pares oyentes, sino que, además, el tipo de palabras que saben es distinto.

Posteriormente Balow, Fulton y Peploe (1971) realizan un nuevo estudio respecto de los niveles de vocabulario y lectura de los estudiantes sordos, para el que utilizan el Metropolitan Achievement Test. Los investigadores examinaron 157 estudiantes sordos entre 13 y 21 años, divididos en tres grupos, según el grado de pérdida auditiva. El primer grupo lo constituían estudiantes con pérdidas auditivas entre 40 y $60 \mathrm{~dB}$., el segundo grupo estudiantes con pérdidas entre 65 y $95 \mathrm{~dB}$. Y el tercer grupo de estudiantes presentaba más de $100 \mathrm{~dB}$ de pérdida auditiva. La respuesta media de la muestra obtuvo un nivel de vocabulario de 4.5 grados. Los autores advierten que esta media aumentó gracias a los mejores niveles presentados por los estudiantes con pérdidas entre 40 y $60 \mathrm{~dB}$., quienes alcanzaron una media de 5,5 grados, que supera en más de un año los resultados de la muestra total. Balow, Fulton y Peploe $(1971,113)$ concluyen que "es fundamental controlar el grado de pérdida auditiva para examinar los niveles de conocimiento de vocabulario en los sordos, ya que esta variable se correlaciona directamente con los niveles de vocabulario oral obtenidos."

Comparando estudiantes sordos hijos de padres sordos y estudiantes sordos hijos de padres oyentes, Charrow y Fletcher (1974, citados por Marschark 1993) descubrieron que los estudiantes sordos de 17 y 18 años con padres oyentes demuestran un peor desempeño en la prueba de vocabulario TOEFL (Test of English as a Foreign Language) que los estudiantes sordos hijos de padres sordos. El patrón de resultados en esta prueba llevó a los autores a indicar que los estudiantes sordos con padres sordos muestran un desempeño similar al presentado por los estudiantes oyentes que aprenden una segunda lengua.

En un estudio realizado con 1.547 estudiantes sordos, Trybus y Karchmer (1977) aportaron nuevos datos al estudio del léxico en la población sorda. Descubrieron que el nivel de vocabulario de los estudiantes de la muestra estaba retrasado uno o más años respecto de su nivel de comprensión escrita. Es decir, los estudiantes sordos comprenden a nivel escrito más de lo que comprenden a nivel de palabra aislada. Los autores señalan que el desempeño en las tareas de vocabulario mejora si las tareas involucran palabras que tienen sólo un significado. Los autores concluyen que, en contraste con los niños oyentes que conocen el nombre de muchos objetos antes de aprender a leer, un gran porcentaje de niños sordos posee pocas representaciones simbólicas verbales y con esta enorme limitación inician el aprendizaje del lenguaje escrito.

Siguiendo esta línea de investigación, Paul en su tesis doctoral realizada en 1984 (Paul y Gustafson, 1991) analizó la comprensión de palabras tomando una muestra de 50 sordos y 50 oyentes. La prueba que elaboró consistía en presentar dibujos que representaban distintas palabras, donde los sujetos debían elegir la opción 
correcta entre cinco alternativas. En algunos casos existía más de una respuesta correcta. Las conclusiones del estudio señalan que los estudiantes sordos tienen un nivel de comprensión de palabras inferior al de los oyentes, que en ambos grupos es más difícil enfrentarse a palabras que presentan polisemia y que la pobreza de vocabulario produce dificultades en la comprensión lectora.

Tomando en cuenta la hipótesis que relaciona el conocimiento de vocabulario con los logros en comprensión lectora, LaSasso y Davey (1987) investigaron el vocabulario y la comprensión lectora de 50 estudiantes con sordera profunda entre 10 y 18 años. Las pruebas utilizadas fueron las subpruebas de vocabulario del Gates-MacGinitie Reading Tests y la prueba de comprensión lectora Stanford Achievement Test. Las tareas incluían una prueba Cloze y cuatro condiciones de pregunta-respuesta. Los investigadores corroboraron su hipótesis inicial, demostrando que los resultados en las pruebas de vocabulario se correlacionan fuertemente con los resultados en comprensión lectora. Nuevamente el conocimiento del vocabulario fue considerado un fuerte indicador de las habilidades de comprensión lectora.

Estos hallazgos fueron confirmados por Paul y Gustafson (1991) en un estudio realizado con estudiantes sordos y oyentes. El objetivo de la investigación fue evaluar la comprensión de palabras con polisemia, a partir de una prueba de vocabulario de imágenes. Los autores pretendían comparar el desempeño de ambos grupos en palabras con uno y dos significados. Junto con esto se esperaba constatar el incremento del vocabulario a medida que aumentaban la edad y la relación entre conocimiento del vocabulario y comprensión lectora. Como se esperaba, los oyentes aventajaron significativamente a los sordos en la realización de la tarea, no obstante ambos grupos seleccionaron primero el significado más frecuente de la palabra. Contrariamente a lo esperado, la selección de palabras con dos significados no mejora según aumenta la edad. Finalmente, los investigadores verificaron la fuerte correlación entre conocimiento de vocabulario y comprensión lectora tanto en estudiantes sordos como oyentes.

En un trabajo llevado a cabo en España por Mies (1992) con 22 estudiantes sordos profundos entre 12 y 17 años, sobre el léxico escrito en la comprensión lectora, la autora analizó agrupamientos de palabras con un mismo origen morfológico. Entre sus observaciones destacan, en primer lugar, errores de inserción de la palabra en un grupo que no corresponde, con una marcada fijación en la primera sílaba. Por ejemplo: si la palabra propuesta es insectos, el sujeto considera que puede agruparla junto con insecticida, innecesario, inefectivo. En segundo lugar, errores al crear un grupo diferente de los propuestos. Por ejemplo: si la palabra presentada es campiña, el sujeto atribuye el mismo lexema a campesina y campesino, pero forma un grupo aparte con campo y acampar que no considera que forman parte del grupo inicial. En tercer lugar, errores por omisión de palabras que no considera pertenecientes a ningún grupo. Por ejemplo: el sujeto agrupa la palabra especie junto con especialidad y especialista, pero considera que la palabra especialización no forma parte ni de este grupo ni de ninguno de los propuestos. La autora señala que en este estudio se observó una relación directa entre la familiaridad en el reconocimiento de la palabra y la ejecución correcta de la tarea. 
Mies $(1992,204)$ señala que "una situación frecuentemente observada entre los estudiantes de su estudio es la utilización de la acepción de una palabra determinada en un contexto en donde es evidente que hay que elegir otra acepción semántica". También observa confusiones de palabras similares que nada tienen que ver con el contexto. Agrega que dichas dificultades contribuyen a hacer más difícil el acceso al significado de las palabras y en definitiva a la comprensión global del texto. La autora aclara que los sordos suelen fijarse en las palabras que les son familiares, independientemente de su relevancia dentro del texto, que actúan con superficialidad y que son poco reflexivos al adjudicar significado a las palabras. En la mayoría de las ocasiones no se plantean, si la interpretación de una palabra es la adecuada al contexto en el que se inserta, sino que lo hacen en función del significado más cotidiano o del único que conocen. Concluye que los alumnos sordos obtienen resultados claramente inferiores a los oyentes en dimensiones como el conocimiento de vocabulario y metacognición léxica, dado el desfase existente en su competencia lingüística. Expresa que existe algún tipo de relación entre el éxito en la captación de la imagen gráfica de la palabra y la capacidad de saber establecer la asociación de afinidades entre la morfología.

En un estudio con alumnos de enseñanza secundaria, Flexer, Wray, Millin, Leavitt (1993) comprobaron que el $75 \%$ de los estudiantes sordos muestra un vocabulario retrasado en más de siete años respecto de sus pares oyentes. También demostraron que los estudiantes con pérdida auditiva usan más sustantivos y verbos que adverbios y conjunciones, y que sus producciones escritas reflejan un estilo directo y carente de expresiones imaginativas o idiomáticas.

Recientemente en Chile, Herrera (2003) llevó a cabo un estudio sobre habilidad lectora y conocimiento léxico en LSCh. Uno de los objetivos de la investigación fue evaluar la relación entre léxico signado y habilidad en tareas de lectura. Para ello se seleccionó una muestra de 30 estudiantes sordos entre 7 y 17 años competentes en LSCh. Se elaboró una prueba de vocabulario para conocer el nivel de competencia en lenguaje de signos. Los resultados del estudio revelan que la habilidad en LSCh correlaciona significativamente con la habilidad en lectura. Los lectores sordos que utilizan la LSCh como primera lengua, y poseen buenos niveles en ella, utilizan códigos dactílicos, signados, ortográficos y articulatorios (todos ellos de base visual) para extraer información lingüística del texto escrito. Se concluye que la habilidad léxica (signada) contribuye significativamente al éxito lector de los estudiantes sordos.

(Foster, 1990 y Valle, 1991, citado en Torres et al., 1995), sostienen que la ruta fonológica de acceso al léxico desempeña un papel de apoyo fundamental en la lectura cuando la ruta visual resulta insuficiente. Esta estrategia de apoyo desempeña un papel relevante en los procesos post-léxicos de comprensión de oraciones, al permitir el doble acceso, primero visual y luego fonológico, al material lingüístico, facilitando de esta manera la tarea lectora.

Los sujetos sordos no disponen, al menos de entrada, de la ruta fonológica de acceso al significado de las palabras y que, por tanto, van a depender de manera crítica de la ruta visual. La ruta visual no es la más eficiente, pero es la única de la que disponen, al menos inicialmente. Los niños sordos al carecer de los mediadores 
fonológicos adecuados no acceden de manera natural, a través del mismo aprendizaje normal que los niños oyentes, a la lectura.

Un sujeto sordo, aunque nunca pueda oír, puede adquirir el uso de la vía fonológica. A primera vista parece contradictorio, pues parecería que puede oír, pero podría utilizar la ruta visual o la vía articulatoria.

"Instruir a los niños sordos en las propiedades fonológicas de las palabras mediante la vía articulatoria consiste en enseñarles a pronunciar las palabras. Ellos nunca se oirán a sí mismos cuando pronuncien dichas palabras, pero, gracias a la adecuada instrucción, sabrán qué hay que hacer para pronunciarlas correctamente". (Quilis y Hernández, 1990, citados en Torres et al., 1995).

Instruir a los niños sordos en las propiedades fonológicas mediante la vía visual, consiste en enseñarles, mediante la modalidad comunicativa adecuada, a segmentar las palabras en unidades fonemáticas. El sistema que en ese momento parece mas prometedor es la Palabra Complementada, que apoya mediante los complementos manuales mediante complementos manuales la pronunciación, marca o destaca las unidades fonemáticas y facilita el desarrollo de la consciencia lingüística de los niños sordos. Se entiende así que Alegría y Cols (citados en Torres et al., 1995), sostienen que este conocimiento es el que creará la consciencia fonológica de los niños sordos y, por lo tanto, facilitará su acceso a la lectura.

Hasta hace pocos años, la mayoría de los estudios evaluaba exclusivamente el léxico oral de los estudiantes sordos, dejando de lado el lenguaje de signos por ser considerado una escasa colección de gestos y pantomimas, sin estructura propia ni mucho menos con una organización interna. Sin embargo, hoy sabemos que los lenguajes de signos son formas de comunicación manual, que dependen fundamentalmente del canal visual para percibir la información lingüística, y son utilizados por las distintas comunidades de sordos en el mundo como su principal medio de comunicación. Por ello, hoy en día poco a poco surgen investigaciones que incorporan el conocimiento del léxico en lenguaje de signos como un elemento de análisis de las habilidades lingüísticas de los sordos. Conocer el nivel léxico (hablado y signado) de una persona sorda implica tener una visión global de sus destrezas lingüísticas, comunicativas y cognitivas, y con ello la posibilidad de desarrollar su potencial académico y social.

La mayoría de los autores concuerda en señalar que la pobreza de vocabulario en los sordos se relaciona con el grado de pérdida auditiva y se correlaciona con las habilidades de lectura. Los investigadores explican que los problemas de lectura de los sordos pueden ser producto del desconocimiento del significado de las palabras que aparecen en el texto escrito, que estos lectores se fijan más en las palabras familiares y usan más sustantivos concretos y verbos familiares que palabras abstractas. Asimismo, ya que su vocabulario es limitado presentan pobres expresiones escritas. Los autores concluyen que el conocimiento de vocabulario es un indicador de las habilidades en lectura, que la falta de vocabulario no puede ser compensada ni sintáctica ni semánticamente, que el desempeño de los sordos es mejor con palabras con un solo significado y, finalmente, que los sordos que poseen un lenguaje fluido y natural desde el nacimiento obtienen mejores resultados en las 
pruebas de conocimiento de vocabulario que los sordos que no tienen un lenguaje consolidado.

\subsubsection{Léxico fonológico}

Este proceso de remodificación fonológica está directamente ligado a la existencia de una entrada fonológica en el léxico interno del lector. En el caso de los oyentes, este proceso está garantizado por el hecho de que conocen de forma oral la mayor parte de las palabras que se encuentran al leer, con lo cual pueden "reconvertir oralmente" las palabras escritas mediante la aplicación de reglas de transformación grafema-fonema. En el caso de los sordos profundos la situación es diferente, ya que, el acceso fonológico a su léxico interno podría estar dificultado a causa de su déficit auditivo (Domínguez y Alonso, 2003, citado en Acosta, 2006).

En la revisión de la literatura existente en torno al análisis de los conocimientos fonológicos por partes de los niños sordos, muestran empíricamente que los niños sordos profundos que muestran mejores habilidades lectoras son aquellos que tienen mayores niveles de conocimiento fonológico (Bebko, 1998; Hanson, 1989; Harris y Beech, 1998; Kelly, 1996;; Leybaert y Alegría, 1995,; Leybaert y Charlier, 1996; Lichtenstein, 1998). Por otra parte, el conocimiento fonológico en los niños sordos correlaciona con el grado de inteligibilidad del habla (Harris y Beech, 1998; Leybaert y Alegría, 1995; citados en García, 2007) y con la lectura (Rodríguez, Domínguez y Alonso, 2003; citados en García, 2007).

Estos estudios indican que el conocimiento fonológico en los sordos, al igual que en los oyentes, se desarrolla en tres niveles: sílaba, rima y fonema. En España algunos trabajos (Asensio, 1989; Augusto, 2000; Rodríguez et al., 2003; citados en García, 2007) demuestran que los niños sordos son capaces de hacer explícitos ciertos aspectos de la estructura de la lengua oral (sílaba y/o fonema); sin embargo, a diferencia de lo encontrado con niños oyentes (Domínguez, 1996; citado en García, 2007), los niños sordos operan mejor con fonemas que con sílabas. Los resultados también indicaron las dificultades que tenían los alumnos sordos para realizar tareas metafonológicas, así como los bajos niveles de conocimiento fonológico con los que comienzan el aprendizaje del lenguaje escrito, como ponen de manifiesto Harris y Beech (1998; citados en García, 2007).

Este déficit puede provocar que el proceso de recodificación fonológica no se desarrolle por el simple hecho de que las representaciones que son capaces de elaborar (es decir, los códigos fonológicos correspondientes a las palabras escritas) son de poca utilidad, si es que no son totalmente inútiles. Es decir, si las representaciones fonológicas son entendidas como secuencias de unidades abstractas construidas en base a la información acústica, será difícil argumentar que los sordos puedan desarrollar representaciones fonológicas cuando no exista esa información auditiva.

Sin embargo, los trabajos de Dodd (1987, citado en Silvestre et al., 1998) fueron los primeros que cuestionaron teóricamente el punto de vista según el cual la información acústica es condición necesaria para el desarrollo de representaciones 
fonológica, proponiendo que la lectura labial, puede proporcionar a los niños sordos, con pérdidas auditivas profundas y prelocutivas, información sobre la estructura fonológica del lenguaje hablado. Esta hipótesis fue elaborada en el marco de una serie de trabajos realizados en la década de los 70 (Alegría, 1999; Dodd, Macintosh y Woodhouse, 1998, citados en Acosta, 2006) que mostraron la influencia de la percepción visual sobre la percepción acústica del habla en personas oyentes o, mejor dicho, la interacción entre la información acústica y visual en el procesamiento del habla, de tal manera que la información visual que acompaña a la producción forma parte del proceso de percepción del habla.

La Lectura Labial (LL) facilita la comprensión de la palabra presentada en malas condiciones de escucha: ruido, personas de edad avanzada, idioma o acento poco habitual, pero también en el caso de un mensaje complejo en el plano semántico.

Por lo tanto, la información visual que acompaña a la producción contribuye a la formación de representaciones fonológicas en las personas oyentes o, dicho de otra forma, las representaciones fonológicas son entidades abstractas construidas por informaciones sensoriales de origen diverso: auditivo, visual y kinestésico. Este hecho es esencial para comprensión del desarrollo de las representaciones fonológicas en los niños sordos profundos, debido a que en su caso la LL puede ser la fuente principal de información fonológica.

Sin embargo, las informaciones fonológicas proporcionadas por la $L L$ en ausencia de información auditiva, son insuficientes, ya que, resultan ambiguas (así, que, un niño sordo no podrá distinguir entre pares de palabras como "papa-mama" o "barcomarco", porque su imagen labial es similar; además, hay un conjunto de sonidos, como la /g/, que no se ven a través de la LL). Con lo cual, "las representaciones fonológicas elaboradas únicamente sobre la base de la LL no dan acceso al léxico interno de los sordos de una forma particular, ya que pueden activar varias palabras." (Ewoldt, 1981, 59).

Esta situación ha llevado a que se hayan desarrollado sistemas de ayudas a la LL que supriman las ambigüedades intrínsecas a ésta, al "visualizar" los fonemas no visibles. Dentro de estos sistemas complementarios, uno de los más difundidos es la Palabra Complementada, creada por Cornett (1967, citado en Alegría, 1999) y ya citada en este trabajo. De esta manera, la PC, permite la percepción del habla de forma completa y sin ambigüedades, de tal forma que cuando se emplea de forma sistemática en la educación de los alumnos sordos, éstos consiguen desarrollar representaciones fonológicas más completas y exactas (Charlier, 1994; Leybaert, 1993; Leybaert y Charlier, 1996; Leybaert y Alegría, 2002; Santana y Torres, 2000), por lo que estos alumnos sordos podrían "emplearlas al realizar tareas metafonológicas" (Harris y Beech, 1998) y en "tareas de lectura y escritura" (Alegría, 1999, 60).

Existe un amplio consenso en que el reconocimiento de las palabras impresas descansa en dos estrategias (Coltheart, 1978; 1980; Dodd, 1980; Jorm \& Share, 1983; Morton \& Patterson, 1980, citados en Gaines, Mandler, Bryant, 1981). Una de las estrategias es conocida con el nombre de "ruta directa o léxica", en la cual la palabra es identificada de forma instantánea, emparejando la palabra escrita con su representación ortográfica almacenada en el léxico, sin necesidad de ningún 
proceso intermedio de análisis o de síntesis. Por el contrario, en la otra estrategia, la "ruta indirecta, fonológica o subléxica", lo que emparejamos con la representación interna no es la palabra escrita, sino la conversión "oral" que hacemos de esa palabra; es decir, analizamos la palabra en segmentos y les asignamos un valor fonológico (y no un significado como en la ruta "directa") mediante la aplicación de las reglas de conversión grafema- fonema. La forma fonológica así creada es utilizada posteriormente para acceder al léxico y, con ello, a toda la información que poseemos de la palabra.

Es posible que los lectores de lenguas transparentes elijan con preferencia o en exclusividad la ruta fonológica, mientras que los lectores de lenguas opacas elijan la ruta léxica. Una versión extrema propone que en las lenguas transparentes no es necesario utilizar la vía léxica (Turvey, Felman y Lukatela, 1984, citado en Lichtenstein, 1998).

La transparencia de la ortografía en español y la simplicidad de las reglas grafemafonema invitan a pensar que el acceso al significado de las palabras escritas se hace siempre a través de la vía fonológica. Dadas las posibilidades explicativas del modelo de doble ruta, pensamos que su aplicabilidad al problema de los sordos merece cierta reflexión.

Las dificultades de los sordos con la lectura llevan a plantear cómo se produce el primer contacto con las palabras; o sea, cómo los sordos acceden a ese eslabón primordial del proceso lector. Algunos autores que han profundizado en el tema (Alegría y Leybaert, 1985; Ewoldt, 1981, citados en Mies, 1992) observan que las personas sordas determinan el significado de una palabra conocida a partir de señales gráficas (longitud, forma global, letra de inicio final). Se supone que, ante las dificultades de acceso a una representación fonológica, el alumno sordo tiende a utilizar con mayor asiduidad la vía léxica, realizando una lectura de tipo logográfico, con los errores que ello puede comportar. La preferencia de la vía léxica no significa que los sordos no utilicen en absoluto la vía subléxica o fonológica.

La utilización de los códigos fonológicos para los sordos plantea varios inconvenientes:

1. El insuficiente dominio del sistema fonológico de la lengua oral y el escaso conocimiento del vocabulario pueden provocar representaciones internas escasas o incompletas.

2. El acceso fonológico a su léxico interno podría estar dificultado a causa de la pérdida auditiva.

3. La gran diversidad de sistemas de comunicación (dactilología, lengua de signos, bimodal, etc.) podrían conducir a otras estrategias de lectura.

Estos inconvenientes nos llevan a dos posibles salidas: renunciar a la fonología como mecanismo de lectura (Heiling, 1994; Svartholm, 1998, citados en Mies, 1992) o buscar otros mecanismos diferentes de acceso a las representaciones fonológicas, como ocurre en las experiencias bilingües. 


\subsubsection{Procesamiento Sintáctico}

Así como las habilidades léxicas son la base para la comprensión del lenguaje, las habilidades sintácticas son un aspecto básico de la comunicación, ya que las palabras aisladas no transmiten información por sí mismas. La estructura sintáctica representa la forma en que los sujetos organizan su lenguaje, el mensaje se comprende a través de las relaciones que se establecen entre las palabras.

Mies (1992, 208) comenta que "el desarrollo sintáctico involucra morfología y sintaxis". Señala que cuando los niños aprenden las formas del lenguaje están descubriendo implícitamente las reglas que las gobiernan. De este modo, los morfemas (la unidad más pequeña de significado de las formas gramaticales) se combinan en las palabras (morfología) y éstas en oraciones (sintaxis).

La capacidad para integrar información a través de unidades lingüísticas es clave para el procesamiento de la información a nivel oracional e intraoracional. En este sentido, el dominio de las estructuras sintácticas resulta fundamental para establecer relaciones que organicen y den sentido al lenguaje. No obstante, el conocimiento sintáctico es uno de los aspectos en que los sordos presentan mayores dificultades. Por ello, la sintaxis se ha convertido en una de las variables más investigadas en el campo de la sordera. Al respecto, Paul y Gustafson $(1991,159)$ plantea que "para los sordos, y posiblemente para los aprendices de una segunda lengua, el conocimiento sintáctico es un buen indicador de la habilidad lectora, porque requiere la destreza para integrar información a través de unidades lingüísticas como palabras, frases y oraciones".

Una de las primeras investigaciones sobre habilidad sintáctica y producción escrita en niños sordos fue realizada por Cooper y Rosenstein (1966, citados en Rodríguez, García, Torres, 1997). Ellos subrayan que el lenguaje escrito de los sordos, comparado con el de los oyentes, presenta diferencias en la distribución de las partes de la oración, contiene estructuras más cortas, simples, rígidas y estereotipadas, además de numerosos errores sintácticos. No obstante, este primer estudio se basó principalmente en la sintaxis del lenguaje oral, dejando de lado las características particulares de las estructuras sintácticas propias de la población sorda.

Con posterioridad Quigley, Wilbur y Montanelli (1976, citados en Nolen, Wilbur, 1985), realizaron uno de los estudios más importantes respecto de las habilidades sintácticas de los sordos, ya que elaboraron una prueba para evaluar específicamente dichas habilidades: el Test of Sintactic Abilities. Examinaron la comprensión de las principales estructuras sintácticas del inglés escrito en sordos de entre 6 y 19 años. Esta prueba estudiaba las principales estructuras sintácticas del inglés, como la negación, la conjunción, la disyunción, la alternación, la formulación de preguntas, los procesos verbales, la pronominalización, la relativización, la complementación y los infinitivos.

Los autores descubrieron que mientras los estudiantes oyentes responden correctamente entre $78 \%$ y $98 \%$ de las 21 estructuras específicas examinadas, los estudiantes sordos responden en forma correcta entre $36 \%$ y $79 \%$ de las 
estructuras. Además, determinan que las habilidades sintácticas del promedio de los sordos de 18 años, son más bajas que el promedio de las habilidades sintácticas de los oyentes de 8 años. En este contexto destacan que la brecha más importante se observa en las tareas relacionadas con la formulación de preguntas, la complementación, la pronominalización, la disyunción y la alternación.

En cambio, observaron un desempeño semejante entre sordos y oyentes en construcciones relativamente simples como oraciones activas, afirmativas, negativas y uso de conjunciones. Los autores concluyen que el patrón de errores de los sordos es similar al de los oyentes, por tanto, ambos grupos comparten estrategias sintácticas, aunque no la misma habilidad para usarlas.

Con el propósito de profundizar los hallazgos realizados hasta aquel momento, Brasel y Quigley (1977, citados por Marschark 1993) realizaron un estudio en el que analizan el desarrollo de las habilidades sintácticas en estudiantes sordos profundos entre 10 y 18 años, divididos en grupos por edad, estatus de audición de los padres y experiencia lingüística inicial. Uno de los grupos se constituyó con niños cuyos padres sordos tenían buenas habilidades en inglés y se comunicaban con sus hijos a través del inglés signado. Un segundo grupo incluía niños sordos con padres sordos menos competentes en inglés que usaban principalmente lenguaje de signos en sus hogares.

El tercer grupo incluía niños que recibían instrucción exclusiva en lenguaje oral y cuyos padres oyentes habían recibido instrucción en el uso de metodologías orales. Un cuarto grupo incluía niños que recibían instrucción oral en el colegio, pero cuyos padres oyentes no tenían instrucción en las metodologías orales empleadas en el establecimiento escolar. La muestra la constituían 24 niños por grupo. Las pruebas utilizadas por los autores fueron el Test of Sintactic Abilities y el Stanford Achievement Test. Los autores descubrieron que el grupo que utiliza el inglés signado presenta el mejor nivel de competencia sintáctica y que los dos grupos manuales (inglés signado y lenguaje de signos) superan a los dos grupos orales en ambas pruebas.

Para Marschark (1993, 32), los resultados de Brasel y Quigley (1977) indican que "una combinación de lenguaje de signos y entrenamiento en lenguaje oral es el medio lingüístico más adecuado para que los niños sordos aprendan a leer, al menos respecto a la adquisición de las habilidades sintácticas y la comprensión escrita". Marschark señala que, aunque es cierto que los dos grupos de niños con padres sordos colectivamente rinden mejor que los dos grupos con padres oyentes, los niños que reciben entrenamiento oral tanto en el colegio como en sus casas presentan habilidades sintácticas comparables a sus pares con padres sordos expuestos a lengua de signos desde el nacimiento. El autor añade que los factores que más benefician el desarrollo de las habilidades sintácticas son la exposición a la sintaxis y la adquisición de un vocabulario extenso.

Con la finalidad de averiguar si la competencia en estructuras sintácticas de los lectores sordos era igual, retrasada o diferente a la de los lectores oyentes, Volterra y Osella (1988, citados por Silvestre et al., 1998) realizaron un estudio con 50 sordos entre 9 y 16 años, y 100 oyentes entre 6 y 11 años, con un nivel lector semejante. Entre los resultados obtenidos destacan que ambos grupos demostraron el mismo 
número de faltas en el uso de artículos, pero de distinto tipo. Por el contrario, en las tareas de utilización de plurales el desempeño de ambos grupos fue similar. Los autores concluyeron que el conocimiento de las dimensiones morfológicas en el estudiante sordo se estanca en algunos aspectos en un momento determinado del proceso de aprendizaje y en otros aspectos adquiere características especiales.

En un estudio realizado en lengua española, Rodríguez, García y Torres (1997) toman como hipótesis la posibilidad de que los problemas de lectura de los sordos no se encuentren en el nivel sintáctico, por lo que éstos serían capaces de aplicar las estrategias sintácticas. Para llevar a cabo la investigación, los autores seleccionaron una muestra de 16 jóvenes sordos profundos prelocutivos entre 15 y 25 años que habían estado expuestos a sistemas de comunicación combinados y un grupo control constituido por 18 jóvenes oyentes entre 15 y 21 años. Los investigadores concluyeron que los sordos resuelven las ambigüedades estructurales en oraciones primarias de la misma forma que los oyentes. Sin embargo, los sordos ante oraciones no-primarias no usan el principio estructural, según el cual se establecen diferencias en el procesamiento en función del tipo de estructura sintáctica que tenga la oración a analizar. Dicho principio implica el aprovechamiento de la información temática y la estructural en la comprensión del marco sintagmático de la oración.

Los autores sostienen que el procesamiento de oraciones no-primarias parece ser cognitivamente más complejo, dados la longitud de las frases y los distintos tipos de información implicada. Igualmente, puesto que los sordos desconocen un mayor número de palabras, presentan más problemas para aplicar principios temáticos, debido al desconocimiento de las propiedades temáticas de algunas palabras.

Rodríguez, García y Torres $(1997,125)$ consideran que "es posible que los jóvenes sordos ante oraciones no-primarias más demandantes de recursos, ya que necesitan disponer tanto de información temática como sintáctica, vean sobrecargada su capacidad de procesamiento, no dispongan de los recursos suficientes y no logren poner en práctica las estrategias sintácticas o temáticas". La conclusión más relevante de esta investigación indica que los sordos son capaces de resolver la ambigüedad sintáctica en oraciones primarias. En cambio, frente a oraciones no-primarias no demuestran el mismo patrón que los oyentes. El hecho de que los sordos dominen las reglas en las oraciones primarias, y no las correspondientes a las estructuras no-primarias, se origina posiblemente por las diferencias existentes entre ambas estructuras y las distintas exigencias que éstas imponen, ya que no sólo la complejidad cognitiva que subyace a ambas estructuras es diferente, sino que, además varía en función del tipo de conocimientos que exige para la resolución de las ambigüedades. Por último, cabe destacar que la población sorda tiene un dominio aceptable de las habilidades sintácticas que permiten la construcción de estructuras sintácticas básicas en oraciones primarias.

Más recientemente, Lichtenstein (1998) consideró necesario investigar de manera integrada las relaciones de las habilidades sintácticas de los sordos y la memoria a corto plazo. Para ello seleccionó una muestra conformada por 86 estudiantes sordos con una media de edad de 20 años. Al realizar el análisis de los errores de escritura, observó que los estudiantes omitían las preposiciones, los artículos, los pronombres, las conjunciones, las cópulas, los auxiliares, los modales y los infinitivos, siendo los 
errores de tipo sintáctico los más relevantes dentro de las medidas evaluadas. El autor concluye que la habilidad para atender a las relaciones estructurales entre palabras podría depender de la habilidad para considerar y procesar una cierta cantidad de material en un tiempo determinado.

Este nuevo hallazgo respecto de las habilidades sintácticas de la población sorda proporciona más datos para comprender el problema. Si como señalan las investigaciones antes expuestas, los estudiantes sordos son capaces de analizar y procesar oraciones simples o primarias de la misma forma que sus pares oyentes y que los problemas aparecen al enfrentarse con estructuras más complejas, entonces la habilidad sintáctica podría depender de la capacidad para procesar el material lingüístico en la memoria a corto plazo.

"El conocimiento sintáctico es un indicador de la habilidad lectora" (Jiménez y Artiles, 1989, 14). Las oraciones que las personas sordas comprenden son más cortas y simples en su estructura sintáctica que las de los oyentes. Son más rígidas, con más errores sintácticos, presentan problemas con las oraciones pasivas, en las cláusulas relativas, el objeto indirecto, en la formulación de preguntas, la complementación, la pronominalización, la disyunción y la alternación. No obstante, los lectores sordos presentan pocas dificultades con las oraciones primarias activas, afirmativas, negativas y en el uso de conjunciones.

Es posible señalar que los sordos muestran mayor eficiencia en las oraciones primarias, pero presentan problemas con las oraciones complejas. La observación de este fenómeno ha llevado a proponer que los sordos desarrollan estructuras sintácticas, pero dichas estructuras no evolucionan a un nivel de mayor complejidad.

Los datos indican que los lectores sordos presentan un retraso, de 10 años aproximadamente, respecto de los oyentes, en el uso de habilidades sintácticas. Cabe destacar que uno de los principales factores de un buen nivel sintáctico en los estudiantes sordos es la exposición al lenguaje (oral o manual) desde el nacimiento y una combinación de lenguaje de signos y destrezas en el lenguaje oral como método educativo.

\subsubsection{Procesamiento semántico}

Otro aspecto incorporado al estudio de la competencia lingüística son las habilidades semánticas y pragmáticas del lenguaje. Este énfasis en la pragmática ha centrado la atención de los investigadores en unidades mayores del lenguaje como el discurso, más que en las palabras y las oraciones.

Un aspecto importante del discurso es el análisis de la comprensión global de la estructura del texto, como la estructura de la gramática de las historias. Algunos estudios han demostrado que los estudiantes sordos parecen comprender la estructura sintáctica más fácilmente, si está conectada a un discurso, que en oraciones simples y que en algunos casos la comprensión de una estructura particular no es necesaria para la comprensión de una unidad mayor del discurso. 
En este sentido, McGill-Franzen y Gormley (1980) estudiaron la comprensión de estudiantes sordos de oraciones pasivas presentadas en contexto o en forma aislada. Los resultados muestran que los niños que no pueden comprender una oración pasiva en forma aislada pueden comprenderla, si ésta es presentada en el contexto de un cuento claramente familiar. Sin embargo, esta investigación ha sido objeto de muchas críticas, sobresaliendo la realizada por Paul y Gustafson (1991, 60 ), quien postula que "al usar materiales de lectura altamente familiares los estudiantes sordos no prestan atención a los detalles de la historia e incluso pueden haber sido capaces de responder a las preguntas sobre la historia, sin leerla, o sin entender el lenguaje en el que ésta ha sido escrita".

Por otra parte, Ewoldt (1981) dirigió un análisis intensivo de la lectura de 4 niños sordos entre 6 y 16 años. Los niños debían leer e interpretar 25 historias en lenguaje de signos presentadas en video. La autora concluyó que los niños sordos poseen habilidades lingüísticas y son capaces de leer y recordar las historias escritas e interpretarlas dentro de su propio lenguaje de signos. Ewoldt opina que los sordos emplean ampliamente el sistema sintáctico y semántico, pero no confían demasiado en la información gráfica. Esto sugiere que los lectores sordos, al igual que los lectores novatos y malos lectores, utilizan principalmente estrategias de lectura descendentes que les llevan a quedarse con una idea general del texto. Respecto del contexto, Ewoldt señala que estos lectores pueden desviar la sintaxis e ir directamente al significado y que la comprensión de estructuras particulares no es imprescindible para comprender el discurso.

En la misma línea de investigación Gaines, Mandler y Bryant (1981) estudian el análisis del discurso en la lectura de estudiantes sordos. Para ello compararon el recuerdo inmediato y diferido de historias. Para este estudio se seleccionó una muestra de 12 niños entre 11 y 15 años, 6 de ellos eran sordos provenientes de escuelas oralistas y 6 eran niños oyentes. Ambos grupos fueron igualados en edad lectora a través del Gates vocabulary test. El procedimiento utilizado se basó en la aplicación de tres "Historias de Mandler" del año 1978.

La primera de ellas era una prosa estándar, la segunda contenía faltas ortográficas y la tercera contenía referencias anafóricas confusas. Los resultados revelan que no existen diferencias entre sordos y oyentes en el recuerdo de la historia con prosa normal; sin embargo, los lectores sordos muestran mayores problemas al recordar la historia con faltas ortográficas y la historia con referencias anafóricas confusas. Los recuerdos de los 6 niños sordos presentan más distorsiones que los recuerdos de sus pares oyentes.

La mayoría de las confusiones de los sordos se debieron a distorsiones semánticas. Los autores concluyen que los sordos utilizan procesos descendentes que les facilitan comprender el significado global de las historias y una cantidad similar de partes de la historia que los oyentes. Sin embargo, el uso exclusivo de estrategias descendentes podría llevar a una falta de comprensión o incluso a pasar por alto detalle importante. Como hemos señalado, esta estrategia es utilizada con frecuencia por los lectores novatos y los malos lectores.

Para profundizar acerca del efecto del contexto en la comprensión de oraciones relativas por parte de los estudiantes sordos, Nolen y Wilbur (1985) realizaron un 
estudio con 50 niños sordos de segundo a sexto grado con una pérdida auditiva superior a $80 \mathrm{~dB}$. En sus resultados las investigadoras señalaron que el efecto del contexto en la comprensión de oraciones relativas es altamente beneficioso para todos los niños, en todos los niveles de lectura. Suponen que los niños sordos, al igual que los oyentes, procuran conectar activamente las ideas de forma significativa mientras leen. Los resultados de este estudio apoyan la teoría de que los niños sordos pueden hacer uso de la información contextual para quitar ambigüedad a aquellas estructuras oracionales difíciles. Las autoras sugieren incorporar estructuras sintácticas nuevas y más complejas utilizando y aprovechando el efecto positivo del contexto en la comprensión del discurso escrito.

Durante los últimos años ha habido una tendencia no sólo a reconocer el papel de la codificación fonológica en la lectura sino a otorgarle un papel principal y no sólo como una posibilidad una vez que se ha accedido a la forma de la palabra en el léxico sino como mediadora del acceso al léxico. La evidencia experimental sugiere que las representaciones fonológicas pueden mediar el acceso al significado en la comprensión lectora. La mediación fonológica se describe como un proceso en el que la representación fonológica de una palabra se deriva de su forma impresa, y ésta actúa entonces como un mecanismo de acceso al léxico fonológico que a su vez da entrada al sistema semántico.

Las investigaciones nos llevan a reflexionar que la comprensión de estructuras sintácticas sencillas, por parte de los lectores sordos, resulta más fácil si están conectadas a un discurso. Las oraciones activas en contexto son más fáciles de comprender que las oraciones presentadas en forma aislada. La introducción de estructuras nuevas resulta más simple y beneficiosa, si se utiliza el contexto. Debemos, por tanto, hacer tenacidad en que el contexto es muy relevante para la construcción del significado por parte de cualquier lector, sea sordo u oyente.

Conviene subrayar que el desarrollo del lenguaje del niño con una deficiencia auditiva severa o profunda no se producirá espontáneamente sino que necesitará de unos apoyos técnicos y logopédicos para conseguirlo.

El ritmo fonológico presenta alteraciones con duraciones alargadas y perturbación de la intensidad. La falta de retroalimentación auditiva hace que se altere la articulación de determinados fonemas.

Por lo que se refiere a la adquisión del vocabulario, Pintner y Patterson (1916, citados en Villalba, 2005) estudiaron longitudinalmente el desarrollo el desarrollo lingüístico de 8 niños con sordera severa y profunda desde los 15 meses hasta los 4 años, comparándolos con el desarrollo lingüístico de niños sin ningún tipo de pérdida auditiva.

Observaron que mientras los niños oyentes normales tardan aproximadamente un mes en pasar de una palabra a diez palabras, y en otro mes adquieren unas 50 palabras, continuando así un ritmo de crecimiento que sigue una progresión geométrica, en cambio, los niños sordos necesitan diez meses para pasar de una a diez palabras y luego adquieren aproximadamente diez palabras cada mes. 
La combinación de dos o más palabras suele ocurrir, tanto en niños sordos como en niños oyentes, cuando el repertorio de su vocabulario ha alcanzado aproximadamente 50 términos. Según los autores antes citados, este hecho suele ocurrir hacia los 18 meses en los niños oyentes y en torno a los 30 meses en los niños sordos.

Conrad (1979, citado en Villalba, 2005) estudió la comprensión lectora de 202 sujetos de 15 años sordos profundos que habían sido educados desde temprana edad en un centro para sordos y encontró que en más del $50 \%$ el nivel de comprensión lectora era menor del correspondiente a los sujetos normo-oyentes de 8 años. Sólo un 2,5\% poseía un nivel de lectura correspondiente a su edad. Este mismo autor encontró una correlación negativa entre el nivel lector y el grado de pérdida auditiva, y una correlación positiva entre el nivel lector y el nivel de inteligencia general de los sujetos.

Cuando se orientó a comprobar el efecto del aprendizaje temprano del lenguaje de signos sobre el desarrollo intelectual, ya que los estudios anteriores olvidaban esta posible influencia, encontró que las puntuaciones en Raven de los niños sordos con padres sordos eran significativamente superiores a las de los niños con sordera hereditaria pero padres oyentes, lo que le condujo a sugerir que los niños no aprenden el lenguaje de los signos porque son particularmente inteligentes sino que son más inteligentes porque han aprendido un lenguaje más pronto.

Posiblemente la investigación de Conrad (1979, citado en Furth, 1981) es muy completa dentro del campo de las diferencias individuales entre los sordos. Su principal objetivo es valorar el papel del habla interna en la ejecución cognitiva de los niños sordos; clarificar no solamente si los niños sordos pueden utilizar el habla interna, sino cuántos niños y en qué condiciones y situaciones son capaces de hacerlo; determinar qué distingue a los niños sordos que aprenden a utilizar el habla interna de aquellos que no lo aprenden, tanto en términos de los requisitos previos como de los posibles beneficios. Tres variables son controladas: el grado de pérdida auditiva, la causa de la sordera y la inteligencia. Los datos obtenidos constatan que la utilización del habla interna está asociada con el grado de pérdida auditiva y las puntuaciones en la prueba de inteligencia. Sus condiciones le permiten elaborar un modelo teórico sobre la comunicación de los niños sordos y plantear la educación bilingüe (manual y oral) como la más adecuada para el desarrollo cognitivo y lingüístico de los niños sordos profundos.

Asensio (1989, citado en Villalba, 2005) exploró en España a 106 estudiantes sordos de 7 a 14 años, y los comparó con 157 escolares normo-oyentes de 7 a 11 años de nivel socioeconómico bajo. Su estudio puso de relieve las siguientes evidencias:

- Los niveles de comprensión lectora de los sordos españoles son semejantes a los reflejados en los estudios realizados en otros países.

- Los alumnos sordos de 14 años no superaban como media el nivel de comprensión lectora obtenido por los oyentes de 9 años.

- Mientras los oyentes progresan significativamente de un curso a otro, los sordos lo hacen mayor lentitud. La lectura mecánica de los sordos, por 
ejemplo, progresaba a un ritmo de 0,28 cursos por año, de tal modo que en siete años de instrucción lectora, los escolares sordos conseguían una lectura mecánica semejante a la que adquieren los oyentes en dos.

Con todos estos resultados se comprende que los alumnos sordos poseen mayor dificultad en la comprensión lectora que los oyentes, siendo necesario una atención progresiva y continua de actividades, para que puedan alcanzar un mejor nivel lector y lingüístico.

\subsection{Reconocimiento de palabras y dificultad lectora}

Las personas que leen bien realizan de manera coordinada y bastante simultánea un conjunto de actividades muy complejas. Algunas de estas actividades están orientadas a reconocer y asignar un significado a los símbolos gráficos, es decir, a reconocer palabras. Este reconocimiento se lleva a cabo de forma global-visual y/o a través de la decodificación fonológica. Esta última parece jugar un papel particularmente importante.

Reconocer las palabras es una condición necesaria, pero no suficiente. Para leer bien se necesitan, además, otras condiciones relacionadas con el dominio de estrategias para comprender textos. Nos referimos a los procesos de creación y confirmación de hipótesis que el sujeto hace a partir del conocimiento previo que tiene sobre el lenguaje y sobre el mundo.

Las dificultades lectoras de los sordos se sitúan tanto en el nivel de reconocimiento de las palabras como en el nivel de la comprensión del texto. Estas dificultades se hallan relacionadas con variables muy diversas entre las que destacaremos:

- Escaso conocimiento general del mundo y pobreza lingüística para verbalizar sus experiencias, y conocimientos.

- Inadecuadas estrategias (procesos) lectoras.

- Escasa motivación hacia la comunicación escrita tanto en lo que se refiere a la lectura como a la escritura.

Los datos experimentales existentes indican que los buenos lectores sordos se parecen a los oyentes en cuanto que utilizan vías fonológicas para reconocer las palabras. Sabemos que la lectura labial, la Palabra Complementada y la dactilología configuran, asimismo, esa vía fonológica y que algunos buenos lectores sordos los utilizan como parte integrante de sus procesos lectores (ver Alegría, 1992, citado en Silvestre et al., 1998).

Sin embargo, uno de los mayores problemas que plantea la pérdida auditiva es un acceso correcto al lenguaje escrito y a la capacidad de alcanzar una competencia lectora adecuada y funcional. Los datos obtenidos por la mayoría de las investigaciones (Conrad, 1979; Quigliy y Paul, 1984, citados en Andrews y Mason, 
1991) constatan las dificultades que los niños sordos encuentran en el aprendizaje de la lectura y la escritura; los problemas que tienen para lograr un progreso lector adecuado; y, las dificultades para alcanzar unos niveles lectores funcionales (en nuestro país ver, P. Ej., los estudios de Asensio, 1989; Mies y Ramspott, 1996; Silvestre et al., 1998, 72). Por ello, hay que identificar cuál son los déficit y dificultades presentados por los niños en el aprendizaje escrito, lo que repercutirá cuándo adultos en su mejor competencia lingüística.

Los niveles lectores relativamente aceptables alcanzados por muchos alumnos hipoacúsicos y postlocutivos confirman la importancia del lenguaje oral en el aprendizaje de la lectura y la escritura. Los resultados de diversas investigaciones (Conrad, 1979; Jensema, 1975, citados en Herrera, 20) muestran; por un lado, que los niños que poseen una pérdida inferir a $85 \mathrm{~dB}$ muestran unos niveles lectores superiores a los que presentan una pérdida auditiva superior: $y$, por otro, que los niños cuya sordera se había producido después de los tres años poseían una comprensión lectora mejor. Estos hechos pueden ser debidos a que estos niños han podido alcanzar una mayor competencia lingüística general que les facilita el acceso al lenguaje escrito.

Si se avanza un poco más en este análisis se pueden señalar algunos aspectos concretos de la incompetencia lingüística general de las personas sordas que parecen ser responsables de sus dificultades en el aprendizaje de la lectura y la escritura. Por un lado, el reducido vocabulario con el que la mayoría de estos alumnos comienzan este aprendizaje, son las dificultades en el aprendizaje de la lectura y la escritura. Las dificultades en la comprensión de determinados términos (como palabras no familiares, vocabulario técnico), el significado unívoco que atribuyen a algunas palabras (p. Ej., cerca, banco, bar), o el desconocimiento de las palabras clave del contenido temático del texto, constituyen limitaciones importantes en su capacidad de comprensión del significado del texto escrito. Por otro lado, otra limitación en esta comprensión son los problemas que generalmente presentan en el conocimiento y dominio de las estructuras sintácticas del lenguaje oral, siendo mayores problemas a medida que la estructura sináptica se hace más compleja (lo cual ocurre en los libros de texto a partir del tercer año de escolaridad); además, los alumnos sordos no parecen hacer uso o hacen mal uso de una serie de claves gramaticales presentes en la oración (palabras funcionales, orden de las palabras).

Por estos aspectos se puede decir que las dificultades que tienen las personas sordas para comprender el lenguaje figurativo, las metáforas, expresiones idiomáticas y pseudopalabras..., que con frecuencia aparecen en el lenguaje oral y escrito. Así, el vocabulario reducido, los problemas en el dominio de las estructuras sintácticas y las dificultades de comprensión del lenguaje figurativo son algunos de los aspectos concretos de la incompetencia lingüística general de los niños sordos que limita su comprensión del material escrito.

Los resultados de diversas investigaciones y de experiencias educativas bilingües, donde se da la enseñanza de dos lenguas distintas (lengua de signos y lengua mayoritaria de la comunidad oyente), parecen poner de manifiesto que seguir un desarrollo lingüístico en lengua de signos desde edades muy tempranas sirve, en muchos casos, para que estos niños adquieran todo un conjunto de habilidades lingüísticas y metalingüísticas que puedan propiciar un mejor acceso al lenguaje 
escrito. De la misma manera, ese conjunto de habilidades favorecerá, si se opta por ello, el aprendizaje del lenguaje oral de la comunidad oyente a la que pertenecen. Esta hipótesis podría, entre otras, explicar por qué los niños sordos expuestos a la lengua de signos obtienen mejores resultados en las tareas de lectura y escritura que los niños sordos educados en un enfoque monolingüe, como han puesto de manifiesto diversos trabajos (ente ellos, Heiling, 1990, citado en Schirmer, 1994).

Además la lengua de signos facilita las experiencias previas con libros, historias, cuentos, etc., obtenidos principalmente a partir de las interacciones que se producen entre personas sordas y adultos (padres y educadores). Estas personas, a través de lengua de signos, podrán disponer de cantidad y variedad de estas experiencias, poseerá un conocimiento de las diversas clases de textos, podrá empezar a descubrir la potencialidad del lenguaje y su poder para crear mundos posibles; de tal manera, que conocerán la funcionalidad de la lectura y del lenguaje escrito.

Hay que señalar que los sordos que emplean la lengua de signos tienen que salvar una serie de dificultades en el aprendizaje del lenguaje escrito: por un lado, deben de leer y escribir en un lenguaje que tiene una estructura morfo-fonológica y sintáctica diferente de la lengua de signos y, por otro lado, la correspondencia entre un signo de la lengua de signos y una palabra del lenguaje escrito es arbitraria, y tampoco existen correspondencias su-lexicales, esto es, a nivel silábico o fonológico, entre estos dos lenguajes. Además, la lengua de signos no proporciona representaciones fonológicas de las palabras que forman el léxico interno, lo cual pueden tener consecuencias importantes en el desarrollo de los procesos de reconocimiento de la palabra escrita.

Hay que reflexionar sobre las personas sordas que ahora son adultas. Estos recibieron información durante su etapa escolar prácticamente nula, a consecuencia de las sesiones de rehabilitación del habla, por lo que dejaron de asistir a muchas de las clases a las que asistieron sus compañeros oyentes. Muchos de estos alumnos sordos en la actualidad presentan traumas académicos relacionados con los exámenes que tenían que hacer cuando eran pequeños, acompañado del retraso lector que presentan.

Como consecuencia de esto, cuando son adultos rechazan la ejecución de cualquier tipo de prueba de capacidad, reduciendo sus estímulos y la motivación a la lectura. Esto nos hace pensar en la necesidad de crear nuevas estrategias que les incite a retomar sus hábitos lectores.

Igualmente el uso de Lenguaje de Signos para la educación de personas adultas sordas, es una herramienta necesaria para que dichas personas comprendan el sentido de las frases y puedan evolucionar. Con esto se conseguirá comprender la representación fonológica de las palabras.

Este proceso de remodificación fonológica está directamente ligado a la existencia de una entrada fonológica en el léxico interno del lector. En el caso de los oyentes, este proceso está garantizado por el hecho de que conocen de forma oral la mayor parte de las palabras que se encuentra al leer, con lo cual pueden "reconvertir oralmente" las palabras escritas mediante la aplicación de reglas de transformación. En el caso de los sordos profundos la situación es distinta, ya que, el acceso 
fonológico a su léxico interno podría estar dificultado a causa de su déficit auditivo. El proceso de recodificación fonológica podría no desarrollarse en el sordo por el simple hecho de que las representaciones que es capaz de elaborar (es decir, los códigos fonológicos correspondientes a las palabras escritas) son de poca utilidad, si es que no son totalmente inútiles; o podría ocurrir que dada la diversidad de sistemas de comunicación a los que se ven expuestos (lengua de signos, sistemas signados, etc.) elaboraran una serie de estrategias de lectura que estuvieran alejadas de la utilización de este tipo de codificación fonológica.

De lo anterior surgen nuevos interrogantes no sólo de cara a un mejor análisis y comprensión de las estrategias que utilizan los sordos para leer, sino también de cara a plantear métodos educativos más adecuados a estas estrategias que utilizan los sordos para leer, adaptándolos al nivel lector presentado por la persona sorda.

Del aprendizaje del proceso lector por medio de estas estrategias de lectura puede depender en gran medida el éxito académico de las personas sordas e igualmente juega un papel importante en integración tanto a nivel educativo como laboral y social.

\subsection{Habilidad lingüística y fracaso lector en los estudiantes sordos}

Tomando en cuenta la hipótesis que relaciona el conocimiento de vocabulario con los logros en comprensión lectora, Lasasso y Davey (1987) investigaron el vocabulario y la comprensión lectora de 50 estudiantes con sordera profunda entre 10 y 18 años. Las pruebas utilizadas fueron las subpruebas de vocabulario del Gates-MacGinitie Reading Tests y la prueba de comprensión lectora Stanford Achievement Test. Las tareas incluían una prueba Cloze y cuatro condiciones de pregunta-respuesta. Los investigadores corroboraron su hipótesis inicial, demostrando que los resultados en las pruebas de vocabulario se correlacionan fuertemente con los resultados en comprensión lectora.

Estos hallazgos fueron corroborados por Paul y Gustafson (1991) en un estudio realizado con estudiantes sordos y oyentes. El objetivo de la investigación fue evaluar la comprensión de palabras con polisemia, a partir de una prueba de vocabulario de imágenes. Los autores pretendían comparar el desempeño de ambos grupos en palabras con uno y dos significados. Junto con esto se esperaba constatar el incremento del vocabulario a medida que aumentaba la edad y la relación entre conocimiento del vocabulario y comprensión lectora. Como se esperaba, los oyentes aventajaron significativamente a los sordos en la realización de la tarea, no obstante ambos grupos seleccionaron primero el significado más frecuente de la palabra. Contrariamente a lo esperado, la selección de palabras con dos significados no mejora según aumenta la edad. Finalmente, los investigadores verificaron la fuerte correlación entre conocimiento de vocabulario y comprensión lectora tanto en estudiantes sordos como oyentes. 
En un trabajo llevado a cabo en España por Mies (1992) con 22 estudiantes sordos profundos entre 12 y 17 años, sobre el léxico escrito en la comprensión lectora, la autora analizó agrupamientos de palabras con un mismo origen morfológico. Entre sus observaciones destacan; en primer lugar errores de inserción de la palabra en un grupo que no corresponde, con una marcada fijación en la primera sílaba. Por ejemplo: si la palabra propuesta es insectos, el sujeto considera que puede agruparla junto con insecticida, innecesario, inefectivo. En segundo lugar, errores al crear un grupo diferente de los propuestos. Por ejemplo: si la palabra presentada es campiña el sujeto atribuye el mismo lexema a campesina y campesino, pero forma un grupo aparte con campo y acampar que no considera que forman parte del grupo inicial. En tercer lugar, errores por omisión de palabras que no considera pertenecientes a ningún grupo. Por ejemplo: el sujeto agrupa la palabra especie junto con especialidad y especialista pero, considera que la palabra especialización no forma parte ni de este grupo ni de ninguno de los propuestos. La autora señala, que en este estudio se observó una relación directa entre la familiaridad en el reconocimiento de la palabra y la ejecución correcta de la tarea.

Mies (1992) señala que una situación frecuentemente observada entre los estudiantes de su estudio, es la utilización de la acepción de una palabra determinada en un contexto en donde es evidente que hay que elegir otra acepción semántica. También observa confusiones de palabras similares que nada tienen que ver con el contexto. Agrega que dichas dificultades contribuyen a hacer más difícil el acceso al significado de las palabras y en definitiva a la comprensión global del texto. La autora aclara que los sordos suelen fijarse en las palabras que les son familiares, independientemente de su relevancia dentro del texto, que actúan con superficialidad y que son poco reflexivos al adjudicar significado a las palabras. En la mayoría de las ocasiones no se plantean si la interpretación de una palabra es la adecuada al contexto en el que se inserta, sino que lo hacen en función del significado más cotidiano o del único que conocen. Concluye que los alumnos sordos obtienen resultados claramente inferiores a los oyentes en dimensiones como el conocimiento de vocabulario y metacognición léxica dado el desfase existente en su competencia lingüística. Expresa que existe algún tipo de relación entre el éxito en la captación de la imagen gráfica de la palabra y la capacidad de saber establecer la asociación de afinidades entre la morfología.

Hasta hace pocos años, la mayoría de los estudios evaluaba exclusivamente el léxico oral de los estudiantes sordos, dejando de lado el lenguaje de signos por ser considerado una escasa colección de gestos y pantomimas, sin estructura propia ni mucho menos con una organización interna. Sin embargo, hoy sabemos que los lenguajes de signos son formas de comunicación manual, que dependen fundamentalmente del canal visual para percibir la información lingüística, y son utilizados por las distintas comunidades de sordos en el mundo como su principal medio de comunicación. Por ello, hoy en día poco a poco surgen investigaciones que incorporan el conocimiento del léxico en lenguaje de signos como un elemento de análisis de las habilidades lingüísticas de los sordos. Conocer el nivel léxico (hablado y signado) de una persona sorda implica tener una visión global de sus destrezas lingüísticas, comunicativas y cognitivas, y con ello la posibilidad de desarrollar su potencial académico y social. 
La mayoría de los autores concuerda en señalar que la pobreza de vocabulario en los sordos se relaciona con el grado de pérdida auditiva y se correlaciona con las habilidades de lectura. Los investigadores explican que los problemas de lectura de los sordos, pueden ser producto del desconocimiento del significado de las palabras que aparecen en el texto escrito, que estos lectores se fijan más en las palabras familiares y usan más sustantivos concretos y verbos familiares que palabras abstractas. Asimismo, ya que su vocabulario es limitado presentan pobres expresiones escritas. Los autores concluyen ( Nolen y Wilbur, 1985, 234), que "el conocimiento de vocabulario es un indicador de las habilidades en lectura, que la falta de vocabulario no puede ser compensada ni sintáctica ni semánticamente, que el desempeño de los sordos es mejor con palabras con un sólo significado y finalmente, que los sordos que poseen un lenguaje fluido y natural desde el nacimiento, obtienen mejores resultados en las pruebas de conocimiento de vocabulario que los sordos que no tienen un lenguaje consolidado como las personas mayores, que ya siendo adultos poseen retraso lector".

Está bien establecido que las personas sordas generalmente presentan importantes dificultades de lectura y ortografía. Hace 20 años en un cuidadoso estudio llevado a cabo Conrad (1979, citado en Herrera, 2003) examinó el nivel lector alcanzado por casi todos los estudiantes que abandonaban la educación especial de niños con deficiencia auditiva de Inglaterra y Gales de 1974 a 1976. El utilizó la Wide-span Reading Test (Brimer, 1972) que consiste en una serie de pares de sentencias, una tiene una palabra que falta que tiene que ser encontrada en la otra sentencia. La edad media de los participantes era de 9 años y 0 meses. En el subgrupo que presenta perdidas auditivas superiores a $86 \mathrm{db}$, aproximadamente el $50 \%$ de los alumnos son totalmente analfabetos (edad de los lectores 7 años y 0 meses con un nivel de 0 en el test). Por ultimo, si se admite que un nivel funcional de la alfabetización de la lectura no se alcanza antes de los 11 o 12 años, menos del 15\% de esta población alcanzó este nivel.

Conrad subraya la notable coincidencia de sus resultados con los obtenidos por Di Francesca para 17000 niños con deficiencias auditivas en USA. La edad de los alumnos de 15 a 16 años de edad y los grupos en este estudio fue de 9; Trybus y Krashmer (1977) examinó una muestra de alrededor de 1000 personas con deficiencias auditivas de 20 años. Ellos encontraron la mediana de lectura, equivalente al alrededor de cuatro, y sólo el $10 \%$ de los más antiguos del grupo han alcanzado los octavos grados en lectura. A veces se supone que la capacidad de lectura mejora después de salir de la escuela. Hammermeister (1971, citado en Tribus y Krashmer, 1977) examinó la adquisición de habilidades de lectura de un grupo de adultos de hasta trece años después de la edad escolar y encontró que la comprensión de lectura no mejoró, a pesar de un aumento de vocabulario.

Por otra parte, las mejoras se observaron entre los 15 y los 18 años (la última edad considerada en el estudio). Un nivel de lectura en torno al tercer grado parece ser alcanzado (Paul y Gustafson, 1991, 61). Diferentes criterios funcionales de lectura han sido propuestos. El nivel de logro de cuarto o quinto grado se acogió como criterio para la alfabetización funcional, ya que normalmente se hace audiencia para la población, y más del $30 \%$ de los ingresados en la escuela se considerarán analfabetos (Furth, 1966; Lichtenstein, 1998; Marschark \&Harris, 1996, citados en Paul y Gustafson, 1991). 
A pesar de esta situación bastante dramática en relación con la media en capacidad de lectura de los estudiantes sordos, hay considerables diferencias individuales, y algunos sordos estudiantes lograron una mejor competencia en lectura que otros alumnos; un factor evidente es el nivel de la pérdida auditiva.

En una reciente investigación llevada a cabo por Jáudenes, Torres, Aguado, Silvestre y Patiño, publicada en 2008, donde se realizó un estudio en el periodo 2005-2006 con la colaboración de las familias con hijos e hijas con discapacidad auditiva atendidas en los Servicios SAAF, miembros de FIAPAS, sobre una muestra de 100 alumnos y alumnas de $3^{\circ}$ y $4^{\circ}$ de Educación Primaria y de $3^{\circ}$ y $4^{\circ}$ de Educación Secundaria, de 13 Comunidades Autónomas, se ha identificado un grupo de alumnos y alumnas con sordera que se aleja, como grupo, de la tendencia a presentar niveles muy bajos de comprensión lectora, que era la tónica en investigaciones anteriores. Estos resultados abren una nueva línea de investigación, en este mismo trabajo se realizan y en función de estos buenos resultados, se ahonda en el estudio de aquellas variables que influyen en la adquisición y desarrollo de una competencia lecto-escritora eficaz. Las conclusiones obtenidas, de gran interés por la novedad de los datos contrastados que las sustentan, se constituyen en un referente de gran valor para la toma de decisiones en materia educativa y social en relación con las personas sordas.

\subsection{Configuración del contexto de aprendizaje}

El aprendizaje de la comprensión lectora es una actividad constructiva que ha de llevar acabo el aprendiz, pero para ello resulta imprescindible la intervención de un educador/a, que ejerza una función de mediación a partir de los conocimientos que el aprendiz ya posee.

El educador/a promoverá la participación guiada en la búsqueda de la comprensión de textos. Para Rogoff (1984, citado en Ferrer, Andréu, Martínez, Asensi, Romero, 2004), la participación guiada supone una situación educativa favorable. Esta participación directa del educador/a, ayuda al aprendiz a contrastar y relacionar su conocimiento previo con el que va a resultar necesario para abordar dicha situación. El aprendiz dispone desde el principio de una visión del conjunto o estructura general que supone la tarea. Con ello, pretende transferir progresivamente la responsabilidad de la ejecución en el desarrollo de las tareas al aprendiz, hasta que se muestre competente en la aplicación autónoma de lo aprendizado. La evolución del programa marcó tanto en el paso de la fase primera a la segunda, el desarrollo de actividades propias de esta transferencia de responsabilidad sobre la resolución de las tareas.

Las aplicaciones educativas, que se han utilizado en esta investigación, son adaptaciones basadas en las investigaciones de Clemente y Domínguez (1999), Cuetos, (2006), Villalba, Ferrer y Asensi (2005) y Ferrer, Andréu, Martínez, Asensi, Romero (2004) y Domínguez y Alonso (2004), quienes indican que las actividades 
fonológicas pueden ser un sistema de facilitación que posibilita mejorar habilidades de procesamiento fonológico de los alumnos Sordos y la creación de representaciones fonológicas completas, exactas y precisas que les garanticen el acceso al código alfabético.

Al existir un dominio insuficiente de la Lengua Oral se ha empleado la Lengua de Signos como medio de comunicación intermedio entre el alumnos y los conocimientos que se desea que adquiera. La Lengua de Signos aporta una serie de beneficios en estos casos:

- Posibilita recabar información

- Facilita apropiarse de las estrategias mentales que el aprendiz percibe en los intercambios eficaces con los instructores.

- Permite dar explicaciones complejas sobre el contenido del texto.

- Ayuda a enriquecer el vocabulario.

- Permite realizar reflexiones sobre aspectos de la Lengua Oral (metalenguaje)

Hay que recordar que la Lengua de Signos no aporta conocimientos sobre aspectos fonológicos de la Lengua Oral.

A la hora de diseñar las actividades, se han seguido los criterios de Clemente y Domínguez $(1999,135)$ que marcan unos criterios o parámetros de dificultad que facilitan o dificultan la realización de las actividades metafonológicas.

- "El nivel lingüístico, es la unidad de palabra sobre la que se va a trabajar, es decir, sílaba o fonema, de forma que a mayor nivel de abstracción mayor dificultad tendrá la tarea.

- La tarea que se emplea para el desarrollo de las actividades, en función de los requisitos cognitivos que los alumnos tienen que usar para solucionarla.

- El lugar, o posición que ocupa el segmento propuesto (sílaba o fonema) dentro de la palabra, es decir, comienzo, medio o final".

Estos criterios ya han sido evaluados sobre alumnos Sordos (Asensio, 1989; Rodríguez et al. 2003, citados en Domínguez y Alonso, 2004). Los resultados coinciden con los de los alumnos oyentes, donde se veía que:

- Es más sencillo una segmentación de tipo fonético que de tipo silábico.

- Es más fácil la segmentación al comienzo de la palabra, después al final y por último en medio. 
Sin embargo, se demostró que los alumnos oyentes realizan ligeramente mejor la tarea de identificación y omisión con fonemas que con sílabas, en todas las posiciones de la palabra, a excepción de la identificación al principio de la palabra y la omisión al final de la palabra.

De esta forma, se podría establecer una secuencia en el aprendizaje de las habilidades metafonológicas en alumnos Sordos (Domínguez y Alonso, 2004, 115):

- Dificultad creciente en función de la tarea: de identificación a omisión.

- En función de la unidad Lingüística: de fonema a sílaba.

- En función de la posición que ocupe la sílaba o el fonema dentro de la palabra: principio, final y medio.

Utilizando como base estos resultados se han diseñado actividades que siguen la secuencia de aprendizaje indicada, creando ejercicios y actividades del tipo:

- Ejercicios de segmentación silábica y fonética.

- Ejercicios de omisión, comparación, construcción con fonemas o sílabas.

- Identificación y búsqueda de sílabas o fonemas.

- Determinar el número de sílabas, de fonemas.

- Reglas de transformación y derivación: Genero, artículos, singular y plural.

También se ha trabajado la comprensión lectora, haciendo hincapié en la comprensión de ciertos verbos, muy comunes en el lenguaje español como son los verbos, ser, estar y tener. La Lengua de Signos, lengua utilizada por la mayoría de los alumnos que han participado en esta investigación, no contempla el uso de algunos verbos, como el verbo ser: por ejemplo, la frase "Yo soy guapo" se interpreta en lengua de signos como "Yo guapo", además, no se conjugan los verbos. El signo es el mismo para amo que para amas, por ejemplo. En cuanto al tiempo, sólo se indica si es pasado o si es futuro. Si no se pone signo de pasado o futuro antes del verbo, es presente. Esta omisión y falta de conjugación de los verbos representa un problema en la comprensión lectora. 

en Castilla y León 


\section{Capitulo IV. TIC y sordera}

La tecnología en general ofrece múltiples instrumentos y funciones cuyo objetivo final ha sido facilitar la vida de las personas e incrementar la eficacia de sus actividades. En esta línea, existe un conjunto de instrumentos y adaptaciones de dispositivos diseñados para cubrir las necesidades específicas del colectivo de personas que cuentan con dificultades para captar y/o interpretar información de naturaleza acústica a través de la audición. Es precisamente en este ámbito donde se concentra el desarrollo de lo que comúnmente se denominan como "ayudas técnicas". Hoy día, parece oportuno ampliar tanto el concepto como su comprensión utilizando desde una perspectiva más amplia, el término de "tecnologías de ayuda". (Ferrer, 2002, 1).

Alcantud y Ferrer (1998, citado en Ferrer, 2002) consideran las tecnologías de ayuda como "cualquier artículo, equipo global o parcial, o cualquier sistema adquirido comercialmente o adaptado a una persona que se usa para aumentar o mejorar capacidades funcionales de individuos con discapacidades".

El concepto genérico de Nuevas Tecnologías (NT) puede resultar ambiguo, sin embargo, es importante, desde nuestra perspectiva, acotar el concepto. Cabero, Salinas y Duarte $(2000,17)$, consideran que una de las características que distinguen a las NT es que "giran en torno a cuatro medios básicos: la informática, la microelectrónica, los multimedia y las telecomunicaciones". En ese sentido, para los propósitos de esta investigación, entendemos por Nuevas Tecnologías, todos los medios desarrollados en torno al surgimiento de la ciencias de la Informática y que permiten la comunicación e interacción con fines educativos; de manera sincrónica o asincrónica; de forma individual o colectiva; que utilizan la computadora como principal medio de comunicación e interacción entre los sujetos del acto educativo y; que permiten acceder a recursos y servicios desde computadoras distantes.

Dentro de esta categoría se encuentran: el hipertexto, los multimedia, Internet, grupos de discusión, video-enlaces, correo electrónico, las charlas sincrónicas o chats, entre otros. La gran capacidad y flexibilidad de las NT para la comunicación y la interacción destacan su función formativa "por cuanto apoyan la presentación de determinados contenidos, lo que puede ayudar a guiar, facilitar y organizar la acción didáctica, así como condicionan el tipo de aprendizaje a obtener, ya que pueden promover diferentes acciones mentales en los alumnos" (Cabero et al., 2000, 144). Sin embargo, aunque se acepta que las nuevas tecnologías poseen un alto potencial en la enseñanza, es necesario analizar las funciones cognitivas en las que impactan dichas tecnologías para tratar de definir qué papel juegan las NT en los procesos de aprendizaje. Una mejor comprensión de ello permitirá un diseño más apropiado en los ambientes virtuales de aprendizaje.

Este concepto remarcaría algo esencial en relación con la aplicación de la tecnología al ámbito de la discapacidad, esto es, el componente de individualización del sistema ayuda-usuario. Cada aplicación es una circunstancia única en función de la naturaleza y grado de la discapacidad. No existen dos exactamente iguales ni en el contexto, ni en las habilidades previas de la persona, ni en el tipo y grado de 
discapacidad, ni probablemente en el objetivo final para el que se diseñan. De forma que hay que prevenirse acerca de generalizaciones en relación con el aprovechamiento de una tecnología en particular y exige vigilar estrechamente la interacción que se establece entre un alumno con sordera y el sistema que utilice.

Todo esto hace apostar por un concepto de tecnologías de ayuda plural advirtiendo que, más que un mero cúmulo de ayudas técnicas destinadas a compensar una disminución sensorial, se ha de centrar la atención en una visión de la tecnología al servicio de las personas con la finalidad de permitir de modo efectivo la equiparación de oportunidades.

El desarrollo de la informática va a suponer un cambio radical en la mejoría de la educación y de la calidad de vida de las personas sordas, con un salto cualitativo muy grande en la importancia de las ayudas tecnológicas.

Por un lado, desde la perspectiva de la reducción de barreras de comunicación, se produjo una inflación superlativa de la comunicación visual, mediante teléfono (mensajes SMS), fax o Internet: para las personas sin audición, esta alternativa a la comunicación audio-oral por teléfono tradicional (una de sus grandes frustraciones al limitar su autonomía personal) ha supuesto un cambio enorme en su vida.

En los últimos años, para aquellas personas con ayudas auditivas más eficaces (sean prótesis o implantes), la tecnología del teléfono móvil se ha adaptado para permitirles incluso usar la transmisión acústica de una forma realmente eficaz.

Las posibilidades de subtitulación, con una presencia creciente en televisión, no han sido sin embargo apenas aprovechadas en toda su extensión: queda todavía todo un futuro por construir.

Cuando la técnica de reconocimiento vocal lo permita, la visualización escrita de lo que dice un hablante, en tiempo real, permitirá un acceso completo y autónomo a la información en cualquier evento público (clases de universidad, conferencia...), supondrá la resolución de muchos problemas de comunicación interpersonal, con un coste que se irá probablemente reduciendo con la generalización del uso de dicha tecnología.

Por otro lado, por primera vez, se están obteniendo resultados realmente eficaces para el conjunto de las personas sordas en la resolución de la propia discapacidad auditiva.

La última generación de prótesis auditiva dota de audición funcional (es decir de la capacidad de entender mensajes orales sin ayuda de la lectura labial) a las personas con sordera media y severa y el implante coclear consigue lo mismo para las personas con sordera profunda adquirida y para los niños con sordera profunda si se implantan precozmente: por primera vez en la historia, una tecnología está consiguiendo realmente que "los sordos oigan".

Disponer de una audición funcional supone para las personas con sordera adquirida en la adolescencia o a la edad adulta superar su situación de dependencia así como 
mantener en la mayoría de los casos su situación laboral y la calidad de sus relaciones sociales, dentro del mundo en el que estaban acostumbrados a vivir.

Disponer de una audición funcional desde la infancia supone para los niños que han nacido con una sordera profunda la oportunidad de acceder al lenguaje oral de una forma casi natural, evitando el largo y penoso adiestramiento anteriormente indispensable y que no todos podían llevar a cabo así como el enorme desfase que se producía siempre ; les permite librarse por lo menos parcialmente des esfuerzo suplementario de atención que suponía el uso de la comunicación visual, sea cual fuese la modalidad empleada ; les abre en suma una oportunidad impensable hace algunos años para la integración social y laboral.

Disponer de una audición funcional cuando, además de la sordera, un niño presenta otras discapacidades (visuales, motoras, cognitivas o psíquicas), en términos relativos, supone una diferencia aún mayor con la situación anterior porque elimina 0 reduce el efecto de la "plurideficiencia".

Son niños que, por la presencia simultánea de otra discapacidad, no pueden o pueden escasamente valerse de los medios de compensación que usan sus compañeros sordos sin trastornos asociados: las consecuencias de la sordera eran entonces dramáticas para el establecimiento de la comunicación interpersonal y el desarrollo de sus habilidades cognitivas y sociales.

En la actualidad, es posible proporcionarles un nivel de audición tan eficaz como en cualquier otro niño lo que cambia profundamente su situación vital.

Otras técnicas electrónicas de apoyo, como la FM, han mejorado también su eficacia en los últimos años, contribuyendo a un mayor rendimiento de las ayudas auditivas individuales en situaciones acústicamente no favorables.

El auge de la informática ha influido también en los métodos de enseñanza, permitiendo por un lado una mayor versatilidad en la presentación y el acceso a los contenidos y, por otro lado, la potenciación de medios alternativos : la visualización de parámetros de la voz y del habla, la automatización de ciertos sistemas de entrenamiento o de aprendizaje, la posibilidad de realizar y de observar simulaciones de fenómenos que, hasta ahora, sólo se explicaban a los alumnos mediante el lenguaje, todos esos recursos son muy útiles para el conjunto de alumnos pero lo son especialmente para aquellos que presentan limitaciones en la comprensión y/o el manejo del idioma.

La respuesta a la discapacidad siempre debe ser a doble sentido: debe intentar dar más capacidad a la persona con discapacidad y al mismo tiempo debe acercar la realidad y la sociedad a las situaciones que difieren del planteamiento mayoritario.

La sordera es una discapacidad que levanta importantes barreras de comunicación: algunas se pueden levantar dando más audición y más lenguaje a las personas sordas, otras permitiendo el acceso a la vida ciudadana común "a pesar" de la discapacidad: es el sentido de muchas medidas sociales como el reconocimiento de la Lengua de Signos y el acceso a un servicio público de intérpretes. 
La tecnología supone ahora una herramienta de primera importancia en este campo de la eliminación de barreras y debe aplicarse de la misma manera: desde la persona con discapacidad, disminuyendo el impacto de ésta cuando es posible y proporcionándole los medios de compensación necesarios y, al mismo tiempo, desde el entorno social, generalizando en todos los ámbitos la aplicación de recursos técnicos y apoyando los programas de desarrollo de tecnologías cada vez más eficaces.

El desarrollo científico como indica Monfort (2006) ha generado muchos "monstruos", pero hay que reconocer con orgullo que este desarrollo sirve también para reducir las diferencias individuales.

La voluntad del centro y la formación específica de los docentes resultan factores imprescindibles para incorporar las TIC al proceso de enseñanza-aprendizaje, aunque hay que seguir avanzando en la mejora de los equipamientos e infraestructuras de los centros educativos. Conviene, por tanto, impulsar la formación específica de los profesores en prácticas innovadoras que utilicen las TIC desde un punto de vista pedagógico.

También conviene desarrollar cursos que contengan contenidos sobre la educación con TIC de las personas con discapacidad. Estos cursos deberían incluir los criterios de accesibilidad y de "Diseño para Todos".

Acumular y compartir experiencias y buenas prácticas de la enseñanza con TIC en aula parece ser la vía más adecuada para evitar errores y actuar acertadamente en el objetivo de la mejora de la calidad de la enseñanza.

Es prioritaria la creación de un portal educativo nacional dirigido a toda la comunidad educativa (profesores, alumnos, padres, centros escolares, instituciones educativas, editoriales, etc.) que aglutine toda la información existente (a nivel internacional, nacional, regional y local) sobre la incorporación de las TIC en el aula.

La realización de nuevos estudios o investigaciones para analizar en profundidad las cuestiones que está planteando la incorporación de las TIC en el proceso de cambio educativo, sería muy útil para la comunidad educativa española en su conjunto. La eficacia de la educación con TIC en el aula, las necesidades de formación de los profesores o un estudio crítico de nuevas experiencias educativas podrían ser temas de investigación.

Conseguir una mayor colaboración entre los grupos profesionales implicados en la educación (funcionarios de las administraciones, directores de centros, profesores, pedagogos, productores de software educativo, etc.) ayudaría a coordinar esfuerzos y a trabajar en una misma dirección.

Se hace necesaria una reflexión sobre el tema de la evaluación de la calidad e idoneidad de los nuevos contenidos educativos.

Se debe seguir impulsando la creación de nuevos materiales y contenidos dirigidos a la educación con TIC en el aula. 
La realización de trabajos colaborativos o la participación en proyectos conjuntos parecen las vías clave para avanzar en el camino de la educación con TIC. Se deben de promover este tipo de proyectos en los que participan grupos de profesores, de alumnos o, incluso, de centros a través de la Red.

La educación con TIC se presenta especialmente favorable para las personas con Necesidades Educativas Especiales y específicas tanto para la mejora de sus habilidades cognitivas como para su normalización e integración.

Convendría continuar en la línea de la investigación de prácticas, materiales y ayudas técnicas que permitan acercar las TIC a la formación de estos grupos sociales.

Por su enorme relevancia, hay que hacer hincapié en la importancia que tienen los profesores en el reto de incorporar las TIC en la educación. Mientras los profesores no echen de menos la tecnología para preparar sus clases y para trabajar en el aula y compaginen o sustituyan los métodos y los recursos tradicionales por los tecnológicos, no se podrá decir que las TIC se han incorporado a la enseñanza o que están facilitando el cambio educativo.

Ahora más que nunca, el papel de los docentes es imprescindible y de ellos y de su actitud dependerá que las TIC sean un factor que influya de forma decisiva en la calidad de la enseñanza.

Como indicaba Cristina Rodríguez Porrero (FIAPAS, 2002, 67), en su ponencia, "la falta de accesibilidad supone la discriminación más cotidiana para las personas con discapacidad. Los avances para conseguir una accesibilidad plena en todos los ámbitos implican tener en cuenta a las personas sordas y con deficiencia auditiva."

A lo largo de este capítulo se recogen los avances más significativos, creados para facilitar la accesibilidad de las personas sordas a su entorno.

Actualmente, cuando se habla de nuevas tecnologías se engloba dentro de ellas, y de forma automática, los avances tecnológicos destinados a facilitar o a aumentar la capacidad auditiva como pueden ser audífonos o implantes cocleares, junto con las actuales tecnologías de la información basadas en las nuevas tecnologías de comunicación basadas en Internet.

Estos dos aspectos que posteriormente se analizarán de forma separada están estrechamente relacionados. Los avances conseguidos en el desarrollo de nuevos e mejores audífonos e implantes cocleares esta estrechamente relacionado con el flujo de información ilimitado entre los distintos grupos de investigadores que se consiguen comunicar e interaccionar a través de la Red.

La aparición en Internet de sitios dedicados a la teleformación o formación continua influye directamente en la capacidad de auto-formación desde los hogares de los interesados.

Dentro de la población de deficiencia auditiva y teniendo en cuenta su diversidad (pérdida auditiva, momento del diagnóstico, tipo de prótesis, presencia de trastornos 
asociados...) se encuentran ciertas características comunes que dificultan el mantener una interacción comunicativa adecuada:

- retraso en la adquisición del habla y dificultades en el desarrollo del lenguaje. Este desfase hace que cometan errores en el empleo de las reglas gramaticales; un mal aprendizaje y un uso inadecuado del vocabulario; comprensión errónea de los mensajes orales, errores en la articulación...

- en el desarrollo de habilidades cognitivas: falta o dificultades para mantener la atención; en el almacenamiento correcto de las imágenes fonológicas de los sonidos del habla; en la estructuración espacio-temporal, pocas o malas estrategias para la resolución de problemas...

Dadas estas características es importante organizar y planificar actividades para crear situaciones comunicativas significativas en la intervención logopédica. En la actualidad contamos con una gran variedad de materiales para trabajar durante la intervención con deficientes auditivos. Muchos de ellos lo encontramos en soporte informático, no obstante, el logopeda deberá conocer qué programas informáticos pueden servirle en cada caso particular.

Se tratará a continuación de enunciar sucesivamente las tecnologías de ayuda para el aprovechamiento de restos auditivos, los productos informáticos desarrollados para su uso en contextos educativos tanto en su aplicación directa a estudiantes con deficiencia auditiva como en relación con la mejora formativa de los profesionales encargados de la intervención en este ámbito, las tecnologías que facilitan el acceso a señales acústicas propias de la vida cotidiana, las alternativas para posibilitar la comunicación a distancia y cuyo beneficio no debe pasar desapercibido para la escuela.

No se hablará de las tecnologías al servicio de la evaluación audiológica, aunque hay que advertir sobre su importancia. En este sentido, la práctica de nuevos procedimientos objetivos de screening y diagnóstico tales como las otoemisiones acústicas, los potenciales evocados de tronco cerebral, la impedanciometría..., métodos que se apoyan de forma decisiva en el uso de instrumental tecnológico cada vez más sofisticado y preciso, está teniendo una notable influencia sobre el desarrollo de los niños sordos al permitir una progresiva generalización de la detección precoz, paso previo de la intervención temprana. 


\subsection{Ayudas Técnicas basadas en Recursos Humanos: Los Intérpretes de Lengua de Signos}

La Ley de Lengua de Signos (Ley 27/2007, 23 de octubre) en su Artículo 4, define a los intérpretes de lengua de signos como: "Profesional que interpreta y traduce la información de la lengua de signos a la lengua oral y escrita y viceversa con el fin de asegurar la comunicación entre las personas sordas, con discapacidad auditiva y sordociegas, que sean usuarias de esta lengua, y su entorno social". Además esta misma ley define al Guía-intérprete diciendo que es el "Profesional que desempeña la función de intérprete y guía de la persona sordociega, realizando las adaptaciones necesarias, sirviéndole de nexo con el entorno y facilitando su participación en igualdad de condiciones".

Y es que en plena era de la comunicación, donde la información vía telefónica, prensa, radio, TV, Internet, ha modificado el orden de valores vitales de la sociedad, un importante colectivo de personas afectadas de deficiencia auditiva en grado profundo, sus familiares y entorno social más próximo, sigue esperando el milagro tecnológico que rompa definitivamente las cadenas del aislamiento comunicativo de estas personas.

El Intérprete de Lengua de Signos es un profesional que resuelve lo que las ayudas técnicas más sofisticadas no pueden solucionar, hoy por hoy, algo tan elemental como la comunicación directa entre una persona sorda, sordociega o signante con otra persona normoyente o no signante, y satisfacer de este modo una de las características fundamentales de la especie humana, "la relación con sus semejantes".

Hoy en día como indica la Federación Española de Intérpretes de Lengua de Signos y Guías-Intérpretes (FILSE) en su página Web (www.filse.org), los/as intérpretes de lengua de signos son un elemento imprescindible para posibilitar el acceso a la información y a la comunicación de las personas sordas. El colectivo de personas sordas en España es de, aproximadamente, doscientas mil, a las cuales van dirigidos de forma directa los servicios que se prestan, a los que habría que añadir todos sus interlocutores.

La actividad profesional de un/a intérprete abarca todos los campos de la vida cotidiana, siendo su concurso especialmente necesario en los ámbitos jurídico, médico, educativo e institucional, entre otros.

Este colectivo se rige por un código deontológico que marca la correcta línea de actuación para los/as intérpretes de lengua de signos y los/as guías-intérpretes que desarrollan su labor en el Estado Español, guardando secreto de los hechos que conozcan en su trabajo y limitándose a interpretar y traducir, sin ejercer ningún tipo de influencia en las manifestaciones de las personas a las que interpreta y ser absolutamente veraz en su transmisión.

La importancia que tienen los intérpretes de la Lengua de Signos Española Signos (Ley 27/2007 - 23 de octubre), se ve reflejada en el Capítulo II, Artículo 9 de la citada Ley, donde se específica que "se encomienda a los poderes públicos 
promover la prestación de servicios de intérpretes en lenguas de signos españolas a todas las personas sordas, con discapacidad auditiva y sordociegas, cuando lo precisen, en las diferentes áreas públicas y privadas"

En la Disposición adicional cuarta. Régimen transitorio de la situación de los intérpretes y profesionales de las lenguas de signos españolas, que aparece publicada en la Ley de Lengua de Signos (Ley 27/2007 - 23 de octubre) dice los siguiente: "El Gobierno de la Nación, a propuesta de las administraciones competentes, de acuerdo con la legislación vigente en la materia, analizará la situación de los intérpretes y profesionales de las lenguas de signos españolas que han adquirido su formación a través de enseñanzas no regladas, con anterioridad a la entrada en vigor de esta Ley, en orden a su regulación administrativa". De esta forma se ha conseguido otorgar validez a los títulos de intérpretes conseguidos en enseñanzas no regladas, consiguiendo que un gran número de personas que han trabajado como Interpretes en asociaciones vean regulada su títulación.

Con la aprobación de la Ley de Lengua de Signos se ha dado mucha importancia a estos profesionales, haciendo de ellos una de las herramientas o ayudas técnicas mas necesarias hoy en día, que estarán presentes en una gran número de situaciones cotidianas para las personas sordas y que descargarán de trabajo a amigos y familiares que en muchas ocasiones realizaban estas tareas. 


\subsection{Tecnologías de Ayuda para el aprovechamiento de restos auditivos}

\subsubsection{Audífonos}

Un audífono es un amplificador, de alta fidelidad y tamaño cada vez más reducido, que consigue hacer los sonidos más altos, pero no necesariamente más claros. Los audífonos reciben el sonido a través de un micrófono, que luego convierte las ondas sonoras en señales eléctricas. El amplificador aumenta el volumen de las señales y luego envía el sondo al oído a través de un altavoz.

Los audífonos son extremadamente útiles para mejorar la habilidad auditiva y comprensión oral de personas con pérdida de audición ocasionada por daños a las células sensoriales del oído interno, llamadas células ciliadas. Este tipo de condición es conocido como pérdida de audición neurosensorial, y los daños pueden ser causados por enfermedades, vejez, medicinas o por lesiones inducidas por el ruido.

Un audífono amplifica las vibraciones sonoras que entran por la oreja. Las células ciliadas detectan las vibraciones de mayor alcance y las convierten en señales neuronales, las cuales son trasladadas al cerebro. Existe una correlación directa entre la severidad de la pérdida auditiva, el daño a las células ciliadas y la amplificación necesaria para que los audífonos puedan remediar el daño. Sin embargo, existen ciertos límites en el grado de amplificación que éstos pueden generar, de tal manera que hasta las vibraciones de mayor alcance no podrán ser convertidas en señales neuronales si el oído interno está demasiado dañado. En este caso el audífono sería ineficaz.

\subsubsection{Tipos de Audífonos}

Existen varios tipos de audífonos, y cada uno de ellos ofrece ventajas diferentes, dependiendo de su diseño, niveles de amplificación y tamaño. Existen cuatro tipos básicos de audífonos para personas con pérdida de audición:

- Los audífonos endoaurales o intraauriculares (ITE, por su sigla en inglés) caben completamente en el oído externo y son usados en los casos de pérdida de audición leve a severa. La caja, que contiene las partes del audífono, se hace de plástico duro. Los ITE pueden acomodar mecanismos técnicos agregados, como la bobina telefónica, una pequeña bobina magnética contenido dentro del audífono que mejora la transmisión de sonido durante las llamadas telefónicas. Los ITE pueden ser dañados por el cerumen de los oídos y su tamaño pequeño puede causar problemas de ajuste y de acoplamiento. Los niños generalmente no los usan porque las carcasas necesitan ser reemplazadas de acuerdo al crecimiento del oído. 
- Los audífonos retroauriculares (BTE, por su sigla en inglés) se usan detrás del oído y están conectados a un molde de oreja plástico que cabe dentro del oído externo. Las partes de éste se ponen en una caja detrás del oído. El sonido se desplaza a través del molde al interior del oído. Los BTE son usados por personas de todas las edades con pérdida de audición leve a profunda. Los BTE que estén mal ajustados pueden acoplarse, causando un silbido producido por el ajuste del audífono o por la acumulación de cerumen o líquido. Este tipo de audífonos son los más utilizados para niños sordos.

- Los audífonos intracanales caben en el canal del oído y están disponibles en dos tamaños.

- El audífono intracanal (ITC, por su sigla en inglés) está diseñado a medida para ajustarse al tamaño y a la forma del canal del oído y se usa en los casos de pérdida de audición leve a moderadamente severa.

- Los audífonos completamente en el canal (CIC, por su sigla en inglés) están ocultos dentro del canal del oído y se usan en casos de pérdida de audición leve a severa.

Debido a su tamaño pequeño, los audífonos intracanales pueden ser difíciles para el usuario de ajustar y extraer y no tienen espacio para añadir otros dispositivos, como la bobina telefónica. "Este tipo de audífonos también pueden ser dañados por el cerumen y el drenaje de los oídos. Normalmente no se recomiendan a los niños." (Pasik, 1990, 60).

- Los audífonos de bolsillo se usan en personas con pérdida de audición profunda. El audífono se adhiere a una faja o a un bolsillo y se conecta al oído por un cable. Debido a su gran tamaño, tiene la capacidad para incorporar muchas opciones de procesamiento de señales, pero se usa generalmente sólo cuando otros tipos de audífonos no se pueden usar.

$\mathrm{Si}$, se realiza una diferenciación en función de su funcionamiento se podrían definir dos tipos de audífonos en función de sus sistemas:

- Analógicos, convierten ondas sonoras en señales eléctricas que luego son amplificadas. Los audífonos análogos/graduables están diseñados de acuerdo a las necesidades del usuario, de tal manera que son programados por el fabricante siguiendo las especificaciones recomendadas por un audiólogo. Los audífonos análogos/programables tienen más de un programa instalado. Un audiólogo los puede programar usando una computadora, y el usuario puede modificarlo de acuerdo al entorno, por ejemplo: un cuarto pequeño y silencioso, un restaurante lleno de gente y zonas amplias o al aire libre, como un estadio o cine. Generalmente los audífonos análogos son más baratos que los digitales.

- Digitales, transforman ondas sonoras en códigos numéricos, similares al código binario de una computadora, antes de ser amplificados. Estos códigos contienen información sobre el nivel y tono de sonidos, de tal forma que el audífono puede ser específicamente programado para amplificar ciertas 
frecuencias. El sistema de circuitos digitales le brinda mayor flexibilidad al audiólogo para graduar el audífono de acuerdo a las necesidades del usuario y las situaciones donde se encuentre. Estos audífonos pueden ser programados para responder a sonidos que provienen de una dirección específica. Además, este sistema digital puede ser adaptado en todo tipo de audífonos.

Hay que recordar, que es conveniente la utilización de dos prótesis si la sordera es bilateral, es decir en ambos oídos, porque así se transfieren señales más naturales y nítidas al cerebro. Además, "esto ayudará al usuario a entender conversaciones con mayor claridad y saber de dónde provienen los sonidos". (Pasik, 1990, 45).

En la mayoría de los casos la amplificación que proporcionan los audífonos no será suficiente por sí misma para que la persona sorda pueda interpretar los sonidos que le llegan; de tal forma que, para que éstos cobren sentido, es necesario el uso continuado de la prótesis y un período de estimulación auditiva.

\subsubsection{Problemas de adaptación}

En ciertas ocasiones es posible que se presenten los siguientes problemas hasta que la persona que lo usar se acostumbre a sus nuevos audífonos:

- $\quad$ Falta de comodidad. Al principio, algunas personas sienten que su audífono no es muy cómodo. En estos casos se recomienda preguntar al audiólogo por cuánto tiempo se lo tiene que poner mientras que se acostumbre.

- Propia voz suena demasiado alta. Hay usuarios que sienten que su voz suena muy aguda al hablar. Esta sensación, conocida como efecto de oclusión, es causada por los audífonos y es muy común en personas que se están acostumbrando a utilizar audífonos. Se puede consultar al audiólogo para saber si existe alguna corrección. Con el transcurso del tiempo, la mayoría de usuarios se acostumbra a esto.

- Interferencia. Un sonido semejante a un silbido puede ser producto de un audífono que no cabe o funciona correctamente, o quizás le ha entrado cerumen o drenaje del oído.

- Sonido de fondo. Los audífonos no aíslan completamente los sonidos que quieren ser escuchados de los otros. Pero, en ciertas ocasiones los audífonos tienen que ser calibrados.

- Zumbidos al usar el teléfono móvil. Algunas personas que usan audífonos o que tienen dispositivos implantados en el oído sufren problemas causados por la interferencia de la frecuencia radial que emiten los teléfonos móviles. Estos tipos de problemas han disminuido notablemente porque se están perfeccionando los audífonos y teléfonos móviles. Se recomienda, cuando se está colocando un nuevo audífono tener el teléfono móvil a mano para asegurarse de que no haya interferencia. 


\subsubsection{Modelos nuevos}

Aunque funcionan de manera diferente que los audífonos ya mencionados, los audífonos implantados están diseñados para incrementar la transmisión de vibraciones sonoras que entran al oído interno. Un implante de oído medio (MEl, por sus siglas en inglés) está adherido a uno de los huesos del oído medio. En vez de amplificar los sonidos que se trasladan al tímpano, los implantes MEI mueven estos huesos directamente. Sin embargo, ambas técnicas amplifican las ondas sonoras que entran al oído interno, de tal manera que pueden ser detectadas por personas con pérdida auditiva neurosensorial.

Una prótesis auditiva oseointegrada (BAHA, por sus siglas en inglés) es un aparato pequeño, adherido al hueso localizado detrás de la oreja, que transmite vibraciones sonoras directamente al oído interno a través del cráneo, evitando así contacto con el oído medio. Estos son generalmente usados por personas con problemas de oído medio o sordera en una sola oreja.

Muchos especialistas en audición opinan que los beneficios no justifican los riesgos, ya que los MEI y BAHA tienen que ser implantados quirúrgicamente.

\subsubsection{Nuevas investigaciones con Audífonos}

Actualmente se están investigando maneras de incorporar en los audífonos tecnología nueva para el procesamiento de señales, el cual es un método empleado para modificar ondas sonoras de amplitud normal en un sonido amplificado lo más adecuado posible para la capacidad auditiva del usuario. Científicos auspiciados por el NIDCD están investigando maneras cómo los audífonos pueden amplificar señales del habla para optimizar su comprensión.

Actualmente se está estudiando el uso de tecnología computarizada para diseñar y ensamblar audífonos más eficientes. Aparte se están explorando métodos para mejorar la transmisión sonora, y reducir la interferencia causada por el ruido y las consecuencias del efecto de oclusión. Investigaciones adicionales se concentran en la forma más eficaz de seleccionar y colocar audífonos a niños y a otros grupos de la población cuya capacidad auditiva es difícil de evaluar.

En otros estudios importantes el enfoque ha sido en los resultados obtenidos en experimentos con animales, con el propósito de diseñar micrófonos para audífonos de mayor alcance. Por ejemplo, científicos auspiciados por el NIDCD están estudiando la diminuta mosca Ormia ochracea porque la estructura de su oreja le permite reconocer el punto de origen de un sonido con facilidad. Esta estructura ha sido empleada como modelo para diseñar y adaptar en los audífonos con micrófonos direccionales en miniatura. Estos micrófonos amplifican los sonidos que provienen de una dirección particular (generalmente la dirección opuesta a la persona), pero no los sonidos que se originan de otras direcciones. Hay mucha esperanza en que este 
tipo de micrófono pueda ayudar a las personas a escuchar sólo una conversación así se emitan otras voces y sonidos en el entorno.

\subsubsection{Implante coclear}

El Implante Coclear es un transductor que transforma las señales acústicas en señales eléctricas que estimulan el nervio auditivo. Estas señales eléctricas son procesadas a través de las diferentes partes de que consta el Implante Coclear, las cuales se dividen en Externas e Internas:

- Externas: Micrófono: Recoge los sonidos, que pasan al Procesador. Procesador: Selecciona y codifica los sonidos más útiles para la comprensión del Lenguaje. Transmisor: Envía los sonidos codificados al Receptor.

- Internas: Receptor-Estimulador: Se implanta en el hueso mastoides, detrás del pabellón auricular. Envía las señales eléctricas a los electrodos. Electrodos: Se introducen en el interior de la cóclea (oído interno) y estimulan las células nerviosas que aún funcionan. Estos estímulos pasan a través del nervio auditivo al cerebro, que los reconoce como sonidos y se tiene entonces- la sensación de "oír".

"Los implantes cocleares precoces requieren una larga fase de entrenamiento auditivo. La audición con nitidez no se logra de forma automática, es fruto de un arduo aprendizaje" (FIAPAS, 2004, 129). Se necesita más de un año para que el niño sea capaz de percibir con cierta seguridad los componentes fonéticofonológicos del habla. Conviene no olvidar que los neonatos oyentes necesitan 1418 meses para identificar el habla. No debe esperarse, por lo tanto, que los implantados lo hagan en menos tiempo.

Ambas partes (externa e interna) se ponen en contacto por un cable y un imán. Prácticamente todos los Implantes Cocleares actuales corresponden a la descripción que se ha hecho hace un momento. Hay diferentes marcas en el mundo. Algunas de ellas, las más antiguas, eran monocanales; es decir, tenían un solo canal o un solo electrodo. Los primeros Implantes en el mundo son de los años cincuenta.

Actualmente, se implantan multicanales y la tecnología entre unos y otros (de los que hay en el mercado) es muy parecida, aún cuando entre unos y otros existen diferencias técnicas. Las diferencias más visibles son el tamaño del procesador (petaca o retroauricular) y el tipo de pilas usadas para su alimentación: pilas normales de $1,5 \mathrm{~V}$, recargables, tipo botón...

Respecto a los monocanales; evidentemente no puede dar la misma información un solo electrodo que varios y cuando se ha atacado al Implante (en referencia a los usuarios postlocutivos) de que no da mucha información, quizá debería puntualizarse de qué generación de Implantes se habla, puesto que, los Implantes Cocleares actuales dan una información muy cercana a la envolvente de la palabra. 


\subsubsection{Criterios generales para implantes cocleares}

Para ser candidato al I.C. es necesario e imprescindible, cumplir los siguientes requisitos (evoluciona en función de las investigaciones y de los resultados):

- Sordera neurosensorial bilateral profunda o total.

- Imposibilidad de beneficiarse de una prótesis auditiva convencional.

- Convicción del paciente de que la mejoría auditiva que le aporte el Implante Coclear le beneficia personal y socialmente.

En el caso de Postlocutivos, los resultados son espectaculares. Con muy poco tiempo de rehabilitación, la inteligibilidad - incluso sin apoyo de lectura labial aumenta considerablemente y muchos de ellos utilizan el teléfono.

Algunas personas - incluidos profesionales poco convencidos - creen que si el Implante no da un $100 \%$ de inteligibilidad no se puede considerar válido, pero a los postlocutivos esta reinserción sonora les es muy válida. Otra cuestión que se plantean los normoyentes, es si "oyen igual que antes" y lo que dicen ellos es que en un primer período la voz suena como metálica; parece ser que este efecto desaparece al poco tiempo

\subsubsection{Limitaciones de un implante coclear}

El I.C. tiene algunas limitaciones o se tienen que tener en cuenta algunos factores:

- Tiempo. Los pacientes deben aprender a interpretar los sonidos que reciben; para esto se necesita tiempo.

- Deportes. Se pueden practicar deportes, siempre que se cuiden los golpes (quizá el fútbol sea uno de ellos y es recomendable que se saquen la unidad exterior). Pero nos consta que hay chicos y chicas que patinan o esquían, por ejemplo. Por supuesto, no se puede nadar con la unidad exterior del Implante, igual que a nadie se le ocurriría hacerlo con un audífono (sacándoselo, problema acabado)

- Aeropuertos. Al contener en su interior materiales metálicos y magnéticos que pueden ser detectados por los sistemas electrónicos de control, hay que pasar por fuera de los controles de los aeropuertos o aduanas (al igual que ocurre con una persona que lleva un Marcapasos). Durante las operaciones de despegue y aterrizaje, en un vuelo de avión, hay que desconectar el Procesador ya que puede provocar interferencias.

- Pruebas Médicas. La Resonancia Magnética nuclear no debe realizarse en la zona de la cabeza; pero esto también ocurre a las personas que llevan prótesis dentales. 
- Descargas Eléctricas. Se han dicho muchos disparates sobre los Implantes Cocleares pero uno de los mayores es el de que atraen a los rayos de las tormentas atmosféricas. No existe ningún peligro en cuanto a los rayos o a las tormentas.

\subsubsection{Criterios de selección}

- Pruebas previas a un Implante Coclear. Antes de proceder a un I.C. es necesario realizar una serie de pruebas para determinar en qué medida puede restablecerse la audición del paciente. Estas pruebas son:

- Audiometría tonal (tonos puros) y verbal (palabras), para saber el grado de audición del paciente y el nivel de discriminación de la conversación.

- Impedanciometría. Comprueba el funcionamiento de la parte vestibular del oído interno.

- Test del Promontorio: Para determinar si la estimulación eléctrica del nervio auditivo produce sensaciones auditivas y el grado de discriminación.

- Test electroneurofisiológico. Radiografías: Se precisa un estudio radiológico mediante T.A.C. de la cóclea para conocer su estado de calcificación y si existe algún grado de malformación de la misma.

- Estudio psicológico y grado de motivación para solucionar su sordera.

- Test logopédico: Para valorar la comprensión, desarrollo del lenguaje, labio lectura.

- Equipo Multidisciplinar. Comprobamos que la decisión de implantar no la toma una sola persona, sino todo un equipo de profesionales que contrastan los resultados de las diferentes pruebas. $Y$ esto es importante, porque algunas de ellas pueden considerarse eliminatorias; es decir, si con una prótesis bien adaptada hay ganancia, ya no es candidato a I.C., si el T.A.C. da como resultado una cóclea osificada, tampoco será el candidato más idóneo en principio...

- Lenguaje de Signos/Motivación. En ningún momento se utiliza como criterio incluyente o excluyente el hecho de que el individuo utilice como forma de comunicación el Lenguaje de Signos. El candidato ideal es aquel que sea oralista, que tenga una buena competencia en lectura labial y que tenga motivación para oír, que crea que el implante pueda beneficiarle. Por todo ello, -y para que no haya incoherencias- una persona sorda hija de padres 
sordos y cuyo entorno no sea oralista y su lengua vehicular sea el Lenguaje de Signos, no pensamos que sea el candidato más adecuado, por el hecho de que puede entrar en contradicción con su propia realidad.

No obstante, una persona sorda, hija de padres oyentes, inmersa en un mundo sonoro, cuyo entorno no conoce el Lenguaje de Signos, aunque ésta sea su forma de comunicarse, puede ser una candidata aceptable.

La diferencia estará en que necesitará más tiempo de rehabilitación y probablemente más esfuerzo y dedicación, puesto que no sólo deberá hacer un trabajo de discriminación auditiva, sino también un ejercicio de estructuración de Lenguaje.

Se cree que la única persona con derecho de decisión es el propio candidato, que tiene que estar bien informado y que a ser posible antes de proceder al Implante tenga la oportunidad de contactar con otros implantados para recibir información de primera mano y con quienes puedan compartir sus dudas, miedos, angustias y expectativas. (Si se trata de un niño, esta decisión recaerá en los padres).

\subsubsection{Intervención y post-operatorio}

Una vez seleccionado el paciente por el equipo multidisciplinar, se pasa a la siguiente etapa: la cirugía.

La intervención se realiza bajo anestesia general; sus riesgos son los propios de toda intervención quirúrgica efectuada a nivel del oído medio y del interno; es decir, prácticamente nulos y que se reducen a los intrínsecos de entrar en cualquier quirófano.

La duración aproximada de la operación es de 2-3 horas. Exige un período de hospitalización de alrededor de 48 horas, exento por lo general de molestias importantes. La recuperación post-operatoria dura normalmente entre 3 y 5 semanas, es decir hasta que se ha producido la cicatrización completa.

A partir de este momento se acoplan las porciones externas del Implante y ya se puede proceder a la abertura de canales. Este proceso significa que se excitan los electrodos y se empieza a enviar información sonora. Cada electrodo es regulado independientemente. A cada persona corresponde un programa individual que es la suma de la regulación de todos y cada uno de sus electrodos.

\subsubsection{Rehabilitación}

Los resultados que se van a alcanzar dependen de cada individuo en particular, pero es importante la colaboración del paciente, la familia, el colegio (si está en edad escolar) y los amigos, para desarrollar una buena rehabilitación. El rehabilitador es una figura importante en este proceso de adaptación del paciente al implante coclear. 
Cualquier persona implantada saca beneficio del implante y pasa por distintas fases de adaptación.

- Detección. En esta fase, el paciente debe ser capaz de indicar la presencia o ausencia del sonido.

- Discriminación. El paciente debe saber si dos sonidos (o dos palabras) son iguales o diferentes, sin comprenderlos.

- Identificación. El paciente debe seleccionar la respuesta correcta de una lista cerrada (CLOSED-SET).

- Reconocimiento. El paciente debe repetir una frase sin la ayuda de un CLOSED-SET. Para ayudar a dar este paso, se dan apoyos que -poco a poco- se van eliminando.

- Comprensión. El paciente debe proporcionar -trabajando sus habilidades de escucha- una respuesta más interactiva que imitativa.

El entrenamiento se hace en un principio con:

- Sonidos ambientales.

- Sonidos musicales.

- Vocales.

- Consonantes.

- Seriaciones

Pasadas las etapas iniciales de la rehabilitación, los sordos con buen pronóstico implantados consiguen identificar el habla con bastante eficacia, en entornos no ruidos, y desarrollan un lenguaje oral correcto (FIAPAS, 2004, 129).

1. Los chicos implantados precozmente, basándose sólo en la audición con el IC, identifican al menos:

- $70 \%$ de palabras aisladas

- $\quad 80 \%$ de las frases

- $90 \%$ de frases contextuales

2. Cuando suman audición IC y labio lectura, entienden el habla con bastante eficacia. Los porcentajes del apartado anterior mejoran sensiblemente.

3. Ejercen el control auditivo de su propia voz, se autocorrigen, regulan los aspectos suprasegmentales: ritmo y entonación.

4. Aprenden por sí mismos vocabulario y expresiones de la lengua oral.

5. Desarrollan un lenguaje oral próximo al de un normo-oyente

- Su vocabulario es mucho más rico que el de los sordos no IC, la estructuración morfosintáctica de su expresión oral es bastante 
más compleja y correcta que las de los no IC, próxima a la de los oyentes

- Los de más edad, los que llevan más tiempo con el IC, utilizan las funciones abstractas del lenguaje, comprenden y emplean frases hechas, y formas figuradas del lenguaje (análisis de muestras)

- Muestran habilidad en el razonamiento verbal, hacen uso del metalenguaje para explicar conceptos.

\section{Mantienen conversaciones interactivas}

7. Comprenden lo que leen con bastante más precisión que antes.

8. Acceden a la información de su entorno de forma más eficaz.

9. Siguen en mejores condiciones que antes la dinámica de las clases de integración.

Las ventajas que ofrece el IC son tantas que los implantados precoces llegan a desarrollar una auténtica dependencia de su prótesis. Los implantados de buen pronóstico llegan a vivir inmersos en la cultura auditiva, lo mismo que los oyentes. Las nuevas generaciones de sordos no pertenecerán ya a una cultura visual. Tendrán en la audición su principal sentido de intercambio y de contacto con el entorno, la visión pasará a ser un sentido complementario en lo que al lenguaje y a la vida de relación se refiere.

Una aportación importante de los IC es la mejora de la comunicación en los hogares. Los padres, una vez pasada la primera fase de la educación, se entienden mucho mejor con sus hijos, lo que les permite inculcar principios y regular la conducta de forma razonada, dialogando, con mayor facilidad con un hijo sordo eran una fuente de conflictos y de ansiedad.

\subsubsection{El implante coclear ayuda al paciente}

- Haciendo que recupere la capacidad de sensación auditiva.

- El oído distingue diferentes sonidos o ruidos.

- Se perciben mejor los sonidos y ruidos cotidianos como el timbre de la puerta, el del teléfono, la música ambiental, el ruido de los coches y las bocinas, las sirenas de ambulancias, ladridos de perro, etc. (es decir, conectándolo con el mundo sonoro).

- Mejora el seguimiento de las conversaciones normales, con la ayuda de la lectura labial. 
- Mejora la voz porque hay control de la misma, gracias a que ahora se oyen (mediante feed-back auditivo) y pasan a regularse mejor.

La finalidad de la rehabilitación es la de conseguir que el paciente saque el máximo provecho de su Implante Coclear. Por ello, ha de familiarizarse con él y aprender a utilizar un nuevo código de sonidos que le llevará a una mejor comunicación con el entorno.

La colocación de un implante coclear precisa den los pre-locutivos de una obligatoria rehabilitación, siendo esta la base más importante para obtener el máximo rendimiento de este sistema auditivo.

\subsubsection{Los nuevos implantes}

Mucho han cambiado en los últimos 20 años los implantes cocleares, pasando a ser una herramienta fundamental para el tratamiento de ciertos tipos de sordera.

En 2007 investigadores de la Universidad de Michigan y California publicaron que se estaban probando un nuevo tipo de implantes, se trataba de un pequeñísimo electrodo que se implantaría directamente en el nervio auditivo y del que se esperaba ayudase a la gente con sordera total a oír con una amplia gama de frecuencias sonoras. Estos implantes implicaban una mejora auditiva considerable, a la vez que posibilitaban que personas con sordera profunda comiencen a escuchar. En 2007 aún se estaban haciendo pruebas con animales. Otra ventaja que presenta este tipo de implantes es el bajo consumo, este echo facilitaba la posibilidad de crear implantes totalmente integrados en el organismo, pasando a ser totalmente invisibles a terceros.

En Febrero de 2008, el doctor Ángel Ramos, jefe de Otorrinolaringología del Hospital Insular de Gran Canaria, realizó una intervención en un paciente colocándole, lo que se llamó por los medios de comunicación, "oído biónico". El tipo de dispositivo implantado almacena todo el mecanismo en el cráneo.

El oído biónico está compuesto por cuatro elementos: micrófono sensor, sistema electrónico de control y amplificación, un transductor que transforma las señales de audio en vibraciones y una batería. Lo más complejo es la fuente de energía, una batería colocada dentro de la zona craneal. Hasta ese momento no existía ninguna prótesis, ningún sistema ni neuroquirúrgico ni neurológico que permitiera la introducción de una batería en el cuerpo humano.

Todo el mecanismo fue encargado a una empresa puntera que suministra al ejército americano y a conocida marca de telefonía. El factor mas importante es la tecnología de las baterías, que gracias a los móviles, avanza rápidamente.

El paciente debe acoplar al mecanismo un cargador durante dos horas cada dos días mediante un imán, y es posible que dentro de 12 o 15 años deba someterse a una pequeña cirugía local para cambiar la batería. Los investigadores confían en 
que para esa época la tecnología haya avanzado lo suficiente para que la batería a colocar sea definitiva.

Los requisitos son estrictos y para esta primera vez se eligió un paciente que tuviera problemas sólo en un oído. La información y sensaciones que el paciente tendría que aportar era de vital importancia para la investigación por eso se eligió una persona sorda con problemas en un oído.

El sistema podría estar operativo a partir de 2009 y puede cubrir las necesidades de un 5 ó 10\% de pacientes con hipoacusia sensorial.

También existen otra clase de implantes que se están probando en el tronco cerebral y son colocados cuando el nervio auditivo está lesionado o no funciona, pero todavía no son muy eficaces en seres humanos.

\subsection{Ventajas e inconvenientes de los ordenadores en la educación}

Es importante como indica Bork $(1986,138)$ "que los educadores que se están informando acerca de la utilización de los ordenadores en la educación comprendan que al igual que cualquier elemento de la tecnología moderna, por el mismo nos son ni buenos ni malos en las aplicaciones pedagógicas". Los aparatos de tecnología potentes como es el caso de los ordenadores son potencialmente buenos y malos. Es por esto que se hace necesario reconocer estos potenciales y tratar de enfatizar lo bueno y aminorar lo malo, si se desea que el uso de la informática mejore la enseñanza.

Es esencial disponer de material bueno para darse cuenta de las ventajas del ordenador. Este elemento por si solo, al igual que una pieza de un equipo, es de poco interés en la educación. Solamente el desarrollo de una variedad de herramientas educativas y de material basado en principios de currículum sólidos permitirá que el ordenador sea útil en la enseñanza. Aprender con ordenadores significa primera y fundamentalmente japrender! 


\subsubsection{Ventajas de los ordenadores en la educación}

Son múltiples las ventajas que aportan los ordenadores y la informática en general, en este apartado se enuncian algunas de las ventajas desde el punto de vista de la educación.

\subsubsection{Los estudiantes se divierten utilizando los ordenadores}

Este primer factor no debe pasarse por alto, hoy en día la informática tiene una capacidad de motivación muy elevada. La gente de todas las edades tiene constantes referencias de los ordenadores a través de periódicos, televisión y películas. A pesar de que no siempre se les ha descrito de forma favorable, para la mayoría de los estudiantes, especialmente para los más jóvenes, se presenta como un aparato sumamente apasionante. Por lo tanto, los estudiantes están preparados para los ordenadores.

En el campo del aprendizaje las cuestiones motivadoras no pueden descuidarse. Para aprender muchas asignaturas distintas es necesario disponer de una cantidad de tiempo y de esfuerzo considerable. No es fácil muchas veces. Cualquier mecanismo de aprendizaje, como los ordenadores y la informática son capaces de motivar a los estudiantes para que aprendan, cualquier mecanismo que haga posible que se disfrute aprendiendo es muy conveniente.

Uno de los factores más importantes que determinan cuánto aprende la gente es el tiempo que dedican a estudiar, los estudiantes que dedican más tiempo trabajando sobre una asignatura concreta tienen más probabilidad de aprender más sobre esta asignatura. Por lo tanto, deberían enfatizarse los factores motivadores, tales como el ordenador, ya que inducen a que los alumnos empleen más tiempo para aprender.

Bork en su libro escrito en 1986 realizaba una reflexión: "Los estudiantes de hoy en día ¿se divierten utilizando el ordenador por el mero hecho de que es una cosa nueva? ¿Qué pasará dentro de 30 años cuando los estudiantes hayan utilizado los ordenadores durante toda su vida y en la mayoría de actividades para el aprendizaje?". Actualmente han pasado 22 años de esta reflexión y queda claro que los estudiantes no se han aburrido de utilizar la informática para estudiar. La respuesta ha dependido de la evolución del ordenador y de la habilidad de los creadores para producir material de aprendizaje atrayente.

\subsubsection{Individualización}

La mayoría de los teóricos del aprendizaje, cualquiera que sea su tendencia, están deacuerdo con el comentario de Sperry (1997, citado en Bork, 1986) de que aprender es un proceso muy individualizado. Los estudiantes tienen habilidades e historiales académicos diferentes, y probablemente sus opiniones acerca del 
concepto de aprendizaje son diversas. El tiempo necesario para aprender puede que sea distinto de un alumno a otro. Un problema central en cualquier sistema educativo es cómo llegar al estudiante de una forma efectiva. Este problema raramente se trata de una forma adecuada en los sistemas educativos actuales. Así, sorprendentemente, la mayoría de los medios disponibles para la educación masiva permiten hoy en día muy poca educación individualizada. El ambiente en una universidad grandes con más de 200 alumnos por clase, proporciona a cada estudiante un nivel de atención individual evidentemente bajo. Cada uno recibe las mismas en la misma proporción. La educación en masa no permite la individualización.

Un libro permite que los buenos lectores lo utilicen de una manera algo más individualizada; pueden pasar de una sección a otra y hacer referencias a otros libros. De todos modos muchos lectores no emplean estas estrategias. Para muchos lectores menos adiestrados, el libro no es un medio más individualizado que una clase conferencia. En este sentido los libros no permiten más que una individualización reducida.

Disponiendo de buen material, los ordenadores pueden proporcionar una dedicación individual adecuada a las necesidades de cada alumno. Se analiza lo que el estudiante introduce, y se adopta una acción apropiada. Esto no significa que los programas informáticos deban tener miles de variantes. En realidad en muchos casos tan sólo son necesarias unas pocas variantes para una situación concreta. Sin embargo, estas pocas variantes significarán mucho para el aprendizaje del alumno.

\subsubsection{Interacción}

La mayoría de los psicólogos coinciden en otro factor con respecto al aprendizaje: el aprendizaje activo funciona mejor que el aprendizaje pasivo. El pasivo parece como sise tratara de hacer un agujero en la cabeza des estudiantes, de introducirle un embudo y "verter" a través de él los conocimientos. Podría decirse que éste es el criterio implícito de muchos instructores en cuanto a las clases. Pero, con el sistema pasivo, los alumnos no aprenden tanto como podrían.

Realmente los psicólogos cognitivos sostienen que es necesaria la internalización de la materia, y que esta internalización sólo se puede lograr a través de la participación activa de los estudiantes.

Como afirma Jeremy Anglin (1986, citado en Bork, 1986): "La adquisición de conocimientos, ya sea reconocer un modelo, la obtención de un concepto, la solución de un problema, o el desarrollo de una teoría científica, es un proceso activo. Debe considerarse al individuo como un participante activo en el proceso de adquirir conocimientos."

Una analogía muy acertada es la diferencia entre ser espectador de un deporte o practicarlo participando en él. Muchas veces, los alumnos son espectadores que observan al instructor.

La palabra interacción en relación al aprendizaje basado en ordenadores, es un término vago. Un buen modelo para la interacción es el de colocar un grupo reducido 
de estudiantes en el despacho del profesor. Un ejemplo de aprendizaje interactivo ampliamente conocido es el de los diálogos de Platón en los que Sócrates se pasea por Atenas con un grupo de varios alumnos. Sócrates actúa como un interrogador, raramente de información. La idea es plantear preguntas a las cuales los alumnos deben encontrar solución por si mismos, de esta forma se estimula a los estudiantes a participar. Aunque los alumnos pueden hacer preguntas es menos común en este sistema. Este método, que puede seguirse de manera muy parecida con el ordenador puede describirse como "descubrimiento dirigido".

Los desarrolladores de software educativo saben que no todas las interacciones tienen el mismo valor. Una situación en la que aparecen tres o más textos densos para leer en la pantalla y que luego ofrece a los estudiantes la posibilidad de contestar sí o no de forma fortuita o de contestar preguntas a base del sistema de elección múltiple. Seguido de más textos densos en la pantalla, no es un planteamiento interactivo, aunque algunas veces se les permitan ciertas interacciones.

Una de las ventajas más importantes del ordenador en la enseñanza es su capacidad de proporcionar experiencias interactivas de aprendizaje. Nada se hace de forma automática. El uso del ordenador no es una garantía de interactividad. De hecho muchos usos de la informática en la educación desafortunados imponen a los estudiantes un papel pasivo en el que toman decisiones relativamente insignificantes.

\subsubsection{Aprender más deprisa}

Una de las ventajas del ordenador en la educación, que muchas veces no se tiene en cuenta pero que, sin embargo, se ha comprobado, es que los alumnos que utilizan los ordenadores aprenden invirtiendo menos tiempo. La mayor ventaja viene dada por la individualización; es decir, los estudiantes no deben dedicar mucho tiempo a temas que ya dominan cuando utilizan buenos modelos de aprendizaje basados en ordenador. Una vez que se verifica que realmente lo saben, la aplicación puede pasar a otros temas; por lo tanto aumenta el aprendizaje, lo que es muy difícil de conseguir en ambientes de clase en los que se planifica y se verifica uniformemente el ritmo de su desarrollo.

La cuestión del tiempo que se emplea para aprender es especialmente importante en ciertos casos, como por ejemplo, en lugares donde el personal es apartado de su trabajo productivo en una compañía para estudiar algo, o cuando el tiempo empleado en la formación forma parte del tiempo libre del que disponen estos mismos trabajadores. 


\subsubsection{Visualización}

Otra ventaja importante de la informática, es su capacidad para proporcionar información visual interactiva. Como indica Bork (1986, 148), "Ios gráficos son sumamente interesantes en el proceso de aprendizaje", tal como se deduce de las investigaciones acerca del cerebro y de las prácticas educativas comunes. Normalmente los libros de texto escolares contienen dibujos o diagramas en casi todas sus páginas. Con frecuencia los profesores utilizan dibujos de varios tipos en las exposiciones en la pizarra.

De ahí que sea tan importante para el aprendizaje el hecho de que hoy en día los ordenadores puedan proporcionar altas prestaciones en sus capacidades gráficas.

\subsubsection{Comunicaciones}

Una importante ventaja potencial de la informática, es su capacidad para estimular la interacción personal mientras se estudia entre alumnos y profesores o entre alumnos. Estas técnicas de comunicación son muy utilizadas hoy en día, en gran medida gracias a la utilización del correo electrónico. En una clase, desarrollada a través de Internet, un instructor puede comunicarse con la clase entera o con los estudiantes de forma personalizada en cualquier momento. No es necesario, que el alumno se encuentre en ese momento delante de su ordenador, el profesor puede enviar información a través del correo electrónico manteniendo así esta comunicación.

En el proceso de aprendizaje, la interacción con otros estudiantes es muy valiosa. Los ordenadores pueden ser muy útiles para estimular el aprendizaje en grupos de diferentes maneras. Se puede diseñar material informático, específico para grupos de interacción reducidos. De esta forma se pueden asignar a los distintos miembros del grupo trabajos individuales y estimular la discusión entre ellos.

\subsubsection{Inconvenientes de los ordenadores en la educación}

Hace años se presentaba como inconveniente a la utilización de la informática en la educación el hecho de la falta de material educativo realmente correcto. Hoy en día este déficit de material se ha solventado, si bien es cierto que ciertos campos y colectivos no cuentan aún con un material educativo de calidad. El auge de Internet supone que cualquier persona puede crear y mostrar al mundo material de todo tipo. En el caso de material educativo, hay que tener en cuenta que será necesaria la intervención de educadores e informáticos, los primeros crearán el material puramente educativo y los segundos serán los encargados en hacer que este material sea accesible al grupo de alumnos deseado. 
El hecho de se pueda disponer de mucha más información acerca de los alumnos es una posibilidad que puede resultar peligrosa. Los organizadores y los educadores deben prestar atención a la información de que dispongan, y de quiénes tienen acceso a ella y a los tipos de control existentes en cuanto a la precisión de la información. Incluso el volumen de información puedes presentar problemas a los profesores, al proporcionar quizá demasiado material para utilizar de una manera razonable. Desde el punto de vista de la administración de sistemas en red, mantener segura la información de la que se dispone es una de las mayores preocupaciones.

Hace años como indicaba Bork en 1986, el precio de los ordenadores personales resultaba muy alto, de esta forma solamente las personas con recursos altos podían disponer de ellos, actualmente el precio es razonable y prácticamente todas las casas disponen de al menos un ordenador con su conexión a Internet.

\subsection{Ayudas informáticas para alumnos con deficiencias auditivas}

La sordera es una discapacidad que levanta importantes barreras de comunicación: algunas se pueden levantar dando más audición y más lenguaje a las personas sordas, otras permitiendo el acceso a la vida ciudadana común "a pesar" de la discapacidad: es el sentido de muchas medidas sociales como el reconocimiento de la Lengua de Signos y el acceso a un servicio público de intérpretes

En los tiempos actuales la aparición y el desarrollo de las nuevas Tecnologías de la Información y la Comunicación (TIC), han supuesto un cambio importante en los modos de vida y de relación interpersonal. La cantidad de información que circula por Internet es prácticamente ilimitada, ofreciendo enormes posibilidades para la adquisición de conocimientos, la formación, el ocio... Todas estas mejoras, sin embargo, deben ir acompañadas de las habilidades necesarias para su utilización y aprovechamiento.

Dentro de estas habilidades entraría el desarrollo de la lectura y mejor conocimiento sintáctico y semántico de las frases y textos. El concepto de accesibilidad universal debe aplicarse también al diseño de las nuevas tecnologías, que si bien constituyen un factor clave en el proceso de integración del colectivo sordo, también pueden convertirse ellas mismas en nuevas barreras de comunicación. Serían una barrera, si no fuesen adecuadamente adaptadas a las necesidades de cada persona sorda y a su nivel educativo y social.

En estos momentos las nuevas tecnologías que podríamos identificar como las más destacables son las siguientes: la televisión educativa (vía satélite); el multimedia educativo (CD-ROM, compact disk interactivo); Internet (Web educativas, e-mail, chats,...); las redes locales para la formación a distancia (videoconferencias); y el material informático para el autoaprendizaje. Todos estos medios con la capacidad de poder ser adaptados a los sujetos sordos para que puedan desarrollar un proceso de aprendizaje funcional, constructivo, significativo y efectivo, recordemos que se 
han de eliminar barreras que impidan una completa formación del alumnado, por lo que se ha de intentar encontrar nuevas soluciones a los problemas existentes y buscar nuevos conocimientos para que la deficiencia auditiva no sea causa de una incompleta educación. A través de los ejemplos expuestos se puede observar el gran adelanto que ha supuesto las nuevas tecnologías como recurso que se incorpora al aula para servir de ayuda hacia una atención a la diversidad.

Para favorecer los procesos de lecto-escritura en el alumnado sordo se han propuesto y desarrollado diversas estrategias y procedimientos específicos (adaptar textos escritos, formular preguntas claras, precisas y directas, potenciar la consulta del diccionario, etc.), y destacan como procedimientos importantes, aunque no son los únicos, la utilización y presentación de recursos y apoyos visuales a través de los diferentes soportes técnicos y tecnológicos hoy en día disponible.

Cualquier centro escolar de infantil, primaria o secundaria tiene un aula de informática para impartir esta disciplina. Pero, aún así, no se puede decir que las Nuevas Tecnologías estén integradas dentro del sistema educativo; concretamente las aplicaciones didácticas de Internet y software educativo aún no están integradas en el currículum escolar como un recurso didáctico y de apoyo al aprendizaje dentro del aula.

¿Qué se puede decir de los Centros que atienden a las Personas Sordas Adultas? Más concretamente el colectivo citado en este trabajo, en el ámbito de Castilla y León.

¿Los Centros tienen ordenadores suficientes para impartir clases de informática a estas personas? ¿Hay suficientes personas adultas interesadas en recibir este tipo de información? ¿Los educadores motivan a los socios para que participen en las actividades del Centro?

¿Por que será que el número de participantes no son proporcionales con la cantidad de socios?

Se realizan estas preguntas porque muchos educadores dicen que muchas Personas Adultas no están preparadas para aceptar las Nuevas Tecnologías como una metodología nueva para su aprendizaje; y muchos Centros no divulgan esta metodología para no apartar a los alumnos de sus actividades internas.

Si se propone una educación de calidad es necesario, como tantas veces se ha repetido en numerosos foros y diversas publicaciones, introducir o integrar en todas las áreas curriculares, a lo largo de las etapas de infantil, primaria, secundaria y universitaria, esta herramienta de aprendizaje.

Cuando se habla de informática educativa o de las aplicaciones informáticas se hace hincapié en la utilización del ordenador -Internet y software educativo- para el aprendizaje, consolidación, ampliación, refuerzo, introducción a contenidos curriculares correspondientes al nivel en que se encuentre el alumno.

Es decir, que no es objetivo de la informática educativa la enseñanza de la utilización del recurso informático en sí; la adquisición de los conocimientos 
necesarios para su utilización será aprendida y adquirida por el alumno mientras lo usa para aprender lo que corresponda según su nivel y empleando aquellas opciones metodológicas más adecuadas y beneficiosas.

¿Qué usos didácticos y cómo se puede utilizar las aplicaciones informáticas en el aula como respuesta a las necesidades especiales derivadas de la diversidad de los sujetos en los contextos educativos?

Se podría clasificar los usos didácticos de las aplicaciones informáticas, según Alba y Sánchez (1996, 367), en aplicaciones:

- "Dirigidas al aprendizaje de contenidos curriculares (herramienta pedagógica).

- Para favorecer o mejorar habilidades, estrategias y el desarrollo de capacidades básicas (cognitivas, motrices,...) en los procesos de enseñanzaaprendizaje (herramienta cognitiva)

- Orientadas a la rehabilitación e intervención educativa y logopédica (herramienta logopédica)."

En general, las aplicaciones informáticas con alumnos sordos han sido principalmente una mezcla de aplicaciones orientadas al desarrollo de capacidades cognitivas y a la adquisición y el aprendizaje del lenguaje oral y de la lecto-escritura. El software educativo dirigido especialmente a los alumnos sordos está orientado a cubrir la necesidad de apoyarse más en estímulos visuales, programas donde prima lo gráfico sobre lo sonoro, programas que introducen iconos o representaciones en lengua de signos o en bimodal, programas que pretenden favorecer el aprendizaje del lenguaje escrito y oral. Por todos son conocidos los programas como Speechiewer III de IBM, programa DI, Babel, Cuenta- Cuentos, el Proyecto L.A.O. (Logopedia Asistida por Ordenador), programas desarrollados con el Sistema EL (Entornos Lingüísticos) como son los modelos de programas como Pili y Chema, Bla bla bla, programa HALE, Módulos Ejemplares, Frutas, Mi Barrio, entre otros.

Además de estas aplicaciones informáticas destinadas a los alumnos sordos que han sido utilizadas frecuentemente en sesiones individuales 0 en el aula de logopedia con grupos reducidos,

- ¿El software educativo hoy día disponible para utilizar en las distintas áreas y aprendizajes curriculares dentro del aula con todos los alumnos de clase puede mejorar y dar respuesta a las dificultades o carencias que los estudiantes sordos presentan en su competencia lingüística y en su comprensión lectora?

- El profesorado de las escuelas infantiles, de los niveles de enseñanza obligatoria y post-obligatoria, e incluso de la universidad: ¿qué aplicaciones informáticas podrían emplear con sujetos sordos o con implantes cocleares dentro del aula?

En la actualidad es muy numerosa la producción de software o programas educativos pensados para su uso en contextos escolares -aplicaciones informáticas 
para aprendizajes curriculares- para destinatarios que no presentan necesidades educativas asociadas a discapacidades psíquicas, cognitivas o sensoriales, sobre las distintas áreas curriculares para las diferentes etapas educativas. La aplicación y utilización didáctica de estos programas facilita al mismo tiempo el desarrollo de estrategias y procesos cognitivos simples y complejos, así como de habilidades lingüísticas, motrices y sociales, y, por otra parte permiten la realización de tareas escolares seleccionadas (programas cerrados) o diseñadas (programas abiertos) según posibilidades, ritmo de aprendizaje, etc., de los sujetos.

Del mismo modo, la utilización de estos programas en muchos casos puede facilitar la evaluación de los aprendizajes de los estudiantes en el aula, así como explorar o averiguar las estrategias que utilizan o no conocen ante situaciones de aprendizaje seleccionadas o diseñadas para ello -esta es una de las principales ventajas de los programas abiertos y semiabiertos- como ejemplo Java, utilizado en este trabajo.

El avance tecnológico ha aportado, en general, al ser humano nuevas y mayores posibilidades de desarrollar un modo de vida más completo y, a su vez, de más amplios horizontes. La incorporación cotidiana del progreso en la tecnología ha supuesto, de esta manera, un progreso social.

Sin embargo, la construcción de una sociedad cada vez más avanzada comporta al mismo tiempo una organización de ésta más compleja, en la que continuamente nuevos y más específicos conocimientos y habilidades se exigen al individuo si éste quiere hacer uso de las posibilidades que se le ofrecen.

En las personas con algún tipo de discapacidad la progresiva complejidad del medio social puede tener el efecto contrario al buscado por el progreso social. En lugar de facilitar y hacer más simple el desenvolvimiento de éstas personas en el medio común, pueden crear barreras insuperables al limitar o impedir, dada la naturaleza y grado de su discapacidad el acceso a los medios tecnológicos.

En el ámbito de la tecnología, si a un sistema tecnológico se le configura de tal modo que son necesarias capacidades cognitivas, sensoriales y motrices del individuo, normalmente discapacitado, estaremos generando un proceso de marginación tecnológica y, en consecuencia, social.

"Las nuevas tecnologías, en el mundo actual y de cara al futuro, abren un camino de esperanza en la Educación Especial y en la vida ordinaria de las personas con necesidades especiales." (González y López, 1994).

El desarrollo de la ciencia y la técnica ha posibilitado diversas soluciones a diferentes problemas de la sociedad; en este sentido la detección de la discapacidad así como la rehabilitación de las personas discapacitadas no queda excepto de ello. Hoy es un problema de la ciencia la atención de todas las personas en un contexto integrador y normalizador con una respuesta a sus necesidades que permita su integración social.

El factor tecnológico es una de las herramientas que contribuye a la detección, rehabilitación e integración de las personas que presentan algún tipo de limitación; en tanto que, por medio de las aplicaciones tecnológicas se puede llegar a mejorar 
las condiciones fisiológicas, incrementar las capacidades funcionales y aumentar el nivel de independencia, adaptando los entornos de la persona para aumentar su nivel de participación social.

Finalmente, la utilización didáctica de la conexión a Internet como herramienta de aprendizaje y de trabajo -aún no generalizada dentro de la escuela-, representa una posibilidad de aplicación informática con usuarios sordos para favorecer y desarrollar la comprensión lectora. El uso de Internet en el ámbito educativo de la escuela y Centros Culturales para Personas Adultas puede facilitar y contribuir a la mejora de habilidades, capacidades y aptitudes, en general, y además es un recurso y medio didáctico para favorecer la alfabetización tecnológica.

Los ordenadores y sus periféricos ofrecen fundamentalmente a los profesionales de la educación la tan necesaria potenciación de la información visual en relación con la intervención ante alumnos con sordera. Pero no se agota ahí su potencial, tal y como refiere Velasco (1997, citado en Ferrer, 2002), son variados los motivos que aconsejan el uso de este tipo de ayudas en personas con deficiencias auditivas. Destacan entre otras las siguientes:

- Facilitan su educación en todas las etapas madurativas.

- Motivan de forma especial comparando con el uso de otro tipo de soportes.

- Posibilitan una tarea educativa sistemática e individualizada.

- Mejoran su competencia lingüística a través de diversas herramientas: programas de habla, voz, vocabulario, labiolectura, comprensión-expresión, capacidades metalingüísticas, lecto-escritura...

- Sustituyen al profesional especializado en tareas pesadas, repetitivas, ante las que el ordenador es más paciente y no se cansa nunca de dar refuerzos.

- Posibilitan la expresión de capacidades del alumno con sordera que sin el medio informático pasarían desapercibidas.

- Aportan elementos integradores por cuanto ante el ordenador está en igualdad de condiciones que el oyente.

- Son útiles en tanto constituyen elementos de futuro. La familiarización con las herramientas informáticas no sólo facilitará la vida adulta sino que posibilitará su inserción laboral.

- Potencian la autonomía al poder acceder a la información y la comunicación sin intermediarios.

- Ayudan en contextos muy diferentes: vida social, pública, cultural, el hogar...

En relación con el lenguaje sobre lo que centraremos nuestra atención, una de las ventajas más notables de los entornos informáticos es la amplia flexibilidad que tienen, lo cual permite contar con software que favorece la labor en diversas áreas. 
Se encuentran soluciones que se centran en la mejora de determinados aspectos del habla, existe una amplia variedad de programas que sirven como apoyo para trabajar de forma individual o global los diferentes niveles de análisis del lenguaje (léxico, morfología, sintaxis...), independientemente del tipo de código que se pretenda desarrollar, lengua oral o lengua de signos; se cuenta con desarrollos específicos para el desarrollo de la lecto-escritura, proliferan los materiales para la formación de los profesionales en este ámbito...(a lo largo de lo siguiente puntos se describen algunos de estos ejemplos).

\subsubsection{Ayudas informáticas para la visualización de parámetros del habla}

En este apartado se recogen ejemplos de programas en cuya base está ofrecer una retroalimentación visual de la expresión oral para que los niños sordos, en ausencia de un feed-back auditivo, puedan ensayar determinados patrones relativos al modo de articulación, la entonación, la intensidad...

\subsubsection{El Sistema VISHA}

Como indica Belloch (2006) el departamento de Ingeniería Electrónica de la Universidad Politécnica de Madrid bajo la dirección de Santiago Aguilera, presentó el sistema VISHA (Visualización del habla) resultante de la investigación desarrollada en Tecnología del Habla aplicada al español. El sistema Visha consta de un conjunto de componentes de hardware (memoria, tarjeta de sonido, etc.) que deben instalarse en el ordenador, y un conjunto de programas de software que permiten el análisis de los parámetros del habla, la síntesis y codificación visual de la señal acústica y el reconocimiento de los sonidos. Es un sistema, por tanto, muy adecuado para el logopeda en los procesos de rehabilitación y estudio del habla.

El software incluido en el sistema Visha, se compone de cuatro programas:

- PCVOX. Permite almacenar la voz para su posterior estudio mediante la representación visual de sus parámetros más representativos. Los parámetros con los que trabaja son: espectograma o sonograma, la forma de la onda, intensidad, entonación. Los segmentos de sonidos pueden ser ampliados, para un estudio más detallado, unidos a otros segmentos, etc.

- ISOTON. Permite visualizar en tiempo real las características de la emisión sonora de los sujetos (intensidad, tono y sonoridad), además es posible imprimir las curvas representativas de la emisión en sus tres parámetros, lo que puede facilitar el análisis de la evolución de las producciones del sujeto. El programa incluye una serie de juegos orientados a la rehabilitación logopédica, en los que se trabaja la entonación, el ritmo, las pausas, la intensidad, etc. 
- SAS. El programa SAS (Sistema de Análisis del Sonido) es un programa concebido para el entrenamiento articulatorio de las vocales en personas que presentan trastornos del habla. Se basa en una reproducción visual de los órganos fonoarticulatorios en el momento de producción de las vocales, con el fin de que sirvan de patrón o referente para el usuario que intentará imitarlos. La posibilidad que tiene el usuario de escuchar sus propias producciones en el mismo momento en que se producen, actúa como elemento de retroalimentación, especialmente importante en los procesos de intervención logopédica.

Todos estos procesos orientados a tomar conciencia del propio aparato fonador y de los movimientos articulatorios implicados en la emisión de los fonemas se llevan a cabo a través de diferentes juegos que facilitan la motivación del sujeto.

- PC AUDIOMETRIAS. Mediante este programa se pueden realizar audiometrías, guardando la información de las mismas en un archivo historial de cada persona.

- EDITOR PREDICTIVO. Es un programa que pueden utilizar las personas con discapacidad motora y dificultades en la emisión de sonidos. El Editor Predictivo es un editor de texto, en el que se utiliza un sistema de barrido para, mediante un pulsador, seleccionar el texto a introducir. Utiliza dos métodos para agilizar la introducción del texto:

- Predicción de la palabra a escribir a partir de las letras indicadas por el usuario.

- Utilización de frases programadas, que pueden ser insertadas en el texto con una sola pulsación.

- TELECO. Es un sintetizador de voz. Existen dos versiones del sintetizador:

- Realiza la síntesis de voz de un texto escrito en un editor.

- Como programa que actúa en segundo nivel, al que se puede enviar texto, para que sea sintetizada la voz, desde cualquier programa del ordenador 


\subsubsection{Speechviewer}

Es el visualizador fonético de IBM, este programa proporciona información visual acerca de diversos parámetros acústicos relativos al habla: presencia/ausencia, intensidad, tono, segmentos fonológicos, espectograma.

Frente al anteriormente visto, cuenta con la ventaja de ofrecer interfaces más conseguidos para niños tanto para comprender la relación entre el fenómeno visual y oral como para la motivación, además de no precisar la instalación de tarjetas de sonido especiales.

De entre los muchos objetivos que el programa plantea, aquellos que podrían resultar de mejor aplicación en personas sordas serían los siguientes:

- Aumentar conocimiento de la presencia de sonido

- Control de vocalización sostenida a intensidad especificada

- Discriminar diferentes grados de intensidad y potenciar su control tanto para incrementar como para disminuir

- Aumentar definición de sílabas en personas que las omiten, marcando los distintos golpes de voz

- Mostrar diferencias entre sonidos sordos-sonoros

Es importante tener en cuenta que cuando se hace uso de los ejercicios relativos a segmentos lingüísticos (precisión, encadenamiento, contraste de fonemas), el programa siempre compara la ejecución que recoge del niño/a en cuestión con un modelo. Los patrones orales de personas sordas están muy alejados de lo normativo, de modo que, aun consiguiendo producciones que para el oído humano resultan completamente inteligibles respecto a su objetivo, el programa puede estar continuamente considerándolas como erróneas al contrastarlas con el modelo. Por tanto, "se debe ser muy cuidadoso respecto a los objetivos que se persigan en niños con sordera a la hora de utilizar programas informáticos de estas características." (Ferrer, 2002, 13)

\subsubsection{Proyecto Fressa 2008}

El proyecto Fressa 2008 comprende un conjunto de programas informáticos realizados por Jordi Lagares Roset destinados a personas con deficiencias motrices y deficiencias auditivas. Dentro de éstas últimas que centran el desarrollo del presente trabajo destacan tres programas:

- Globus 3, consistente en un visualizador de sonidos que a través de ejercicios diferentes permite al alumno obtener una representación gráfica tanto de la presencia/ausencia como de la intensidad de su voz, permitiendo el control 
sobre la modulación de tal parámetro a partir de información visual en lugar de auditiva.

- Reconeixement de fonemas. En un entorno lúdico ofrece la posibilidad de practicar la producción de fonemas. Al igual que los anteriores, compara la señal de entrada ofrecida por el niño con un patrón previamente almacenado.

- Reconeixement de vocals. Exactamente igual que el anterior pero trabajando con vocales.

Este tipo de programas resulta de gran interés al poner a disposición de los profesionales de forma gratuita y accesible a través de Internet (www.xtec.cat/ jlagares) software que ofrece prestaciones similares a las proporcionadas por los dos ejemplos antes descritos. Sólo será necesario contar con un PC dotado de tarjeta de sonido y un micrófono.

\subsubsection{Ayudas informáticas para la estimulación del desarrollo del lenguaje}

Son múltiples los programas que han sido creados, y que siguen surgiendo, en relación con el desarrollo del lenguaje. Muchos de ellos tienen como esquema general la presentación de estímulos gráficos a través de la pantalla del ordenador que se convierten en la excusa para trabajar determinadas áreas como el nivel léxico (generalmente deficiente en niños con sordera), aspectos morfológicos, la construcción de frases utilizando correctamente todos sus componentes...

Citaremos en este apartado algunos de los programas que mayor extensión han tenido en el ámbito de la intervención de niños con deficiencia auditiva.

\subsubsection{LAO}

LAO (Logopedia Asistida por Ordenador). Fue uno de los primeros desarrollos que consiguió un mayor calado en el ámbito específico de la intervención en niños con deficiencia auditiva. Recogiendo la descripción ofrecida por Ruiz y Sáiz (1998, citado en Ferrer, 2002), este programa incorpora diversos componentes:

- EL (Generador de Entornos Lingüísticos) que permite confeccionar aplicaciones con el objetivo de trabajar estructuración espacio-temporal, discriminación auditiva, percepción visual, memoria, desarrollo léxico y morfosintáctico. Se acompaña de un ejemplo: "Casa y Familia" que permite observar las posibilidades cuanto a actividades que este generador ofrece.

- SIFO (Segmentación Silábica y Fonológica), cuyo objetivo es el de trabajar habilidades metalingüísticas relativas a la segmentación silábica y fonológica dada su estrecha relación con la lectura. El módulo que trabaja la 
segmentación silábica se concreta en la actividad "La Feria", mientas que "Épocas" permite practicar con el fonema. La base de datos gráfica y textual que sirven como base para el desarrollo de las actividades es modificable por el profesor de modo que permite la individualización del trabajo.

- INTELEX. Compuesto por una parte de un diccionario (Intelex Diccionario) que ofrece la definición de doce mil entradas léxicas aportando información complementaria a través de ejemplos, dibujos, escenas, apoyo basado en imágenes relativas a la Lengua de Signos... El diccionario puede cargarse y permanecer activo para consultas cuando se le requiera mientras se realiza la lectura de textos.

Por otra parte, está el "Intelex Didáctico" que permite la realización por parte del profesional de ejercicios variados relacionados con textos, frases y palabras de manera completamente individualizada. Además, cuenta con otras posibilidades como por ejemplo "Intelex Tus Cuentos" que trabajan en el alumno la composición de textos narrativos para practicar en habilidades relativas al conocimiento de la estructura del texto.

LAO nació con la intención de que el profesional encargado de la intervención pudiera hacerse cargo de desarrollar sus propias actividades. En el momento actual, existe una amplia variedad de programas que obedecen al concepto de "sistema de autor", es decir, el educador puede crea sus propias actividades, esto implica una mayor cultura informática entre los profesionales de la educación.

\subsubsection{PHONOS I y PHONOS II}

El primero de ellos tiene como objetivo esencial el trabajo de vocabulario con el niño mientras que el segundo ofrece la posibilidad de iniciar el trabajo de combinación léxica favoreciendo la estructuración de frases simples. Resultan programas que simplemente juegan con la posibilidad de que el ordenador ofrezca un medio más atractivo para el niño por cuanto ninguna de las actividades propuestas convierte en imprescindible al ordenador. En este sentido, "la informática juega un papel de apoyo pedagógico sin modificar en exceso el trabajo de intervención". (Ferrer, 2002, 15) 


\subsubsection{DI. Programa de Iniciación en la Lectura Labial}

Como indica su creadora Fernández-Escandón, el programa DI es el resultado de la aplicación de la informática a la metodología tradicional de intervención logopédica en el entrenamiento de la lectura labial.

Con el programa DI se ofrece la posibilidad de visualizar en movimientos los puntos de articulación de cada fonema y las secuencias articulatorias que dan lugar a la palabra.

Simultánea y progresivamente a la visualización de la secuencia articulatoria es posible obtener la representación escrita y pictórica de su significado.

"Se ofrece una herramienta de trabajo aplicable en las primeras etapas de entrenamiento en la lectura labial, que facilita y hace más atractiva la tarea de aprendizaje, discriminación y fijación de los puntos de articulación de cada fonema y las secuencias articulatorias que dan lugar a la palabra."

El programa Di es un programa educativo dirigido a la población sorda, niños y adultos, que precisen ser iniciados en el aprendizaje de la lectura labial.

La simplicidad en el manejo conseguido en la implementación hace posible que:

- Resulte accesible a aquellos profesionales de la logopedia que carezcan de conocimiento informático.

- Pueda ser utilizado de forma individual por el beneficiario sordo para el afianzamiento y ejercitación de los conceptos trabajados previamente con el logopeda.

Este programa aunque esté especialmente diseñado para personas con problema auditivo es también interesante para el tratamiento de algunos problemas del lenguaje, rehabilitación de los trastornos de articulación, e incluso para el aprendizaje de la lectoescritura.

\subsubsection{EXLER}

EXLER fue creado por la Escuela de Patología del Lenguaje del Hospital San Pablo de Barcelona, enmarcado en el proyecto R\&D Programme Medical and Health Research 1987-1992 de la Comunidad Económica Europea. Es un ejemplo de aplicación no pensada en principio para niños con deficiencias auditivas sino para personas con afasias adquiridas, pero que también resulta de aplicación en este ámbito de referencia.

Se trata de un programa polivalente subdividido en diversos módulos. Su campo de aplicación abarca desde la rehabilitación de las funciones cognitivas en adultos o niños hasta el trabajo de los distintos aspectos cognitivos en el aula normal. 
- Módulo 1

- La Granja. La escena de una granja da pie a introducir palabras agrupadas en dos grandes categorías: Cosas/Herramientas y Animales. La categoría Animales se ampliará con otros animales no representados en la escena inicial.

- La Casa. La escena inicial introduce vocabulario del exterior de una casa y del jardín de la misma. Durante el ejercicio se ampliará el vocabulario de cada uno de los dos subconjuntos temáticos.

- Los Niños. Este ejercicio, que se inicia con unos niños leyendo en su habitación, trabaja tres categorías: Muebles, Juguetes, Cosas para leer y escribir. A medida que avanza el ejercicio, estas categorías se ampliarán con otros elementos no presentes en la escena inicial.

- La Cocina. La escena de una familia en la cocina de una casa da lugar a trabajar un conjunto de veinte palabras y a la introducción del concepto Recipiente/No recipiente.

- El Baño. La escena inicial presenta el cuarto de baño de una casa, dando lugar a trabajar un total de veinte palabras de uso cotidiano.

- Módulo 2

- El Pescador. La historia de un pescador que va a pescar al río nos da pie para trabajar el vocabulario del entorno de su casa, los instrumentos de pesca, el paisaje, el pez y el comedor.

- El Pueblo Pescador. Un pueblo de pescadores nos permite trabajar el vocabulario básico en torno al ambiente de la pesca y de algunos elementos del fondo marino.

\subsubsection{Clic}

Clic es una de las herramientas con mayor incidencia en nuestro país, fue creado por Francesc Busquets. Este software gratuito y también de acceso libre a través de Internet permite crear distintos tipos de actividades: rompecabezas, asociaciones, sopas de letras, crucigramas y actividades de texto; contando con la posibilidad de incorporar en las mismas texto, imágenes, sonidos e incluso vídeos. A través de la red telemática educativa de Cataluña (http://clic.xtec.net/es/clic3/index.htm) se puede descargar tanto el programa como múltiples actividades relacionadas, entre otras, con el área del lenguaje. Todas han sido creadas por diversos profesionales de muchos puntos del país y han sido depositadas en dicha Web para su difusión y utilización por parte de cualquier persona interesada en su uso. Existen de hecho ejemplos de actividades desarrolladas por profesionales vinculados al área de la sordera que dirigen sus objetivos a aspectos de especial interés para sus estudiantes. 
Clic 3.0 es una plataforma para la realización de actividades educativas que funciona en entornos Windows (3.1 o superior), y está disponible en siete idiomas: catalán, español, vasco, gallego, francés, inglés y alemán.

Clic es el "padre" de JCLIC herramienta de la que hablará mas adelante y que constituye una pieza muy importante en esta investigación. De hecho todos los materiales creados con Clic son compatibles para JClic como se indica en su Web oficial (http://clic.xtec.net/es/clic3/index.htm).

\subsubsection{Ayudas informáticas para el desarrollo de la lecto-escritura.}

Todos los programas informáticos o software educativo para el desarrollo de habilidades y estrategias cognitivas y lingüísticas, programas de informática educativa -abiertos y cerrados- para aprendizajes curriculares, programas multimedia, Internet, así como diversas aplicaciones de programas estándar programas generales destinados a una población más amplia como procesadores de texto, programas de autoedición, base de datos, hojas de cálculo, etc.-, pueden ser utilizados con fines didácticos en este caso para favorecer la comprensión lectora y, por consiguiente, los aprendizajes curriculares, con los medios o adaptaciones necesarias y adecuadas a las posibilidades de los alumnos sordos.

\subsubsection{Signe}

Programa creado por Benjamín Vidiella (citado en Ferrer, 2002), disponible de forma gratuita a través de la red telemática educativa de Cataluña (http://www.xtec.es/recursos/prg_educ/signe.htm) en su sección dedicada a la educación especial. Permite combinar cada unidad léxica del texto escrito con una representación icónica, siendo en principio pensado para utilizar imágenes relativas a la Lengua de Signos; si bien, el hecho de que permita incorporar las imágenes que desee el profesional, abre la posibilidad de utilizar cualquier tipo de representación gráfica (signos, sistemas pictográficos, fotos...) que dé pie a una asociación significante-significado en la lectura. 


\subsubsection{SIMICOLE}

Su elaboración fue llevada a cabo por la Unidad de Investigación Acceso de la Universitat de València (http://acceso.uv.es), en colaboración con la Asesoría Universitaria de Estudiantes con Discapacidad de la misma universidad y la Federación de Personas Sordas de la Comunidad Valenciana (FESORD-CV).

Los programas multimedia destinados a diversos aprendizajes curriculares constituye otra oportunidad poco conocida y explorada con estudiantes sordos para la mejora y el desarrollo de los procesos que participan en la comprensión lectora; es interesante mencionar el Programa SIMICOLE como un claro ejemplo de aplicación multimedia para favorecer la comprensión lectora de adultos sordos.

"El objeto de esta iniciativa es facilitar recursos para que puedan mejorar sus destrezas lectoras e incorporarse consecuentemente con mayores garantías de éxito a programas académicos y profesionales" (Ferrer et al., 2004, 11, 12).

Se ha planteado un modelo de de instrucción estructurado en dos fases marcadas fundamentalmente por dos aspectos diferenciales:

- Primera fase se ha desarrollado actividades que enseñan, practican y consolidan estrategias para comprender, seleccionar y estructurar las ideas principales del texto.

- Segunda fase el aprendiz prosigue la instrucción de forma individual asistido por ordenador mediante un programa SIMICOLE 2002.

Esta herramienta informática sirve de apoyo en el marco de un programa global denominado LEECOM (LEE y COMprende) cuya finalidad es la mejora de habilidades implicadas en la comprensión lectora en personas sordas adultas.

El programa informático queda conformado por un total de 30 textos relativos a diez temas (Ocio y Tiempo Libre, Los Medios de Comunicación, El Mar, La Ciencia, La Ecología, Política y Economía, La Mujer, Valencia, La Salud y La Universidad), que se reparten en tres niveles de dificultad a razón de 10 textos por nivel. Cada uno de los textos cuenta con:

- Elementos que ayudan a situar a la persona en el contenido del texto:

- El título, que anticipa la temática.

- Una imagen que ayuda a evocar ideas relacionadas con el texto.

- Una introducción que centra con mayor concreción el tema que desarrolla el texto. Dicha introducción aparece asimismo en Lengua de Signos Española.

- Un texto en el que se va a contar con la definición de palabras y expresiones de difícil comprensión, tanto en lengua oral escrita como en LSE.

- Un conjunto de ejercicios de entrenamiento y práctica donde se pretende:

- Mejorar aspectos morfológicos y sintácticos de dificultad especial para las personas con sordera 
- Incrementar el repertorio léxico de la persona y practicar con palabras y expresiones contenidas en el texto

- Situar en la información esencial del texto y ayudar a estructurar su información

Cada uno de los ejercicios alude a un objetivo operativo, de modo que internamente el programa acumula los resultados que la persona va alcanzando en relación con una taxonomía de objetivos referida a tres bloques (aspectos léxico-semánticos, aspectos morfosintácticos y aspectos relativos a la comprensión del texto) que se subdivide en diversas áreas.

- Un ejercicio de resumen en su doble finalidad: como instrumento de práctica que permite incidir sobre la mejora de la comprensión lectora y como soporte para el proceso de evaluación de la comprensión lectora, como fuente de información para quien quiera conocer aspectos sobre los que intervenir en el proceso de comprensión, tanto de carácter lingüístico como cognitivos en relación con la selección y organización de ideas.

- Un ejercicio de inferencia en el que se plantea la respuesta a una cuestión que obliga a trascender la información del texto, lo cual nos permite aproximarnos a la "comprensión situada" del texto, que va más allá de la representación de la información presente de modo explícito.

- Una síntesis de los resultados que permita al aprendiz situar cuantitativamente su evolución en relación con los tres bloques genéricos de ejercicios para el texto que está desarrollando y para el conjunto de textos realizados hasta ese momento.

- Un módulo de acceso restringido para el tutor en el que se puede acceder a la consulta de textos, ejercicios y resultados para todos los aprendices. 


\subsubsection{Ayudas informáticas para el aprendizaje de la lengua de signos}

Las posibilidades que ha abierto el tratamiento, almacenamiento y reproducción de la imagen desde un punto de vista informático han abierto posibilidades antes impensables para la transmisión de la lengua de signos, bastante limitada con anterioridad por la ausencia de una representación escrita compartida por sus usuarios. Por ello, es de remarcar la aparición de determinadas ayudas que suponen apoyos de bastante consideración tanto para el aprendizaje como para el avance en la investigación lingüística de este tipo de lenguas.

\subsubsection{Gestos}

Programa dirigido a personas que quieran iniciarse en la lengua de signos española. Desarrollado por el Institut de Ciències de L'Educació de la Universitat de Barcelona.

\subsubsection{2. ¡A Signar!}

Es un programa interactivo elaborado por FESORD (Federación de Personas Sordas de la Comunidad Valenciana) para el aprendizaje a distancia de la Lengua de Signos.

Está dividido en 6 grandes áreas temáticas relacionadas con entornos de nuestra vida cotidiana: familia, escuela, ocio, salud, personas, viajes y vacaciones. Incluye tres niveles de dificultad con vocabulario específico, textos, juegos y ejercicios interactivos apoyados con vídeos en Lengua de Signos.

Puede adquirirse en: $h t t p: / / w w w . f e s o r d . o r g / m a t e r i a l e s \_f r m V e n t a . a s p ? i d=103$

\subsubsection{Signos 97-98 (Diccionario de Lengua de Signos Española)}

Desarrollado por Joaquín Rodrigo de la Universidad de Alicante. Incluye más de 1000 entradas visuales incorporando un análisis de los parámetros de cada una de ellas (configuración, lugar, orientación, movimiento y componentes no manuales). El programa proporciona un signo a través de un vídeo, una definición de la palabra, la posibilidad de consultar sinónimos y los parámetros del signo. 


\subsubsection{DILSE. Diccionario Básico de Lengua de Signos}

Recopila una parte del vocabulario básico de la Lengua de Signos Española. Presenta una sección de juegos interactivos en los que el usuario podrá poner a prueba su nivel de comprensión de la Lengua de signos (usuarios oyentes) ó del español (usuarios sordos).

La búsqueda de los signos se puede hacer de forma bidireccional: a partir de la lengua de signos española ó a partir del castellano.

\subsubsection{DILSE. Diccionario de neologismos de la lengua de signos}

Contiene signos nuevos que han ido surgiendo en distintos ámbitos especializados: educativo, jurídico, sanitario, etc. acompañados de una palabra o expresión del español por la que se puede traducir, una definición y un ejemplo. También recoge una definición en Lengua de Signos Española y una ilustración para explicar el significado del signo de forma más clara. La búsqueda de entradas léxicas es bidireccional: se puede acceder a los signos a través de la palabra o desde la descripción formal de las características de cada uno de los signos.

Más información y distribución: http://www.fundacioncnse.org

\subsubsection{Diccionarios online}

Actualmente se empiezan a encontrar diccionarios en red, lo que popularmente se ha dado en llamar "diccionarios online". La LSE también se ha aprovechado de este tipo de recursos, en http://www.planetavisual.net se puede acceder a un diccionario en red en LSE.

La página http://www.manosquehablan.com.ar/diccionario contiene un completo Diccionario de la Lengua de Signos Argentina, además de presentar los diferentes alfabetos dactilológicos de varios países como, Alemania, Argentina, Brasil, Chile, España, Estados Unidos, Francia, Italia, Méjico, Noruega y Perú.

\subsubsection{Aprendizaje a través de Internet}

Muchos contenidos son los que se pueden encontrar en Internet para aprender Lengua de Signos, en la mayoría de las ocasiones cursos online y no gratuitos.

Por ese motivo cabe destacar el proyecto Ensigna, desarrollado por la Universidad de Santiago de Compostela, que tiene como objetivo aplicar las nuevas tecnologías de información y la comunicación de ultima generación para llevar a cabo experiencias innovadoras para la enseñanza y el aprendizaje de la Lengua de Signos Española. 
Se trata de un curso pilo que se basa en la utilización de una metodología de enseñanza innovadora que favorezca el aprendizaje de LSE utilizando para esto las TIC que favorecen la comunicación multidireccional y por lo tanto la interactividad entre los usuarios finales.

Para mas información se puede consultar la página http://ensigna.cesga.es

\subsubsection{Ayudas informáticas para la formación en sistemas de comunicación aumentativos de aplicación en niños con deficiencias auditivas.}

Bajo la coordinación de Santiago Torres se han desarrollado dos cursos en formato CDROM de gran valor para el aprendizaje y práctica de la Comunicación Bimodal por un lado, y de la palabra complementada por otro, aprovechando como en los casos recién descritos para la lengua de signos la posibilidad de presentar simultáneamente imagen, texto y vídeo.

El Bimodal y la Palabra Complementada son sistemas de Comunicación Aumentativa usados por personas con deficiencias auditivas severas y profundas.

"El primero usa signos manuales con valor lingüístico, por lo general tomados de la lengua de signos usada por los sordos del lugar, mientras que el segundo usa complementos o códigos manuales sin valor lingüístico, encaminados simplemente a despejar las ambigüedades de la lectura labial" (Torres, S. 2003, citado en Sebastián, 2005).

Para facilitar la enseñanza de ambos sistemas, bajo la coordinación de Santiago Torres de la Universidad de Málaga, se han desarrollado cursos en formato CD-Rom que presentan simultáneamente imagen, texto y video.

\subsubsection{Bimodal - 2000}

El bimodal expresa un mismo concepto mediante dos sistemas de códigos independientes, el acústico, dirigido a la audición, y el manual dirigido a la vista.

El Programa Multimedia para el Aprendizaje del Bimodal, es un curso multimedia para el aprendizaje autónomo de los signos manuales. Se encuentra dividido en tres partes bien diferenciadas:

- Introducción: hace un recorrido por los aspectos compartidos por el bimodal y la Lengua de Signos, como es la dactilología, el género, el número, los tiempos verbales, etc.

- Vocabulario: Se ha ordenado por los campos semánticos más relacionados con el ambiente socio-educativo del niño. 
- Frases: Se presentan unas 200 frases, se muestra como se hacen en bimodal y también en lengua de signos.

Cada parte contiene 18 lecciones, en cada lección nos encontramos con 10 frases y de 26 a 28 palabras.

Más información y descarga:

http://www.juntadeandalucia.es/averroes/recursos_informaticos/programas/bimodal2 000.php3 y

http://www.juntadeandalucia.es/averroes/recursos_informaticos/programas/bimodal2 000_2.php3

\subsubsection{La Palabra Complementada}

El CD-Rom de La Palabra Complementada es un programa multimedia interactivo destinado a las personas que deseen aprender La Palabra Complementada de forma progresiva y visual, incorporando secuencias de video para una mejor comprensión de los conceptos. Se estructura en un tutorial y ocho lecciones

Pueden conseguirse en la página Web http://www.juntadeandalucia.es/averroes/recursos_informaticos/programas/lpc.php3.

\subsubsection{Dactilología}

El alfabeto dactilológico es el alfabeto manual utilizado por la comunidad sorda. Utiliza posiciones de la mano para cada una de las letras del alfabeto ordinario. No suele utilizarse como sistema de comunicación sino como complemento a la lengua de signos para referirse a nombres propios o para expresar alguna idea cuyo signo no conocemos.

El programa "clic" "Leo, escribo y signo" utiliza el alfabeto dactilológico.

En el portal www.planetavisual.net disponemos de un traductor dactilológico: http://www.planetavisual.net/right/diccio/index.htm. 


\subsection{Tecnologías de ayuda para la vida cotidiana de aplicación en el medio escolar}

Nuestra vida cotidiana incluye múltiples situaciones donde se precisa de información auditiva para comprender nuestro entorno y anticipar sucesos. La escuela no es un medio ajeno a las mismas: unos golpes en la puerta advierten que alguien quiere entrar al aula debiéndose interrumpir lo que en ese momento estuviera sucediendo, los timbres y/o sirenas informan de que finaliza una actividad y se pasa a otra (entrar a clase, iniciar el recreo, terminar la jornada...); un niño precisa en ocasiones de un teléfono en el centro para comunicarse con sus padres y avisarles de que necesitaría acudir al médico porque se encuentra mal; en un vídeo documental que un profesor decide mostrar en clase para reforzar un determinado aprendizaje el acceso a su información podría quedar bastante restringido para un alumno sordo...

Ante este tipo de situaciones podríamos tener dos maneras de enfocar la búsqueda de soluciones:

a. Podríamos juzgarlas como irrelevantes: La persona que toca la puerta tarde o temprano entrará en el aula y el niño sordo será consciente de su presencia. Si el resto de los niños comienzan a recoger sus cosas y toman el bocadillo, el niño sordo no será el único que quede sentado en el aula. $A$ los padres siempre puede haber otra persona que sea quien requiera su presencia a través del teléfono. Siempre habrá quien de forma resumida cuente "de qué va" el vídeo que se está mirando.

b. O podríamos considerar la introducción de determinadas ayudas que acercaran al niño sordo la información de forma inmediata. Un interruptor conectado a una luz intermitente podría avisar de que alguien desea entrar en clase. La sirena del colegio podría originar también una luz intermitente que denotara la presencia de tal información acústica. Un dispositivo telefónico para sordos podría permitir la comunicación directa del estudiante con sus padres, o el uso del servicio de intermediación podría hacer llegar la información compatibilizando múltiples formas de comunicación a distancia. La previsión de contar con material subtitulado podría solventar si los procesos lectores son suficientes el acceso a la información en material videográfico.

Optar por la primera vía suele ser en ocasiones justificado bajo criterios económicos. Si bien, otras veces no son tales aspectos los que impiden la adopción de lo que se recoge como segunda alternativa, sino otros más preocupantes: factores actitudinales. Téngase en cuenta que no se está discutiendo acerca de la conveniencia de hacer un determinado desembolso, se está simplemente cuestionando si facilitar o no un acceso igualitario a la información circundante (lo cual también nos define como seres sociales), si fomentar o no las posibilidades de autonomía.

Desde esta perspectiva, las escuelas específicas de atención a niños sordos y los centros de integración preferente de niños con deficiencias auditivas deberían ser 
conscientes de que tan importante es contar con este tipo de ayudas y adaptaciones, como de estar bien equipados en cuanto a sillas, mesas, pizarras...

\subsubsection{Avisadores luminosos y/o vibrotáctiles}

Existen diversos sistemas que permiten recoger el inicio de una señal acústica proveniente de fuentes sonoras (timbres, sirenas, teléfonos...) convirtiéndola según modelos en un avisador lumínico o en una vibración. Se componen de una unidad central o receptor que detecta la activación de alguna de esas fuentes y transmite al receptor la señal pudiendo, según modelos, especificar de dónde procede el suceso sonoro que se acaba de desencadenar.

En la mayoría de ocasiones, no es precisa la adquisición de dispositivos especiales para la recepción de determinadas señales. Un especialista en electricidad podría rápidamente disponer el montaje de una sencilla instalación creando un circuito que conecte el timbre de la puerta a una bombilla. Así pues, podemos acudir a soluciones estándares presentes en el mercado, pero también podemos hacer uso de sencillas adaptaciones que pongan al alcance del niño sordo la información sonora. En una escuela sería común acudir a señales luminosas para el acceso simultáneo de más de un alumno, en el hogar ya sería más común el uso de dispositivos vibrotáctiles.

Recientemente un grupo de investigadores coreanos han mostrado uno de sus inventos, se trata de una pulsera y dos anillos (Vibering Sensor) se compone de una pulsera y dos anillos que detectan el ruido cercano. El aparato actúa como vibrador cuando la persona tiene algún objeto que emite sonidos fuera de su campo de visión, como por ejemplo, un coche. Una vez lo detecta, el sistema calcula la distancia en la que se encuentra el emisor y su posición. Si el objeto es un coche, la persona tendrá la oportunidad de apartarse a tiempo y evitar algún que otro percance. La pulsera muestra además un icono ilustrativo que también proporciona información acerca del objeto. Pero la utilidad de Vibering Sensor va un poco más allá ya que es capaz de detectar frases cortas que pronuncian otras personas, como por ejemplo "Lo siento" o también el nombre de quien lo lleva. Así la persona puede saber si se están dirigiendo a él. Estas instrucciones aparecen en la pantalla LED, en la que también se puede visualizar la hora cuando no hay ningún ruido alrededor. Sin duda, otro de los inventos enormemente positivos para atenuar las dificultades de los que tienen que convivir en una ciudad con una deficiencia física. Ahora sólo falta que alguien se anime a fabricarlo. 


\subsubsection{Ayudas para la comunicación a distancia}

La barrera que suponía la utilización de la voz para la comunicación a distancia se comenzó a romper con los avances técnicos que permitieron la transmisión de texto a través de la vía telefónica con aparatos como el videotex, también el fax abrió una vía de comunicación que sigue siendo de gran importancia para las personas sordas.

Las limitaciones del fax respecto a la ausencia se superaban con el uso de los denominados teléfonos de texto o DTS (Dispositivos telefónicos para sordos). Se trataba de pequeñas terminales con un teclado alfanumérico y una pequeña pantalla, que permitían la comunicación mediante texto a través de la línea telefónica. Los modelos diferían unos de otros en características tales como la posibilidad de contar o no con contestador automático, el número de entradas que permitía la agenda, el tamaño del visor, su autonomía, el ser portátil o no, la presencia o ausencia de teclas especiales para enviar un mensaje de socorro...

Toda esta tecnología, con el paso de los años y los nuevos descubrimientos ha quedado obsoleta, como era de esperar. Actualmente existe la posibilidad de realizar videoconferencias, realizar una video-llamada a través del móvil aprovechando la tecnología 3G, o utilizar una Blackberry o un teléfono de última generación como completo equipo de comunicaciones portátil.

Mención aparte merece la incidencia que la extensión de Internet ha tenido para el ámbito de la comunicación a distancia en las personas sordas. El establecimiento de redes informáticas, la interconexión de ordenadores ha abierto nuevas vías de futuro que permiten el intercambio de múltiples fuentes de información de modo simultáneo: texto, voz e incluso imagen. En este sentido, el correo electrónico emula las posibilidades del fax, el popular "chateo" las del DTS (existen de hecho canales exclusivos para el contacto entre personas sordas) y la videoconferencia las que progresivamente incorporará el videotelefóno. El inconveniente de la videoconferencia en su uso "casero" en relación con la posibilidad de la utilización de Lengua de Signos para las transmisiones es que muchas veces se produce una imagen entrecortada y poco nítida dificultando la comprensión del mensaje. Para solucionar este tipo de problemas recientemente dos empresas informáticas han anunciado que próximamente presentarán la videoconferencia de alta calidad destinada fundamentalmente al colectivo de Personas Sordas. Lo que proponen Logitech y Skype no es nada que no se pudiera hacer hasta ahora, pero lo han enfocado muy bien. Si Logitech tiene cámaras que aumentan la nitidez con que vemos a otra persona y Skype ofrece comunicación gratuita a través de Internet entre sus usuarios con mucha eficiencia, juntando ambos productos se obtiene un sistema de videoconferencia de alta calidad de bajo coste que por ejemplo ya va a empezar a usar la Asociación de Sordos de Madrid y que les dará una herramienta económica para videoconferencias con resolución VGA y 30 fps. La clave de estas webcams es que cuentan con lentes Carl Zeiss y sistema de autofocus, dos aspectos que ayudan mucho a que los gestos del lenguaje de signos se vean con claridad. 
En cualquier caso, el avance de la tecnología al servicio de Internet parece imparable, y las consecuencias que ha tenido para la sociedad de la información también se dejan notar sobre el ámbito de la sordera. De este modo, no sólo la comunicación a distancia se modifica ampliamente sino que las posibilidades de acceso a la información sin barreras se multiplican. Comienzan a consolidarse "portales" de Internet que ofrecen una amplia gama de servicios e información en relación con las personas sordas, incluyendo por supuesto aspectos relativos a su educación

Otro de interés ubicado en nuestro país es la "Biblioteca de Signos" desarrollada por la Universidad de Alicante (http://www.cervantesvirtual.com/portal/signos) donde se puede acceder a información sobre literatura, lingüística, un foro de investigadores, temas sobre cultura y comunidad sorda, aspectos relativos a la educación bilingüebicultural, referencias sobre materiales didácticos... Es un lugar pensado tanto para personas sordas como para profesionales interesados en todo cuanto rodea a la lengua de signos y su investigación.

Recientemente, una empresa murciana ha presentado una aplicación para que las personas con discapacidad auditiva puedan navegar por cualquier contenido en Internet. El programa, denominado SigNOW!, se basa en el aprovechamiento de las tecnologías de la realidad virtual y animación en tres dimensiones, y emplea el lenguaje de signos a través de un avatar (representación gráfica de una persona), que explica por signos el contenido y la información a la que puedan acceder las personas sordas.

La aplicación, puede emplearse siempre que se requiera accesibilidad en lenguaje de signos, ya sea como apoyo a un texto escrito o como mecanismo principal de comunicación, en numerosos soportes, como portales Web, administración electrónica, cajeros automáticos, quioscos interactivos, pantallas de información y guías interactivas

Se pueden encontrar muchas más noticias e información relacionada con las nuevas tecnologías al servicio de las personas Sordas en www.tecnosord.com.

\subsubsection{Ayudas visuales: Subtitulado}

Esta herramienta también es fundamental para las personas sordas y a continuación se verán diferentes campos donde se utiliza.

- El teletexto: las personas sordas tienen la oportunidad de ver algunos de los programas de televisión con subtítulos ¿Cómo se puede acceder al teletexto? Lo primero, se necesita una televisión que ofrezca este servicio. Para ver los subtítulos es necesario dar al botón que indica teletexto y marcar 888 con lo cual los subtítulos aparecerán al momento en la televisión. Este código es diferente en cada país. 
- Paneles informativos: muy adecuados para la eliminación de barreras de comunicación en ámbitos como el transporte público, hospitales, centros educativos...

- El DVD: ha sido muy importante para este colectivo debido a que es una forma de acceder al ocio porque se pueden ver las películas subtituladas en castellano.

La utilización de subtítulos se está fomentando después de la aprobación de la Ley de Lengua de Signos, desde el punto de vista educativo contar con este tipo de ayudas supone fomentar el uso del lenguaje oral y por lo tanto favorecer su utilización y su aprendizaje.

\subsection{La lectura a través de los tiempos y las nuevas tecnologías}

En este proceso, de cambio profundo de las estructuras sociales y económicas, del mundo profesional y de las relaciones familiares, los sistemas de comunicación, que cada día nos sorprenden con nuevas tecnologías, juegan un papel de indudable protagonismo. Los nuevos medios de comunicación nos ofrecen, casi a diario, posibilidades insospechadas que pretenden facilitar las relaciones humanas; posibilidades que pueden enriquecer la convivencia, pero que, al tiempo, pueden hacerla más difícil...

Es indudable que los medios audiovisuales, la televisión digital, los vídeos, los CDROM y especialmente la "informática multimedia", están ya presentes en todos los ámbitos de la vida social: la empresa, la escuela, la familia, el ocio... A través de Internet es posible acceder, de forma sencilla y prácticamente inmediata, tanto a la información, exhaustiva y sobre cualquier tema, como a la comunicación con interlocutores de cualquier parte del mundo.

Es también hoy una realidad patente como los alumnos, han alcanzado un dominio importante de estos medios: hay que decir que la informática, Internet y, en general, las tecnologías de la información "no tienen secretos para ellos", forman parte de su vida cotidiana, de su ocio, de su trabajo escolar, han nacido y han convivido con ellos desde el principio $y$ de forma natural. Esta situación, con implicaciones educativas y de desarrollo personal tan positivas, también puede provocar esa "profunda preocupación por la cultura escrita". Los alumnos, ¿están igualmente familiarizados con la lectura y con la escritura?, ¿están desarrollando una competencia similar en su compresión y expresión oral y escrita?

Durante siglos, los conocimientos se almacenaban en la memoria y eran transmitidos de generación en generación por medio de la palabra hablada. Cuando apareció la escritura, la tradición oral era tan fuerte que no pudo imponerse de manera inmediata. Johannes Gutenberg (citado en Pastor, 2000), tropezó con incomprensibles y dificultades, pero la letra impresa se fue imponiendo como medio de transmisión de conocimientos. Había que aprender a leer pues la comprensión escrita era tan necesaria como la comprensión oral. 
Ahora hay un momento semejante: "Nos encontramos a medio camino entre lo impreso y lo visual, como en otros siglos se estuvo entre la oralidad y la escritura" (Pastor, 2000, 23).

Con la aparición de la imagen en movimiento, y gracias a su enorme fuerza y atractivo, el lenguaje audiovisual se ha ido imponiendo frente a la letra escrita. En esta línea, están surgiendo voces autorizadas que se preguntan si se perderá el camino recorrido en la difícil carrera de la alfabetización de las capas más extensas de la sociedad, para volver a los tiempos en que el libro era un objeto precioso solo al alcance de unas elites.

Durante quinientos años, desde la invención de la imprenta, el monopolio de la comunicación cultural lo ha ejercido el libro; pero el hecho de que ahora lo comparta con otros medios, ¿hace temer por su existencia en el futuro? Los principales expertos en esta cuestión consideran, sin ningún género de dudas, que "el hecho de que el libro no sea hoy el único instrumento de comunicación y de transmisión de la cultura, no quiere decir que no posea un papel específico e insustituible" (Pastor, 2000, 27). Así, por ejemplo, Michel Gault, (citado en Pastor, 2000) considera que el libro es y seguirá siendo insustituible como vehículo de fantasía, de exploraciones interiores, de meditación, de recreación.

Por su parte, José Jiménez Lozano (citado en Pastor, 2000) haciéndose eco de esta preocupación, escribía: "la televisión o el Internet quitan mucha lectura ¿a quién? Seguro que no será a un lector, por la sencilla razón de que lo que da la lectura no lo pueden ofrecer otras cosas, y viceversa; así que cada cual sabrá lo que busca y lo que necesita".

Los testimonios autorizados sobre el poder evocador de las palabras, que se hace patente en la letra escrita, son innumerables. Ramón María de Valle-Inclán dejó escrito: "Las palabras son espejos mágicos donde se evocan todas las imágenes del mundo". Stephen Kingn el autor del primer libro en Internet, hacía las siguientes declaraciones: "Aunque Internet ofrece grandes posibilidades, no creo que haya nada que pueda reemplazar a la palabra impresa y a los libros encuadernados".

Así pues, no es verdad que «una imagen vale más que mil palabras»; hay una equivocación en los términos que habrá que invertir, pues es cada palabra la que sugiere, la que encierra, mil imágenes.

"No debemos temer por una posible desaparición del libro" (Pastor, 2000, 37). La realidad nos ha mostrado que, el libro no será un objeto formalmente igual al actual: quizá se cambie el soporte de papel por un soporte informático; quizá el texto aparezca en una pantalla y no se pueda pasar la mano por la superficie de sus páginas; quizá para pasar sus hojas y avanzar en su lectura haya que apretar el botón derecho o izquierdo del "ratón". Pero ahí estará el texto escrito conteniendo, bajo esos signos, una obra de arte en la que se adentrará.

La lectura será siempre necesaria. La sociedad necesita buenos comunicadores, hombres que sepan pensar con orden y claridad, expresarse bien y saber escuchar. $Y$ esta competencia comunicativa tiene su fuente de alimentación y entrenamiento en la lectura. 


\subsection{Aplicación de las Nuevas Tecnologías en los procesos educativos}

El contexto en el que se desarrolla el proceso formativo a comienzos del siglo XXI es muy diferente al que se tenía diez años atrás, siendo las NTIC (Nuevas Tecnologías de la Información y la Comunicación) las responsables y las protagonistas de los cambios sufridos.

Hare (2000, citado en García y García, 2002) cita como factores clave de estos cambios: el estatus de recurso activo de gran valor que toma la información; el aumento de la información en formato digital, así como de usuarios finales consumidores de dicha información; la mayor necesidad de la formación continua de los profesionales, que exige modelos de enseñanza y aprendizaje más flexibles; y el asentamiento de una cultura de la globalización, que rompe barreras físicas y temporales.

Un espacio virtual educativo efectivo debe canalizar tres vertientes básicas de las NTIC. Primeramente, la capacidad de trabajo en red, que permita una localización geográficamente dispersa de los participantes y un sincronismo o un asincronismo de las actividades formativas, según sea necesario. En segundo lugar, facilidades multimedia e hipermedia que permitan contar con información digital heterogénea y representada en diferentes formatos (texto, gráficos, sonido...) pudiéndola relacionar fácilmente. Y, por último, una interacción persona-ordenador sencilla, intuitiva, pedagógica y completa, soportada por interfaces de usuario donde se potencie la noción de usabilidad de las mismas, en lugar de buscar la espectacularidad y el encantamiento momentáneo del usuario.

La Web es el ejemplo paradigmático de servicio que mejor integra los tres ejes descritos, siendo el caldo de cultivo idóneo sobre el que plantear la definición de un espacio virtual educativo o portal educativo según la terminología Web, aunque no el único.

Sin embargo, conviene advertir que en el contexto de la comunicación oral la propia biología humana deja evolutivamente dispuesto a la competencia oral en el marco social adecuado. La escritura, que aplica la capacidad gráfica humana a la comunicación simbólica, con el aprendizaje de la competencia en el uso de la interfaz lecto-escritora deja dispuesto el fundamento para convertir al sujeto en autor y productor de recursos para la comunicación, independientemente de su nivel, utilidad y calidad; desde el niño que redacta al literato que crea una obra maestra. El sistema informacional introduce un sistema de comunicación que se apoya en una teoría (la Teoría de la información), en una tecnología (las Tecnologías de la Información y la Comunicación). Por ello, el sistema de comunicación informacional plantea dos categorías de producción de objetos, que requieren competencias diferentes: la de los que son capaces de producir teoría y tecnología (de hardware y software) y la de los que poseen los conocimientos que se pueden vehicular a través del sistema informacional. Precisamente esta separación de competencias es la que 
plantea la necesidad de reflexionar sobre el problema de las interfaces sistema informacional-usuario. Las interfaces más desarrolladas son las de ordenadorusuario, haciendo a éstos cada día más "familiares" y próximos a quienes no son ni científicos ni técnicos.

La aplicación del sistema de comunicación informacional a procesos de formación requiere de otras interfaces: las de facilitación de procesos de construcción de contenidos de formación mediante software de "segundo orden", que se convierten en facilitadores de actividad dentro del marco que posibilitan, por ejemplo, herramientas de autor de "primer orden". A interfaces de "segundo orden" es a las que hace referencia el contenido de este trabajo.

\subsubsection{Servicios de un espacio virtual educativo}

En general, un espacio virtual educativo debe ofrecer un conjunto de servicios educativos funcionales a los participantes en el proceso formativo. Éstos pueden soportar una interacción síncrona, cuando los participantes están presentes "en línea" al mismo tiempo mientras se lleva a cabo el servicio, o asíncrona, cuando la presencia de todos los participantes no es requerida para desarrollar la actividad.

Los servicios educativos pueden clasificarse diversos grupos no disjuntos entre sí (García et al.., 1999, citados en García y García, 2002):

- Servicios de comunicación: Facilitan la comunicación entre los protagonistas del proceso formativo (estudiantes y profesores). En este grupo se incluyen servicios tan populares como el correo electrónico, foros de discusión (síncronos como los chat, o asíncronos como los grupos de noticias), seminarios virtuales, videoconferencias o publicación de documentos en formato digital.

- Servicios de información: Ofrecen información genérica estructurada y dispuesta de forma eficiente para un uso específico. Ejemplo de este servicio son las páginas Web.

- Grupos de trabajo cooperativo: Ofrecen la posibilidad de que varias personas trabajen juntas utilizando ordenadores y tecnología informática, facilitando el trabajo en equipo y un intercambio eficiente de información. Ejemplos de servicios de este grupo serían entre otros los seminarios virtuales con varios participantes activos, aplicaciones de tiempo real compartidas como escritura o dibujos cooperativos, sistemas de flujos de trabajo o agendas comunes.

- Servicios de administración: Permiten la gestión administrativa de las diversas entidades que conforman el dominio del problema del ámbito educativo, esto es, profesores, alumnos, cursos, informes estadísticos...

- Servicios de entretenimiento: Son servicios, educativos o no, diseñados en su mayor medida para el ocio, como juegos en línea o tablones de noticias. 
- Servicios y herramientas de autor mediante las cuales los formadores pueden producir unidades de actividad que, al tiempo que recuperan los modos escritos de oferta de conocimiento, pueden incorporar el modo oral, el icónico, y el audiovisual, dotados de reticularidad, organización topológicas y navegables en función de los intereses particulares del usuario.

Estos servicios quedan establecidos en el espacio virtual educativo dentro de un conjunto de componentes software de carácter pedagógico, junto a un repositorio de información, donde quedarán almacenados los diferentes activos de información que se intercambian en el proceso educativo.

La interacción de los participantes en dicho proceso educativo se hace a través de dichos componentes software, en sus versiones cliente y servidor, donde normalmente el cliente manejado es un clásico navegador Web, que da acceso al resto de los componentes

De esta forma lo educadores aportan al sistema su experiencia, sus conocimientos en forma de contenidos, que el sistema o espacio virtual educativo almacena en un repositorio de información formado a su vez por recursos o componentes software pedagógicos. Los usuarios finales o alumnos para formase pueden realizar todo tipo de peticiones al sistema.

\subsubsection{Ventajas y riesgos de los servicios educativos virtuales}

La entrada en escena de los espacios educativos virtuales aporta grandes ventajas que complementan positivamente el proceso educativo tradicional. Sin embargo, el trabajo con las NTIC implica cambios en muchas áreas, y también algunos riesgos.

La introducción de las NTIC en el proceso educativo aporta los siguientes beneficios potenciales como indican García y García (2002):

- Descentralización del proceso educativo: El seguimiento de las clases desde lugares geográficamente distantes, ya sea de forma síncrona o asíncrona, potencia la enseñanza a distancia, las tutorías no presenciales y los seminarios virtuales.

- Aumento de la calidad y la accesibilidad de los materiales didácticos: Los multimedia cambian el concepto del libro tradicional, no buscando suplantarlo sino completarlo. El texto y las fotografías se ven completadas ahora con datos en cualquier tipo de formato imaginable (vídeo, animación, sonido...) y localizados en cualquier lugar del mundo.

- Procesos de aprendizajes personalizados: Al tener acceso a materiales didácticos de calidad dentro de un proceso educativo asíncrono, el alumno puede progresar según su capacidad y tiempo. 
- Facilidad para el trabajo colaborativo: El trabajo en equipo se ve facilitado desde el mismo instante en que mejoran y se potencian los medios de comunicación disponibles entre los participantes en una actividad docente.

- Acceso universal a los recursos: Permitiendo acceso a recursos localizados de prácticamente cualquier parte del mundo.

- Capacidad de adaptación o configuración del entorno de trabajo: El contexto de trabajo del usuario se adapta dependiendo de su nivel, su idioma u otras características, permitiendo un rendimiento más óptimo del interesado.

No obstante, las NTIC presentan también constricciones y riesgos más que desventajas o inconvenientes, normalmente derivados de su mala utilización, de su comprensión equivocada o de las complejidades inherentes al empleo de las NTIC como instrumento de autor. Entre estos riesgos García y García (2002) citan los siguientes:

- Desplazamiento de profesores y/o alumnos del proceso educativo: Las NTIC obligan tanto a los docentes como a los alumnos a un replanteamiento de la naturaleza de la enseñanza y el aprendizaje. Los profesores, en su papel de transmisores de conocimiento, deben aprender a manejar las herramientas que permiten canalizar su conocimiento y experiencia en materiales didácticos asimilables por los alumnos. Los alumnos deben estar abiertos a la utilización de las NTIC y a que las referencias de consulta no se limitan a las notas de clase.

- Dispersión de la información: Internet es una fuente inagotable de información, que fácilmente puede llegar a desbordar a cualquiera, y donde la calidad de los materiales accesibles es sumamente variable. Por este motivo, la mera existencia de información no basta para configurar un espacio virtual educativo (Moreno, et al..., 2000aㅡ, citados en García y García, 2002); debe ser información contrastada, clasificada y accesible a través de los medios oportunos.

- Falta de calidad en los componentes educativos software: Los servicios educativos ofertados en un espacio virtual no siempre tienen la calidad suficiente para su uso efectivo. La calidad debe mirarse desde las perspectivas técnica y pedagógica, de forma que los componentes cumplan los requisitos para los que fueron diseñados, pero además lo hagan de forma que ayuden al proceso educativo. En este aspecto los mecanismos de interacción ofrecidos por las interfaces de los componentes software son de vital importancia. Una interfaz bien diseñada debe guiar al usuario (ya sea alumno o profesor) en la actividad docente en que se halle inmerso, mientras que una interfaz incorrectamente pensada perderá al usuario en el software, y lo más grave, en el caso de los alumnos, puede inducirles a errores de concepto graves que invaliden su proceso formativo. 


\subsection{El aprendizaje en entornos virtuales: e-formación}

El desarrollo de la Web se puede calificar sin duda alguna como el componente fundamental que ha revolucionado y popularizado el uso de Internet, gracias a ser un medio de difusión y comunicación abierto, flexible y de tecnología muy simple, lo cual ha dado origen a un amplio abanico de aplicaciones como el comercio electrónico, la banca electrónica o los sistemas de entretenimiento en línea, por mencionar algunos.

El sector educativo ha encontrado en esta tecnología un excelente medio para romper con las limitantes geográficas y temporales que los esquemas tradicionales de enseñanza-aprendizaje conllevan, revolucionando, y cambiando a la vez, el concepto de educación a distancia. Su adopción y uso han sido amplios, lo que ha permitido un desarrollo rápido y consistente en el que la Web ha ido tomando distintas formas dentro de los procesos educativos.

La Web se convierte en la infraestructura básica para desarrollar los procesos de enseñanza-aprendizaje no presenciales, combinando servicios síncronos y asíncronos, lo que ha dado lugar a un modelo conocido como e-formación o elearning, cada vez más valorado, no como sustituto de la formación presencial tradicional, sino más como un complemento que se ha de adaptar según las necesidades y nivel de madurez del público receptor de esta formación (García y García, 2001, citado en García, 2005), que puede ir desde ser una actividad complementaria muy concreta y residual en los estudios de primaria y secundaria, a ser un modelo únicamente no presencial en la formación a distancia o formación continua empresarial. No obstante como indicaba García (2005), las aproximaciones mixtas, que combinan actividades formativas presenciales y no presenciales, toman cada vez más fuerza y se posicionan como una importante alternativa. 


\subsubsection{Definición de e-formación}

El concepto de e-formación o e-learning como es conocido en Internet, se define de muchas formas diferentes fundamentalmente debido a la diversidad de quien hace uso de él, cada uno con su idiosincrasia y su ámbito de aplicación.

Desde la perspectiva de su concepción y desarrollo como herramienta formativa, los sistemas de e-learning tienen una dualidad pedagógica y tecnológica. Pedagógica en cuanto a que estos sistemas no deben ser meros contenedores de información digital, sino que ésta debe ser transmitida de acuerdo a unos modelos y patrones pedagógicamente definidos para afrontar los retos de estos nuevos contextos. Tecnológica en cuanto que todo el proceso de enseñanza-aprendizaje se sustenta en aplicaciones software, principalmente desarrolladas en ambientes Web, lo que le vale a estos sistemas el sobrenombre de plataformas de formación. (García, 2005)

Desde la perspectiva de su uso se podría distinguir la visión que tienen sus usuarios finales, que con independencia de su madurez y formación, verán al sistema elearning como una fuente de servicios para alcanzar su cometido formativo. No obstante, también es factible diferenciar una visión de organización, en la que se definen el alcance y los objetivos buscados con la formación basada en estos sistemas, distinguiéndose una visión académica y una visión empresarial.

Si se toma como referencia la raíz de la palabra, e-learning se traduce como "aprendizaje electrónico", y como tal, en su concepto más amplio puede comprender cualquier actividad educativa que utilice medios electrónicos para realizar todo o parte del proceso formativo.

Existen definiciones que abren el espectro del e-learning a prácticamente a cualquier proceso relacionado con educación y tecnologías, como por ejemplo la definición de la American Society of Training and Development que lo define como "término que cubre un amplio grupo de aplicaciones y procesos, tales como aprendizaje basado en Web, aprendizaje basado en ordenadores, aulas virtuales y colaboración digital. Incluye entrega de contenidos vía Internet, intranet/extranet, audio y vídeo grabaciones, transmisiones satelitales, TV interactiva, CD-ROM y más".

Otros autores acotan más el alcance del e-learning reduciéndolo exclusivamente al ámbito de Internet, como Rosenberg (2001, citado en García, 2005) que lo define como: "el uso de tecnologías Internet para la entrega de un amplio rango de soluciones que mejoran el conocimiento y el rendimiento. Está basado en tres criterios fundamentales:

1. El e-learning trabaja en red, lo que lo hace capaz de ser instantáneamente actualizado, almacenado, recuperado, distribuido y permite compartir instrucción o información.

2. Es entregado al usuario final a través del uso de ordenadores utilizando tecnología estándar de Internet. 
3. Se enfoca en la visión más amplia del aprendizaje que van más allá de los paradigmas tradicionales de capacitación".

Desde la perspectiva que ofrece la experiencia en el desarrollo y explotación de plataformas e-learning, García (2005) define e-learning como "la capacitación no presencial que, a través de plataformas tecnológicas, posibilita y flexibiliza el acceso y el tiempo en el proceso de enseñanza-aprendizaje, adecuándolos a las habilidades, necesidades y disponibilidades de cada discente, además de garantizar ambientes de aprendizaje colaborativos mediante el uso de herramientas de comunicación síncrona y asíncrona, potenciando en suma el proceso de gestión basado en competencias".

En todas estas definiciones, se acaba haciendo mención explícita o implícita a lo que se viene llamando en triángulo del e-learning (Lozano, 2004, citado en García, 2005), formado por:

- la tecnología (plataformas, campus virtuales...).

- los contenidos (calidad y estructuración de los mismos se toman como elementos capitales para el éxito de una iniciativa de e-formación).

- los servicios (siendo el elemento más variopinto que engloba la acción de los profesores, elementos de gestión, elementos de comunicación, elementos de evaluación...).

Variando el peso de estos tres componentes se obtienen diferentes modelos de eformación, de igual forma que variando las variables y recursos con los que cuenta un profesor se obtienen diferente políticas de docencia presencial.

En la práctica, para llevar a cabo un programa de formación basado en e-learning, se hace uso de plataformas o sistemas de software que permiten la comunicación e interacción entre profesores, alumnos y contenidos. Se tienen principalmente dos tipos de plataformas: las que se utilizan para impartir y dar seguimiento administrativo a los cursos en línea o LMS (Learning Management Systems) y, por otro lado, las que se utilizan para la gestión de los contenidos digitales o LCMS (Learning Content Management Systems) (García, 2005)

\subsubsection{LMS y LCMS}

Entre las herramientas más utilizadas para los ambientes o sistemas e-learning están los Sistemas de Administración de Aprendizaje o LMS, también ampliamente conocidos como plataformas de aprendizaje. Un LMS es un software basado en un servidor Web que provee módulos para los procesos administrativos y de seguimiento que se requieren para un sistema de enseñanza, simplificando el control de estas tareas. Los módulos administrativos permiten, por ejemplo, configurar cursos, matricular alumnos, registrar profesores, asignar cursos a un alumno, llevar informes de progreso y calificaciones. También facilitan el aprendizaje distribuido y colaborativo a partir de actividades y contenidos preelaborados, de 
forma síncrona o asíncrona, utilizando los servicios de comunicación de Internet como el correo, los foros, las videoconferencias o el chat.

La complejidad y las capacidades de las plataformas varían de un sistema a otro, pero en general todas cuentan con funciones básicas como las que se han mencionado. Entre las plataformas comerciales más comunes se encuentran Blackboard (http://www.blackboard.com) y WebCT (http://www.webct.com), mientras que las más reconocidas por parte del software libre son Moodle (http://moodle.org) y Claroline (http://www.claroline.net).

Los Sistemas de Administración de Contenidos de Aprendizaje o LCMS tienen su origen en los CMS (Content Management System) cuyo objetivo es simplificar la creación y la administración de los contenidos en línea, y han sido utilizados principalmente en publicaciones periódicas (artículos, informes, fotografías...). En la mayoría de los casos lo que hacen los CMS es separar los contenidos de su presentación y también facilitar un mecanismo de trabajo para la gestión de una publicación Web. Los LCMS siguen el concepto básico de los CMS, que es la administración de contenidos, pero enfocados al ámbito educativo, administrando y concentrando únicamente recursos educativos y no todo tipo de información.

LCMS se define como un sistema basado en Web que es utilizado para crear, aprobar, publicar, administrar y almacenar recursos educativos y cursos en línea (Rengarajan, 2001, citado en García, 2005). Los principales usuarios son los diseñadores instruccionales que utilizan los contenidos para estructurar los cursos, los profesores que utilizan los contenidos para complementar su material de clase e incluso los alumnos en algún momento pueden acceder a la herramienta para desarrollar sus tareas o completar sus conocimientos.

El proceso de trabajo dentro de un LCMS requiere de control en cada fase del contenido, esto conlleva un proceso editorial para controlar la calidad de los contenidos creados, así como para permitir y organizar su publicación.

Como conclusión, se puede afirmar que tanto los LMS como los LCMS se pueden generalizar como sistemas de gestión de aprendizaje ya que los primeros gestionan la parte administrativa de los cursos, así como el seguimiento de actividades y avance del alumno; mientras que los segundos gestionan el desarrollo de contenidos, su acceso y almacenamiento. En el mercado, los más comunes son los LMS ya que la complejidad de los LCMS los ha llevado a un desarrollo más lento. 


\subsubsection{Importancia de la e-formación}

Los sistemas que promueven los procesos de enseñanza-aprendizaje a través de sistemas de e-learning tienen una gran importancia para consolidar la denominada Sociedad del Conocimiento. Estos medios abren la puerta para la formación básica o avanzada a una importante cantidad de personas, que pueden ver mejorada su cualificación personal o su situación profesional. Estos sistemas tienen un campo enorme de aplicación ya que la formación puede orientarse de forma complementaria a nivel de educación primaria y secundaria, de forma complementaria o exclusiva a nivel universitario, de postgrado o de formación continua, y de formación especial a medida en las empresas o las necesidades de ciertos colectivos.

No obstante, el campo del e-learning está en sus fases iniciales y le falta un largo camino por recorrer hasta alcanzar su madurez y consolidación. A lo largo de este camino se hace necesaria la colaboración de dos campos altamente interesados el pedagógico y el tecnológico. Los resultados con enriquecedores cuando los interesados trabajan conjuntamente, mientras que se empobrecen estos resultados si una de las dos partes ignora a la otra.

Como indica García (2005) el factor humano, se convierte en la pieza más importante cuando se quiere acometer una estrategia basada en la e-formación. En un proceso de enseñanza-aprendizaje ni las plataformas tecnológicas, ni los modelos pedagógicos son el fin sino el medio para conseguir el objetivo último del proceso, esto es, aumentar el conocimiento y la formación de las partes implicadas. De forma que se tiene que tener presente que en los extremos de estos medios se encuentran personas que han de creer en los beneficios que pueden aportar estas soluciones. Sin su aceptación, compromiso y entrega será imposible que el elearning triunfe en una organización.

\subsection{Importancia de los recursos educativos para las Personas Sordas}

En España hay 3,528.221 personas con discapacidades o problemas de salud, lo que supone un $9 \%$ de la población total (Encuesta sobre Deficiencias, Discapacidad y Estados de Salud, 2005). De este total, hay alrededor de un millón de personas en España afectadas por una discapacidad auditiva de distinto grado y tipo (INE, 2000).

Es interesante aportar unos datos presentados por un representante del CERMI (Comité Español de Representantes de Minusválidos) en la entrega del Premio FIAPAS 2002: "el $66 \%$ de los discapacitados de la Comunidad Europea no tienen estudios de secundaria y sólo un $5 \%$ han obtenido estudios de licenciado". Por supuesto, que estos datos hacen referencia a todos los discapacitados, incluido el colectivo de personas con discapacidad auditiva, pero son porcentajes muy significativos que llaman la atención sobre las barreras, los obstáculos y las 
dificultades de los alumnos con necesidades educativas especiales para alcanzar una formación y una educación de calidad.

En el "Informe sobre los procesos de inserción laboral de los trabajadores con discapacidad auditiva" (CIMOP, 2000) se pone de manifiesto la importancia de la educación para alcanzar la integración social de las personas con dicha discapacidad.

El nivel de estudios finalizados por las personas discapacitadas es inferior de los finalizados por las personas sin discapacidad, según se desprende del informe "Las personas con discapacidad y su relación con el empleo" (Encuesta de Población Activa del segundo trimestre de 2002). Pero, si además realizamos una comparación dentro del grupo de población discapacitada, las personas con discapacidad auditiva son las que presentan un nivel formativo inferior, según el citado "Informe sobre los procesos de inserción laborales de los trabajadores con discapacidad auditiva". Siguiendo con este informe, las diferencias detectadas se pueden explicar en base a varios factores. Por una parte, la discapacidad auditiva afecta a la capacidad de aprendizaje, lo que implica una dificultad añadida al proceso educativo. Además, la falta de integración escolar de este colectivo tiene una gran relevancia en su escolarización.

Los programas de integración o inclusión que aborden y superen las raíces de los distintos procesos estructurales de exclusión o separación, que en principio pudieran favorecer la aproximación y la familiarización de las personas sordas con la sociedad del conocimiento y de la información, así como con lo que constituyen sus instrumentos, nuevas tecnologías de inmensas potencialidades características, que han dotado al ser humano de una enorme, y siempre creciente, capacidad para ampliar las vías de acceso a la información y a la cultura, como no había sucedido jamás, a fin de que dichas personas sordas consigan superar su proverbial desarraigo, alcancen a mejorar su, hoy por hoy, poco envidiable calidad de vida, y logren así participar, de una manera activa y plena, como ciudadanos en la vida política, al igual que en la toma y en la ejecución de las decisiones que les puedan concernir, tanto en el ámbito del Estado al que pertenecen, como en el de las distintas comunidades en las que pudieran encontrarse integrados.

Refería Manuel Calvo Hernando (1923, citado en Storch, 2005), cuando al hablar de los problemas que concluirán por generar en un futuro más o menos inmediato las nuevas tecnologías de la información y de la comunicación que conocen ritmos crecientes de renovación, y de sus proyecciones en la política, la economía, el trabajo, la cultura, la comunicación y las relaciones cívicas, considera que "pondrán en peligro a ciertos grupos sociales y crearán una Apocalipsis comunicativas cuyos efectos últimos son, hoy por hoy, impredecibles".

Ante estas dificultades, las tecnologías de la información y la comunicación (TIC) suponen un medio de integración y acceso a la educación muy importante para las personas con discapacidad auditiva: adaptan la metodología de enseñanzaaprendizaje al déficit que presentan los alumnos y posibilitan el acceso a la tele formación. Sin embargo, la proliferación de numerosas experiencias relacionadas con desarrollo de TIC adaptadas a la educación de personas con discapacidad 
auditiva ha generado una cierta descoordinación y desinformación acerca de los recursos existentes.

Por tanto, nos encontramos ante una situación compleja. Por una parte, la educación es un pilar básico para avanzar hacia la igualdad de derechos del colectivo de personas con discapacidad auditiva, y las TIC se materializan como un instrumento muy importante para alcanzar este objetivo. Por otra parte, existe un gran desarrollo de instrumentos que no siempre son fácilmente asequibles o conocidos por la población a la que van dirigidos.

Como ejemplo, tenemos el Curso LECTOR, presentado y creado especialmente para este proyecto, formado por un conjunto de aplicaciones informáticas que sirven para realizar diversos tipos de actividades educativas: rompecabezas, asociaciones, ejercicios de texto, palabras cruzadas... Las actividades están directamente dirigidas a los usuarios, de acuerdo con sus necesidades y dificultades lectoras.

Dentro de este marco, este proyecto pretende difundir recursos educativos TIC existentes para personas con discapacidad auditiva, con la finalidad directa de favorecer su utilización y, de manera indirecta, potenciar la integración social de este colectivo.

Para el desarrollo de las actividades de LECTOR se contó con varias herramientas, comúnmente utilizadas, dentro y fuera de la educación. Existe un gran número de aplicaciones educativas creadas con JClic. Pero es necesario un trabajo específico sobre ellas para desarrollar aplicaciones adaptadas a las necesidades puntuales de las personas sordas.

Hoy día no se puede hablar de Tecnología de la Información y Comunicación sin hablar de Internet, la red de redes, que llega a todos los lugares y hace posible realizar todo tipo de operaciones desde cualquier punto de acceso. Aprovechando esta propiedad, se ha pensado en "mostrar" todas esas actividades educativas, uniendo Moodle con JClic. A continuación se detalla que es exactamente JClic y que Moodle y como a través de otras herramientas se consigue atención sobre el Curso LECTOR. 


\subsection{JClic}

JClic está formado por un conjunto de aplicaciones informáticas que sirven para realizar diversos tipos de actividades educativas: rompecabezas, asociaciones, ejercicios de texto, palabras cruzadas...

Las actividades no se acostumbran a presentar solas, sino empaquetadas en proyectos. Un proyecto está formado por un conjunto de actividades y una o más secuencias, que indican el orden en qué se han de mostrar.

El antecesor de JClic es Clic, una aplicación que desde 1992 ha sido utilizada por educadores y educadoras de diversos países como herramienta de creación de actividades didácticas para sus alumnos.

JClic está desarrollado en la plataforma Java, es un proyecto de código abierto y funciona en diversos entornos y sistemas operativos.

En las páginas de actividades de la zona clic se ofrecen dos maneras de acceder a los proyectos JClic:

- Visualizar las actividades en un applet. Un applet es un objeto incrustado en una página Web. Los proyectos que se ven de esta manera no quedan almacenados en el disco duro: JClic los descarga, los utiliza y finalmente los borra.

Si el applet JClic no se pone en marcha correctamente hay que comprobar la configuración del sistema Java del ordenador. Se recomienda también echar un vistazo a la página en la que se explica el proceso de carga de los applets.

- Instalar las actividades en el ordenador. JClic tiene un asistente que permite descargar las actividades y guardarlas en la biblioteca de proyectos del ordenador. La biblioteca se crea la primera vez que se pone en marcha JClic, o cuando se intenta hacer la primera instalación de un proyecto. Para ver los proyectos de la biblioteca será necesario descargar e instalar JClic. Como en el caso anterior, si el instalador no se pone en marcha es probable que sea necesario comprobar la configuración del sistema Java del ordenador.

\subsubsection{Componentes}

JClic está formado por cuatro aplicaciones:

- Jclic/applet. Un "applet" que permite incrustar las actividades JClic en una página Web.

- Jclic/player. Un programa independiente que una vez instalado permite realizar las actividades desde el disco duro del ordenador (o desde la red) sin que sea necesario estar conectado a Internet. 
- Jclic/autor. La herramienta de autor que permite crear, editar y publicar las actividades de una manera más sencilla, visual e intuitiva. Esta herramienta permite crear y modificar proyectos JClic, en un entorno visual muy intuitivo e inmediato. También ofrece la posibilidad de convertir al nuevo formado los paquetes hechos con Clic 3.0, y otras prestaciones como la publicación de las actividades en una página Web o la creación de instaladores de proyectos.

- Jclic/reports. Un módulo de recogida de datos y generación de informes sobre los resultados de las actividades hechas por los alumnos. Este módulo permite gestionar una base de datos en la que se recopilarán los resultados obtenidos por los alumnos al realizar las actividades de los proyectos JClic. El programa trabaja en red y ofrece también la posibilidad de generar informes estadísticos de los resultados.

El primero de los componentes se instala la primera vez que se ejecuta un proyecto que contenga alguna actividad JClic. La otras tres se pueden instalar en cualquier ordenador mediante WebStart. Cuando se ejecuta la instalación de WebStart se instalan: JClic, que es la aplicación principal, y sirve para visualizar y ejecutar las actividades. Permite crear y organizar una biblioteca de proyectos, y escoger entre diversos entornos gráficos y opciones de funcionamiento. Además de instalarse JClic Autor, JClic Reports y una serie de actividades de ejemplo esa es una buena forma de aprender y de descubrir las posibilidades que ofrece JClic. Desde esta opción se permite descargar nuevas actividades y formar nuevas bibliotecas de actividades.

\subsubsection{Compatibilidad y nuevas posibilidades}

El desarrollo del JClic se ha hecho intentando respetar al máximo la compatibilidad con el programa Clic 3.0, de manera que los paquetes de actividades existentes puedan ser automáticamente reconocidos por la nueva plataforma.

Éstas son algunas de las novedades del JClic con respecto a Clic 3.0:

- Uso de entornos gráficos de usuario ("skins") personalizables, que contienen los botones y el resto de elementos gráficos que enmarcan las actividades.

- Uso de gráficos BMP, GIF, JPG y PNG

- Incorporación de recursos multimedia en formato WAV, MP3, AVI, MPEG, QuickTime y Flash 2.0, entre otros, así como de GIFs animados y con transparencia.

- Sonidos de eventos (hacer clic, relacionar, completar, acertar, fallar...) configurables para cada actividad o proyecto.

- Generadores de formas ("shapers") que controlan el aspecto de las casillas de las actividades: con JClic ya no es necesario que sean siempre rectangulares.

- Mejoras visuales: Posibilidad de escribir código HTML en las casillas, incrustación de fuentes "TrueType", texto con estilos, uso de gradientes y colores semitransparentes ... 
- Nuevas características de las actividades: tiempo máximo, número máximo de intentos, orden de resolución, actividades de memoria con dos bloques de contenido, etc.

Podéis ver estas características en funcionamiento echando un vistazo al paquete de actividades de demostración de JClic.

\subsubsection{Arquitectura abierta}

Clic tiene una arquitectura abierta que permite ampliar o adaptar sus funcionalidades en diversos aspectos. Se pueden crear nuevos módulos Java que extiendan el funcionamiento del programa en:

- Nuevos tipos de actividades, extendiendo la clase abstracta "Activity"

- Sistemas de creación automática de contenidos, a partir de la clase abstracta "AutoContentProvider" (en estos momentos la única implementación de esta clase es el módulo "Arith")

- Entornos gráficos de usuario, extendiendo la clase "Skin" o suministrando nuevos esquemas XML a "BasicSkin".

- Motores primarios de ejecución de actividades, extendiendo "ActivityContainer"

- Generadores de recortes y formas, extendiendo la clase abstracta "Shaper"

- Sistemas de informes, extendiendo la clase "Reporter" Licencia Pública General de GNU (GPL). Eso permite utilizarlo, distribuirlo y modificarlo libremente siempre que se respeten determinadas condiciones, entre las que cabe destacar el reconocimiento

\subsubsection{Servidor de Informes JClic}

JClic dispone de un sistema de registro de los resultados de las actividades. JClic reports es el módulo encargado de recopilar los datos (tiempo empleado en cada actividad, intentos, aciertos, etc.) y presentarlos después en informes estadísticos de diversos tipos.

JClic reports se basa en un esquema cliente - servidor. El servidor puede ser cualquier ordenador de la red, y los clientes son de dos tipos: las aplicaciones JClic (applet i player), que envían al servidor las puntuaciones obtenidas por los usuarios al realizar las actividades, y los navegadores Web (Firefox, Opera, Explorer...) desde los que se pueden consultar los resultados y administrar la base de datos.

Para poner en funcionamiento al servidor son necesarios tres elementos:

- Un sistema de bases de datos, en el que se almacenará la información. Debe soportar transacciones SQL y disponer de algún conector JDBC u ODBC. Hay 
muchos sistemas, tanto comerciales como libres, que cumplen estos requisitos: mySQL, MS-Access, PostgreSQL, Oracle, etc.

- Un conector que permita la comunicación entre la base de datos y el programa JClic reports. Los conectores utilizados por las aplicaciones Java son del tipo JDBC, pero también se pueden utilizar conectores ODBC.

- El programa JClic reports, que realiza dos funciones

- Por un lado ofrece a los clientes JClic la información necesaria para identificar a los usuarios, iniciar las sesiones de trabajo y recibir los resultados: nombre de la actividad, número de intentos y aciertos, tiempo empleado, etc. JClic reports almacena esta información en la base de datos mediante el conector.

- La segunda función consiste en procesar los datos almacenados y mostrarlos en diversos formatos. Esta consulta se puede realizar desde cualquier navegador Web: Firefox, Safari, Internet Explorer, etc.

En este esquema como indican desde http://clic.xtec.net, se muestran los diversos elementos del sistema y sus interacciones:

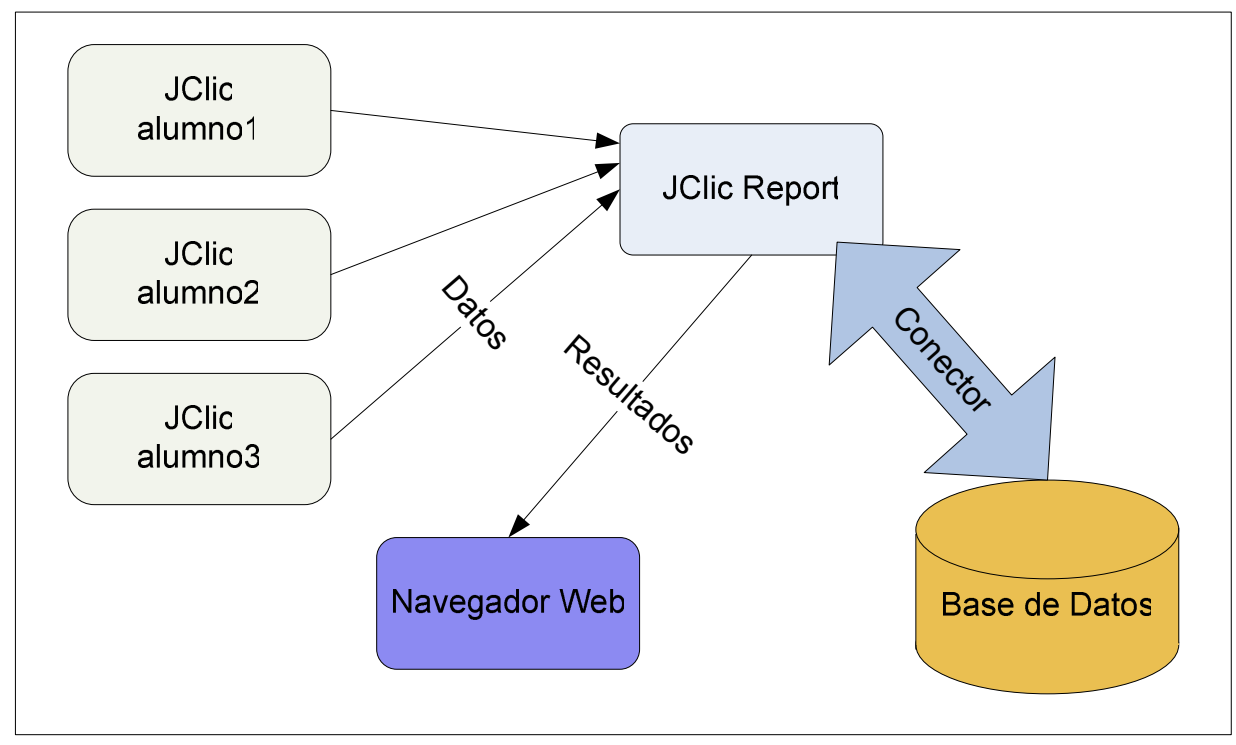

Figura 7. Elementos de JClic Reports

Este esquema será de gran utilidad para comprender posteriormente como se ha integrado JClic con Moodle y como es posible mantener JClic dentro de este tipo de sistemas.

La comunicación entre JClic reports y sus clientes (JClic applet, JClic player, navegador Web, etc.) se puede establecer de dos maneras:

- Por conexión directa (modalidad estándar). En esta modalidad JClic reports abre una ventana en el servidor en la que se muestra información de lo que 
va haciendo, y ofrece unos botones para pararlo, ponerlo en marcha y consultar los resultados desde un navegador.

- Mediante un servidor de aplicaciones Java (modalidad avanzada) Esta modalidad no requiere ningún entorno gráfico. JClic reports actúa como un conjunto de servlets integrados en un servidor de aplicaciones J2EE.

Para configurar el sistema de informes de JClic hay que seguir cuatro pasos, que afectan a los cuatro elementos que aparecen numerados en el esquema:

1. Crear una base de datos.

2. Configurar el conector.

3. Configurar el servidor de informes JClic reports.

4. Configurar los clientes JClic para que hagan uso del servidor de informes.

Los pasos a seguir para realizar estas operaciones serán diferentes según el tipo de base de datos y entorno operativo.

\subsection{Moodle}

Moodle fue creado por Martin Dougiamas, quien fue administrador de WebCT en la Universidad Tecnológica de Curtin, Australia, graduado en Ciencias de la Computación y Educación. Basó su diseño en las ideas del constructivismo en pedagogía que afirman que el conocimiento se construye en la mente del estudiante en lugar de ser transmitido sin cambios a partir de libros o enseñanzas y en el aprendizaje colaborativo. Un profesor que opera desde este punto de vista crea un ambiente centrado en el estudiante que le ayuda a construir ese conocimiento con base en sus habilidades y conocimientos propios en lugar de simplemente publicar y transmitir la información que se considera que los estudiantes deben conocer

Moodle es una aplicación Web a la que se accede por medio de un navegador Web (Firefox, Internet Explorer, etc.). Esto significa que para utilizar Moodle, se necesita un ordenador con un navegador Web instalado y con conexión a Internet. Por supuesto también se necesita conocer la dirección Web del servidor donde Moodle se encuentra alojado.

Moodle ofrece una cantidad limitada de información desde su página principal, para poder acceder a otros contenidos y para poder acceder al sistema se debe estar registrado como usuario del mismo. Moodle utiliza un interfaz fácil e intuitivo con lo que resulta sencillo familiarizarse rápidamente. 


\subsection{1. ¿Qué es Moodle?}

Moodle es un paquete de software para la creación de cursos y sitios Web basados en Internet. Es un proyecto en continuo desarrollo, diseñado para dar soporte a un marco de educación social constructivista.

La palabra Moodle era al principio un acrónimo de Modular Object-Oriented Dynamic Learning Environment (Entorno de Aprendizaje Dinámico Orientado a Objetos y Modular).

Uno de los temas más candentes dentro del entorno del e-learning es la programación orientada a objetos, cuyo elemento fundamental es, como su nombre indica, el objeto. El "objeto" se define como un conjunto complejo de datos y programas que poseen estructura y forman parte de una organización. A partir de esta concepción de programación orientada a objetos, se comienza a hablar de Objetos de Aprendizaje, un nuevo concepto relacionado más con la perspectiva pedagógica.

Los Objetos de Aprendizaje son elementos de un nuevo tipo de e-learning originados en el paradigma de orientación a objetos. Son entidades digitales, en general de reducido tamaño, diseñadas para ser distribuidas a través de Internet, facilitándose por tanto el acceso a ellas simultáneamente por muchos usuarios. Los diseñadores las combinan como componentes instruccionales reutilizables para construir componentes mayores al servicio de objetivos diferentes y en distintos contextos. Cada Objeto de Aprendizaje debe ser autocontenido y puede incluir en su estructura otros objetos. Su reducido tamaño también facilita que puedan ensamblarse para soportar objetivos instruccionales individuales.

Para hacer posible la sociedad del conocimiento precisamos un sistema de elaboración y distribución de conocimiento capaz de promover el aprendizaje más eficaz y barato que la formación actual, mayoritariamente presencial.

Moodle se diseñó, por tanto, para poder desarrollar contenidos de acuerdo a la filosofía de los Objetos de Aprendizaje y, por tanto, de la programación orientada a objetos.

Moodle está considerado como un LMS (Learning Management System) que no es más que un Sistema de Gestión de Aprendizaje que ayuda a los educadores a crear comunidades de aprendizaje en línea

\subsubsection{Objetos de Aprendizaje}

Para facilitar el análisis del concepto "Objeto de Aprendizaje" conviene hacerlo desde una doble perspectiva no siempre tenida en cuenta:

- Perspectiva informática

- Perspectiva didáctica 


\subsubsection{Perspectiva informática}

La aproximación mediante objetos de aprendizaje plantea exigencias operativas importantes al almacenamiento y distribución informática. Son críticas las siguientes funcionalidades:

- Accesibilidad

- Modularidad

- Interoperabilidad

- Reutilizabilidad

Al dotar a los Objetos de Aprendizaje de estas funcionalidades pretendemos pasar de la producción artesana actual de cursos a una producción y distribución masiva, personalizada y a demanda con un significativo impacto en costes.

\subsubsection{Perspectiva didáctica}

Tal como hemos visto la misión de la arquitectura informática es facilitar un acceso rápido a contenidos (información) si bien no produce aprendizaje. Acceder a información tiene gran interés en muchas situaciones pero en sí mismo no garantiza un proceso de aprendizaje.

Una persona puede aprender de muchas maneras, la interacción constante con el entorno que nos rodea provoca un aprendizaje permanente. Cuando queremos aprender un conocimiento o dominar una habilidad el mero acceso a información no conduce necesariamente a su aprendizaje. Para ello es necesario dotar el contenido de una cierta estructura y ejecutar un conjunto de actividades que lo produzcan. Acceder a información no es aprender.

Por tanto y desde una perspectiva didáctica se debe:

1. Estructurar los contenidos de los entornos virtuales que sustituyan o complementen a los entornos reales

2. Utilizar métodos instruccionales que faciliten su aprendizaje.

La idea es que los Objetos de Aprendizaje permitan mediante su combinación crear el soporte necesario para lograr los objetivos propuestos dentro de un contexto en el que, frente a la enseñanza presencial, están ausentes elementos básicos de motivación y refuerzo. 


\subsubsection{Arquitectura de Moodle}

Moodle se distribuye gratuitamente como Software libre (Open Source) (bajo la Licencia pública GNU). Básicamente esto significa que Moodle tiene derechos de autor (copyright), pero que el usuario tiene algunas libertades. Puede copiar, usar y modificar Moodle siempre que acepte algunas cláusulas:

- Proporcionar el código fuente a otros.

- No modificar o eliminar la licencia original

- Aplicar esta misma licencia a cualquier trabajo derivado de él.

Moodle puede funcionar en cualquier ordenador en el que pueda correr PHP, y soporta varios tipos de bases de datos (en especial MySQL).

Todas estas características hacen que Moodle sea un producto activo y en constante evolución.

\subsubsection{Diseño general}

Promueve una pedagogía constructivista social, al ser un entorno colaborativo con distintas funciones para la interacción y la construcción del conocimiento de forma grupal.

El Constructivismo afirma que el aprendizaje es especialmente efectivo cuando se realiza compartiéndolo con otros. Esa experiencia puede ser cualquier cosa: una frase pronunciada o un mensaje en Internet, o elementos más complejos como una pintura, una casa o una aplicación informática.

El concepto del constructivismo social amplía las ideas comentadas en un grupo social que construye su aprendizaje unos con otros, creando en colaboración una cultura de compartir contenidos y significados. Cuando uno se sumerge dentro de una cultura como está, estamos aprendiendo continuamente como ser una parte de esa cultura a muchos niveles.

La perspectiva constructivista ve al alumno implicado activamente en su aprendizaje para que le de significado, y este tipo de enseñanza busca que el alumno pueda analizar, investigar, colaborar, compartir, construir y generar basándose en lo que ya sabe.

- Apropiada para el $100 \%$ de las clases en línea, así como también para complementar el aprendizaje presencial.

- Su interfaz es sencilla, ligera, eficiente, y compatible.

- Es fácil de instalar en casi cualquier plataforma que soporte PHP. Sólo requiere que exista una base de datos (y la puede compartir).

- Con su completa abstracción de bases de datos, soporta las principales marcas de bases de datos (excepto en la definición inicial de las tablas). 
- La lista de cursos muestra descripciones de cada uno de los cursos que hay en el servidor, incluyendo la posibilidad de acceder como invitado.

- Los cursos pueden clasificarse por categorías y también pueden ser buscados - un servidor Moodle puede albergar miles de cursos.

- Se ha puesto énfasis en una seguridad sólida en toda la plataforma. Todos los formularios son revisados, las cookies encriptadas, etc.

- La mayoría de las áreas de introducción de texto (recursos, mensajes de los foros, entradas de los diarios, etc.) pueden ser editadas usando el editor HTML, tan sencillo como cualquier editor de texto de Windows.

\subsubsection{Administración del sitio Moodle}

- El sitio es administrado por un usuario administrador, definido durante la instalación.

- Los "temas" permiten al administrador personalizar los colores del sitio, la tipografía, presentación, etc., para ajustarse a sus necesidades.

- Pueden añadirse nuevos módulos de actividades a los ya instalados en Moodle.

- Los paquetes de idiomas permiten una localización completa de cualquier idioma. Estos paquetes pueden editarse usando un editor integrado.

- El código está escrito de forma clara en PHP bajo la licencia GPL, fácil de modificar para satisfacer sus necesidades.

\subsubsection{Gestión de usuarios}

- Los objetivos son reducir al mínimo el trabajo del administrador, manteniendo una alta seguridad.

- Soporta un rango de mecanismos de autenticación a través de módulos de autenticación, que permiten una integración sencilla con los sistemas existentes.

- Método estándar de alta por correo electrónico: los estudiantes pueden crear sus propias cuentas de acceso. La dirección de correo electrónico se verifica mediante confirmación.

- Puede utilizar LDAP: las cuentas de acceso pueden verificarse en un servidor LDAP. El administrador puede especificar qué campos usar.

- IMAP, POP3, NNTP: las cuentas de acceso se verifican contra un servidor de correo o de noticias (news). Soporta los certificados SSL y TLS.

- Base de datos externa: Cualquier base de datos que contenga al menos dos campos puede usarse como fuente externa de autenticación.

- Cada persona necesita sólo una cuenta para todo el servidor. Por otra parte, cada cuenta puede tener diferentes tipos de acceso.

- Una cuenta de administrador controla la creación de cursos y determina los profesores, asignando usuarios a los cursos.

- Seguridad: los profesores pueden añadir una "clave de acceso" para sus cursos, con el fin de impedir el acceso de quienes no sean sus estudiantes. 
Pueden transmitir esta clave personalmente o a través del correo electrónico personal, etc.

- Los profesores pueden dar de baja a los estudiantes manualmente si lo desean, aunque también existe una forma automática de dar de baja a los estudiantes que permanezcan inactivos durante un determinado período de tiempo (establecido por el administrador).

- Se anima a los estudiantes a crear un perfil en línea de sí mismos, incluyendo fotos, descripción, etc. De ser necesario, pueden esconderse las direcciones de correo electrónico.

- Cada usuario puede especificar su propia zona horaria, y todas las fechas marcadas en Moodle se traducirán a esa zona horaria (las fechas de escritura de mensajes, de entrega de tareas, etc.)

- Cada usuario puede elegir el idioma que se usará en la interfaz de Moodle (inglés, francés, alemán, español, portugués, etc.)

\subsubsection{Gestión de cursos}

- El profesor tiene control total sobre todas las opciones de un curso.

- Se puede elegir entre varios formatos de curso tales como semanal, por temas o el formato social, basado en debates.

- Ofrece una serie flexible de actividades para los cursos: foros, diarios, cuestionarios, materiales, consultas, encuestas y tareas.

- En la página principal del curso se pueden presentar los cambios ocurridos desde la última vez que el usuario entró en el curso, lo que ayuda a crear una sensación de comunidad.

La mayoría de las áreas para introducir texto (materiales, envío de mensajes a un foro, entradas en el diario, etc.) pueden editarse usando un editor HTML WYSIWYG integrado.

- Todas las calificaciones para los foros, diarios, cuestionarios y tareas pueden verse en una única página ( $\mathrm{y}$ descargarse como un archivo con formato de hoja de cálculo).

- Registro y seguimiento completo de los accesos del usuario. Se dispone de informes de actividad de cada estudiante, con gráficos y detalles sobre su paso por cada módulo (último acceso, número de veces que lo ha leído) así como también de una detallada "historia" de la participación de cada estudiante, incluyendo mensajes enviados, entradas en el diario, etc. en una sola página.

- Integración del correo. Pueden enviarse por correo electrónico copias de los mensajes enviados a un foro, los comentarios de los profesores, etc. en formato HTML o de texto. 


\subsubsection{Los módulos}

- Tarea. Asigna tareas en línea o no; los alumnos pueden enviar sus tareas en cualquier formato (como MS Office, PDF, imagen, a/v etc.).

- Chat. Permite la comunicación en tiempo real de los alumnos.

- Consulta. Los profesores crean una pregunta y un número de opciones para los alumnos. Utilice este módulo para hacer votaciones rápidas sobre un tema.

- Charla. Permite el intercambio asincrónico privado entre el profesor y un alumno o entre dos alumnos.

- Foros. Las aportaciones en los foros permiten un intercambio asincrónico del grupo sobre un tema compartido. La participación en foros puede ser una parte integral de la experiencia de aprendizaje, ayuda a los alumnos a aclarar y desarrollar su comprensión del tema.

- Lección. Permite crear y gestionar un conjunto de "páginas enlazadas". Cada página puede terminar con una pregunta. Según la respuesta elegida por el alumno se va adelante, atrás, a otra página o a la misma página en la lección. Se califica al terminar.

- Glosario. Crea una recopilación de los términos más usados en un curso. Tiene muchas opciones de representación incluyendo lista, enciclopedia, $F A Q$, diccionario y otras.

- Diario. Refleja el aprendizaje, registra y revisa las ideas.

- Etiquetas. Añade descripciones con imágenes en la página principal del curso.

- Cuestionario. Permite cuestionarios incluyendo preguntas de verdaderofalso, opción múltiple, respuestas cortas, asociación, preguntas al azar, numéricas, incrustadas en el texto y todas ellas pueden tener gráficos.

- Material. Sirve para incluir contenidos en un curso; pueden ser: texto sin formato, archivos subidos, enlaces Web, Wiki o HTML (Moodle tiene los editores incorporados) o una referencia bibliográfica.

- Encuesta. Este módulo ayuda a crear cursos más eficaces ofreciendo una variedad de las encuestas (COLLES, ATTLS), incluyendo el muestreo de incidentes críticos.

- Taller. Sirve para el trabajo (Word, PP etc.) en grupo. Permite a los participantes diversas formas de evaluar los proyectos de los demás, así como proyectos-prototipo. Finalmente el profesor califica los trabajos.

\subsubsection{Ventajas y desventajas de Moodle}

Una de las características más atractivas de Moodle, que también aparece en otros gestores de contenido educativo, es la posibilidad de que los alumnos participen en la creación de glosarios, y en todas las lecciones se generan automáticamente enlaces a las palabras incluidas en estos.

Además las instituciones educativas, podrán poner su Moodle local y así poder crear sus plataformas para cursos específicos en la misma institución y dando la dirección 
respecto a Moodle, se moverá en su mismo idioma y podrán abrirse los cursos a los alumnos que se encuentren en cualquier parte del planeta.

Como desventaja comentar que algunas actividades pueden ser un poco mecánicas, dependiendo mucho del diseño instruccional para Moodle lo que lo hace más dinámico y atractivo. Por estar basado en tecnología PHP la configuración de un servidor con muchos usuarios debe ser cuidadosa para obtener el mejor desempeño. Falta mejorar su interfaz de una manera más sencilla en comparación con otros sistemas de este tipo como Dokeos (www.dokeos.com)

\subsection{Integración de JClic y Moodle}

Con la aparición de un módulo que integra JClic y Moodle, se puede integrar las actividades de JClic dentro de un especio de Moodle, quedando registradas las calificaciones obtenidas en las actividades de JClic, en las fichas personales de los usuarios de Moodle. De esta forma, los profesores podrán luego obtener los correspondientes informes de evaluación.

En el apartado 9.4 de este capítulo, se ha definido como es posible que funcione el servidor de informes que proporciona JClic, en este momento esta definición adquiere una gran importancia, no sería posible integrar JClic y Moodle si no fuera por que ambos sistemas trabajan un una base de datos similar, el modulo que integra estos dos sistemas se aprovecha de esta característica. El esquema antes mencionado quedaría en esta ocasión como se ve a continuación:

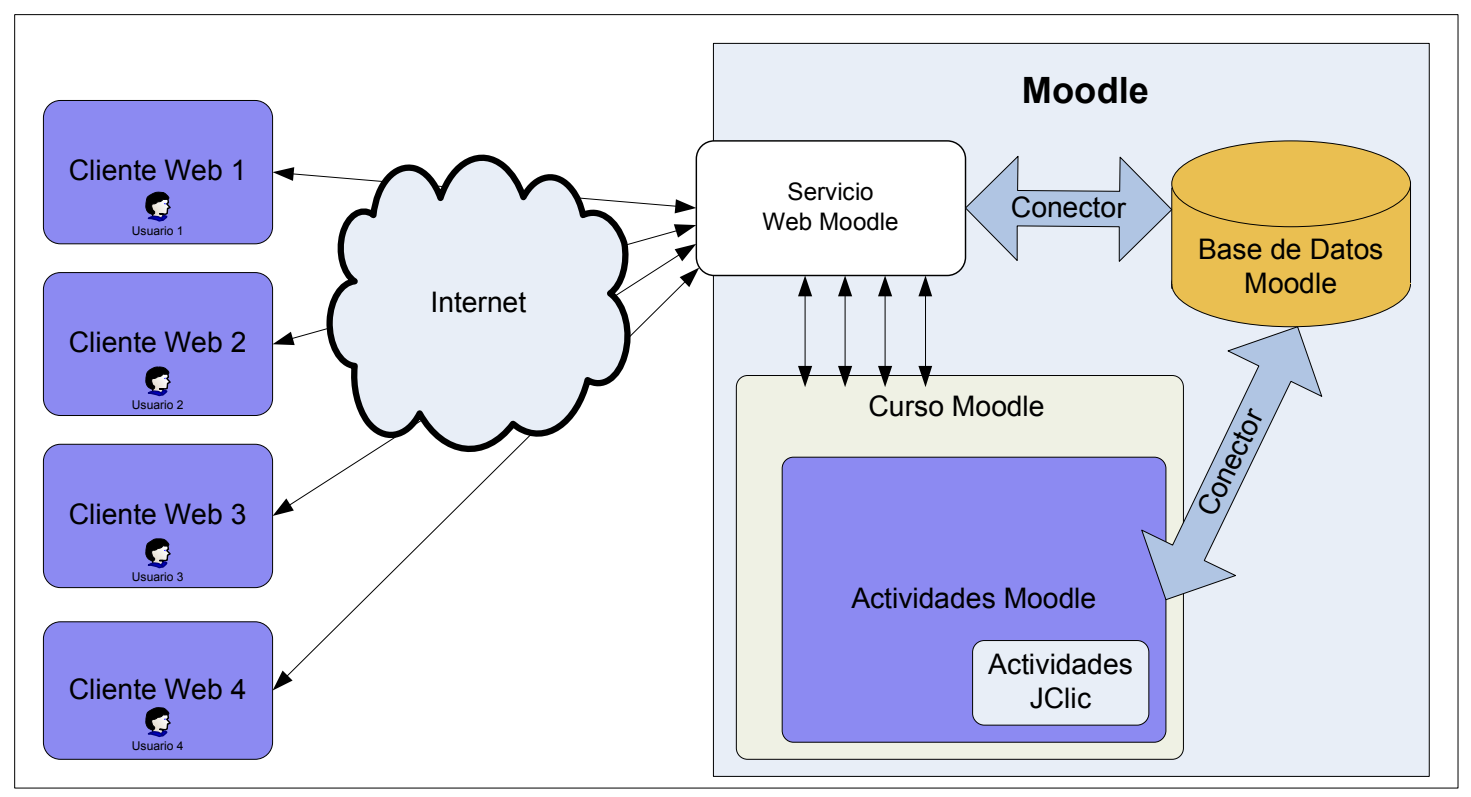

Figura 8. Integración de JClic en Moodle 
En esta ocasión los usuarios, se conectan con un cliente Web (Internet Explorer, Firefox,...) a través de Internet con el servicio Web de Moodle, este servicio Web son los archivos que forman la página Web, en este caso educa.signando.com. Existen varios conectores contra la Base de Datos de Moodle, el servicio Web depende de este conector para formar el contenido de las páginas, además mantiene la lista de usuarios de los cursos. Los cursos en Moodle están montados a partir de actividades formadas con los distintos módulos antes mencionados. El paquete que integra JClic con Moodle permite considerar las aplicaciones JClic como un módulo más de Moodle. Todas las actividades utilizan un conector contra la Base de Datos, de esta forma la actividad que los usuarios realizan sobre cada una de estas actividades queda reflejada en ella. JClic, como ya se vio, también puede hacer uso de esta Base de Datos para almacenar los resultados de la ejecución de las actividades que contiene. La conexión que se mantiene con los clientes Web es suficiente para mostrar la información que JClic muestra.

Existen dos posibilidades para agregar actividades JClic en Moodle:

1. Utilizar actividades ya creadas y colgadas de la página de JClic en España ( http://clic.xtec.cat/es/jclic/index.htm). Actualmente existen más de 1000 proyectos disponibles.

2. Crear tus propias actividades e incluirlas en Moodle. Para poder incluir una actividad de JClic en Moodle, previamente el administrador de la plataforma tendrá que instalar el módulo correspondiente de JClic.

Para la integración de JClic en Moodle, en este caso, se ha usado la segunda de las opciones. Hay que recordar que actualmente existe muy poco material educativo orientado a la educación de Personas Adultas Sordas. Con la creación, por mi parte, del curso LECTOR se ha conseguido incrementar el material educativo en esta área.

En este caso, educa.signando.com (espacio Moodle) mantiene el Curso LECTOR, el cual contiene a su vez, elementos de Moodle, como son los Test o documentos que contienen explicaciones y actividades educativas creadas con JClic. De esta forma se entrelazan los dos sistemas, tomando en cada caso lo mejor de cada uno.

\subsection{Joomla!}

Joomla es un sistema gestor de contenidos dinámicos (CMS o Content Management System) que permite crear sitios Web de alta interactividad, profesionalidad y eficiencia. La administración de Joomla está enteramente basada en la gestión online de contenidos...

Se dice "gestión online" porque todas las acciones que realizan los administradores de sitios Joomla, ya sea para modificar, agregar, o eliminar contenidos se realiza exclusivamente mediante un navegador Web (browser) conectado a Internet, es decir, a través del protocolo HTTP (Protocolo de transferencia de hipertexto). 
Nada más que esto es necesario para el usuario de Joomla para publicar información en la Red Global, y mantenerla siempre actualizada y fresca. Esto convierte a Joomla en una poderosa herramienta de difusión de Información, de Marketing Online, y también de negocios por Internet.

Con Joomla se pueden crear sitios Web de noticias, sitios corporativos, sitios Web de presencia, portales comunitarios, e incluso también puede crearse con Joomla sistemas que funcionen en redes cerradas (Intranets) para gestionar información interna (comunicaciones, usuarios, etc.) de compañías o empresas de negocios. Con esto último podrán advertir que el ámbito de aplicación de Joomla no es exclusivo de Internet.

Joomla está programado en lenguaje PHP (Hypertext Pre Processor) y SQL (Structure Query Language). Utiliza bases de datos relacionales, más específicamente MySQL. Tanto PHP como Mysql son programas Opensource de libre distribución y uso, y al ser Joomla una aplicación WEB, funciona obviamente en servidores de páginas Web (HTTP Servers). Estos servidores de páginas Web pueden ser de pruebas (Esto es, por ejemplo, Joomla funcionando en un servidor instalado en la misma máquina del usuario que lo administra), o también servidores comerciales de producción (Esto es, cuando publicamos un sitio Web basado en Joomla alojado en una empresa proveedora del servicio de hosting).

El funcionamiento de Joomla se lleva a cabo gracias a sus dos principales elementos:

1. La base de datos Mysql: allí es donde se guarda toda la información y la mayor parte de la configuración del sistema, de una forma ordenada y en distintas tablas, las cuales cada una de ellas almacena información específica y determinada.

2. Los scripts PHP: son los que ejecutan las acciones de consulta y realizan modificaciones en la base de datos convirtiendo los datos en simples páginas Web interpretables por los navegadores de Internet (Browsers) y perfectamente inteligibles para los usuarios navegantes y administradores.

Existen también otro tipo de archivos que realizan importantes tareas dentro de Joomla (archivos XML, scripts Javascript JS, CSS, etc.), pero el motor fundamental de todo CMS (y de Joomla en particular) son los dos enunciados anteriormente.

Como se indica en el Manual del Usuario escrito por White y Wallace (2006), Joomla, realiza un gran trabajo gestionando el contenido necesario para que un sito Web funcione. Pero para mucha gente, el verdadero potencial de Joomla recae en la arquitectura de la aplicación, que posibilita que miles de desarrolladores en el mundo puedan crear potentes add-ons y extensiones. 


\subsection{Joomla y Moodle}

Joomla y Moodle son dos sistemas completamente independientes uno del otro, Joomla es lo conocido como CMS (Content Management System o Sistema de Gestión de Contenidos en español) mientras que Moodle es un LMS, la idea de utilizar uno $u$ otro surge de las necesidades que se presentaron a lo largo del proyecto.

Joomla permite la creación de espacios Web, dinámicos y potentes, esto hace que sea un sistema adecuado para la publicación de todo tipo de información. Se pensó que la página www.signando.com, sistema Joomla podría servir como portal de acceso a educa.signando.com, sistema Moodle y como espacio para la divulgación de todo tipo de noticias relacionadas con las Personas Sordas.

Moodle permite la creación de cursos y está orientado a la educación como ya se ha indicado, su apariencia aunque configurable no es tan "atractiva" como la que se le puede dar a un espacio creado en Joomla.

Aprovechando las ventajas de cada uno de los sistemas que son totalmente independientes, es como se ha llegado a crear este conjunto de páginas que se encuentran claramente unidas por un objetivo común educar a las personas sordas y al entorno que las rodea, esta educación además de estar basada en la formación con los cursos que muestra educa.signando.com también se consigue informando de las necesidades y peculiaridades de este colectivo a través de signando.com.

Las estadísticas de visitas y accesos indican que la idea inicial de hacer de www.signando.com, el portal inicial, ha sido todo un éxito, consiguiendo que un gran número de las visitas recibidas en educa.signando.com vengan directamente desde esta otra Web.

En conclusión, se han utilizado dos sistemas completamente independientes desde el punto de vista informático, pero completamente compatibles desde el punto de vista de la formación, asumiendo cada una de las páginas un rol diferente dentro de este papel educativo. A la vez se ha utilizado el sistema CMS como portar de entrada al LMS 

en Castilla y León 


\section{Capítulo V. Desarrollo Empírico}

Se han realizado muchas investigaciones relacionadas con la capacidad lectora de Personas Sordas. Schirner (2001, citado en Domínguez, 2006), obtuvo las siguientes conclusiones en estudios realizados con alumnos sordos:

- Las dificultades que tienen las personas sordas en la comprensión y producción de las estructuras sintácticas de la oración, sobre todo a medida que éstas son más compleja (Quigley y Paul, 1984). La percepción parcial del habla que tienen estos alumnos hace que normalmente identifiquen las palabras de contenido (verbo y sustantivos) y en menor medida las palabras funcionales (preposiciones, artículos).

- Estas dificultades con la sintaxis pueden ser un factor menos importante para la comprensión que las habilidades de reconocimiento de la palabra.

- Las dificultades sintácticas pueden disminuir la habilidad de los niños sordos para aplicar su conocimiento de vocabulario mientras leen.

- Los contextos limitados (tales como historias breves) son más difíciles de comprender para los niños sordos que los contextos amplios (historias largas o novelas).

- El material reescrito, controlando la longitud y complejidad de las oraciones puede ser más difícil de entender por los alumnos sordos debido a la ausencia de coherencia textual.

Por lo tanto, el conocimiento de vocabulario y de la sintaxis constituye una dificultad importante para el aprendizaje de la lengua escrita y el progreso en ese conocimiento no se produce posteriormente dadas las recíprocas relaciones que se establecen entre el conocimiento de la lengua y la habilidad en lectura (el llamado "efecto Mathew"; Stanovich, 1986), es decir, el conocimiento pobre de la lengua escrita puede producir unas habilidades lectoras también pobres y, como consecuencia, estas dificultades en la lengua escrita privan a estos adultos de una fuente importante de conocimiento lingüístico.

Estudios (Morais, Cary, Alegría y Bertelson, 1979) muestran que personas adultas analfabetas obtienen unas puntuaciones muy bajas en tests de conocimiento fonológico. Si este conocimiento se desarrollara espontáneamente durante la infancia, las personas adultas analfabetas deberían mostrar ciertos niveles de conocimiento fonológico. Debido a esto no es así, los autores concluyen diciendo que el conocimiento fonológico no surge espontáneamente y que la situación más frecuente que permite que la habilidad de análisis fonológico se desarrolle es aprender a leer y escribir en un sistema alfabético, planteamiento que está apoyado por los estudios de Read (1986, citado en Clemente y Domínguez, 1999) con sujetos que han aprendido a leer en un sistema no alfabético: el chino. Por tanto, según estos trabajos el desarrollo del conocimiento fonológico es una consecuencia del aprendizaje de la lectura. 
Al analizar estas investigaciones, es posible constatar que existe una fuerte relación entre habilidad lingüística y logros en lectura. Como se ha señalado, una explicación de ello es que los problemas de lectura de los sordos se originan en un déficit lingüístico global. Es decir, no sólo una mejor habilidad lingüística contribuye al logro lector, sino que el aumento de la experiencia con el lenguaje escrito contribuye a desarrollar habilidades lingüísticas. Asimismo, es posible que la correlación entre lectura y lenguaje resulte, debido a que ambas están relacionadas a una tercera variable.

En los últimos tiempos, ha prosperado la idea de investigar las correlaciones entre logro lector y habilidad lingüística en los sordos, utilizando un diseño de investigación. Con el fin de establecer con mayor claridad y en forma más definitiva la dirección de esta relación. Dicho diseño permitiría estudiar ampliamente el lenguaje infantil y las habilidades cognitivas antes de iniciar el aprendizaje de la lectura; de este modo sus progresos serían estudiados intensivamente durante las primeras etapas de adquisición.

En el trabajo presentado para lograr la Suficiencia Investigadora se realizó una investigación en la Asociación de Personas Sordas de Salamanca, donde se demostró que la utilización del Programa Lector a lo largo de algo más de 6 meses mejora levemente las habilidades lectoras de estos alumnos.

En esta investigación se quiere continuar con el trabajo que se presentó para la suficiencia investigadora. Para ello se cuenta con la colaboración de la Federación de Asociaciones de Personas Sordas de Castilla y León. Esto hará que el ámbito de trabajo sea mayor, además se utilizarán herramientas basadas en las Nuevas Tecnologías. Internet será el medio a través del cual los alumnos puedan trabajar las actividades del nuevo LECTOR, facilitando así que se pueda utilizar esta aplicación desde cualquier ordenador y a cualquier hora.

La investigación desarrollada con personas Sordas Adultas en el Centro Cultural de Sordos de Salamanca durante el período de abril del 2006 hasta mayo del 2007 mostró que el uso del Programa Lector (de Castro, 2006), produce una mejora significativa en la lectura de oraciones de estas personas haciendo uso de estrategias sintácticas a través de actividades educativas.

El Programa Lector, que fue creado como un proyecto Jclic, puede ser adaptado, además de a las personas con discapacidad auditiva, para el uso en cualquier discapacidad, pudiendo extenderse a otras discapacidades mentales y físicas, gracias a la potencia de adaptación que le otorga JClic. Para que esto sea posible es muy importante realizar un análisis de los resultados, esta evaluación detallada mostrara la necesidad de cada persona, y dará como resultado las actividades adaptadas de acuerdo con sus dificultades de lecto-escritura.

A partir de los resultados de ese trabajo previo, en la investigación presentada a continuación se convirtió el Programa Lector en Curso educativo en Moodle dentro de una página Web (educa.signando.com). A partir de ahora y a lo largo de toda la investigación se hará referencia a este curso como LECTOR. 
Con la utilización de recursos informáticos aplicados a la educación, se pretende difundir una serie de recursos educativos TIC, existentes, y muy utilizados para otros fines educativos, en este caso permiten desarrollar curso para personas con discapacidad auditiva. El objetivo es el de favorecer la utilización de estas tecnologías para aumentar los conocimientos relacionados con la lecto-escritura aplicados sobre el colectivo de Personas Sordas adultas. 


\subsection{Objetivos e Hipótesis}

El objetivo general fue, comprobar si el curso LECTOR es una herramienta válida para el desarrollo de estratégias sintácticas para las personas sordas adultas.

Este objetivo se concretó con otros más específicos:

1. Determinar el nivel lector alcanzado por las Personas Sordas Adultas pertenecientes a la Federación de Asociaciones de Personas Sordas de Castilla y León; para ello se evaluarán los niveles de eficiencia lectora y uso de estrategias sintacticas al inicio del trabajo con estas personas y se compararán con los valores obtenidos por Soriano (2004) y Soriano et al. (2006), cumpliendo la hipotesis de que las Personas Sordas Adultas poseen unos niveles de eficiencia lectora comparables a los niveles obtenidos por alumnos oyentes de $5^{0}$ de Primaria 0 menores y de uso de estrategias sintacticas equivalentes a alumnos oyentes de 3-4을 de Primaria o menores, obteniendo por lo tanto un nivel funcional de niños de entre 11 y 12 años.

2. Diseñar actividades para la enseñanza de estrategias sintácticas y mejorar la eficiencia lectora aplicando recursos educativos basados en las nuevas tecnologias, formando el curso LECTOR, planteando la hipotesis de que el trabajo con estas actividades TIC, favorecen el desarrollo de estrategias sintacticas y aumenta la eficiencia lectora.

3. Evaluar la eficacia de las actividades de LECTOR en el desarrollo de estrategias sintácticas, comparando nuevamente los resultados obtenidos con los valores que obtuvo Soriano (2004) que confirmará la hipotesis principal planteada para esta tesis; si el curso Lector es una herramienta válida para el desarrollo de estrategias sintacticas en Personas Sordas Adultas.en Castilla y León.

La pretensión del primer objetivo es valorar el nivel lector de las Personas Sordas adultas pertenecientes a los Centros Educativos de la Federación de Asociaciones de Personas Sordas de Castilla y León, utilizando para ello la Prueba de Evaluación de la Eficiencia Lectora (PEL) (Carrillo y Marín, 1997). A partir de ellos establecer niveles de trabajo con el curso LECTOR.Para evaluar el nivel de uso de estrategias sintacticas que las personas adultas sordas tienen en la lectura de oraciones, se cuenta con la Prueba de Evaluación de las Estrategias Sintácticas (PEES) (Soriano, Pérez y Domínguez, 2006). La primera hipótesis planteada debe demostrarse comparando los valores obtenidos en estas pruebas, con los que obtuvo Soriano en 2004, consiguiendo de esta manera el nivel funcional de los participantes en la investigación.

Diseñar actividades que formen LECTOR supone crear un curso, dentro de un entorno de fácil manejo, que permita el trabajo continuo desde cualquier ubicación. Este objetivo, se podrá cumplir con la ejecución del diseño de actividades para la enseñanza de estrategias sintácticas. Estas actividades estarán dirigidas a los 
participantes, analizando las relaciones entre el nivel lector que consiguen y las estrategias que utilizan durante la lectura de frases. Desarrollar el trabajo con el conjunto de las actividades de LECTOR es un objetivo básico para la investigación ya que con el trabajo con LECTOR se intenta mejorar el nivel lector de los participantes Del tiempo dedicado a este desarrollo dependen en gran medida los resultados que se puedan obtener.

El último objetivo, evaluar la eficacia de LECTOR dará respuesta al objetivo general marcado para esta investigación, comprobar que el trabajo con LECTOR es válido para el desarrollo de estrategias sintácticas en Personas Sordas. Para poder demostrar estos resultados habrá que evaluar el tipo de estrategias que las personas Sordas usan después del trabajo con LECTOR. Esta demostración se hará comparando los resultados obtenidos con las Pruebas de Eficiencia Lectora y Evaluación de Estrategias Sintácticas antes y después del trabajo con LECTOR, obteniendo nuevamente resultados sobre el nivel lector que muestran los participantes. Si el nivel aumenta indicará que la hipotesis planteada es cierta y por lo tanto LECTOR es una herramienta válida. 


\subsection{Diseño de la Investigación}

\subsubsection{Participantes}

Para la realización de esta investigación se ha contado con la colaboración de las Asociaciones que forman parte de la Federación de Asociaciones de Personas Sordas de Castilla y León.

Castilla y León, cuenta con una población con discapacidad de cerca de 152.000 personas, de las que el 5,4 por ciento sufren discapacidad auditiva (cerca de 8.000 personas).

Distribuidas de la siguiente manera (ver tabla 3):

\begin{tabular}{|c|c|}
\hline Provincia & Personas con Discapacidad Auditiva \\
\hline Ávila & 543 \\
Burgos & 871 \\
León & 2352 \\
Palencia & 580 \\
Salamanca & 1198 \\
Segovia & 379 \\
Soria & 249 \\
Valladolid & 1490 \\
Zamora & 523 \\
\hline
\end{tabular}

Tabla 3. Personas con Discapacidad Auditiva por Provincias en Castilla y León

A lo largo de este apartado se verá reflejada la estructura de la muestra de colaboradores, hay que recordar que en el momento de la investigación no se contó con la colaboración de las Asociaciones de Segovia y Soria, estas dos ciudades en el momento de la investigación aún no tenían constituidas sus Asociaciones, además la Asociación de Salamanca quedó excluida de la investigación por haberse realizado una investigación similar en 2006, investigación que como ya se ha explicado, sirvió de muestra piloto para la realización del presente trabajo.

Uno de los problemas encontrados a lo largo de la investigación ha sido la falta de participantes. Después del esfuerzo de visitar cada una de las Asociaciones para mantener reuniones con los responsables, de cada una de ellas y de intentar motivar a los educadores para que estos a su vez motivaran a los socios a participar, no se recibió el nivel de participación esperado. En la tabla 4, se puede observar el bajo nivel de colaboración de los socios de las Asociaciones colaboradoras. 


\begin{tabular}{|c|c|c|c|}
\hline $\begin{array}{c}\text { Total socios de } \\
\text { los Centros }\end{array}$ & $\begin{array}{c}\text { Participantes } \\
\text { activos }\end{array}$ & $\begin{array}{c}\text { Participantes } \\
\text { inscritos } \\
\text { Lector }\end{array}$ & $\begin{array}{c}\text { Inscritos que } \\
\text { han colaborado }\end{array}$ \\
\hline 430 & 142 & 55 & 35 \\
\hline
\end{tabular}

Tabla 4. Descripción de Socios y Participantes

Con estos valores se puede decir que solamente un 33\% (142) de los socios de los Centros, son participantes activos de las actividades de las Asociaciones. De estos solo el 38\% (55) realizó su inscripción para participar en esta investigación, finalmente el $63 \%$ (35) de los inscritos colaboró a lo largo de toda la investigación, esto supone un $8,1 \%$ del total de los socios. Este es uno de los problemas con los que las Asociaciones se encuentran, el nivel de participantes es muy bajo, y de estos, el número de participantes activos que finalizan completamente las colaboraciones se antoja, excesivamente reducido. Aún así, han sido 35 las personas que han participado en esta investigación.

En la tabla 5 se puede observar los participantes en el curso LECTOR, junto con los datos que ellos mismos proporcionaron a partir del formulario descrito en el punto siguiente.

\subsubsection{Formulario de información personal}

Para poder recoger datos sobre las características de los participantes en la investigación se solicitó una serie de datos con los que se formaba su perfil. Los datos solicitados han sido los siguientes:

- Iniciales (nombre + apellido1 + apellido 1) Ej.: Manuel García Pérez enviaría MGP. En ningún momento se han solicitado nombres completos, con esto se ha querido conservar el anonimato de los participantes.

- Provincia.

- Edad.

- Sexo. (Hombre o Mujer)

- Profesión. (Estudiante, Ama de Casa, Pensionista, Trabajador por cuenta ajena, Trabajador por cuenta propia).

- Dirección de correo electrónico válida. Esta dirección de correo que los participantes han proporcionado se ha utilizado para enviarles 
información, no solo del alta en el sistema sino también para informarles del nivel lector obtenido en las primeras pruebas y el comienzo y finalización del curso.

- Estudios realizados. (Sin estudios, Primaria, Secundaria, Universitarios)

- Tipo de Sordera: (Prelocutiva, Postlocutiva).

- Número de Audífonos. $(0,1,2)$.

- Uso de Lengua de signos. (si/no).

- Uso de Lengua oral. (si/no).

Esta información una vez recibida se almacena dentro de la base de datos de educa.signando.com. Los participantes una vez recibida esta información fueron matriculados como estudiantes del curso LECTOR.

Como se podrá ver en los siguientes puntos, estos datos recibidos han sido analizados detalladamente creando una descripción de los participantes. Además estas variables se han utilizado para realizar los análisis de nivel y uso de estrategias sintácticas en Lectura. 


\begin{tabular}{|c|c|c|c|c|c|c|c|c|}
\hline & 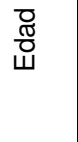 & $\begin{array}{l}\stackrel{\times}{x} \\
\stackrel{\infty}{\infty}\end{array}$ & 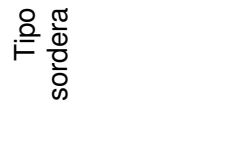 & 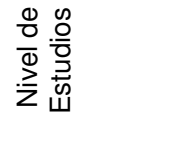 & 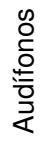 & $\begin{array}{l}\frac{\overline{0}}{y} \\
\frac{0}{0} \\
\frac{0}{0}\end{array}$ & 山 & 오 \\
\hline P01 & 36 & Mujer & Prelocutiva & Primaria & 1 & Trabajador por cuenta propia & $\mathrm{Si}$ & $\mathrm{Si}$ \\
\hline P02 & 22 & Mujer & Por enfermedad & Secundaria & 1 & Estudiante & $\mathrm{Si}$ & $\mathrm{Si}$ \\
\hline P03 & 70 & Hombre & Por enfermedad & Primaria & 0 & Trabajador por cuenta propia & No & $\mathrm{Si}$ \\
\hline P04 & 29 & Mujer & Prelocutiva & Secundaria & 0 & Trabajador por cuenta ajena & $\mathrm{Si}$ & $\mathrm{Si}$ \\
\hline P05 & 34 & Hombre & Por enfermedad & Sin estudios & 1 & Trabajador por cuenta ajena & $\mathrm{Si}$ & Si \\
\hline P07 & 56 & Mujer & Prelocutiva & Primaria & 0 & Ama de Casa & $\mathrm{Si}$ & No \\
\hline P08 & 47 & Mujer & Prelocutiva & Primaria & 0 & Trabajador por cuenta ajena & $\mathrm{Si}$ & $\mathrm{Si}$ \\
\hline P09 & 40 & Hombre & Prelocutiva & Universitario & 0 & Trabajador por cuenta ajena & $\mathrm{Si}$ & $\mathrm{Si}$ \\
\hline P10 & 23 & Mujer & Prelocutiva & Secundaria & 0 & Estudiante & $\mathrm{Si}$ & $\mathrm{Si}$ \\
\hline P11 & 27 & Mujer & Por enfermedad & Primaria & 0 & Pensionista & $\mathrm{Si}$ & $\mathrm{Si}$ \\
\hline P12 & 29 & Mujer & Prelocutiva & Secundaria & 1 & Trabajador por cuenta ajena & $\mathrm{Si}$ & $\mathrm{Si}$ \\
\hline P13 & 20 & Hombre & Prelocutiva & Secundaria & 1 & Estudiante & $\mathrm{Si}$ & No \\
\hline $\mathrm{P} 14$ & 67 & Hombre & Prelocutiva & Primaria & 0 & Pensionista & $\mathrm{Si}$ & No \\
\hline P15 & 14 & Hombre & Prelocutiva & Primaria & 1 & Estudiante & $\mathrm{Si}$ & $\mathrm{Si}$ \\
\hline P16 & 53 & Hombre & Prelocutiva & Primaria & 0 & Trabajador por cuenta ajena & $\mathrm{Si}$ & No \\
\hline P17 & 57 & Hombre & Prelocutiva & Primaria & 0 & Pensionista & $\mathrm{Si}$ & No \\
\hline P18 & 62 & Mujer & Por enfermedad & Universitario & 0 & Ama de Casa & No & $\mathrm{Si}$ \\
\hline P19 & 20 & Hombre & Prelocutiva & Secundaria & 1 & Estudiante & $\mathrm{Si}$ & $\mathrm{Si}$ \\
\hline P20 & 35 & Mujer & Prelocutiva & Secundaria & 1 & Trabajador por cuenta ajena & $\mathrm{Si}$ & $\mathrm{Si}$ \\
\hline P21 & 23 & Mujer & Por enfermedad & Secundaria & 1 & Estudiante & $\mathrm{Si}$ & $\mathrm{Si}$ \\
\hline P22 & 19 & Hombre & Prelocutiva & Secundaria & 0 & Estudiante & $\mathrm{Si}$ & $\mathrm{Si}$ \\
\hline P23 & 70 & Hombre & Prelocutiva & Sin estudios & 0 & Pensionista & No & No \\
\hline P24 & 65 & Mujer & Prelocutiva & Primaria & 0 & Ama de Casa & $\mathrm{Si}$ & No \\
\hline P25 & 57 & Mujer & Prelocutiva & Primaria & 0 & Ama de Casa & $\mathrm{Si}$ & No \\
\hline P26 & 39 & Hombre & Prelocutiva & Sin estudios & 0 & Estudiante & $\mathrm{Si}$ & $\mathrm{Si}$ \\
\hline P27 & 30 & Mujer & Por enfermedad & Secundaria & 1 & Trabajador por cuenta ajena & $\mathrm{Si}$ & $\mathrm{Si}$ \\
\hline P28 & 50 & Mujer & Prelocutiva & Primaria & 0 & Pensionista & $\mathrm{Si}$ & No \\
\hline P29 & 29 & Mujer & Por enfermedad & Secundaria & 0 & Trabajador por cuenta ajena & $\mathrm{Si}$ & $\mathrm{Si}$ \\
\hline P30 & 49 & Mujer & Prelocutiva & Primaria & 0 & Ama de Casa & $\mathrm{Si}$ & $\mathrm{Si}$ \\
\hline P31 & 50 & Mujer & Prelocutiva & Primaria & 0 & Trabajador por cuenta ajena & $\mathrm{Si}$ & No \\
\hline P32 & 27 & Hombre & Prelocutiva & Secundaria & 1 & Trabajador por cuenta ajena & $\mathrm{Si}$ & $\mathrm{Si}$ \\
\hline P33 & 36 & Mujer & Prelocutiva & Secundaria & 0 & Trabajador por cuenta ajena & $\mathrm{Si}$ & $\mathrm{Si}$ \\
\hline P34 & 34 & Mujer & Prelocutiva & Secundaria & 0 & Trabajador por cuenta ajena & $\mathrm{Si}$ & No \\
\hline P35 & 57 & Hombre & Prelocutiva & Primaria & 0 & Trabajador por cuenta ajena & Si & No \\
\hline
\end{tabular}

Tabla 5. Descripción de los participantes 


\subsubsection{Características de los Participantes}

\subsection{Sexo}

En la tabla 8 se puede observar que el grupo de participantes analizado, estaba formado por 15 hombres y 20 mujeres distribuidos en los diversos Centros de Personas Sordas Adultas de Castilla y León.

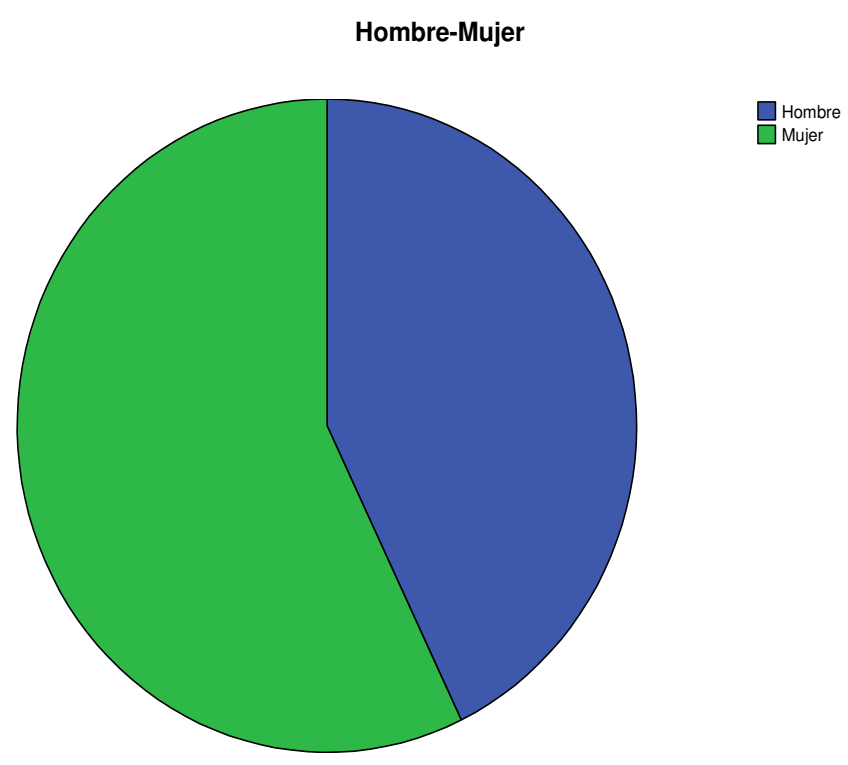

Figura 9. Gráfico Hombres y Mujeres

\begin{tabular}{|l|r|r|}
\hline \multicolumn{3}{|c|}{ Descriptivos } \\
\hline & Frecuencia & Porcentaje válido \\
\hline Hombre & 15 & 42.9 \\
Mujer & 20 & 57,1 \\
Total & 35 & 100,0 \\
\hline
\end{tabular}

Tabla 8. Porcentaje de Participantes en función del género

Es interesante destacar como estos valores porcentuales donde los hombres son el $42,9 \%$ y las mujeres son el $57,1 \%$, son prácticamente iguales que los tomados en la investigación realizada por de Castro (2006) en Salamanca, donde el $42,3 \%$ de los participantes eran hombre y el $57,7 \%$ restante mujeres. 


\subsection{Nivel de Estudios}

En las tablas 6 y 7 se puede observar que el $8,6 \%$ del grupo lo forma personas sin estudios y que su media de edad es inferior a 48 años. Sin embargo, las personas con estudios de Primaria, forman el $45,7 \%$ y su edad media es de casi 50 años. Personas sordas con estudios secundarios se han encontrado 14, formando el $40,0 \%$ de la muestra, con edades medias inferiores a 27 años.

Como situación excepcional, dos de las personas que realizaron las evaluaciones tienen estudios universitarios, siendo su media de edad de 51 años.

\begin{tabular}{|ll|r|r|}
\hline & Frecuencia & \multicolumn{2}{c|}{$\begin{array}{c}\text { Porcentaje } \\
\text { válido }\end{array}$} \\
\hline Válidos & Sin estudios & 3 & 8,6 \\
& Primaria & 16 & 45,7 \\
& Secundaria & 14 & 40,0 \\
Universitarios & 2 & 5,7 \\
Total & 35 & 100,0 \\
\hline
\end{tabular}

Tabla 6. Frecuencia según nivel de estudios

\begin{tabular}{|l|r|r|r|r|r|}
\hline & $\mathrm{N}$ & Media & $\begin{array}{c}\text { Desviación } \\
\text { típica }\end{array}$ & \multicolumn{1}{c|}{ Mínimo } & Máximo \\
\hline & $\begin{array}{c}\text { Límite } \\
\text { inferior }\end{array}$ & $\begin{array}{c}\text { Límite } \\
\text { superior }\end{array}$ & Límite inferior & $\begin{array}{c}\text { Límite } \\
\text { inferior }\end{array}$ & $\begin{array}{c}\text { Límite } \\
\text { superior }\end{array}$ \\
\hline Sin estudios & 3 & 47,67 & 19,502 & 34 & 70 \\
Primaria & 16 & 49,56 & 14,783 & 14 & 70 \\
Secundaria & 14 & 26,86 & 5,776 & 19 & 36 \\
Universitarios & 2 & 51,00 & 15,556 & 40 & 62 \\
Total & 35 & 40,40 & 16,277 & 14 & 70 \\
\hline
\end{tabular}

Tabla 7. Descriptivos

Según esta muestra las medias de edades de las personas sin estudios, con estudios de primaria y universitarios son similares, pero sus desviaciones típicas son altas, lo que indica un grado de dispersión de las edades elevado. De forma que en este caso, las edades no reflejan diferencias significativas respecto a su nivel educativo, en otras investigaciones como la realizada por de Castro (2006), el nivel educativo de los participantes mantenía una relación directa con la edad media de estos. Existía una relación inversamente proporcional en entre la edad y el nivel educativo, de esta forma los participantes que mayor edad tenían un menor nivel educativo. Estos resultados hablaban por sí solos sobre el progreso que la educación ha sufrido con el paso de los años. En el actual caso de estudio esta diferenciación no queda tan clara, lo que lleva a pensar que muchos de los participantes adquirieran este nivel educativo posteriormente a su etapa escolar. 


\subsection{Tipo de Sordera}

Se ha querido diferencia el tipo de sordera de los participantes para realizar posteriores análisis relacionados con su capacidad lectora. En la tabla 8 aparece que las 27 personas con sordera prelocutiva forman el $77,1 \%$ de la muestra, mientras que las 8 personas con sordera postlocutiva representan el 22,9\%.

\begin{tabular}{|ll|r|r|}
\hline & & \multicolumn{1}{|c|}{$\begin{array}{c}\text { Porcentaje } \\
\text { válido }\end{array}$} \\
\hline Válidos & Sordera Prelocutiva & 27 & 77,1 \\
& Sordera Postlocutiva & 8 & 22,9 \\
& Total & 35 & 100,0 \\
\hline
\end{tabular}

Tabla 8. Porcentaje de participantes en función del tipo de sordera

\subsection{Número de Audífonos}

La utilización de ayudas técnicas para el aprovechamiento de restos auditivos resulta de gran ayuda para integrarse en el medio en el que se vive, más adelante se analizarán si estas ayudas dentro de este grupo de trabajo suponen o no una ayuda en el nivel lector.

En la tabla 9 se observa que ninguna persona de la muestra utiliza dos audífonos y ninguna ha tenido implante coclear. Queda reflejado que 23 personas no hacen uso de audífonos y con un audífono existen 12 alumnos formando el 34,3\%.

\begin{tabular}{|rl|r|r|}
\hline & Frecuencia & $\begin{array}{c}\text { Porcentaje } \\
\text { válido }\end{array}$ \\
\hline Válidos & 0 & 23 & 65,7 \\
& 1 & 12 & 34,3 \\
& Total & 35 & 100,0 \\
\hline
\end{tabular}

Tabla 9. Porcentaje de participantes en función del número de audífonos 


\subsection{Profesión}

La integración de las Personas Sordas en el mundo laboral supone para este colectivo una de sus mayores preocupaciones. En la tabla 10 y en función de la profesión obtenemos que el $22,9 \%$ de las personas son estudiantes, el $14,3 \%$ son pensionistas y otro $14,3 \%$ son amas de casa y el $42,9 \%$ son trabajadores por cuenta ajena.

Cabe destacar que un $42,9 \%$ de las personas que han participado trabajan por cuenta ajena, mientras que solamente el 5,7\% lo hacen por cuenta propia.

\begin{tabular}{|ll|r|r|}
\hline & Frecuencia & \multicolumn{2}{|c|}{ Porcentaje válido } \\
\hline Válidos & Estudiante & 8 & 22,9 \\
& Pensionista & 5 & 14,3 \\
Ama de Casa & 5 & 14,3 \\
Trabajador por & 2 & 5,7 \\
cuenta propia & & \\
Trabajador por & 15 & 42,9 \\
cuenta ajena & 35 & 100,0 \\
Total & & \\
\hline
\end{tabular}

Tabla 10. Porcentaje de participantes en función de la profesión

\subsection{Lengua de Signos}

En la tabla 11 se puede observar como las personas sordas con conocimientos de lengua de signos forman el $91,4 \%$ de la muestra, siendo las personas que no lo dominan el 8,6\%. También hay que destacar que este alto nivel de usuarios que utiliza la Lengua de Signos en su vida diaria utiliza esta lengua para comprender la lengua escrita, los educadores hacen uso de ella para explicar conceptos, ideas o palabras que son de vital importancia para comprender la lengua escrita.

\begin{tabular}{|ll|r|r|}
\hline & Frecuencia & \multicolumn{2}{|c|}{$\begin{array}{c}\text { Porcentaje } \\
\text { válido }\end{array}$} \\
\hline Válidos & $\mathrm{No}$ & 3 & 8,6 \\
& $\mathrm{Si}$ & 32 & 91,4 \\
& Total & 35 & 100,0 \\
\hline
\end{tabular}

Tabla 11. Porcentaje de participantes en función del uso de LSE 


\subsection{Lengua Oral}

En la tabla 12 que se observa, que la frecuencia de personas sordas que tienen lengua oral es prácticamente el doble de las que no tienen. Siendo sus valores del $34,3 \%$ para las personas que no tienen lenguaje oral y $65,7 \%$ las que si lo tienen.

\begin{tabular}{|ll|r|r|}
\hline & Frecuencia & $\begin{array}{c}\text { Porcentaje } \\
\text { válido }\end{array}$ \\
\hline Válidos & No & 12 & 34,3 \\
& Si & 23 & 65,7 \\
& Total & 35 & 100,0 \\
\hline
\end{tabular}

Tabla 12. Porcentaje de participantes en función del uso de LO

En definitiva, se trata de un grupo formado en su mayoría por mujeres, con edad media superior a 40 años, con estudios mayoritariamente de Primaria y Secundaria, que dominan la Lengua de Signos y hacen uso de Lengua Oral, un gran número de ellos no utilizan audífonos y se encuentran integrados dentro del mercado laboral. 


\subsubsection{Instrumentos de Recogida de Datos}

Con el objetivo de evaluar el nivel lector de las personas sordas participantes en esta investigación, así como el tipo de estrategias que emplean para alcanzar ese nivel se emplearon dos pruebas:

- Prueba de Eficiencia Lectora (Carrillo y Marín, 1997)

- Prueba de Evaluación estratégicas sintácticas (Soriano, Pérez y

Domínguez, 2006).

Ambas pruebas fueron diseñadas para evaluar a personas sordas y han sido empleadas con este mismo objetivo en investigaciones previas (Pérez, 2005; Soriano, 2004)

En los Anexos I y II se encuentran estas dos pruebas. Para el desarrollo de esta investigación se realizó una adaptación de estas pruebas a un módulo Moodle, de tal manera que formaban parte del curso LECTOR, los participantes han tenido que realizarlas desde Internet.

\subsubsection{Prueba de Eficiencia Lectora}

Esta prueba de evaluación del nivel lector (Carrillo y Marín, 1997) parte de una concepción de la lectura en términos de eficiencia, de modo que combina los dos elementos básicos que definen la eficiencia lectora: la comprensión y la rapidez (ver Anexo I).

Las personas evaluadas necesitan comprender el significado de la frase para contestar adecuadamente $\mathrm{y}$, al mismo tiempo, tienen que hacerlo con la mayor rapidez posible para conseguir el mayor número de respuestas correctas en cinco minutos.

\subsection{Material}

La prueba considera distintos factores que pueden afectar tanto a la comprensión como a la velocidad lectora. Estos son los factores que afectan a la complejidad de la frase:

a) Complejidad sintáctica: definida por el número de palabras que integran la frase. Hay dos niveles: frases largas de más de ocho palabras (complejidad alta) y frases de complejidad baja (ocho palabras o menos).

b) Complejidad semántica: definida por la frecuencia léxica de las palabras de contenido que integran la frase. Hay también dos niveles: simples, cuando las 
frases están construidas con palabras de alta frecuencia léxica, y complejas, cuando la frase contiene alguna palabra con baja frecuencia léxica.

c) Complejidad ortográfica: definida por el número medio de consonante por vocal en la frase. Una frase es compleja ortográficamente cuando alguna de las palabras tiene dos o más consonantes seguidas.

d) Características de la opción correcta o palabra omitida. Se manipulan la complejidad ortográfica, definida por el número de consonantes por vocal; y la frecuencia léxica, definida como alta o baja.

e) Características de las opciones incorrectas o distractores. Están construidas siguiendo el siguiente criterio:

- Una pseudopalabra con parecido fonológico con la opción correcta (se sustituye una letra de la opción correcta por otra con un sonido similar).

- Una pseudopalabra con parecido ortográfico con la opción correcta (se sustituye una letra de la opción correcta por otra de similares características visuales).

- Una palabra con cierto parecido con la opción correcta pero con un significado que no permite construir una expresión coherente con la frase precedente. Esta opción actúa como distractor semántico para evitar que se utilice la estrategia de prescindir de la lectura de la frase y elegir únicamente la secuencia que se corresponde con una palabra, rechazando las pseudopalabras.

La adaptación de la Prueba consiste en una actividad del tipo encuesta de Moodle, esta actividad se encuentra englobada dentro del Cursos LECTOR en educa.signando.com. En la actividad aparecen las 64 frases escritas y las palabras a seleccionar en cada frase. Los participantes deben seleccionar sus respuestas realizando un clic sobre la contestación que consideren oportuna. Las instrucciones de la prueba y los ejemplos de la misma, aparecen en la primera página. 
Como ejemplo a continuación se ve uno de los ítems que forma la prueba como se vería originalmente en papel y a continuación el mismo ítem pero ya en educa.signando.com

14. El coche está en...

movimiento movimienlo mortadela moviniento

\begin{tabular}{|c|c|c|}
\hline 14 & El coche está en & \\
\hline & & \\
\hline & Seleccione una & a. movimiento \\
\hline & Tespuesta. & b b. movimienlo \\
\hline & & c. mortadela \\
\hline & & 0 d. moviniento \\
\hline
\end{tabular}

Imagen 1. Frase de la Prueba de eficiencia lectora.

Una copia de la prueba original completa se recoge en Anexo I. Los 64 ítems están ordenados siguiendo un criterio de dificultad creciente. Este criterio está definido por el número de letras que forman la frase correcta al completo. El tiempo total para contestar la prueba es de 5 minutos. Para evitar que los participantes copien resultados y gracias a las posibilidades que Moodle presta, las posibles soluciones aparecen colocadas aleatoriamente en cada una de las ejecuciones del test. En esta prueba en todas y cada una de las frases que forman el test la palabra solicitada aparece al final de la frase.

\subsection{Criterios de corrección}

El criterio de puntuación empleado para su corrección es dar un punto por respuesta correcta (máximo 64 puntos). Esta puntuación determina el nivel lector. La corrección se realiza automáticamente, una vez que el participante da por terminada la actividad la aplicación realiza una corrección y deja los resultados en la base de datos, estos datos que posteriormente se pueden consultar son de vital importancia para el objetivo de esta investigación.

\subsubsection{Prueba de Evaluación de Estrategias Sintácticas}

El objetivo de esta prueba (Soriano, Pérez y Domínguez, 2006), ver Anexo II, es comprobar si los participantes son capaces de utilizar un procesamiento sintáctico durante la lectura de frases, o bien se basan fundamental o exclusivamente en la semántica. Distintas investigaciones señalan esta última estrategia como la utilizada 
en lengua escrita por las personas sordas dadas sus dificultades de procesamiento sintáctico (Quigley y Paul, 1984; King y Quigley, 1985; Pérez, 2005; Soriano, 2004).

\subsubsection{Material y criterios seguidos para su elaboración}

La Prueba de Evaluación de Estrategias Sintácticas (PEES) (Soriano, Pérez y Domínguez, 2006), consta de 64 frases a las que le falta una palabra (ver Anexo II) y pretende establecer la precisión con la que se lleva a cabo la lectura en distintos tipos de frases. Cada frase introductoria está clasificada en tres categorías independientes: longitud, complejidad ortográfica y familiaridad semántica:

- Según la longitud las frases pueden ser cortas o largas. Una frase corta no tiene más de cinco palabras. Una frase larga tiene seis o más palabras.

- Según la complejidad ortográfica las frases pueden ser simples y complejas. Son simples aquellas que no contienen ninguna palabra de ortografía compleja. Una palabra con ortografía compleja es aquella que presenta cuatro o más sílabas y/o dos o más grafemas consonánticos juntos. Cuando una frase tiene, al menos, una palabra con ortografía compleja se clasifica como frase compleja.

- Por último, según la familiaridad semántica las frases introductorias pueden ser frecuentes o infrecuentes. Una frase frecuente es aquella en la que todas las palabras que la componen tienen un nivel alto de frecuencia (según el diccionario de frecuencias de las unidades lingüísticas del castellano de Alameda y Cuetos (1995). Algunas de las palabras utilizadas en la prueba y su grado de familiaridad según el citado diccionario aparecen en Anexo II. Además, se incluyeron otras palabras consideradas como frecuentes que, aunque no aparecían en el diccionario como tales, en estos momentos no cabe ninguna duda de que lo son (p. ej.: móvil, Internet, ordenador). Una frase es infrecuente si alguna de las palabras que la componen tiene una frecuencia baja $(F<10)$ según el citado diccionario.

Según estas tres dimensiones independientes, con dos categorías cada una sus creadoreas, obtuvieron ocho tipos diferentes de frases, como podemos ver a continuación en su versión original y en su adaptación como actividades del tipo encuesta de Moodle dentro de LECTOR:

i. Corta, simple, frecuente: Ej. Luís lee muy (libros, bien, biblioteca, periódico)

\begin{tabular}{|llll|}
\hline 1 a & Luís lee muy... & \\
Puntos: 1 & & \\
& Seleccione una & $\circ$ & a. libros \\
& respuesta. & 0 & b. bien \\
& & \\
& & c. biblioteca \\
& & d. periódico \\
\hline
\end{tabular}


Imagen 2. Ejemplo de frase corta, simple y frecuente

ii. Corta, compleja, frecuente: Ej. Las estrellas brillan en la (cielo, astros, oscuridad, firmamento).

\begin{tabular}{|c|c|c|}
\hline 17 屈 & Las estrellas bril & Ian en la \\
\hline 1 & Seleccione una & o a. cielo \\
\hline & respuesta. & b. astros \\
\hline & & c. oscuridad \\
\hline & & 0 d. firmamento \\
\hline
\end{tabular}

Imagen 3. Ejemplo de frase corta, compleja y frecuente

iii. Corta, simple, infrecuente: Ej.: El rocío dejó mucha (humedad, gotas, Iluvias, hierba)

\begin{tabular}{|c|c|c|}
\hline 11 盾 & El rocío dejó mu & \\
\hline & Seleccione una & o a. humedad \\
\hline & & b. gotas \\
\hline & & o c. lluvia \\
\hline & & O d. hierba \\
\hline
\end{tabular}

Imagen 4. Ejemplo de frase corta, simple e infrecuente

iv. Corta, compleja, infrecuente: Ej.: Observaba el movimiento del (péndulo, mirada, rápido, velocidad)

\begin{tabular}{|c|c|c|}
\hline & Observaba el m & vimiento del ... \\
\hline Puntos: 1 & Solocriono un & $\circ$ a nóndula \\
\hline & respuesta. & a. periudio \\
\hline & & b. mirada \\
\hline & & O c. rápido \\
\hline & & o d. velocidad \\
\hline
\end{tabular}

Imagen 5. Ejemplo de frase corta, compleja e infrecuente

v. Larga, simple, frecuente: Ej.: Miró la hora en el reloj y se (tiempo, asustó, tarde, puntual)

\begin{tabular}{|c|c|c|}
\hline 40 & Miró la hora en & reloj y se \\
\hline & & \\
\hline & Seleccione una & a. tiempo \\
\hline & respuesta. & b. asustó \\
\hline & & c. tarde \\
\hline & & d. puntual \\
\hline
\end{tabular}


Imagen 6. Ejemplo de frase larga, simple y frecuente

vi. Larga, compleja, frecuente: Ej.: La última vez que estuve pescando cogí un (trucha, río, caña, resfriado)

\begin{tabular}{|c|c|c|}
\hline 41 扄 & La última vez qu & estuve pescando cogi un \\
\hline & Seleccione una & a trucha \\
\hline & & b. río \\
\hline & & O c. caña \\
\hline & & o d. resfriado \\
\hline
\end{tabular}

Imagen 7. Ejemplo de frase larga, compleja y frecuente

vii. Larga, simple, infrecuente: Ej.: En aquella tapia hay un (dibujo, pilas, caja, jugar) de una noria.

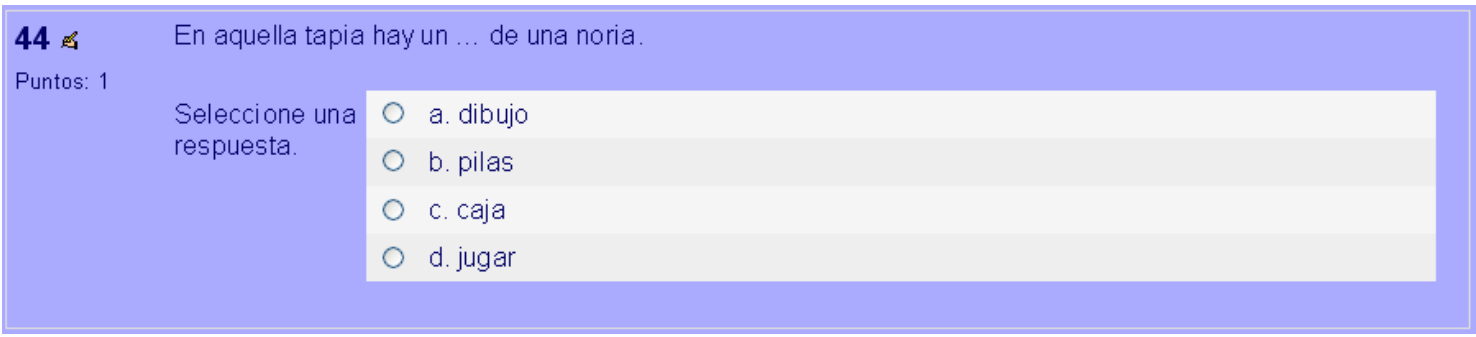

Imagen 8. Ejemplo de frase larga, simple e infrecuente

viii. Larga, compleja, infrecuente: Ej.: El fuego se propagó rápidamente porque el bosque era (árboles, frondoso, quemado, incendio).

\begin{tabular}{|c|c|c|}
\hline 49 屈 & El fuego se prop & agó rápidamente porque el bosque era \\
\hline & Seleccione una & a árboles \\
\hline & respuesta. & b. frondoso \\
\hline & & o c. quemado \\
\hline & & d. incendio \\
\hline
\end{tabular}

Imagen 9. Ejemplo de frase larga, compleja e infrecuente

Cada una de las 64 frases se completa con una palabra presentada con otras tres que actúan de distractores, todos ellos semánticos. En 7 de las frases y en un ejemplo, la palabra que falta y que hay que seleccionar de las cuatro opciones aparece en medio, en el resto de las frases son presentadas al final. En todas ellas, no obstante, la elección de la palabra correcta exige por parte del evaluado la lectura completa de la frase y la utilización de las claves sintácticas presentes en la oración. $\mathrm{Si}$, por el contrario, realiza un tratamiento semántico superficial de la frase, cometerá 
errores, que le conducirán a elegir alguno de los distractores semánticos. Como en el caso anterior y para evitar que los participantes copien resultados también en este test se han aprovechado las posibilidades de Moodle, de forma que, las posibles soluciones aparecen colocadas aleatoriamente en cada una de las ejecuciones del test.

\subsection{Criterios de corrección}

El criterio de puntuación empleado para su corrección es dar un punto por respuesta correcta (máximo 64 puntos). Se contabiliza el número de aciertos durante los cinco minutos de duración de la prueba y también el número de errores durante los cinco minutos y en el tiempo total empleado. Se permitió que los alumnos rellenasen las 64 oraciones o que lleguen a un punto a partir del cual les fuera muy difícil contestar a las preguntas. La corrección se realiza automáticamente, una vez que el participante da por terminada la actividad la aplicación realiza una corrección.

\subsubsection{Procedimiento seguido para la administración de las pruebas}

La Prueba de Eficiencia Lectora, en su versión original, permite tanto la evaluación individual como colectiva. En el caso de las personas sordas se optó por la evaluación individual. Los educadores de cada centro explicaban las instrucciones con antelación. En ellas se especificó que, cuando un ítem era difícil de contestar, lo mejor era saltarlo y continuar con el siguiente. Se les informó que la duración de la prueba era de cinco minutos. En este tiempo se anota el número de ítems resueltos, pero se les permitía terminar la prueba a fin de obtener datos acerca del tiempo total que necesitaban para resolverla completamente. Este procedimiento se ha seguido igualmente en la adaptación que se ha hecho de la prueba indicada dentro de LECTOR.

Respecto a la Prueba de Estrategias Sintácticas, tambien en su versión original, el procedmiento seguido es similar al anterior, las personas son evaluadas de modo individual. Los educadores de cada centro explican las instrucciones con antelación, se explica a los alumnos que cuando un ítem les resulta complicado de resolver es mejor continuar y no contestar. Se insiste en la necesidad de leer la frase hasta el final antes de resolverla, así como leer las todas las opciones posibles antes de contestar. A los cinco minutos se toma el valor de aciertos y preguntas contestadas obtenido y se permite terminar la prueba con el objetivo de valorar el tiempo total de ejecución. La Prueba de Estrategias Sintacticas adaptada dentro de LECTOR, conserva este procedimiento original.

En todos los casos necesarios, las instrucciones a los participantes sordos se presentaron en Lengua de Signos Española (LSE).

Uno de los requisitos necesarios para obtener unos resultados fiables, es permitir una única oportunidad de resolver las dos primeras actividades (Pre-test Eficiencia Lectora y Pre-test Estrategias Sintácticas) a cada participante. Esta característica es 
avisada a cada unos de los participantes al comenzar su resolución, de esta forma, los usuarios pueden repetir cualquier actividad excepto estas dos en el pre-test y en el post-test. En la imagen 10 se puede ver el aviso que aparece antes de comenzar a realizar una de estas actividades dentro de LECTOR. Independientemente de este aviso se hace necesario que los educadores avisen a los participantes de esta cuestión.

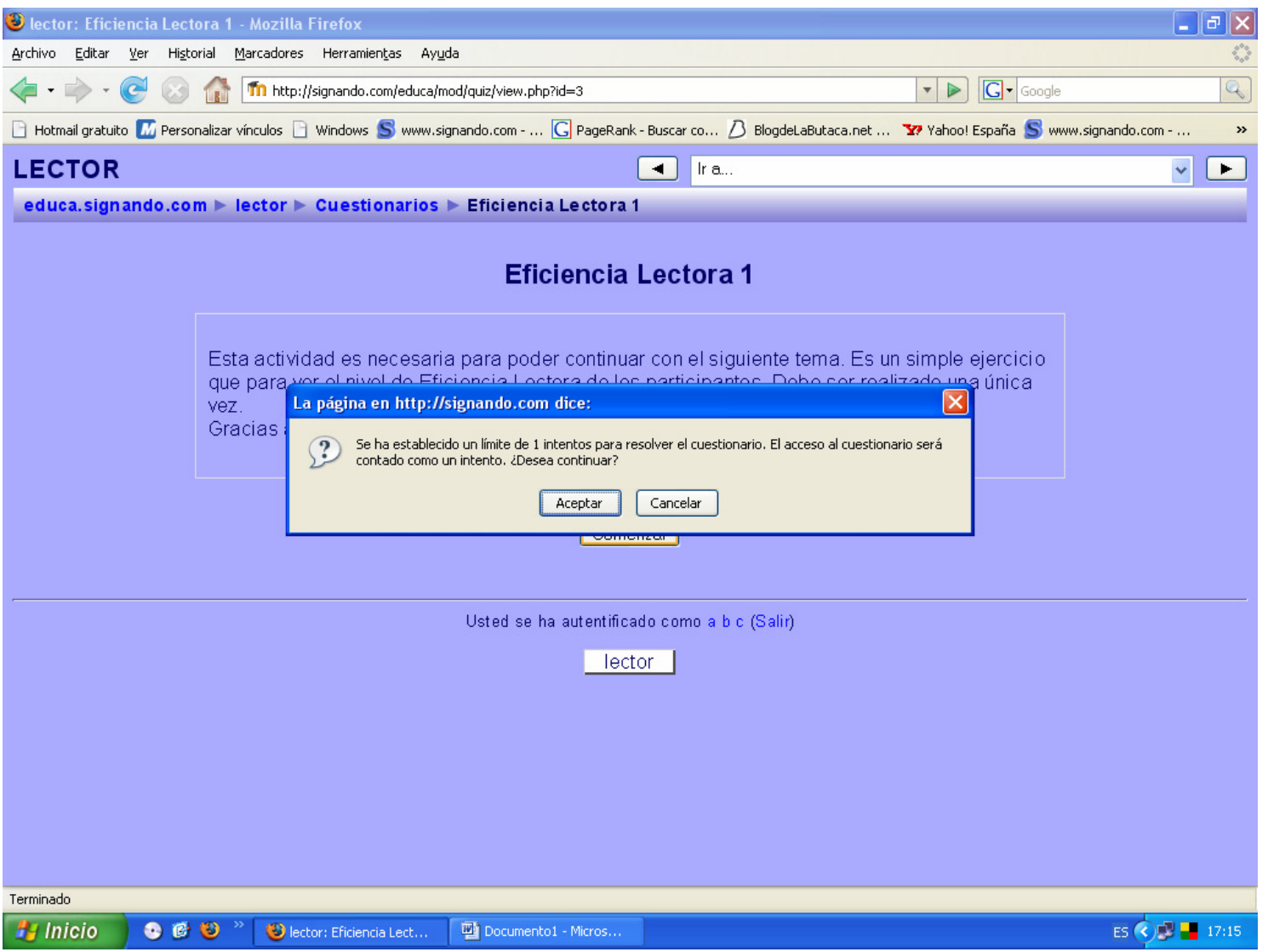

Imagen 10. Aviso de inicio de test de Eficiencia Lectora

Estas dos actividades son los test descritos en el Anexo I y Anexo II adaptadas como Cuestionarios Moodle, ya se han visto en punto anteriores pequeños ejemplos de la apariencia de las preguntas realizadas utilizando Moodle, en la siguiente figura se ve una captura de pantalla de prueba de Eficiencia Lectora donde se puede ver la apariencia simple e intuitiva de las actividades, mantener una apariencia sin excesiva información es fundamental para conseguir que los participantes se centren en resolver las cuestiones planteadas. 


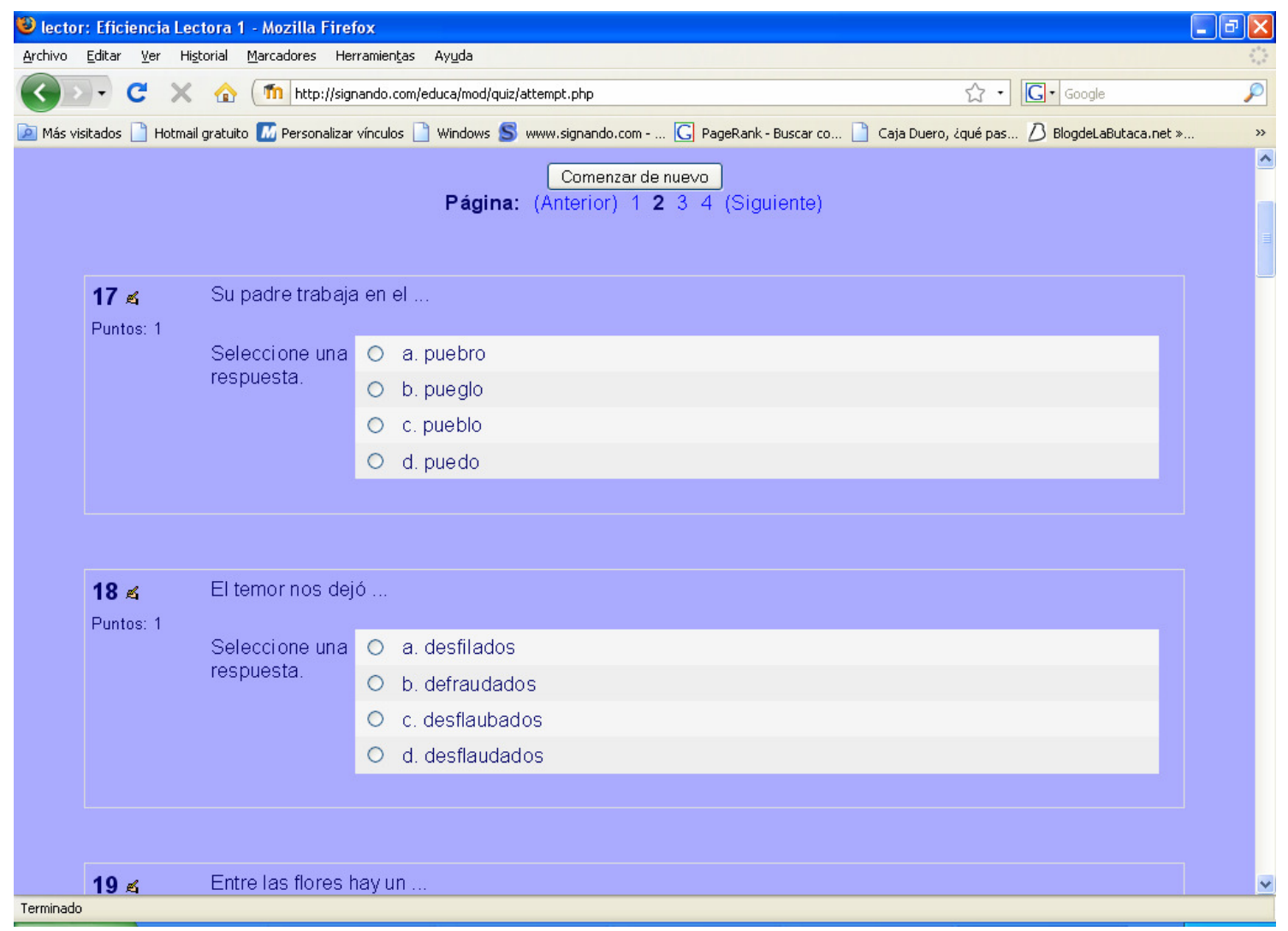

Imagen 11. Muestra de preguntas del test de Eficiencia Lectora

En el caso de esta prueba, se divide todo el test en 4 páginas, al final de cada una de las páginas existe la posibilidad de Guardar sin Enviar y continuar o Enviar todo y Terminar, se recomendó a los participantes que una vez considerada como finalizada la prueba seleccionaran Enviar todo y Terminar. En este momento el sistema recuerda que solo existía una posibilidad de realizar esta prueba y que si se cierra ya no se podrán cambiar las opciones elegidas. Con un aviso como el que se ve a continuación.

\section{La página en http://signando.com dice:}

Aceptar el mensaje de la imagen 12 implica realizar el registro de los resultados en la Base de Datos, este registro, del que se informa al participante como se ve en la imagen 13 , se realiza automáticamente y de forma totalmente transparente al usuario. 
El acceso posterior a estos resultados almacenados en la base de datos por parte de los administradores, permite saber los resultados obtenidos por cada participante, resultados necesarios, en este caso, para la creación de actividades adaptadas a las necesidades específicas del grupo.

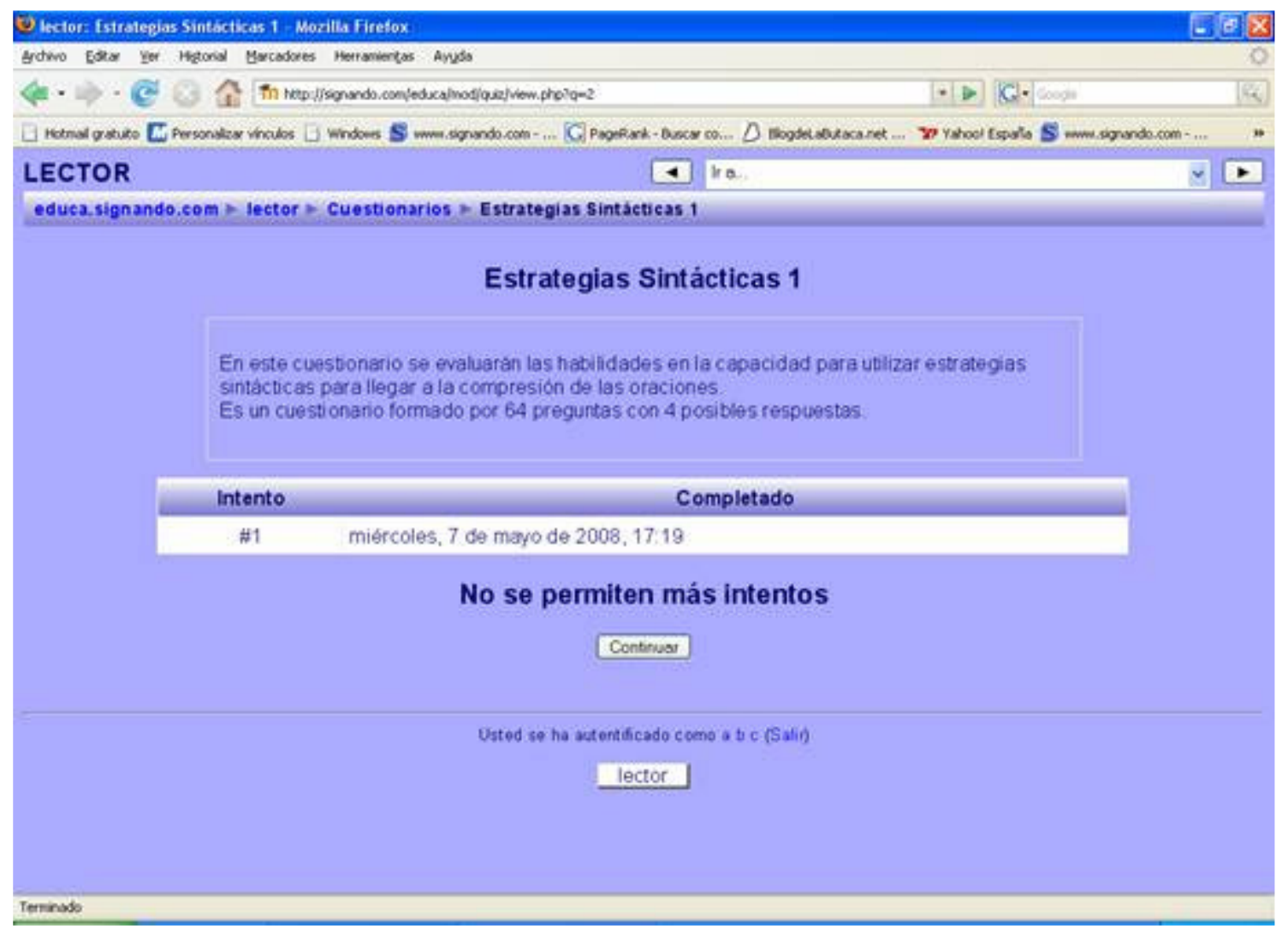

Imagen 13. Resumen de ejecución de prueba de Estrategias Sintácticas

El proceso descrito anteriormente es básicamente el mismo tanto para Eficiencia Lectora 1 y 2 como para Estrategias Sintácticas 1 y 2, las únicas diferencias son: el Cuestionario que hay que resolver y el hecho de que la prueba de estrategias sintácticas muestra todas las frases de forma continua y no separadas por páginas.

La posibilidad de realizar los test en el momento que se desee, siempre dentro de unos límites marcados por los administradores permitió que mientras los distintos usuarios que aún no habían realizado los pre-test, se pudiera comprobar los resultados de los que ya los habían realizado y se fueron desarrollando actividades adaptadas a los distintos niveles. 


\subsubsection{Periodo de Enseñanza}

El objetivo fundamental de esta investigación es demostrar que el trabajo con LECTOR es válido como herramienta que favorezca el aprendizaje y la comprensión de la lecto-escritura. Con este objetivo se diseñaron una serie de actividades para favorecer el desarrollo de estrategias sintácticas y conseguir mayor comprensión lectora.

Durante el periodo de enseñanza se ha contado con la ayuda de los educadores de las distintas Asociaciones colaboradoras, que han resuelto dudas relacionadas no solo del funcionamiento del curso, sino también de las palabras o frases que los alumnos no conocían.

La duración de este periodo de enseñanza fue de 6 meses comprendidos entre noviembre de 2007 y abril del 2008. A lo largo de este periodo de tiempo se fue evaluando las necesidades específicas de los participantes. Revisando sus necesidades se fueron creando actividades educativas que los participantes fueron realizando. La enseñanza estuvo marcada por la libertad del trabajo desde casa, de forma que en caso de dudas los alumnos podían consultar con los administradores del curso LECTOR y con los educadores de cada una de las Asociaciones colaboradoras.

\subsubsection{Actividades}

Una vez obtenidos los resultados de los dos test que forman el pre-test se decidió, en base a los resultados obtenidos por Soriano (2004), agrupar a los participantes en tres niveles claramente separados por el número de aciertos en las pruebas.

- Nivel 1. Participantes cuyo resultado medio está entre 0 y 15, equivalente a $2^{\circ}$ de Primaria (Soriano, 2004).

- Nivel 2. Participantes cuyo resultado medio está entre 16 y 36, equivalente a 3ำ de Primaria (Soriano, 2004).

- Nivel 3. Participantes que obtuvieron como resultado medio más de 36, equivalente a niveles superiores a $3^{\circ}$ de Primaria (Soriano, 2004).

En función de los resultados y de las necesidades específicas de cada usuario se crearon bloques de actividades, un bloque para cada nivel.

Las actividades creadas con Jclic a lo largo de la investigación se fueron situando en cada bloque. El número de actividades que forma cada bloque no es fijo, viene marcado por las necesidades de cada grupo. Es necesario crear pequeñas actividades fáciles para el nivel 1, esto provoca que este nivel sea el que tenga mayor número de actividades. Sin embargo, las actividades de nivel superior 
entrañan mayor dificultad y, por lo tanto, más tiempo para realizarlas por eso hay menos.

Al realizar la división de colaboradores en los distintos niveles, se comprobó que en ciertos casos, personas que habían obtenido un nivel 2 mostraban resultados medios en uno de los test y bajos en el otro. En un primer momentos se pensó en que en estos casos los participantes deberían realizar las actividades del Nivel 1 antes de pasar al Nivel 2. Una vez analizado detenidamente los resultados se decidió hacer esto con todos los participantes, se consideró necesario reforzar los conocimientos que supuestamente los participantes de nivel 2 mostraban, de esta forma todos los participantes debían comenzar realizando las actividades de nivel 1, independientemente del nivel obtenido en las pruebas. En todo momento si los alumnos consideraban muy fáciles las actividades del nivel inferior podían pasar al siguiente.

\subsubsection{Curso Lector}

Para facilitar la posibilidad de que los usuarios trabajaran con las actividades desde cualquier ubicación, se desarrollo educa.signando.com. Esta página contiene, entre otros cursos disponibles, el curso LECTOR y todas sus actividades.

El curso LECTOR, del que ya se ha hablado en otras ocasiones a lo largo de este trabajo, es un curso de creación propia, integrado dentro de educa.signando.com, espacio Web creado bajo Moodle, las actividades de este curso están desarrolladas apoyándose en las posibilidades y recursos que presta Moodle, de esta forma LECTOR integra actividades creadas con los módulos propios de este sistema, visto en el Capítulo IV, con actividades creadas con JClic.

Este curso ha sido creado y adaptado exclusivamente para la realización de este trabajo ya que se han considerado las necesidades específicas del grupo con el que se ha trabajado. El entorno gráfico ha sido diseñado para permitir un acceso sencillo e intuitivo, aspectos importantes para conseguir la participación y la motivación de los participantes.

La imagen 14 muestra la apariencia de la página educa.signando.com a cualquier persona que se conecte. Esta información será proporcionada a todos los usuarios estén o no registrados. 


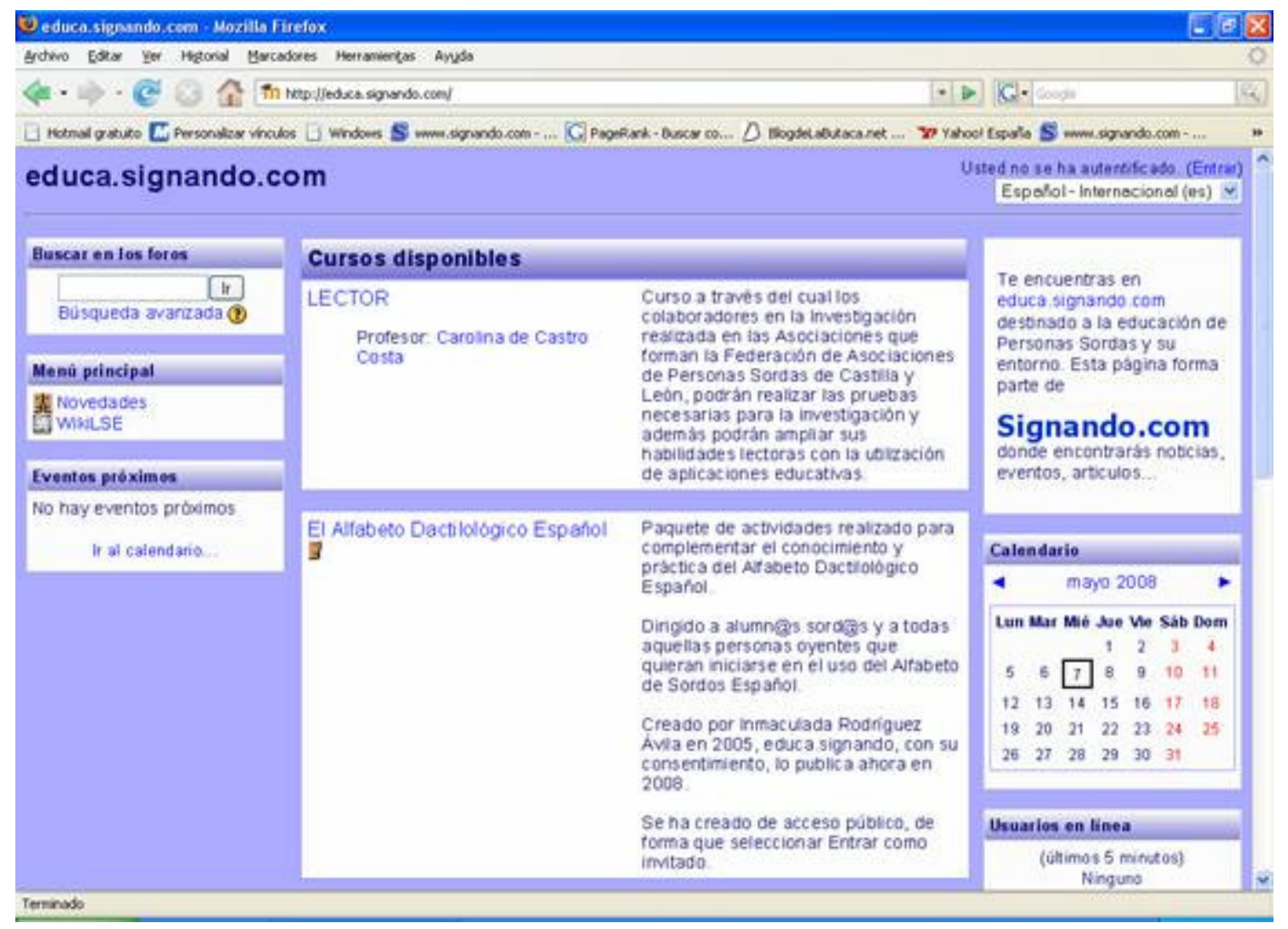

Imagen 14. Pantalla principal de educa.signando.com

Los usuarios que solicitaron trabajar con el programa LECTOR, enviaron ciertos datos personales, útiles para el estudios de casos. Con esta información los administradores han creado usuarios personales para cada colaborador y se les ha matriculado en el curso LECTOR.

Los datos de acceso necesarios para participar en el curso, se enviaron a través de correo electrónico a la dirección de correo proporcionada. De esta forma el acceso al curso es totalmente confidencial.

La información solicitada para poder formar parte de educa.signando.com y ser admitido como participante del curso LECTOR se puede ver en la imagen 15. 


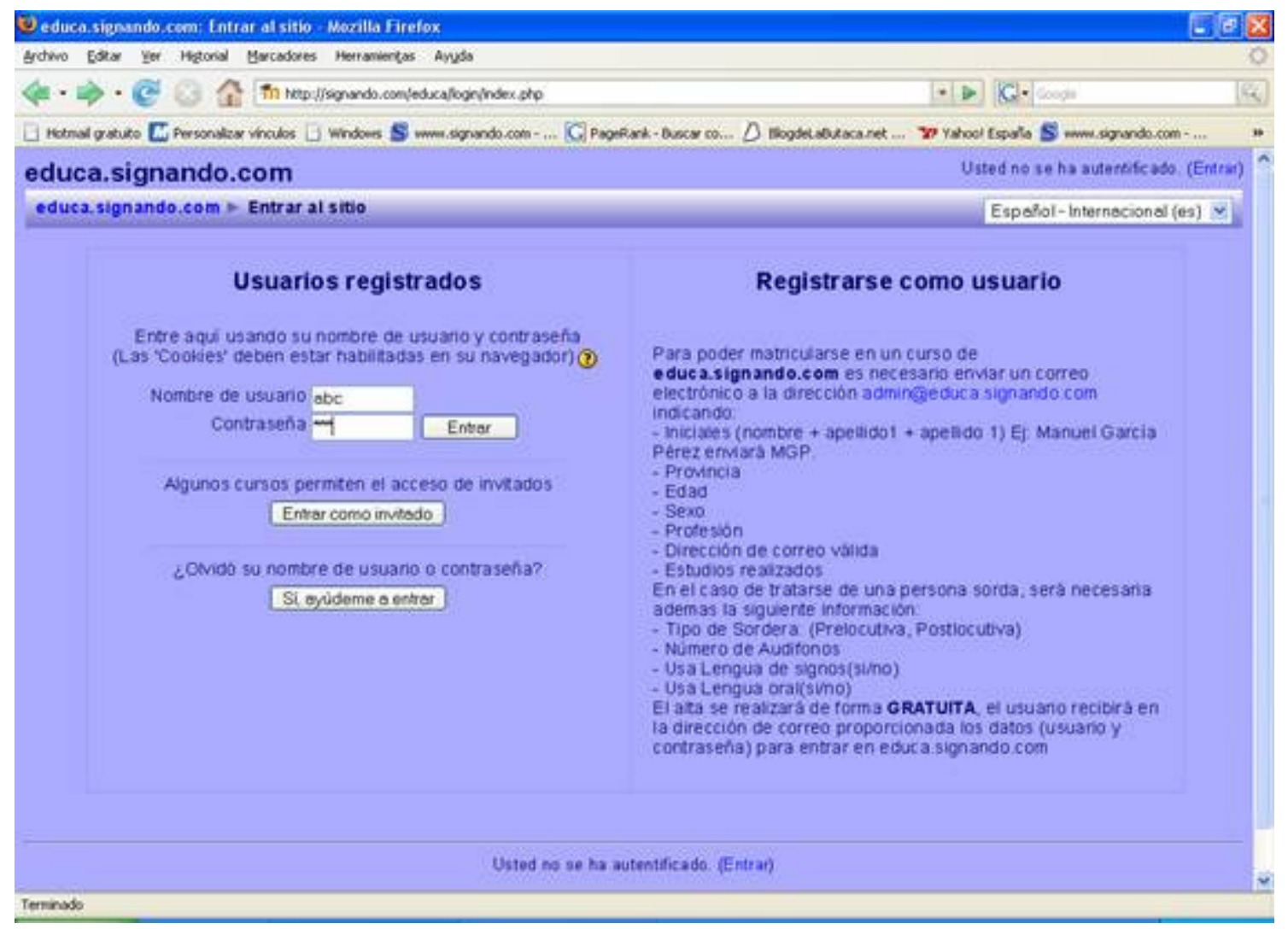

Imagen 15. Pantalla de inicio de sesión

Los participantes con su usuario y contraseña pueden iniciar sesión en el curso LECTOR, rellenando los datos nombre de usuario y Contraseña como se ve en la parte izquierda de la imagen anterior.

Existe la posibilidad de permitir accesos en modo invitado, pero para el propósito de la investigación esta propiedad no tenía mucho sentido al necesitar mantener un control de los accesos y resultados de la actividad de los alumnos. En otros cursos como Alfabeto Dactilológico es posible iniciar sesión con un usuario invitado, este curso es distinto al LECTOR y se ha mostrado como ejemplo de la capacidad de educar que muestran la integración de JClic en Moodle.

Cuando un usuario inicia sesión la apariencia de la aplicación cambia adaptándose a los permisos concedidos a cada usuario. En el caso de la imagen 16, abc solo está matriculado en el curso LECTOR, si formará parte de otros cursos en su página de usuario se mostrarían todos los cursos para los que está matriculado. 


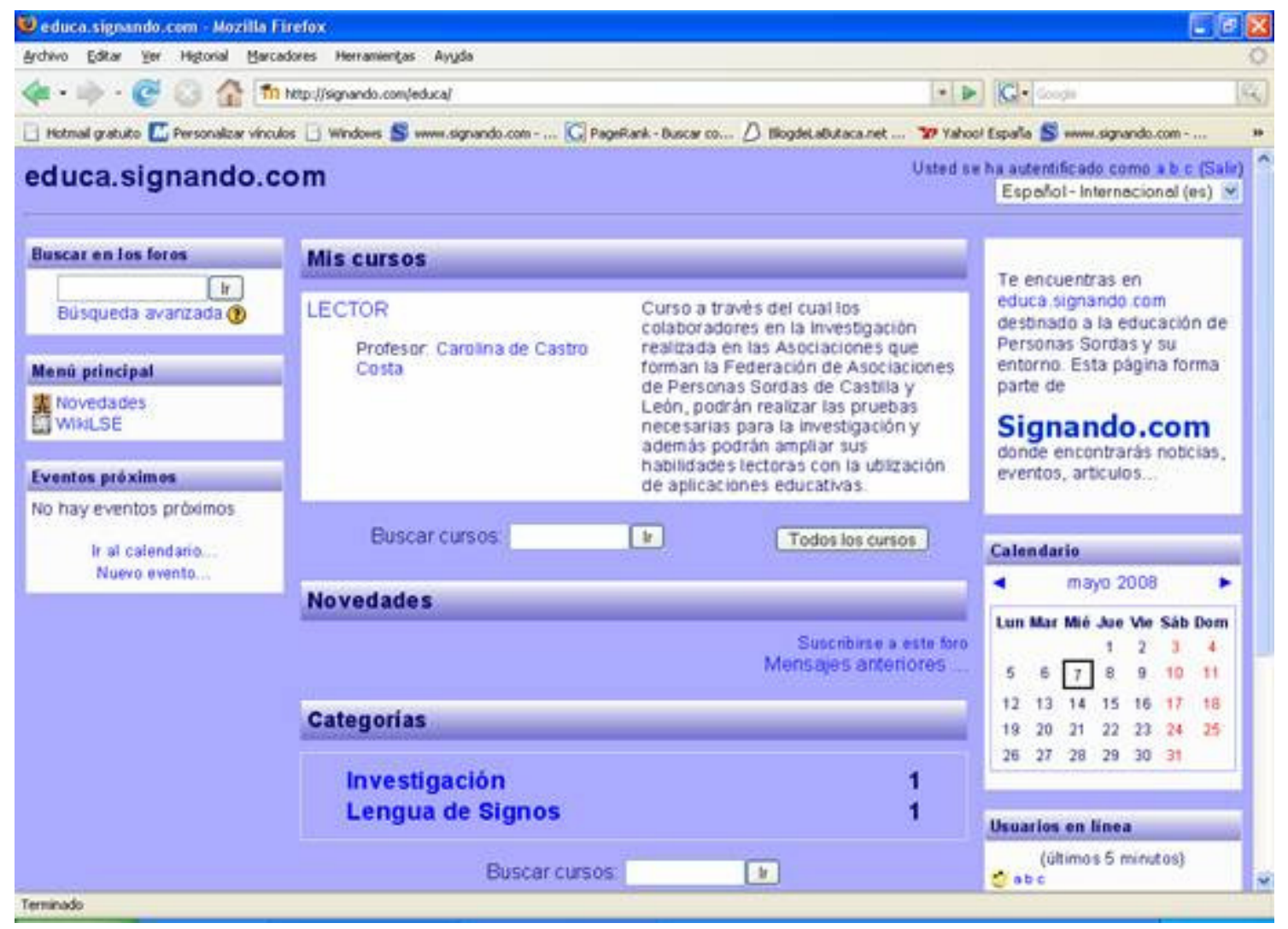

Imagen 16. Pantalla principal de usuario matriculado en el curso LECTOR

Como se puede ver en la imagen 16, existen otros elementos como son el calendario o un listado de las novedades de la página. En este sentido el calendario ha sido de gran utilidad ya que en él se han avisado de diferentes eventos relacionados con las Asociaciones y con el Curso, por ejemplo se publicó el calendario de visitas a las distintas Asociaciones y la fecha de comienzo y finalización del curso LECTOR.

Para comenzar el curso solo hay que seleccionar la opción LECTOR y automáticamente aparece el diagrama de temas del curso.

La arquitectura del Curso, como se puede ver en la imagen 17 y en la tabla 16 es la siguiente: el curso LECTOR esta dividido en Lecciones Moodle $(1,2 \ldots)$ que a su vez se subdividen en temas $(1.1,1.2, \ldots)$, que pueden estar creadas a partir de JClic (1.1) o de módulos propios de Moodle (1.5) que a su vez pueden contar con "subtemas", creados igual que en el caso anterior a partir de módulos Moodle o Jclic (1.5.1).

Cada uno de los temas creados con JClic puede contener más de una actividad. 
Desarrollo de Estrategias Sintácticas y Semánticas en Lectura a través de LECTOR en Personas Sordas Adultas en Castilla y León

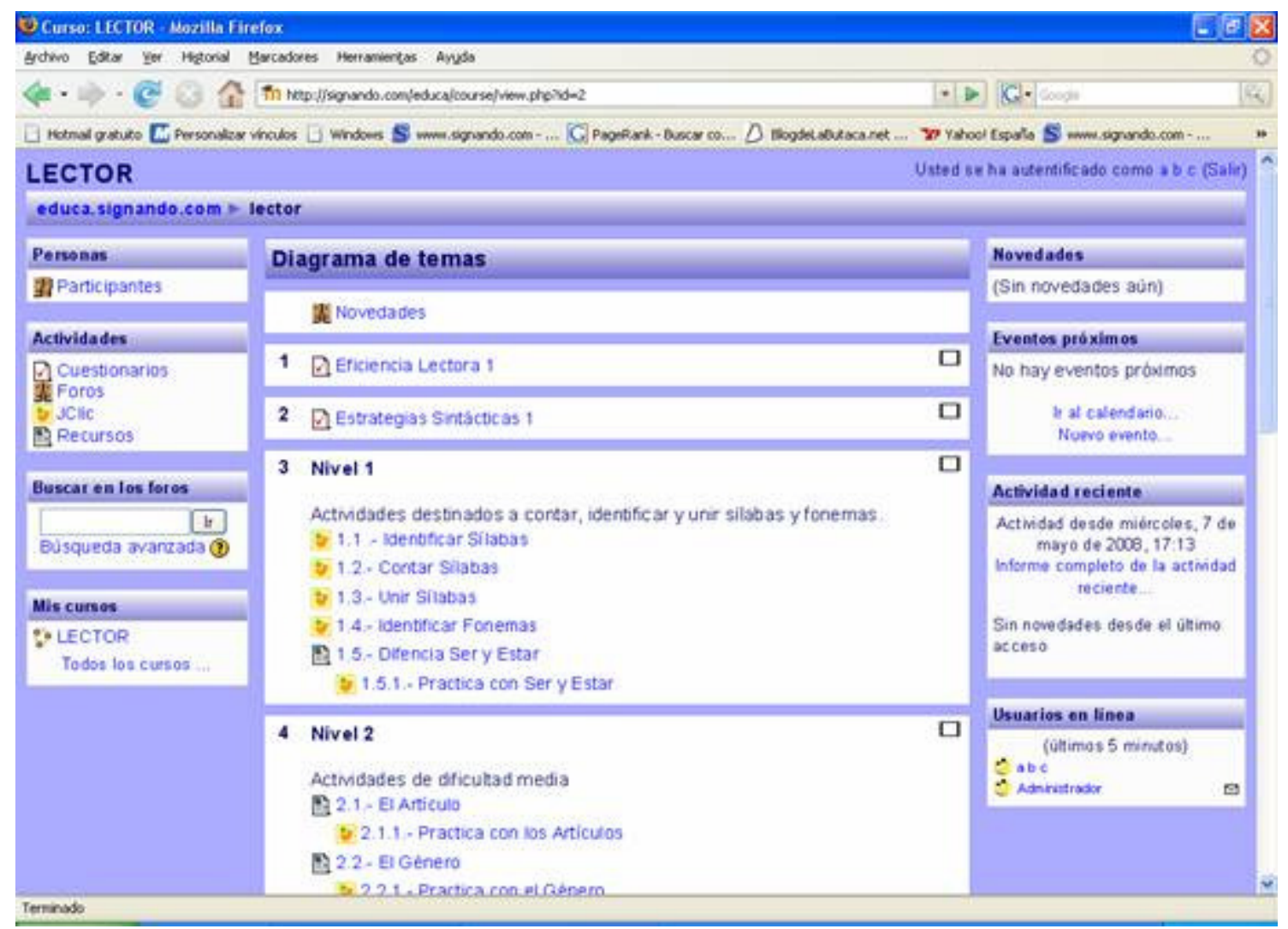

Imagen 17. Pantalla principal del curso LECTOR

Como ya se ha indicado en la definición del proyecto se dividieron las actividades en 3 niveles, atendiendo a su dificultad de resolución. En la tabla 13 se puede ver la estructura del curso LECTOR. 


\begin{tabular}{|l|}
\hline \multicolumn{1}{|c|}{ LECTOR } \\
\hline Eficiencia Lector 1 \\
\hline Estrategias Sintácticas 1 \\
\hline \\
Nivel 1 \\
1.1.- Identificar Sílabas \\
1.2.- Contar Sílabas \\
1.3.- Unir Sílabas \\
1.4.- Identificar Fonemas \\
1.5.- Diferencia Ser y Estar \\
1.5.1.- Practica con Ser y Estar \\
\hline \\
Nivel 2 \\
2.1.- El Artículo \\
2.1.1.- Practica con los Artículos \\
2.2.- El Género \\
2.2.1.- Practica con el Género \\
2.3.- Pronombres Personales \\
2.3.1.- Practica los Pronombres Personales \\
2.4.- Verbo Tener \\
2.4.1.- Verbo Tener 1 \\
2.4.2.- Expresiones usuales con "tener" \\
2.4.3.- Verbo Tener 2 \\
2.5.- Plural y Singular \\
2.5.1.- Practica con el Plural y el Singular \\
\hline Nivel 3 \\
3.1.- Ciudad \\
3.1.1.- Actividades de la Ciudad \\
3.2.- El Presente en Verbos Regulares \\
3.2.1.- Practica El Presente en Verbos Regulares \\
3.2.2.- La forma Negativa \\
3.2.3.- Practica la forma Negativa \\
\hline Eficiencia Lectora 2 \\
\hline Estrategias Sintácticas 2 \\
\end{tabular}

Tabla 13. Estructura de Actividades que forman el Curso Lector

En las imágenes 18 y 19 se pueden ver ejemplos de actividades del Nivel 1. Ambas forman parte del tema 1.2 Contar Sílabas. Cada uno de los temas son proyectos JClic que contienen varias actividades 
La primera de ellas se trata de una actividad realizada en JClic integrada en Moodle, donde se busca conseguir que los alumnos sean capaces de separar las sílabas que forman una palabra. La actividad es del tipo Respuesta Escrita.

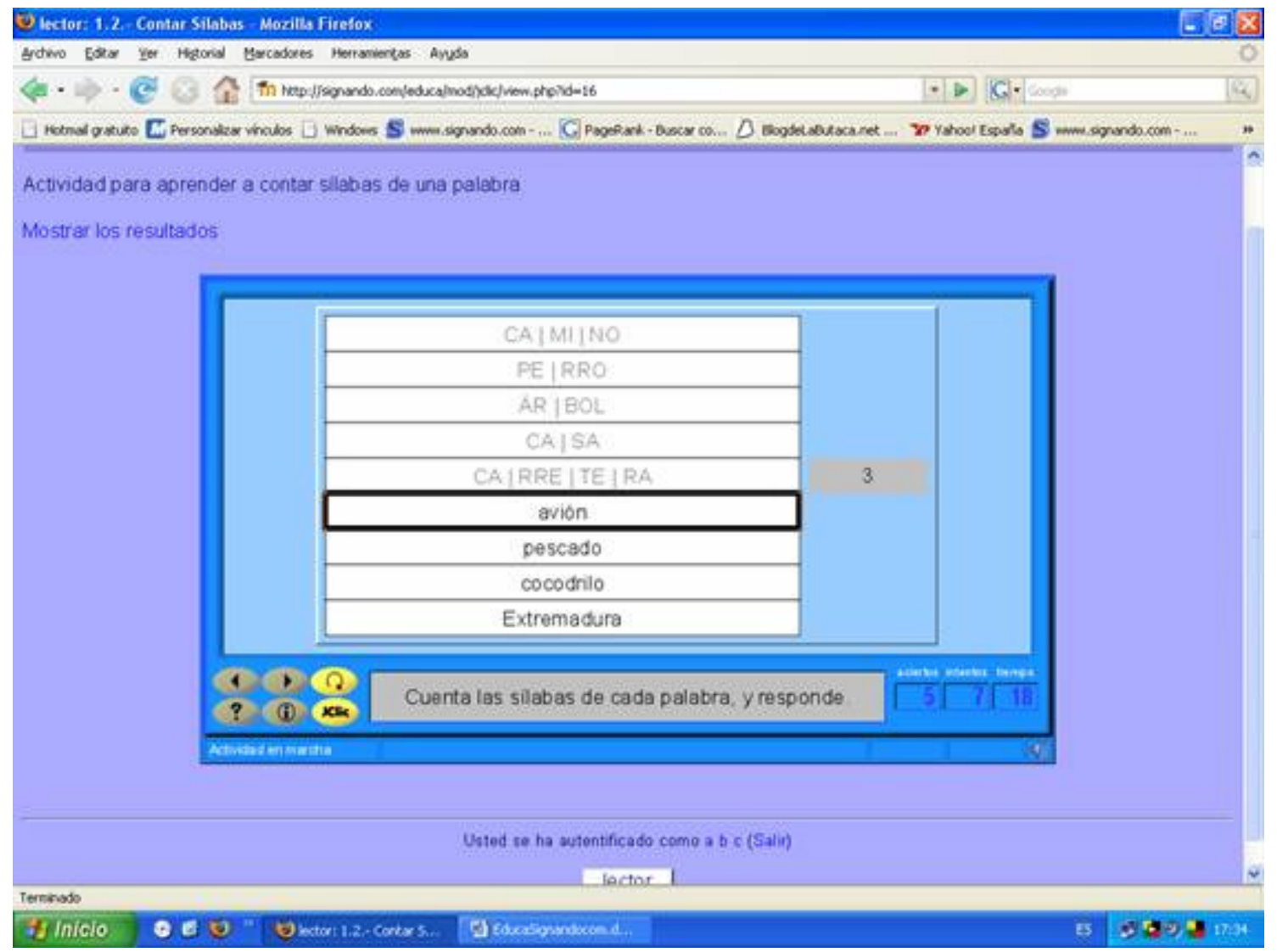

Imagen 18. Actividad 3 del tema 1.2.- Contar Silabas

En la columna de la izquierda se muestran las diferentes palabras y en la casilla de la derecha se espera una respuesta, como se indica en la actividad "Cuenta las sílabas de cada palabra y responde". Una vez realizada la contestación, la palabra cambia a un estado inactivo y se muestra simulando la separación de las sílabas.

La segunda de las actividades mostradas como ejemplo de Nivel 1 aparece en la imagen 19, es un Puzzle, que muestra tres imágenes con las palabras que las identifican junto a ellas (avión, vaca y ratón) y estas mismas palabras separadas en sílabas y el número de las sílabas que la forma. Esta actividad permite resolver un puzzle aplicando conocimientos relacionados con contar sílabas.

Todas las actividades cuentan con una serie de contadores en la parte inferior derecha, de derecha a izquierda, contador de tiempo, aciertos e intentos. Estos datos también son almacenados en la base de datos. Como ya se ha indicado las actividades forman parte de proyectos JClic que son los temas del Curso, para poder avanzar dentro de las actividades JClic existen las dos flechas que aparecen abajo a la izquierda. 


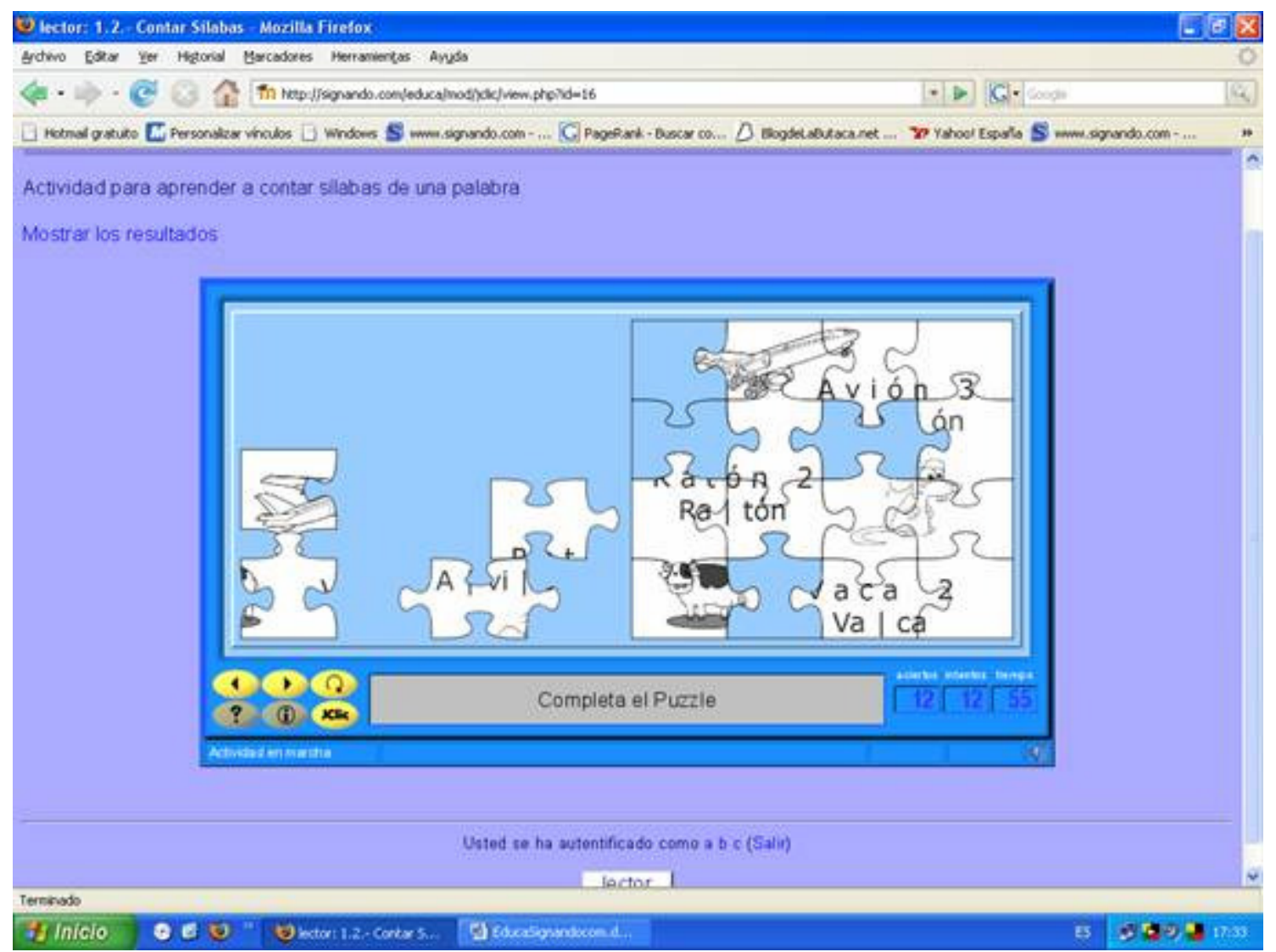

Imagen 19. Actividad 2 del tema 1.2.- Contar Silabas

El curso LECTOR aprovecha la navegabilidad que proporciona Moodle para moverse por los diferentes temas o lecciones que forman el curso. Por un lado, se puede realizar esta navegación a través del menú que aparece en la parte superior derecha Ir a... se puede navegar por todos los temas disponibles de los distintos niveles o lecciones, como se ve en la imagen 20. 


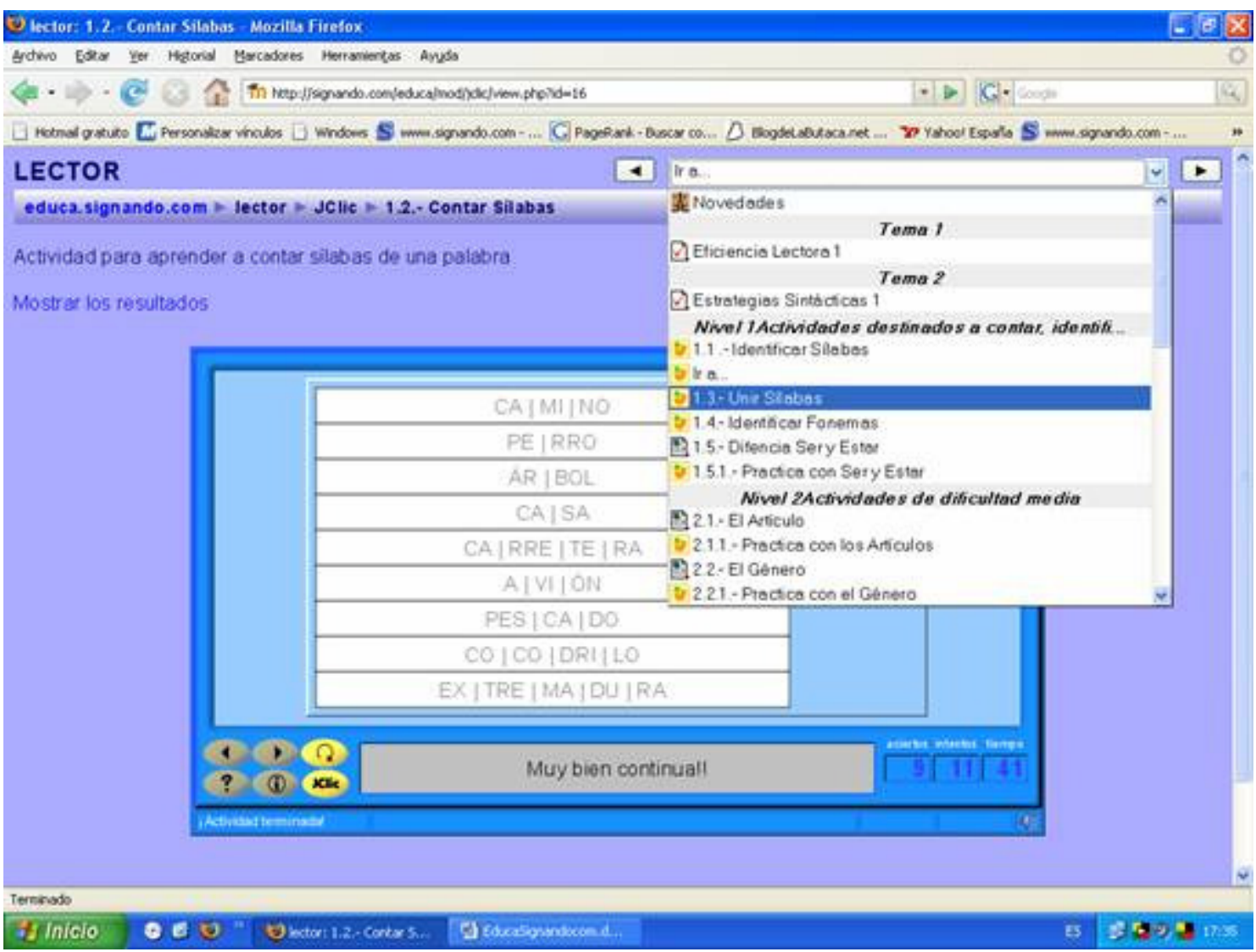

Imagen 20. Menú de navegación de LECTOR

Si lo que se desea es ir a la página principal del curso en todas las ventanas que se habrán dentro del curso aparece un botón blanco abajo donde pone lector, si se pulsa este botón se abandona la actividad o el tema en el que se encuentre y la aplicación traslada al usuario a la pantalla de inicio del curso anteriormente vista en la imagen 17.

\begin{tabular}{|c|c|c|c|}
\hline \multicolumn{4}{|c|}{ ECGuso: LECTOR - Nozilla Firefox } \\
\hline \multicolumn{2}{|c|}{ 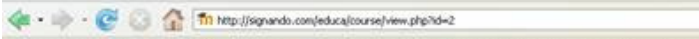 } & & $\mathrm{Cr}$ \\
\hline \multicolumn{4}{|c|}{ 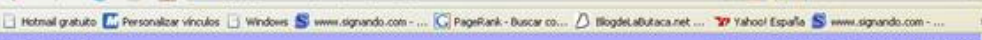 } \\
\hline \multirow{2}{*}{\multicolumn{2}{|c|}{$\begin{array}{l}\text { LECTOR } \\
\text { educa.signando.som + lector }\end{array}$}} & \multicolumn{2}{|c|}{ Usted se ha autertificado cama ub c (Salir)? } \\
\hline & ctor & & \\
\hline \multirow{3}{*}{$\begin{array}{l}\text { Penosas } \\
\text { Panticipantes }\end{array}$} & Diagrama de temas & \\
\hline & & & \multirow[t]{2}{*}{ (Sin novedaces aün) } \\
\hline & Novedades & & \\
\hline \multirow{2}{*}{ 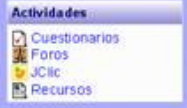 } & 1 Q Eficiencia Lectora & 마 & \\
\hline & 2 Q Estrategas sintácticas 1 & ㅁ & \\
\hline Buscar en los fores & 3 Nivel 1 & ㅁ & Actividad reciente \\
\hline \multirow{2}{*}{ 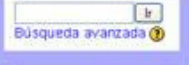 } & Actmidades destinasos a cortar, identifcar y uriz silso as $y$ fonemas. & & \multirow{3}{*}{ 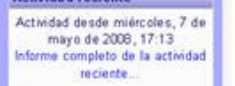 } \\
\hline & 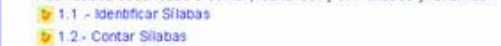 & & \\
\hline Miscursos & 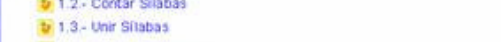 & & \\
\hline \multirow{8}{*}{$\begin{array}{l}\text { P. LECTOR } \\
\text { Todos los custos }\end{array}$} & 2.1.4. identicar Fonemas & & \multirow{2}{*}{$\begin{array}{l}\text { Sin novessdes des dee en ütimo } \\
\text { accoso }\end{array}$} \\
\hline & Q 1.5. Drencia Sery Estar & & \\
\hline & 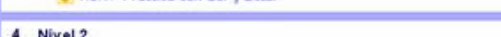 & & Usuatios on linea \\
\hline & & & C. (Ühimos 5 mainstos) \\
\hline & Actmidades de sficulad media & & 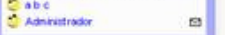 \\
\hline & D.2.1. Practica con los Aaticulos & & \\
\hline & 22. EGenero & & \\
\hline & W221. Practica con netaenero & & \\
\hline
\end{tabular}


Como ya es ha indicado la dificultad de las práctica va creciendo en función del tema en el que se encuentre el participante y del nivel con el que esté trabajando. Se mostrarán a continuación dos actividades del Nivel 2.

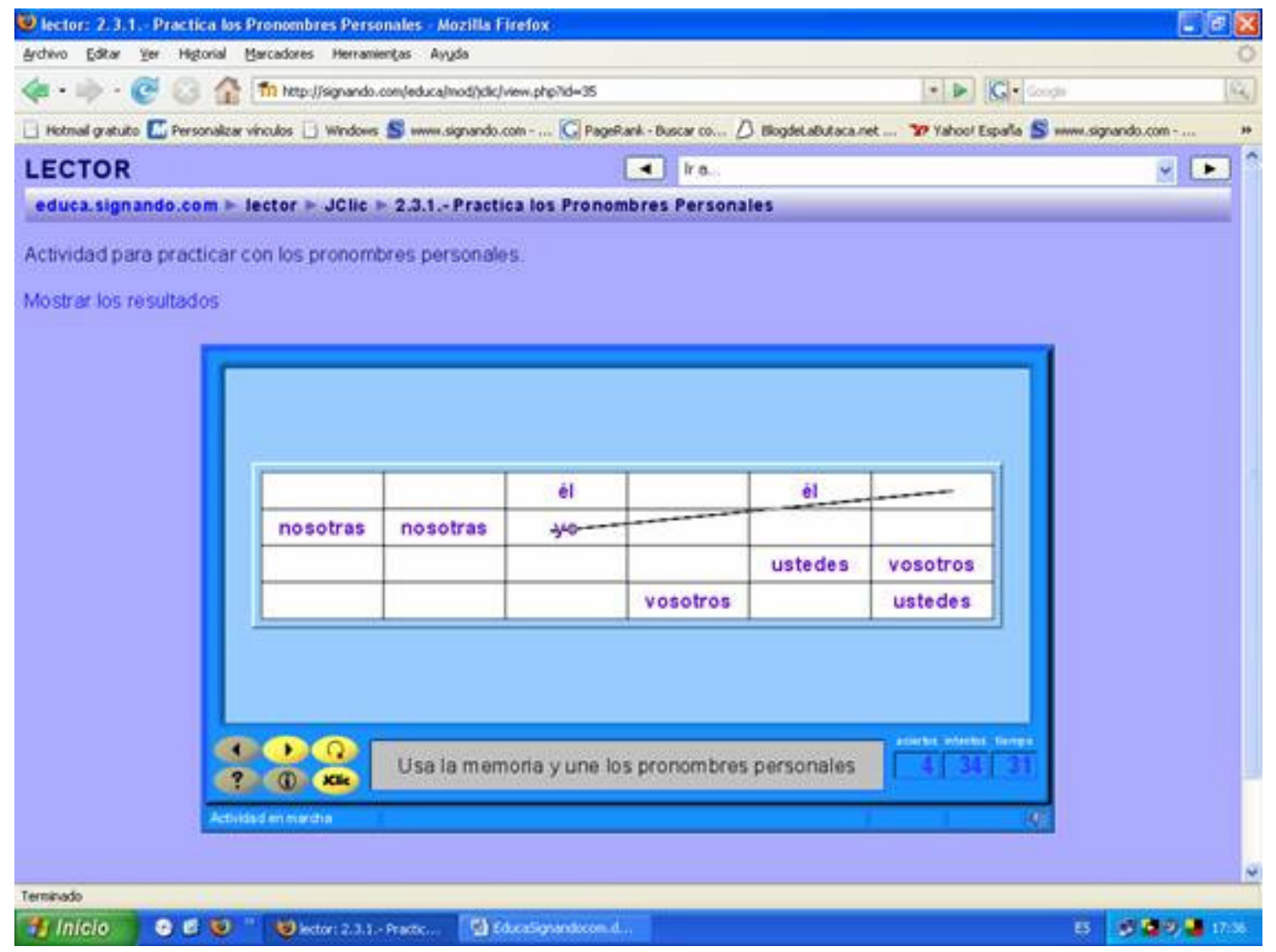

Imagen 21. Actividad 1 del subtema 2.3.1.- Practica los pronombres personales

Esta es una actividad de memoria con pronombres personales, tema 2.3.1 Practica los Pronombres Personales, en esta actividad los alumnos deben resolver el panel uniendo con flechas las casillas en las cuales se encuentran los mismos pronombres, en el cuadro existen dos casillas por pronombre, si la opción elegida es correcta se muestra el resultado sino los paneles seleccionados se vuelven a ocultar, con esta actividad además de ayudar a conocer los pronombres se ha intentado fomentar la memoria y fundamentalmente la diferenciación entre palabras como nosotros y vosotros, palabras en apariencia similares que se diferencian en una única letra.

Antes de realizar esta actividad, como sucede con alguna otra, el curso LECTOR permite mostrar información teórica relacionada con el tema, en este caso el tema 2.3 muestra el uso de los pronombres personales en función de la persona que se está usando, como se ve en la imagen 22. 


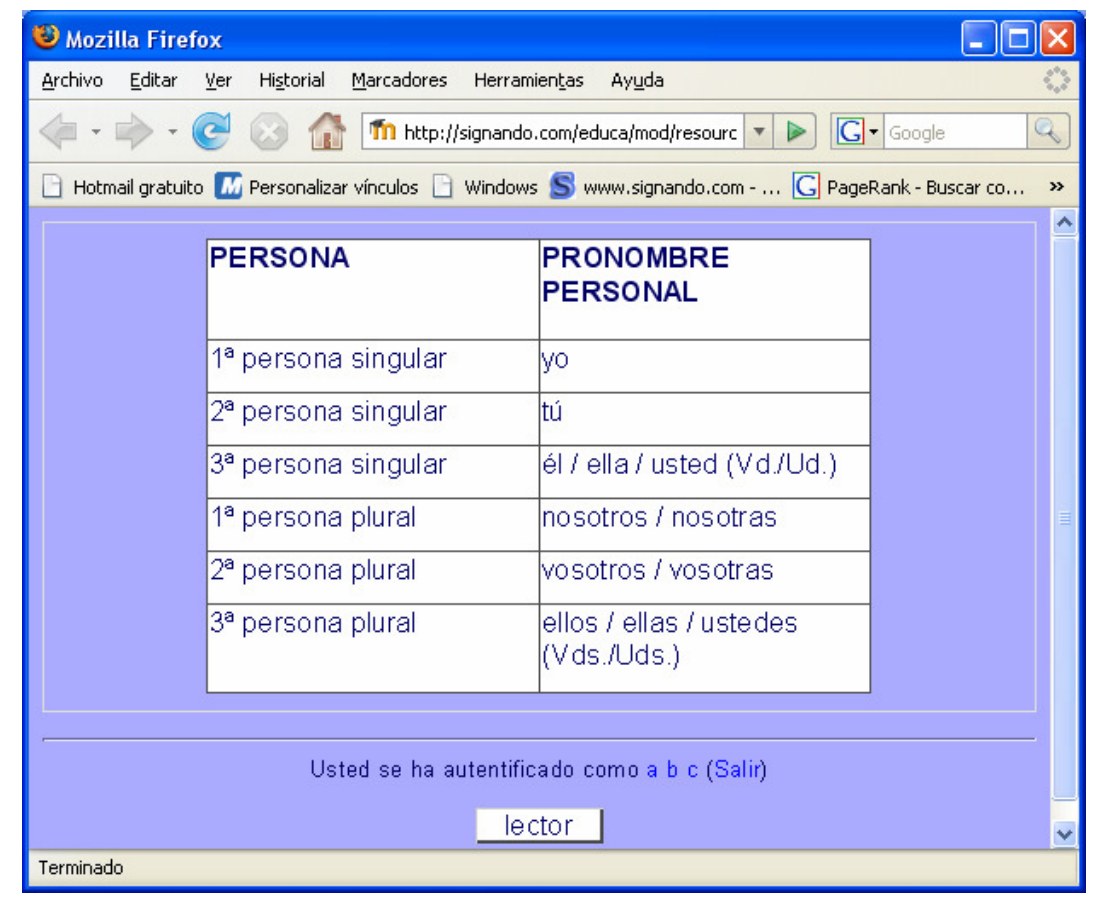

Imagen 22. Tema 2.3 Pronombres Personales

Este tipo de ventanas informativas son de ayuda para los participantes y para los educadores que pueden consultar el tema sobre el que los participantes están trabajando y ayudarles a comprender su uso.

Como siguiente ejemplo de actividad del Nivel 2, se muestra una actividad 2 del tema 2.4.1 que es del tipo asociación de elementos. Como se ve en la imagen 23, la tarea consiste en seleccionar la forma correcta del verbo tener para cada frase y unir la forma correcta con la frase usando una flecha. 


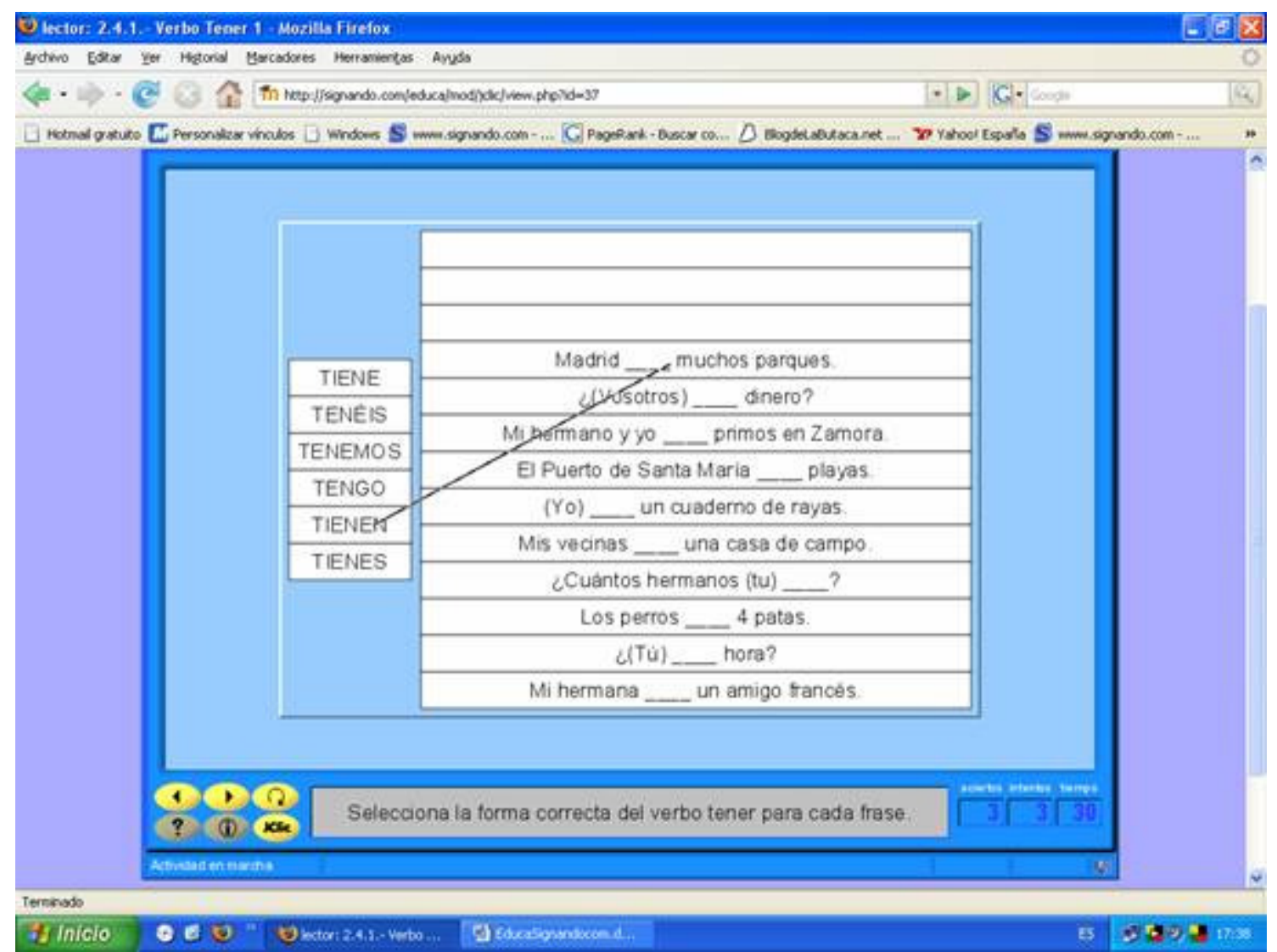

Imagen 23. Actividad 2 del subtema 2.4.1.- Verbo Tener 1

Además de comprender la frase debe seleccionar la forma correcta del verbo lo que implica un análisis de la oración y el reconocimiento de la forma verbal necesaria.

Como ya se ha explicado existen módulos creados solamente con información relacionada con el tema tratado, la actividad del subtema 2.4.2, mostrada en la imagen 24, muestra frases comunes en las que se utiliza el verbo tener. Este tipo de ventanas se pueden mantener abiertas mientras se trabaja con el siguiente tema. 
Desarrollo de Estrategias Sintácticas y Semánticas en Lectura a través de LECTOR en Personas Sordas Adultas en Castilla y León

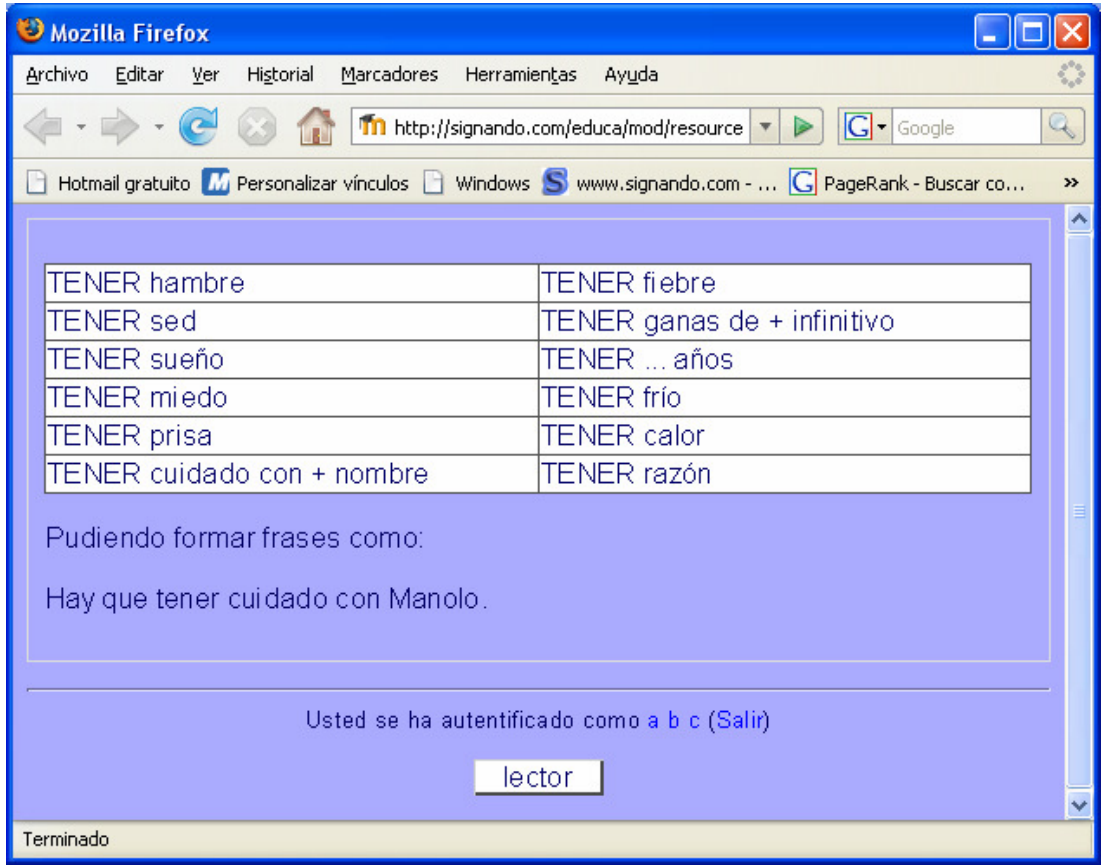

Imagen 24. Subtema 2.4.2.- Expresiones usuales con "tener"

A medida que el nivel de los participantes es mayor, las actividades son también de mayor dificultad y en consecuencia las explicaciones también tienen que serlo. En la imagen 25 se observa una explicación teórica que aparece en el Nivel 3, en el que se habla de los verbos irregulares y sus conjugaciones.

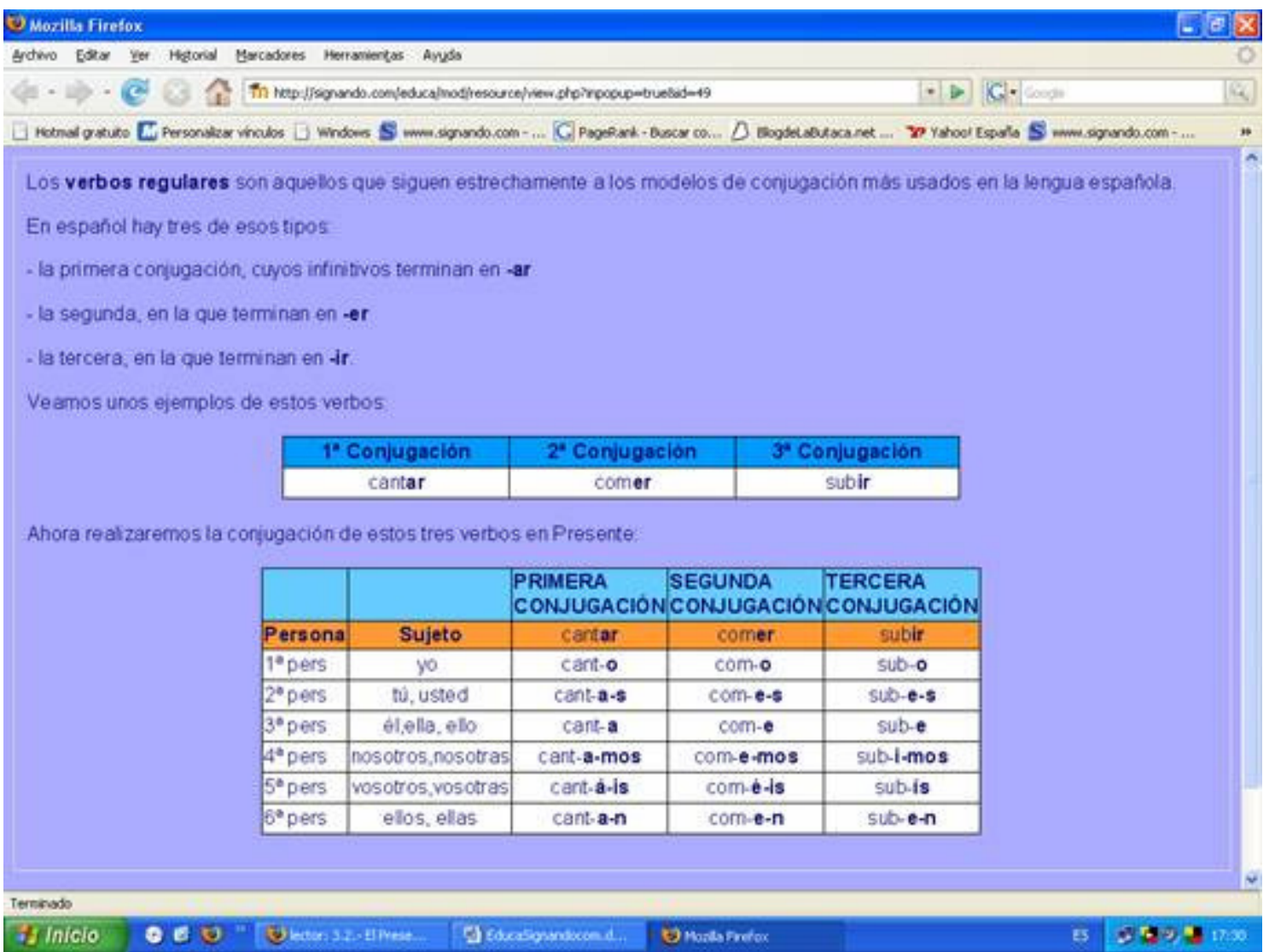


Imagen 25. Tema 3.2.- El Presente en Verbos Regulares

Una vez que los participantes con ayuda o no de los educadores creen comprender el tema tratado pueden pasar a realizar las actividades.

El ejemplo anterior está creado para resolver actividades como la que se ve a imagen 26.

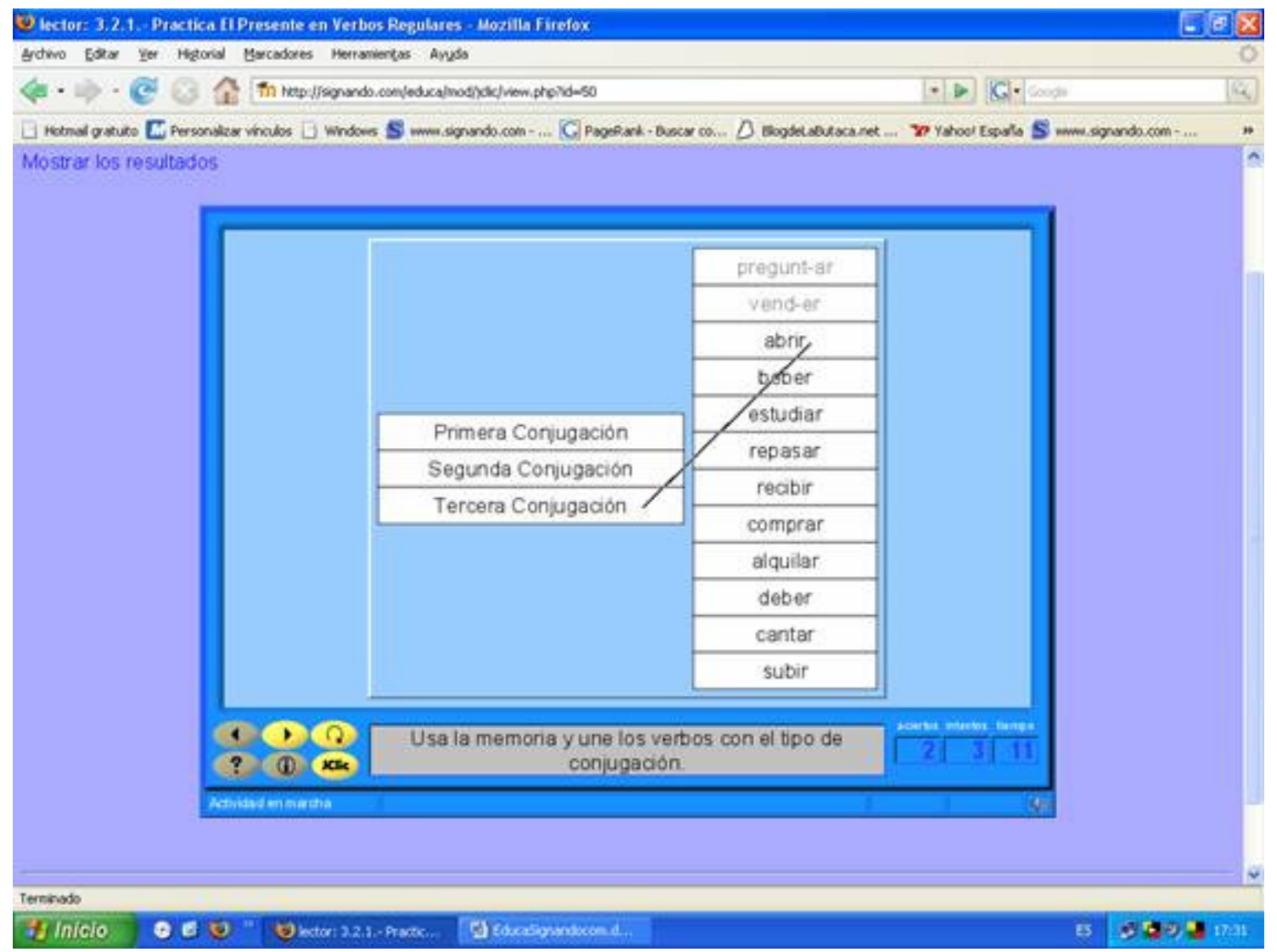

Imagen 26. Actividad 1 del subtema 3.2.1.- Practica el Presente en Verbos Regulares

Se trata de realizar la actividad que recuerda los conocimientos explicados con anterioridad, uniendo los verbos con el tipo de conjugación a la que pertenecen. Cuando un verbo es resuelto este aparece desactivado y se puede observar como el verbo separa su terminación que es lo que le define dentro de cada conjugación.

Se ha mantenido un grupo de actividades no relacionadas con el nivel entregado a los participantes, estas actividades fueron creadas con el propósito de mostrar las capacidades de creación de herramientas educativas a la Federación y Asociaciones de Personas Sordas de Castilla y León. Aunque se mantienen, se ha considerado que estas actividades solo podrían ser resueltas por los participantes que mostraron un nivel lector más alto. 
Para finalizar el curso lector aparecen las lecciones 7 Eficiencia Lectora 2 y 8 Estrategias Sintácticas 2 que no son más que los test que los alumnos han realizado al comienzo de la investigación.

La flexibilidad de este tipo de cursos es enorme, permite crear todo tipo de contenidos que permiten mantener en constante evolución la herramienta. En el caso de esta investigación las actividades son estas, pero si fuera necesario adaptarlo a otros grupos o colectivos no requiere de un gran esfuerzo, siempre que se cuenten con los conocimientos necesarios. El proceso de trabajo dentro de un curso como LECTOR requiere de control en cada fase del contenido, esto conlleva un proceso de edición para controlar la calidad de los contenidos creados, así como para permitir y organizar su publicación. Adquirir estos conocimientos supone a los educadores un trabajo extra, que en muchas ocasiones resulta complicado de comprender. Como indicaba García (2005) este tipo de herramientas se pueden ver desde la perspectiva de su concepción y desarrollo como herramienta formativa. El curso LECTOR al fin y al cabo es un sistema de e-learning de forma que tiene esa dualidad pedagógica y tecnológica. Pedagógica en cuanto a que este tipo de sistemas no deben ser meros contenedores de información digital, sino que ésta debe ser transmitida de acuerdo a unos modelos y patrones pedagógicamente definidos para afrontar los retos de estos nuevos contextos. Tecnológica en cuanto que todo el proceso de enseñanza-aprendizaje se sustenta en aplicaciones software, desarrolladas en ambientes Web.

Resulta, por tanto, necesaria la colaboración de dos campos altamente interesados el pedagógico y el tecnológico. Como indica García (2005) el factor humano, se convierte en la pieza más importante cuando se quiere acometer una estrategia basada en la e-formación. En un proceso de enseñanza-aprendizaje ni las plataformas tecnológicas, ni los modelos pedagógicos son el fin sino el medio para conseguir el objetivo último del proceso, esto es, aumentar el conocimiento y la formación de las partes implicadas.

Creer en estos medios es básico no solo para los educadores o los técnicos sino también para los alumnos, si no creyera por todas las partes implicadas, en que el medio utilizado puede llevar a conseguir educar o formar no tendría sentido trabajar sobre el.

Aunque en este tipo de sistemas el tecnológico lo realicen profesionales en esa área, el educador siempre debe tener unos conocimientos básicos de las opciones que estos sistemas ofrecen, para así poder utilizarlos y conseguir que la herramienta final tenga mayor valor educativo. 


\subsubsection{Procedimiento}

\subsubsection{Esquema Cronológico del Trabajo}

Mucho se ha escrito y existe gran literatura en la que se investiga la capacidad lectora y el proceso de aprendizaje de la lectura de los niños sordos, pero son escasas las investigaciones que tratan este mismo tema desde el punto de vista de adultos sordos. A lo largo de esta investigación se ha trabajado para poder comprender la capacidad lectora de un grupo de adultos sordos dentro del ámbito de Castilla y León.

El primer contacto con las necesidades de investigar sobre este tema, surge con la realización de prácticas de un Master en Educación de Personas con Discapacidad Sensorial: Visual y/o Auditiva en el Centro Cultural de Personas Sordas de Salamanca. A lo largo de estas prácticas entre en contacto con educadores y alumnos, todos ellos adultos, que trabajaban para poder comunicarse con el mundo en el que vivían, buscaban, en un trabajo duro para ellos, comprender la información que la sociedad muestra en forma escrita y deseaban poder participar en ella a través de la escritura. Existían casos puntuales, en el que algún socio, por aislamiento o falta de medios, no sabían lengua de signos y habían creado su propio lenguaje de comunicación, conocido únicamente por sus familiares.

De este primer contacto, surgió poco después y en forma de trabajo de Suficiencia Investigadora para la Universidad de Salamanca, una investigación de la capacidad lectora de los socios antes indicados. El trabajo titulado "Desarrollo de Estrategias Sintácticas en Lectura en Personas Sordas Adultas a través del Programa Lector" y presentado en Mayo del 2006, investiga el desarrollo de estrategias sintácticas por parte de los Socios del Centro Cultural de Personas Sordas de Salamanca. Para facilitar este desarrollo se desarrolló una aplicación informática creada a partir de JClic que se llamó Programa Lector. Esta aplicación contiene actividades educativas que permiten a los educadores trabajar ciertos aspectos del lenguaje con los alumnos. Para que estos pudieran trabajar las actividades fue necesario instalar el Programa Lector en los ordenadores del Centro Cultural para que, posteriormente pudieran ser utilizados por los socios. El Programa Lector, por su forma sencilla de trabajo y su interfaz amena facilitó en gran manera su aceptación inmediata. Esta aceptación impulsó su utilización, que posteriormente se transformaría en la obtención de mejores capacidades lectoras.

El grupo de trabajo estaba formado por 26 adultos (11 hombres y 15 mujeres), con una media de edad superior a 49 años. Los niveles de estudios mostraban que el $42.3 \%$ de los integrantes no tenían estudios y que su media de edad era superior a 57 años, claro reflejo de la educación que recibían las personas sordas hace mas de 55 años, momento en el cual el número de escuelas especializadas en educación de niños sordos era muy pequeña. Las personas con estudios de primaria suponían el $38.5 \%$ de la muestra siendo su media de edad de 36 años y medio. Estos dos grupos formaban el $80 \%$ de la muestra, de forma que las personas con menor nivel educativo son las que presentaban mayores necesidades educativas. También se encontraron 4 personas con estudios de secundaria y una persona con estudios 
universitarios, esta última fue descartada de la investigación. Todos ellos con edades inferiores a 37 años.

Atendiendo al tipo de sordera, existían 9 personas con sordera prelocutiva y 17 con sordera postlocutiva.

En la muestra se comprobó que un alto incide de participantes $73,1 \%$ no utilizaba ayudas técnicas como audífonos. De las personas que si utilizaban audífono se encontraron dos con edades inferiores a 25 años que aún estaban estudiando de forma que podrían ampliar su nivel académico ayudadas seguramente por los audífonos que empleaban.

El $88.5 \%$ de los participantes utilizaba Lengua de Signos y el $46,2 \%$ indicaron usar Lenguaje Oral.

Quedó reflejado que las personas mayores de 50 años son las que han tenido más problemas para alcanzar un mejor nivel educativo. Problemas como: falta de educación especializada y falta de acceso a medios técnicos (audífonos). Además, este tipo de personas, en muchos casos, han sido excluidos en su ambiente escolar y arrastran problemas de seguridad cuando se enfrentan a pruebas de lectura. Por el contrario, las personas más jóvenes, han podido acceder a planes educativos adaptados a sus necesidades y ahora presentan mejor nivel.

De este trabajo se obtuvieron diversos resultados entre los que destaca el hecho de haber conseguido, después del desarrollo del Programa Lector, un pequeño aumento de su capacidad lectora. Se comprobó que existía una mejora leve, en la Eficiencia Lectora después de haber trabajado las actividades que forman Lector. Durante la intervención se contó con la participación de una educadora que utilizaba Lengua de Signos para resolver dudas.

Los resultados obtenidos en este estudio en Salamanca, sirvieron como proyecto piloto para la investigación presentada en este trabajo, surgiendo en ese momento esta investigación.

El objetivo era comprobar si la aplicación creada para el desarrollo de estrategias sintácticas en lectura Programa LECTOR, era eficaz en una muestra mayor de personas sordas adultas.

Para el desarrollo de esta investigación se decidió cambiar el soporte a través del cual los participantes pudieran realizar sus prácticas y poder así desarrollar estrategias sintácticas. A lo largo del trabajo de suficiencia investigadora, mencionado anteriormente, fueron necesarias continúas visitas al Centro Cultural de Personas Sordas de Salamanca para instalar nuevas actividades en lo ordenadores de la asociación. Considerando las largas distancias existentes entre las diferentes sedes que forman la Federación de Asociaciones de Castilla y León y Salamanca, se decidió restringir estas visitas a una por Asociación, tomando en este momento la decisión de presentar la aplicación a los participantes a través de Internet, gracias a esto la actualización de aplicaciones se podría hacer de forma centralizada y desde cualquier punto de acceso a la Red. De esta forma se hace que la herramienta fuera accesible desde cualquier sitio con conexión a Internet. No obstante, se mantuvo un primer contacto con la Federación de Asociaciones de Castilla y León, se pactó una reunión con el presidente de la Federación y una serie de colaboradores en el 
ámbito de la educación, con anterioridad a la reunión la dirección recibió el proyecto de Tesis que posteriormente fue expuesto para conocimiento de los allí reunidos. De esta primera reunión se salió con el compromiso por parte de la Federación de consultar a cada una de las Asociaciones que forman la Federación en Castilla y León si querían participar. La idea del acceso desde cualquier sitio y el contenido totalmente innovador de la investigación animaron a las Asociaciones a participar.

A lo largo del siguiente mes a esta aceptación, se sucedieron los viajes a las diferentes Asociaciones que deseaban participar como queda reflejado en el Anexo IV. En cada una de las visitas, se realizan reuniones con los presidentes y educadores de cada Asociación, quieres recibían una explicación del sentido de la investigación, formación del funcionamiento del Programa LECTOR y el compromiso de asesorar ante cualquier dificultad que se planteara. A cambio ellos se comprometieron a hacer que los socios de sus Asociaciones participaran, en la medida de lo posible, en la investigación. La idea era la siguiente, los educadores de las distintas asociaciones recogerían una serie de datos, que posteriormente se han utilizado como variables de investigación, para que el administrador de la página educa.signando.com pudiera dar de alta a los usuarios, los usuarios recibirían en su correo electrónico el usuario y contraseña de acceso al curso, a partir de este momento los participantes podían comenzar a utilizar la herramienta, realizando en primer lugar los pre-test mencionados en los Anexos II y II, que ya se encontraban codificados en el Curso LECTOR.

El hecho de que los pre-test estuvieran ya codificados supuso un avance, ya que de forma automática y según los participantes iban realizando los test, se obtenían los resultados, gracias a los cuales se fueron montado las actividades.

Se había decidido hacer 3 grupos (1-nivel bajo, 2-nivel medio y 3-nivel alto) (descrito en el apartado 3) completamente independientes pero observando los resultados obtenidos, se decidió hacer 3 grupos, como se había pensado, pero siendo visibles las actividades de los 3 niveles para todos los participantes, de esta forma los participantes con menor nivel comenzarían realizando las actividades del Nivel 1, pero si estas actividades les resultaban fáciles podrían hacer las de los siguientes niveles. Además, el nivel 1 suponía un importante método para hacer recordar a las personas de los niveles superiores sus conocimientos previos, fundamentales para poder progresar en el aprendizaje de la lectura.

El tiempo destinado a la enseñanza y aprendizaje fue de 6 meses, haciendo coincidir las fechas con otros cursos impartidos por algunas de las Asociaciones. A lo largo de este tiempo los participantes, con la ayuda de los educadores de cada Asociación, trabajaron las actividades y resolvieron sus dudas, bien a través de los educadores o a través del correo electrónico con los administradores de la herramienta. Poco a poco el número de actividades fue creciendo mostrando nuevas actividades cada semana, de esta forma los usuarios podían elegir entre realizar nuevas actividades o repetir alguna de las ya hechas. Hay que recordar, que excepto las actividades de los test que solo se podían realizar una vez por usuario el resto no tienen limitación, se pueden realizar tantas veces como el alumnos considere necesario. 
Pasados los 6 meses de aprendizaje, los usuarios fueron recibiendo notificaciones para que realizasen los postest. Una vez realizadas estas pruebas se cerró el Programa LECTOR.

Los datos obtenidos de los postest fueron almacenados junto con los datos de los pretest y los que definen al grupo. Con esos datos se realizaron diferentes análisis con ayuda del SPSS. Los resultados obtenidos se presentan en el apartado 7 de este trabajo.

\subsubsection{Método}

El método seguido en esta investigación fue el siguiente:

1. Diseño y creación del espacio Web

2. Visita a las Asociaciones de Castilla y León

3. Pretest:

a. Prueba de Eficiencia Lectora (Anexo I)

b. Prueba de Estrategias Sintácticas en (Anexo II)

4. Diseño de actividades adaptadas a las necesidades presentadas, formando el Curso LECTOR.

5. Desarrollo de actividades del Curso LECTOR

6. Postest (utilizando las mismas pruebas que se usaron en el pretest).

Una vez localizado el informático que podría desarrollar esta idea, se comenzó con el diseño de la página Web. En este momento surgió la idea de crear un portal que tuviera además del contenido necesario para esta tesis, información relacionada con su desarrollo y noticias o eventos del mundo de las personas sordas. De esta forma, nació signando.com que contiene educa.signando.com, que es donde se encuentra el Curso LECTOR.

Se consideró necesaria una visita a cada Asociación para poder explicar el funcionamiento de las páginas Web. De esta forma se visitaron en este orden las siguientes Asociaciones:

1. Asociación de Personas Sordas de León

2. Asociación de Personas Sordas de la Comarca del Bierzo (Ponferrada)

3. Asociación de Personas Sordas de Zamora

4. Asociación de Personas Sordas de Aranda de Duero y la Ribera

5. Asociación de Personas Sordas de Burgos

6. Asociación de Personas Sordas de Palencia

7. Asociación de Personas Sordas de Valladolid

En todas ellas se mantuvo una reunión con el educador, intérpretes y presidente. Fue expuesta la necesidad de contar con la participación de los socios; se explicó de forma práctica el funcionamiento de la página. De esta forma, cada Asociación debería proporcionar una lista de personas interesadas en colaborar con la investigación. Una vez recibida esta información, le sería devuelto un correo electrónico a cada participante con sus datos de acceso (usuario y contraseña). 
Al cabo de unas semanas durante las cuales los educadores informaron a los socios sobre la posibilidad de participar en esta tesis, se empezaron a recibir correos de los educadores con la información que se le había solicitado. En el momento de la recepción de estos correos se comienza el proceso de alta de usuarios. Esta alta genera un usuario y una contraseña personal para cada usuario. Estos datos fueron enviados a los participantes indicándoles que debían realizar las dos primeras actividades que se encontraban publicadas en educa.signando.com.

Poco a poco los participantes fueron realizando las actividades; estos dos primeros test fueron muy importantes para evaluar su nivel lector. Los test utilizados fueron: Prueba de eficiencia lectora (Carrillo y Martín, 1997) y Prueba de evaluación de estratégicas sintácticas (Soriano, Pérez y Domínguez, 2006).

A medida que los usuarios realizaban los test el sistema proporcionaba los resultados. De esta forma se crearon tres niveles:

- Nivel 1, entre 0 y 15 respuestas acertadas (este grupo fue considerado como de Nivel Bajo.

- Nivel 2, entre 15 a 35 respuestas acertadas (este grupo fue considerado de Nivel Medio.

- Nivel 3, entre 35 y 64 respuestas acertadas (este grupo fue considerado de Nivel Alto.

Para la definición de los tres niveles, se ha contado con los resultados obtenidos por Soriano (2004) en el estudio con lectores oyentes sobre las dos pruebas empleadas en esta investigación. De esta forma sus resultados indican que los participantes con media de aciertos inferior a 15 son de $2^{\circ}$ de primaria, los participantes con media de aciertos 31,30 son de $3^{\circ}$ de primaria y los participantes con medias superiores a 40 forman parte del grupo de $4^{\circ}$ a $6^{\circ}$ de primaria.

Atendiendo a estos resultados y viendo el número de participantes se decidió realizar esta división en tres niveles, de esta forma en el Nivel 1 se encuentran los participantes con un nivel de $2^{\circ}$ de primaria, en el Nivel 2 los participantes con nivel de $3^{\circ}$ de primaria y en el nivel Nivel 3 los participantes con niveles superiores a $3^{\circ}$ de primaria.

Esta información fue proporcionada a cada uno de los participantes, para este momento ya existían actividades adaptadas para cada uno de los niveles. Estas actividades están basadas y adaptadas de libros de español para extranjeros, actividades relacionadas con el Programa LEECOM (Sistema de Instrucción de la Comprensión Lectora asistido por ordenador para personas sordas adultas, 2004) y el programa para la enseñanza de habilidades metalingüísticas, desarrolladas por Clemente y Domínguez (1999).

En un correo informativo se les indicaba el tipo de actividades que tenían que realizar. En el caso de las personas de Nivel 2, se les indicó también que deberían realizar las actividades de Nivel 1, para reforzar conocimientos. 
Mientras los usuarios trabajaban con las actividades ya creadas, se fueron creando nuevas actividades, de esta forma los participantes se mantenían constantemente en contacto con la herramienta.

Una vez aplicada la intervención con LECTOR y siguiendo el calendario preestablecido y pactado con las Asociaciones, se informó a los participantes que debían realizar las dos últimas actividades. Estos dos últimos test son los post-test que han servido para elaborar los resultados de esta investigación.

Se analizaran los datos estadísticos del pre-test y pos-test en función de las distintas variables independientes y dependientes, para esta labor se utilizará el programa SPSS.

\begin{tabular}{|l|l|}
\hline Variables independientes & Variables dependientes \\
\hline Edad & Aciertos en Eficiencia Lectora \\
\hline Nivel de estudios & Aciertos en Estrategias Sintácticas \\
\hline Sexo & Errores en Eficiencia Lectora \\
\hline Numero de audífonos & Errores en Estrategias Sintácticas \\
\hline Tipo Sordera & Aciertos por tipo de frase \\
\hline Profesión & Errores por tipo de frase \\
\hline LSE & \\
\hline LO & \\
\hline
\end{tabular}

Tabla 3. Variables 


\subsection{Resultados y Discusión de los Resultados}

\subsubsection{Evaluación del Nivel de Eficiencia Lectora}

El objetivo fundamental de esta parte del trabajo es, determinar cual es el nivel de eficiencia lectora que han mostrado los participantes en la investigación. Para evaluar esta cuestión se empleó la Prueba de Eficiencia Lectora (Carrillo y Marín 1997).

Los resultados obtenidos en esta prueba aparecen en la tabla 13.

\begin{tabular}{|c|c|c|c|c|}
\hline Participantes & $\begin{array}{c}\text { Contestadas } 5 \\
\text { min Pretest } \\
\text { EficLect }\end{array}$ & $\begin{array}{c}\text { Aciertos } 5 \\
\text { min Pretest } \\
\text { EficLect }\end{array}$ & $\begin{array}{c}\text { Contestadas } 5 \\
\text { min Postest } \\
\text { EficLect }\end{array}$ & $\begin{array}{l}\text { Aciertos } 5 \\
\text { min Postest } \\
\text { EficLect }\end{array}$ \\
\hline P01 & 38 & 27 & 60 & 48 \\
\hline P02 & 64 & 61 & 59 & 58 \\
\hline P03 & 36 & 11 & 32 & 27 \\
\hline P04 & 38 & 34 & 47 & 46 \\
\hline P05 & 44 & 40 & 58 & 55 \\
\hline P06 & 16 & 16 & 64 & 63 \\
\hline P07 & 20 & 5 & 17 & 8 \\
\hline P08 & 16 & 15 & 19 & 16 \\
\hline P09 & 36 & 23 & 50 & 45 \\
\hline P10 & 16 & 14 & 31 & 29 \\
\hline P11 & 31 & 27 & 64 & 59 \\
\hline P12 & 56 & 46 & 60 & 50 \\
\hline P13 & 56 & 51 & 49 & 47 \\
\hline P14 & 16 & 2 & 10 & 7 \\
\hline P15 & 51 & 50 & 50 & 37 \\
\hline P16 & 21 & 18 & 64 & 59 \\
\hline P17 & 31 & 18 & 40 & 38 \\
\hline P18 & 64 & 61 & 64 & 63 \\
\hline P19 & 61 & 57 & 64 & 58 \\
\hline P20 & 16 & 16 & 60 & 58 \\
\hline P21 & 64 & 60 & 64 & 62 \\
\hline P22 & 56 & 53 & 64 & 64 \\
\hline P23 & 13 & 11 & 40 & 40 \\
\hline P24 & 56 & 20 & 32 & 20 \\
\hline P25 & 43 & 6 & 30 & 30 \\
\hline P26 & 30 & 30 & 30 & 30 \\
\hline P27 & 56 & 52 & 53 & 50 \\
\hline P28 & 27 & 16 & 30 & 29 \\
\hline P29 & 51 & 50 & 53 & 52 \\
\hline P30 & 32 & 11 & 22 & 16 \\
\hline P31 & 16 & 12 & 53 & 52 \\
\hline P32 & 42 & 31 & 49 & 42 \\
\hline P33 & 27 & 20 & 34 & 29 \\
\hline P34 & 35 & 17 & 27 & 22 \\
\hline P35 & 16 & 7 & 18 & 15 \\
\hline
\end{tabular}

Tabla 13. Respuestas emitidas y número de aciertos en 5 minutos dados por los participantes en PEL (pre-postest) 
Como se puede observare en la tabla 14 los resultados obtenidos en el pre-test indican que la media de preguntas contestadas en 5 minutos fue de 36,89 de las cuales fueron acertadas una media de 28,23. Estos valores cambian en el pos-test donde se ve que se contestaron una media de 44,60 preguntas de las que se acertaron 40,69. Es decir, se han contestado como media menos preguntas en el pre-test que en el pos-test pero se han acertado más. Aunque la desviación típica en el número de preguntas contestadas aumenta, este valor disminuye en el caso de aciertos. Lo que supone que el resultado de aciertos medio en el post-test es más significativo que el mismo resultado en el pre-test.

\begin{tabular}{|l|r|r|r|r|}
\hline & \multicolumn{1}{|c|}{ Mínimo } & \multicolumn{1}{c|}{ Máximo } & \multicolumn{1}{c|}{ Media } & Desv. típ. \\
\hline Contestadas 5 min Pretest EficLect & 13 & 64 & $\mathbf{3 6 , 8 9}$ & 16,831 \\
Aciertos 5 min Pretest EficLect & 2 & 61 & $\mathbf{2 8 , 2 3}$ & 18,615 \\
Errores 5 min Pretest EficLect & 0 & 37 & 8,66 & 9,343 \\
Contestadas en total Pretest EficLect & 13 & 64 & 45,43 & 19,571 \\
Total Aciertos Pretest EficLect & 2 & 63 & 35,26 & 21,645 \\
Total Errores Pretes EficLect & 0 & 40 & 10,29 & 10,329 \\
Contestadas 5 min Postest EficLect & 10 & 64 & $\mathbf{4 4 , 6 0}$ & 16,704 \\
Aciertos 5 min Postest EficLect & 7 & 64 & $\mathbf{4 0 , 6 9}$ & 17,189 \\
Contestadas en Total Postest EficLect & 10 & 64 & 49,69 & 18,008 \\
Total Aciertos Postest EficLect & 7 & 64 & 45,66 & 18,426 \\
Total Errores Postest EficLect & 0 & 13 & 4,03 & 3,560 \\
\hline
\end{tabular}

Tabla 14. Medias y Desviaciones típicas de las puntuaciones obtenidas por los participantes en la PEL.

Al realizar un ANOVA sobre las puntuaciones de aciertos entre Pretest y Postest (ver tabla 15), vemos que nos se observan resultados significativos ( $F=1.050 ; p>0.05)$.

\begin{tabular}{|c|c|c|c|c|}
\hline & & $\begin{array}{c}\text { Media } \\
\text { cuadrática }\end{array}$ & $F$ & Sig. \\
\hline $\begin{array}{l}\text { Aciertos } 5 \text { min Pretest } \\
\text { EficLect * Aciertos } 5 \\
\text { min Postest EficLect }\end{array}$ & $\begin{array}{l}\text { Inter-grupos (Combinadas) } \\
\text { Intra-grupos } \\
\text { Total }\end{array}$ & $\begin{array}{l}351,410 \\
334,833\end{array}$ & 1,050 & ,494 \\
\hline
\end{tabular}

Tabla 15. Anova de Aciertos en 5 minutos en Pretest y Postest en la Prueba de Eficiencia Lectora

Si se comparan estos resultados por los obtenidos por Soriano (2004) donde se analizo a lectores oyentes con esta misma prueba consiguiendo discriminar los 
niveles educativos a los que pertenecía cada participante, se observa como, en el pretest los participantes, con una media de aciertos de 28,23 , se sitúan en un nivel de estudios entre $2^{\circ}$ y $3^{\circ}$ de Primaria, mientras que en el postest con media 40,69 sitúa a los participantes en un nivel de estudios superior a $4^{\circ}$ de primaria.

\subsubsection{Estudio de la Eficiencia Lectora en función del Nivel de Estudios}

Un dato muy significativo que se puede resaltar de los datos obtenidos (tabla 16), es el aumento de la media de aciertos de las personas sin estudios. La media en el pretest fue de 27 mientras que en el pos-test son de 41,67 de media.

En cuanto a los valores de la media de los alumnos de primaria, también se ha encontrado un gran aumento pasando de ser esta media de 16,31 en el Pre-test a ser de 32,75 en el Pos-test, lo que supone prácticamente el doble.

Los alumnos de secundaria no muestran un gran aumento en la media de aciertos, pasando de ser esta media de 40,14 en el Pre-test a ser de 47,64 en el Pos-test. Sin embargo, la desviación típica ha disminuido, lo que indica que los resultados de los alumnos de secundaria se encuentran ahora más cerca de la media.

En el caso de este estudio solamente dos personas tienen estudios universitarios. Hubo un aumento significativo de aciertos, pasando de tener 42 aciertos de media en el pre-test ha tener 54 en el pos-test. La desviación típica se redujo pasando de 26,87 a 12,728, este descenso tiene una explicación. En el pre-test uno de los participantes tuvo 23 aciertos y la otra 61. En el pos-test la primera de las personas aumentó ampliamente su resultado, consiguiendo 45 aciertos, mientras que la segunda acertó 63 . Este es el motivo por el cual la desviación típica ha disminuido.

\begin{tabular}{|ll|r|r|r|}
\hline & & & & \multicolumn{1}{c|}{$\begin{array}{c}\text { Desviación } \\
\text { típica }\end{array}$} \\
\hline Aciertos 5 min & Sin estudios & 3 & 27,00 & 14,731 \\
Pretest EficLect & Primaria & 16 & 16,31 & 11,505 \\
& Secundaria & 14 & 40,14 & 17,536 \\
& Universitarios & 2 & 42,00 & 26,870 \\
& Total & 35 & 28,23 & 18,615 \\
Aciertos 5 5 min & Sin estudios & 3 & 41,67 & 12,583 \\
Postest EficLect & Primaria & 16 & 32,75 & 18,817 \\
& Secundaria & 14 & 47,64 & 13,048 \\
& Universitarios & 2 & 54,00 & 12,728 \\
& Total & 35 & 40,69 & 17,189 \\
\hline
\end{tabular}

Tabla 16. Media y desviación típica pre/post-test- Eficiencia Lectora por Estudios 


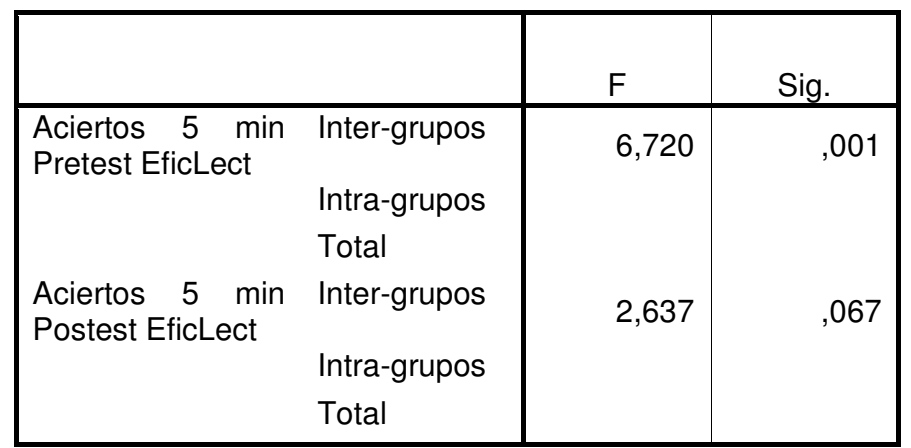

Tabla 17. Prueba de ANOVA número de Aciertos en 5 minutos pre/post test Eficiencia Lectora por Estudios

Si se comparan estos resultados con los mostrados por Soriano (2004) donde la media de aciertos de las personas sordas que participaron en su investigación fue de 49,57 y les situaba entre $5^{\circ}$ y $6^{\circ}$ de Primaria, con los obtenidos en esta investigación, se comprueba que el nivel de estudios al que corresponde una media tan alta corresponde con los participantes con estudios superiores de esta investigación.

La prueba de ANOVA para comparar medias entre grupos señala diferencias significativas $(F=6,720 ; p=0.001)$, lo que indica que existen diferencias de medias entre los grupos (ver tabla 17). La prueba de ANOVA para el pos-test muestra que $F=2,637$ con una significación del 0,067. Al ser este ultimo valor mayor que 0,05, podemos aceptar la hipótesis de igualdad de medias. Esto indica que las medias de los distintos grupos en el pos-test se encuentran muy próximas.

Soriano (2004) en su investigación encontró que el nivel de estudios y la lectura estaban significativamente correlacionados $r=0,580 \quad(p<0,030)$. Estos mismos resultados también se encuentran reflejados en esta investigación como se puede ver en la tabla 18 , donde se puede ver que $r=0,610(p<0,003)$.

\begin{tabular}{|c|c|c|c|c|}
\hline Variables de control & & & $\begin{array}{c}\text { Aciertos } 5 \\
\text { min Pretest } \\
\text { EficLect }\end{array}$ & $\begin{array}{l}\text { Aciertos } 5 \\
\text { min Postest } \\
\text { EficLect }\end{array}$ \\
\hline \multirow[t]{6}{*}{ Estudios } & Aciertos $5 \mathrm{~min}$ & Correlación & 1,000 & ,610 \\
\hline & Pretest EficLect & Significación (bilateral) & &, 000 \\
\hline & & gl & 0 & 32 \\
\hline & Aciertos $5 \mathrm{~min}$ & Correlación & 610 & 1,000 \\
\hline & Postest EficLect & Significación (bilateral) & ,000 & . \\
\hline & & gl & 32 & 0 \\
\hline
\end{tabular}

Tabla 18. Correlación Aciertos en 5 minutos Pretest y Postest Prueba de Eficiencia Lectora 


\subsubsection{Estudio de la Eficiencia Lectora en función del Lenguaje Oral}

Analizando los resultados en función de la utilización de Lengua Oral, podemos observar (tabla 19) como las personas que lo usan tienen una mayor media de aciertos 35 que los que no lo usan 15,25. Estos valores se repiten en el pos-test 45,96 contra 30,58 .

En este caso, en el pre-test, en la prueba de Anova se ve que $F=11,659$ con significación del 0,002, de forma que existen diferencias significativas entre los resultados obtenidos por los grupos (tabla 20).

En el pos-test estos valores son de $F=7,517$ y $p=0,01$ demostrando que existen diferencias significativas entre las personas que usan la LO y las que no lo usan.

\begin{tabular}{|c|c|c|c|c|}
\hline & & $\mathrm{N}$ & Media & $\begin{array}{c}\text { Desviación } \\
\text { típica }\end{array}$ \\
\hline \multirow[t]{3}{*}{$\begin{array}{l}\text { Aciertos } 5 \mathrm{~min} \\
\text { Pretest EficLect }\end{array}$} & & 12 & 15,25 & 12,729 \\
\hline & $\mathrm{Si}$ & 23 & 35,00 & 17,741 \\
\hline & Total & 35 & 28,23 & 18,615 \\
\hline \multirow[t]{3}{*}{$\begin{array}{l}\text { Aciertos } 5 \mathrm{~min} \\
\text { Postest EficLect }\end{array}$} & No & 12 & 30,58 & 16,994 \\
\hline & $\mathrm{Si}$ & 23 & 45,96 & 15,083 \\
\hline & Total & 35 & 40,69 & 17,189 \\
\hline
\end{tabular}

Tabla 19. Media y desviación típica pre/post-test- Eficiencia Lectora por uso de Lenguaje Oral

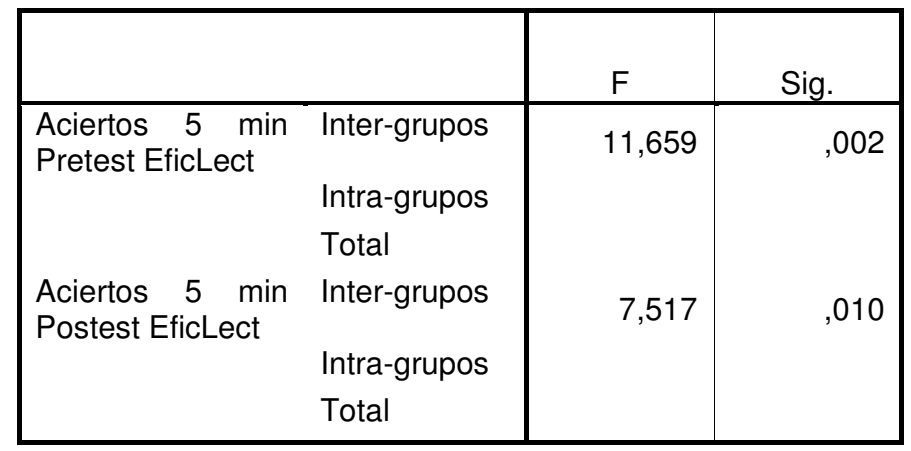

Tabla 20. Prueba de ANOVA número de Aciertos en 5 minutos pre/post test Eficiencia Lectora por uso de Lenguaje Oral

Estos resultados vienen a respaldar lo demostrado en otra investigación (Augusto et al, 1999) donde se demostró que las personas con Lenguaje Oral conseguían mejor reconocimiento de las palabras y significado gracias al proceso fonológico. Sin 
embargo, después del trabajo con LECTOR los alumnos que no usan LO progresaron más que los que si lo usan.

\subsubsection{Estudio de la Eficiencia Lectora en función del Número de Audífonos}

Como se podía esperar las personas que utilizan audífono obtuvieron mejores resultados (ver tabla 21). Aunque la progresión de los que no usan audífono fue mayor. Sin embargo la desviación típica de los que no usan audífono, aumentó ligeramente, mientras que la de los que usan un audífono disminuyó casi a la mitad entre el pre-test y el pos-test.

La prueba de ANOVA (ver tabla 22) indica que existen diferencias de igualdad de medias, al ser $F=14,462$ y $p=0,001$ en el pre-test y $F=10,802$ y $p=0,002$ en el postest.

\begin{tabular}{|c|c|c|c|c|}
\hline & & $\mathrm{N}$ & Media & $\begin{array}{l}\text { Desviación } \\
\text { típica }\end{array}$ \\
\hline \multirow[t]{3}{*}{$\begin{array}{l}\text { Aciertos } 5 \mathrm{~min} \\
\text { Pretest EficLect }\end{array}$} & & 23 & 20,91 & 15,550 \\
\hline & 1 & 12 & 42,25 & 16,159 \\
\hline & Total & 35 & 28,23 & 18,615 \\
\hline \multirow{3}{*}{$\begin{array}{l}\text { Aciertos } 5 \mathrm{~min} \\
\text { Postest EficLect }\end{array}$} & 0 & 23 & 34,61 & 17,655 \\
\hline & 1 & 12 & 52,33 & 8,038 \\
\hline & Total & 35 & 40,69 & 17,189 \\
\hline
\end{tabular}

Tabla 21. Media y desviación típica pre/post-test- Eficiencia Lectora por Número de Audífonos

\begin{tabular}{|ll|c|c|}
\hline & & F & Sig. \\
\hline $\begin{array}{l}\text { Aciertos 5 min } \\
\text { Pretest EficLect }\end{array}$ & Inter-grupos & 14,462 &, 001 \\
& $\begin{array}{l}\text { Intra-grupos } \\
\text { Total }\end{array}$ & & \\
$\begin{array}{l}\text { Aciertos 5 min } \\
\text { Postest EficLect }\end{array}$ & 10,802 &, 002 \\
& $\begin{array}{l}\text { Inter-grupos } \\
\text { Total }\end{array}$ & \\
\hline
\end{tabular}

Tabla 22. Prueba de ANOVA número de Aciertos en 5 minutos pre/post test Eficiencia Lectora por Número de Audífonos

En Soriano (2004) el uso de prótesis auditivas, como en este caso, marcó diferencias significativas en Lectura entre participantes. 


\subsubsection{Estudio de la Eficiencia Lectora en función del Tipo de Sordera}

En esta investigación se ve (tabla 23) como las personas con sordera prelocutiva tienen peor media de aciertos 23,19 que las personas con sordera postlocutiva 36,96. Las medias en el post-test muestran este mismo resultado, aunque la diferencia de medias es menor. Estos datos concuerdan con los encontrados por Domínguez (2004)

\begin{tabular}{|c|c|c|c|c|}
\hline & & $\mathrm{N}$ & Media & $\begin{array}{l}\text { Desviación } \\
\text { típica }\end{array}$ \\
\hline \multirow[t]{3}{*}{$\begin{array}{l}\text { Aciertos } 5 \mathrm{~min} \\
\text { Pretest EficLect }\end{array}$} & & 27 & 23,19 & 15,765 \\
\hline & Sordera Postlocutiva & 8 & 45,25 & 18,188 \\
\hline & Total & 35 & 28,23 & 18,615 \\
\hline \multirow{3}{*}{$\begin{array}{l}\text { Aciertos } 5 \mathrm{~min} \\
\text { Postest EficLect }\end{array}$} & Sordera Prelocutiva & 27 & 36,96 & 16,958 \\
\hline & Sordera Postlocutiva & 8 & 53,25 & 11,536 \\
\hline & Total & 35 & 40,69 & 17,189 \\
\hline
\end{tabular}

Tabla 23. Media y desviación típica pre/post-test- Eficiencia Lectora por Tipo de Sordera

\begin{tabular}{|ll|c|c|}
\hline & & F & Sig. \\
\hline $\begin{array}{l}\text { Aciertos 5 min } \\
\text { Pretest EficLect }\end{array}$ & Inter-grupos & 11,296 &, 002 \\
& $\begin{array}{l}\text { Intra-grupos } \\
\text { Total }\end{array}$ & & \\
Aciertos 5 min & Inter-grupos \\
Postest EficLect & Intra-grupos \\
& Total & & \\
& & \\
\hline
\end{tabular}

Tabla 24. Prueba de ANOVA número de Aciertos en 5 minutos pre/post test Eficiencia Lectora por Tipo de Sordera

Respecto al resultado de la prueba de Anova (ver tabla 24), tanto en el pre-test $(F=11,296 ; p>0,05)$, como en el post-test, $(F=6,425 ; p=0,16)$, indica que no existe igualdad de media entre grupos, en ninguna de las dos pruebas. 


\subsubsection{Estudio de la Eficiencia Lectora en función de la Edad Media}

La edad media de los participantes se sitúa en los 40 años, en función de este valor, se ha realizado una prueba de T para muestras independientes de los aciertos en 5 minutos con un valor de corte de 40 años. De esta forma se han generado 2 grupos ( $>=40$ años $-<40$ años).

Las personas menores de 40 años presentan una media de aciertos de 37,60 en el pretest y 47,95 en el postest, muy superior a los mayores de 40 años 15,73 en pretest y 31 en postest (tabla 25).

\begin{tabular}{|c|c|c|c|c|c|}
\hline & Edad & $\mathrm{N}$ & Media & $\begin{array}{c}\text { Desviación } \\
\text { típ. } \\
\end{array}$ & $\begin{array}{l}\text { Error típ. de } \\
\text { la media }\end{array}$ \\
\hline \multirow{2}{*}{$\begin{array}{l}\text { Aciertos } 5 \mathrm{~min} \\
\text { Pretest EficLect }\end{array}$} & $>=40$ & 15 & 15,73 & 13,854 & 3,577 \\
\hline & $<40$ & 20 & 37,60 & 16,217 & 3,626 \\
\hline \multirow{2}{*}{$\begin{array}{l}\text { Aciertos } 5 \mathrm{~min} \\
\text { Postest EficLect }\end{array}$} & $>=40$ & 15 & 31,00 & 17,984 & 4,643 \\
\hline & $<40$ & 20 & 47,95 & 12,680 & 2,835 \\
\hline
\end{tabular}

Tabla 25. Media y desviación típica Aciertos en 5 minutos pre/post-test Eficiencia Lectora por Media de Edad

Soriano (2004) en su investigación encontró correlación entre edad y nivel lector $\mathrm{r}=-$ $0,727(p<0,005)$, en este caso y como se puede ver en la tabla 26 también existe correlación $r=-0,662(p<0,01)$.

\begin{tabular}{|ll|r|r|}
\hline & & & $\begin{array}{c}\text { Aciertos 5 } \\
\text { min Pretest } \\
\text { EficLect }\end{array}$ \\
\hline Edad & Correlación de Pearson & 1 &,- 662 \\
& Sig. (bilateral) & &, 000 \\
Aciertos 5 min & $\mathrm{N}$ & 35 & 35 \\
Pretest EficLect & Correlación de Pearson &,- 662 & 1 \\
& Sig. (bilateral) &, 000 & 35 \\
\hline
\end{tabular}

Tabla 26. Correlación entre Aciertos en 5 minutos y Edad.

En función de los resultados obtenidos se podría decir que, en cuanto al tiempo empleado en resolver la prueba tenemos que señalar que, excepto las participantes P18, P19 y P21, que finalizan las pruebas (pre-test y pos-test) antes del tiempo concedido, el resto de participantes necesita más tiempo de resolución. Carrillo y Marín (1997) ponen de manifiesto que lectores expertos oyentes resuelven la prueba 
completa en dos minutos. Este incremento podría ser debido la lentitud con la que leen las frases cuando son conscientes de que deben comprender bien los ítems presentados, porque se les va a evaluar.

Otros estudios (Marchesi, 1987, citados en Silvestre et al., 1998) también señalan, como uno de los principales problemas de los lectores sordos, la escasez de vocabulario y conocimientos sobre la lengua oral con la que se enfrentan a la lectura.

Teniendo en cuenta la evolución de los distintos grupos en función de su nivel educativo, queda reflejado que las personas con niveles de estudios inferiores registran la mayor evolución aunque las personas con niveles más altos consiguen mejores resultados en las pruebas. Esto hace pensar que el trabajo con LECTOR ha favorecido en mayor medida a los participantes con niveles más bajos.

El estudio de la utilización del Lenguaje Oral demuestra, que las personas con esta capacidad conseguían mejor reconocimiento de las palabras y significado gracias al proceso fonológico, como indicaron en su investigación Augusto, et al (1999).

Entre los participantes que han conseguido las mejores puntuaciones en la prueba existen algunos rasgos coincidentes tales como el uso de audífonos, uso del Lenguaje Oral o mayores niveles logrados en la educación. Quizás este último rasgo les haya proporcionado una mayor experiencia en resolver tareas similares a las que hemos presentado. Este tipo de rasgos que provocan mejores resultados coinciden con los encontrados por Soriano (2004).

Los resultados obtenidos apoyan la hipótesis de partida que LECTOR es útil para conseguir mayor eficiencia lectora facilitando la comprensión de palabras y frases.

\subsubsection{Evaluación de las Estrategias Sintácticas}

El objetivo de esta prueba PEES (Soriano, Pérez y Domínguez, 2006) es evaluar las estrategias semánticas y/o sintácticas empleadas en la lectura de frases. La hipótesis que se maneja es que la lectura de las personas sordas adultas depende más de conocimientos semánticos globales que de la utilización de las estrategias sintácticas disponibles en el texto.

Los resultados obtenidos por Soriano et al. (2006) permiten obtener un baremo donde se comparan los resultados obtenidos en esta prueba realizada por alumnos sordos y oyentes. 


\subsubsection{Análisis del tipo de Estrategia Lectora}

Los resultados alcanzados por las personas sordas adultas en la Prueba de Evaluación de Estrategias Sintácticas en lectura aparecen en la tabla 27.

\begin{tabular}{|l|r|r|r|r|}
\hline & Media & Desv. típ. & Mínimo & Máximo \\
\hline Contestadas 5 minutos Pre-Test Estrategias Sintácticas & 42,54 & 17,609 & 10 & 64 \\
Número Acierto 5 minutos Pre-Test Estrategias Sintácticas & $\mathbf{2 8 , 5 7}$ & 22,386 & 0 & 61 \\
Errores 5 minutos Pre-Test Estrategias Sintácticas & 13,97 & 13,511 & 0 & 53 \\
Contestadas 5 minutos Post-Test Estrategias Sintácticas & 41,54 & 19,547 & 9 & 64 \\
Aciertos 5 minutos Post-Test Estrategias Sintácticas & 34,57 & 20,330 & 6 & 63 \\
Errores 5 minutos Pos-Test Estrategia Sintácticas & 6,97 & 8,515 & 0 & 49 \\
Contestadas Pre-test Estrategias Sintácticas & 55,20 & 16,035 & 15 & 64 \\
Número Aciertos Pre-Test Estrategias Sintácticas & 35,40 & 23,903 & 0 & 63 \\
Errores Pre-Test Estrategias Sintácticas & 19,80 & 18,346 & 1 & 59 \\
Contestadas Pos-test Estratégias Sintácticas & 47,63 & 19,838 & 12 & 64 \\
Número Aciertos Post-Test Estrategias Sintácticas & 39,31 & 20,718 & 9 & 63 \\
Errores Pos-Test Estrategia Sintácticas & 7,29 & 5,894 & 0 & 28 \\
\hline
\end{tabular}

Tabla 27. Tabla de Medias y Desviación típica. Contestadas, Aciertos y Errores Pre/Post Test en Estrategias Sintácticas 


\begin{tabular}{|c|c|c|c|c|c|c|c|c|c|c|c|c|}
\hline & $\begin{array}{c}\text { Contest } \\
\text { adas } 5 \\
\text { minutos } \\
\text { Pre-Test } \\
\text { Estrateg } \\
\text { ias } \\
\text { Sintáctic } \\
\text { as }\end{array}$ & $\begin{array}{c}\text { Número } \\
\text { Acierto } \\
5 \\
\text { minutos } \\
\text { Pre- } \\
\text { Test } \\
\text { Estrate } \\
\text { gias } \\
\text { Sintácti } \\
\text { cas }\end{array}$ & $\begin{array}{c}\text { Errores } \\
5 \\
\text { minutos } \\
\text { Pre- } \\
\text { Test } \\
\text { Estrate } \\
\text { gias } \\
\text { Sintácti } \\
\text { cas }\end{array}$ & $\begin{array}{c}\text { Contest } \\
\text { adas } \\
\text { Pretest } \\
\text { Estrateg } \\
\text { ias } \\
\text { Sintáctic } \\
\text { as } \\
\end{array}$ & $\begin{array}{c}\text { Número } \\
\text { Aciertos } \\
\text { Pre- } \\
\text { Test } \\
\text { Estrate } \\
\text { gias } \\
\text { Sintácti } \\
\text { cas }\end{array}$ & $\begin{array}{l}\text { Errores } \\
\text { Pre- } \\
\text { Test } \\
\text { Estrate } \\
\text { gias } \\
\text { Sintácti } \\
\text { cas } \\
\end{array}$ & $\begin{array}{c}\text { Contest } \\
\text { adas } 5 \\
\text { minutos } \\
\text { Post- } \\
\text { Test } \\
\text { Estrateg } \\
\text { ias } \\
\text { Sintáctic } \\
\text { as }\end{array}$ & $\begin{array}{c}\text { Aciertos } \\
5 \\
\text { minutos } \\
\text { Post- } \\
\text { Test } \\
\text { Estrate } \\
\text { gias } \\
\text { Sintácti } \\
\text { cas }\end{array}$ & $\begin{array}{l}\text { Errores } \\
5 \\
\text { minuto } \\
\text { s Pos- } \\
\text { Test } \\
\text { Estrate } \\
\text { gia } \\
\text { Sintácti } \\
\text { cas }\end{array}$ & $\begin{array}{c}\text { Contest } \\
\text { adas } \\
\text { Postest } \\
\text { Estrateg } \\
\text { ias } \\
\text { Sintáctic } \\
\text { as } \\
\end{array}$ & $\begin{array}{l}\text { Número } \\
\text { Aciertos } \\
\text { Post- } \\
\text { Test } \\
\text { Estrate } \\
\text { gias } \\
\text { Sintácti } \\
\text { cas } \\
\end{array}$ & $\begin{array}{c}\text { Errores } \\
\text { Pos- } \\
\text { Test } \\
\text { Estrate } \\
\text { gia } \\
\text { Sintácti } \\
\text { cas }\end{array}$ \\
\hline P01 & 20 & 4 & 16 & 64 & 10 & 54 & 64 & 15 & 49 & 64 & 15 & 9 \\
\hline P02 & 64 & 54 & 10 & 64 & 54 & 10 & 50 & 45 & 5 & 64 & 55 & 9 \\
\hline P03 & 52 & 5 & 47 & 64 & 7 & 57 & 29 & 19 & 10 & 29 & 19 & 10 \\
\hline P04 & 32 & 24 & 8 & 64 & 39 & 25 & 59 & 55 & 4 & 64 & 56 & 8 \\
\hline P05 & 53 & 50 & 3 & 64 & 61 & 3 & 64 & 62 & 2 & 64 & 62 & 2 \\
\hline P06 & 32 & 32 & 0 & 64 & 63 & 1 & 32 & 32 & 0 & 64 & 63 & 1 \\
\hline P07 & 15 & 2 & 13 & 15 & 2 & 13 & 17 & 11 & 6 & 17 & 11 & 6 \\
\hline P08 & 13 & 8 & 5 & 64 & 41 & 23 & 22 & 11 & 11 & 64 & 36 & 28 \\
\hline P09 & 48 & 23 & 25 & 64 & 27 & 37 & 36 & 28 & 8 & 36 & 28 & 12 \\
\hline P10 & 61 & 55 & 6 & 61 & 55 & 6 & 56 & 51 & 5 & 64 & 58 & 6 \\
\hline P11 & 64 & 55 & 9 & 64 & 55 & 9 & 40 & 28 & 12 & 40 & 28 & 12 \\
\hline P12 & 49 & 44 & 5 & 57 & 51 & 6 & 64 & 57 & 7 & 64 & 57 & 7 \\
\hline P13 & 64 & 55 & 9 & 64 & 55 & 9 & 60 & 47 & 13 & 64 & 50 & 14 \\
\hline P14 & 29 & 0 & 29 & 29 & 0 & 29 & 17 & 11 & 6 & 17 & 11 & 6 \\
\hline P15 & 62 & 56 & 6 & 64 & 58 & 6 & 59 & 56 & 3 & 64 & 61 & 3 \\
\hline P16 & 28 & 18 & 10 & 64 & 41 & 23 & 35 & 28 & 7 & 64 & 50 & 14 \\
\hline P17 & 49 & 4 & 45 & 64 & 5 & 59 & 21 & 14 & 7 & 21 & 14 & 7 \\
\hline P18 & 64 & 61 & 3 & 64 & 61 & 3 & 64 & 63 & 1 & 64 & 63 & 1 \\
\hline P19 & 64 & 52 & 12 & 64 & 52 & 12 & 64 & 57 & 7 & 64 & 57 & 7 \\
\hline P20 & 47 & 37 & 10 & 64 & 55 & 9 & 58 & 50 & 8 & 64 & 56 & 8 \\
\hline P21 & 64 & 59 & 5 & 64 & 59 & 5 & 64 & 61 & 3 & 64 & 61 & 3 \\
\hline P22 & 63 & 58 & 5 & 64 & 59 & 5 & 64 & 61 & 3 & 64 & 61 & 3 \\
\hline P23 & 17 & 5 & 12 & 17 & 5 & 12 & 9 & 9 & 0 & 12 & 12 & 0 \\
\hline P24 & 37 & 12 & 25 & 37 & 12 & 25 & 29 & 13 & 16 & 29 & 13 & 16 \\
\hline P25 & 57 & 4 & 53 & 64 & 5 & 59 & 23 & 23 & 0 & 23 & 23 & 0 \\
\hline P26 & 10 & 10 & 0 & 64 & 58 & 6 & 10 & 10 & 0 & 64 & 58 & 6 \\
\hline P27 & 52 & 48 & 4 & 64 & 60 & 4 & 60 & 52 & 8 & 64 & 54 & 10 \\
\hline P28 & 30 & 3 & 27 & 64 & 6 & 58 & 29 & 29 & 0 & 29 & 29 & 0 \\
\hline P29 & 49 & 48 & 1 & 64 & 63 & 1 & 64 & 63 & 1 & 64 & 63 & 1 \\
\hline P30 & 30 & 3 & 27 & 36 & 6 & 30 & 15 & 6 & 9 & 22 & 9 & 13 \\
\hline P31 & 29 & 29 & 0 & 64 & 29 & 35 & 33 & 33 & 0 & 33 & 33 & 0 \\
\hline P32 & 59 & 52 & 7 & 62 & 55 & 7 & 64 & 61 & 3 & 64 & 61 & 3 \\
\hline P33 & 29 & 17 & 12 & 29 & 17 & 12 & 34 & 23 & 11 & 34 & 23 & 11 \\
\hline P34 & 25 & 7 & 18 & 25 & 7 & 18 & 24 & 11 & 13 & 24 & 11 & 13 \\
\hline P35 & 28 & 6 & 22 & 28 & 6 & 22 & 21 & 15 & 6 & 21 & 15 & 6 \\
\hline Total & 35 & 35 & 35 & 35 & 35 & 35 & 35 & 35 & 35 & 35 & 35 & 35 \\
\hline
\end{tabular}

Tabla 28. Respuestas emitidas y número de aciertos en 5 minutos dados por cada uno de los participantes en PEES (pre y postest). 
Los resultados obtenidos en el pre-test en 5 minutos (tabla 28) indican que la media de preguntas contestadas fue de 42,54 de las cuales fueron acertadas una media de 28,57, esto sitúa a los participantes en un nivel equivalente, según Soriano et al. (2006) a alumnos oyentes dentre el $3^{\circ}$ y y $4^{\circ}$ de Primaria. Estos valores cambian en el pos-test donde vemos que se contestaron una media de 41,54 preguntas de las que se acertaron 34,57, colocandoles si se sigue usando el baremo de Soriano et al. (2006), en un nivel equivalente entre $4^{\circ}$ y $5^{\circ}$ de Primaria.

En la tabla 29 se puede observar como en la prueba de ANOVA demuestra que existe significación entre las respuestas acertadas en el pretest y el postest $(F=7,050 ; p=0,01)$.

\begin{tabular}{|c|c|c|c|c|}
\hline & & $\begin{array}{c}\text { Media } \\
\text { cuadrática }\end{array}$ & $F$ & Sig. \\
\hline $\begin{array}{l}\text { Número Acierto } 5 \\
\text { minutos Pre-Test } \\
\text { Estrategias Sintácticas * } \\
\text { Aciertos } 5 \text { minutos Post- } \\
\text { Test Estrategias } \\
\text { Sintácticas }\end{array}$ & $\begin{array}{l}\text { Inter-grupos (Combinadas) } \\
\text { Intra-grupos } \\
\text { Total }\end{array}$ & $\begin{array}{r}693,746 \\
98,402\end{array}$ & 7,050 & ,001 \\
\hline
\end{tabular}

Tabla 29. Anova de Aciertos en 5 minutos Pretest y Postest Prueba de Estrategias Sintácticas

Estos valores indican que las personas sordas han contestado menos preguntas en el pos-test, pero acertaron más. Después de hacer las actividades con LECTOR, fueron capaces de leer y comprender mejor el contexto de las frases, tardando más en resolver cada pregunta correctamente. Este razonamiento es válido también a la hora de valorar las preguntas contestadas y acertadas en total.

La desviación típica de los aciertos en 5 minutos, es alta, lo que indica un alto grado de dispersión de los resultados, provocado por la baja homogeneidad del grupo. Esta dispersión también queda reflejada en la desviación típica de los errores. 


\subsubsection{Estudio del uso de estrategias sintácticas y semánticas en función del Nivel de Estudios}

En este apartado se analizarán los resultados de la PEES en función de los diferentes niveles de estudios de los participantes.

Estos resultados sitúan, a los participantes en una media de aciertos en función del nivel de estudios, en 28,57 en el Pre-test sobre una media de aciertos de 34,57, en el post-test (tabla 30). Se percibe un suave avance de los resultados, aunque hay que valorar la desviación típica de estas medias, muy elevada en ambos casos. Esto indica que existen grandes diferencias entre miembros participantes antes y después del trabajo.

\begin{tabular}{|c|c|c|c|c|}
\hline & & $\mathrm{N}$ & Media & $\begin{array}{c}\text { Desviación } \\
\text { típica }\end{array}$ \\
\hline \multirow[t]{5}{*}{$\begin{array}{lr}\text { Número } & \text { Acierto } \\
\text { minutos } & \text { Pre-Test } \\
\text { Estrategias } & \text { Sintácticas }\end{array}$} & Sin estudios & 3 & 21,67 & 24,664 \\
\hline & Primaria & 16 & 15,06 & 18,365 \\
\hline & Secundaria & 14 & 43,57 & 16,332 \\
\hline & Universitarios & 2 & 42,00 & 26,870 \\
\hline & Total & 35 & 28,57 & 22,386 \\
\hline \multirow{5}{*}{$\begin{array}{l}\text { Aciertos } 5 \text { minutos Post- } \\
\text { Test } \quad \text { Estrategias } \\
\text { Sintácticas }\end{array}$} & Sin estudios & 3 & 27,00 & 30,315 \\
\hline & Primaria & 16 & 21,50 & 12,559 \\
\hline & Secundaria & 14 & 49,57 & 15,042 \\
\hline & Universitarios & 2 & 45,50 & 24,749 \\
\hline & Total & 35 & 34,57 & 20,330 \\
\hline
\end{tabular}

Tabla 30. Media y desviación típica Aciertos 5 minutos pre/post-test- Estrategias Sintácticas por Estudios

La desviación típica obtenida en las personas sin estudios en los aciertos de 5 minutos en el pre-test nos da un valor muy alto. Este valor indica que en este grupo existen grandes diferencias en el estudio cuantitativo de estrategias sintácticas. En el pos-test en este mismo nivel de estudios la desviación típica aumenta al mismo ritmo que la media de aciertos. Esto indica que sigue habiendo diferencias.

Otro dato muy significativo que se puede resaltar es el aumento de la media de aciertos de las personas con nivel educativo de primaria y secundaria, que indican un aumento homogéneo en ambos casos.

La tabla 31 muestra el estudio de ANOVA demuestra que existen diferencias significativas entre los diferentes grupos en el pre test $(F=6,491 ; p=0,002)$ y en el pos-test $(F=8,384 ; p=0,000)$. Soriano en su investigación del 2004 comprobó que existían diferencias significativas entre los grupos de lectores oyentes en función del nivel educativo alcanzado. En el caso de lectores sordos estas diferencias entre grupos se mantenían. 


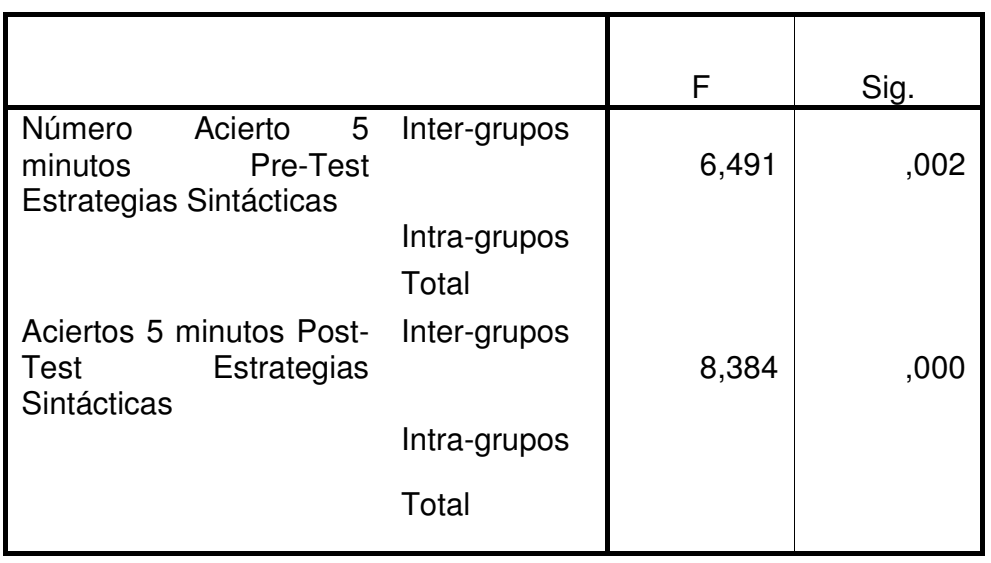

Tabla 31. Prueba de ANOVA número de Aciertos en 5 minutos pre/post test Estrategias Sintácticas por Estudios

\subsubsection{Estudio del empleo de estrategias sintácticas y semánticas en función del Uso de Lenguaje Oral}

Analizando los resultados de la PEES en función de la utilización de Lengua Oral, se puede observar (tabla 32) como las personas que lo usan tienen una mayor media de aciertos 37,17 que los que no lo usan 12,08. Estos valores se repiten en el postest con resultados de 42 contra 20,33. La desviación típica en el caso de personas que no usan lenguaje oral en el pre-test, es muy elevada $(15,774)$, lo que da a entender una gran dispersión de los resultados obtenidos por este grupo.

\begin{tabular}{|c|c|c|c|c|}
\hline & & $\mathrm{N}$ & Media & $\begin{array}{c}\text { Desviación } \\
\text { típica }\end{array}$ \\
\hline \multirow{3}{*}{$\begin{array}{lr}\text { Número } & \text { Acierto } \\
\text { minutos } & \text { Pre-Test } \\
\text { Estrategias } & \text { Sintácticas }\end{array}$} & No & 12 & 12,08 & 15,774 \\
\hline & $\mathrm{Si}$ & 23 & 37,17 & 20,602 \\
\hline & Total & 35 & 28,57 & 22,386 \\
\hline \multirow{3}{*}{$\begin{array}{l}\text { Aciertos } 5 \text { minutos Post- } \\
\text { Test } \quad \text { Estrategias } \\
\text { Sintácticas }\end{array}$} & No & 12 & 2033 & 11773 \\
\hline & $\mathrm{Si}$ & 23 & 42,00 & 20,030 \\
\hline & Total & 35 & 34,57 & 20,330 \\
\hline
\end{tabular}

Tabla 32. Media y desviación típica Acertadas en 5 minutos pre/post-test- Estrategias Sintácticas por Uso de Lenguaje Oral 
Un ANOVA (tabla 33) demuestra que en el pre-test existían diferencias entre los grupos de personas hacen uso del Lenguaje Oral y las que no los usan $(F=13,568$; $p<0,001)$. Esta diferencia se repite en el post-test $(F=11,802 ; p<0.002)$.

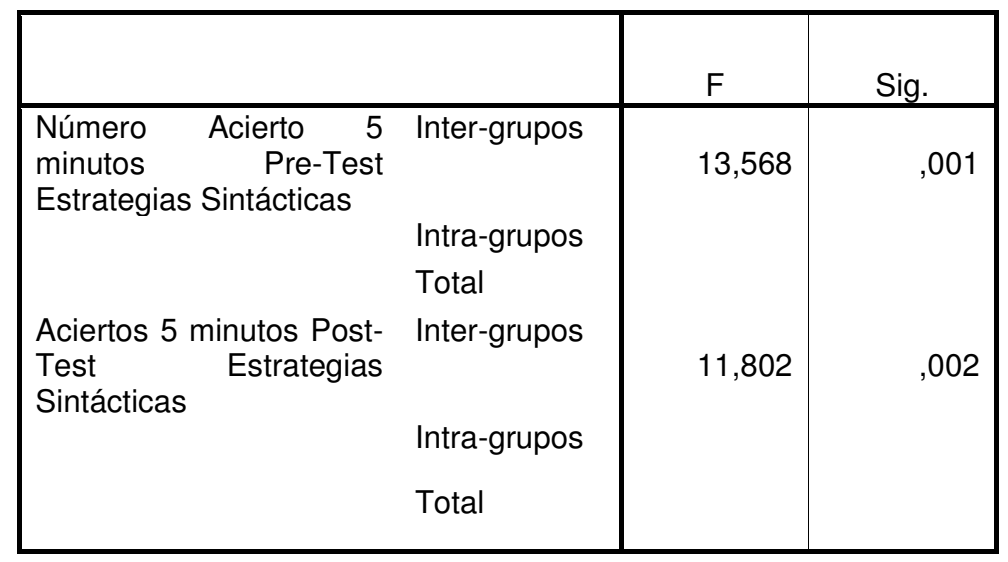

Tabla 33. Prueba de ANOVA número de Aciertos en 5 minutos pre/post test Estrategias Sintácticas por Uso de Lenguaje Oral

Estos resultados también vienen a respaldar lo hallado en otra investigación (Augusto et al., 1999) donde se demostró que las personas con Lenguaje Oral conseguían mejor reconocimiento de las palabras y significado. 


\subsubsection{Estudio del uso de estrategias sintácticas y semánticas en función del Número de Audífonos}

Como sucedía en la prueba de Eficiencia Lectora las personas con audífonos obtienen mejores resultados que los que no lo usan. Los resultados del pos-test nos indican que las progresiones no han sido similares en todos los casos. Los participantes que no utilizan audífonos aumentaron su media de aciertos en casi 7 preguntas, mientras que los que usan un audífono solo aumentaron su media de aciertos en 4 preguntas (tabla 34 ).

\begin{tabular}{|c|c|c|c|c|}
\hline & & $\mathrm{N}$ & Media & $\begin{array}{c}\text { Desviación } \\
\text { típica }\end{array}$ \\
\hline \multirow{3}{*}{$\begin{array}{lr}\text { Número } & \text { Acierto } 5 \\
\text { minutos } & \text { Pre-Test } \\
\text { Estrategias } & \text { Sintácticas }\end{array}$} & 0 & 23 & 19,87 & 20,687 \\
\hline & 1 & 12 & 45,25 & 15,208 \\
\hline & Total & 35 & 28,57 & 22,386 \\
\hline \multirow{3}{*}{$\begin{array}{ll}\text { Aciertos } 5 \text { minutos Post- } \\
\text { Test } & \text { Estrategias } \\
\text { Sintácticas } & \end{array}$} & 0 & ?2 & 2671 & 18860 \\
\hline & 1 & 12 & 49,58 & 13,833 \\
\hline & Total & 35 & 34,57 & 20,330 \\
\hline
\end{tabular}

Tabla 34. Media y desviación típica Acertadas en 5 minutos pre/post-test- Estrategias Sintácticas por Número de Audífonos

Un ANOVA (tabla 35) para comparar medias indica que los valores entre los distintos grupos por números de audiófonos son diferentes $(F=14,017 ; p<0,001)$ en el pre-test. En el pos-test estos valores siguen distintos $(F=13,666 ; p<0,001)$.

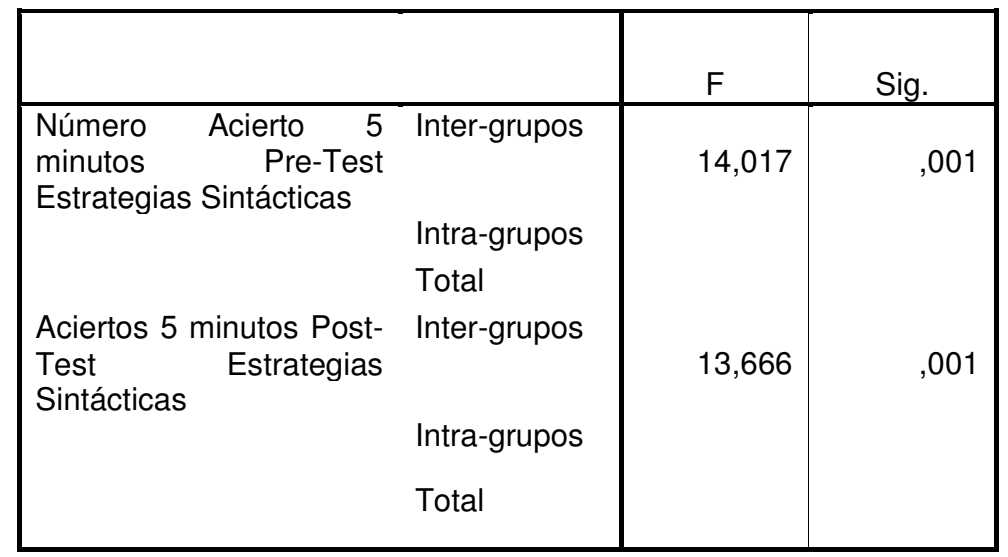

Tabla 35. Prueba de ANOVA número de Aciertos en 5 minutos pre/post test Estrategias Sintácticas por Número de Audífonos 


\subsubsection{Estudio del uso de estrategias sintácticas y semánticas en función del Tipo de Sordera}

Como se puede observar en la tabla 36 , la mayor media de aciertos corresponde a personas con sordera prelocutiva y esta diferencia se mantiene en el pos-test.

Hay que destacar el valor de la desviación típica, que indica el grado de dispersión de alumnos con sordera prelocutiva perteneciente al pre-test donde el valor de la media es 22,96 y su desviación típica es de 20,659.

\begin{tabular}{|c|c|c|c|c|}
\hline & & $\mathrm{N}$ & Media & $\begin{array}{l}\text { Desviación } \\
\text { típica }\end{array}$ \\
\hline \multirow{3}{*}{$\begin{array}{lcr}\text { Número } & \text { Acierto } & 5 \\
\text { minutos } & \text { Pre-Test } \\
\text { Estrategias } & \text { Sintácticas }\end{array}$} & Sordera Prelocutiva & 27 & 22,96 & 20,659 \\
\hline & Sordera Postlocutiva & 8 & 47,50 & 17,833 \\
\hline & Total & 35 & 28,57 & 22,386 \\
\hline \multirow{3}{*}{$\begin{array}{l}\text { Aciertos } 5 \text { minutos Post- } \\
\text { Test } \\
\text { Sintácticas }\end{array}$} & Sordera Prelocutiva & 70 & 000 & 19400 \\
\hline & Sordera Postlocutiva & 8 & 49,13 & 17,200 \\
\hline & Total & 35 & 34,57 & 20,330 \\
\hline
\end{tabular}

Tabla 36. Media y desviación típica Acertadas en 5 minutos pre/post-test- Estrategias Sintácticas por Tipo de Sordera

Los resultados obtenidos indican que las personas con sordera postlocutiva tienen mejores resultados, pero progresan más los alumnos que presentan sordera prelocutiva.

El estudio de ANOVA (tabla 37), indica que entre Sordera Postlocutiva y sordera prelocutiva no hay igualdad de medias en el pre-test $(F=9,203 ; p=0,005)$ y en el postest $(F=6,114 ; p=0,019)$.

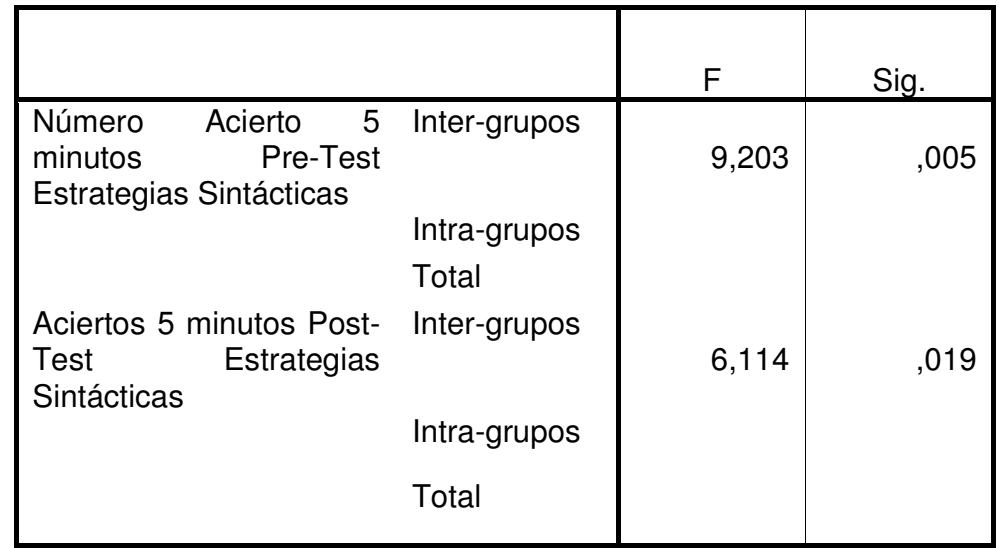

Tabla 37. Prueba de ANOVA número de Aciertos en 5 minutos pre/post test Estrategias Sintácticas por Tipo de Sordera 
De otras investigaciones (Anderson y Freebody, 1979;136), se deduce que los alumnos sordos pueden en algunos momentos leer igual de bien o mal las palabras conocidas que desconocidas (en este caso una palabra infrecuente-tapia), pero comprenden pocas palabras de las categorías menos familiares, derivadas y de parecido ortográfico (como el ejemplo la palabra jugador)

Podemos constatar que en función de los resultados alcanzados, hay un desarrollo de las estrategias sintácticas, después de utilizar una herramienta como LECTOR.

Se puede concluir, de acuerdo con los resultados obtenidos, que hay unos niveles muy bajos de los alumnos sordos al finalizar la escolaridad obligatoria y que la propuesta de utilizar nuevas tecnologías en la educación de personas sordas adultas, favorecen la motivación a la lectura y un mejor nivel en la comprensión de textos.

Queda demostrado desde el punto de vista de Estrategias Sintácticas que LECTOR favorece su utilización y desarrollo, con mayor media para los grupos de usuarios que suelen presentar más problemas para su comprensión. Con lo cual se confirma la hipótesis.

\subsubsection{Relación entre Nivel Lector y uso de Estratégias Sintácticas}

Se puede comprobar, utilizando los gráficos de dispensión que se generan al relacionar el nivel de Eficiencia Lectora con el uso de Estrategias Sintácticas, como en el Pretest (ver figura 10), los resultados indican que existen grandes diferencias entre los participantes, se puede apreciar como un número elevado de participantes obtienen un valor bajo en sus resultados inferior a 10 en la Prueba de Estrategias Sintácticas, mientras que otro grupo se mantiene por encima de 50 en ambas pruebas. 


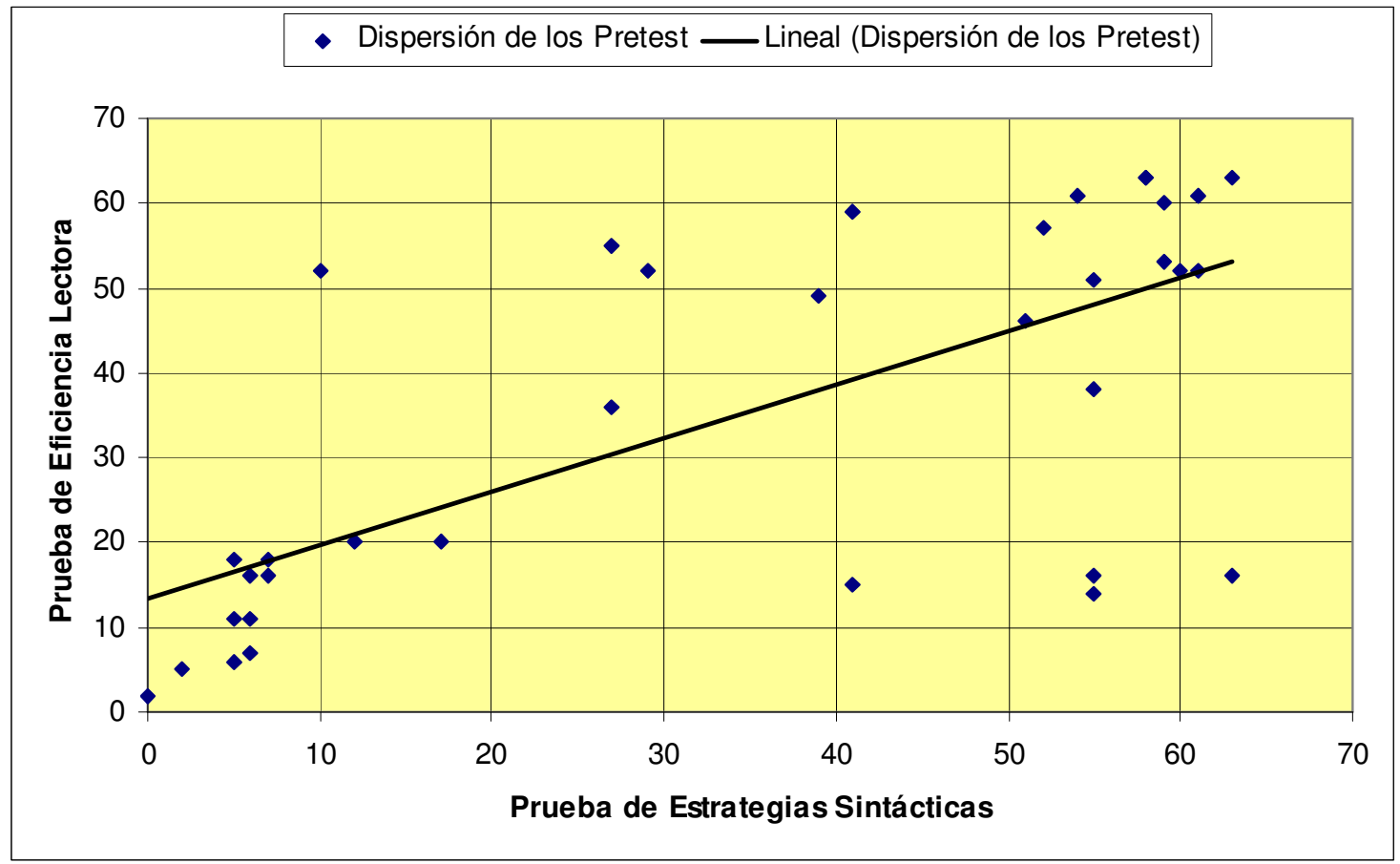

Figura 10. Dispersión en la relación entre Eficiencia Lectora y uso de Estrategias Sintácticas en Pretest.

Si se comparan estos resultados por los conseguidos en el Postest (figura 11), se observa como la muestra evoluciona, el grupo de participantes de menor nivel consiguen mejores calificaciones, haciendo que la dispersión de los resultados disminuya.

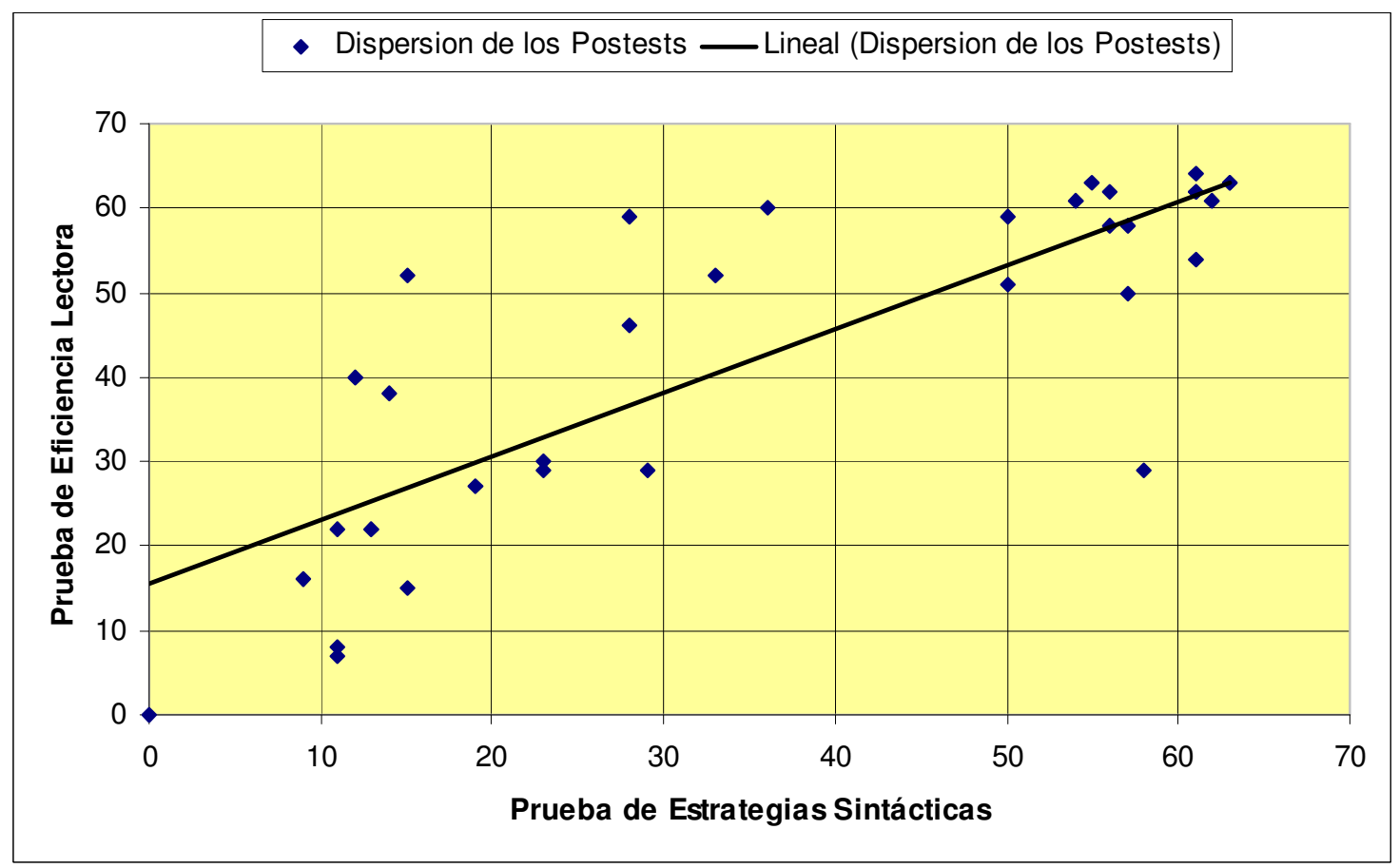

Figura 11. Dispersión en la relación entre Eficiencia Lectora y uso de Estrategias Sintácticas en Prostest. 


\subsection{Discusión General e Implicaciones Educativas}

El aprendizaje de la lectura constituye una de las tareas más importantes a las que se tiene que enfrentar el niño con sordera. Aunque el lenguaje escrito tiene el potencial para suministrar, al niño con sordera, un modo alternativo de comunicación que le permite acceder a mucha información, gran proporción de niños con sordera nunca llegan a alcanzar unos niveles de lectura competentes (Allen, 1986; Asensio, 1989; Conrad, 1979; Di Francesca, 1972; Lewis, 1996; Trybus y Karchmer, 1977, citados en Puyuelo y Alagón, 1999). El $80 \%$ de los adolescentes con sordera son analfabetos, y la fuente principal de estas dificultades es de origen lingüístico. Los niños con sordera leen mal porque conocen mal la lengua oral (Alegría y Leybaert, 1986, citados en Coll, Martín, Mauri y Miras, 1994). Actualmente estos valores han cambiado, porque la tasa de analfabetismo ha disminuido dentro del colectivo de personas sordas, apoyándose sobre las ayudas técnicas y las nuevas tecnologías. Dentro de las nuevas tecnologías, se encuentran las ayudas técnicas, como son audífonos e implantes cocleares, que favorecen que las personas sordas puedan acceder al mundo de oyentes.

Cuando se pretende desvelar las principales dificultades de los estudiantes sordos en el momento de enfrentarse con el aprendizaje de la lectura, uno de los primeros factores que aparece es la competencia lingüística. Para realizar este análisis es fundamental considerar las variables individuales que influyen en la sordera (grado de pérdida, edad de comienzo, sistemas de comunicación, estatus de audición de los padres, etc.), puesto que de ellas depende, en gran medida, el nivel lingüístico que presenta el estudiante sordo y el dominio del lenguaje oral o gestual que posee al iniciar el aprendizaje de la lectura. Para participar de esta investigación, los alumnos proporcionaron ciertos valores (tipo de sordera, edad, profesión, estudios, número de audífonos...) que han servido para definir el grupo, sobre lo que se ha trabajado. Estos datos sirvieron para conocer cada persona.

A lo largo de esta investigación se han evaluado una serie de objetivos generales, conseguir estos objetivos permitirá definir si se confirma o no la hipótesis planteada.

El primero de los objetivos generales requería analizar y definir los niveles de eficiencia lectora y uso de estrategias sintácticas al inicio de la participación en esta investigación. Para ello los participantes han realizado la Prueba de Eficiencia Lectora y la Prueba de Evaluación de las Estrategias Sintácticas comparando los resultados obtenidos con los alcanzados por Soriano (2004). En esa investigación un grupo de lectores oyentes realizó estas mismas pruebas facilitando de esta forma un baremo válido para realizar una comparación con otros lectores, Soriano en su investigación determinó un nivel escolar de lectura basado en los resultados de los alumnos oyentes. En función de este baremo se ha podido llegar a definir el nivel lector presentado por los participantes sordos en esta investigación, cuyo nivel medio en eficiencia lectora, les sitúa en un nivel escolar de lectura entre $2^{\circ}$ y $3^{\circ}$ de Primaria. Soriano sitúa los niveles de eficiencia lectora en niveles equivalentes de $5^{\circ}$ de Primaria o menores, de forma que los participantes en esta investigación, como media, quedan por debajo de estos niveles, aunque dentro de los valores encontrados por Soriano (2004). Respecto al nivel en el uso de estrategias sintacticas, los resultados obtenidos en la primera prueba indican que los 
participantes tienen un nivel medio equivalente a unos oyentes de entre $3^{\circ}$ y $4^{\circ}$ de primaria, confirmando los resultados obtenidos por Soriano et al. (2006).

La revisión llevada a cabo respecto de las habilidades lingüísticas y el fracaso lector de los estudiantes sordos nos permiten tener una perspectiva pormenorizada de la situación de estos estudiantes. Existe un consenso respecto a que los sordos, al concluir su etapa de escolarización, no leen mejor que los oyentes de cuarto grado de enseñanza primaria. Las causas de los desfavorables resultados en comprensión lectora han sido atribuidas a una gran cantidad de motivos. Entre los cuales destacan:

a) que la forma del lenguaje de signos es estructuralmente diferente de la del lenguaje oral.

b) que la experiencia lingüística de los sordos generalmente es limitada.

c) que los estudiantes sordos reciben menor calidad y cantidad en instrucción lectora.

d) que los profesores de sordos tienen un entrenamiento insuficiente en lectura.

e) que los estudiantes sordos presentan restricciones en la competencia lingüística a nivel léxico, sintáctico, semántico y discursivo.

f) Problemas en el plano fonológico del lenguaje

Respecto de las habilidades léxicas, como causantes de las dificultades lectoras, la mayoría de los investigadores coinciden en señalar que los estudiantes sordos disponen de un vocabulario reducido. Esta pobreza de vocabulario se relaciona con el grado de pérdida auditiva y se correlaciona con las habilidades de comprensión lectora. Sin embargo, cabe recordar que la mayoría de las pruebas de vocabulario evalúa exclusivamente lenguaje oral y son escasos los estudios que recogen el vocabulario en lenguaje de signos como medida de la habilidad léxica de una persona sorda. Respecto a las habilidades sintácticas, se ha concluido que los estudiantes sordos desarrollan estructuras sintácticas sencillas, pero dichas estructuras no evolucionan a un nivel superior. Por lo tanto, el conocimiento de vocabulario y el conocimiento sintáctico predicen el éxito en la comprensión lectora. Respecto al nivel semántico y pragmático, se ha comprobado que los lectores sordos pueden usar la información contextual para quitar ambigüedad a algunas estructuras oracionales sencillas.

Ante las dificultades que se pueden presentar en el aula, debido a que la enseñanza ha de establecer un determinado ajuste hacia el alumno con discapacidad auditiva, se debe de contar con un extenso abanico de estrategias y recursos para adaptar el currículum al alumno, para ello, la innovación y la creatividad habrán de estar al servicio del Sistema Educativo para que se pueda contar con un flujo constante de nuevos proyectos en beneficio de la atención hacia el alumno con discapacidad auditiva para que éstos puedan educarse en una igualdad de oportunidades. Es decir, la necesidad de evaluar los conocimientos previos de las personas sordas 
adultas, es imprescindible, para saber adaptar las actividades de acuerdo con las necesidades del grupo.

La falta de eficiencia en la lectura también se atribuye a que, para los niños que se comunican con signos, el lenguaje oral es un lenguaje extranjero (Paul y Gustafson, $1991,54)$. Otros autores han señalado que una posible causa es que los niños sordos no formulan suficientes preguntas cuando se enfrentan a un texto escrito o que tienen menos interacciones con el significado de la lectura durante sus años preescolares (LaSasso, 1993, 436). Por consiguiente, el déficit en la competencia lingüística se postula como uno de los principales factores del fracaso lector de los estudiantes sordos. La investigación llevada a cabo demuestra que los alumnos en edad adulta, aún teniendo un bajo nivel lector, si motivados por medio de actividades, pueden mejorar su competencia lingüística y obtener un mejor nivel lector.

Asimismo, Limbrick, McNaughton y Clay (1992, 308-314) destacan dos explicaciones atribuidas a los bajos niveles de lectura obtenidos por los estudiantes sordos:

- Déficit lingüístico global del lenguaje oral observado en las personas sordas

La pobreza lectora puede estar relacionada con la calidad y cantidad de la instrucción lectora que reciben. En este sentido, los datos aportados por estos autores coinciden con los de King y Quigley (1985, citados en Limbrick, McNaughton y Clay 1992), al recalcar que los profesores de los niños sordos no reciben la instrucción suficiente en las metodologías de la enseñanza de la lectura.

Por ello, los investigadores explican que los problemas de lectura presentados por los niños sordos no son específicos de la lectura, sino el reflejo de un déficit global en su conocimiento léxico, sintáctico, semántico y pragmático del lenguaje oral, que limita sus progresos en el aprendizaje de la lectura. En este sentido, Alegría y Leybaert (1989, citado en Villalba) señalan que la impotencia lingüística constituye el principal obstáculo en la adquisición de la lectura por parte de los sordos. Argumentan que el problema central del sordo, comparándolo con el mal lector, es que ninguno de ellos transforma el texto escrito en una representación fonológica. La carencia lectora representada por los alumnos que han participado en esta investigación, muestran un bajo nivel lector, vienen a corroborar los resultados obtenidos por Alegría y Leybaert.

Mies $(1992,204)$ señala que una situación frecuentemente observada entre los estudiantes de su estudio es la utilización de la acepción de una palabra determinada en un contexto en donde es evidente que hay que elegir otra acepción semántica. También observa confusiones de palabras similares que nada tienen que ver con el contexto. Agrega que dichas dificultades contribuyen a hacer más difícil el acceso al significado de las palabras y en definitiva a la comprensión global del texto. La autora aclara que los sordos suelen fijarse en las palabras que les son familiares, independientemente de su relevancia dentro del texto, que actúan con superficialidad y que son poco reflexivos al adjudicar significado a las palabras. De igual manera los resultados obtenidos también dan la razón a los resultados de Mies, donde indica que las personas sordas fijan en palabras que les son familiares, 
cuando realizan la lectura de una frase. Estas dificultades contribuyen a que estos alumnos tengan menos acceso al significado de las palabras, dentro de un contexto. Esto las lleva a cometer errores, al ser poco reflexivos y realizar una lectura superficial.

Analizando los resultados se llegó a la conclusión de que realizan un tipo de lectura superficial de las frases. Este análisis, indicó que analizan solamente el contexto general, no interpretan el sentido de las oraciones, se centran sobre las palabras más representativas de las frases y seleccionan la opción que más relación tiene con esa palabra representativa. En la mayoría de las situaciones se comprobó que realizan asociaciones mentales basadas en imágenes, provocado por la falta de representaciones auditivas. En anteriores investigaciones se ha demostrado que las personas que tienen menor conocimiento del significado de las frases a menudo son malos lectores.

Por ejemplo: Decidió llevar perilla para parecer... (Guapo, ser, mayor, moderno) Los resultados obtenidos indicaron que la opción más elegida fue" guapo", asociando la perilla como palabra representativa de la oración con una imagen visual (guapo).

Cuando dotan de un significado erróneo a la palabra escrita, este fallo no se produce por haberla percibido globalmente, pues la regla de correspondencia grafemafonema está bien aplicada, sino al dotar a la palabra leída de un significado.

Muchos de los datos analizados en esta investigación se asemejan a otras investigaciones realizadas por Schirner (2001, citado en Domínguez, 2006), cuando detectó las siguientes conclusiones en estudios realizados con alumnos sordos:

- Las dificultades que tienen las personas sordas en la comprensión y producción de las estructuras sintácticas de la oración, sobre todo a medida que éstas son más compleja (Quigley y Paul, 1984). La percepción parcial del habla que tienen estos alumnos hace que normalmente identifiquen las palabras de contenido (verbo y sustantivos) y en menor medida las palabras funcionales (preposiciones, artículos).

- Estas dificultades con la sintaxis pueden ser un factor menos importante para la comprensión que las habilidades de reconocimiento de la palabra.

- Las dificultades sintácticas pueden disminuir la habilidad de los niños sordos para aplicar su conocimiento de vocabulario mientras leen.

- Los contextos limitados (tales como historias breves) son más difíciles de comprender para los niños sordos que los contextos amplios (historias largas o novelas).

- El material reescrito, controlando la longitud y complejidad de las oraciones puede ser más difícil de entender por los alumnos sordos debido a la ausencia de coherencia textual.

El conocimiento de vocabulario y de la sintaxis de este grupo de adultos sordos constituye una dificultad importante para el aprendizaje de la lengua escrita y el progreso en ese conocimiento no se produce posteriormente dadas las recíprocas relaciones que se establecen entre el conocimiento de la lengua y la habilidad en lectura (el llamado "efecto Mathew"; Stanovich, 1986), es decir, el conocimiento 
pobre de la lengua escrita puede producir unas habilidades lectoras también pobres y, como consecuencia, estas dificultades en la lengua escrita privan a estos adultos sordos de una fuente importante de conocimiento lingüístico.

Sin embargo, el hecho de que algunos sordos tengan buenas habilidades en lenguaje oral, pero limitadas habilidades en lectura, sugiere que los problemas en lectura de esta población no resultan simplemente de deficiencias en el lenguaje oral, sino que pueden estar asociadas a deficiencias en los procesos cognitivos específicos implicados en la lectura. En este sentido, se ha descubierto que la habilidad para reconocer palabras de forma rápida y exacta está relacionada con el logro lector. Existe consenso entre los investigadores en que la relación entre reconocimiento de palabras y logro lector no está suficientemente desarrollada en los sordos.

Al analizar estas investigaciones, es posible constatar que existe una fuerte relación entre habilidad lingüística y logros en lectura. Como se ha señalado, una explicación de ello es que los problemas de lectura de los sordos se originan en un déficit lingüístico global. Sin embargo, como argumenta Stanovich (1986), existen diversas otras interpretaciones posibles cuando se descubre una correlación entre logro lector y alguna otra habilidad cognitiva. La relación puede ser una "causa recíproca". Es decir, no sólo una mejor habilidad lingüística contribuye al logro lector, sino que el aumento de la experiencia con el lenguaje escrito contribuye a desarrollar habilidades lingüísticas. Asimismo, es posible que la correlación entre lectura y lenguaje resulte, debido a que ambas están relacionadas a una tercera variable.

El segundo de los objetivos marcados: Diseñar actividades para la enseñanza de estrategias sintácticas y mejorar la eficiencia lectora aplicando recursos educativos basados en las nuevas tecnologias, formando el curso LECTOR, planteando la hipotesis de que el trabajo con estas actividades TIC, favorecen el desarrollo de estrategias sintacticas y aumenta la eficiencia lectora. Se ha comprobado la utilidad que este tipo de actividades presenta para la educación de este colectivo de personas. La eficiencia o no de este curso vendrá demostrado a continuación, cuando se evalue el tercero de los objetivos. Independientemente de estos resultados se puede considerar que el trabajo que los participantes han realizado con estas actividades basadas en nuevas tecnologías ha sido todo un éxito gracias a la buena aceptación que los participantes tuvieron desde el principio.

La hipótesis planteada en el tercero objetivo se demuestra después de evaluar a los participantes una vez finalizado el trabajo con LECTOR. De esta forma se ha demostrado que los participantes aumentaron su nivel de eficiencia lectora pasando a situarse con una media de 40,69 aciertos en un nivel de estudios equivalente, según Soriano (2004) a niños oyentes de $4^{0}$ de Primaria. En este aspecto y recordando los resultados obtenidos al comienzo de la investigación, se observa una significativa mejoría. Respecto al uso de estrategias sintacticas los resultados indican que una vez que los participantes han trabajado con lector, aumenta su nivel del uso de estrategias sintacticas, pasando de tener un nivel equivalente a alumnos oyentes dentre $3^{\circ}$ y $4^{\circ}$ de Primaria a ubicarse en un nivel de $4^{\circ}$ y $5^{\circ}$ de Primaria, basandose siempre estos resultados obtenidos por Soriano et al. (2006). Quedando demostrada la hipótesis de esta investigación. 
Dentro de este marco, este proyecto ha pretendido difundir recursos educativos TIC existentes para personas con discapacidad auditiva, con la finalidad directa de favorecer la utilización de LECTOR, que ha aumentado el nivel lector de este grupo de Personas Sordas Adultas, colaborando en la integración social de este colectivo, para que adquiriesen mejores estrategias de lectura y mayor independencia en su contexto laboral y social

Participar y hacer participe al colectivo de personas sordas de las nuevas tecnologías ha servido para encontrar un nuevo medio de comunicarse y relacionarse entre ellos, consiguiendo una integración social fuera de las Asociaciones. La integración en este caso es debido a la flexibilidad conseguida por Internet.

Con la utilización del recurso que representa LECTOR, se perciben tres características muy significativas: la innovación, la imaginación y la creatividad que son tres factores que confluyen en las nuevas tecnologías y más concretamente en Internet. Y como instrumentos innovadores presentan una serie de características: Interactividad, que permite la posibilidad de dialogar con el programa, utilizando potentes funciones de búsqueda, indagación, experimentación, etc. que superan las posibilidades de recursos más tradicionales; Modularización de la información , por cuanto se puede acceder a ella desde diferentes puntos; y por último, Acceso multiusuario, independientemente de factores espacio-temporales, pudiendo ser utilizado una misma aplicación por muy diferentes personas en el mismo momento y desde ubicaciones remotas.

LECTOR, creado a partir de las actividades Jclic integradas en Moodle, puede ser adaptado no solo a Personas con discapacidad sensorial, puede extenderse a otras discapacidades mentales y físicas. Lo importante es que en el análisis de los resultados sea evaluado detalladamente la necesidad de cada persona para adaptar las actividades de acuerdo con sus dificultades de lecto-escritura. Estas actividades pueden ser creadas a partir de libros de enseñanza del español a extranjeros, que delimitan grupos de actividades centradas en los niveles de aprendizaje de cada grupo de alumnos. Estas actividades se apoyan en una base científica con fundamentación teórica y con resultados contrastados, que demuestran que es posible aprender español gracias al trabajo continuo con estas actividades.

Se han cumplido los objetivos de diseñar LECTOR y diseñar actividades para la enseñanza de estrategias sintácticas a través de LECTOR. Y es que LECTOR contiene todas las herramientas que han sido necesarias para la realización de esta investigación. El curso, contiene un juego de actividades educativas creadas a partir de cursos de español para extranjeros, adaptadas a las necesidades específicas de la muestra, de acuerdo con su nivel lector, también se han utilizado dos de los cuatro programas de enseñanza de habilidades metalingüísticas desarrollados por Clemente y Domínguez $(1999,148,170)$, programa de omisión de fonemas y programa de identificación de fonemas. Algunas de las actividades están dirigidas para la realización de tareas metafonológicas, además de los programas citados anteriormente, también se han usado actividades del Proyecto de trabajo "Los animales" cuya experiencia se viene realizando desde el curso escolar 1999/2000 en un Centro de Sordos de Madrid, el Colegio Hispano-Americano de la palabra. Un 
ejemplo de este tipo de actividades es aquella en la que se trabaja con la omisión de silaba en todas las posiciones de la palabra, final, inicial y medio (Domínguez 2006, 138 y 139).

La muestra de personas, se ha encontrado cómoda trabajando con una aplicación informática a través de Internet. Internet es algo muy utilizado pero su utilización para trabajar con actividades educativas fue para este colectivo toda una novedad. La facilidad para utilizar las actividades de forma privada, pudiendo realizar actividades todas las veces que fueran necesarios y desde sus propias casas, provocó una gran aceptación. Este nivel de aceptación aumentó su motivación para seguir trabajando sobre la mejora de su nivel lector. No fue necesario realizar ningún tipo de curso para la utilización de la herramienta, el trabajo con LECTOR era el objetivo y los participantes aprendieron a trabajar con la aplicación indirectamente. El hecho de ir a los Centros y tener un contacto físico con los participantes y explicar la función de las actividades, hizo que hubiera una mejor mayor acercamiento de los alumnos a las actividades propuestas. Con la explicación en Lengua de Signos por parte de los monitores, los alumnos tuvieron más confianza, sintiéndose seguros y entendiendo la explicación de lo que era LECTOR.

Respecto a la participación, ha quedado reflejado el bajo grado de motivación que presentan los socios de las distintos Centros. Cabe destacar como de los 430 socios, solo acabaron participando 35 personas lo que supone un $8.1 \%$. Esta falta de interés tiene varias posibles lecturas:

- Falta de motivación

- Resistencia para realizar pruebas y exámenes

Continuamente, a lo largo del trabajo con LECTOR se ha mantenido un contacto continuo con los participantes, enviándoles a cada momento sus resultados y sus niveles de lectura. De esta forma se ha conseguido incentivarles para que no dejasen de trabajar las actividades. Existen diferentes estudios que demuestran que si se entrena a los alumnos en actividades de auto-evaluación, supervisión y planificación mejora su rendimiento (Palincsar y Brown, 1984, citados en Sánchez, 1998).

Se ha demostrado que las personas sordas adultas han obtenido pequeñas mejoras; hay que tener en cuenta que el progreso no ha sido muy grande, pero si se ha comprobado que existe una mejora leve, en la compresión y eficiencia lectora después de haber trabajado las actividades que forman LECTOR.

Por lo tanto, los resultados cosechados, relativos al nivel obtenido por los lectores sordos adultos, parecen indicar que se confirma la hipótesis que manejamos, es decir, que LECTOR, es una herramienta valida para el desarrollo de estrategias sintácticas y semánticas para las personas sordas adultas.

En el último tiempo ha prosperado la idea de investigar las correlaciones entre logro lector y habilidad lingüística en los sordos, utilizando un diseño de investigación longitudinal. Con el fin de establecer con mayor claridad y en forma más definitiva la dirección de esta relación. Dicho diseño longitudinal permitiría estudiar ampliamente 
el lenguaje infantil y las habilidades cognitivas antes de iniciar el aprendizaje de la lectura; de este modo sus progresos serían estudiados intensivamente durante las primeras etapas de adquisición.

De este ensayo se desprende que la enseñanza de la lectura en los sordos debería comenzar de forma temprana; de esta forma se refuerza la relación entre habilidades lingüísticas en lenguaje oral y logros en lectura. Por otro lado, si una buena habilidad en lenguaje oral es prerrequisito para aprender a leer, entonces los niños sordos deberían tener un cierto grado de dominio de estas habilidades antes de comenzar la instrucción lectora

Promocionar el hábito de la lectura desde edades tempranas influye no sólo en la capacidad lectora sino en el desarrollo integral del niño o niña.

Antes de los 2 años la lectura significa la toma de contacto con el texto impreso, comenzando por diferenciar dibujos y objetos de las grafías, conocer que ambos se relacionan entre sí, y más adelante empezar a conocer la estructura de las historias narradas, que contienen principio, desarrollo y final. A nivel cognitivo-emocional, la lectura emergente significa acercarse a otras realidades $y$, aunque muy ligada a los sentidos (estadio sensorio-motor), es transmisora de emociones (a través de las voces, el tono...).

Cuando la lectura aparece, surge la necesidad de acercarse y familiarizarse con un nuevo objeto lúdico que es el libro, para el cual se puede dedicar un momento mágico del día. A partir de los 2 años, el niño deja de ser prelingüístico, por lo que esta lectura emergente se dirige ahora hacia el progreso del lenguaje y al enriquecimiento de su vocabulario. Con ello se va formando los cimientos para el posterior desarrollo de la lectura. Cuando el niño inicie el aprendizaje de los grafemas (algunos expertos afirman que debería ser a partir de los 3 años) empezará, a su vez, la interpretación de que esos pequeños trazados son las letras. A partir de este momento se abre un camino de infinitas posibilidades para el desarrollo de la persona. Incluso la lectura pasará a convertirse en un acto individual, privado, en el que el niño o niña disfruten de los mundos mágicos de las lecturas y sigan desarrollándose como personas a partir de los libros y por ellos mismos.

Se puede constatar que el empleo de la lengua de signos en los modelos educativos bilingües está permitiendo impulsar la enseñanza-aprendizaje del lenguaje escrito como segunda lengua, aprovechando la competencia lingüística en la lengua de signos, lo cual puede repercutir en una serie de aspectos que provocan que la situación de partida de los alumnos Sordos al iniciar el aprendizaje de la lectura y la escritura sea bastante diferente a la que presentan los niños educados en una opción monolingüe

Durante esta investigación, al trabajar la aplicación LECTOR con los alumnos adultos sordos, la lengua de signos sirvió como una mediadora del aprendizaje, durante la realización de las actividades se fueron presentando dudas, estas dudas eran planteadas a los educadores de cada Asociación quienes las resolvían haciendo uso de la Lengua de Signos. Esta práctica ha facilitado que los alumnos 
tuviesen una mejor comprensión de las frases y pudiesen obtener mejores resultados en el post-test.

Se puede comprobar que la Lengua de Signos resulta una herramienta imprescindible, ya que muchos textos presuponen ciertos conocimientos que en algunos casos no están en la mente del lector Sordo, por lo que es necesario indagar sobre lo que los alumnos conocen y aportarles la información que necesiten para enfrentarse al nuevo texto. Con la aprobación de la nueva Ley por la que se reconocen las lenguas de signos españolas y se regulan los medios de apoyo a la comunicación oral de las personas sordas, con discapacidad auditiva y sordociegas, se ha dado un paso adelante en relación con la integración de las Personas Sordas.

Conseguir los objetivos generales implica poder demostrar si la hipótesis planteada es válida y en este momento se puede decir que se han alcanzado todos los objetivos que se marcaron en su inicio. El objetivo inicial de esta tesis pasaba por determinar el nivel lector de los participantes, evaluar el tipo de estrategias utilizadas por los participantes, diseñar LECTOR creando actividades educativas para la enseñanza de estrategias sintácticas, desarrollar estas actividades con el grupo de participantes y evaluar la eficacia de estas actividades demostrando así que LECTOR es una herramienta educativa válida.

Como ya se ha indicado anteriormente parte del contenido de las actividades mostradas forman parte del Programa de enseñanza de habilidades metalingüisticas creado por Clemente y Domínguez (1999). La utilidad de programas de este tipo con sujetos que presentan dificultades de aprendizaje de la lectura ya ha sido comprobado también de forma experimental. Por ejemplo, los trabajos de Rueda (1993, citado en Clemente y Domínguez, 1999) y Rueda, Sánchez y González (1990, citados en Clemente y Domínguez, 1999) muestran que entrenar a niños disléxicos en habilidades de segmentación mejora sus capacidades de conocimientos fonológicos y su escritura. Entrenar estas habilidades con personas adultas sordas a través de actividades de este tipo resulta, observando los resultados obtenidos, un recurso válido para la educación lectora de este colectivo de personas.

Para concluir, indicar que los resultados obtenidos vienen a demostrar que el colectivo de Personas Adultas Sordas mostraban unos niveles lectores bajos, y que el trabajo que ellos han realizado sobre un entorno educativo basado en nuevas tecnologías, ha dado sus frutos en un periodo de tiempo relativamente pequeño. Si este trabajo se realizara de forma constante y durante un periodo de tiempo más prolongado, se deberian lograr mejores resultados. 


\section{BIBLIOGRAFÍA}

Acosta, V.M (Dir.) (2006). La sordera desde la diversidad cultural y lingüística: Construyendo centros inclusivos en la educación del alumnado con sordera. Barcelona: Editorial Masson.

Acosta, V.M y Moreno, A.M. (2003). Dificultades del lenguaje: una perspectiva educativa. Madrid: Editorial Bordón.

Aguado, G., Ripoll, J.C. y Domezáin, M. J. (2003). Comprender el Lenguaje Haciendo Ejercicios. Madrid: Entha Ediciones.

Alba, C., y Sánchez, M.P. (1996). La utilización de recursos tecnológicos en los contextos educativos como respuesta a la diversidad. En Gallego, D, Alonso, C y Cantón, I (Coords.) Integración curricular de los recursos tecnológicos. Barcelona: Oikos-Tau, 351-376.

Alcantud, M. F. y Soto. P. F. J. (2003). Tecnologías de ayuda en personas con trastornos de comunicación. Colección Logopedia e Intervención. Valencia: Editorial Nau Libres.

Alegría, J. y Leybaert, J. (1985). Adquisición de la lectura en el niño sordo: un enfoque psico-lingüístico. Investigación y Logopedia. III Simposio de Logopedia. Madrid: CEPE, 83, 211-232.

Alegría, J. (1999). Condiciones de la Adquisición de la Lectura en el niño Sordo. Revista Logopedia Foniatría y Audiológica, XIX, 3, 126, 128, 130.

Almirall, R., Ardanuy, M., Casanova, J., Cedillo, P., Cervantes, C., Frigola, S., Fuertes, C., Galcerán, F., González, M., González, I. J Valmaseda, M. B., Molins, E., Muño, E., Pájaro, N., Rexach, M., Rodríguez, P., Valmaseda, M. B. y Vinardell, M. (1998). Experiencias Bilingües en la educación del niño sordo. Barcelona: Editora Mayo.

Alonso, P. (1995). Personas con Discapacidad. Perspectivas psicopedagógicas y rehabilitadoras. Madrid: Editorial Siglo XXI.

Andrews, J. F., y Masson, J. M. (1991). Strategy usage among deaf and hearing readers. Exceptional Children, 9, 537, 538, 540.

Anguera, M.T. (1999). Psicología Clínica: Aplicaciones. Barcelona: Universidad de Barcelona.

Arancibia, V., Herrera P., Strasser, K., (1999) Psicología de la educación. México: Editorial Alfaomega.

Ardila, A. (1991). Errors resembling semantic paralexias in spanish-speaking aphasics. Brain and Language, 41, 437. 

en Castilla y León 
Augusto, J.M., Adrián, J.A. y Martínez de Antoñana, R. (1999). Estudios sobre el conocimiento fonológico en los niños sordos. En Velasco, C. y Domínguez, A. B. Lenguaje escrito y sordera: Enfoques Teóricos y Derivaciones prácticas. Salamanca: Universidad Pontificia de Salamanca.

Balow, B., Fulton, H. y Peploe, R. (1971). Reading comprehensión skills among hearing-impaired adolescents. Volta Review, 73, 113-119.

Bebko, J. (1998). Learning, language, memory and reading: The role of language automatization and its impacted on complex cognitive activities. Journal of Deaf Studies and Deaf Education, 3(1), 4-13.

Bellés, R., y Teberosky, A. (1989). Producción e interpretación de textos escritos por niños sordos pequeños integrados en escuelas ordinarias. Convocatoria de Proyectos de Investigación Educativa. Didáctica. Madrid.

Belles, R. (2000). La construccio interactiva de l'escriptura en nens i nenes sords petits mitjancant la dactilología. Support. Revista Catalana d’Educació Especial i Atenció a la Diversitat, 40, 69-70.

Belloch, C. (2006). VISHA (Visualización del Habla). Extraído el 12 de Agosto de 2008 desde www.uv.es/bellochc/pdf/visha.pdf.

Betancourt, J., (2001). Sistema didáctico interactivo para la enseñanza de los mecanismos en diseño industrial. Tesis para optar por el grado de Doctor en Diseño en la Línea de Nuevas Tecnologías. México: Universidad Autónoma Metropolitana.

Bisquera Alzina, R. (1996). Orígenes y desarrollo de la orientación psicopedagógica. Madrid: Editorial Nancea.

Bork, A. (1986). El ordenador en la enseñanza. Análisis y perspectivas de futuro. Barcelona: Editorial Gustavo Gili.

Bradley, L., y Bryant, P.E. (1978). Difficulties in auditory organisation as a possible cause of reading backwardness. Nature, 271, 746.

Bravo Valdivieso, L. (2004). La conciencia fonológica como una posible "zona de desarrollo próximo" para el aprendizaje de la lectura inicial. Revista Latinoamericana de Psicología, 36, 21-32.

Cabero, J., Salinas, J., Duarte, A., Domingo, J., (2000) Nuevas tecnologías aplicadas a la educación. Madrid: Ed. Síntesis.

Carmona, M., Gómez, A. y González, J. M. (1998). Psicología del lenguaje. Investigación y Teoría. Madrid: Editorial Trotta, S.A.

Carrillo, M y Marín, J. (1997). Prueba de Eficiencia Lectora. Documento interno sin publicar. Universidad de Murcia. 
Caselli, C., y Pagliari, L. (1991). La competenza linguistica di bambini e adulti sordi nella lingua e scritta. Scuola e Didactica, 91, 70.

Caselli, C., Masoni, P., Ursono, M., Pace, C, y Skliar, C. (1996). La competencia narrativa en los niños sordos: estrategias morfosintácticas, de coherencia y cohesión del texto. Buenos Aires: Fono Audiología, 70

Castañeda, S., Almaguer, M. (1993). Manual para el curso de Psicología cognitiva. México: Ed. ITESM.

Clemente, M. y Domínguez, A. B. (1999). La enseñanza de la Lectura Enfoque psicolingüístico y sociocultural. Madrid: Ediciones Pirámide.

Coll, C., Martin, E., Mauri T. y Miras, M. (1994). El Constructivismo en el Aula. Barcelona: Colección Biblioteca de Aula. $2^{\circ}$ edición.

Coltheart, M. (1980). Deep dyslexia: a review of the syndrome. In M. Coltheart, K. E. Patterson \& J. C. Marshall (eds.), Deep dyslexia. London: Routledge \& Kegan Paul.

Cuetos, F. (2006). Psicología de la lectura. Madrid: Praxis grupo Wolters Kluwer España S.A. Sexta edición.

De Castro, C. (2006). Desarrollo de Estrategias Sintácticas en Lectura en Personas Sordas Adultas a través del Programa Lector. Universidad de Salamanca. Tesina no publicada.

De Mejia, A. y Tovar, L.A (1999). Perspectivas Recientes Del Bilingüismo Y de La Educación Bilingüe En Colombia. Universidad del Valle.

De Vega, M y Cuetos, F. (1999). Psicolingúistica del español. Madrid: Editorial Trotta, S.A.

De Vega, M., Carreiras, M., Gutiérrez-Calvo M. y Alonso, M. L. (1990). Lectura y comprensión. Una perspectiva cognitiva. Madrid: Alianza Editorial. Universidad de la Laguna.

Dhondt, J. (1998). La Alta Edad Media. Vol: 10. Madrid: Editorial Bruño.

Díaz, J. (1996). Para leer mejor. Madrid: Editorial Bruño.

Díaz-Estébanez, E. y Valmaseda, M. (1995). En el camino hacia una educación de calidad para alumnos sordos. Infancia y aprendizaje. 69-70, 45-60.

Diez, B. y Alonso, M. I. (1993). Lectoescritura. Una propuesta para alumnos/as con necesidades educativas especiales. Madrid: Editorial Escuela Española.

Dijk, V. (1978). La ciencia del texto. Barcelona: Paidos. 
Domínguez, A. B. (1994). El aprendizaje de la lectura en los niños sordos. Una revisión del estado actual de la investigación. Conferencia inaugural curso 1994-95 de la Escuela de Logopedia. Universidad Pontificia de Salamanca.

Domínguez, A.B. y Alonso Baixeras, P. (2004). La educación de los alumnos sordos hoy. Perspectivas y respuestas educativas. Málaga: Ediciones Aljibe.

Domínguez, A. B. (2006). La Lengua escrita en los alumnos sordos en Acosta (Dir). La sordera desde la diversidad cultural y lingüística: Construyendo centros. Barcelona: Editorial Masson.

Dyson, A. (1990). The word and the world. Reconceptualizing griten language development. Paper presented AERA. Boston.

E.I. Piruetas (2002). Niños sordos y oyentes compartiendo la vida. Aula de Educación Infantil. Escuela infantil Piruetas.

Ewoldt, C. (1981). A psycholinguistic description of selected deaf children reading in sign language. Reading Research Quarterly, 17(1), 58-89.

Fernández-Escandón, I (n.d). DI. Ministerio de Educación, Política Social y Deporte. Centro Nacional de Información y Comunicación Educativa. Extraído de http://w3.cnice.mec.es/recursos/pntic98/fichas/di.htm el 14 de Agosto de 2008.

Fernández M. P. (1992). Interacción social y comunicación verbal en bebés. Revista Logopedia Foniatría y Audiológica, 11(1): 10-18.

Fernández, M. P. (1992): Los inicios de la comunicación y la sordera prelocutiva. Estado de la cuestión. Revista de Logopedia, Foniatría y Audiología. 12(2), 93-103.

Fernández, M. P. (1993). Estrategias comunicativas en el niño sordo en contexto familiar. Interacción comunicativa. Díadas homogéneas y díadas heterogéneas [tesis doctoral]. Barcelona: Universidad de Barcelona, 30.

Fernández, M. P. (1994). Sordera y comunicación en contextos lingüísticos diferentes. El Faro del Silencio 1994, 137 y 138.

Fernández, M.P. y Pertusa. (1995). Reflexiones sobre la escritura y la alfabetización de los niños sordos. Departament de Psicologia Evolutiva i de l'Educació. Universitat de Barcelona.

Ferreiro, E., y Teberosky, A (1991). Los sistemas de escritura en el desarrollo del niño. México: Siglo XXI.

Ferrer, A. M., Andréu, A. B., Martínez, M. C., Asensi, M.C. y Romero. R. (2004). LEECOM: Programa de instrucción de la comprensión lectora para personas sordas (Incluye CD). Universitat De Valencia. Servei De Publicacions. 
Ferrer, A.M. (2002). Las Tecnologías de Ayuda en la respuesta educativa del niño con discapacidad auditiva. II Congreso Nacional de Nuevas Tecnologías y Necesidades Educativas Especiales. TECNONEET 2002. Murcia. Extraído de http://acceso.uv.es/Unidad/pubs/2002-tecnoneet/index.html el 12 de Agosto de 2008.

FIAPAS. (2002). I Congreso Europeo de Familias de Deficientes Auditivos. Libro de Ponencias. Madrid: FIAPAS.

FIAPAS. (2004). Manual Básico de Formación Especializada sobre Discapacidad Auditiva. Madrid: FIAPAS.

Flexer, C., Wray, D., Millin, C. J. y Leavitt, D. (1993). Mainstreamed college students with hearing loss: Comparison of receptive vocabulary to peers with normal hearing. Colta Review, 95(2), 125-133.

Furth, H. (1981). Pensamiento sin lenguaje: Implicaciones psicológicas de la Sordera. Madrid: Ediciones Marova, S.L.

Gaines, R., Mandler, J. y Bryant, P. (1981). Immediate and delayed story recall by deaf children. Journal of Speech and Hearing Research, 24, 463-469.

Gallego, C. (2000). Aproximación histórica conceptual a la metodología de la enseñanza de la lectura. Wold Association of Early Childhood Educators: Wold Conference on Reading and Writing. Valencia, España, 20.

García, F.J. (2005). Estado actual de los sistemas e-learning. Teoría de la Educación: Educación y Cultura en la Sociedad de la Información. Volumen 6 (2) Ediciones Universidad de Salamanca. Extraído el 26 de Agosto del 2008 de http://www.usal.es/ teoriaeducacion/

García, F.J. y García, J. (2002). Los espacios virtuales educativos en el ámbito de Internet: un refuerzo a la formación tradicional. Educación y Cultura en la Sociedad de la Información. Volumen 3. Ediciones Universidad de Salamanca. Extraído el 26 de Agosto del 2008 de http://www.usal.es/ teoriaeducacion/

García, J. N. (1997). Manual de Dificultades de Aprendizaje. Lenguaje, LectoEscritura y Matemáticas. Universidad de León. Madrid: Narcea, S.A. de Ediciones.

García, J. N. (2007). Dificultades del Desarrollo: Evaluación e intervención. Madrid: Ediciones Pirámide.

Gascón, A. (2006, octubre). Historia de la Lengua de Signos. Extraído el 06-08-08 desde www.cultura-sorda.eu.

GATE (Gabinete de Tele-Educación). (2006). Manual de Moodle. Universidad Politécnica de Madrid. Extraído el 12 de Junio de 2007 desde http://moodle.org. 
González, A. (1988). El procedimiento cloze: aplicaciones a la evaluación de la comprensión lectora y a la investigación del proceso lector. Madrid: Editorial de la Universidad Complutense.

González, A. (1992). Estrategias Metacognitivas en la lectura. Tesis de Psicología, Facultad de Psicología. Madrid: Universidad Complutense de Madrid.

González, A. (2006). Capítulo 4. Lectura labiofacial. Universidad Complutense de Madrid. Extraído el 12 de Septiembre de 2008 desde www.uam.es/personal pdi/psicologia/agonzale/Asun/2006/Libros/SistemasAlt ernatComunic/cap4llf.pdf.

González, C. (2007). Unas bases psicológicas de la educación especial. Madrid: Editorial Club Universitario.

González, F. A. (2004). Estrategias de comprensión lectora. Madrid: Editorial Síntesis.

Guedes, A. (s.d.). Los sordos y el fracaso escolar. Extraído el 18 de Septiembre de 2008 desde http://www.sitiodesordos.com.ar/br_guedes2.htm

Halliday, A. (1985). An Introduction to Functional Grammar. Australia: Edward Arnold.

Hanson, V. (1989). Phonology and reading: Evidence from profoundly deaf readers. En D. Shankweiler y I. Lieberman (Eds.), Phonology and reading disability: Solving the reading puzzle. Ann Arbor, Ml.: University of Michigan Press.

Harris, M. y Beech, J.R. (1998). Implicit phonological awareness and early reading development in prelingually deaf children. Journal of Deaf Studies and Deaf Education, 3, 205-216.

Hauser, A. (1998). Historia de la literatura y el arte - Vol: II. Madrid: Editorial DEBATE.

Herrera, V. (2003). Desarrollo de habilidades lectoras en sujetos sordos signantes, a partir del uso de códigos dactílicos. Tesis doctoral no publicada. Universidad Complutense de Madrid.

Jáudenes, C., Torres, S., Aguado, G., Silvestre, N. y Patiño, I (2008). Estudio sobre la situación educativa del alumnado con discapacidad auditiva. Madrid: FIAPAS.

Jiménez, J. E. y Artiles, C. (1989). Cómo prevenir y corregir las dificultades en el aprendizaje de la lecto-escritura. Madrid: Editorial Síntesis.

Johnson-Laird, P. N. (1983). Mental models: Towards a cognitive science of language, inference, and consciousness. Cambridge, MA: Harvard University Press. 
Johnson-Laird. P.N.(1996).Images, models, and propositional representations. In De Vega et al. Models of visuospatial cognition. New York: Oxford University Press.

Kelly, L. (1996). The interaction of syntactic compentence and vocabulary during reading by deaf students. Journal of Deaf Studies and Deaf Education, 1(1). 75-90.

Lasasso , C. y Davey, B. (1987), The relationship between lexical knowledge and reading comprehension for prelingually, profoundly hearing impaired students. The Volta Review, 89, 211.

Lasasso, C. (1993). Reading compression of deaf readers. The impact of too many or too few questions. American Annals of the Deaf, 138(5), 435-441.

Laseras, T. (1999). La educación de las alumnas y alumnos sordos. Aula de innovación educativa. Madrid: Editorial Graó. 83 y 84.

Leybaert, J. y Alegría, J. (1995). Spelling development in hearing and deaf children: evidence for the use of morpho-phonological regularities. Reading and Writing: An Interdisciplinary Journal, 7, 89-109.

Leybaert, J. y Charlier, B. (1996). Visual speech in the head: The effect of Cued Speech on rhyming, remembering and spelling. Journal of Deaf Studies and Deaf Education, 1, 234-248.

Lichtenstein, E. H. (1998). The relationships between reading processes and English skills of deaf college students. Journal of Deaf Studies and Deaf Education 3 (2), 80 - 82.

Limbrick, E., McNaughton, S., y Clay, M. (1992). Time engaged in reading. A critical factor in reading achievement. American Annals of the Deaf, 137 (4), 309314.

Lluisa, M. y Brucart, J. (1987). La sintaxis. Barcelona: Editorial Crítica.

Majon, D. G. (1993). Adaptaciones curriculares: Guía para su elaboración. Málaga. Editora Aljibe.

Marschark, M. (1993). Psychological Development of Deaf children. New York: Oxford University Press, 20, 32.

Maruny, C. L., Ministral, M. M. y Miralles, T. M. (1993). Escribir y Leer - Materiales curriculares para la enseñanza y el aprendizaje del lenguaje escrito, de tres a ocho años - Vol.: II. Editorial Edelvives.

Maxwell, M. (1984). A deaf child's natural development of literacy. Sign Language Studies, 44, 191-224. 
Maxwell, M. (1986). Beginning reading and deaf children. American Annals of the Deaf, 3, 14-20.

McGill-Franzen A., y Gormley, K. (1980). The influence of context on deaf readers' understanding of passive sentences. American Annals of the Deaf 125, 937942.

Mies, B. A. (1992). El léxico escrito en la comprensión lectora: estudio de un grupo de alumnos sordos profundos. Revista Logopedia Foniatría y Audiológica, XII (4), $203-210$.

Monfort, M. y Juárez, A. (1988). El ordenador y los trastornos del lenguaje escrito. Madrid: Publicado por el Real Patronato de prevención y de atención a personas con minusvalía, 64 y 65 .

Monfort, M. (2006). Sordera y Tecnología. Extraído el 5 de Agosto de 2008 desde:http://observatorio.cnice.mec.es/modules. php?op=modload\&name=Ne ws\&file $=$ article $\&$ sid $=391$.

Morais, J., Cary, L., Alegría, J., \& Bertelson, P. (1979). Does awareness of speech as a sequence of phones arise spontaneously? Cognition, 7, 323-331.

Moscardó, I. (2009). Barómetro de hábitos de lectura y compra de libros en el primer trimestre de 2009. Federación de Gremio de Editores de España, Madrid. Extraído el 24 de Junio de 2009 desde http://www.federacioneditores.org/0_Resources/Documentos/NP_Lectura_200 9.pdf

Musselman, C. L. (1995). Enseñar una comunicación eficaz a los padres de niños sordos: el papel de la información visual, Madrid: CEPE.

Musselman, C. L. (2000). How do children who can't hear learn to read an alphabetic script? A review of the literature on reading and deafness. Journal of Deaf Studies and deaf education, 5, 9-31.

Muñiz, V. (1992). Introducción a la filosofía del lenguaje II - Cuestiones semánticas. Barcelona: Editorial del Hombre.

Myklebust, H. (1960). The Psychology of Deafness. New York. Grune y Stratton.

Myklebust, H. (1971). Psicología del Sordo. Madrid: Editorial Magisterio Español.

Newport, E., y Meier, R. (1985). Acquisition of American Sign Language. En: Slobin, D. I.: (ed.) The crosslinguistic study of language acquisition. Hillsdale: Psychology Press Erlbaum.

Nolen, S. y Wilbur, R. (1985). The effects of context on deaf students comprehension of difficult sentences. American Annals of the Deaf, 130(3), 231-234. 
Nunes, T. y Bryant, P. (2004). Handbook of Childen's Literacy. Boston: Kluwer Academic Publishers , 461

NIDCD (2007) National Institute on Deafness and Other Communication Disorders. (2007, Abril) Los Audífonos. Extraído el 3 de Agosto de 2008 desde http://www.nidcd.nih.gov/health/spanish/hearingaid_span.asp.

Ortiz, L. y Burgos, M. (1999). La escritura y la lectura. Extraído el 10 de Julio de 2008 desde http://www.letralia.com/75/ar01-075.htm

Padden, C. y Perlmutter, D. (1987). American sign language and the architecture of phonological theory. Natural Language and Linguistic Theory, 5, 335-375.

Pastor, C. (2002). Hacer familia. Madrid: Ediciones Palabra.

Pasik, Y. (1990). Audioprótesis. Enfoque medico, fonoaudiológico y electroacústico. Buenos Aires. El Ateneo.

Paul, P. V. y Gustafson, G. (1991). Hearing-impaired students`comprehension of high-frequency multi-meaning words. Remedial and Special Education, 12, 53-61.

Pérez, A. (2001). El texto y sus múltiples lecturas. Ocho estrategias de crítica literaria. Madrid: Ediciones Palabra.

Polaino-Lorente, A., Ávila. C. y Rodríguez. M. (1991). Educación especial personalizada. Madrid: Ediciones Rialp.

Puyuelo, M. y Alagón, P. (1999). Deficiencia auditiva. Aspectos neuropsicológicos y comunicativos. Intervención por medio de software educativo y técnicas de biofeed-back. First Internatinal Congress on Neuropshychology in Internet, 66 y 67.

Puyuelo, M., Torres, S., Santana, R., Segarra, M. y Vilalta, E. (2001). Intervención del lenguaje. Metodología y recursos educativos. Aplicaciones específicas a la deficiencia auditiva. Barcelona: Editorial Masson.

Puyuelo, M. (2001). Metodología y recursos educativos: aplicaciones específicas a la deficiencia auditiva. Barcelona: Elsevier España

Quigley, S. y Paul, P.V (1984). Language and Deafness. San Diego. Collage Hill.

Román, T. (2001). Lectura y escritura significativas para grupos con discapacidad auditiva y visual. México: Universidad Nacional Autónoma de México.

Rodríguez, J. M., García, J. y Torres, S. (1997). El uso de estrategias sintácticas en sujetos sordos. Revista de Psicología del Lenguaje, 2, 117-135. 
Romero, J. F. y González, M.J. (2001). Prácticas de comprensión Lectora. Estrategias para el aprendizaje. Psicología y Educación. Madrid: Alianza Editorial.

Sacks, O. (1994). Veo una voz. Viaje al mundo de los sordos. Madrid: Grupo Anaya; Anaya y Mario Muchnik.

Sánchez, A. A. (1997). Intervención psicopedagógica en educación especial. Barcelona: Ediciones Universidad de Barcelona.

Sánchez, E. (1998). Comprensión y redacción de textos. Madrid: Edebé.

Sánchez, J. I. (2005). Educación de la Persona Sorda: Análisis Sistémico para Diseñar Modelos de Intervención. IV Foro de Pediatría de Atención Primaria de Extremadura. Talleres. 25, 26.

Schirmer, B. R. (1994). Language and Literacy Development in Children who are Deaf. New York. Maxwell Macmillan International.

Schlick, M. (1936). The Philosophical Review. Duke University Press, 45, 339-369.

Silvestre, N., Cambra, C., Laborda, C., Mies, A., Ramospott, A., Rosich, N., Serrano, C. y Valero, J. (1998). Sordera, comunicación y aprendizaje. Editorial Massón, S.A. AELFA (boletín no 1/2004) Herramientas informáticas para la intervención en logopedia, 30, 34, 40, 50, 59, 60, 62-70.

Sebastián, M. (2005). Programas de Ordenador para Personas con Discapacidad Auditiva. Boletín del CEAPAT. No. 52, 7

Soriano, J. (2004). Estrategias de acceso al lenguaje escrito de personas adultas sordas. Tesis Doctoral no publicada. Universidad de Zaragoza.

Soriano, J., Pérez, I. y Domínguez, A. B. (2006). Evaluación del uso de estrategias sintácticas en lectura por alumnos sordos con y sin implante coclear. Revista de Logopedia, Foniatría y Audiología, 26 (2), 72-83.

Solé, I. (1992). Estrategias de lectura. Barcelona: Editorial GRAÓ.

Stanovich, K. (1986). Matthew effects in reading: some consequences of individual differences in the acquisition of literacy. Reading Research Quarterly, 21(4), 360-406.

Stenzel, J. (1935). Filosofía del Lenguaje. Madrid: Editorial Revista de Occidente. 170.

Storch, G. y Morales, J. I. (2005). Estatuto jurídico de las lenguas de señas en el derecho español: Aproximaciones. Madrid: Editorial Ramón Areces, 16-19.

Tébar, L. (1996). Estrategias metacognitivas aplicadas a la Lectura eficaz. Madrid: I Congreso de Lectura Eficaz. 
Torres, S., Sánchez, L. M. (2003). Deficiencia Auditiva (Evaluación, intervención y recursos psicopedagógicos). Madrid: Editorial CEPE.

Torres, S., Rodríguez, J. M., Santana, R., González, C. (1995). Deficiencia Auditiva (Aspectos psicoevolutivos y educativos). Granada: Ediciones Aljibe.

Triadó, C., y Fernández, M. P (1992). La mediación semiótica en el sordo. Algunas reflexiones. Revista de Logopedia, Foniatría y Audiología, 12(4), 213-222.

Trybus, R., y Karchmer, M. (1977). School achievement scores of hearing impaired children: National data on achievement status and growth patterns. American Annals of the Deaf, 122, 62-69.

Veinberg, S. (2002). Perspectiva socioantropológica de la Sordera. Publicado en http://www.cultura-sorda.eu en febrero de 2007. Extraído el 14 de Septiembre de 2008 de www.cultura-sorda.eu. 2, 10.

Villalba, A.; Ferrer, A. y Asensi, Mạ.C. (1999). La comprensión lectora en universitarios con déficit auditivo. Revista de Logopedia, Foniatría $y$ Audiología, XIX (1), 26, 27, 33-39.

Villalba, A., Ferrer, A. y Asensi, B. C. (2005). La Lectura en Los Sordos Prelocutivos: Propuesta para un programa de entrenamiento. Ediciones Enther.

Wells, G. (1987). Aprendices en el dominio de la lengua escrita. Psicología y Educación. Realizaciones y tendencias actuales en la investigación y en la práctica. Aprendizaje Visor, MEC.

White, S. y Wallace A. (2006). Manual de Usuario Joomla! 1.0.x. Extraído de www.joomlaspanish.org 20 de Julio de 2007. 


\section{ANEXO I. Prueba de Eficiencia Lectora}

Prueba de Eficiencia Lectora (PEL) creada por Carrillo y Marín (1997)

Apellidos,

Nombre

Curso
Edad
A $\quad$ E $\quad$ T

\section{Colegio}

\section{INSTRUCCIONES}

Vamos a hacer un ejercicio en el que tenéis que leer tan rápido como sepáis pero sin equivocaciones porque debéis entender bien lo que dice cada frase.

Veréis que a cada frase le falta la última palabra para quedar completa.

Lo que tenéis que hacer es encontrar la palabra que falta buscándola entre las cuatro opciones (palabras y pseudopalabras) que hay debajo de cada frase.

Cuando la hayáis encontrado hacéis una marca en el cuadrado que lleva delante. Y rápidamente pasáis a solucionar la siguiente frase.

Vamos a hacer un ejemplo:

Primero tenemos que leer la frase: Tu pelota es de color...

Y a continuación leemos todas las palabras para señalar la que completa mejor la frase (leer alternativas: rogo, roco, robo, rojo)... como la correcta es rojo, hacemos una cruz en el cuadrado que tiene delante.

Marca con una $\mathrm{X}$ en el $\square$ la palabra que mejor complete la frase.

1. Tu pelota es de color ...
rogo
roco
robo
rojo

2. El caballo tenía la pata ...

cardón

$\square$ calor

cartón

carpón

Cuando yo os lo indique abrís el cuadernillo y comenzáis todos a la vez. No os distraigáis porque sólo tendréis cinco minutos para completar el mayor número de frases. Cuando pasen los cinco minutos yo diré "arriba el lápiz" y todos deberéis cerrar el cuadernillo. 


\section{Ana puso la ...}

mella

mesa

mefa

meva

2. Han roto el ...
cardón
$\square$ calor
cartón
carpón

3. Le ocultaban la ...
$\square$ verlad
$\square$ vertad
vendar
verdad

\section{Mi amigo viene en ...}
bicho
bini
bidi
bici

\section{El tren dio un ...}
fienazo
fremazo
frenazo
fleclazo

\section{Han atrapado un ...}
caslor
$\square$ cantos
caspor
castor

\section{Fue a comprar ...}
$\square$ picadillo
picadicho
picadiño
picotear

\section{Laura elige un ...}

tripita

trificio

triciclo

trivicio

\section{Me visita cada dos ...}
deas
$\square$ días
diga
dúas

10. Está viendo la ...
$\square$ tetevisión
teléfono
$\square$ televisión
terevisión

11. Lucia no ahorra ...
decorado
debasiado
demaniado
demasiado

12. Aquí se oye al ...
trompepista
tropezaba
trompefista
trompetista

13. Juan sale de su ...
halitación
$\square$ habitación
$\square$ habitafión
habitaron 


\section{El coche está en ...}
movimiento
movimienlo
mortadela
movimiento

15. Anoche se comió el ...
carro
$\square$ tumón
$\square$ turrón
turón

16. Toma el lápiz y el ...
roculador
rotulador
rolulador
rotundo

\section{Su padre trabaja en el ...}
puebro
pueglo
pueblo
puedo

18. El temor nos dejó ...
desfilados
$\square$ defraudados
defraubados
deflaudados

19. entre las flores hay un ...
$\square$ tudipan
tufipán
tutora
tulipán

20. Hemos viajado por todo el ...
mumbo
mundo
mudo
munto

21. Allí se acoge a muchas ...
personas
perchonas
pernonas
pértigas

22. Le gustaba hablar con sus ...
amistad
$\square$ amigos
amibos
amipos

23. Tres satélites giraban ...
alrebedor
alcachofa
alrededor
alsededor

24. La larga sequía afectó al ...
vinedo
villedo
violeta
viñedo

\section{Todas las caretas eran ...}
diferidas
diferenles
dicerentes
diferentes

26. Debido a su lesión lleva ...

rotillera

robillera

rodillera

rodapiés 


\section{Su hermano estudia en la ...}

$\square$ universidad $\quad \square$ unidersidad $\quad \square$ unipersonal $\quad \square$ universilad

28. El capitán mandó subir el ...

$\square$ perizcopio $\quad \square$ periférica $\quad \square$ periscotio $\quad \square$ periscopio

29. Aceleró hasta el límite de ...
vellosidad
verocidad
velocidad
veloridad

30. La serpiente encantaba con su ...
migada
mirada
ministro
micada

31. Aquella conclusión no estaba ...
razosada
ratonera
razonada
razomada

32. Ese comisario encarceló a los ...
pistonear
pistoreros
pistoteros
pistoleros

33. La cuñada de Sara no pudo llegar a ...
tiembo
tiesto
tiespo
tiempo

34. Ella afirma que no la dejará en toda la vida ...
vida
vino
vila
vira

35. Que tu barco nuevo, zarpe mañana es ...
$\square$ imporible
$\square$ imposible
$\square$ imbosible
impureza

36. Luis quiere dar de comer a todos los ...
animarles
animates
animales
alimales

37. Tengo un soldado tan pequeño como un ...
guifante
guisante
guisanle
guiarte

38. Para hacer el viaje tuvo que pedir ...
injormación
inzormación
información
imposible

39. Ese niño pide más ayuda para hacer el ...
protesta
problema
probrema
proglema 
40. Juana nos relata fábulas con mucha ...

$\square$ imaginafión $\quad \square$ imapinación $\quad \square$ imantado $\quad \square$ imaginación

41. Tu coche es tan viejo que se le caen las ...

$\square$ tuercas $\quad \square$ tuelcas $\quad \square$ tuestas $\quad \square$ tuescas

42. En la caja rota ni abuelo puso tu juego de ...

$\square$ bohos $\quad \square$ bolos $\quad \square$ bobos $\quad \square$ bodos

43. Para señalar el sur debes usar una buena ...
burbuja
brújula
blujula
brúgula

44. Todos los días oigo las noticias que da la ...
logutora
localiza
$\square$ locutora
loculora

45. Esa niña pequeña no dejó de llorar en toda la ...
node
nolle
nota
noche

46. No ha comprado el libro y tiene que usar ...

$\square$ fotógrafos $\quad \square$ fotonopias $\quad \square$ fotocobias $\quad \square$ fotocopias

47. Esas muchachas se van a resfriar por andar ...
despalzas
dercalzas
descalzas
descartas

48. Con el lápiz que me has traído no he podido ...
escribir
$\square$ estribir
$\square$ escrilir
exprimir

49. Si no tienes cuidado y fallas asume las ...
colsecuencias
conejeras
consetuencias
consecuencias

50. Olvidó conectar el cable antes de llamar por ...
telémetro
telézeno
teléfono
teléjono

51. Tu necesitas trabajar mucho para tener mas ...
expediencia
experiencia
expresado
experiescia

52. Para coser la camisa cogió la aguja, el hilo y el ...
delal
$\square$ dedos
$\square$ dedal
deval 
53. Por enganchar mal el remolque quedaron los bordes ...
rocosos
rofados
rozalos
rozados

54. Si desiertas temprano mañana podrás venir con ...
nosopros
norteños
nonotros
nosotros

55. En el nuevo taller de Félix reparan muy rápido los ...
quemadores
quemazores
quemadorres
querradores

56. El martes había un equipo de cirujanos operando en el ...
quirólano
quirófano
quilófano
quitamelo

57. Durante las vacaciones, caminábamos por la playa buscando ...
éramos
erinos
$\square$ erizos
erixos

58. Las sillas que has dejado por la mañana no he podido ...
traslatarlas
trasladarlas
trasfadarlas
transparentes

59. El domingo por la tarde no podremos salir a pescar con mi ...
$\square$ farrilia
famidia
familia
famosa

60. Los cuatro compañeros van a la sierra porque les gusta la ..
naturaleza
natunaleza
nacionalidad
naturalefa

61. Era necesario para su salud tratar adecuadamente su problema de ...
cocido
corazón
conazón
covazón

62. Antes de que muriera le prometió firmemente que nunca dejaría de ...
proteguerla
proteperla
proteinas
protegerla

63. Tu padre trabajaba como fontanero antes de que su jefe lo dejara ...
desempleabo
desempleado
desplegado
desempreado

64. Ten mucho cuidado para que la máquina no caiga al agua, ya que no es ...

sumergible

sumengible

sunergible

sustituirle 


\section{ANEXO II. Prueba de Estrategias Sintácticas}

Prueba creada por Soriano, Pérez y Domínguez (2006).

\section{INSTRUCCIONES}

Vamos a hacer un ejercicio en el que tenéis que leer tan rápido como sepáis pero sin equivocaciones porque debéis entender bien lo que dice cada frase. Veréis que a cada frase le falta la última palabra para quedar completa. Lo que tenéis que hacer es encontrar la palabra que falta buscándola entre las cuatro que hay debajo de cada frase. Cuando la hayáis encontrado hacéis una marca $X$ en el cuadrado que lleva delante. $Y$ rápidamente pasáis a solucionar la siguiente frase.

Vamos a hacer un ejemplo: Primero leeremos la frase: Nosotros estamos en... y a continuación leemos todas las palabras para señalar la que completa mejor la frase (leer alternativas: bar, mercado, peligro, colegio)... como la correcta es peligro, hacemos un cruz en el cuadrado que tiene delante.

1 , Nosotros estamos en...

$\square$ bar $\quad \square$ mercado $\quad \square$ peligro $\quad \square$ colegio

2. Juan tiró el balón a...
$\square$ campo
portero
$\square$ césped
$\square$ portería

3. En el colegio hay... un de música.
$\square$ goma
$\square$ profesor
$\square$ pelota
sacapuntas

Cuando yo lo indique pasa a la siguiente hoja y comienzas. No te distraigas porque sólo tienes cinco minutos para completar el mayor número de frases. Cuando pasen los cinco minutos yo diré "arriba el lápiz" y deberás parar. 
1. Luís lee muy...
$\square$ libros
$\square$ bien
biblioteca
$\square$ periódico

2. Dime qué deseas...
$\square$ cumpleaños
querer
$\square$ amigos
$\square$ conseguir

3. El herido se...
$\square$ sangre
$\square$ desmayó
$\square$ hospital
$\square$ guerra

4. Mis zapatos son ...
$\square$ planos
$\square$ tacón
$\square$ cuero
$\square$ sucios

5. Mi suegra adquirió...
$\square$ hijo
$\square$ madre
$\square$ muebles
$\square$ tienda

6. El balón es de ...
$\square$ amigo
$\square \mathrm{gol}$
$\square$ cuero
$\square$ portero

7. Era feliz con los ...
$\square$ animales
$\square$ sorpresa
$\square$ regalo
$\square$ contento

8. El edificio nuevo se ...
$\square$ vive
$\square$ bonito
$\square$ reciente
$\square$ quemó 
9. Observaba el movimiento del ...
$\square$ péndulo
$\square$ mirada
$\square$ rápido
$\square$ velocidad

10. Después del desayuno nos ...
$\square$ café
$\square$ peinarse
$\square$ marchamos
$\square$ colegio

11. El rocío dejó mucha ...
$\square$ humedad
$\square$ gotas
$\square$ lluvias
$\square$ hierba

12. Todas las aulas parecen ...
$\square$ colegio
$\square$ desiertas
$\square$ mesas
$\square$ grande

13. Su hebilla es poco ...
$\square$ cinturón
$\square$ metal
moderna
$\square$ zapato

14. La tormenta desencadenó una ...
$\square$ lluvias
$\square$ catástrofe
$\square$ truenos
$\square$ viento

15. Aquella travesura le hizo ...
$\square$ enfadarse
$\square$ castigo
$\square$ juego
$\square$ niño

16. El león del zoo es ...
$\square$ rey
$\square$ enjaulado
$\square$ domador
$\square$ viejo 
17. Las estrellas brillan en la ...
$\square$ cielo
$\square$ astros
$\square$ oscuridad
$\square$ firmamento

18. Las historias de dragones son ...
$\square$ cuento
$\square$ fuego
$\square$ fantásticas
$\square$ princesas

19. Su pelo estaba cubierto de ...
$\square$ sombrero
$\square$ blancos
$\square$ canas
$\square$ sucios

20. La película del sábado era ...
$\square$ acción
$\square$ triste
$\square$ cine
noche

21. La obra de teatro fue ...
$\square$ sábado
$\square$ actores
$\square$ butaca
$\square$ divertida

22. Las vacaciones de verano son ...
$\square$ playa
$\square$ largas
$\square$ agosto
$\square$ sol

23. El teléfono sonó y me ...
$\square$ descolgué
$\square$ asustó
$\square$ hablé
$\square$ móvil

24. Tuvo una verruga en la ...
$\square$ grano
$\square$ pie
$\square$ pequeña
$\square$ rodilla 
25. El perro lame a su ...
$\square$ lengua
$\square$ chupar
$\square$ dueño
$\square$ ladra

26. Este cómic es un poco ...
$\square$ violento
$\square$ humor
lectura
dibujo

27. Diego se agobia si Manuel ...
$\square$ teléfono
pesado
entró
$\square$ llama

28. Colocó el kivi en una ...
$\square$ frutero
$\square$ postre
$\square$ neveras
bandeja

29. Resuelve adivinanzas con mucha ...
$\square$ inteligente
$\square$ facilidad
$\square$ listo
$\square$ rápido

30. El tigre apresó a la ...
$\square$ selva
$\square$ escopeta
$\square$ gacela
$\square$ conejo

31. La carpa del circo era ...
$\square$ payaso
$\square$ león
$\square$ colores
enorme

32. Los jugadores fueron agrupados por ...
$\square$ fútbol
$\square$ ganaron
$\square$ juntos
$\square$ sorteo 
33. Sé que es pequeño pero muy ...
$\square$ fuerte
$\square$ grande
$\square$ personas
enano

34. La colonia tiene un olor muy...
$\square$ fragancia
$\square$ perfume
$\square$ aroma
$\square$ agradable

35. Para agrupar sus papeles utilizó una ...
$\square$ periódico
$\square$ grapa
$\square$ juntar
$\square$ clasificar

36. Nada de lo que dijo ayer era ...
$\square$ verdad
$\square$ habló
$\square$ conservar
$\square$ pasado

37. Mantuvieron una gran complicidad... todo su matrimonio.
$\square$ mientras
$\square$ durante
$\square$ pareja
boda

38. Pilar y yo tenemos bikinis nuevos muy ...
$\square$ modernos
$\square$ piscina
$\square$ verano
$\square$ calor

39. El caviar y las gulas con muy ...
$\square$ lujos
$\square$ alimentos
$\square$ salmón
$\square$ caros

40. Miró la hora en el reloj y se ...
$\square$ tiempo
$\square$ asustó
$\square$ tarde
$\square$ puntual 
41. La última vez que estuve pescando cogí un ...
$\square$ truca
$\square$ río
$\square$ caña
$\square$ resfriado

42. Cuando se conectó a Internet, la red estaba ...
$\square$ ordenador
$\square$ web
saturada
$\square$ ratón

43. Fotocopiamos el libro porque no teníamos dinero para ...
$\square$ leerlo
$\square$ adquirirlo
$\square$ robarlo
mancharlo

44. En aquella tapia hay un ...
$\square$ dibujo
$\square$ pilas
$\square$ caja
$\square$ jugar

45. La avería de la tubería del baño fue ...
$\square$ charco
$\square$ inundación
$\checkmark$ fontanero
$\square$ grave

46. Decidió llevar perilla para parecer ...
$\square$ mayor
$\square$ guapo
$\square$ ser
moderno

47. Construir puzzles de más de quinientas piezas es ...
$\square$ pensando
$\square$ tiempo
$\square$ complejo
$\square$ juego

48. Si llueve no iré a recoger ...
$\square$ setas
$\square$ paraguas
$\square$ calarse
$\square$ salir 
49. El fuego se propagó rápidamente porque el bosque era ...
$\square$ árboles
$\square$ frondoso
$\square$ quemado
$\square$ incendio

50. La... de su compañero le produjo una gran desilusión.
$\square$ error
$\square$ actuación
$\square$ amigo
$\square$ ayudar

51. Mi tío conoce un camino nuevo para llegar a aquella ...
$\square$ paseo
$\square$ andar
$\square$ roca
excursión

52. Al pino no se le caen sus hojas con las ...
$\square$ heladas
$\square$ otoño
$\square$ caducas
perder

53. Ir a mucha velocidad con el coche en carretera es ...
$\square$ viaje
$\square$ peligroso
$\square$ potencia
$\square$ camino

54. El problema no era fácil de solucionar porque fallaban algunos ...
$\square$ encontrar
$\square$ datos
$\square$ número
$\square$ división

55. Como tenía sueño, la abuela le arropó con una ...
$\square$ manta
$\square$ acostar
$\square$ tapar
$\square$ cama

56. La única novela que le leí era muy larga, pero me pareció ...
$\square$ grueso
$\square$ Biblia
$\square$ interesante
$\square$ páginas 
57. La nieve no nos dejó ... de la excursión a la cueva
$\square$ disfrutar
$\square$ paisaje
$\square$ blanco
$\square$ frío

58. La ambulancia se dirigió... al lugar donde se produjo el accidente.
$\square$ sirena
$\square$ camilla
$\square$ rápidamente
carretera

59. El trayecto a París me pareció interminable porque el tren estaba ...
$\square$ TALGO
$\square$ Francia
$\square$ sólo
$\square$ lleno

60. Aunque no le importa su forma de vestir, muchas veces lleva vestidos ...
$\square$ arreglarse
$\square$ trajes
$\square$ marca
$\square$ elegantes

61. Cuando fuimos de... nos alojamos en la pensión más barata de toda la ciudad.
$\square$ playas
$\square$ descansar
$\square$ veraneo
$\square$ hotel

62. La tutora dijo a los niños que se pusieran la chaqueta ... de salir al patio.
$\square$ para
$\square$ recreo
$\square$ antes
$\square$ frío

63. La batuta se rompió cuando el... marcaba el compás de la pieza de música al coro.
$\square$ canción
$\square$ discos
$\square$ orquesta
$\square$ director

64. Mi equipo ha ganado la liga de fútbol gracias a la ... que ha tenido todo el campeonato.
$\square$ regularidad
$\square$ entrenador
$\square$ goles
triunfo 

en Castilla y León 


\section{ANEXO III. Curso LECTOR vista del Administrador}

Para realizar la investigación se ha contado, como ya se ha dicho en otros puntos, con educa.signando.com, este espacio web está creado con Moodle.

En este Anexo se puede ver como es la apariencia de la aplicación y del Curso LECTOR desde el punto de vista de un usuario, se verá la parte del administrador, a nivel de página y del Curso LECTOR.

Existen dos formas de iniciar sesión en educa.signando.com.

1a.- Seleccionar (Entrar) en la parte superior derecha. Esta opción da acceso a la administración de educa.signando.com

2a.- Pinchando sobre LECTOR, esta acción da acceso al menú de administración del curso LECTOR.

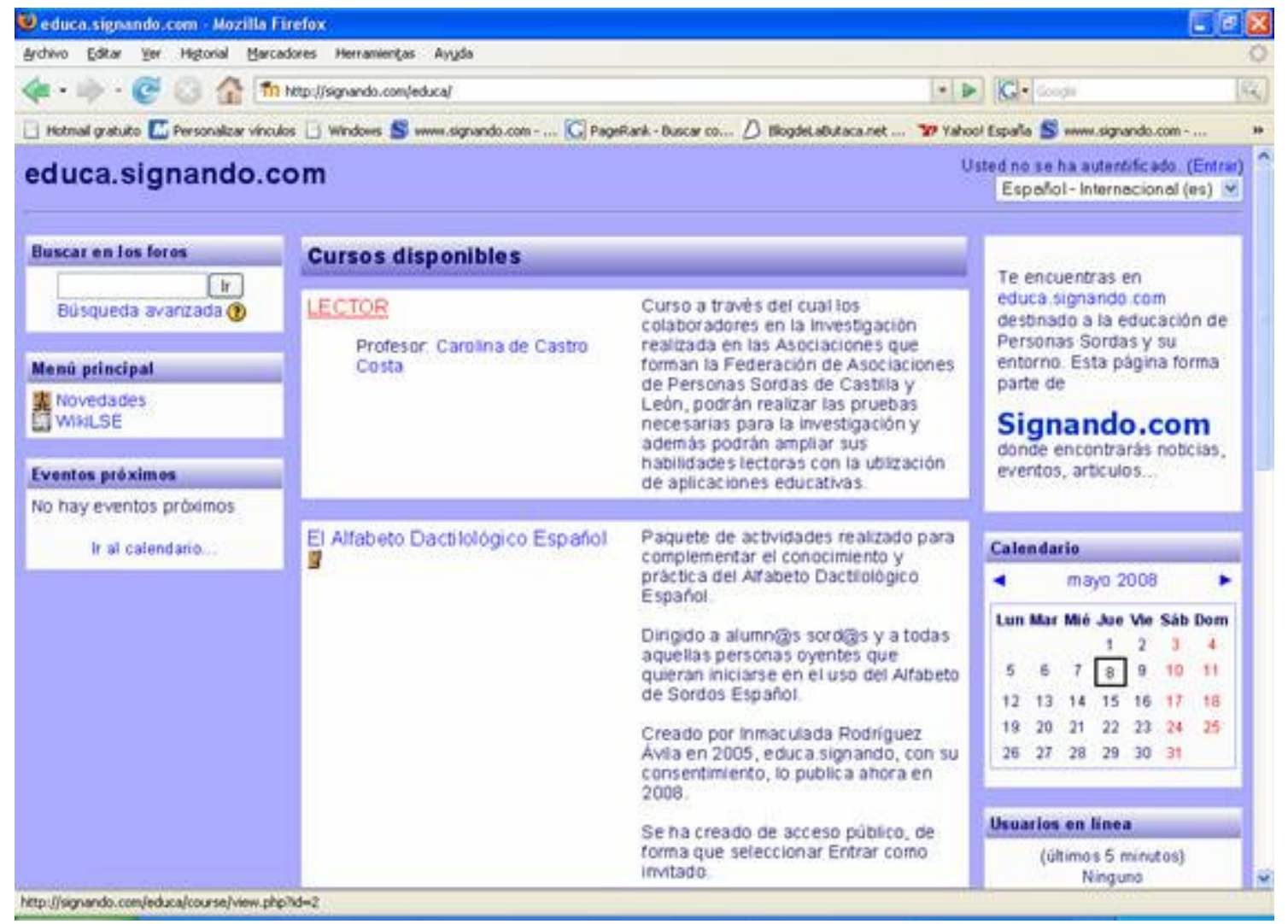

Imagen 27. Página principal de educa.signando.com

En esa educa.signando.com existen dos formas de iniciar sesión seleccionando LECTOR o pulsando sobre (Entrar) en ambos casos se solicita un usuario y contraseña (imagen 28). 
Desarrollo de Estrategias Sintácticas y Semánticas en Lectura a través de LECTOR en Personas Sordas Adultas en Castilla y León

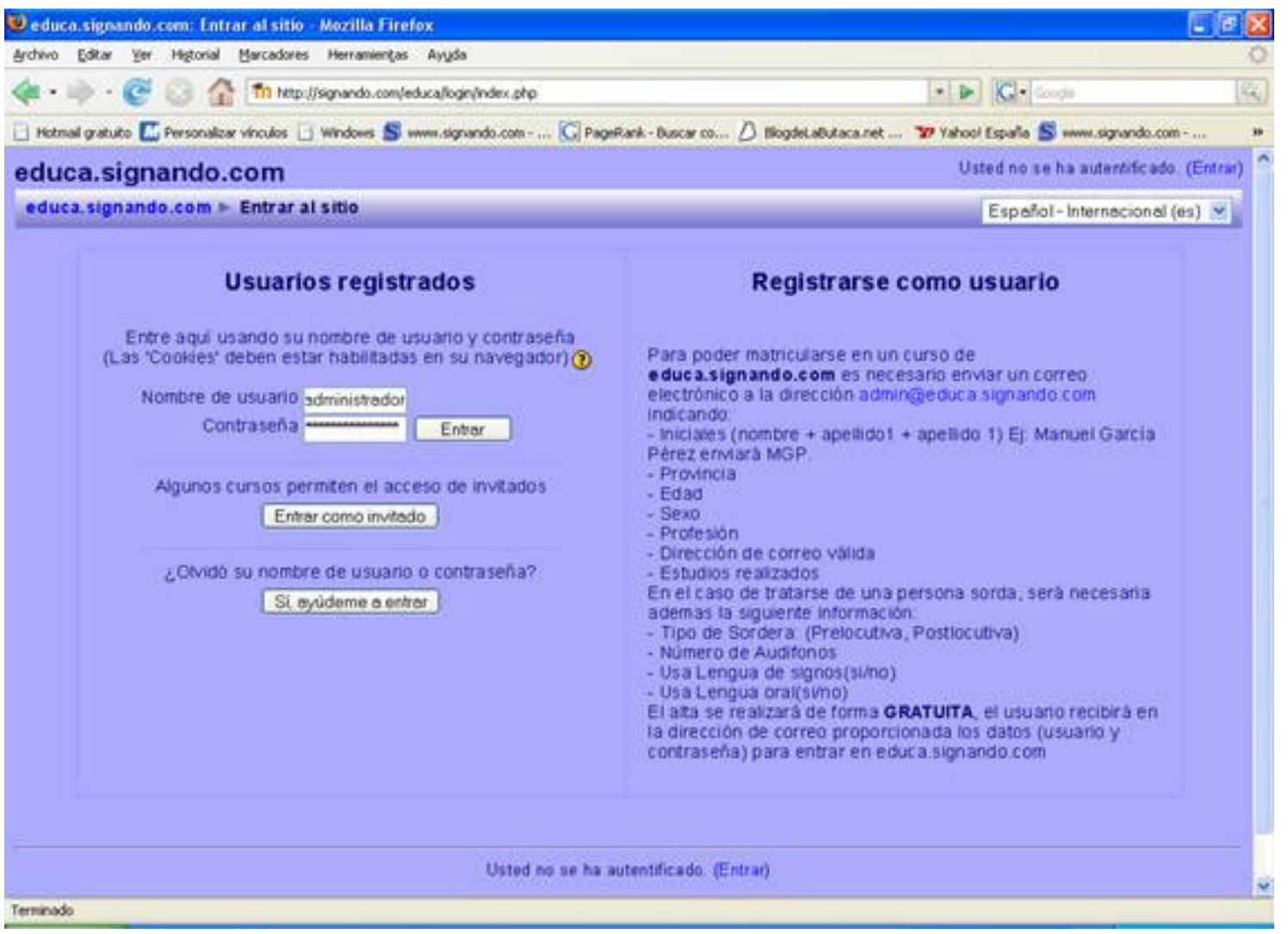

Imagen 28. Inicio de sesión dentro de educa.signando.com 


\section{ADMINISTRACION DE EDUCA.SIGNANDO.COM}

En esta página (imagen 29) es desde donde se parte, desde aquí entrando con un usuario administrador se gestiona todo, desde el punto de vista de la investigación se puede decir que es desde donde se realiza la administración de cursos y la administración de usuarios.

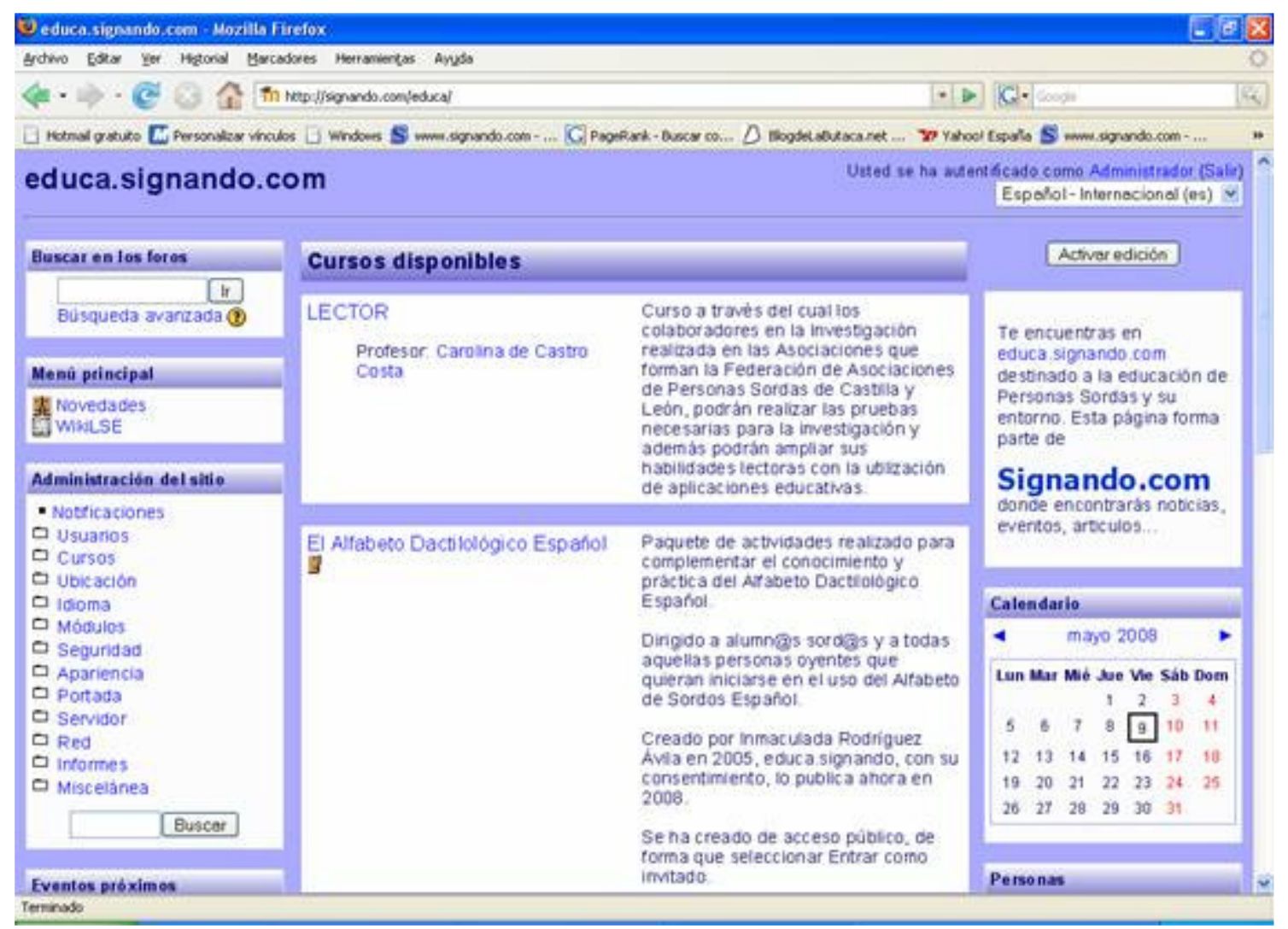

Imagen 29. Página principal del administrador de educa.signando.com

Todo el trabajo de administración se realiza desde el Menú de Administración del Sitio. En educa.signando.com este menú está en la parte inferior izquierda como se ve en la imagen 30. 


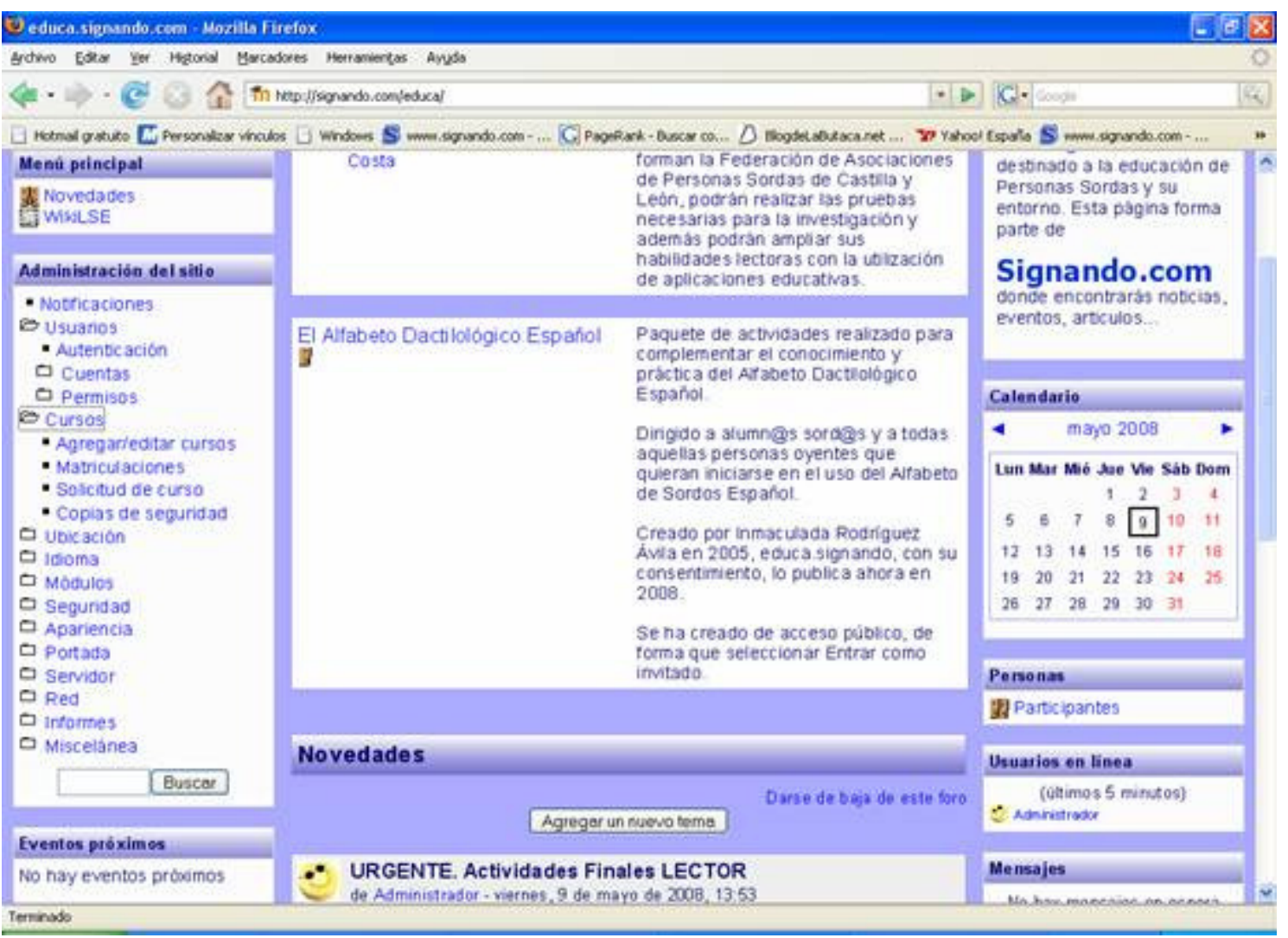

Imagen 30. Parte inferior de la página principal del administrador de educa.signando.com

Seleccionando la opción de Usuarios $\rightarrow$ Cuentas $\rightarrow$ Agregar usuario se puede agregar un nuevo usuario. En las siguientes imágenes (31 y 32) se pueden ver los campos que son necesarios completar. 


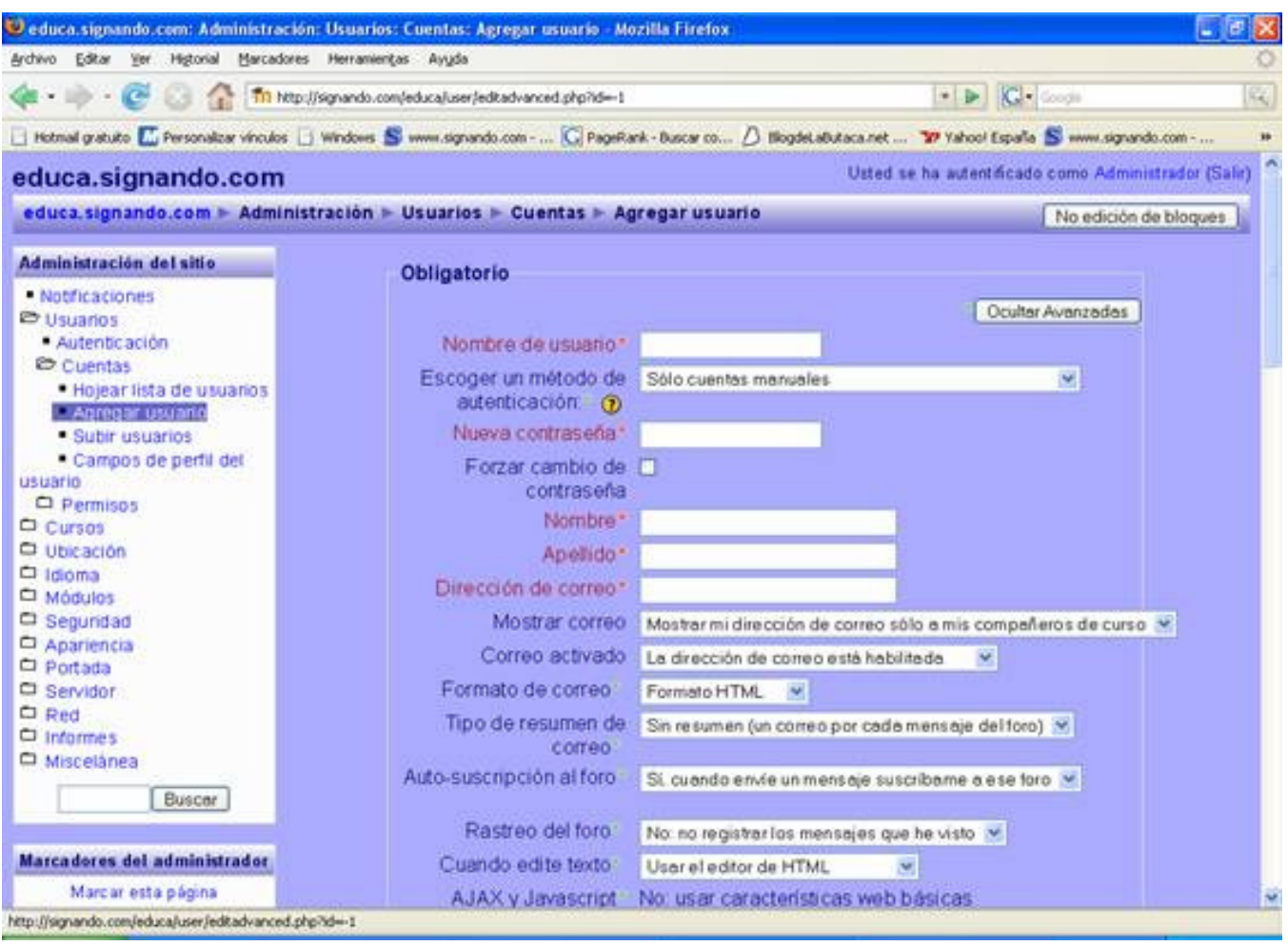

Imagen 31. Campos necesarios para crear un nuevo usuario (parte 1)

En esta imagen (ver imagen 32) se puede ver la información que va a formar las variables independientes dentro de la tesis.

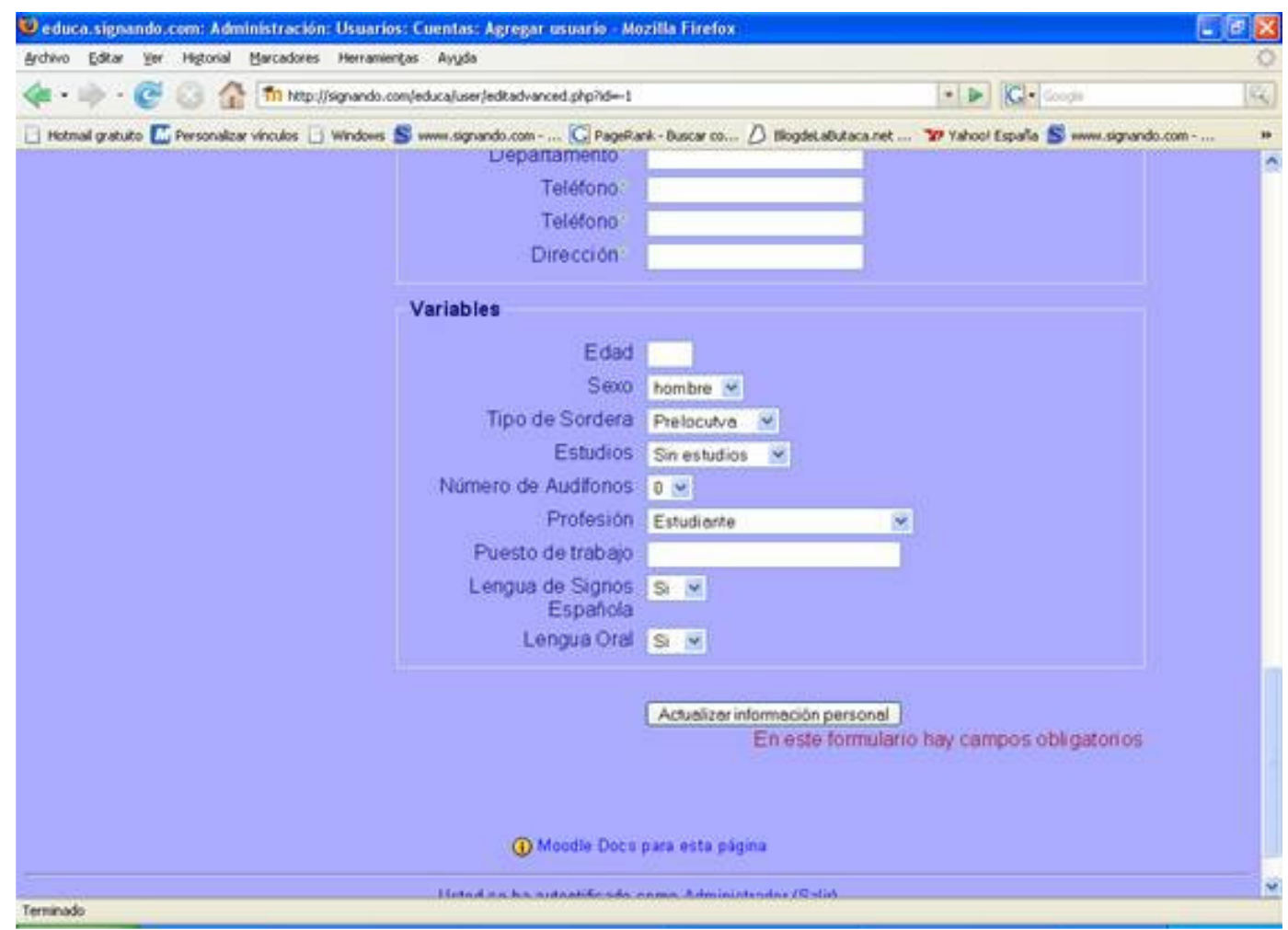

Imagen 32. Variables independientes 
En el menú de Cursos $\rightarrow$ Agregar/editar cursos es donde están definidas las categorías a las que pertenecerán todos los cursos creados como se ve en la imagen 33 LECTOR pertenece a la categoría Investigación.

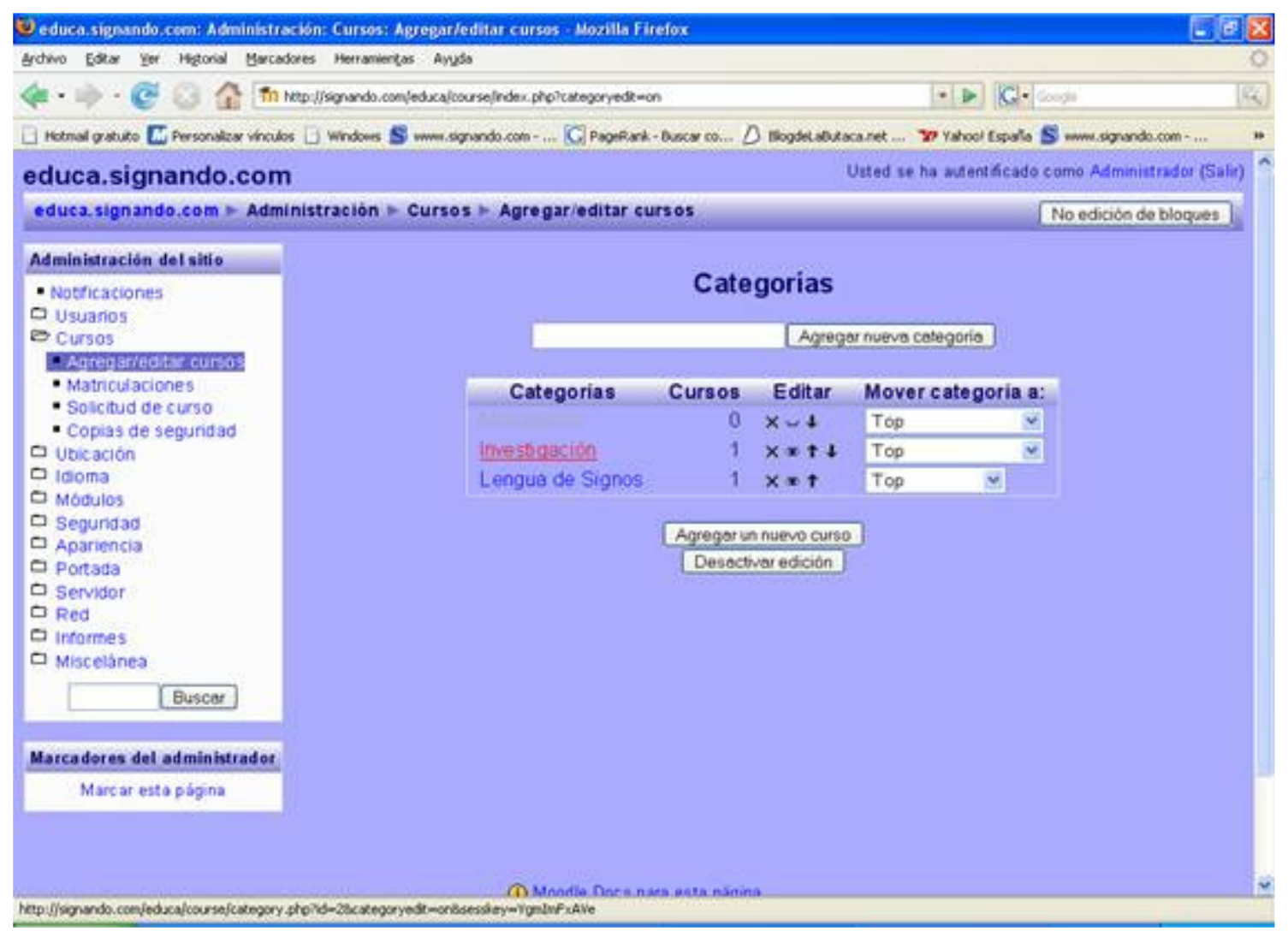

Imagen 33. Categorías 
Desarrollo de Estrategias Sintácticas y Semánticas en Lectura a través de LECTOR en Personas Sordas Adultas en Castilla y León

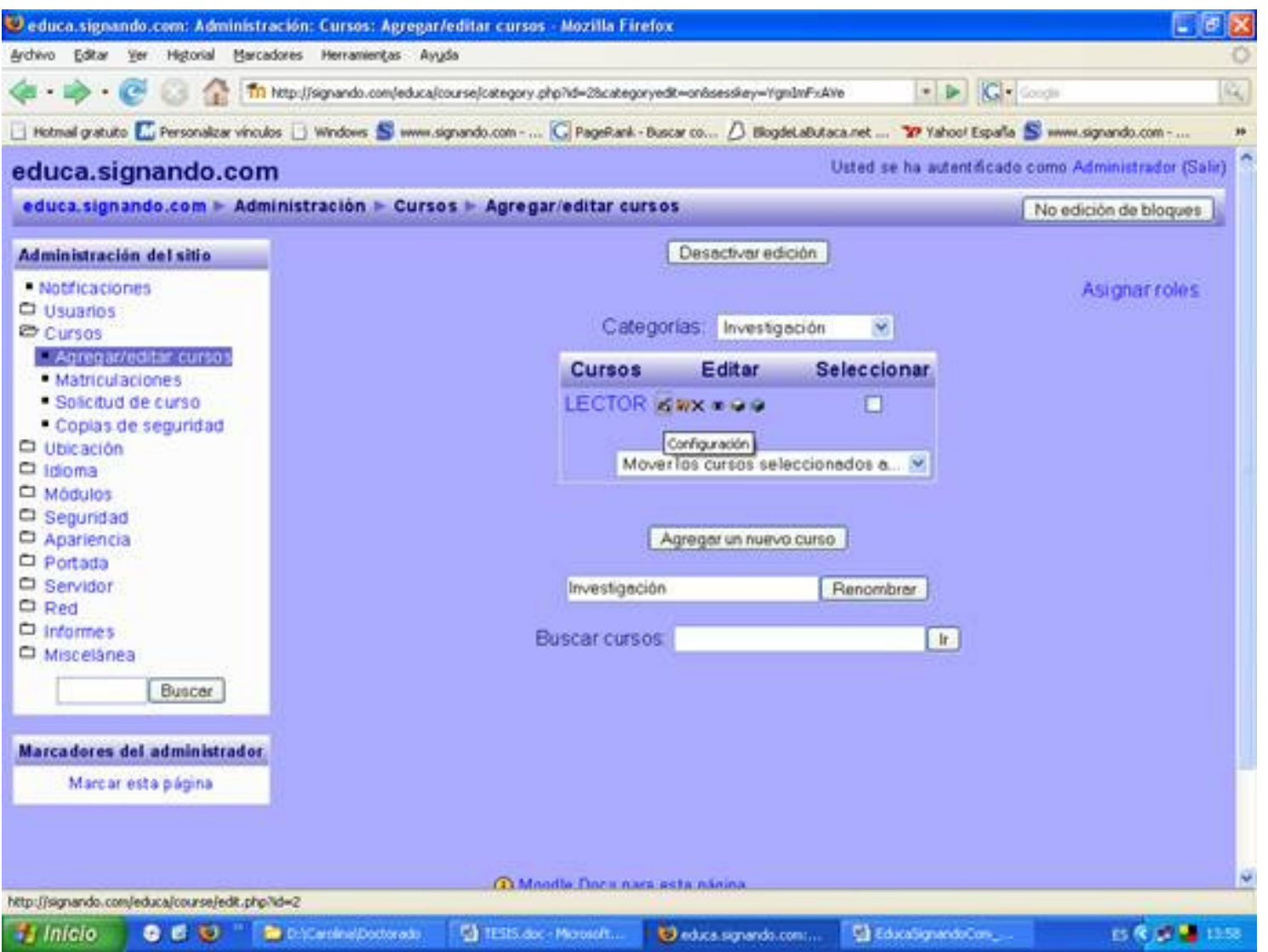

Imagen 34. Opción de Configuración de Curso LECTOR

Seleccionando la opción Configuración (marcada en la imagen 34) se entra en la configuración de cada curso. 


\section{ADMINISTRACION DEL CURSO LECTOR}

Una vez realizado el inicio se sesión con un usuario administrador se muestra la siguiente información (ver imagen 35), puede parecer similar a la de usuario pero contiene un mayor numero de opciones.

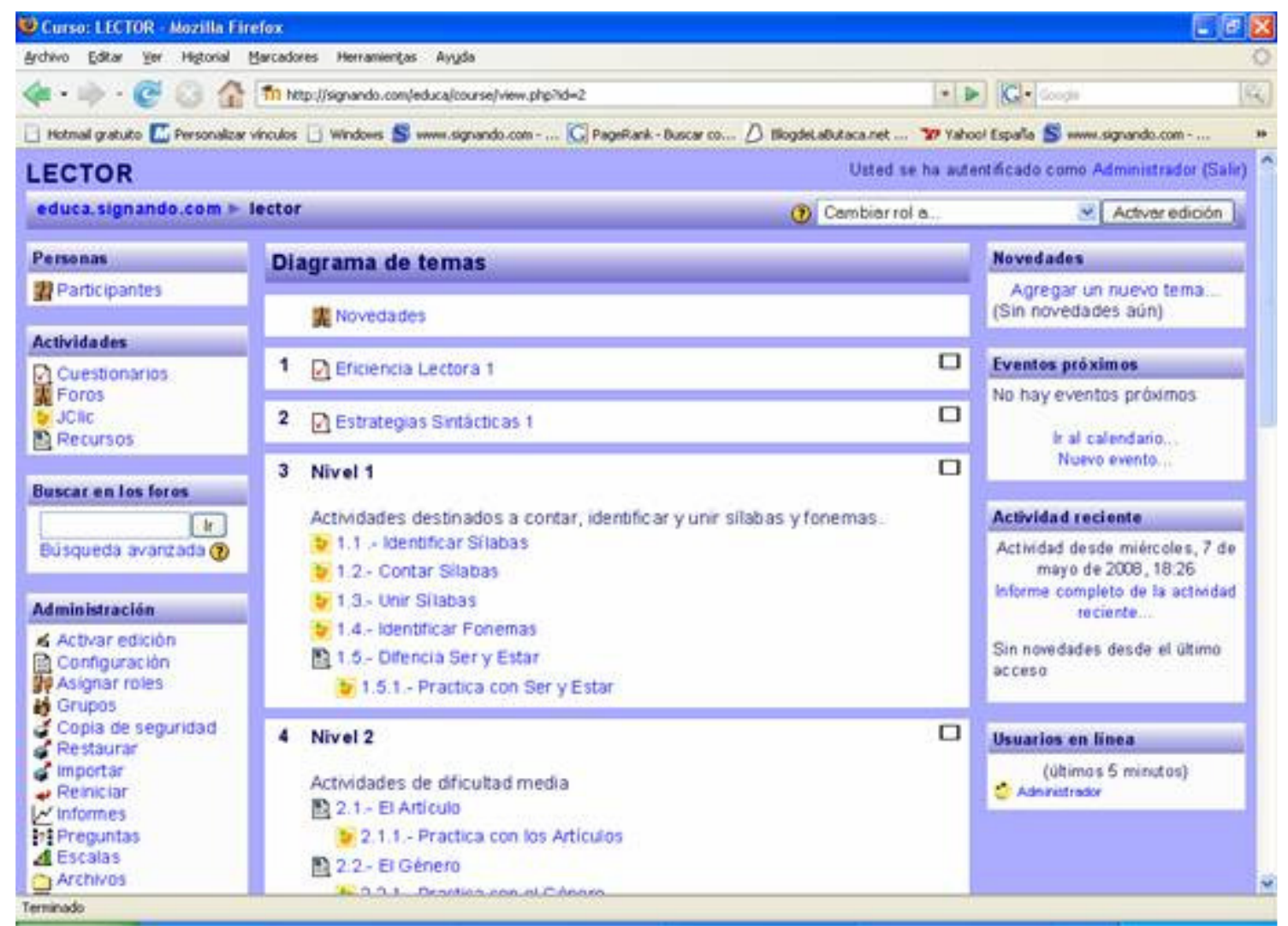

Imagen 35. Página principal del curso LECTOR

Desde esta ubicación si se selecciona, por ejemplo, Eficiencia Lectora 1, aparece una nueva pantalla (ver imagen 36), que permite comprender las posibilidades que existen para administrar actividades. Pudiendo ver los resultados, tener una vista previa e incluso poder editar la actividad.

En la parte superior se muestra un pequeño resumen de la actividad sobre la que se está interesado. 
Desarrollo de Estrategias Sintácticas y Semánticas en Lectura a través de LECTOR en Personas Sordas Adultas en Castilla y León

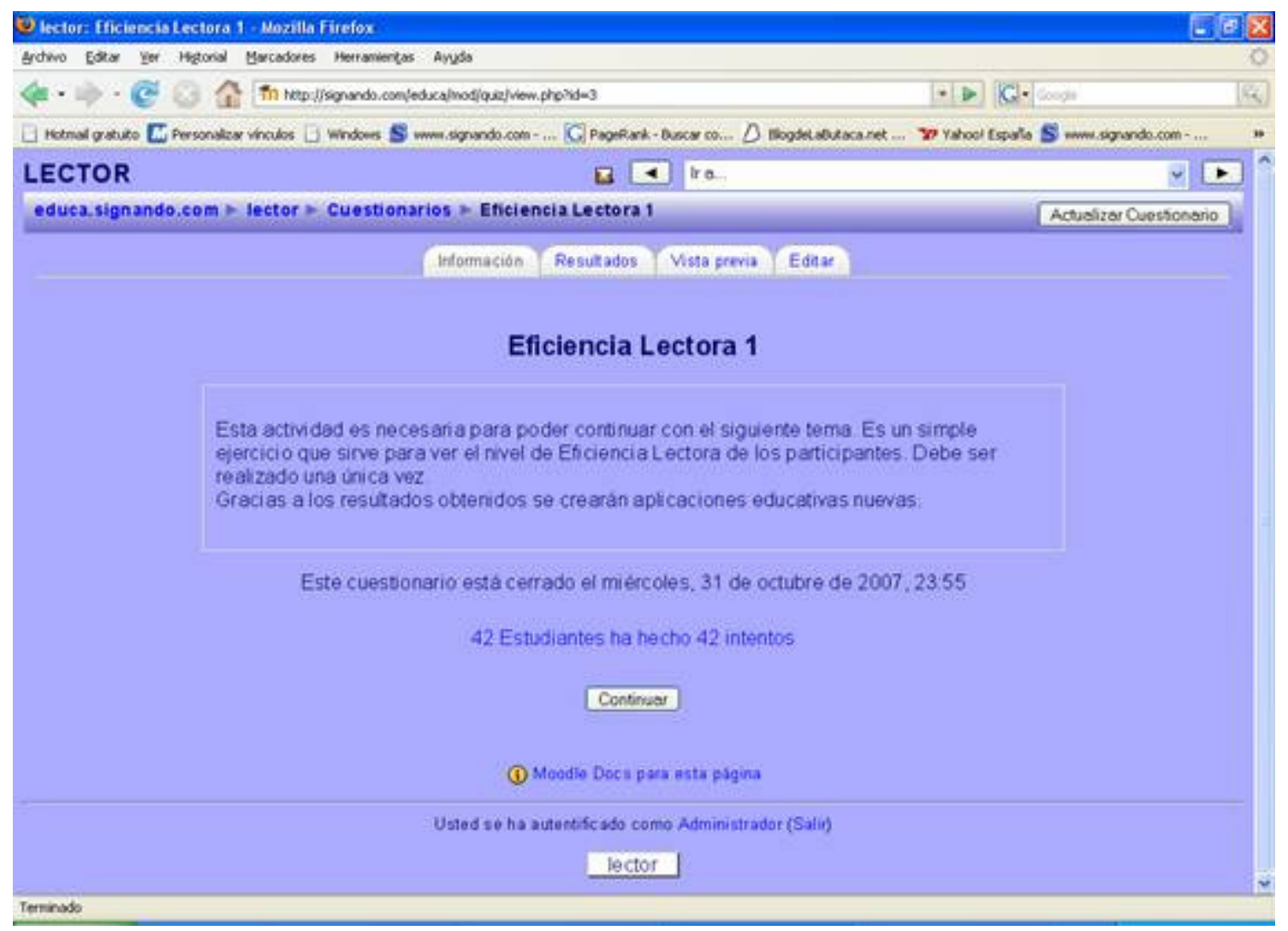

Imagen 36. Prueba de Eficiencia Lectora 1.

Seleccionando la opción Resultados se puede ver un listado de los usuarios que han participado y sus resultados de forma muy resumida (ver imagen 37 ). 


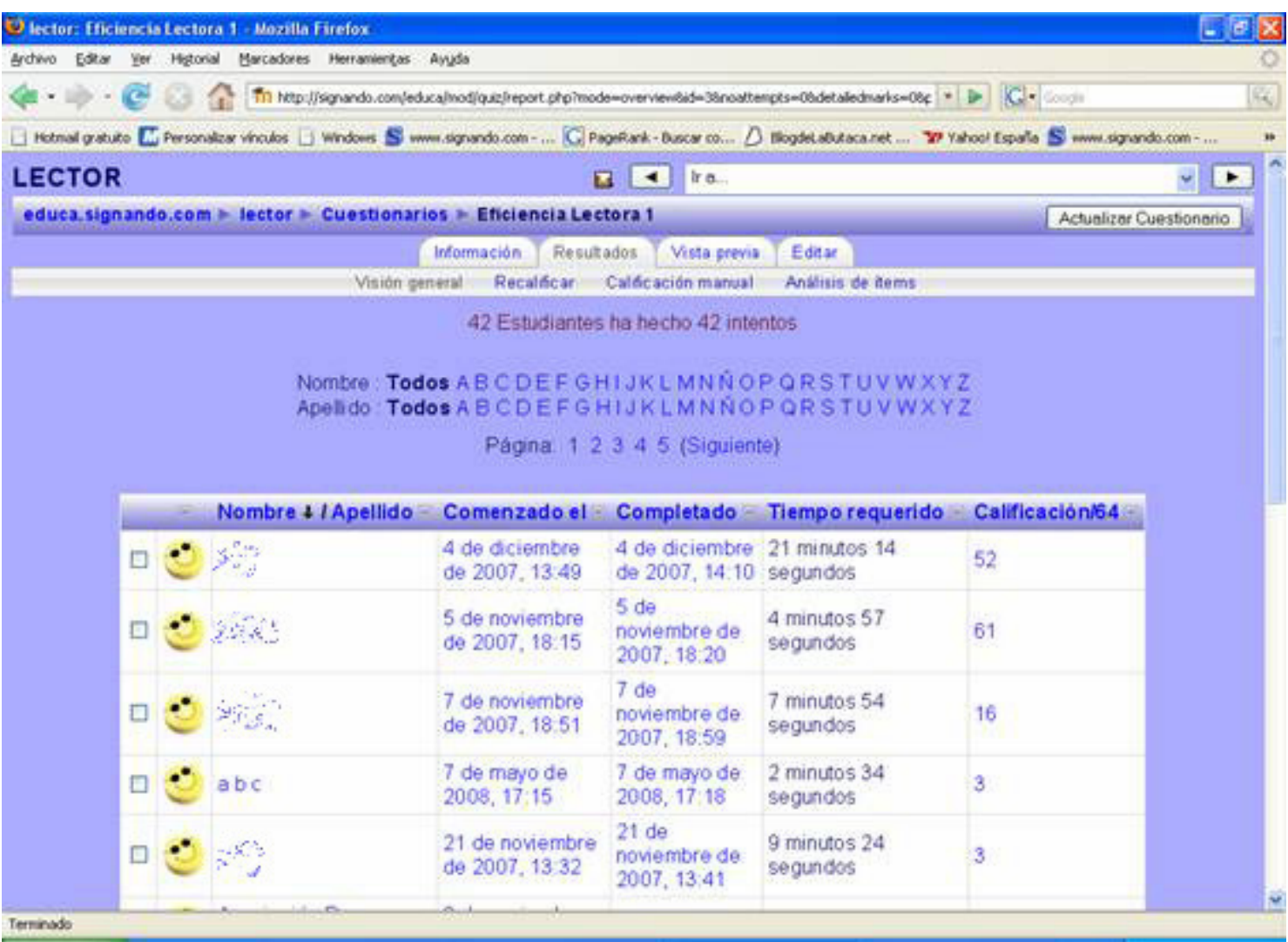

Imagen 37. Participantes y resultados

Existe la posibilidad de obtener información mas detallada obteniendo el resultado individualizado de cada una da las preguntas que fueron contestadas. En esta la imagen 38 se está mostrando la información relacionada a la resolución de la Prueba Eficiencia Lectora 1. 


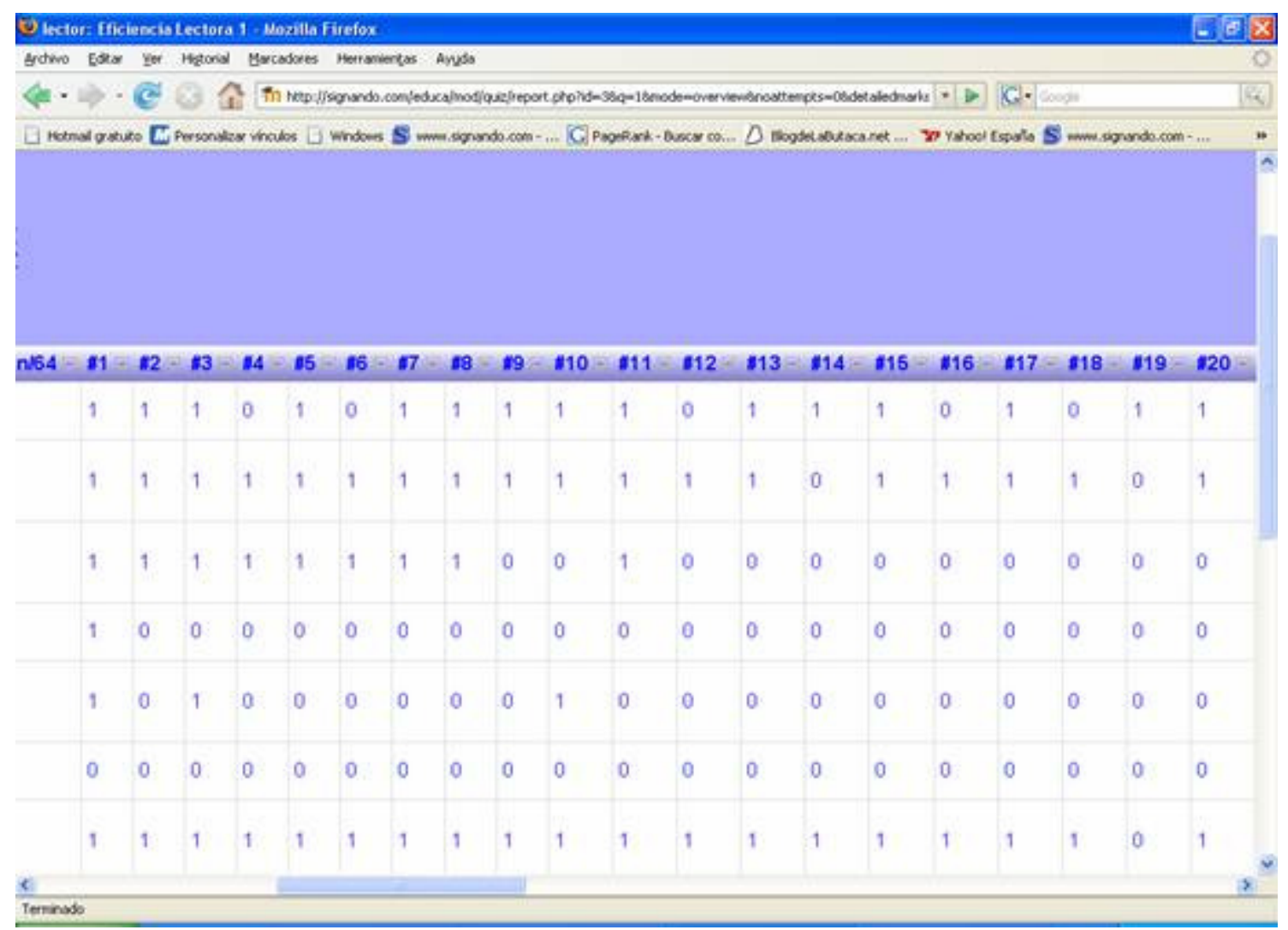

Imagen 38. Resultados detallados Prueba de Eficiencia Lectora

Si en la pantalla de resultado se selecciona una de las fechas, tanto de comienzo como de completado, se puede observar el resultado anterior pero con las preguntas y la contestación elegida para cada caso (ver imagen 39). 
Desarrollo de Estrategias Sintácticas y Semánticas en Lectura a través de LECTOR en Personas Sordas Adultas en Castilla y León

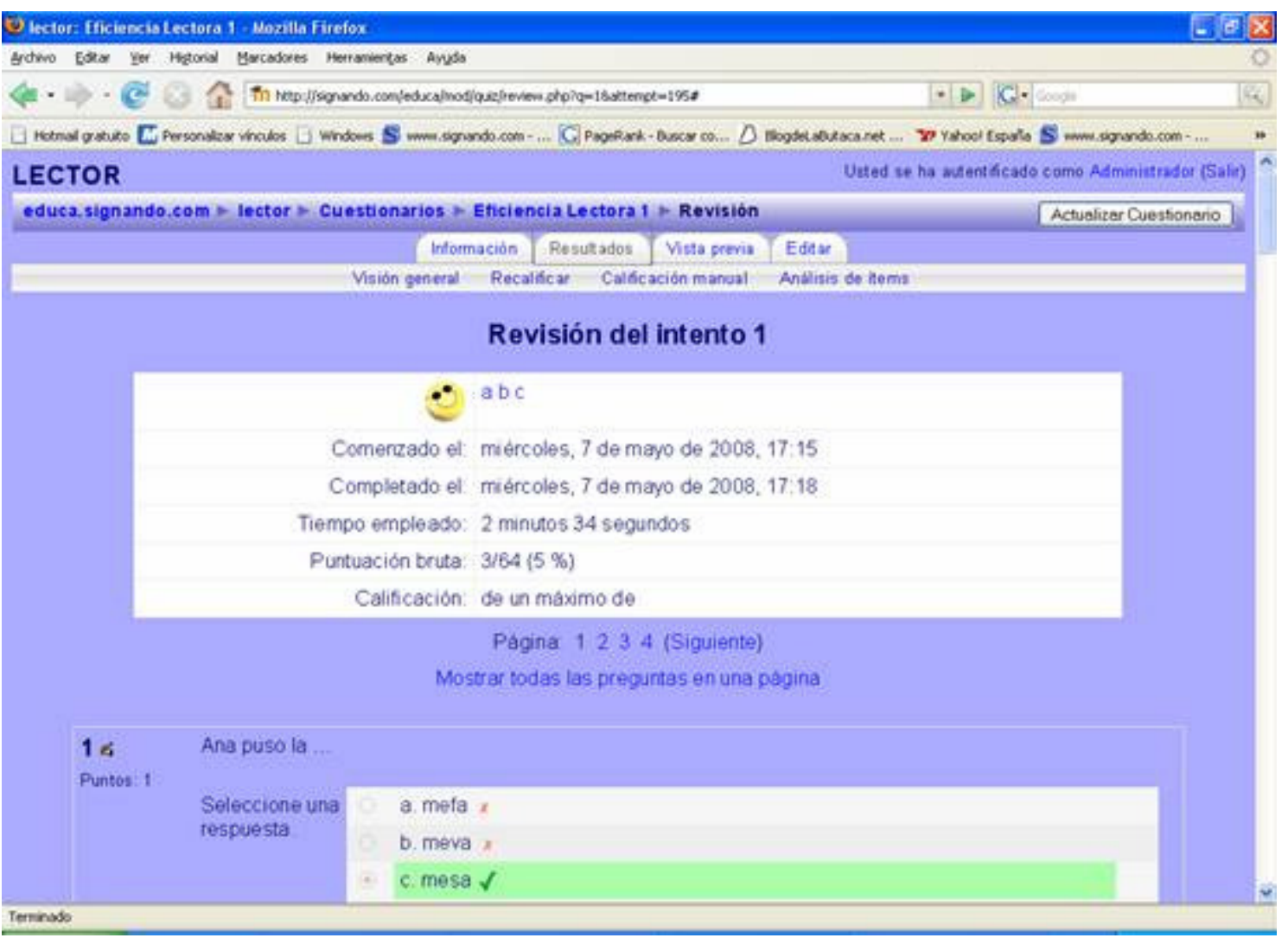

Imagen 39. Revisión del Intento 1

Pudiendo llegar al análisis de cada ítem, donde se muestran valores estadísticos (ver imagen 40), como Desviación Típica (DT), relacionados con la resolución general de cada frase. 
Desarrollo de Estrategias Sintácticas y Semánticas en Lectura a través de LECTOR en Personas Sordas Adultas en Castilla y León

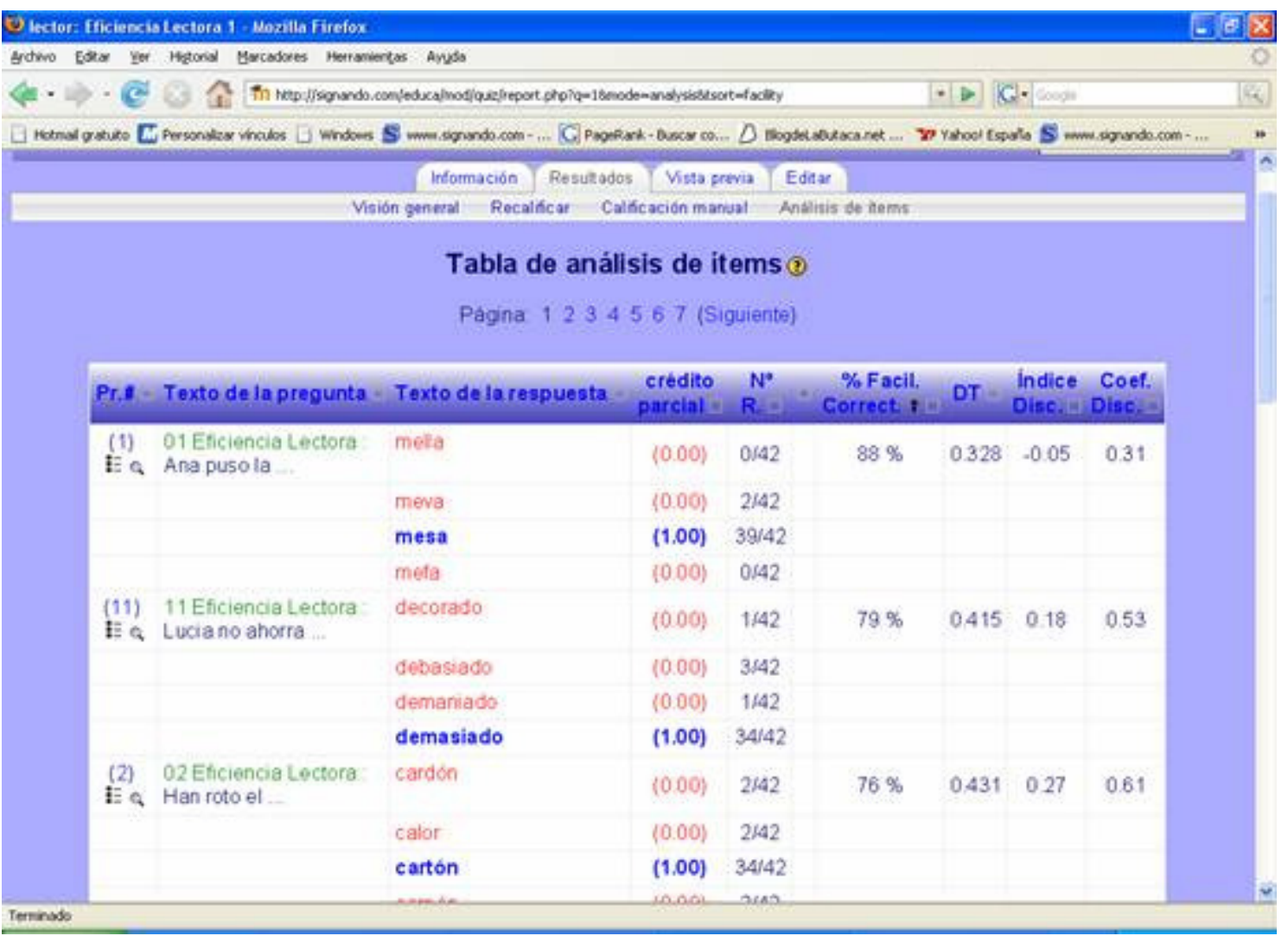

Imagen 40. Tabla de análisis de ítems, valores estadísticos 


\section{Menú de Administrador}

La herramienta permite desde el Menú de Administrador conseguir informes en función de varios campos. Este menú se encuentra en la página principal del administrador, su ubicación en el caso de LECTOR es abajo a la izquierda, este tipo de menús como el resto de módulos se pueden colocar en la ubicación que se desee.

\section{Informes}

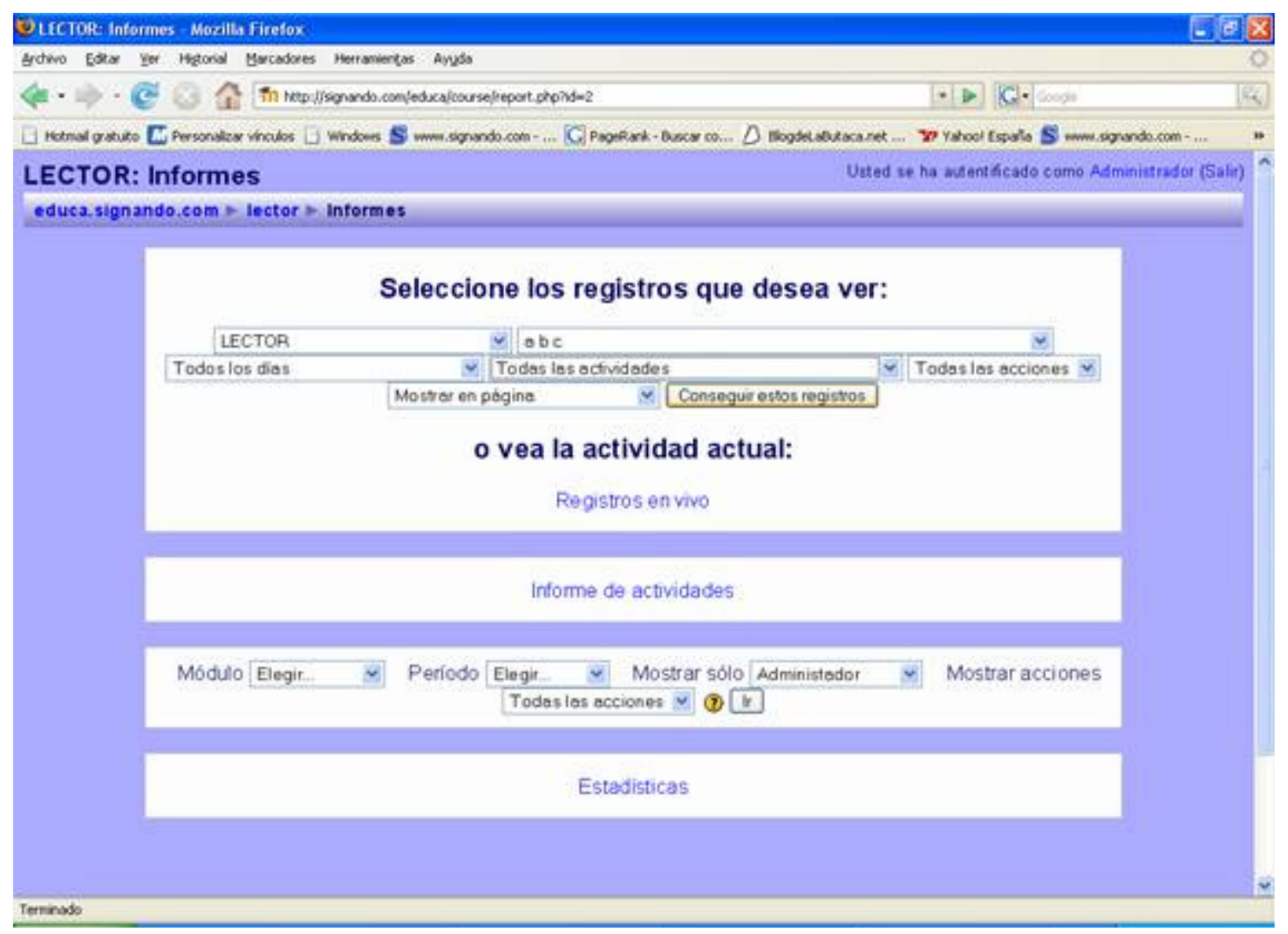

Imagen 41. Creación de Informes

La información que muestra, desde el punto de vista del administrador y de los educadores, es muy relevante, ya que se puede llegar a conseguir con mucho detalle, por ejemplo, cual ha sido el trabajo realizado por un alumno en un día concreto (ver imagen 42). 
Desarrollo de Estrategias Sintácticas y Semánticas en Lectura a través de LECTOR en Personas Sordas Adultas en Castilla y León

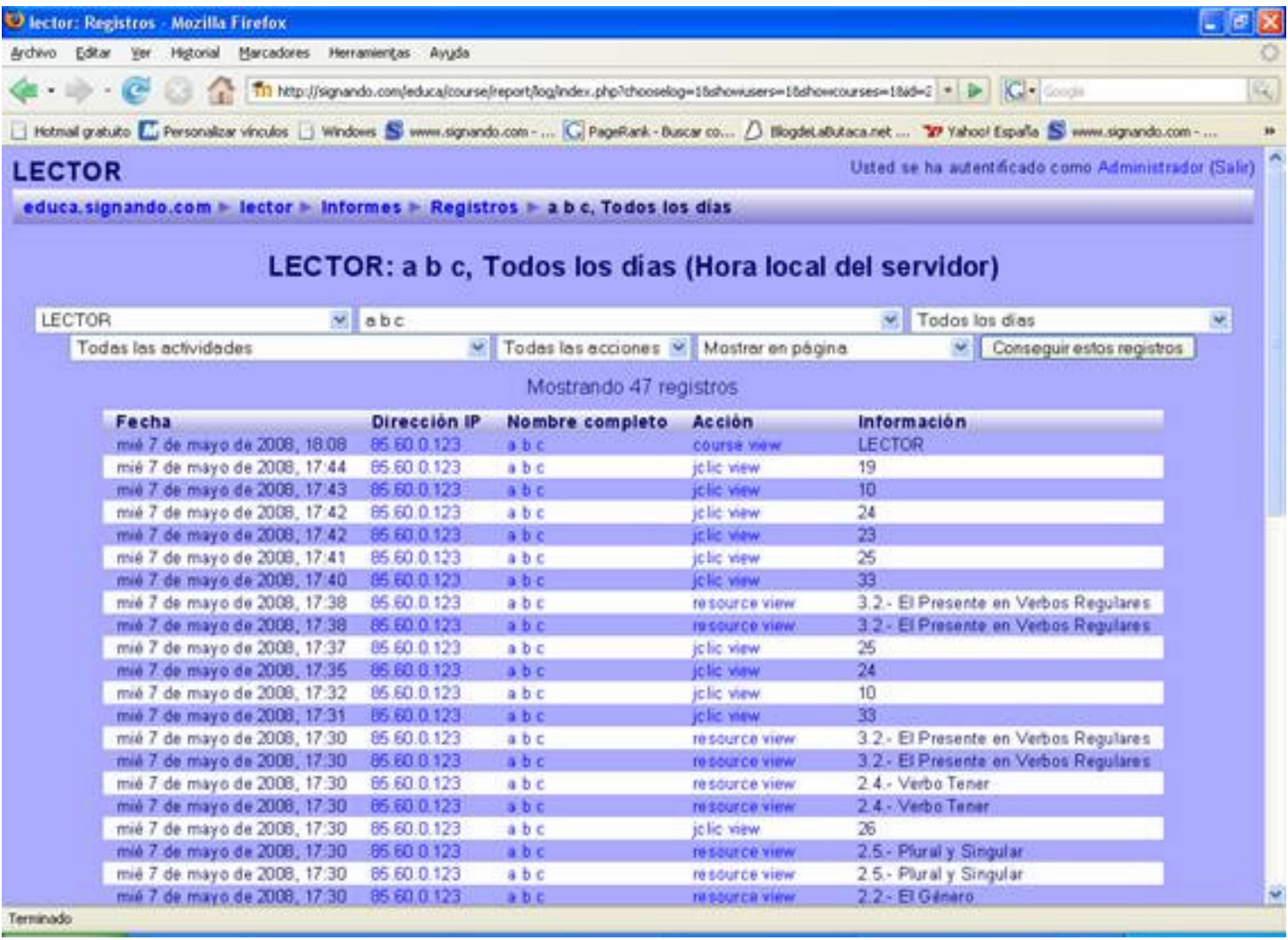

Imagen 42. Informes del usuario a b c 


\section{Participantes}

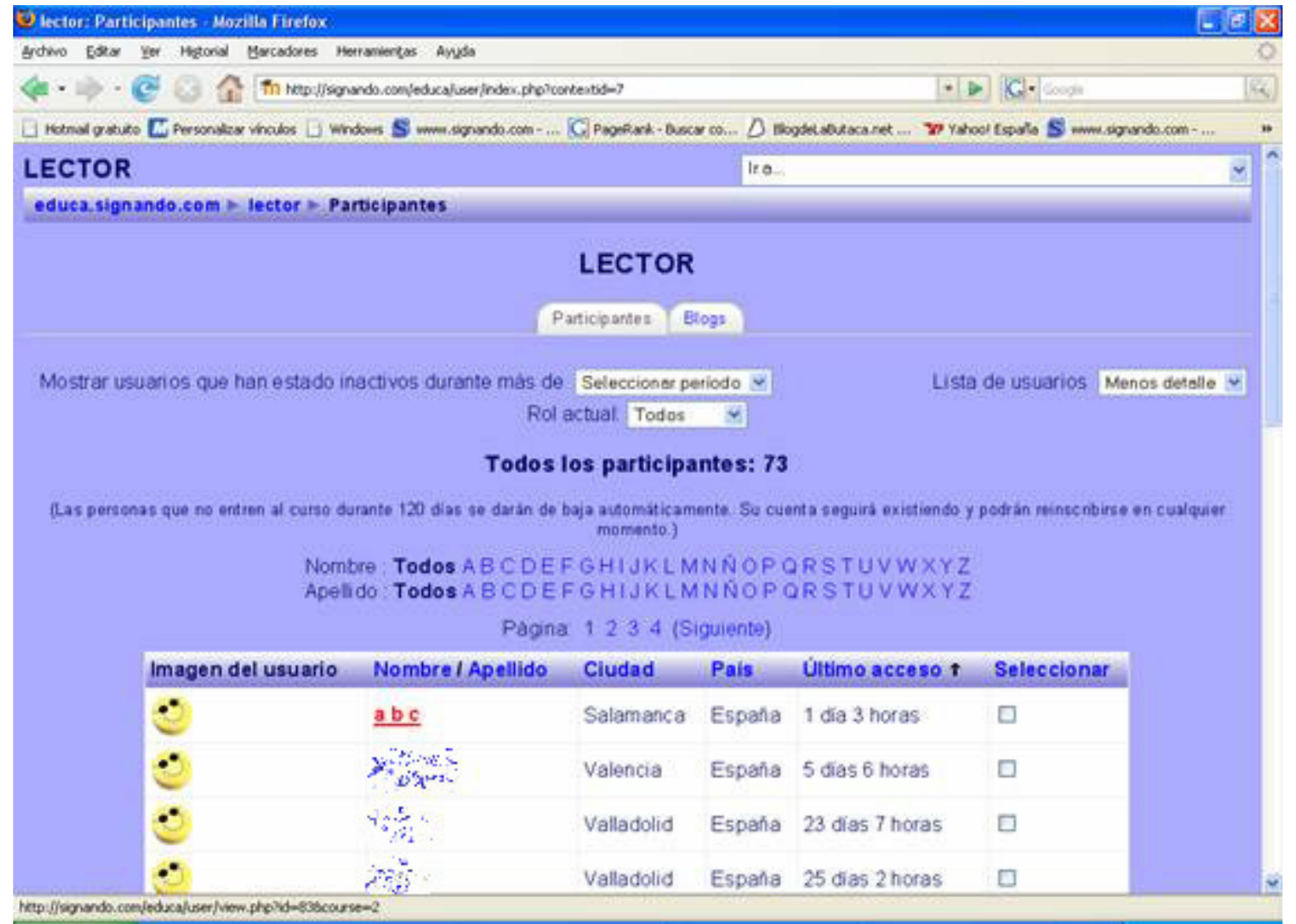

Imagen 43. Todos los participantes

Esta información (ver imagen 43) en el caso del Curso LECTOR ha sido introducida por el educador o administrador, encargado de realizar la matriculación manual de los alumnos en el curso. Para la investigación se crearon una serie de variables independientes que son las que se pueden ver en la imagen 44. 


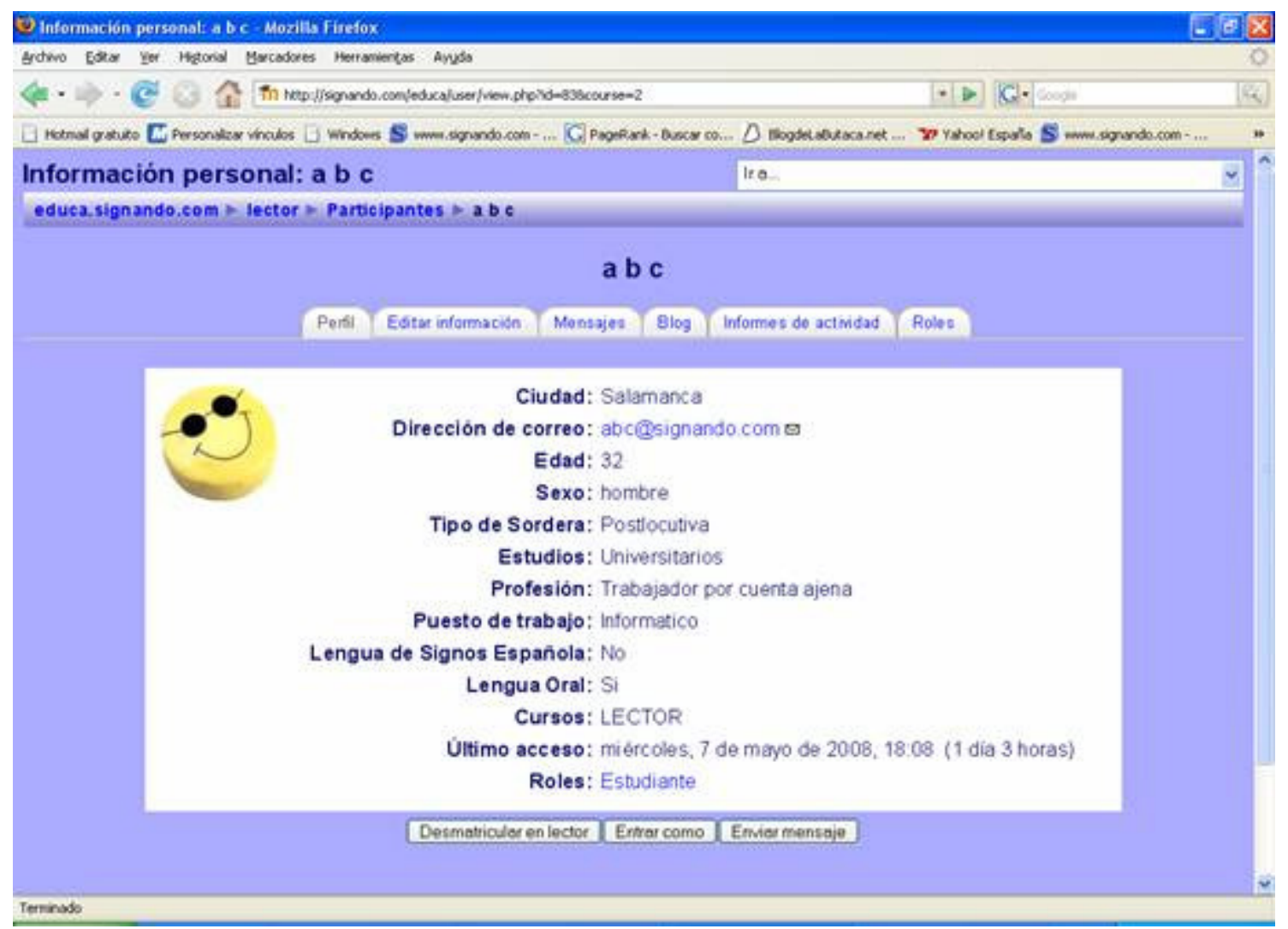

Imagen 44. Detalles de Participante

A través de esta ventana se puede llegar a ver unos Informes de Actividad del alumno elegido, este informe es menos detallado que los vistos anteriormente (ver imágenes 45 y 46$)$. 
Desarrollo de Estrategias Sintácticas y Semánticas en Lectura a través de LECTOR en Personas Sordas Adultas en Castilla y León

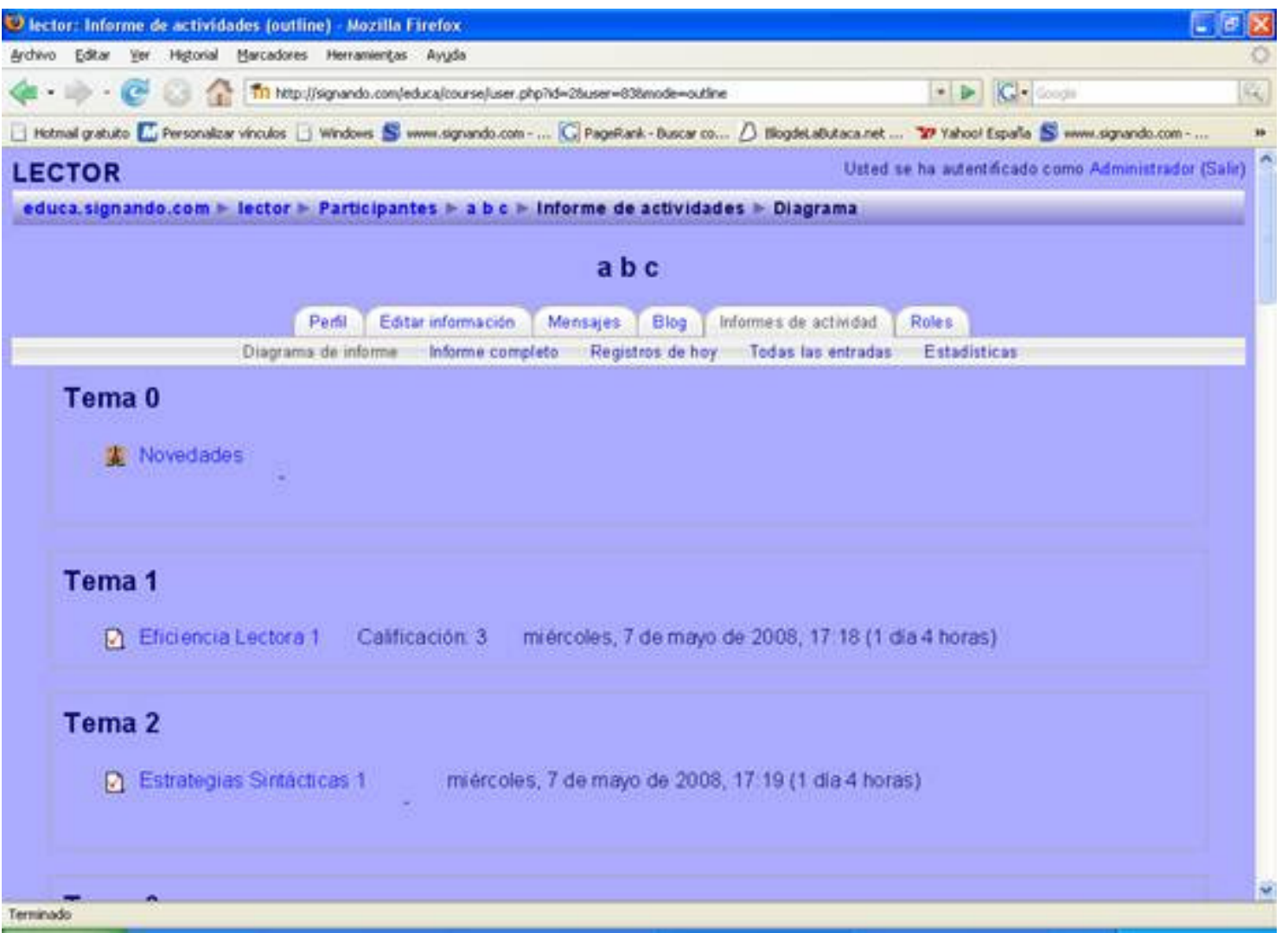

\section{Imagen 45. Informes de participante}

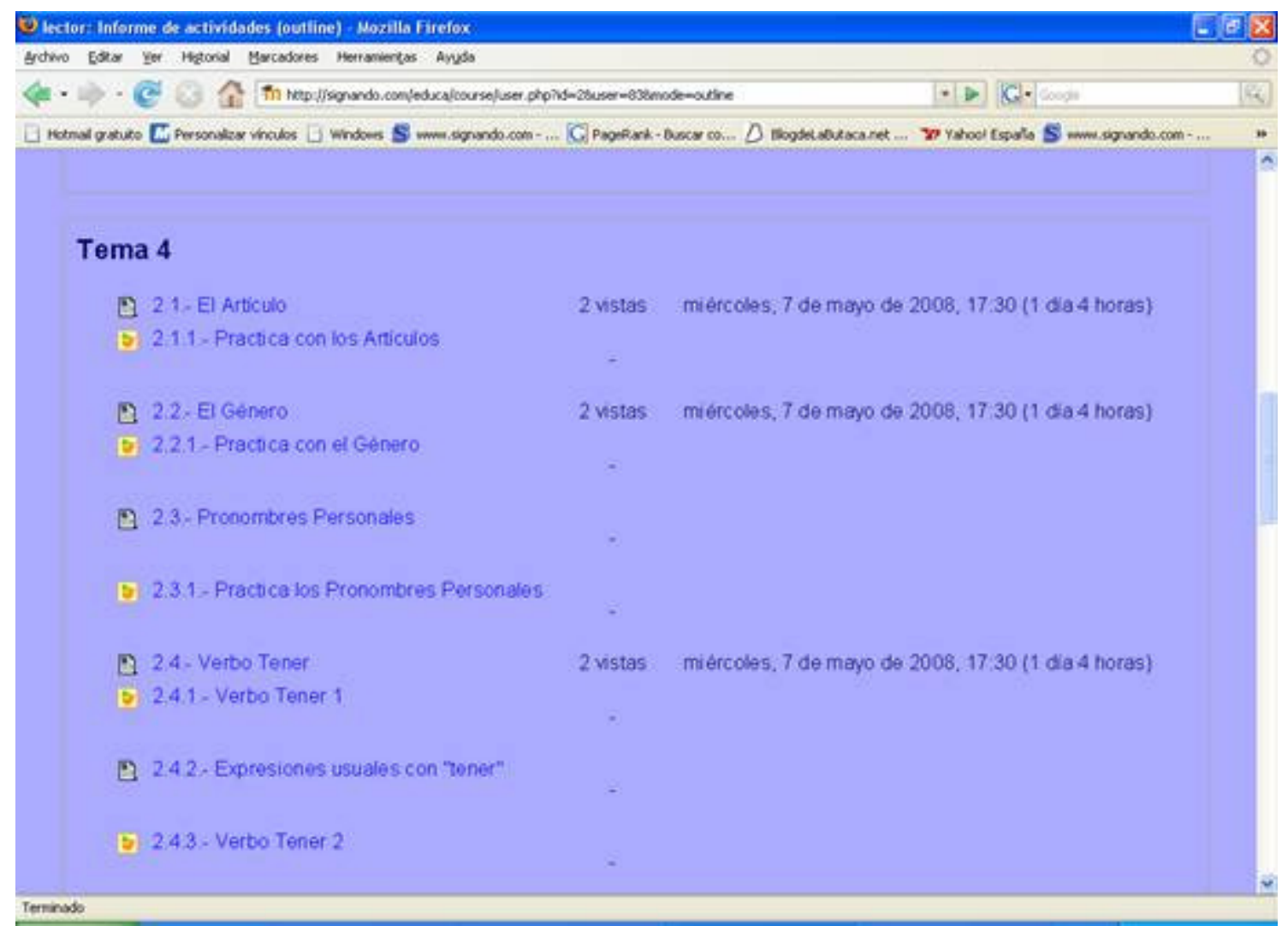

Imagen 46. Informes de participante 
Desde esta ventana se pude ir a cada una de las actividades para analizar de forma detallada que trabajo se ha realizado sobre cada una.

\section{Asignar Roles}

Seleccionando la opción Asignar Roles del menú administrador obtenemos la información de cómo está montado el Curso, cual es su estructura y cuantas personas están matriculadas (imagen 47).

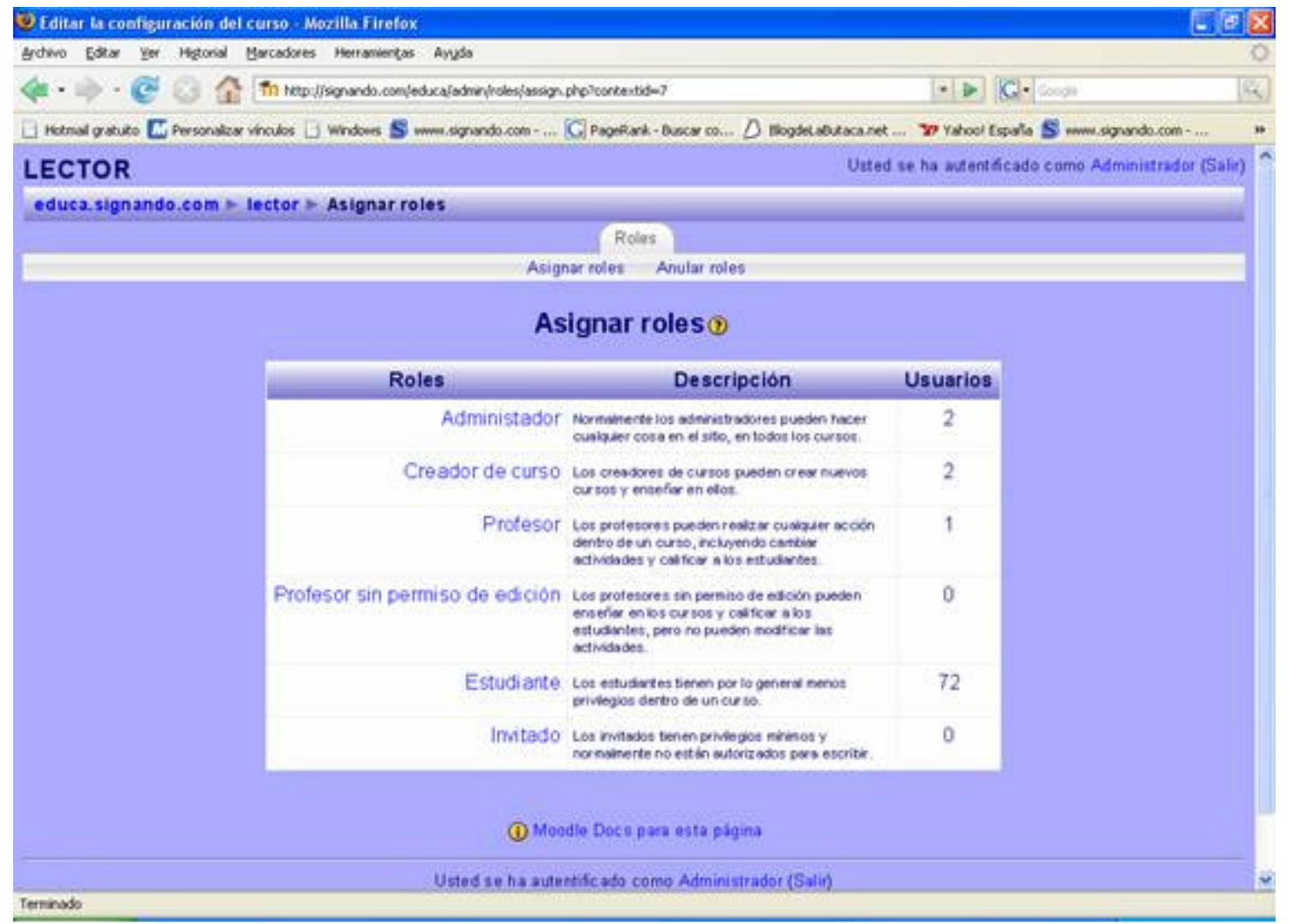

Imagen 46. Asignar roles 


\section{Activar edición}

Esta opción es muy útil para colocar y editar las actividades.

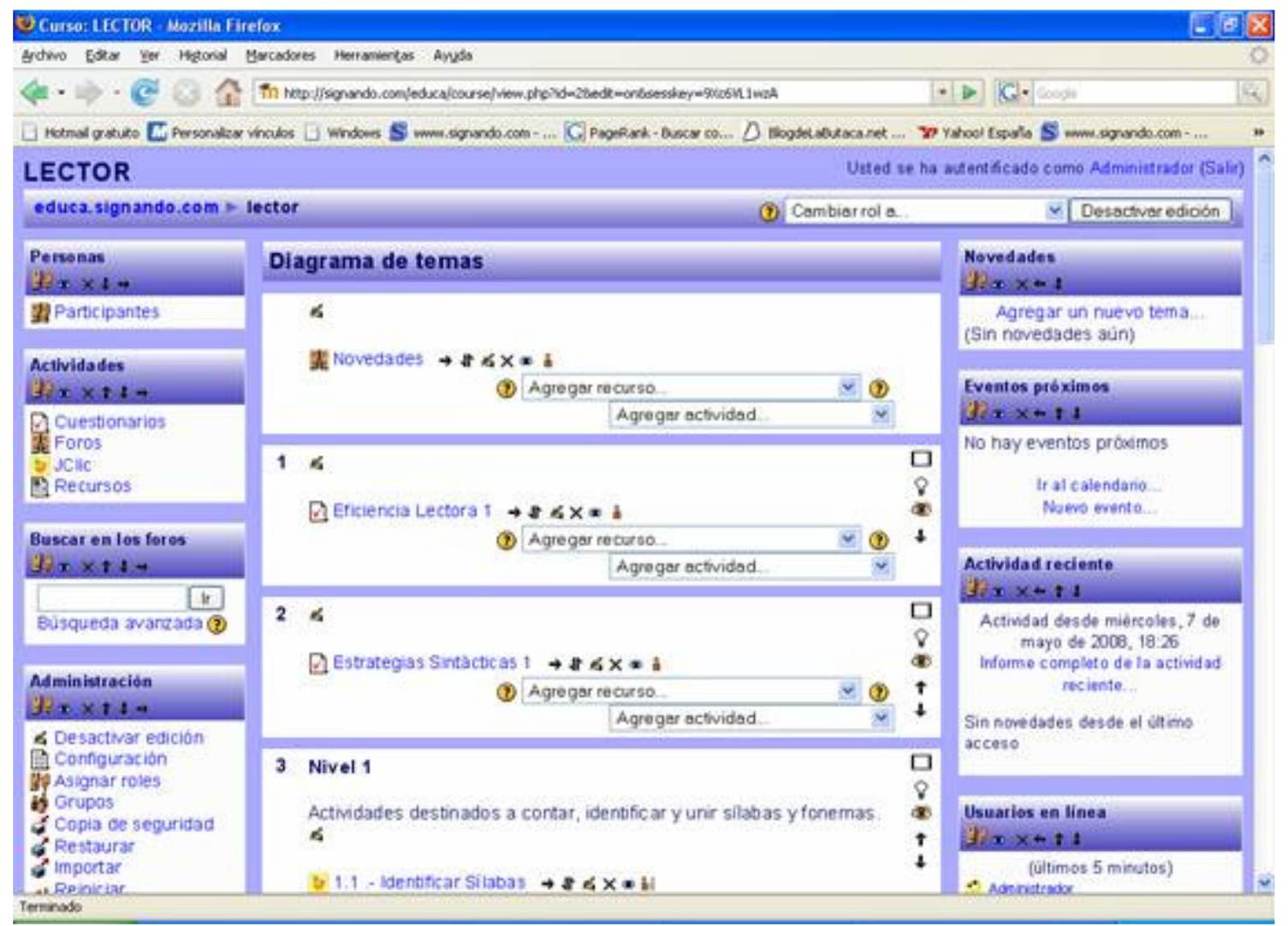

Imagen 47. Activación de edición del curso LECTOR

Para editar el contenido de una actividad (imagen 47) solo hay que pulsar la mano que tiene una pluma. Seleccionando esta opción se puede observar el contenido descrito cuando fue creado (ver imágenes 48 y 49). 
Desarrollo de Estrategias Sintácticas y Semánticas en Lectura a través de LECTOR en Personas Sordas Adultas en Castilla y León

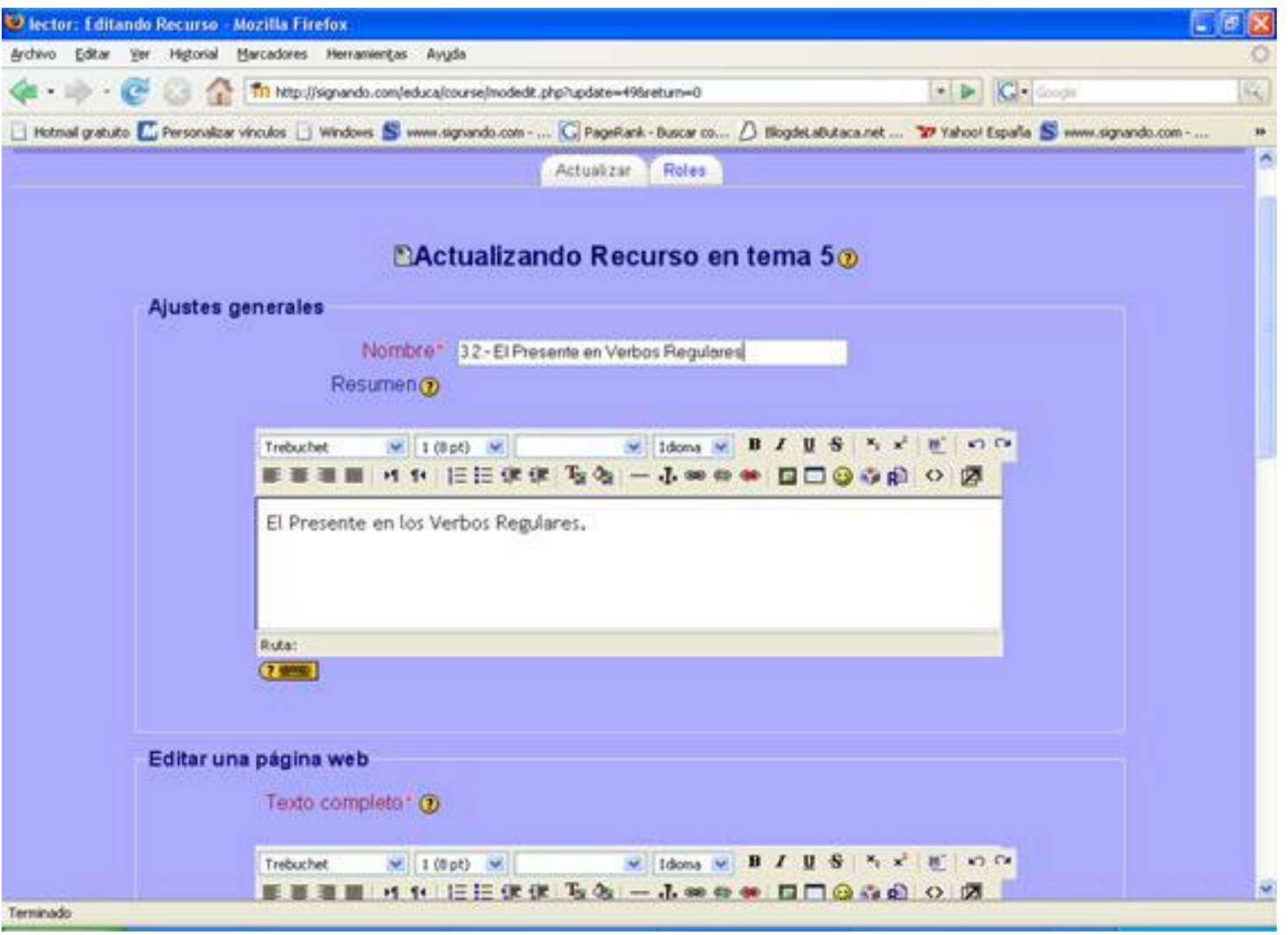

Imagen 48. Actualización de recurso en Tema 5

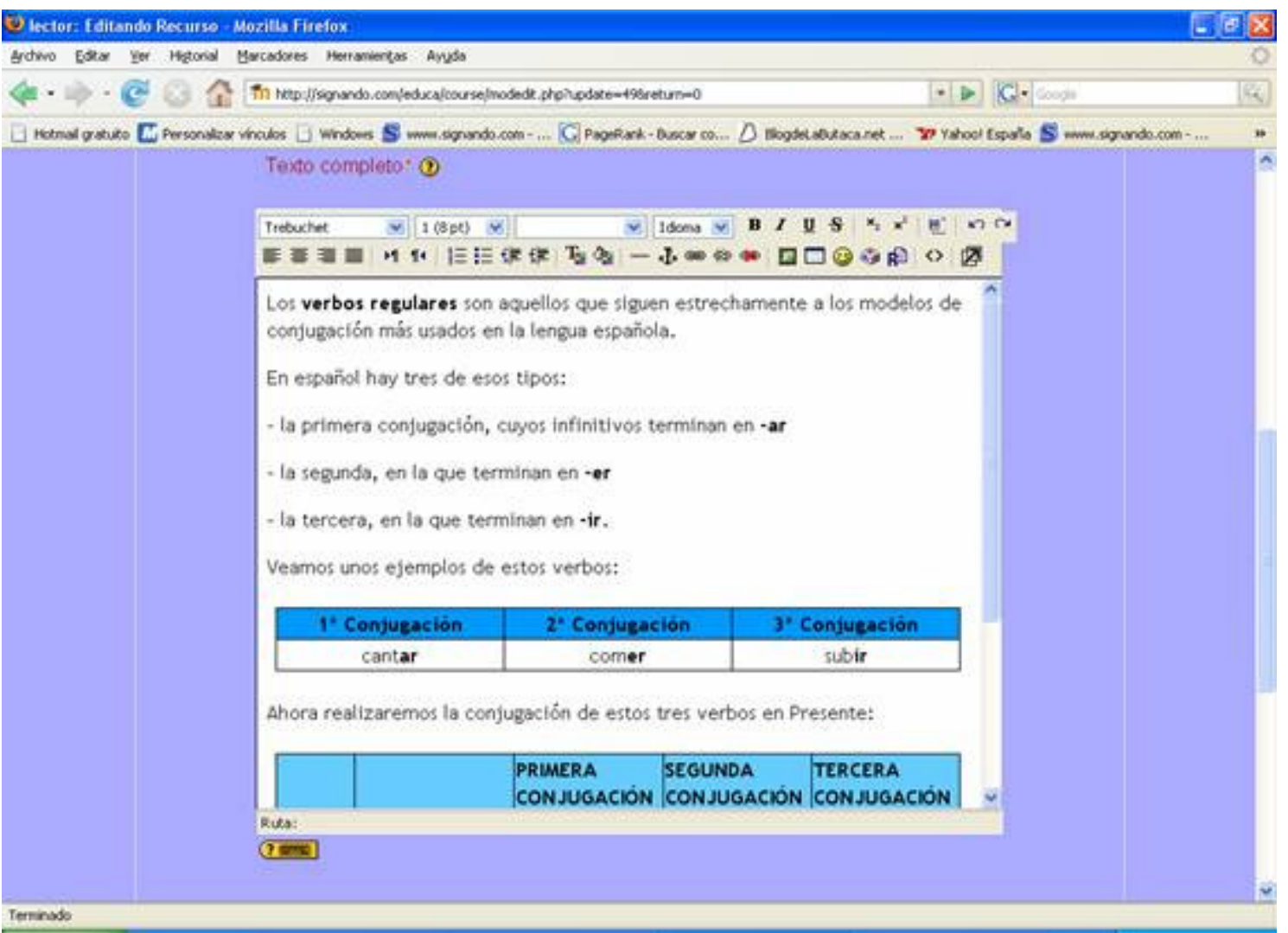

Imagen 49. Actualización de recurso 
Para crear una nueva actividad existe un menú desplegable (ver imagen 50) que permite seleccionar que tipo de actividad se quiere realizar, como se ha indicado a lo largo de la Tesis se ha usado Jclic para la creación de actividades, existe un modulo de Moodle que permite incluir este tipo de actividades en los cursos.

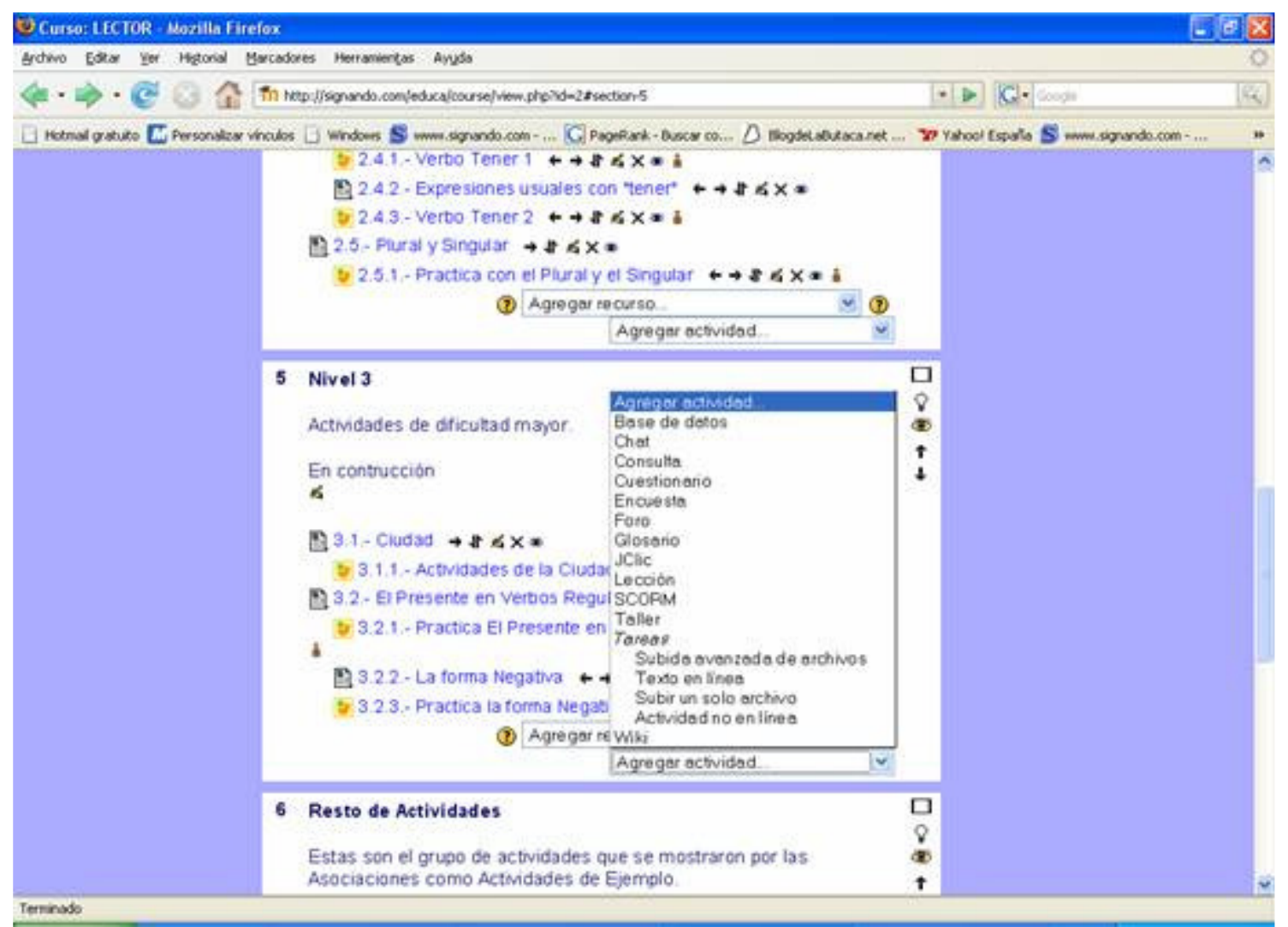

Imagen 50. Menú nueva actividad

\section{Configuración}

Esta opción está relacionada con la configuración del propio curso, como se ve en las siguientes imágenes (51, 52 y 53), esta ha sido la configuración del curso LECTOR. 
Desarrollo de Estrategias Sintácticas y Semánticas en Lectura a través de LECTOR en Personas Sordas Adultas en Castilla y León

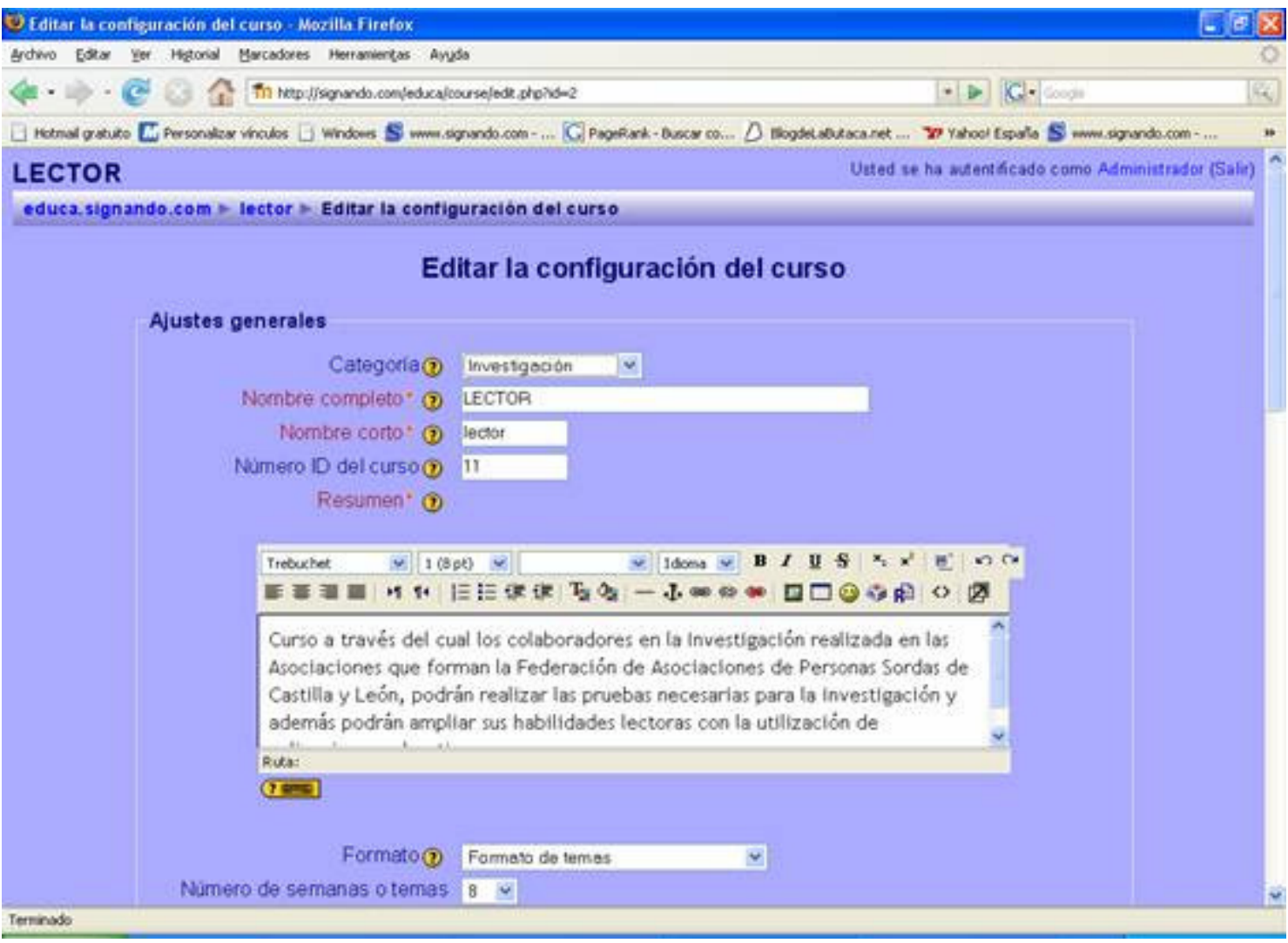

\section{Imagen 51. Configuración curso LECTOR}

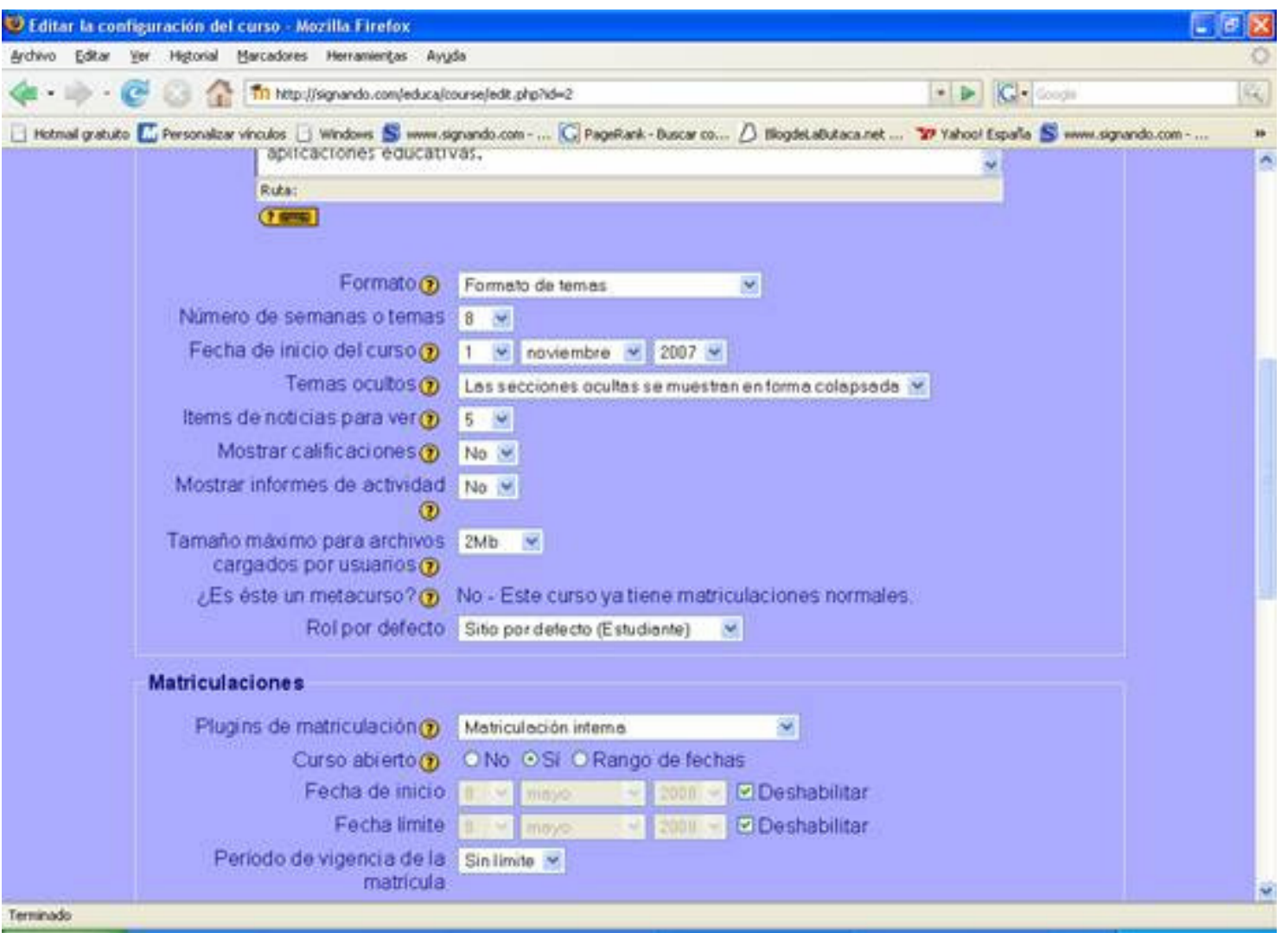

\section{Imagen 52. Configuración curso LECTOR}


Desarrollo de Estrategias Sintácticas y Semánticas en Lectura a través de LECTOR en Personas Sordas Adultas en Castilla y León

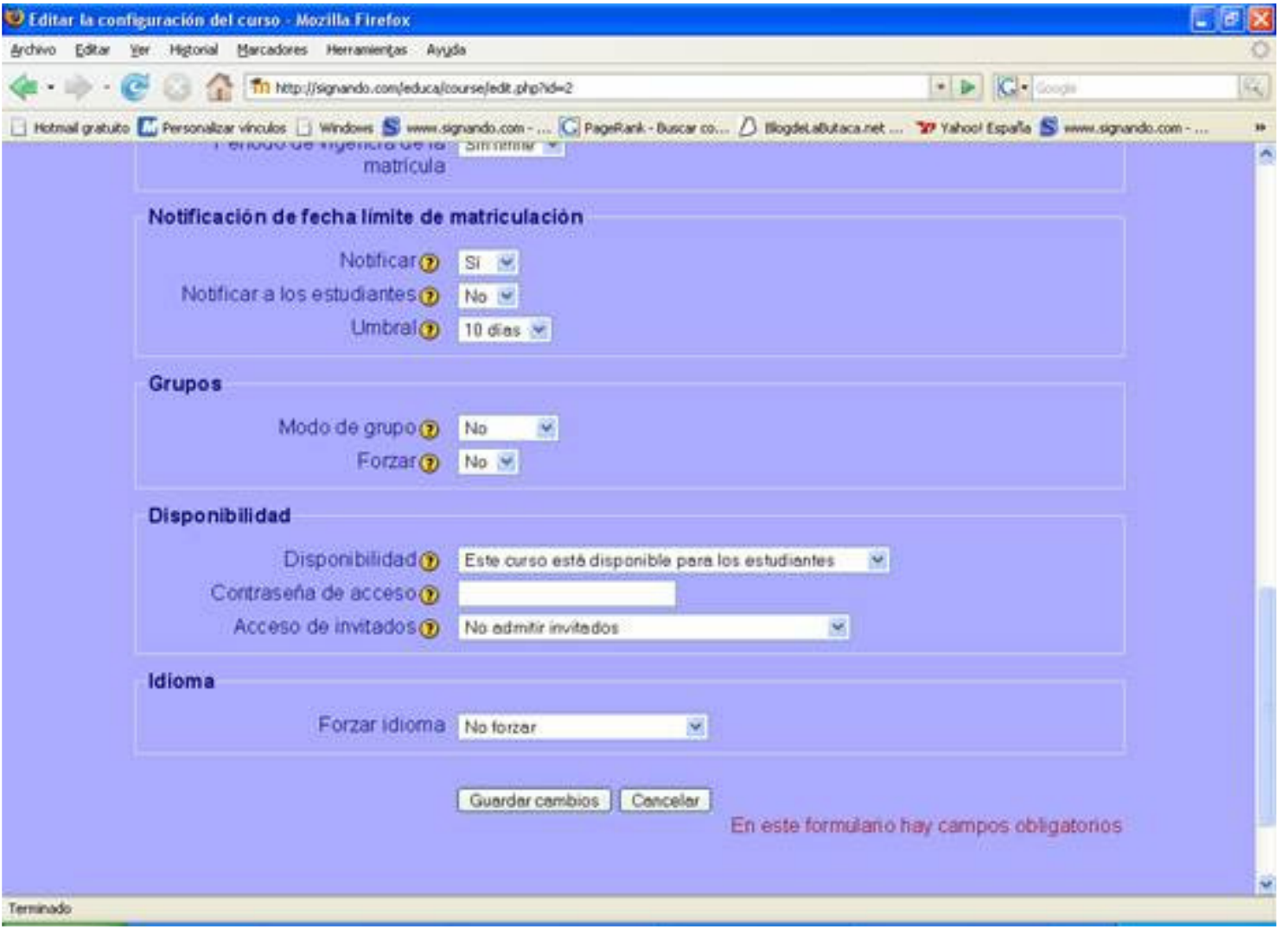

\section{Imagen 52. Configuración curso LECTOR}




\section{Menú Eventos Próximos}

Existen otros bloques interesantes pero destaca por su utilidad el de Eventos Próximos (ver imagen 54) en el se han ido dejando anotaciones que los usuarios han podido ir viendo, por ejemplo la fecha de finalización de los pre y pos test.

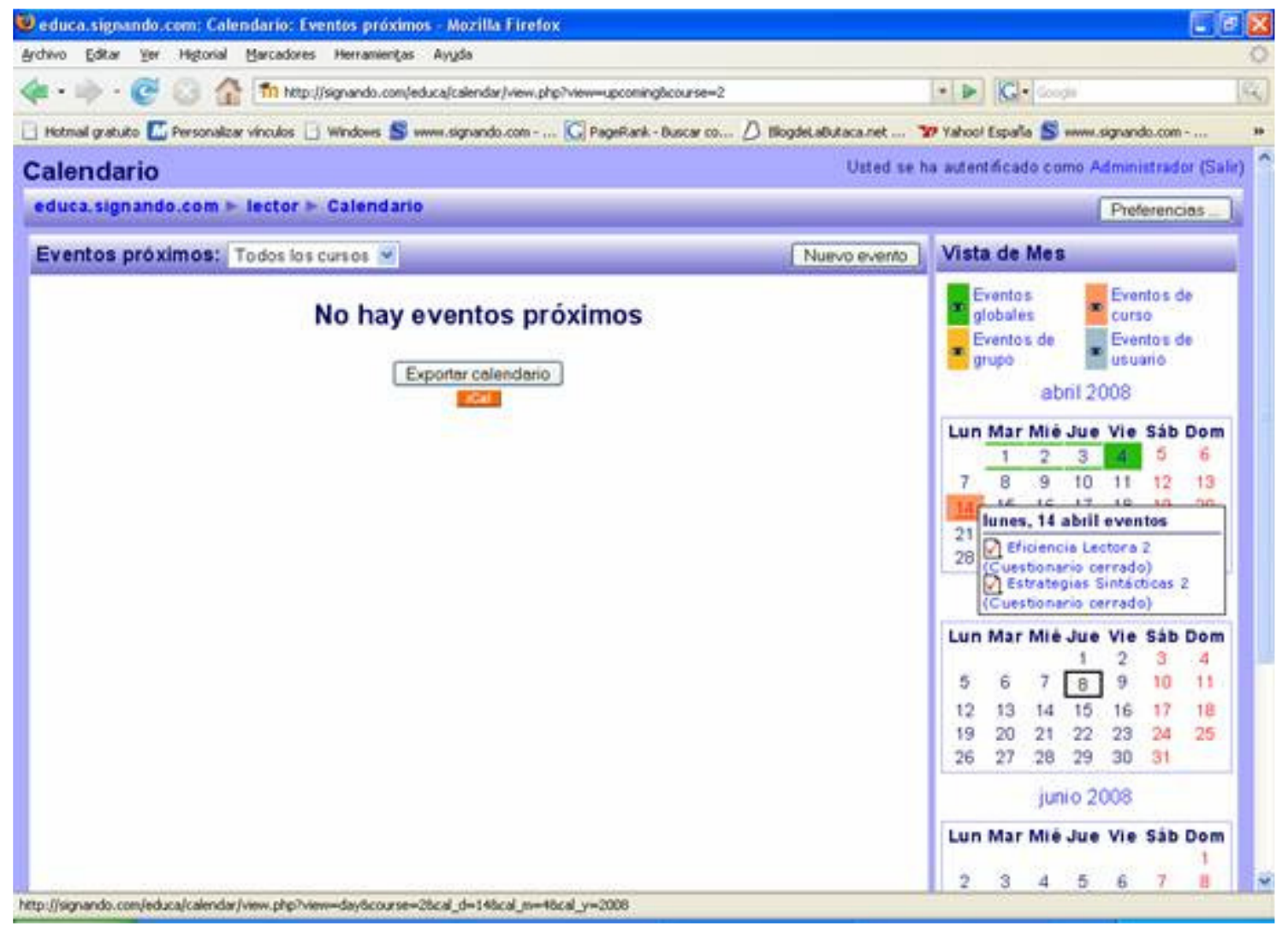

Imagen 54. Eventos Próximos 

en Castilla y León 


\section{ANEXO IV. Colaboraciones}

\section{Proyecto de Colaboración con Centro Cultural de Personas Sordas de Salamanca}

Todo el mundo sabe de la necesidad que tiene el hombre de estar informado. Esta necesidad llega a ser fundamental para el conocimiento del medio que nos rodea. Sin esta información las personas se pueden encontrar en un mundo desconocido.

Actualmente, las Personas Sordas tienen grandes dificultades para acceder a la información, solo aquellos que han recibido una educación y han trabajado la lectura pueden mantenerse informados a través de diarios o noticiarios televisivos traducidos por intérpretes de Lengua de Signos.

Un periódico, una revista o la televisión son los medios utilizados por todas las personas para recibir información, pero desde hace unos años ha surgido un medio que llega a todo el mundo, Internet. Con la ventaja de que la información que se muestra en Internet puede ser adaptada a las necesidades de la persona que la va a recibir, todo un avance sin lugar a dudas.

El auge de Internet ha generado un nuevo medio para la distribución de información, pero son muy pocos los portales que presentan adaptaciones para la comprensión por parte de Personas Sordas, el uso de videos en Lengua de Signos es la opción mas utilizada. La mayoría de las web se basan en documentación escrita, esto hace que no sean accesibles a un gran número de Personas Sordas, de forma que este medio que parecía perfecto no lo es tanto sin un trabajo extra.

Muchos han sido los avances realizados en el mundo de la programación de páginas web, la introducción de información en formato multimedia, hacen que esta vía sea mucho mas potente que en sus orígenes, se ha pasado de recibir información de forma escrita o con fotos a poder tener videos y a interactuar con aplicaciones en Internet.

Con la ayuda de las nuevas tecnologías, y observando las necesidades especificas que presentan las personas sordas y su entorno, hemos pensado en crear una página web que fortaleciera los medios para recibir información. Por todo esto surgió www.signando.com, una página pensada para informar a las personas sordas y a su entorno. Recogerá eventos, noticias de carácter general, artículos científicos basados en investigaciones y reportajes o entrevistas, todo relacionado con el mundo de las Personas Sordas.

Actualmente, www.signando.com lleva 67 días en línea y ya hemos recibido más de 200 visitas, muchas de ellas realizadas desde España, pero tenemos un gran número de visitas de América: Méjico, Venezuela, Colombia, Perú, Bolivia, Republica Dominicana, Argentina, Chile y Estados Unidos desde Miami, y eso que solamente se muestra información de forma escrita. 
El objetivo principal es que en la página todo artículo o noticia publicada tenga un video de un intérprete en Lengua de Signos.

Siempre se dará la opción al lector de leer la noticia de forma escrita, pensamos que el trabajo que actualmente se está realizando en las distintas Asociaciones de Personas Sordas para aumentar la comprensión lectora esta siendo muy bueno, y creemos que siempre es necesario motivar a los alumnos para que lean antes de ver el video en Lengua de Signos.

Existe también un subdominio dirigido a la educación: educa.signando.com. Esta página contiene actualmente el Curso LECTOR, aplicación a través de la cual las personas que participan en una investigación de la Universidad de Salamanca podrán realizar los test y trabajar sus habilidades lectoras a través de la página.

Tenemos pensado aumentar el contenido, creando cursos dirigidos a Personas Sordas y a Personas Oyentes. De esta forma los cursos que queremos crear son de Lengua de Signos, comenzando por uno básico para aprendices, tanto sordos como oyentes. Ya hemos recibido correos solicitando la creación de estos cursos.

Es por todo esto que solicitamos la colaboración del Centro Cultural de Personas Sordas de Salamanca, para disponer de un intérprete de Lengua de Signos para hacer posible la creación de videos en los reportajes. Este interprete traduciría los artículos e demás contenidos de esta página. Este servicio deberá prestarse de forma altruista, ya que nosotros no disponemos de medios para contratar un intérprete. Hay que tener en cuenta que Signando.com ha sido creada desinteresadamente, con el objetivo de favorecer futuras investigaciones relacionadas con la Educación de Personas Sordas Adultas. Los derechos de la página, es desarrollo y el mantenimiento económico que necesita es sostenido por nosotros.

Acudimos a ustedes, porque desde el principio de la investigación hemos contado con su colaboración y nos gustaría mantenerla.

Muchas gracias por su interés. 


\section{CERTIFICADO}

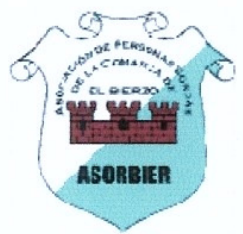

La Asociación de Personas Sordas de la Comarca del Bierzo, certifica que Carolina de Castro Costa; NIE: x6340860J, investigadora de la Universidad de Salamanca en Educación de Personas Adultas, estuvo en Ponferrada para explicar el funcionamiento de su proyecto de investigación: "Desarrollo de estrategias sintácticas en lectura en Personas Sordas Adultas a través del Programa Lector, en Castilla y León".

Este proyecto será de fundamental importancia para el desarrollo y valoración de propuestas y materiales didácticos para la enseñanza-aprendizaje del lenguaje escrito a alumnos sordos.

Con la utilización de un Programa informático adaptado a las necesidades de los alumnos, motivará el acceso a actividades y textos a través de la web: www. signando.com / educa.signando.com.

Carolina, ha hecho en total, $290 \mathrm{Km}$ desde Castellanos de Moriscos (Salamanca) hasta Ponferrada. Aproximadamente, 3 horas de coche.

Los gastos económicos del viaje y de la investigación fueron sostenidos por la misma, sin ninguna ayuda de Beca o colaboración.

Para que quede constancia en Ponferrada (León), a 8 de octubre de 2007.

Firma del Educador

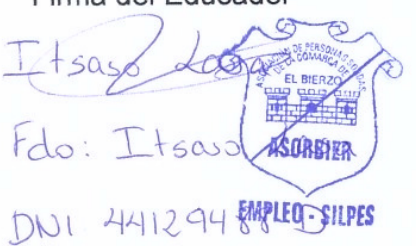

Firma de la investigadora

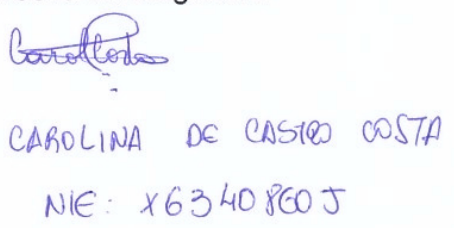

$$
\begin{aligned}
& \text { CAROLINA DE CASTEO COSTA } \\
& \text { NIE: } \times 6340860 \mathrm{~J}
\end{aligned}
$$

Certificado Asociaciones

Signando.com 


\section{CERTIFICADO}

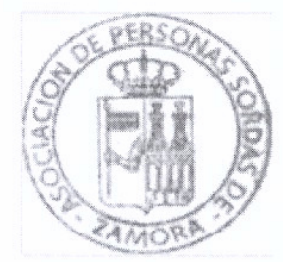

La Asociación de Personas Sordas de Zamora, certifica que Carolina de Castro Costa; NIE: x6340860J, investigadora de la Universidad de Salamanca en Educación de Personas Adultas, estuvo en Zamora para explicar el funcionamiento de su proyecto de investigación: "Desarrollo de estrategias sintácticas en lectura en Personas Sordas Adultas a través del Programa Lector, en Castilla y León".

Este proyecto será de fundamental importancia para el desarrollo y valoración de propuestas y materiales didácticos para la enseñanza-aprendizaje del lenguaje escrito a alumnos sordos.

Con la utilización de un Programa informático adaptado a las necesidades de los alumnos, motivará el acceso a actividades y textos a través de la web: www.signando.com/ educa.signando.com

Carolina, ha hecho en total, $70 \mathrm{Km}$ desde Castellanos de Moriscos (Salamanca), hasta Burgos. Aproximadamente, 1 hora y 5 minutos de coche. Los gastos económicos del viaje y de la investigación fueron sostenidos por la misma, sin ninguna ayuda de Beca o colaboración.

Para que quede constancia en Zamora, a 16 de octubre de 2007.

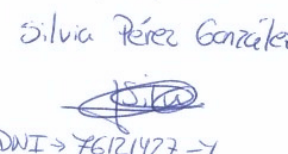

Firma del Educador

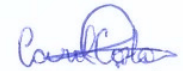

CAROLINA DE CASTIO COSTA Firma de la investigadora

Certificado Asociaciones

Signando.com 


\section{CERTIFICADO}

La Asociación de Sordos de León "San Juan Bautista", certifica que Carolina de Castro Costa; NIE: x6340860J, investigadora de la Universidad de Salamanca en Educación de Personas Adultas, estuvo en León para explicar el funcionamiento de su proyecto de investigación: "Desarrollo de estrategias sintácticas en lectura en Personas Sordas Adultas a través del Programa Lector, en Castilla y León".

Este proyecto será de fundamental importancia para el desarrollo y valoración de propuestas y materiales didácticos para la enseñanza-aprendizaje del lenguaje escrito a alumnos sordos.

Con la utilización de un Programa informático adaptado a las necesidades de los alumnos, motivará el acceso a actividades y textos a través de la web: www.signando.com / educa.signando.com.

Carolina, ha hecho en total, $230 \mathrm{Km}$ desde Castellanos de Moriscos (Salamanca) hasta León. Aproximadamente, 2 horas y 40 minutos de coche.

Los gastos económicos del viaje y de la investigación fueron sostenidos por la misma, sin ninguna ayuda de Beca o colaboración.

Para que quede constancia en León, a 4 de octubre de 2007.

Firma del Educador

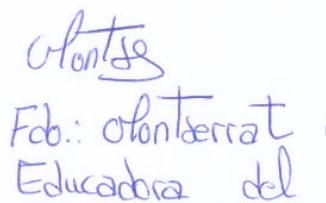

Firma de la investigadora

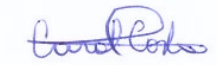

CAROLINA DE CASTRO COSTA

NIE: $\times 6340860 \mathrm{~J}$ D.Nin-71. $551.695-Y$

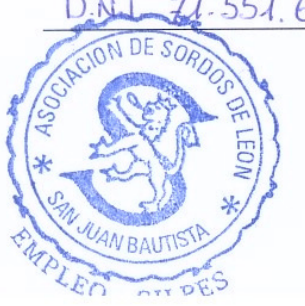

Certificado Asociaciones

Signando.com 


\section{CERTIFICADO}

La Asociación de Personas Sordas de Aranda de Duero y la Ribera (APSAR), certifica que Carolina de Castro Costa; NIE: x6340860J, investigadora de la Universidad de Salamanca en Educación de Personas Adultas, estuvo en Aranda de Duero para explicar el funcionamiento de su proyecto de investigación: "Desarrollo de estrategias sintácticas en lectura en Personas Sordas Adultas a través del Programa Lector, en Castilla y León".

Este proyecto será de fundamental importancia para el desarrollo y valoración de propuestas y materiales didácticos para la enseñanza-aprendizaje del lenguaje escrito a alumnos sordos.

Con la utilización de un Programa informático adaptado a las necesidades de los alumnos, motivará el acceso a actividades y textos a través de la web: www. signando.com / educa.signando.com.

Carolina, ha hecho en total, $210 \mathrm{Km}$ desde Castellanos de Moriscos (Salamanca) hasta Aranda de Duero (Burgos). Aproximadamente, 3 horas de coche.

Los gastos económicos del viaje y de la investigación fueron sostenidos por la misma, sin ninguna ayuda de Beca o colaboración.

Para que quede constancia en Aranda de Duero (Burgos), a 9 de octubre de 2007.

Firma del Educador

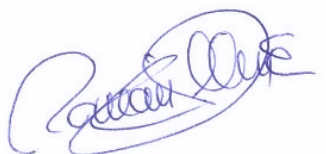

Firma de la investigadora

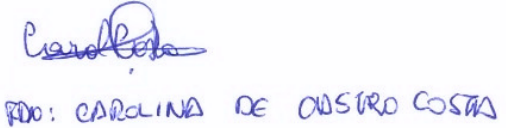

FDO: ROMANDENEAgIA Miquel

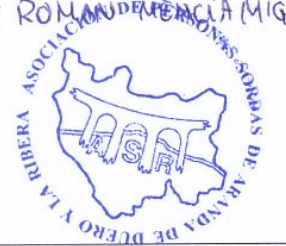

Certificado Asociaciones

Signando.com 


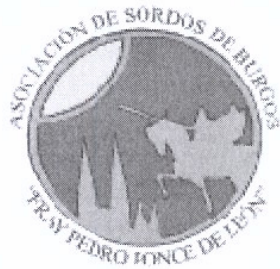

La Asociación de Personas Sordas de Burgos "Fray Pedro Ponce de León", certifica que Carolina de Castro Costa; NIE: x6340860J, investigadora de la Universidad de Salamanca en Educación de Personas Adultas, estuvo en Burgos para explicar el funcionamiento de su proyecto de investigación: "Desarrollo de estrategias sintácticas en lectura en Personas Sordas Adultas a través del Programa Lector, en Castilla y León".

Este proyecto será de fundamental importancia para el desarrollo y valoración de propuestas y materiales didácticos para la enseñanza-aprendizaje del lenguaje escrito a alumnos sordos.

Con la utilización de un Programa informático adaptado a las necesidades de los alumnos, motivará el acceso a actividades y textos a través de la web: www.signando.com / educa.signando.com

Carolina, ha hecho en total, $234 \mathrm{Km}$ desde Castellanos de Moriscos (Salamanca), hasta Burgos. Aproximadamente, 2 horas y 29 minutos de coche. Los gastos económicos del viaje y de la investigación fueron sostenidos por la misma, sin ninguna ayuda de Beca o colaboración.

Para que quede constancia en Burgos, a 17 de octubre de 2007.

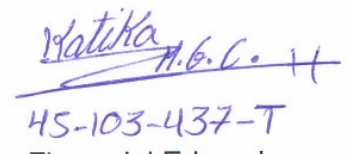

Firma del Educador

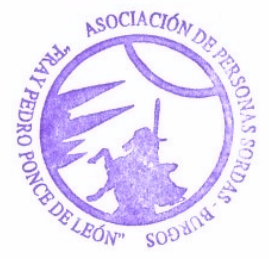

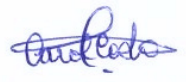

carolina dé castro costa

Firma de la investigadora

Certificado Asociaciones

Signando.com 


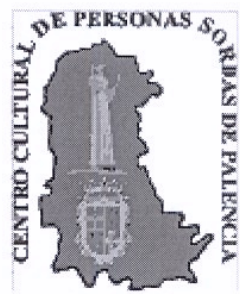

El Centro Cultural de Personas Sordas de Palencia (CCSP), certifica que Carolina de Castro Costa; NIE: x6340860J, investigadora de la Universidad de Salamanca en Educación de Personas Adultas, estuvo en Palencia para explicar el funcionamiento de su proyecto de investigación: "Desarrollo de estrategias sintácticas en lectura en Personas Sordas Adultas a través del Programa Lector, en Castilla y León".

Este proyecto será de fundamental importancia para el desarrollo y valoración de propuestas y materiales didácticos para la enseñanza-aprendizaje del lenguaje escrito a alumnos sordos.

Con la utilización de un Programa informático adaptado a las necesidades de los alumnos, motivará el acceso a actividades y textos a través de la web: www.signando.com / educa.signando.com

Carolina, ha hecho en total, $156 \mathrm{Km}$ desde Castellanos de Moriscos (Salamanca) hasta Palencia. Aproximadamente, 1 hora y 47 minutos de coche. Los gastos económicos del viaje y de la investigación fueron sostenidos por la misma, sin ninguna ayuda de Beca o colaboración.

Para que quede constancia en Palencia, a 24 de octubre de 2007.

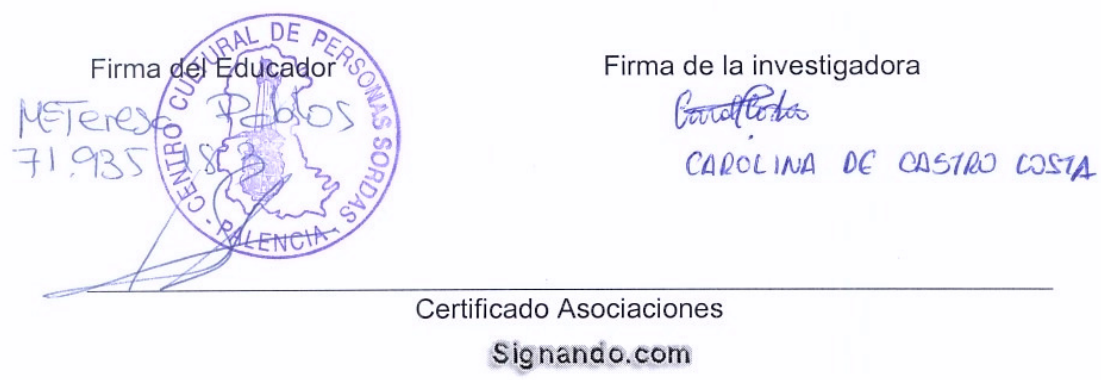




\section{CERTIFICADO}

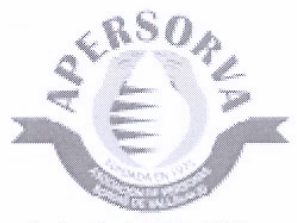

La Asociación de Personas Sordas de Valladolid (APERSORVA), certifica que Carolina de Castro Costa; NIE: x6340860J, investigadora de la Universidad de Salamanca en Educación de Personas Adultas, estuvo en Valladolid para explicar el funcionamiento de su proyecto de investigación: "Desarrollo de estrategias sintácticas en lectura en Personas Sordas Adultas a través del Programa Lector, en Castilla y León".

Este proyecto será de fundamental importancia para el desarrollo y valoración de propuestas y materiales didácticos para la enseñanza-aprendizaje del lenguaje escrito a alumnos sordos.

Con la utilización de un Programa informático adaptado a las necesidades de los alumnos, motivará el acceso a actividades y textos a través de la web: www.signando.com / educa. signando.com

Carolina, ha hecho en total, $110 \mathrm{Km}$ desde Castellanos de Moriscos (Salamanca) hasta Valladolid. Aproximadamente, 1 hora y 15 minutos de coche.

Los gastos económicos del viaje y de la investigación fueron sostenidos por la misma, sin ninguna ayuda de Beca o colaboración.

Para que quede constancia en Valladolid, a 25 de octubre de 2007.

Firma del Educador

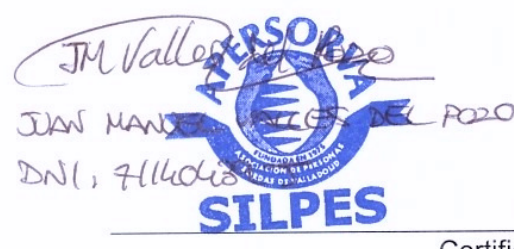

Firma de la investigadora

carolina de castro cosita

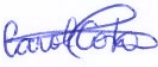

Certificado Asociaciones

Signando.com 